



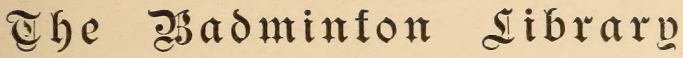

$$
\text { OF. }
$$

SPORTS AND PASTIMES

EDITĘD BY

HIS GRACE THE DUKE OF BEAUFORT, K.G.

$$
\text { ASSISTED BY ALFRED E. T. WATSON }
$$

ATHLETICS and FOOTBALL 


\section{BIBLIOGRAPHICAL NOTE.}

First Edition, April I 887 ; Reprinted September 1888, November 1889; New Edition, revised, zuth mumerous Additions, July I894. 
Eacter fr.

trantena.

$y$ mas 1905 


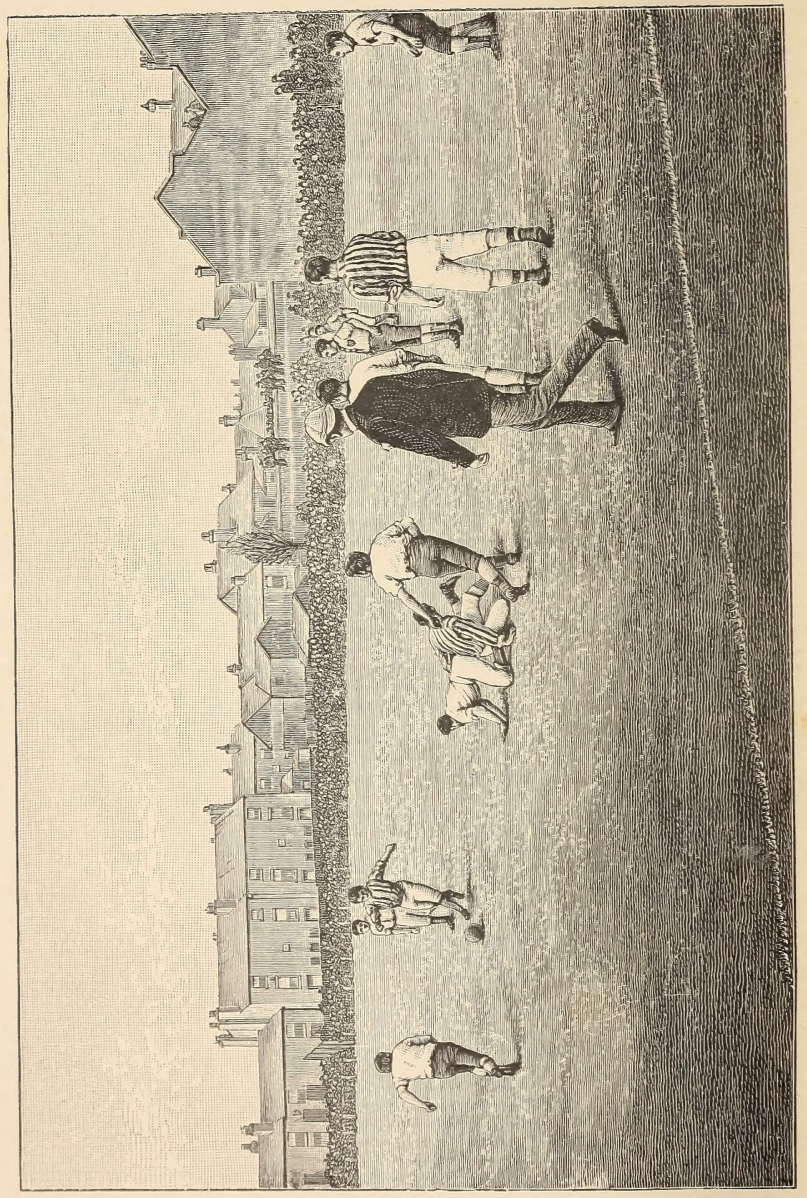




\title{
ATHLETICS ANd FOOTBALL
}

\author{
BY \\ MONTAGUE SHEARMAN
}

WITH A CONTRIBUTION ON PAPER-CHASING BY W. RYE AND AN INTRODUCTION BY SIR RICHARD WEBSTER, Q.C., M.P.

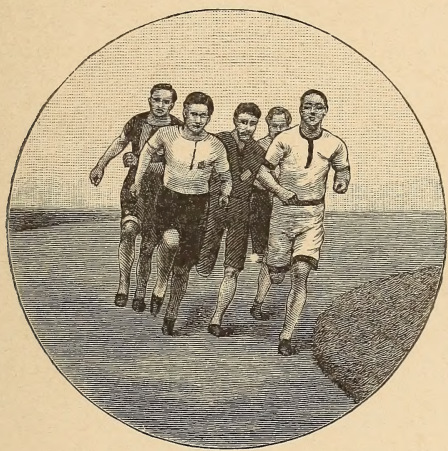

WITH NUMEROUS ENGRAVINGS AFTER STANLEY BERKELEY AND INSTANTANEOUS PHOTOGRAPHS BY G. MITCHELL

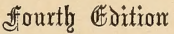

WITH THE ADDITION OF CHAPTERS ON

FOOTBALL IN THE UNITED STATES

BY WALTER CAMP, NEW HAVEN, CONN.

AND

AUSTRALIAN FOOTBALL

BY A. SUTHERLAND, DROMANA, VICTORIA

\section{LONDON}

L O N G A N S, GREEN, I 894

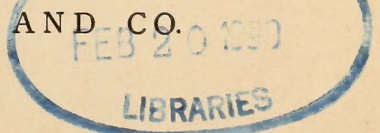





\section{DEDICATION}

TO

\section{H.R.H. THE PRINCE OF IVALES.}

\section{BADMINTON : March, I887.}

HAVING received permission to dedicate these volumes, the Badminton Library of Sports and Pastimes, to His Royal Highness the Prince of Wales, I do so feeling that I am dedicating them to one of the best and keenest sportsmen of our time. I can say, from personal observation, that there is no man who can extricate himself from a bustling and pushing crowd of horsemen, when a fox breaks covert, more dexterously and quickly than His Royal Highness; and that when hounds run hard over a big country, no man can take a line of his own and live with them better. Also, when the wind has been blowing hard, often have I seen His Royal Highness knocking over driven grouse and partridges and high-rocketing pheasants in first-rate 
workmanlike style. He is held to be a good yachtsman, and as Commodore of the Royal Yacht Squadron is looked up to by those who love that pleasant and exhilarating pastime. His encouragement of racing is well known, and his attendance at the University, Public School, and other important Matches testifies to his being, like most English gentlemen, fond of all manly sports. I consider it a great privilege to be allowed to dedicate these volumes to so eminent a sportsman as His Royal Highness the Prince of Wales, and I do so with sincere feelings of respect and esteem and loyal devotion.

BEAUFORT. 


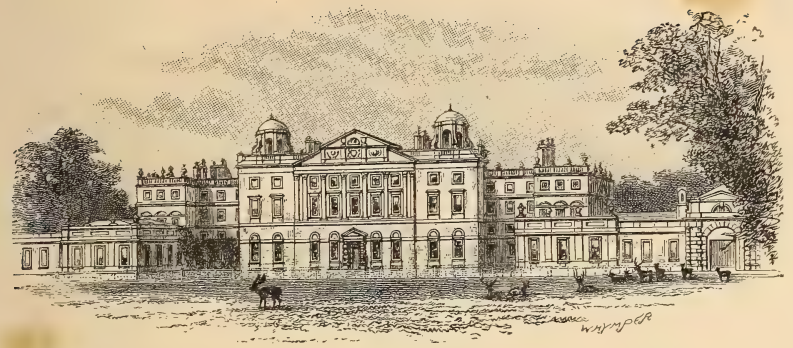

BADMINTON.

\section{PREFACE.}

A FEW LINES only are necessary to explain the object with which these volumes are put forth. There is no modern encyclopædia to which the inexperienced man, who seeks guidance in the practice of the various British Sports and Pastimes, can turn for information. Some books there are on Hunting, some on Racing, some on Lawn Tennis, some on Fishing, and so on ; but one Library, or succession of volumes, which treats of the Sports and Pastimes indulged in by Englishmen-and women-is wanting. The Badminton Library is offered to supply the want. Of the imperfections which must be found in the execution of such a design we are 
conscious. Experts often differ. But this we may say, that those who are seeking for knowledge on any of the subjects dealt with will find the results of many years' experience written by men who are in every case adepts at the Sport or Pastime of which they write. It is to point the way to success to those who are ignorant of the sciences they aspire to master, and who have no friend to help or coach them, that these volumes are written.

To those who have worked hard to place simply and clearly before the reader that which he will find within, the best thanks of the Editor are due. That it has been no slight labour to supervise all that has been written he must acknowledge; but it has been a labour of love, and very much lightened by the courtesy of the Publisher, by the unflinching, indefatigable assistance of the SubEditor, and by the intelligent and able arrangement of each subject by the various writers, who are so thoroughly masters of the subjects of which they treat. The reward we all hope to reap is that our work may prove useful to this and future generations. 


\section{AUTHOR'S PREFACE.}

Tire Author gratefully acknowledges the assistance of several friends. $\mathrm{He}$ is especially indebted to $\mathrm{Mr}$ WALter RYE for antiquarian information; to the Editors of The Sporting Life for permitting him access to a file of the Sporting Magazine and of old Bell's; to Messrs C. W. Foley, J. H. Farmer, and J. E. VinCENT, from whom he derives his accounts of Eton, Harrow, and Winchester football respectively, and to his brother, Mr JoHn Silearman, for much help.

A word must be added about the illustrations to this volume. Many are engraved from instantaneous photographs, taken by Mr. G. Mitchell, who attended some of the chief football matches and athletic gatherings of the season. The veritable attitude and action of the men have thus been obtained. So far as the author is aware, the present is the first occasion in which the newest development of photography has been utilised for illustrating a work upon athletic sports.

The Temple: October 1887. 



\section{O N T E N T S.}

\section{ATHLETICS.}

CHAPTER PAGE

I. The History of Athletic Sports in England 3

II. A Modern Championship Meeting . . . 54

III. Running AND Runners . . . . • . 68

IV. Walking and Walkers . • . • . I26

V. Jumping, Weight-Putting, etc. • • • . 143

VI. TRAINING • . . . . . . . . 170

ViI. Athletic Meetings . • • . . . . 186

VIII. Athletic Government . • • . • . 224

Paper-Chasing and Cross-Country Running • 255

FOOTBALL.

I. HISTORY • . . . . . . . 269

II. The School Games : • . . . . . 303

III. The Rugbi Union Game • • . • 318

IV. The Association Game • . . . . 358

V. Football as a Sport . . . . . . 388

VI. Football in the United States . • . . 395

Vil. Australian Football . . . . • 414

APPEndix • • • • • • • • • 437

INDEX • • • • • • • • • • $45 \mathrm{I}$ 



\section{ILLUSTRATIONS.}

(Engraved on wood by J. Cooper and G. Pearson.)

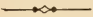

FULL-PAGE ILLUSTRATIONS.

ARTIST

The Dribbling Game . . From a photograph . Frontispiece A HuRdLe Race . . . " ", . To face p. 120 A Grass Course . . . " , " . , 186 The Hounds . . . . Stanley Berkeley . , , 262 The Rugby Union Game . From a photograph . " " 318 The Association Game . . ", " . " , 358

\section{ILLUSTRATIONS IN TEXT.} A RACE (Vignette on Title Page) . . . From a photografh

A Steeplechase - . . . . . Stanley Berkeley . xv Harry VIII. Throwing the Hammer . , , , 3 Sports in time of Queen Elizabeth • , , , , I4 Cripples' Race . • - . . . , , , I7 A Bootless EFFort . . . . . . , , , , . Ig $\left.\begin{array}{cl}\text { Race Between Elderly Fat MAN } \\ \text { AND MAN With Jockey ON Back }\end{array}\right\} \quad, \quad, \quad, 29$ Man on Stilts v. MAN RunNing . . , , , 3 I

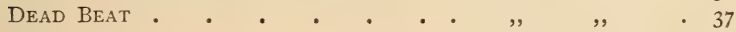
Ready to Start . . . . From a photograph . 69 Starting-Old Style . . . . (From photographs 75

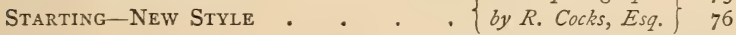
STARTED . . . . . From a photograph . 77 
ARTIST PAGE SPRINTING OF TO-DAY . . . . From a photograph .83 A Vert Fast Sprinter . . . . , , , . 93 In Condition . . . . . . Stanley Berkeley . 97 OUt of Condition . . . . . . , , , , 99 Steeplechase-WATER-JUmp - . . From a photograph . II7 WALKING RACE . . . . . . , , , , . I 27

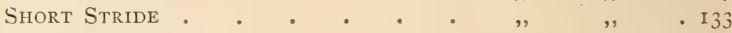

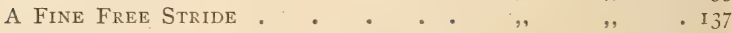

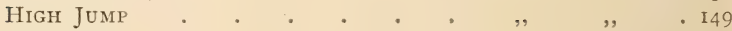

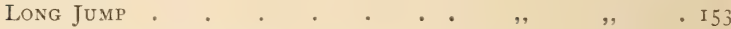
Putting the Shot-First Position . " , Putting ine Shot-Second Position . , , , 157 THROWING HAMMER . . . . . , , , , . I6 I

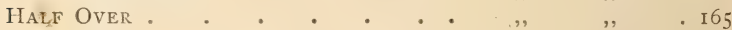

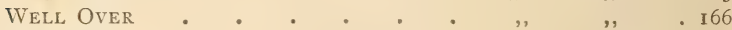

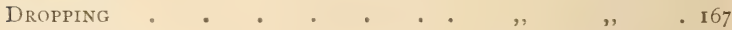

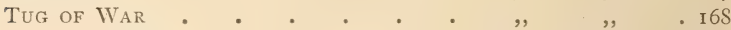
'No Smoking' . . . . . . Stanley Berkeley . I 79

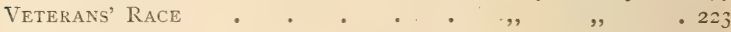
The Hares . . . . . . . , , . , , 255 'Collared' . . . . . . . . . . . . . . . 269 Rugbi Football . . . . . . From a photograph . 319 'A FAST FORINARD GAME' . . . " , , " . 326

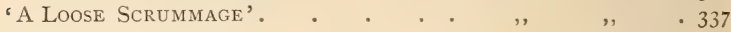

Three-QuARTER Back : 'AN ANxious ? ,, ,, 347

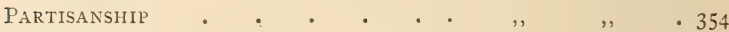

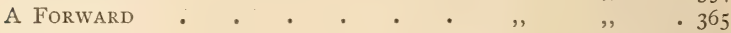

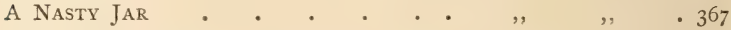

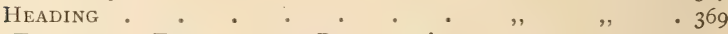
'To keep an Eye upon the Prowlers' • , , 37 I

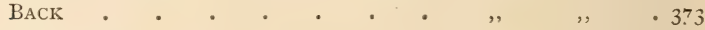

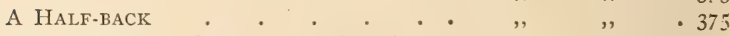
Defending the Goal : . . . " , " , 377

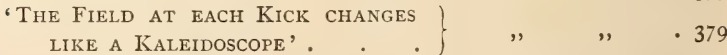
An American Player . . . . " " , . 400 Plan of American Football Field. . . . . 40 i A Good Scrimmage . . . . . From a photograph . 408 SNAP-BACK AND QUARTER-BACK . . . ", , . 409 Plan of Australian Football Field . . • • . 422 


\section{INTRODUCTION.}

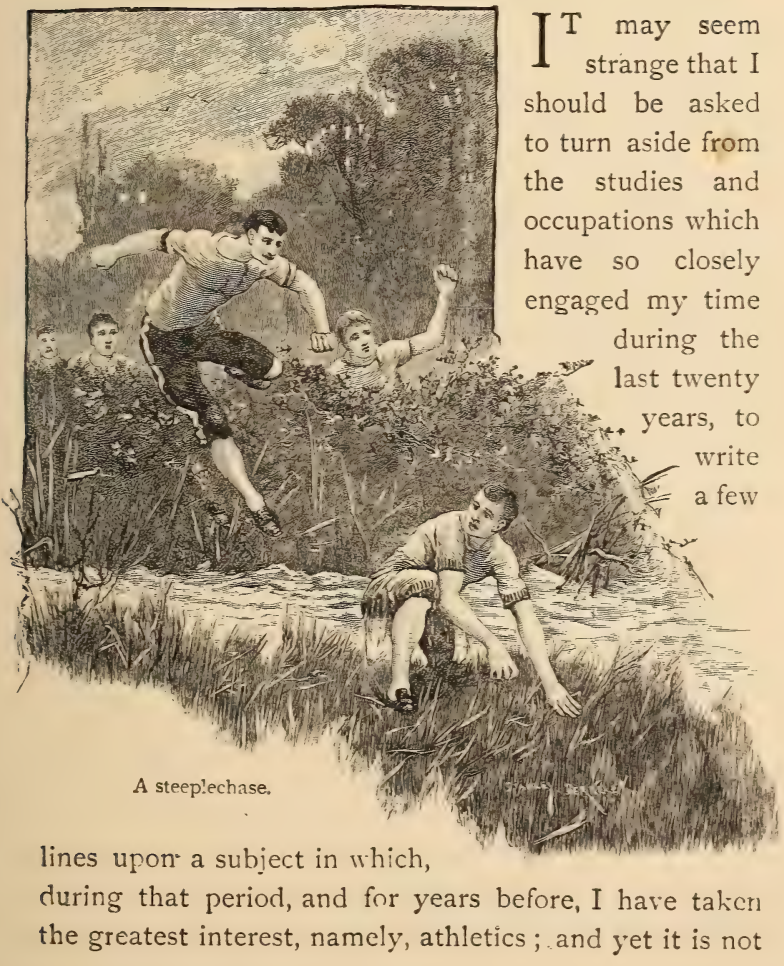


altogether unfitting, inasmuch as I am probably as well qualified as any to speak from personal experience of the advantages which are gained in a sedentary life from the power of practising active exercises. Except cycling and lawn-tennis, both of which have becti practically invented during the last fifteen years, no pursuit has seen so great an advance or revival as athletic sports. It may be, and it probably is, the case (as those who read the pages of this book will learn), that for a great many years prior to the year I 850 athletic sports had been from time to time pursued by both amateurs and professionals, who had with more or less assiduity, according to the particular ability or powers of the competitor, performed before the public; there had been, no doubt, remarkable instances of individual men who possibly had been as great at running, walking, jumping, and swimming as those who have excelled in modern times; but it is perfectly certain that prior to the date last mentioned-I mean the year 1850-athletics were not practised as a recognised system of muscular education, nor was there any authentic record of individual performances. I doubt, moreover, whether either times or distances were taken and measured with sufficient accuracy to make the earlier records in any way trustworthy.

Speaking of our Universities, I have seen the foundation of the present prosperous clubs at both Cambridge and Oxford, and, with the exception of the Crick-run at Rugby and the steeplechase at Eton, prior to I850 no public school had any established athletic contest. I do not, however, propose in the few lines which I intend to 
pen to attempt any history of athletic sports ; the following pages will, I am sure, contain records attractive both to the athlete and the public, of those who, in years gone by and down to the present time, have excelled on the road, the turf, and the running-path. I wish for a few moments to regard the subject from the point of view of the consideration of the advantages to be gained in the practice of athletics, and, secondly, to make a few suggestions as to the best mode in which these advan. tages may be increased so as to be of still greater utility and benefit.

We are brought face to face in England, and other populous countries, with the difficult problem which is called into existence by over-population, and the utter absence of space and opportunity for the youth of the present day to find sufficient scope for his energies. The tendency to crowd into the curriculum of both school and college a large and ever-increasing number of subjects has rendered the strain of education far heavier than in times gone by, and this tension will certainly increase.

In old days, when a fair grounding in Greek and Latin, or a moderate knowledge in mathematics, was a sufficient preparation for almost any profession (the brilliant few being left to excel in those subjects by the sheer force of their natural abilities), the culture of the body and the simultaneous development of physical and mental strength were of less importance, or at any rate their value was less recognised. I need scarcely remind those who read these pages that, thirty years ago, it was the exception for a senior wrangler or a senior classic to 
figure in the University boat or the eleven. The names of those few who did excel stand out among their contemporaries, and it was by no means an uncommon experience to find that those who had surpassed in intellectual contests in school and college utterly broke down in their professions in after life. I attribute this in no small degree to the fact that for many boys and men there was scarcely any inducement to develop or use their physical strength, nothing which led them to those pursuits which, without engrossing the mind too much, develop the body gradually and contemporaneously with mental growth. How many a first class man at Oxford, or wrangler or first class classic at Cambridge, could only find exercise in the daily and monotonous grind of an hour or an hour and a half's walk; cricket and boating both taking up too much time, and not unfrequently leading many to expenses which they could ill afford?

I maintain that one great good which has arisen from the stimulus given from the years I 860 to 1870 to athletic sports is the facility which those pursuits afford for the development of physical strength, and the inducement to active exercise offered to men who, either from want of inclination or want of means, would otherwise never have taken any. I have known intimately a great many reading men, who have told me how deeply they regrettcd that there was nothing of the kind in their time, and many others have assured me of the advantages which they have derived from the interest which these pursuits have given to them, and the inducement to take exercises which otherwise they would have wholly neglected. It 
must not be forgotten that more genuine exercise can be got in a shorter space of time from running than probably from any other pursuit, except boxing and gymnastics, with the great advantage of the former over the two latter that the exercise is taken in the open air.

There is, moreover, the great interest which attaches to the contests in other colleges, universities, and clubs, affording an object of attraction at times when it is not necessary for men themselves to compete, and bringing together men who otherwise would remain unknown to one another, whereby acquaintanceships and friendships are formed which are of the greatest value. A very distinguished judge who joined the Inns of Court rifle corps in the earliest days of its existence told me that ho much regretted that there was no rifle corps when he was called to the bar, as he was satisfied that many young men reading for the bar were by such means brought into contact with older members of the profession, whom under ordinary circumstances they would have had no opportunity of meeting.

It is unnecessary here for me to enlarge upon the immense advantage to be gained from the simultaneous development of physical and mental power ; that subject has been so fully treated, and the beneficial results so conclusively demonstrated, by those who have studied the matter from a scientific and medical point of view, particularly in conncction with the Swedish system, that any argument of mine would be out of place. I can only say that I am firmly convinced that the brain is better developed, and is more capable of sustained effort, 
if its growth be accompanied by a proportionate physical development than in the case of the brain over-developed without any corresponding bodily improvement.

I desire here to say a few words upon the subject of the best method of athletic training in schools. I am of course aware that superlative excellence and cases of remarkable prowess are to a great extent inborn-or to put the converse, that some boys and men, however much they practise, will never succeed in reaching the standard readily attained by born athletes. But superlative excellence in special cases is by no means that which is most to be aimed at. Innate talent for any pursuit will as a rule develop itself whatever be its surroundings, but I think at all public schools boys should be taught to run properly. There is as much difference between good running and bad running as there is between good rowing and bad rowing, and the standard of excellence will be certainly increased by a high normal standard among the average boys.

To mention one other point, it will be admitted that no boy is more likely to do harm in a school than the loafer. Ask the masters of any public school what class of boys cause them the most anxiety, or bring the least credit on a school; they will tell you the boys who loaf, and have no zest for play or work.

Numbers of boys are not strong enough to play football, or are not successful at cricket, and cannot afford the expense of racquets. To many of these the incentive to exercise by the prospect of being able to compete in races and other athletic tests is an incalculable bencfit, 
particularly if one or more of the masters, who have often themselves been distinguished in muscular pursuits, superintend and take an interest in their training and practice.

All boys should, in my opinion, be made to take some regular exercise of the kind best suited to them, and in the first instance under regular and careful supervision.

Attention to such a matter as this will prevent boys from being made to play games for which they are not adapted; for instance, very little practice or tuition in running would find out the boys who are unfitted for football or incapable of extreme exertion; and, again, the boys who show a turn of speed in advance of their age will develop more rapidly into high-class performers. I am, however, altogether opposed to any boys being made to race too long distances, particularly game and plucky boys who do not know when they are beaten. I think no boy under fourteen should run a race of greater length than half a mile; he may trot longer distances $s a$ as to strengthen the muscles of the feet, legs, and back, care being taken that he runs throughout as much as possible in good form.

Only those who have had personal experience of results have the slightest idea of the improvement made by a few lessons in the proper style of running, getting well on to the tnes with a springy tread, the hips working freely, the chest out and arms well carried. I am satisfied that the growth of boys is improved, and that their lungs are strengthened, by moderate and judicious coaching.

In strong corroboration of this I would call attention 
to the extraordinary improvement in times and performances which has taken place during the last twenty years. This has, no doubt, been to a certain extent duc to a circumstance to which I have already referred-namely, the inaccuracy of the old records both as to distances and times; but, allowing for unwarranted conclusions bascd on comparison, there can be little doubt that five-andtwenty years ago the number of men who in ordinary condition could run a mile in five minutes was exceedingly few, so much so that anything under five minutes was supposed to be good time for amateurs, whereas at the present time $4 \mathrm{~min}$. $30 \mathrm{sec}$. may be taken to be below the standard of first-class performances, and, as the following pages will show, the mile has been run by undoubted amateurs under $4 \mathrm{~min} .25 \mathrm{sec}$. The inprovement in the quarter-mile is quite as remarkable, although it was more speedily attained, being due to improvement in style. lietween I 865 and 1872 the standard time was reduced from 55 seconds to 50 and $5 \mathrm{I}$; the time of the other distances-as, for instance, half-mile and three mileshas correspondingly improved. In the hurdles it is exceedingly difficult to make out any comparison; nor do I think there has been the same improvement in pace, although the number of first-class performers has increased enormously.

Probably the most remarkable instance is the im. provement in jumping, both in height and length. It is not many years ago that to clear six feet was considered beyond human powers, and to cover $22 \mathrm{ft}$. $6 \mathrm{in}$. and $23 \mathrm{ft}$. little short of an impossibility, and yet both these feats 
have been performed by more than one athlete. I do not wish to close these observations without some refer. ence to such contests as throwing the hammer and putting the weight: in my opinion they are contests which should be encouraged, as they afford scope to those who are unable to compete in running and jumping, and are very valuable for the development of the chest and arms.

The same arguments may also with justice be employed in favour of walking ; and while on the subject of walking, I wish to call particular attention to the extraordinary feats of long-distance walking which have been performed in late years, by which I mean distances of 40 and 50 miles and upwards, which are, in my opinion, of far greater value than the so-called performances of walking eight or more miles in the hour by a mode of progression so nearly resembling a shamble or trot as to defy the most watchful of judges. I have known many instances of development of chest, lungs, and great improvement of general stamina, resulting in a vastly improved constitution, from steady walking of long distances.

I gladly take this opportunity of paying a tribute to the great services rendered to athletic pursuits by the late J. G. Chambers. Esq., of Eton and Cambridge, who for years devoted himself to initiating and maintaining contests of all kinds, and by his untiring energy and foresight did probably more than any one in modern times to maintain and improve the standard of athletics among both amateurs and professionals. 
Before concluding, it is right that I should say one word upon that which may be called the moral aspect of athletics. That their practice tends to encourage self-control, self-reliance, without undue confidence, and a proper appreciation of other men's merits, there can be no doubt ; moreover, they promote that spirit of good-fellowship which enables the beaten man to go up and honestly congratulate the victor who has conquered him; but, beyond this, as I have already said, the contests and gatherings offer the opportunity of making lasting friendships and connections which are often of the greatest value in after life. A reputation once earned by the boy or man in such pursuits follows him to other professions, and has more than once contributed in no small degree to early success in the work of life. To those who in the past or in the present have taken interest in athletic sports, or wish to know their history, or who feel, as I do, that they afford the opportunity of innocent and healthy pleasure, as well as of bodily development, I commend the study of these pages, compiled by one who has ample means of knowledge, and a ripe judgment with which to gauge the accuracy and authenticity of any records of the performances which he describes.

RICHARD E. WEBSTER

Temple: October 1887 . 
A THLETICS 



\section{CHAPTER I.}

THE HISTORY OF ATHLETIC SPORTS IN ENGLAND.

Hanc olim veteres vitam coluere Sabini,

.... sic fortis Etruria crevit

Scilicet et rerum facta est pulcherrima Roma.

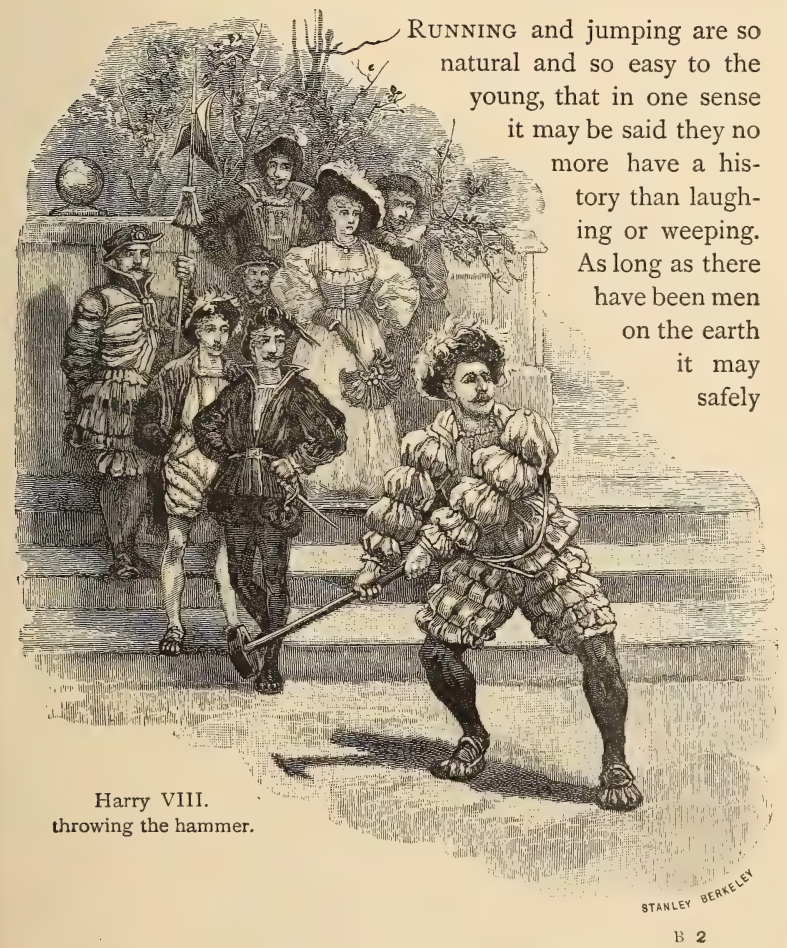


be asserted that there have been running matches; and in every warlike nation feats of strength, speed, and endurance of the body have excited admiration. With but few nations, however, have athletic exercises formed an art and become a feature of national life; and where this has been the case there is a history, and an interesting history, of the practice of feats of strength and speed. To write such a history of English athletic sport is no easy task; for, as far as this writer is aware, it has never been seriously attempted before. The learned Strutt, whose work is such a mine of wealth to sporting antiquarians, contents himself with informing his readers that ' it is needless to assert the antiquity of foot-racing, because it will readily occur to everyone that occasions continually present themselves which call forth the exertions of running. . . O Originally, perhaps, foot-races had no other incitement than emulation, or at best the prospect of a small reward, but in process of time the rewards were magnified, and contests of this kind were instituted as public amusements-the ground marked out and judges appointed to decide upon the fairness of the race and to bestow the reward.' Such an à priori method of writing history will hardly account satisfactorily for the present form of athletic sport in England. The only other writer, as far as we are aware, who has attempted to explain the origin of English athletics to modern readers has given an excellent essay upon Greek athletics, and has then assured us that 'in one respect our position is like that of the Romans. Athletics are not indigenous with us.' It is our object in the present chapter to show with what success we can that competitions in running, jumping, and hurling of heavy weights are not only indigenous to the land, but have been one of the chief characteristics of both town and country life in England as far back as chronicles will reach; and that athletic sports, though they have had their days of waxing and waning, have always been a feature of life in 'Merrie England.'

It is difficult to obtain much information of the sports of 
the people in the middle ages as distinguished from the sports of the nobles. Just as the Roman historian expresses his opinion that the ancient Greeks were no better than the ancient Romans, the latter only suffering from the lack of eloquent chroniclers, so it is probable that the populace produced as good runners as Henry V. and his Court ; but in the days of chivalry the bards only chronicled the feats of persons of quality. The monarch in question 'was so swift a runner that he and two of his lords, without bow or other engine, would take a wild buck in a large park.' Long before his time we know that the youth of London had their summer as well as their winter sports. FitzStephen, the monk of Canterbury, born in London, writes in the reign of Henry II. that the young Londoners had open spaces allotted to them near the City, where they practised, amongst other exercises, 'leaping, wrestling, casting of the stone, and playing with the ball.' No mention is made of running, but we can hardly imagine that leaping matches would be known and not running matches. FitzStephen is no mean observer of sport, and his description of 'sliding' on the ice in winter is almost as minute as that of Dickens in 'Pickwick.' The knightly youths, however, were taught to run, jump, and wrestle in the days of chivalry, as well as the citizens; but this was, of course, chiefly as a military training, the feats by which they earned the greatest glory, as well as the smiles of the fair, being performed on horseback, as befitted persons of equestrian rank. In the romance quoted by Strutt, called 'The Knight of the Swan,' a certain duchess, Ydain by name, brought up her sons in 'all maner of good operacyons, vertues and maners : and when in their adolescence they were somewhat comen to the age of strength they were taught to runne, to just, and to wrestle.' Again, in the poem entitled 'Knyghthode and Batayle,' written early in the fifteenth century, we find :

In rennynge the exercise is good also

To smyte, first in fight and also whenne

To take a place our foemen will forerenne. 
And for to lepe a dike is also good,

For mightily what man may renne and lepe

May well devict and safe 'is party kepe.

In another romance also quoted by Strutt, that of 'The Three Kings' Sons,' it is said of a certain knight, 'The king for to assaie him made justes and turnies, and no man did so well as he in runnyng, playing at the pame, shotyng, and castyng of the barre, ne found he his maister.'

The running and weight-putting, to which the townsmen of London were so much addicted, were not always favoured by the kings of England, who were afraid that the practice of archery might fall into disuse ; and we find Edward III. especially prohibiting weight-putting by statute; but the statute, although never repealed, appears to have been more honoureci in the breach than in the observance, for at the time of the decline of chivalry ' casting of the barre' was still a common pursuit. Henry VIII. certainly in one respect chose his amusements better than some of his predecessors; while Edward II. found his favourite amusement in 'cross and pile' (or, as it is now known, 'pitch and toss'), the much-married monarch, in his early days, was greatly devoted to this 'casting of the barre.' Even after his accession to the throne, his daily amusements embraced weightputting, dancing, tilting, leaping, and running. The example of a monarch has, it is well known, a most persuasive effect, and hence it is not astonishing to find from a contemporary writer (Wilson) that all active sports, both on horseback and on foot, including leaping, running, and bar-throwing, became fashionable amusements.

In the succeeding age, however, we begin to find foot exercises less thought of by the upper classes. Richard Pace, the secretary to King Henry VIII., could advise noblemen's sons to pursue their sports, 'and leave study and learning to the children of meaner people;' but although his advice was, no doubt, followed by many of his readers, the 'new learning' gradually took hold of the upper classes, and cultivated minds began to be rather contemptuous of rough bodily exercises. 
Still, throughout the reign of Henry VIII. gentlemen were accustomed to write in favour of pedestrian as well as of equestrian exercises. Sir William Forest, in his 'Poesye of Princelye Practice,' holds that a prince should

In featis of maistries bestowe some diligence.

Too ryde, runne, lepe, or caste by violence

Stone, barre or plummett, or such other thinge,

It not refuseth any prince or kynge.

About the same time that worthy knight, Sir Thomas Elyot, wrote the manual of education for a gentleman, 'The Boke called the Governour,' from which many succeeding writers borrowed largely without any acknowledgment. Sir Thomas, who was in many senses before his time, expresses himself strongly against the system of unnecessary flogging and in favour of a judicious mixture of athletics and learning for a boy. 'A discrete master,' he says, 'may with as much or more ease both to himself and his scholler lead him to play at tennis or shoote.' In the sixteenth chapter of his work he speaks of 'Sundrye fourmes of exercise necessarye for a gentilman,' and there are, he says, 'some exercises which with health join commoditie :' 'Touching such exercises as may be used within the house or in the shadowe, such as deambulations, labouryng with poyses made of ledde, lifting and throwing the heavy stone or barre, playing at tennis and diverse semblable exercises I will for this time pass over,' and he exhorts his readers to study Galen De Sanitate tuendâ upon the subject. What follows about running and jumping is curious, as it makes it plain that Sir Thomas knew that there were some people who decried these sports as being vulgar. He says, 'Rennyng is bothe a good exercise and a laudable solace' (we presume by solace he means pastime, and not consolation in the sense in which a certain well-known athlete of modern times stated that, whenever he was suffering from disappointed love, he took a walking tour to work it off). He defends running by the argumentum ad hominem, showing that Achilles, Alexander, 
and others were famous runners, and that Epaminundas not only ran but jumped every morning before breakfast for health and amusement. He goes on : 'Nedes must rennynge be taken for a laudable exercise sens one of the mooste noble capitaynes of all the Romans took his name from it' (meaning Papirius Cursor). In this argument he seems to us to be meeting the scholars of the 'new learning,' who, while they studied' the classics and classical models, were irreverent enough to decry athletics. That they did so there is no doubt from other sources. Roger Ascham, in his great book, 'Toxophilus,' says roundly that 'running, leaping, and quoiting be too vile for scholars.'

However, although in the sixteenth century opinions were divided as to whether running, leaping, and bar-casting were genteel or not, there is no doubt whatever that the common people were little affected by this, and went on with their amusements as before. A very few years after 'The Boke called the Governour' was published, we learn from one of the Harleian MSS. that as the great foothall match which was usually played upon the Roodee at Chester became productive of much inconvenience, it was decided to substitute a footrace; and accordingly, instead of the shoemakers presenting the drapers, ' in the presence of the Mayor at the Cross on the Rodehee,' with a football of the 'value of three shillings and fourpence or above, by consent of all parties concerned the ball was changed into six glayves of silver of the like value, as a reward for the best runner that day upon the aforesaid Rodehee.' This affords a curious picture of sixteenth-century manners. Instead of the annual football match, 'Shoemakers v. Drapers,' the 'Championship of Chester' footrace is substituted.

Shakespeare, no doubt, saw some running matches both amongst gentle and simple folk. His own experiences of all kinds are reproduced in his pages, and 'private matches' and public competitions are alike mentioned by him. In the First Part of 'Henry IV.,' Act II., Scene 4, we have Falstaff offering 
to run Poins: 'I could give a thousand pounds I could run as fast as thou canst,' says the stout knight. In the Third Part of 'Henry VI.' Act II., Scene 3, we have another allusion to foot-racing:

Forspent with toil as runners with a race,

I lay me down a little while to breathe.

We are, however, anticipating, for there is evidence nearly a century before Shakespeare of the fondness of the common people for athletic sports. Strutt quotes the following lines from Barclay's 'Eclogues,' first published in I508. A shepherd says :

\section{I can both hurle and sling,}

I runne, I wrestle, I can well throwe the barre, No shepherd throweth the axeltree so farre; If I were merry, I could well leape and spring, I were a man mete to serve a prince or king.

A very curious piece of information given in Russell's 'History of Guildford' has a bearing on the sports of the sixteenth century. In a certain law case to decide in $\mathrm{I}_{597}$ the title to a field near the town, one John Durich, gentleman, figuring as 'the most ancient inhabitant,' who is common in such trials, said that he had known the ground for fifty years, and when a scholar at the Free School did 'runne there and play at cricket.' The most admirable description, however, of the popular sports of the sixteenth century is that often quoted from, the work of the younger Randel Holme or Holmes, one of the wandering minstrels and merry-makers of the North country. Speaking, it is believed, of the men of Lancashire, in lines which show him to be better as a sportsman than as a poet, he says :

Any they dare challenge for to throw the sledge,

To jump or leape over a ditch or hedge,

To wrastle, play at stoole-ball or to runne,

To pitche the barre or to shoote of a gunne,

5 To play at loggets, nine holes or ten pinnes,

To trie it out at football by the shinnes;

At ticke-tacke, saw nody, maw and ruffe,

At hot cockles, leap frogge and blind man's buffe, 
To drink the halfer pottes or deale at the whole canne,

Io To play at chesse or pue or inkehorne,

To daunce the morris, play at barley breake,

At al exploites a man can think or speake,

At shove-groate, venter point and cross and pile,

At 'beshrew him that's the last at any stile,'

I5 At leapinge over a Christmas bonfire,

Or at the drawing dame out of the myre,

At shoote-cocke, Gregory, stoolball and what not,

Pick point, toppe and scourge to make him holt.

It would require the length of an essay to explain all the above sports, many of which are still familiar under different names. 'Stool-ball ' is the rudimentary form of cricket, the one player defending the stool while the other threw the ball at it. Probably, however, in one of the two lines in which 'stool-ball' is mentioned, it is a mistake for 'stow-ball' or golf. It is evident, therefore, that in the sixteenth century football and many other well-known pastimes were common. But for our purposes the verses are more useful as showing how the different forms of athletic sport were beginning to be systematised. In line $\mathbf{I}$ we have Throwing the Hammer, in line 2 the Long Jump and the High Jump, in line 3 running, and in line 4 'pitching' or 'putting' the weight, as distinct from 'throwing' the hammer with a sling round the head. Line I4 also describes a very curious kind of sprint-racing, which, we believe, was also practised by Roman schoolboys ('occupet extremum scabies'). A party of lads are together, and one suddenly starts off without any warning to run to a mark, which he names; the others join in and race to the mark. The last in pays a forfeit or gets a kick, as the case may be. It is one of the best tests of speed and quickness in starting, and is much like the common practice of modern sprinters of 'taking each other on at starts,' one starting when he likes and the other following him as best he can.

It is clear enough, then, that the common people had their regular athletic sports in the Elizabethan age, but that at this 
time people of fashion took little part in them. Pageants, processions, and masques were the amusements of Elizabeth's court, or bear-baitings or bull-baitings, and last, but not least, dramatic exhibitions. Nowhere in Robert Laneham's long account of the revels at Kenilworth, nor in Nichol's account of the 'Progresses of Queen Elizabeth,' are there, as far as we are aware, any allusions to pedestrian sports. In the succeeding reign the fashion turned again, as we shall presently see. Curiously enough, however, our best notion of the universal popularity amongst the lower classes of different forms of athletic sport is gathered from the Puritan writers, who were the bitter opponents of such pastimes. The Puritans, however, at the first did not oppose the sports themselves so much as the occasions upon which they were practised. What these occasions were is abundantly clear. The ordinary times for running, leaping, football and such like pastimes were Sundays and Church festivals, and the usual arena the churchyard; the greater and more uproarious festivities took place on the last days of the country fairs. The fairs, as being the more important, perhaps deserve attention first. The greater part of the trading of the country in the Elizabethan age was conducted by means of the fairs; horses, cattle, and all necessaries for the season were bought at them. In Harrison's 'Description of England,' published at this time, a list is given of the 'more important' fairs, which mentions three or four hundred of these gatherings. It is scarcely to be wondered at, by those who know the peculiar faculty of the Englishman to combine business with sport, that when the business was over, or even before, sporting competitions should follow, the whole affair concluding, as the Puritan writers assert (and probably with some truth), with general orgies of intoxication and riot. Of the nature of the sports at these fairs, which, doubtless, continued in much the same form as long as the fairs themselves were held, we shall have to give some further account afterwards, but running, jumping, and weight-putting seem to have been invariable features of the programme. The 
Puritans, however, did their best to suppress all these sports entirely. John Northbrooke, writing as early as 1577 , and demanding a Government supervision of fairs, alludes to the festivals in the following complimentary terms: 'There would not be so many loytering idle persons, ruffians, blasphemers, swingebucklers, tossepottes, etc. etc.' (there is a crescendo of abuse, and the extract must of necessity be Bowdlerised) 'if these dunghills and filth in commonweales were removed.' Stubbs, another Puritan writer, the author of the 'Anatomie of Abuses,' expresses himself against the fairs in equally strong terms. His attitude to sport in general may be gathered from the fact of his speaking of 'tennise, bowles, and such like fooleries.' If the fairs, however, were 'dunghills,' the practice of sports at the wakes, or Church festivals, and on ordinary Sundays, was still more shocking to the reformers. In 1570 one of them paraphrased into English, and dedicated to Queen Elizabeth, the foreign work of one Kirchmaier, who, as he wrote in Latin, adopted the name of Naogeorgus. The translator, Barnabe Googe, says of the people on Sundays :

Now when their dinner once is done, and that they well have fed, To play they go, to casting of the stone, to runne or shoote,

To toss the light and windy ball aloft with harde or foote.

Some others trie their skill in gonnes, some wrastell all the day And some to schoole of fence do goe to gaze upon the play.

About the same time Thomas Cartwright, in his admonition to Parliament, asserts that the parson is as bad as his flock. 'He pusheth it over (the service) as fast as he can galloppe: for either he hath two places to serve, or there are some games to be playde in the afternoon.' However, we need say no more as to the Puritan efforts to suppress athletic sports. The merits of the Puritans can hardly obtain a fair hearing in a history of sport ; they, no doubt, succeeded for a time in discountenancing it, and in putting down its practice very effectually upon Sundays, but when the Puritan government fell, its fall, to paraphrase Ridley's words, 'lighted such a fire' of sporting enthusiasm as has never yet been extinguished in England. 
However, under the first two Stuart kings both the upper classes and such of the lower classes as were not converted to Puritanism showed an undiminished vigour for athletic sports. Peacham, who published his 'Compleat Gentleman' in I622, gives a list of the sports which a gentleman should practise. First of all comes, of course, riding. It is the 'great and most noble' sport, for 'kings have always delighted to ride.' Throwing the hammer and wrestling are low-class sports, 'not so well beseeming nobility but rather soldiers in a camp;' 'neither,' he goes on, 'have I read or heard of any prince or general commended for wrestling save Epaminondas and Achmat, the last emperor of Turkey.' This worthy, it appears, made a 'record' for hammer-throwing, and 'there was reared in Constantinople, for one extraordinary cast which none could come near, two great pillars of marble.' Our modern 'recordbreakers' receive a medal sometimes, but the event is not recorded upon marble pillars, because, perhaps, the recordbreakers are not emperors. Peacham, however, thinks highly of running, and in its praise he gives a shameful plagiarism from the book of Sir Thomas Elyot, to which we have referred before. Running is good because Achilles and Alexander were runners, and jumping is good because Epaminondas and Alexander jumped before breakfast. However, he gives his own opinion that these exercises are 'commendable.' Whatever may have been the merits or demerits of the Stuarts, there can be no question that sportsmen owe a debt of gratitude to them. James I., though he was not an athlete himself, and though he objected to football, yet gave a general encouragement to sports, both by precept in his work, 'Basilikon Doron,' and by practice in frequently acting as referee or judge. The following extract from the 'Basilikon Doron,' which was a work of precepts to his son, is interesting: 'And amongst all unnecessaire things which are lawful and expedient I think exercises of the body most commendable to be used by a young prince. For albeit I grant it to be most requisite for a king to exercise bis engine, which surely with idleness will 
rouste and become blunt, yet certainly bodily exercises are very commendable as well for baunishing idleness as for making the body able and durable for travell.' ' The exercises that I would have you use, although but moderately, not making a craft of them' (which means, we suppose, that a prince should be an amateur, not a 'pro '), ' are running, leaping, wrestling, fencing, dancing, and playing at the caitch, or tennise, archerie, pallemalle, and such like other fair and pleasant field games.' Both Peacham and his Majesty seem to despise hammer-throwing, the former expressing his dislike, and the latter saying nothing

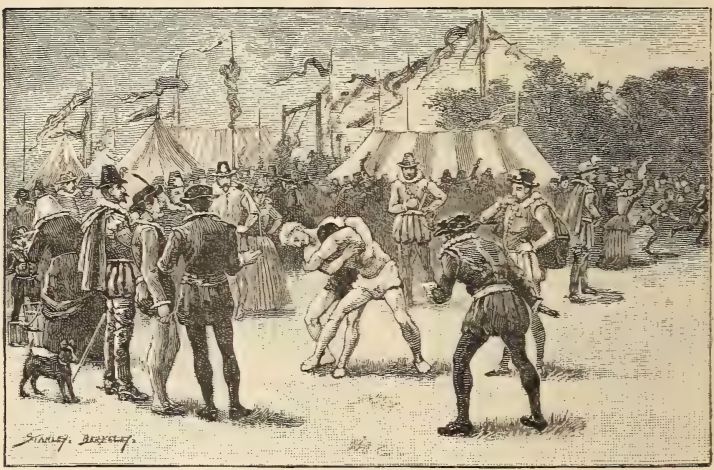

Sports in time of Queen Elizabeth.

of it, from which it appears that fashion had changed since the time of Henry VIII.

Although we can hardly fancy James I. running or jumping, there is little doubt that athletic skill was honoured in his Court. In Arthur IVilson's life of James I., published in I653, we hear of the royal favourite, the Duke of Buckingham, that 'no man dances better; no man runs or jumps better.' 'Indeed,' remarks the sarcastic chronicler, 'he jumps higher than ever Englishman did in so short a time, from a private gentleman to 
a dukedom.' Another chronicler mentions the duke's fame as a 'leper,' which may or may not be another jest. What, however, is more interesting is the knowledge that not only the Court but the people at this time went on with their athletic matches in spite of Puritan opposition. From the 'Annals of King James and King Charles,' published in I68I, we glean the following. As in the case of some of the preceding extracts, the sense is more obvious than the grammar is correct. 'The Reformers,' says the annalist, 'took exception against the people's lawful pleasures and holidays ; and at last against all sports and publick pastimes, exercises innocent and harmless, such were leaping, dancing, running, or any mastery for to goal or prize, May-poles or Church ales as deboshed idle persons. In some of these pastimes several counties excelled, and to entertain community with their mirth the Court progresses took delight to judge of their wagers on their journeys to Scotland, which the people observing took occasion themselves to petition the King for leave to be merry.' The result of this petition was the issue by James I. of the well-known 'Book of Sports' in I6I 7, by which the people were permitted to have certain sports upon Sundays after church. The edict provoked little opposition at this date, but when it was republished by Charles I., in the eighth year of his reign, it formed one of the chief causes of complaint brought against him by the Puritan party. All the world knows that not long afterwards the Puritans proved stronger in the field; but we have something more than a suspicion that Cromwell's Ironsides must have been brought up in the national athletic sports, or they would not have displayed such skill and endurance. Indeed, their complicity in such criminal sports is rendered highly suspicious from the fact that a round cropped head is to this day the outward and visible sign of a pugilist or a pedestrian.

Before we deal with the sporting period of the Restoration, however, we must not omit to mention the account given of the common sports of the earlier part of the sixteenth century 
by Burton, the author of the 'Anatomy of Melancholy.' Burton's book was not published until 1660 ; but he had then been dead twenty years, and had spent the twenty years or so previous to his death in compiling the work. If report be true, during the composition of the celebrated work he became so melancholy himself that nothing could extort a smile from him but listening to the ribaldry of the bargemen at Folly Lock, at Oxford; this specific never failed, it is said, to clear away his sadness for some time. His disposition, however, did not prevent his being a very keen observer of the country sports. $\mathrm{He}$ points out clearly the pastimes both of the gentry and of the people: 'Ringing, bowling, shooting, playing with keel-pins, tronks, coits, pitching of bars, hurling, wrestling, leaping, running, fencing, mustering, swimming, playing with wasters, foils, footballs, balowns, running at the quintain, and the like, are common recreations of the country folks; riding of great horses, running at rings, tilts and tournaments, horse-races and wild-goose chases, are disports of greater men, and good in themselves, though many gentlemen by such means gallop quite out of their fortunes.' He goes on to say that the country recreations take place at May-games, feasts, fairs, and wakes. This extract, backed by those we have already given, shows conclusively the universal prevalence of athletic sports in the early part of the seventeenth century.

That athletic feats were performed even under the Puritan government would seem to be the case if any reliance can be placed on the following piece of information, which is stated, in the 'Gentleman's Magazine' of I797, to be taken from a contemporary record. The whole account, however, is so obviously absurd, that were it not amusing it could hardly deserve for any other reason to find a place in an historical chapter. 'A butcher of Croydon' (says No. I47 of the 'Weekly Intelligencer'), 'on December I, 1653, ran twenty miles, from St. Albans to London, in less than an hour and a half, and the last four miles so gently that he seemed to meditate, and not to ensult on the conquest, but did make it rather a recreation than 
a race.' At the present the best known record for twenty miles on a cinder path is I hour $5^{2} \mathrm{~min} .51 \frac{1}{5} \mathrm{sec}$.

With the Restoration, and the revulsion against Puritanism which led to the Restoration, came a great burst of athletic enthusiasm. Not only were the May-poles set up again, as every schoolboy knows, but the footballs were brought out once

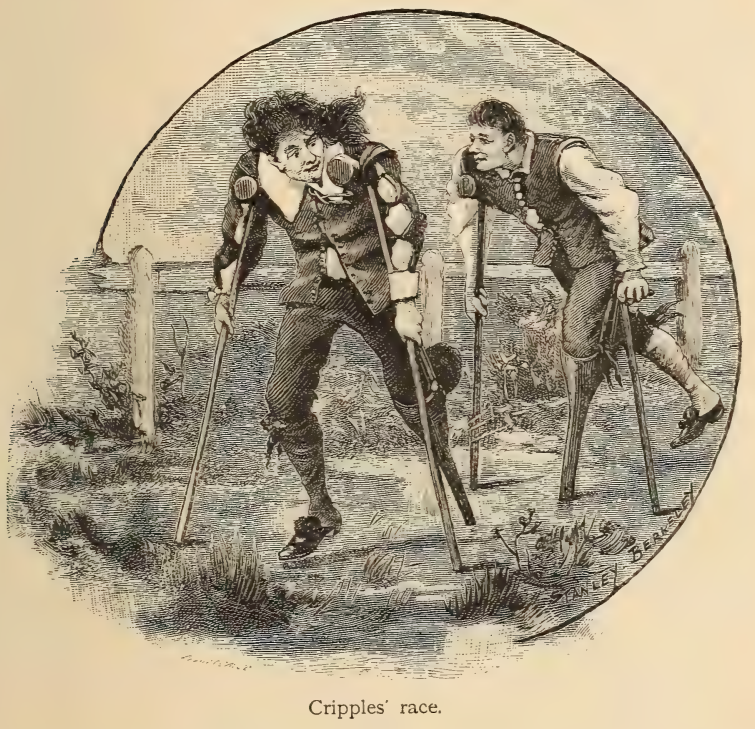

more into the streets and fields ; the decision of pedestrian contests also became frequent, and attracted much popular favour. Indeed, one may almost say that from the reign of Charles II. to the present time a complete and continuous history of pedestrianism could be obtained. So great was the relief in being able to resume the popular sports that even cripples took to foot-races. In the second series of the 'Loyal Protestant' we 
hear of a foot-race between two lame men, on Newmarket Heath, in the presence of the king himself. 'At 3 of the clock in the afternoon there was a foot-race between 2 cripples, each having a wooden leg. They started fair' (a fact which even then seems to have deserved chronicling amongst pedestrians) ' and hobbled a good pace, which caused great admiration and laughter among the beholders; but the tallest of the two won by 2 or 3 yards.' However, there were plenty of contests more interesting than this, and Pepys makes frequent reference to them. On August 10, I660, the diarist makes an entry : 'With Mr. Moore and Creed to Hide Park by coach, and saw a fine foot-race three times round the Park between an Irishman and Crew, that was once my Lord Claypoole's footman.' On July 30 , I663, there is another entry which is even more significant of the popularity of foot-racing: "The towne talk this day is of nothing but the great foot-race run this day on Banstead Downes, between Lee, the Duke of Richmond's footman, and a tyler, a famous runner. And Lee hath beat him; though the king and Duke of York, and all men almost, did bet three to four to one upon the tyler's head.' One cannot suppress the thought when hearing of such an 'upsetting of a pot,' and knowing of the wiles of professional sportsmen, that the 'tyler' upon this occasion found it more lucrative to lose than to win. Not only, however, were the 'professionals' busy with running at this time, but the amateurs were also to the fore. Two noblemen, my lords of Castlehaven and Arran (a son of my lord of Ormond's), rivalled the exploit of Henry V., and 'they two alone did run down and kill a stoute bucke in St. James's Parke.' This was for a wager, and came off in the presence of the king. These two, however, were not the only athletic noblemen. Pepys says of the Duke of Monmouth that 'he is the most skittish leaping gallant that ever I saw; always in action, vaulting or leaping or clambering.' Macaulay, in the second chapter of his 'History,' has given the same picture of him: 'He mingled in every rustic sport, wrestled, played at quarter-staff, and won foot-races in his boots against fleet 
runners in shoes.' Again one is tempted to make the reflection that in those days it was not 'good form' to beat a royal duke; for it is hardly credible that a man in jack-boots should be able to beat a 'crack' suitably attired. We know from Pepys that the courtiers played in this way at tennis with their monarch; and the old diarist, who says Charles was but a moderate player, calls their conduct 'beastlie.' This rough-andready way of handicapping by the weight of the boots seems long to have been popular. Most readers will recollect the

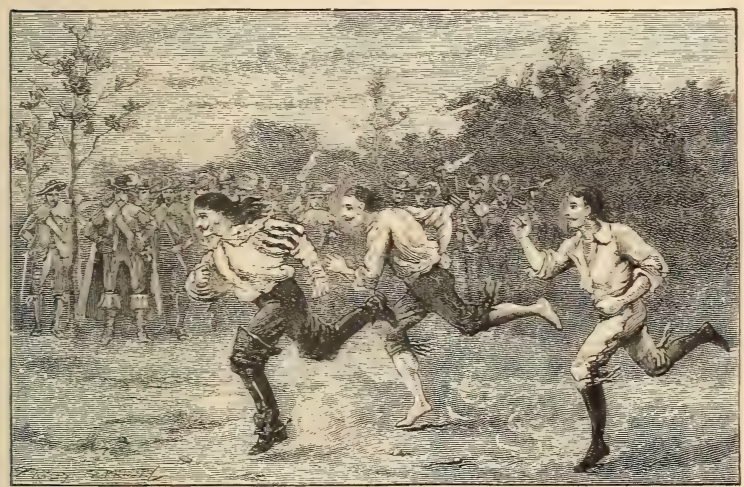

A bootless effort.

foot-race in 'Humphry Clinker' between the lean author and the fat publisher for a bowl of punch. The former, as a handicap, borrows a great pair of riding-boots from his antagonist, and after a close race, when the publisher (running in his stockings) is getting 'blown,' the impecunious author runs off with the boots on his feet, leaving only a pair of ragged shoes behind, and is seen no more. Monmouth, at any rate, never risked such a catastrophe.

No doubt it was about this time that the growth of a regular 
professional class of pedestrians was encouraged by the general custom of the fashionable gentlemen of the period who kept 'footmen' or 'running footmen' in their service. When gentlemen took to having town and country houses as well, and travelled about the abominable roads of the period, a running footman could travel much faster than the family coach, and could even go further in a day than a man on horseback. It is small wonder that, in an age given up to betting, matches should have been made by gentlemen between their footmen, and the footman of the period was often a professional pedestrian kept for the purpose. In any case a strong runner would easily find a footman's place, and his regular business of carrying messages on foot, or travelling in front of the family coach to make arrangements for the journey, would keep him in good fettle for such matches as his master might make for him. The good roads of the end of last century began to put an end to the running footman, and the railway system has completed his downfall; as a rule there is little in the footman of the present day to suggest that the original ancestor of the type performed marvellous pedestrian feats. A curious story which is told of the celebrated 'Old Q.' shows how a good runner could find his running powers available for procuring him service in a family. 'Old Q.' used to engage his footmen by a species of competitive examination. Every candidate for a vacancy was rigged out in the footman's uniform and given the regular staff to carry, and then had to 'show his paces' by running up and down in front of the house. One abominably hot day 'Old Q.' reclined on a balcony, and a candidate was running so well that the nobleman made him go on running and running in the heat for the pleasure of looking at him. Finally he shouted to him from the balcony, 'You will do for me.' 'Yes,' said the man, who had by this time resolved not to take service with such a master, 'and these things' (pointing to the gold-laced uniform) ' will do for me,' whereupon he ran off with them, and was quite a good enough runner to outstrip pursuit.

From the time, therefore, of the rise of running footmen 
we find a regular line of professional runners, some in and some out of service; and accounts of the most important matches between the more famous of them are to be gathered from many contemporary records, while more occasionally one hears of the amateurs - that is, of gentlemen who back themselves to run against time or against each other for a wager. From the 'Luttrell Papers' it appears that in I69o 'Mr. Peregrine Bertie, son to the late Earl of Lindsey, upon a wager, ran the Mall in St. James's Park eleven times in less than an hour.' In the same records for the year 1699 there are several curious entries. Mention is made of William Joyce, the Kentish strong man, who pulled over a dray-horse in a tug-of-war, and could lift $20 \mathrm{cwt}$. He performed at the playhouse in Dorset Garden, the price of admission being, boxes ros. and pit 5 s., from which he must have amassed something considerable. Another entry is also remarkable: a 'sporting man' was fined $9 l .45$. for swearing in the space of five hours. This the writer seems to consider a 'record' in the way of swearing.

One of the most graphic descriptions of a foot-race between two pedestrians, who were also 'running footmen,' is given in the diary of Sir Erasmus Phillips, who was an undergraduate at Oxford in the year I720. The extract (which we gather from a correspondent to 'Notes and Queries') is as follows: 'Rode out to Woodstock : dined at the Bear (2s. $6 d$.). In the evening rode to Woodstock Park, where saw a foot-race between Groves (Duke of Wharton's running footman) and Phillips (Mr. Diston's). My namesake ran the four miles round the course in $18 \mathrm{~min}$. and won the race, and thereby his master Ioool., the sum Groves and he started for. On this occasion there was a most prodigious concourse of people.' The alleged time is, of course, absurd, and shows that the distance cannot have been the full four miles, or that there was some other error in calculation; but the concourse of people to such an exceedingly 'out of the way' place as Woodstock is remarkable as showing the popular interest taken in the race.

But before we settle down to give any chronological sketch 
of the sport of pedestrianism and its regular paid exponents, it may be advisable to turn aside for the present, to show how far the nation still continued to indulge in running, jumping, and weight-throwing at country fairs and festivals. The Puritans had apparently succeeded in putting a stop to Sunday athletic meetings, but at the fairs and wakes the same sports went on as long as these fairs had any existence ; while many of them, indeed, continued in one shape or another until they were replaced by the athletic meeting which is now almost invariably an annual affair in every country town. We have seen that, up to the time of Burton, the old country sports flourished with undiminished vigour. It is abundantly clear that they survived the Rebellion both in town and country. Stow, in his 'Survey of London,' published in I69o, after quoting FitzStephen, says that the exercises mentioned by him have 'lasted to our time.' Strype, who published in I 720 another edition of Stow's Survey, mentions 'pitching the bar' amongst the pursuits of the lower classes of his day in London; while a later writer, Maitland, in his 'History of London,' published in r 739, also describes footraces and leaping matches amongst the amusements of the lower classes. A paper in the 'Spectator' tells the same tale as Strype and Maitland - that by the beginning of the eighteenth century athletic pastimes were considered low-class sports. In No. I6I of the second volume of the 'Spectator,' Addison wrote a paper, professing to come from a country correspondent in the West of England, describing a 'Country Wake, which in most parts of England is the ere-feast of the Dedication of our Churches.' As a matter of fact, Addison is known to have been describing a festival which he had seen at Bath. The green, he says, was covered with a promiscuous multitude of all ages and both sexes. 'The whole company were in their holiday clothes, and divided into several parties, all of them endeavouring to show themselves in those exercises wherein they excelled.' There was in one place a ring of cudgel-players, in another a football match, in another a ring of wrestlers. The prize for the winners of these competitions was a hat, "which is always 
hung up by the person who gets it in one of the most conspicuous parts of the house, and looked upon by the whole family as something redounding much more to their honour than a coat-of-arms.' One young fellow, who 'carried an Air of Importance in his looks,' appeared to have a reason for his pride, for 'he and his ancestors had won so many hats that his parlour looked like a haberdasher's shop.' The young maids also, it seems, took part in the diversions, for a farmer's son being asked what he was gazing at, says 'that he was seeing Betty Welch, his sweetheart, pitch a bar.' That running matches were also common at these wakes is clear from the comment of the 'Spectator' upon the letter. He says that a country fellow who wins a competition is usually likely to win a mistress at the same time, and 'nothing is more usual than for a nimble-footed wench to get a husband at the same time she wins a smock.' A smock, or, as another writer says, 'a sheshirt,' was the regular prize for women at these rustic sports, and a hat for men, so that the pot-hunters and pot-huntresses of the day had less temptation to turn their prizes into money than comes to the winners of the silver and plated trophies of the present day.

Bath, however, was not the chief place in the West of England remarkable for its athletic meetings. Strutt, who wrote in I8or, gives an account of two important annual gatherings in the WVest Country, one on the Cotswold Hills in Gloucestershire, and the other upon Holgaver Moor, near Bodmin in Cornwall. To the first he says that 'prodigious multitudes constantly resorted. Robert Dover, an attorney of Barton-on-the-Heath, in the county of Worcester, was forty years the chief director of these pastimes. They consisted of wrestling, cudgel-playing, leaping, pitching the bar, throwing the sledge, tossing the pike, with various other feats of strength and activity. Captain Dover received permission from James I. to hold these sports, and he appeared at their celebration in the very clothes which that monarch had formerly worn, but with much more dignity in his air and aspect.' 'I do not 
mean to say,' he goes on, 'that the Cotswold games were invented or even first established by Captain Dover : on the contrary, they seem to be of much higher origin.' Strutt then shows by a quotation from Heath's description of Cornwall, published in $\mathbf{I 7 5 0}$, that a meeting of a similar nature was held near Bodmin. ' The sports and pastimes here held,' says Heath, 'were so well liked by Charles II. when he touched here on his way to Sicily, that he became a brother of the jovial society. The custom of keeping this carnival is said to be as old as the Saxons.'

There can be no question that the connection between fair and wakes and athletic sports was kept up well into the present century, and indeed in some out-of-the-way corners of England has lasted almost to the present time. But as the fairs decayed in importance, owing to improved facilities for travelling and trading, so did the glory of these popular athletic meetings depart with them. Still, side by side with the growing and flourishing profession of pedestrianism in the towns, these rustic sports kept their place, until finally, when the great athletic movement of recent years swept over the country, it renovated and rehabilitated these annual gatherings. The paper from which we have just quoted in the 'Spectator' gives a very minute account of the one at Bath at the beginning of the eighteenth century. There is abundant evidence that their character did not substantially alter, although they undoubtedly diminished in number and importance. In the first volume of Hone's 'Everyday Book' there is a communication from 'Mr. Carter, the antiquary,' describing the great 'May fair' held in the fields near Piccadilly at the end of the eighteenth century. The builder has covered the fields of Mayfair long since, and only the name survives to show what vulgar sports were held in that now fashionable quarter. There were shows of jugglers, a booth for boxers, another booth for cudgel-players, a ring for fire-eaters, \&c. ' 'The sports not under cover,' says Mr. Carter, who had been an eyewitness, 'were ass-racing, grinning for a hat, running for a shift, and an infinite variety of other similar 
pastimes.' Another correspondent of Hone's gives a similar account of Avingham fair in the North Country. After the dancing was over, the sports began in the presence of the mayor. Amongst the contests were 'foot-racing for hats, handkerchiefs, and she-shirts. The several races run, and the prizes distributed, they return to the last and gayest of their mirthful scenes, viz. evening dancing and drinking, finally departing "fu' blythe that night." " In the same book there is a long account of 'Hungerford revel' in Wiltshire. The chief amusement at this festival was, of course, the cudgel-play which 'Tom Brown' has so well described for us. Besides this, however, the festival included in 1826 the following programme : (1) Girls running for smocks ; (2) Climbing the greasy pole for bacon; (3) Old women drinking hot tea for snuff; (4) Grinning through horse-collars ; (5) Racing between old women for a pound of tea; (6) Hunting a pig with a soaped tail ; (7) Jumping in sacks for a cheese ; (8) Donkey racing. There was another revel, called the 'Peppard revel,' earlier in the year, and the 'Reading Mercury' of May 24, I8I9, has an advertisement of the sports, promising eighteenpence to every man who breaks a head at cudgel-play, and a shilling to every man who has his head broke. One of the most interesting communications in the 'Everyday Book' has reference to the North. A writer in 1826 regrets that in most of the great Northern towns the 'wakes' are dying out, 'although still held annually in nearly all the parochial villages of the North and Midlands.' The writer says, however, that in Sheffield (as we should naturally expect of this great home of pedestrianism) the 'wake' was still kept up. 'At Little Sheffield and in Broadlane the zest of the annual festivity is heightened by ass-races, foot-races (masculine) for a hat, foot-races (feminine) for a chemise, and grinning matches.' Perhaps the most interesting extract from Hone to an athlete is his account of the 'Necton Guild' in Norfolk, which was undoubtedly the first English athletic club. In I8I 7, Major Mason, of Necton, in Norfolk, determined to organise the local 'wake' into a regular athletic 
meeting. He allowed no stalls, stands, or booths for variety entertainments. Proceedings commenced with a procession headed by the 'Mayor of the Guild,' and a circle was formed round a maypole. Then began the sports, which were as follows :-(I) Wrestling; (2) Foot-races; (3) Tingling matches; (4) Jumping in sacks; (5) Wheelbarrow-races blindfold; (6) Spinning matches; (7) Whistling matches ; (8) Grinning matches; (9) Jumping matches. After the presentation of the prizes, the nature of which is not described, the dancing began, the strictest order and decorum being preserved by the beadles and other officers of the guild. This annual meeting, which commenced in I8I9, was still being held in 1826 , but we can find no further trace of its history. 'Numerous, respectable, and fashionable companies' generally attended the meetings of the Necton Guild, which appear to have been universally approved. Major Mason, of Necton, certainly deserves a niche in the temple of athletic fame for his institution of the guild.

These wakes were not confined to England alone. Hone tells us also of an Easter gathering at Belfast (which is to the present time the scene of an excellent athletic meeting), where running and jumping matches were the chief features of the day, and of another meeting at Portaferry, in County Down, where these amusements were diversified with 'kissing games.' 'The men kissed the females without reserve, whether married or single.' To clear the men, howerer, from the charge of rudeness, it should be said that the 'kissing is taken quite as a matter of course, without any coyness.' The author sagely remarks that 'tradition is silent as to the origin of this custom.'

We have, however, said enough of these fairs and the rustic athletic gatherings which took place at them. They doubtless grew rarer and rarer during the present century, but it is equally doubtless that some of them have survived quite up to the present day, although most of them have been replaced by regular athletic meetings held under modern and organised rules. The present writer, however, in the year I $88_{5}$, witnessed a wake in a small Cornish town, where, besides the round- 
abouts, \&c., there was in the evening an athletic meeting. The events were, running, jumping, a wheelbarrow race (blindfold), a sack race, and a greasy pole, and the prizes were either hats or garments, or of an edible or potable nature. From inquiry it appeared that the annual meeting was 'older than anybody could recollect.' We have little doubt that it was as old as the foundation of the town itself, as all the wakes were originally festivals of the foundation of the churches.

We have thus far followed the history of rustic sports up to the present time, because there is no doubt that these meetings kept alive the athletic spirit throughout England, and each of them served as a nucleus for an athletic club and helped to create a centre when the modern revival of athletic sports came about. We have also been obliged, in a certain way, to anticipate matters, because through the eighteenth and earlier part of the nineteenth centuries there were two distinct streams of athleticism, the country wakes and the professional pedestrianism which began in time to rank as a branch of legitimate sport, in the same manner as the prize ring.

We have seen that there has been a regular history of professional pedestrianism ever since the Restoration, but it must not be supposed that both under the Merry Monarch and in the eighteenth century, given up, as it was, to wagering and betting of all kinds, there were no matches between amateurs. Thackeray, who knew the period he was writing about in the 'Virginians,' and also understood something of the capacities of the human body for athletic purposes, tells of a match between Harry Warrington and Lord March and Ruglen, who jumped for a wager. The Virginian wins with $2 \mathrm{r} \mathrm{ft}$. 3 in., beating his lordship, who could only cover I $8 \mathrm{ft}$. 6 in.; and Harry goes on in his letter to Virginia to state that he knew there was another in Virginia (Col. G. Washington) who could jump a foot more. Thackeray's correctness contrasts favourably with that of other writers of this century, some of whom, like Wilkie Collins in his 'Man and Wife,' undertake to write of athletic feats without taking the trouble to acquire any knowledge of them. Such 
faults are possibly venial with writers who simply introduce them incidentally, though these latter sometimes make strange blunders. Scott, in his 'Lady of the Lake' (Canto V. Stanza 23), makes Douglas perform a ridiculous feat of weight-putting :

Their arms the brawny yeomen bare

To hurl the massive bar in air.

When each his utmost strength had shown.

The Douglas rent an earth-fast stone

From its deep bed, then heaved it high, And sent the fragment through the sky $A$ rood beyond the farthest mark.

We have some suspicion that Thackeray was thinking of this when, in his 'Rebecca and Rowena,' he makes Cœur de Lion 'fling a culverin from him as though it had been a reed. It lighted three hundred yards off on the foot of Hugo de Bunyon, who was smoking a cigar at the door of his tent, and caused that redoubted warrior to limp for some days after.' There is another absurd feat, in the way of jumping, in the 'Lady of the Lake' (Canto III. Stanza I 2):

And from the silver beach's side Still was the prow three fathom wide, When lightly bounded to the land The messenger of blood and brand.

Eighteen feet for a 'standing long jump' is a 'record' which is hardly likely to be beaten (Io ft. $9 \frac{3}{4}$ in. is the best known at present at an athletic meeting). A list of such mistakes might be indefinitely multiplied, but we will only give one other here. Henry Kingsley, in ' Geoffrey Hamlin,' makes his 'muscular Christian' curate run four miles in twenty minutes, then vault over a gate, take off his hat to a lady, and draw his watch out of his pocket to time himself; after which, being apparently not in the least out of breath, he enters upon a conversation about the benefits of athletics. No wonder this curate became a dignitary of the colonial church. He deserved the honour. 
The annals of the eighteenth century are full of accounts of wagers for the performance of athletic feats, both sublime as well as ridiculous. The majority of the genuine athletic performances are those of professional pedestrians, amateurs only figuring occasionally in these wagers, and often in prepos-

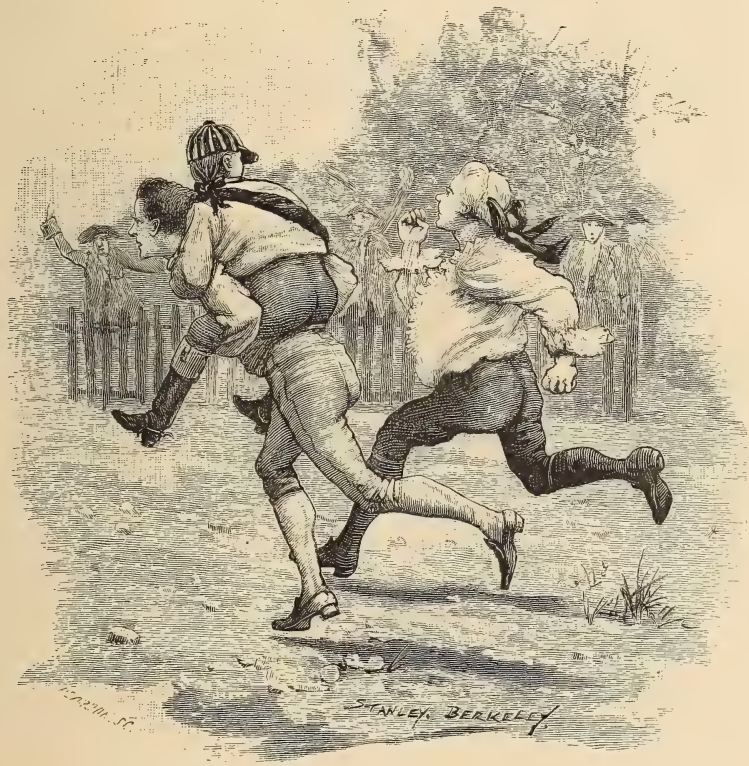

Race between elderly fat man and man with jockey on back.

terous ones. Luttrell's 'Diary' tells us of a wager made by a German of sixty-four years old to walk 300 miles in 'Hide Park' in six days, which he did 'within the time, and a mile over.' In I 780 the 'Gentleman's Magazine' tells us that a man of seventy-five years old ran four miles and a half round 
Queen Square in $5^{8}$ minutes. Eight years later a young gentleman, with a jockey booted and spurred on his back, ran a match against an elderly fat man (of the name of Bullock) running without a rider. The more extraordinary the wager the more excitement it often caused amongst the public. A fish-hawker is reported to have for a wager run seven miles, from Hyde Park Corner to Brentford, with $56 \mathrm{lbs}$. weight of fish on his head, in 45 minutes! Another man trundled a coach-wheel eight miles in an hour round a platform erected in St. Giles's Fields. Another extraordinary match was one between a man on stilts against a man on foot, the former receiving twenty yards start in a hundred and twenty yards. What is more astounding is that the man upon the stilts won the match.

A few examples may also be given of the many genuinely interesting matches which were brought off. As regards the alleged times, however, many of them are as obviously absurd as that supposed to have been done in the four-mile race in Woodstock Park, of which we have already spoken. An Italian is said to have run from Hyde Park Corner to Windsor in an hour and three-quarters. Another man walked from Bishopsgate to Colchester and back (IO2 miles) in twelve hours! In I750 two well-known 'peds,' Abron and Temple, ran a fourmile match for 100 guineas a side, the former winning. In 1762 another man, for a wager of thirty guineas, walked seven miles just within an hour and five minutes on the Kingsland Road. Many of the matches (and these were the most popular ones) consisted of feats of endurance and long-distance matches against time. One Mr. John Hague, in $\mathrm{I}_{7} 62$, walked roo miles in $23 \mathrm{hrs}$. I5 min. How little notion the public had of the speed at which a good man could travel is evident from the nature of many of the matches which were made. A clerk, for instance, won a wager of fifty guineas by walking four miles in less than fifty minutes. This bet was made in 1766 , and four years afterwards we hear of another man winning a wager by running a mile through the streets between Charter- 
house Wall and Shoreditch Church gates in 4 minutes. In I 777 we hear of a performance in Yorkshire which is possibly correct in time : Joseph Headley, a pedestrian, running two miles in $9 \mathrm{~min} .45 \mathrm{sec}$. on the Knavesmire. The racecourse or the high road appears to have been about this period the usual arena of genuine pedestrian matches. In I 780 a pedestrian of Penrith walked fifty miles in I 3 hours on the Newcastle racecourse. In 1785 one Woolfit, another pedestrian, walked forty miles a day for six consecutive days, between 6 A.M. and 6 p.M., on the high road. Soon afterwards a man named York ran four miles on the Egham racecourse in $24 \frac{1}{2}$ minutes. In 1787 Walpole, a butcher from Newgate Market, ran a mile with a well-known pedestrian of the name of Pope, along the City Road, and beat him in the time of 4 min. 30 sec. $-a$ good performance if true. In 1788 there was enormous excite-

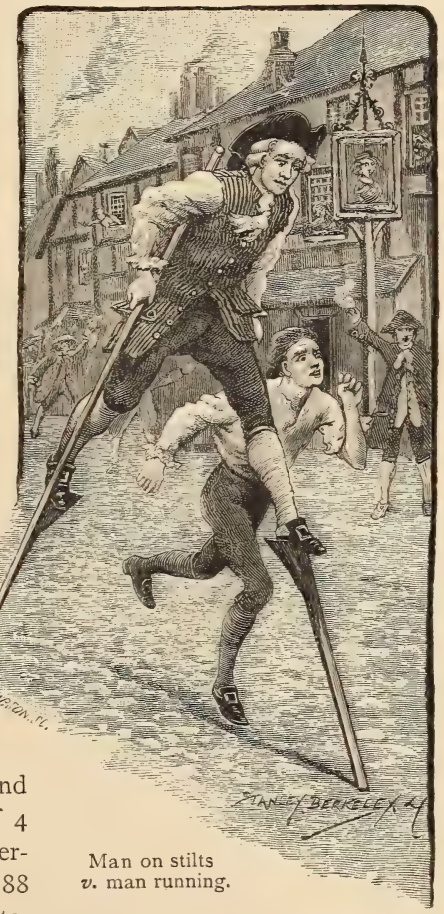
ment over a race between a pedestrian named Evans and Father Time at Newmarket, Evans being backed to run his ten miles within the hour. $\mathrm{He}$ is credited with covering the distance in 
$55 \mathrm{~min}$. I $8 \mathrm{sec}$., thereby putting $\mathrm{I} 0,000 \mathrm{l}$. or thereabouts into the pockets of those who backed him. In the same year another pedestrian, named Wild, ran four miles in $2 \mathrm{I}$ min. I $5 \mathrm{sec}$. on the Knutsford racecourse. The next year witnessed a remarkable feat of endurance, one Savagar, a labourer, walking 404 miles in 6 days along the road between Hereford and Ludlow, and going over a hill two miles long three times every day. All the stipulated reward for this feat was a sum of ten guineas, and he would, doubtless, have preferred to have lived in the time when Rowell, and some other pedestrians, a few years ago, netted many thousands by their long 'go-as-you-please' contests.

In I79I we hear of some aristocratic amateurs on the path. Lord Paget, Lord Barrymore, Captain Grosvenor, and the Hon. Mr. Lamb ran a race across Kensington Gardens for a sweepstake of 100 guineas. The spectators appear to have been numerous, and Lord Paget after a close race beat Mr. Lamb, Captain Grosvenor being third. In I793 another amateur, Colonel the Hon. Cosmo Gordon, appears to have assisted his friends to a good thing, as he undertook for a wager to walk five miles along the Uxbridge Road in an hour. $\mathrm{He}$, however, was himself a true amateur, as he engaged, if he won, to devote the stakes to a fund for the relief of the widows and children of soldiers and sailors. The gallant colonel walked his five miles from Tyburn to Ealing easily within the hour-as well he might.

The greatest interest which was excited over peciestrian feats at this time always arose from long-distance competitions, in which endurance rather than speed or skill was exhibited. The most eminent athlete of all in this line (at any rate until the appearance of Captain Barclay Allardice) was Mr. Foster Powell, a lawyer's clerk of New Inn, who may almost be said to have been the long-distance champion for a quarter of a century. He was born at Horseforth, near Leeds, in 1734 , and was thirty years old before he performed his first celebrated feat, which consisted of running fifty miles on the 
Bath Road in seven hours, doing his first ten miles within the hour. After this he travelled abroad, exhibiting his feats of pedestrianism in Switzerland and France, and it was not until I 773 that for a heavy wager he performed the feat of going on foot from London to York and back in less than six days-to wit, in 5 days 18 hours - the distance being 402 miles. In I 777 he went from London to Canterbury and back (I I 2 miles) in less than twenty-four hours, thousands of spectators watching him on the road and greeting his return. Eleven years afterwards, being then fifty-five years of age, he ran a mile match against a Mr. Smith of Canterbury, who was too speedy for the elderly pedestrian, and beat him. At the age of fiftyseven Powell again went from London to York and back in 5 days 18 hours, and two years afterwards beat his own 'record' again by doing the same distance in 5 days $15 \frac{1}{4}$ hours. It is hardly strange that so great a performer should have excited enormous interest, and the number of his recorded feats (the genuineness of which there seems no reason to doubt) would almost fill a book by themselves. 'Absurd as it may appear,' says an encyclopædist in I823, 'so desirous were people to have a sight of him that he was engaged at Astley's Amphitheatre for twelve nights, where he exhibited his pace in a small circle.' He died, however, soon after this, never having recovered from the effects of his last and most severe journey to York, and lies buried in the east corner of St. Paul's Churchyard. From the contemporary accounts of his appearance he seems to have been of medium height and spare of person.

Probably the performances of Foster Powell did much to spread the popularity of pedestrianism as a sport, for we invariably find that one great performer brings a host of inferior imitators. In Powell's time pedestrianism 'boomed' again, and the waning popularity of the sport was again revived by the performances of Barclay Allardice. The feats of the latter pedestrian, indeed, called into existence a product which had never been known before-a book on pedestrianism. In I8I 3 
a fellow-countryman of Allardice (who always ran under the name of Barclay) compiled a work, 'Pedestrianism, or An Account of the Performances of Celebrated Pedestrians during the last and present Century, with a Full Narrative of Captain Barclay's public and private Matches, and an Essay on Training.' It is from this work, published in Aberdeen by Mr. IValter Thom in I8I 3 , that we derive our account of many of the eighteenth-century feats which we have mentioned above. We can hardly blame Mr. Thom for following the prevailing fashion of the age in his advice on training. The diet he recommends is beef, mutton, stale bread, strong beer, and Glauber salts; the exercise, constant morning walking and sweating. 'The patient,' he says, 'should be purged with constant medicines, sweated by walking under a load of clothes and by lying between feather-beds.' Fish, vegetables, cheese, butter, eggs, are strongly forbidden, and the use of an occasional emetic is suggested. Let modern athletes be thankful that they are trained upon a different system.

Mr. Thom begins by stating that he had originally only intended to make an account of Captain Barclay, but then thought it advisable to ad preliminary chapters upon the captain's more eminent predecessors in athletic fame. This preliminary part he divides into four heads-(I) matches of several days' continuance; (2) one day matches; (3) those which were performed in one or more hours, and required good wind and great agility; (4) those completed in seconds or minutes, which showed great swiftness. From this somewhat crude division it could only be expected that he would swallow a number of marvellous stories as to distance and time; but, in spite of these defects, the book is genuinely interesting.

It would be tedious to give a list of the long-distance performances recorded by Mr. Thom and the 'Sporting Magazine,' the best of them being those of Foster Powell; but it is worth notice that the performers are from every class of societyofficers in the army, country gentlemen, farmers, labourers, butchers many of them being professional pedestrians and 
having no other occupation. Some of the more marvellous deeds are as follows:-Levi Whitehead, of Bramham, four miles on Bramham Moor in 19 minutes; Mr. Haselden, of Milton, a private gentleman, ten miles on the Canterbury road in 53 minutes 'with ease.' This last performance was in the year 1809 . In February $1808 \mathrm{Mr}$. Wallis, a gentleman of Jermyn Street, two miles in 9 minutes 'in two starts,' with a minute's interval between each start.

Though it is understood that the times are to be regarded sceptically, Thom's work gives a very vivid picture of the popularity of athletic sports during the twenty years preceding the publication of his work in I8I3. Three pedestrians, Howe, Smith, and Grey, appear frequently to have competed in twenty-mile and ten-mile races. In 1793 two pedestrians, Barrett and Wilkman, ran a ten-mile match on Kersal Moor, the former winning in 57 minutes. In 1805 Lieutenant Warren and Mr. Bindall, an artist, ran a match of seven miles on the Uxbridge road, the artist winning by a quarter of a mile. Time given as 35 minutes. In I 805 , James Farrer, for a wager of 200 guineas, ran against time on Knutsford racecourse, doing four miles in $20 \mathrm{~min} .57 \mathrm{sec}$. One of the best-known 'peds' of this time was Abraham Wood, a Lancashire man, who, however, had his colours lowered in a four-mile race by Joseph Beal, a Yorkshire lad of nineteen, who beat the champion in $2 \mathrm{I} \mathrm{min.}$ I $8 \mathrm{sec}$. Beal is also credited with two miles in $9 \mathrm{~min} .48 \mathrm{sec}$. on York racecourse in a match with another 'ped,' Isaac Hemsworth, of Bolton, Lancashire.

In 1809 Captain Dane and Mr. Davies ran a mile match in Bayswater fields, the captain winning by 'about 2 lengths,' in 4 min. $5^{6} \mathrm{sec}$. Two other amateurs, Lord F. Bentinck and the Hon. Edward Harbord, also ran a mile in 1804 for 100 guineas, the latter winning easily, and his lordship was shortly afterwards beaten by a Mr. Mellish in another match over the Beacon course. In $1805 \mathrm{Mr}$. Harbord tried sprinting in a match with Lord F. Beauclerk at Ioo yards; the latter won by two yards. The winner afterwards met at the same 
distance the Hon. Mr. Brand, and won easily, 'the latter gen. tileman becoming quite winded before he had run fifty paces.' Both these matches were brought off at Lord's Cricket Ground. Besides these, Thom gives the names of Colonel Douglas, Mr. Lambert, Lieutenant Hankey, Captain Aiken, Lieutenant Fairman, and Captain Agar as being prominent amateurs about his time; and, indeed, it appears that the amateur pedestrians were chiefly officers in the army. This inclines us to believe the story which is often repeated, but for which we can find no sufficient verification, that about I 8 I 2 there was a regular annual athletic meeting at Sandhurst, which was afterwards discontinued.

Thom is of opinion that next after his pet hero, Captain Barclay, Abraham Wood, of Mildrew, in Lancashire, was the best runner of his time. His best reported performances were $20 \mathrm{~min}$. 2 I sec. for four miles over the York course, against one John Brown, who had previously beaten Wood over a similar distance on the Knavesmire. Wood, however, seems to have been a fair performer at shorter distances as well, as in I 809 he beat Shipley, of Nottingham, at a quarter mile on the well-known Knutsford course in 56 seconds. Sprinting appears to have been less popular than racing at longer distances at this time; but such sprinters as there were must have been marvellous men if the times recorded are accurate. Curley, the Brighton shepherd, ran a match against Grinley, a 'ped,' in I805, 'on the walk leading to the gate of Kensington Garden,' Grinley winning by a head in I $2 \frac{1}{2}$ seconds. Next year Grinley again beat his antagonist on Hampton Court Green over I 20 yards, upon this occasion doing 'level time.' Curley, however, beat another 'ped,' Cooke, a soldier, over a sprint; but Cooke, for a wager of fifty guineas, beat Mr. Williams, a gentleman, by a yard and a half. In I808, however, Skewball, the famous Lancashire shepherd, ran I40 yards in $\mathrm{I} 2$ seconds at Hackney! This is perhaps the best specimen of the incapacity of the writers of that day to distinguish between possible and impos. sible times. 
Captain Barclay Allardice is, of course, best known by his feat of walking 1,000 miles in 1,000 hours at Newmarket. The performance, no doubt, startled everybody at the time, although it has frequently been since surpassed. He was, however, a fine all-round performer. He was born in I779, and had such an unextinguishable love for athletic sports, that when he was only 5 he won a wager by walking six miles in an hour on the Croydon road. When twenty-one he made a match of 5,000 guineas to walk ninety miles in $2 \mathrm{I} \frac{1}{2}$ hours, and won it with ease, amidst the plaudits of thousands of spectators. $\mathrm{He}$ soon afterwards beat a Mr. Ward over a quarter of a mile in

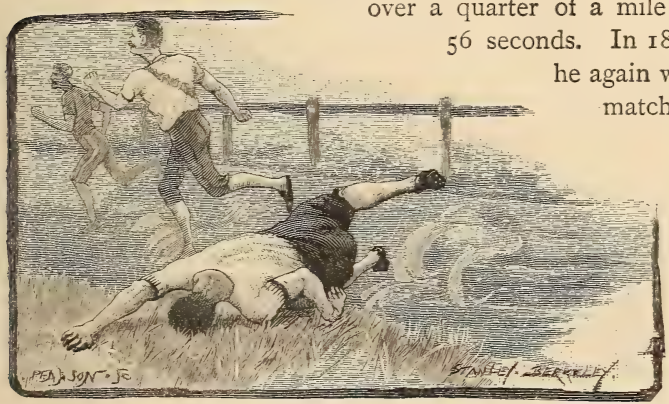

Dead beat.

at that distance against Mr. Goulbourne, of the Royal Horse Guards, at Lord's Cricket Ground, and won easily in I min. I 2 sec. He also won two mile races in matches with amateurs in $5 \mathrm{~min} .7 \mathrm{sec}$. and $4 \mathrm{~min}$. $50 \mathrm{sec}$, and was for the years I796-1808, when he performed the 1,000 miles in 1,000 hours feat, the most prominent runner of the day. Nay, more, in the words of Thom, "he ever evinced inflexible adherence to strict principles of honour and integrity, and whether as transacting with mankind individually, or as a public character responsible for his opinion and conduct at the shrine of his country, he 
always proved his sincere respect for the rights of others and his unfeigned attachment to the British constitution.'

Be that, however, as it may, he certainly deserves the thanks of modern athletes for his success in rendering athletic sports a popular pastime for gentlemen. There was, as is well known, no distinction in his time between professionals and amateurs, and gentlemen made matches with each other and with pedestrians as they pleased, and we find the great Barclay entering on a contest of endurance with Abraham Wood, and running him 'off his legs.' But throughout the first five-and-twenty years of the present century the ball which Barclay had started was kept rolling by plenty of successors ; indeed, up to about I825 so many amateurs made matches at Newmarket, or on the Uxbridge Road, or at Lord's Cricket Ground, and so much interest was displayed by spectators in these contests, that it seems wonderful that the system of athletic meetings for amateurs should not have arisen half a century earlier than was actually the case, though, as we have already stated, there is some evidence that there were regular meetings at Sandhurst early in the century. After about I825, however, the popularity of foot races amongst amateurs appears to have waned, and we hear of few gentlemen engaging in matches. We believe, neverthe less, that of the amateur generation of the early part of this century there is still a survivor. The present Lord Tollemache, ${ }^{1}$ after running several sprint races, was backed by a friend to run any man in England over Ioo yards. The challenge was accepted on behalf of a Mr. MacNamara, and the match came off at the usual venue of Lord's Cricket Ground, Lord Tollemache again proving a winner. The late Mr. Horatio Ross, who only died recently, also distinguished himself in his early years as a walker of long-distance matches. However, though there were fewer amateurs in the field, professional pedestrianism continued steadily to increase throughout the century, and we find a regular succession of celebrated short-distance and long-dis. tance runners who challenged and wrested championships from each other in the same manner as the champions of the ring.

1 This was written in 1887 when the late Lord Tollemache was living. 
As the period to which we are now referring is almost a modern one, and as our business in this work is with athletic sports as a pastime for amateur and not with the business of professional pedestrians, we can hardly give here a history of the pedestrianism of the nineteenth century, for which such ample materials exist in the pages of the 'Sporting Magazine' and 'Bell's Life.' Some few memorable performances, however, claim attention as showing the steady progress of athletic ability. In 1825 James Metcalf (champion) gave J. Halton (ex-champion) 20 yards in a mile, for a stake of $\mathbf{r}, \infty \circ 0$ guineas, on the Knavesmire, and the champion won in the time of $4 \mathrm{~min}$. $30 \mathrm{sec}$; but it is not for another fifteen or twenty years that we hear of this time being approached, and not until 1849 that we know of its being beaten by W. Matthews of Birmingham, who did his mile in 4 min. $27 \mathrm{sec}$. Between 1825 and 1838 or 1839 or thereabouts, although pedestrian matches at all distances were common enough, pedestrianism was hardly the popular sport that it became later on. We find that in the colunns of 'Bell's Life' it was the custom for many years to mention the future pedestrian fixtures at the end of that part of the paper which came under the heading of 'The Ring.' About the latter date (1838) 'Bell's Life' began to give pedestrianism a heading to itself, and every week there is a list of some twenty or thirty events. Between 1840 and $185^{\circ}$ pedestrianism had another 'boom,' and as usual when the sport was popular, the amateurs began to turn out again and make matches with each other or with the pedestrians. A curious instance of the difference of fashion may be seen from the varying practice of amateurs as to giving their real names in these contests. In 1838 'Bell's Life' gives an account of a cross-country steeplechase match got up by six medical students of Birmingham, who 'for several reasons' concealed their real names, and the account describes them under the pseudonyms of 'Sprightly,' 'Rustic,' 'Chit-chat,' 'Neversweat,' 'Vulcan,' 'The Spouter.' The umpires selected a mile course, and, after an eventful race, 'The Spouter' won 
and 'Neversweat' was second. Five years afterwards the amateurs were running in their own names again, and the public were looking on at their matches with applause. Captain Hargraves and Mr. Fenton attracted a large crowd to a mile match which they ran in 1843 . It was not long after this that we find professional pedestrianism in what were almost its palmiest days. ' Billy' Jackson (the American Deer), J. Davies (the Lame Chicken), and Tom Maxfield (the North Star) ran a mile match upon the Slough Road, over what is still known as 'Maxfield's mile,' amidst an enormous concourse of people and 'immense enthusiasm.' About this date 'Bell's Life' had every week a list of nearly fifty fixtures of matches to come off, and pedestrianism as an institution was an accomplished fact. In $185^{\circ}$ ' the major portion of the sporting population of Liverpool, Manchester, Newcastle, and the other great towns' turned out to see 'Tommy' Hayes beat 'Johnny' Tetlow, over four miles on the Aintree racecourse; and in 1852 , when George Frost (the Suffolk Stag) won the championship belt at the old Copenhagen Grounds by a ten miles race, lithographs of the contest were published and sold by the thousand. Such was the popularity of pedestrianism at this period that it is hardly to be wondered that it should have aided other causes in setting the amateur movement going.

The 'Volunteer movement' is usually put forward as the explanation of the outburst of athletic spirit throughout the kingdom about this period. The more probable, and perhaps more philosophical explanation, of the impulse which undoubtedly began in the towns is that it was the natural product of the over-pressure of modern commercial and professional life. Hours of work being long, there comes a craving amongst adults for violent exercise, and that craving has led to the popularity of various athletic games, which are now so universally practised. Whatever may be the cause, however, of the 'athletic movement,' there can be little doubt that the first amateur athletic sports were suggested by the performance of professional 'peds,' and that whenever there was an unusual 
galaxy of pedestrian ability the amateurs began to imitate them. We have seen that, between 1845 and I852, there was great public interest shown in pedestrianism, and it is accordingly not surprising to find that the first regular athletic meetings begin to be heard of about this time. In 1849 there was a regular organised athletic meeting at the Royal Military Academy, Woolwich, which was continued till 1853 , when it was abandoned. In I850 Exeter College, Oxford, started a meeting, which has been continued annually down to the present day. The following account of the first of these, which has been sent to us by one of the competitors himself, can hardly fail tc be interesting to modern athletes; and the programme, which is probably the sole extant specimen, is in itself interesting enough to justify its reproduction in these pages.

'Exeter College, Oxford, was one of the first institutions to start an athletic gathering, and it may not be uninteresting to give a narrative, collected mainly from the recollection of eyewitnesses, of the first set of sports ever held there, and of the gentlemen who were the originators and first performers.

"The year was I850. It was the evening after the College Steeplechase (vulgarly called the "College Grind "). Some four or five congenial spirits, as their manner was, were sipping their wine after "hall" in the "rooms" of one, R. F. Bowles (brother to John Bowles, the well-known coursing squire, of Milton Hill). Besides the host there were James Aitken, Geo. Russell, Marcus Southwell, and Halifax Wyatt. The topic was the event of the day, and the unsatisfactory process of 'negotiating' a country on Oxford hacks. "Sooner than ride such a brute again," said Wyatt, whose horse had landed into a road on his head instead of his legs, "I'd run across two miles of country on foot." "Well, why not?" said the others; "let's have a College foot grind;" and so it was agreed.

'Bowles, who always had a sneaking love for racing-born and bred as he was near the training grounds on the Berkshire Downs-suggested a race or two on the flat as well. Again 
the party agreed. The conditions were drawn up, stakes named, officials appointed, and the first meeting for "Athletic Sports" inaugurated.

"On the first afternoon there was to be a "chase," two miles across country, 24 jumps, $I l$. entry, Ios. forfeit ; and on a subsequent afternoon, a quarter of a mile on the flat, 300 yards, 100 yards, I 40 yards over io flights of hurdles ro yards apart, one mile, and some other stakes for "beaten horses," open to members of Exeter College only. The stewards of the "Exeter Autumn Meeting" were R. F. Bowles and John Broughton; Secretary, H. C. Glanville; Clerk of the course, E. Ranken ; and a well-known sporting tradesman in Oxford, Mr. Randall, was asked to be Judge. Mr. Randall is still alive, and though over 80 years of age, is a regular attendant at Henley, Putney, or Lord's, whenever there is a University contest.

'Notice of the meeting, with a list of the stakes, was posted in the usual place-a black board in the porter's lodge. Plenty of entries were made, in no stake less than 10 : for the steeplechase there were 24 who started.

'Among the competitors were Jas. Aitken, J. Scott, Geo. Russell, Jno. Broughton, R. F. Bowles, D. Giles, H. J. Cheales, H. Wyatt, Jas. Woodhouse, C. J. Parker, P. Wilson, M. Southwell, H. C. Glanville, H. Collins, E. Knight, and some nine others.

'The betting was -2 to I $v$. Aitken, 2 to I $v$. Cheales, 8 to I ข. Giles, 9 to I $v$. Wyatt, Io to I $v$. Parker, Io to I v. Scott, I 2 to I $v$. Broughton, I 5 to I $v$. Woodhouse.

'The course chosen was on a flat marshy farm at Binsey, near the Seven Bridge Road: it was very wet, some fields "swimming" in water, the brooks bank high, and a soft take-off, which meant certain immersion for most, if not all, the competitors. Twenty-four went to the post, not 24 hard-conditioned athletes in running "toggery," but 24 strong active youngsters in cricket shoes and flannels, some in fair condition, some very much the reverse, but all determined to "do or die." Plenty of folk, on horse and foot, came to see this novelty (for in Modern, 
as in Ancient Athens, men were always on the look out for "some new thing"), and in this instance, judging from the excitement, and the encouragement given to the competitors, the novelty was much appreciated.

'As about half of the 24 starters left the post as if they were only going to run a few hundred yards, they were necessarily soon done with. Aitken, gradually coming through all these, had the best of the race until one field from home, when WVyatt and Scott, who had been gradually creeping up, ran level. They jumped the last fence together. Wyatt, who landed on firmer ground, was quickest on his legs, and ran in a comparatively easy winner; there was a tremendous struggle for the second place, which was just obtained by Aitken.

' The time, according to the present notion of running, must no doubt have been slow, but the ground was deep, the fences big and all the competitors were heavily handicapped by wet flaniels bedraggling their legs.

' Of the flat races, which were held in Port Meadow, on unlevelled turf, no authentic record has been preserved of the winners of all the events. The hurdle-race was won by $\mathrm{E}$. Knight, R. F. Bowles being second. The roo yards by Wyatt, and he also won one or two of the other shorter races; but for the mile he had to carry some pounds of shot in an oldfashioned shot-belt round his loins, and ran second to Aitken, who won. Listen to this, ye handicappers of the present day!

'Such is the history of the first set of athletic sports. But now a word or two as to the original patrons and performers, for we would not have the athletes of the present day think that the last generation were altogether "unprofitable servants."

'Marcus Southwell, R. F. Bowles, and Geo. Russell (now Sir Geo. Russell, Bart., of Swallowfield), were perhaps more patrons than performers. But Southwell was a fine horseman, and could walk six miles in the hour without training: he, alas! was killed when on a tour in America by a horse falling on him. Bowles and Russell could both row, play cricket, and run a bit, and they perhaps were the most energetic in getting 
up the first edition of sports. There is a longer record of services against the name of James Aitken, beyond winning the mile race, and being second for the two miles. As a cricketer he played in the Eton eleven, at Oxford in the University eleven against Cambridge in 1848,1849 , and 1850 , and was captain of the eleven in $185^{\circ}$. As an oarsman he rowed against Cambridge at Putney in 1849 , was one of the Oxford eight and four that rowed over for the Grand and Stewards at Henley in 1850 , rowed in the Oxford eight that beat Cambridge at Henley in $185 \mathrm{I}$, and won the Goblets together with the present Mr. Justice Chitty. He was ordained soon after leaving the University, and has had neither time nor opportunity for following up rowing or cricket to any great extent, but he has worked as hard and conscientiously in his parish as he did at No. 5 thwart in the University boat, and they say that even now, at lawn tennis, few of the young ones can hold their own against the Rev. James Aitken, vicar of Chorleywood, in Hertfordshire.

'Halifax Wyatt, another of the performers, was born in the "Duke's Country"-no doubt a point in his favour-and in his younger days was known to the noble editor of the Badminton Library, both in the hunting-field and on the tented sward, when I.Z. used to play at Badminton. At Oxford he won, as stated, the two miles and some of the shorter races in the sports. He played against Cambridge in the University eleven $185^{\circ}$, $\mathrm{I} 85 \mathrm{I}$, and in his college eleven in $\mathrm{r} 849, \mathrm{I} 85^{\circ}, \mathrm{I} 85 \mathrm{I}$. He rowed in the O.U.B.C. eight-oared races in $1849,1850,185 \mathrm{I}$, in the O.U.B.C. fours I849, and O.U.B.C. sculls $185^{\circ}$. Since leaving Oxford he has played a great deal of county cricket, in Gloucestershire, Devonshire, and Cheshire, and is an I.Z., M.C.C., Harlequin, \&c. He did but little afterwards in running, but when quartered with the 4 th Battalion Devonshire Regiment, at Limerick, he ran a Ioo yards match for $5 \circ$ l. against a Canadian in the 89th Regiment, and beat him. H. Wyatt retired from the Devon Regiment as Lt. Colonel, and has now for some years past managed the Earl of Sefton's 


\section{EXETER AUTUMN MEETING.}

STEWARDS. - R. F. BOWLES, ESQ., J. A BROUGHTON, ESQ.

SECRETARY.-H. C. GLANVILLE, ESQ.

Clerk of the Course.-H. RANKen, esQ. Judge.-Mr. Randall.

The Welcome Sweepstakes, of a quarter of a mile :-

Mr. Page
", Broughton
", Collins
", Glanville
", Bowles
", Cole
", Johnstone

Mr. Wyatt

", Winwood

" Marshall

", Cheales

,. Knight

", Nicholls

, Aitken

The Bancalari Sweepstakes, 300 yards and a distance. Heats :-

Mr. Broughton

" Page
", Rowville
", Wyatt
Mr. Winwood

„Aitken

", Marshall

" Manley

" Terry

The Jonathan Sweepstakes, Ioo yards :-

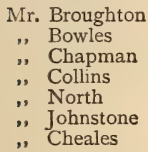

Mr. Broughton

", Bowles

"Chapman

". Collins

", Johnstone

, Cheales
Mr. Paul

," Todd

" Medley

", Wyatt

, Knight

", Yonge

$$
\begin{aligned}
& \text { Mr. Stubbs } \\
& \text { ". Aitken } 2 \\
& \text {, Venables } \\
& \text {," Stent } \\
& \text {, Gresson } \\
& \text {,"Wingfield }
\end{aligned}
$$

A Hurdle Race, over 10 flights, at Io yards apart, I 40 yards :-

Mr. Chapman

, Bowles

, Knight

, Broughton

", Wyatt

, Cheales
Mr. Venables

, Stent

". Wilson

, Norman

" Aitken

The Scurry Stakes, I 50 yards, to name and close on the day of the races.

The Aristocratic Stakes, of 60 yards, to name and close on the day of the races.

The Consolation Stakes, for beaten horses, 100 yards. 
extensive estates in Lancashire, and is a first-rate hand in "looking on" at all those sports in which formerly he took such an active part.

"This is a slight sketch of the men who "set the ball rolling," but though their first meeting was evidently popular, the thing went slowly for a time. In 1851, Exeter College followed up the autumn meeting of $185^{\circ}$ with a summer meeting on Bullingdon, and we think that both a high and broad jump were introduced in the programme. In these sports both $\mathrm{C}$. A. North and J. Hodges distinguished themselves, the latter, by the way, not long after for a wager riding $5 \circ$, driving $5 \circ$, and walking 50 miles in 24 consecutive hours. Lincoln College, Oxford, was the next to take up the idea and held some sports. Then a college in Cambridge. After this the thing went like wildfire, spreading simultaneously on every side; and after Colleges and Schools, first in London and then in the provinces clubs were formed for the promotion of athletic sports.

Kensington Grammar School began their regular sports in ${ }_{1} 8_{52}$, and we believe there are several other private schools round London which have had annual foot races and jumping matches since about the same time, which we have little doubt were suggested, or at any rate encouraged, by the interest taken by the boys' parents in 'The American Deer,' 'The Suffolk Stag, 'The Greenwich Cowboy,' and other pedestrian worthies of the same kidney. In 1853 Harrow and Cheltenham both started athletic meetings; and Durham University also had a gathering which however, appears to have died a natural death.

Undoubtedly there were races at several of the public schools before this date, but they can hardly be called athletic meetings. The pastime of 'hare and hounds,' as an amusement for schoolboys, is quite as old as any other English athletic pastime. Strutt gives a quotation from an old comedy, written towards the close of the sixteenth century, in which an 'idle boy' says:

'And also when we play and hunt the fox I outrun all the boys in the schoole.' 
This is no doubt an allusion to 'hare and hounds,' and Strutt himself, writing in I80I, gives the following account of the pastime which he calls 'hunt the fox' or 'hunt the hare' : 'One of the boys is permitted to run out, and having law given him - that is, being permitted to go to a certain distance from his comrades before they can pursue him-their object is to take him, if possible, before he can return home.' The Crick Run at Rugby appears to have been founded in 1837 , and at Shrewsbury there is known to have been a school steeplechase a very few years afterwards, while in 1845 Eton started an annual steeplechase, sprint races and hurdle races, which came off on the road all on different days. Curiously enough, this is the first mention that we can find anywhere of short hurdle races. ${ }^{1}$ Hurdle racing, now so popular amongst amateurs, is almost entirely an amateur sport. In I 853 'Bell's Life ' has an account of two amateurs competing in an 'all round' competition, which included the following events : A mile race, walking backwards a mile, running a coach wheel a mile, leaping over fifty hurdles, each $3 \mathrm{ft}$. 6 in. high (the present regulation height), stone picking, and weight putting; and in the same year the 'Times ' contains an account of a match between Lieut. Sayers and 'Captain Astley' in a flat race and a hurdle race. All the school meetings, which began about 1852 and 1853 , as we have seen, included hurdle racing in their programmes, and even up to the present day the chief homes of hurdle racing are the public schools and universities. The pastime of hurdle racing, however, can hardly be entirely modern, as Professor Wilson ('Christopher North') appears to have been an adept at something of a similar nature early in the century. The Professor of Noral Philosophy had so distinguished a reputation as an athlete that his name should not be omitted from a chapter on athletic history. Hone has an anecdote of his 'taking down' a brother private in the

1 In 1837 and 1838 we had hurdle races at most of the tutors' and dames' houses at Eton, as I know from the fact of having run in and won races of the sort there in those years. One hundred yards over ten hurdles was the usual course. - B. 
militia at Kendal. The latter boasted that he had never been beaten in a jumping competition, and Wilson accordingly challenged him to jump for a guinea. The unbeaten champion could only cover 15 feet, Wilson clearing 2 I feet, to his opponent's amazement.

About 1852 , then, it came to be considered a recognised and reasonable form of sport for a school or college to devote a day or an afternoon to a meeting for competitions in the old English sports of running, jumping, and throwing of weights ; but the notion of open competitions, championships, or contests between the Universities in athletic sports, in the same way that they were already competing in cricket and boat-racing, was still far from dawning on the English mind. Races and jumping matches were still considered school pastimes like 'tag' or 'prisoner's base,' and even at the Universities their progress towards popularity was very slow. The following is the information given as to this progress by the writer of 'Modern Athletics': 'At the two Universities there were no athletic sports of any description until I850, when Exeter College, Oxford, took the initiative and held a meeting, which has since been repeated annually. In 1856 , and even in 1858 , "Bell's Life," in its report of these sports, styles them "rural and interesting revels," and again, " a revival of good old English sports." . . Exeter College was alone until I855, when mention is first made of any sports at Cambridge, St. John's College and Emmanuel taking the lead. At Oxford, Balliol, Wadham, Pembroke and Worcester followed the example of Exeter in $185^{6}$; Oriel in 1857, Merton in 1858 , Christchurch in 1859 , and in $186 \mathrm{I}$ separate college meetings had become general. At the close of I860, the Oxford University sports, open to all undergraduates, owed their foundation to the exertions of the Rev. E. Arkwright, of Merton College. At Cambridge the University sports had already been founded in 1857 , but annual meetings of the separate colleges were not frequent as at the sister University until I863.' How suddenly the importance of athletics increased at the Universities in $\mathbf{1 8 6 4}$, the first year of the Inter- 
Varsity meeting, may be gathered from some remarks of Sir Richard Webster made at the annual dinner of the London Athletic Club in I886, when he said that for winning half-adozen strangers' races in one year he had received a few pounds in coin, while the next year $ə$. friend whose performances had been of the same order received about $40 l$. worth of prizes from the silversmiths.

Soon after 1860 these athletic meetings had become a regular feature of school and college life. Trinity College, Dublin, instituted a meeting in 1857 , which has since had a continuous existence and undiminished popularity. In England, Rugby School held its first regular meeting in $185^{6}$, Winchester in 1857 , and Westminster and Charterhouse in $186 \mathrm{r}$. Ey this latter year all the public schools, as well as the Universities, were holding sports, and there is little doubt that the growth and popularity of the public school system has done much not only to foster but to spread the spirit of athletic competition throughout the kingdom. Lads who have gained health, pleasure, and reputation from athletic pursuits at school are hardly likely to drop their tastes as soon as school is left behind, and it is certain that the athletic movement was largely aided by the impetus it received from the return of the old public school boys to their homes throughout the country.

While, however, the schools were beginning to take up athletic sports in a tentative way soon after $185^{\circ}$, it is not until more than ten years afterwards that we begin to hear of a class of amateur athletes, as distinguished from professional 'peds,' holding meetings of their own. The pages of 'Bell's Life' during this period occasionally show us that amateurs were matching themselves against the professionals, and we find not only records of amateur matches where the contestants are described as amateurs (as in 1853 one between Mr. Green and Mr. Martin at 150 yards), but also cases of amateur meeting 'ped' (as in the preceding year the match between Green, 'the amateur,' and Michael Turner). The time, however, was getting ripe for amateurs, as we find even the highly respectable 
' imes' newspaper recording matches like the one mentioned above between Lieut. Sayers and Captain Astley, and another between Mr. Whaley and the Hon. Arthur Wellesley, who ran a match for $I_{50}$ guineas on the Donnybrook Road in 1854 . Something was, however, wanting to set athletic meetings going outside schools, colleges, and bodies such as the Honourable Artillery Company, which held its first fixture for its own members in 1858 , and the required impetus was probably given by a renewed burst of public excitement over professional pedestrianism in $\mathrm{I} 860$ and the following years. In $\mathrm{I} 860 \mathrm{~L}$. Bennett, better known as 'Deerfoot,' a Canadian Indian, appeared on the scene in England, and there began a series of matches between him and the best English pedestrians, which excited the public interest even more than the great period of ten years or so before. The performances of Bennett, Lang, Siah Albison, Teddy Mills, Jack White, and a score of other celebrities of this period set the public talking again about foot-racing, and in the winter of I86I the West London Rowing Club held an athletic meeting, thinking that their rowing men might like some hard work and exercise to keep them in training during the winter season. As far as we can discover, the first 'open race' for amateurs was held in the summer of I 862, when Mr. IV. Price, a promoter of pedestrian handicaps, decided to offer at the Hackney Wick grounds a 'handsome silver cup' to be competed for by 'amateurs only,' thinking doubtless that this would prove a new attraction to sightseers. The report of this open amateur handicap, which took place on July 26 , I 862, shows that as a means of provoking speculation in the betting way it was rather a failure ; but to amateurs the race is interesting for other reasons. In the first heat the reporter says that the betting was 6 to 4 in favour of Mr. Green, who beat Mr. Johnson, but that 'not much was done.' In another heat Mr. Spicer (who belonged, by the way, to the Honourable Artillery Company) started off at mark with Mr. Chinnery, who was afterwards to make so great a name as a holder of many champion ships. On this occasion, however, Mr. Spicer outlasted Mr. Chinnery, and beat him. 
On August 30 in the same year Mr. Price offered prizes for two more open races at a quarter and three-quarters of a mile. In the former, 'Mr. Martin,' whom athletes will perhaps be surprised to hear was no other than the veteran Civil Service walker, Mr. C. M. Callow, was one of the competitors, as also was Mr. Walter Rye, afterwards champion walker, who, however, appeared in his own name. Another of the competitors was Mr. C. H. Prest (afterwards a celebrated amateur, but of somewhat doubtful 'amateurity'), who ran under the name of Baker. There was at the time a prevalent idea that an amateur athlete should conceal from the world his taste for athletics, as the report of this meeting in a sporting paper mentions the runners who had appeared in the mysterious style as Mr. R-e, Mr. N-m, and so forth. Possibly, however, the reporter, acting on the principle 'omne ignotum pro magnifico,' thought to lend importance to the budding amateurs by thus throwing an air of mystery over their names. At this second meeting at Hackney Wick, Mr. Chinnery, in the three-quarter mile race, had again to succumb to the redoubtable Mr. Spicer, although receiving ten yards' start from him.

It is not until the next year that the stray London amateurs made any effort to form themselves into a club. In June of the year 1863 certain gentlemen, including in their numbers some of those who had figured at the West London Rowing Club meetings and Price's handicaps, founded the Mincing Lane Athletic Club, calling the club after that well-known trade centre, in which the majority of the founders were engaged in business. In 1864 they held their first meeting at the West London grounds at Brompton on April 9, but so little attention was paid to it that we cannot find that a report of the meeting appeared in any paper. Another meeting was held on May 2 I of the same year, in which Mr. Chinnery won the mile race, and on that occasion a full report of the proceedings was published in all the sporting journals. During the year two challenge cups for 220 yards and io miles walking races were presented to the club, which has ever since been 
a flourishing institution. In the spring of I866 the club changed its name, and became, as it now is, the London Athletic Club.

It is from the year $\mathrm{r} 864$, indeed, that amateur athletic sports as an institution may be said to date. Not only did a regularly constituted athletic club begin in that year to hold open races, but the same season witnessed the institution of the Inter-University sports. Negotiations were carried on in 1863 between the two Universities as to the holding of an Inter-'Varsity contest; but before anything could be arranged, the summer term with its cricket and boating arrived, and it was found impossible to get the athletes together. However, on March 3, I864, the Cambridge men came over and met their Oxford brethren on the Christchurch Cricket Ground. On this occasion neither side won the 'odd event,' for the excellent reason that there was no 'odd event' to win. The programme consisted of eight contests, and four were won by each University. Since then it is hardly necessary to say that the meeting has been annual, although the University athletes did not come to London until 1867 .

The same year, I864, saw the Civil Servants hold their first meeting - a meeting which still is an annual and important event ; but it wanted yet a year or two before amateur athletics became general throughout the provinces as well as in London. In I 865 several football and cricket clubs promoted meetings, but it is not until I 866 that we hear of athletics being generally practised throughout the kingdom. By this time the amateurs had decided to have nothing to do with the professional 'peds' of the day, owing to the 'roping' and 'squaring' tactics of some, of them which were notorious. At the beginning of 1866 , when the Amateur Athletic Club was formed by some old University and London athletes, the prospectus anrounced that the club was formed to 'supply the want of an established ground upon which competitions in amateur athletic sports might take place, and to afford as completely as possible to all classes of gentlemen amateurs the means of practising and competing against 
cne another, without being compelled to mix with professional runners.' The newly formed Amateur Athletic Club held a championship meeting in the spring of I866, which was a conspicuous success, and this was the first of the long series which are still being continued under the management of the Amateur Athletic Association. The intention of the founders of the Amateur Athletic Club was no doubt to place their club in the same position with athletes as the M.C.C. stood to cricketers, and the design at first seemed to promise well, for the championship meetings were very successful, and in two years' time the club opened a splendid running ground for amateurs at Lillie Bridge, which immediately became the headquarters of amateur athletics. The active athletes, however, continued to ally themselves more with the L.A.C. than the A.A.C., and the latter club soon ceased to hold any meetings but the championship.

It is hardly necessary, however, to pursue the history of athletics since the year I866. By that year sports had been instituted in most of the large provincial towns as well as in many rural districts. 'The Athlete,' a record published in I867, gives an account of nearly a hundred meetings held in England, and the same publication for the ensuing year shows that the number had then swelled to nearly a hundred and fifty. The progress of amateur athletics has since been rapid and continuous, and there is now hardly a single town throughout the country which does not have its annual athletic meeting. But by the year I 866 amateur athletics had definitely taken their present form, and though clubs have waxed and waned, and popular farour has ebbed and flowed at intervals, a generation of Englishmen has recreated itself with athletic sports in the same shape. The system of sports which had its growth in England has been successfully transplanted not only to Canada, Australia, and other British colonies, but to the United States ; and it is now no rare event to find Englishmen, Irishmen, Scotchmen, Americans, and colonists competing together in the championship meetings of the Old Country. 


\section{CHAPTER II.}

\section{A MIODERN CHAMPIONSHIP MEETING.}

IN the foregoing chapter we have shown how the pastimes of running, leaping, and hurling of weights, which have always been followed by Englishmen as a means of amusement and for the display of rivalry, began rather more than a quarter of a century ago to be developed into a systematic sport, and have come at the present time to be considered, like racing and cricket, as national institutions. As regards social attention, athletic sports were probably at their zenith from I 870 to 1875 , for at that time the 'masses' had not begun to appear as amateur athletes upon the running-path. So far as wide-spread popularity amongst all classes is concerned, athletics have reached a height at the present time from which they may possibly fall, but which they can hardly exceed. As erery pastime has its day, and it is possible that another age may know no more of athletic sports than the present age knows of cambuc or the quintain, it may not be out of place at the present time to try to present to the uninitiated reader such a meeting as may be witnessed to-day, so far as the pen can avail to describe a stirring scene of life and movement. Every pursuit has its classic days-days which are vividly impressed upon the memory of those who study the sport. One of these was the Oxford and Cambridge meeting of 1876 , when M. J. Brooks, the Dark Blue President, jumped $6 \mathrm{ft} .2 \frac{1}{2} \mathrm{in}$. in height, when there was scarcely a foot of standing room at Lillie Bridge, and over I, Iool. was taken from the fashionable crowd that thronged to see Young Oxford compete against Young Cambridge. Another classic day was the championship meeting of I88 I, when I 2,000 people went to the Amateur Championship meeting at the Aston 
Lower Grounds, Birmingham, to see the pick of the English, Irish, and Scotch athletes meet the Americans, Myers and Merrill, for the English championship titles. Yet another such was the championship meeting of 1886 , held on July 3 , at the London Athletic Club grounds at Stamford Bridge-a gathering which for more reasons than one deserves to be preserved in accurate recollection.

The first event upon the programme is fixed for three o'clock, and by that time some two thousand spectators have assembled. About five or six hundred of these are at the lower end of the ground in the open walk reserved for the 'shilling public'; the remainder are near the stands and on the gravel at the head of the ground. They have paid two shillings for admission, and by a glance at them you can see that many hail from the country, and that all have come for pure sport. There may be, perhaps, a hundred ladies on the ground, but not more. The championship is a 'business' meeting, and the majority of the spectators know thoroughly the form of the men competing, and are already discussing the chances. All open betting is forbidden by the rules of the Amateur Athletic Association; but where there are sporting men, some will have their fancy, and betting there will be, but for small and often trifling amounts, and almost entirely between friend and friend. The day is a perfect day for athletics, very warm, so that men's muscles are supple and without a trace of stiffness, and with a slight breeze blowing up towards the stands, so that the times of the runners in the sprint races and hurdles are sure to be fast.

And now, before the runners come out, let us take a glance at the centre of the ground. On a large table facing the grand stand, but within the railings, are set out the handsome silver challenge cups, which each winner holds for the year of his championship only, but of which he can never obtain the absolute possession. Between the cups as they stand on the table are spread the gold, silver, and bronze medals of the Association. Each winner is to receive a small gold championship medal, which, let us hope, will remain an heirloom in his family. The second man in each race has a 
silver medal to keep. The bronze medals are for a different purpose, and may be regarded more as certificates of merit than as prizes. In most of the competitions, when a man is placed neither first nor second, but has done a performance which is of championship merit-for instance, has finished his half-mile under $2 \mathrm{~min}$. $2 \mathrm{sec}$, or his mile under $4 \mathrm{~min}$. 30 sec. - he is awarded the 'standard' medal.' No standard medals are given for the hundred yards or hurdle races, from the difficulty of satisfactorily fixing a standard and timing men to see whether they are within the standard time. Close by the winning post are gathered the reporters and the officials, while the rest of the greensward enclosed by the railings and cinder track is bare; for the orders are strict that none but the recognised representatives of leading papers and the officials are to be allowed inside the enclosure. There are about a dozen reporters, therefore, inside the track with the officials. The judges, who have in athletics, as well as in all other work, arduous and delicate work, are all tried men. The first on the list is A. J. Puttick, an old runner of the London Athletic Club, whose gigantic form is always to be seen at a gathering at Stamford Bridge, sometimes, as now, in a frock coat and glossy hat, and at others in that quaint æsthetico-athletic garb which marks his double character of amateur athlete and amateur violoncellist. Close by him is 'Jack' Reay, who a few years ago was champion hurdler, and the best flat race runner in the Civil Service. These two, together with G. P. Rogers, the Secretary of the London Athletic Club, and C. H. Mason, of the same club, once amateur champion at a mile and ten miles, are four of the men who have led the athletic movement in the metropolis for the last dozen years, and are, perhaps, the four best judges in London. The two last named are both on the ground to-day as members of the conimittee, but are not judging. The two other judges are E. B. Holmes, one of

1 The standards are not the same for every year. They are fixed by the championship committee of the A.A.A. for each year, and the general tendency has been to raise them to accord with the gradual improvement in times and performances. 
the best of the well-tried officials of the Midland district, and H. Beardsell, of the Huddersfield Athletic and Cricket Club, whose sound sense and judgment make him as able a judge as he is a debater on the councils of the Amateur Athletic Association. Besides the judges there is a referee, who has absolute discretion to decide when judges differ; but when the judges are up to their work, as on this occasion, the referee's position is an honourable sinecure. Then there is the starter, $R$. Cameron, of Liverpool, well known to stand no trifling from the runners. For some years the starter at these meetings has been the professional 'Tom' Wilkinson, of Sheffield, but Wilkinson being otherwise engaged on this afternoon, the popular voice pointed out Cameron as the best starter amongst amateurs. The starter is helped by a 'marksman,' who places the men on the scratch, so that the starter may not have to move from the position he has once taken up, and may fire his pistol when he likes. The marksman of to-day is C. V. Hunter, one of the leading spirits of the Blackheath Harriers' Club, who is to be seen upon every Saturday afternoon officiating in some capacity at an athletic meeting. The remaining officials are the timekeepers-three in number-for in these days of 'record-breaking' there must be no doubt about times. After each race the three are to compare their watches and then announce the official times. All have 'fly-back' stop watches marking the division of the second into fifths. If all agree upon one time that is the official time; if all three differ, the middle time is given; if one watch differ from the other two, the 'verdict of the majority' stands as the official time. Besides the official timekeepers, there is another timekeeper, who, with the assistance of a 'standard judge,' decides who have got within the standard times. The 'standard timekeeper 'stands at the elbow of the 'standard judge,' and when, as for instance, in the first race, the half-mile, $2 \mathrm{~min}$. $2 \mathrm{sec}$. has been reached, the timekeeper, keeping his eye upon the watch, says 'Now,' and the judge, with his eyes fixed on the line, sees what runners have got within the standard, and will win the 
'standard medal.' Last, but not least, are the two 'clerks of the course,' whose business it is to call out the names of the runners in the dresșing-rooms, and see that they come out. upon the course up to time. In a club meeting, where there are many handicaps with large entries, the 'clerks of the course' have the hardest, as well as the most responsible, part of the day's work, as if they fail, or get behindhand, the whole meeting becomes demoralised. Here, there, everywhere, now on the track, now in the dressing-room, now soothing the feelings of this or that grumbler (for an athletic meeting is seldom without some competitor or spectator with an imaginary grievance), is Mr. Herbert, the energetic and courteous secretary of the A.A.A., who has had all the burden of preparing. for the meeting upon his shoulders.

The first race upon the programme is the half-mile, for which there were ten entries; but five of these fail to turn up at the post, Bryden and Nalder keeping themselves for the mile and the others making no appearance at the meeting. And here let us say that the championship meeting has since I880. been absolutely open to any competitor of any station in life provided he has not run for money or run against a professional in public ; so that the old 'gentleman-amateur' who enters for a championship knows that he may have to run a mile against a postman or put the weight against a blacksmith. The five starters for the half-mile are Haines, a countryman from Faringdon, in Berkshire, who runs gamely, but with a stiff, awkward action at the hips, which must waste his strength. Then there are the two crack Londoners, both members of the South London Harriers' Club, E. D. Robinson and Stuart Howard, of whom the latter was for some time thought the coming champion until he was beaten by Robinson in a level half-mile at the Croydon sports. Robinson is a tall bony-looking athlete, with a tremendous and rather slouching stride, which always induces the spectator to think that he is going more slowly than is actually the case. Stuart Howard has decidedly a more taking style than his club-mate, as he runs with his chest thrown back 
and erect, and his legs shooting straight out; but a high action is often more taking than successful. The field is made up with two other Londoners, J. A. P. Clarke and Bessell, neither of whom is much in the hunt to-day, though Clarke has done some fine times at a mile. When the pistol fires Haines dashes off with the lead at a hot pace but with laboured action; Robinson hanging close behind him. The first lap (half the distance) is completed in $55 \frac{2}{5} \mathrm{sec}$., Haines moving by this time with greater effort than ever. When another hundred yards are passed, however, Robinson spurts by him, and going up the back stretch seems to have the race at his mercy. Meanwhile Howard is creeping up, gets to Haines' shoulder at the top of the ground, and when the three enter the straight, I 20 yards from home, Robinson is half a dozen yards in front of the other pair. Howard shoots away from Haines in pursuit of the leader and gains slowly upon him, but Robinson, who is clearly tiring, can still keep his long stride, which brings him home a couple of yards in front of Howard in I min. $59 \mathrm{sec}$. A fine race and a fine performance is the opinion, for both men are clean run out, and to beat $2 \mathrm{~min}$. is what only some eight or ten amateurs have ever been able to do. Next come the heats of the 100 yards race. Ever since I 868 at the championship meeting the track has been roped off with iron posts and cords, so that each runner may have a clear course to himself. Just now sprinting is watched with peculiar interest, as there are four runners on the path, Cowie, Ritchie, Wood, and the new celebrity Wharton, of each of whom his friends aver that he is 'the fastest man who ever put on a shoe.' Cowie, for the three last years champion at this distance, has unfortunately broken down in training by a sinew giving way, to the intense disappointment of the public, who, however, are looking forward to seeing Wharton, of Darlington, who is a 'coloured gentleman.' The first heat, with Cowie absent, attracts little attention, and is won by Shaw, of Hereford. In the next heat Ritchie, the Bradford crack ; Wood, who trains on his farm in Norfolk; Levick, a speedy little 
Londoner, and Peter James, from Sydney, New South Wales, are the competitors. Ritchie gets away a trifle sharper than Wood, and when both are moving the Yorkshireman is half a yard ahead. With this distance between them they rush over the hundred, and Ritchie wins by a short head in $10 \frac{1}{5}$ sec., Levick being outpaced, and the colonial nowhere. Both Ritchie and Wood are well built for sprinting : the former is of middle height, has a tremendous chest, bull-head and large thighs. Wood is almost a giant, being heavily built all over, has a 40 -inch chest and scales over twelve stone. The third heat is known to be a moral for Wharton, but there is intense curiosity to see him move. When at the post with Bassett, of Norwood, Nicholas, of Monmouth, and a Londoner, C. S. Colman, he is seen to shape well, standing like a rock with his feet close together. At the crack of the pistol he is off like lightning, running in a wondrous fashion. Sprinting of many kinds has been seen : some sprint bent forward, some with the head and shoulders thrown back, but here is a man running away from his field with body bent forward and running almost on the flat of his foot. There is short time for wonder, however, as Wharton is half a dozen yards in front of Bassett when he bursts the worsted-for a worsted stretched between the posts breast-high has long since replaced the old-fashioned tape at athletic meetings. There is a hush in the crowd, while the three timekeepers put their heads together; for it is seen that the winner has done a fine performance. All three watches agree in marking Io sec. or 'level-time,' and when the telegraph board shows the figures a cheer bursts from the crowd, for at last after years of struggling and disputing a genuine 'leveltime' performance has been accomplished. Half an hour later Wharton comes out for the final to meet Shaw, Ritchie, Wood, and Bassett (the last two of whom as 'seconds' in the two fastest heats run again), and he is once more greeted with a cheer. In the final Wharton is not off so fast, and at ten yards Wood and Ritchie are in front of him; then the foreigner rushes ahead and is leading by two yards twenty yards from home. This time, however, he appears to tire a little-and no 
wonder, for sprinting is a violent effort and leaves the bones and muscles aching; Wood and Ritchie close on him a little, and Wharton wins by a good yard, with Wood this time a foot in front of Ritchie. The time again is ro sec., 'level time' twice in an afternoon-a marvel indeed!

Meanwhile between the heats and final of the hundred a gigantic Irishman, J. S. Mitchell, of the Gaelic Athletic Club, from Emly, County Limerick, has won the hammer throwing (a I $6 \mathrm{lb}$. hammer, four feet long, thrown from a $7 \mathrm{ft}$. circle), with a throw of tro ft. 4 in., his opponent, J. D. Gruer, of the London Scottish R.V., making but a poor show this year; and the two heats of the 120 yards hurdle race have been run off. In the first, C. F. Daft, of the Notts Forest Fuotball Club, and S. Joyce, of the Cambridge U.A.C., are first and second, while in the other heat (from which Croome, the Oxonian, who won the Inter.'Varsity Hurdles, is an absentee), G. B. Shaw, ${ }^{1}$ of the Ealing Harriers, and S. O. Purves, another Cantab, fill the first two places. Then comes the pole jump, in which F.G.F. Thompson, of the L.A.C., fails at ro ft., and Tom Ray, of Ulversion (who so far has never been beaten at this sport, and holds the present record of Ir ft. $4 \frac{1}{4}$ in.), ${ }^{2}$ wins his fifth championship with a leap of $\mathrm{I} \mathrm{ft}$. A marvellous jumper is Ray. He is a tall, rather heavy man, of fine proportions. Grasping the pole about its middle, he takes his leap, and when the pole is perpendicular, poises it almost at a standstill, raises himself clear up it by sheer force of arm, and shoots himself over the bar. Sometimes he poises the pole too long, and the present writer can once recollect, when he was acting as one of the judges at the Northern Counties Championship, seeing

1 Shaw left England for New Zealand, where he won the championship, and returned to England again, and during the years I89I, I892 and I893 was the best English hurdler. In the latter year he once covered the usual distance well inside $16 \mathrm{sec}$. In $I 89 \mathrm{I}$ and 1892 he was beaten in the championship by D. D. Bulger, a very speedy Irishman. In 1892 he was only beaten by a few inches in 16 sec., the third man, Batger, the New Zealand champion, being only a foot behind Shaw. Never did three such good hurdlers meet in one race before, and of the three I think Godfrey Shaw was the best upon his best day.

2 Ray was beaten at Southport on June 2, I888, by E. L. Stones, who jumped II ft. 7 in. The pair tied for the championship in 1888 , but in 1889 Stones beat Ray. 
the pole and jumper, after a moment of suspense, fall (to his great relief) upon the other judge. Then comes the final heat of the hurdle race. Daft, last year's champion, and Joyce, the Cantab, have another rattling race. For the first eight hurdles they rise together; at the ninth Daft has the slightest possible advantage, and as neither man is rising an inch too high, or thus wasting an ounce of strength, it is evident that the 'run in' will decide the race. Over the tenth hurdle Daft again has a shade of advantage, and, running on faster, wins by a yard in sixteen seconds, another 'record'-the second during the afternoon. Next comes the quarter-mile race-won last year by Myers, the flying American, but by this time Myers, like W. G. George, another amateur champion, has joined the professional ranks. There is little chance of another record being done in this event, for since first Myers in America cut into the old record of $50 \frac{2}{5}$ (done both by Colbeck in 1868 and J. Shearman in 1877 ), he has more than once beaten 49 seconds, and done times which probably no man, either professional or amateur, has ever touched. The race this year is set down for two heats, but as Cowie is hors de combat, and four others do not put in an appearance, the six runners are sent off in one heat. This is lucky for Wood, as he has two 'hundreds' out of him, while Lyle Smith, the Civil Service 'crack,' comes up fresh for this race. The other four starters are Wharton, whose phenomenal performance in the sprint makes people wonder what he is going to do in the quarter ; E. D. Robinson, who is nearly as good at this distance as at a half-mile; W. Lock, of Windsor, and Norman Jones, who are good men, but hardly good enough for their company. When the pistol fired for a moment everyone held his breath, for Wharton was seen to be flying off almost at top speed with the same extraordinary flat-footed action. Wood, who knew by experience how fast his opponent could travel, was determined not to let him get away, and so the pair ran away from their field down the long straight of nearly 300 yards, upon which the first part of the quarter is run at Stamford Bridge. But when a little more 
than 300 yards had been run it was evident that Wharton had shot his bolt; he died away and stopped, and Wood was left a hundred yards from home with a ten-yard lead; but upon him, 100 , it was evident that the pace had told, and it seemed doubtful whether he could last to the end. Slowly but surely Lyle Smith and Robinson, who were coming up behind, gained on the leader, and nothing but pluck and condition brought Wood in two yards in front of Smith, a yard behind whom was Robinson, the winner's time being $49 \frac{4}{5} \mathrm{sec}$ - a great time, for there are but few men like Myers, and no one until he showed the way ever got within 50 seconds. Here, as is always the case, the fast time was due to the pace-maker, as, besides the first three, Jones and Lock finished within the standard of 52 sec. ; and five men in one race finishing within $5^{2} \mathrm{sec}$. is almost a phenomenon.

The quarter being over, the mile, which is usually considered the race of the day, succeeded. For this there are eight entries, of whom seven are going to the post, and certainly they are a good representative lot. T. R. Bryden, of the Clapham Rovers F.C., was looked upon early in the season as a probable champion as soon as last year's champion, Snook, of Shrewsbury, was adjudged by the Amateur Athletic Association to have forfeited his claim to rank as an amateur. Then there is F. J. Cross, the Inter'Varsity runner, who in the spring showed himself good for 4 min. 27 sec. on any day. Haines, of Faringdon, is also having another try for a championship at another distance, and there is the dark horse from the West Country, T. B. Nalder, of Bristol ; it is rumoured, indeed, that a good many West countrymen have come up to put their money upon him. Besides these, Mabey, of the South London Harriers, has shown some good form of late, and Hill and Leaver, of the same club, are also starters. The race itself, however, is hardly in doubt from the start. Nalder gets off briskly with a lead, and is followed by Haines, Cross, and Bryden. The IVest countryman is a small thick-set man, with a fine free action and a good workmanlike style, running without effort, and 
with a long springy stride. For half a mile the positions arc unaltered, but in the third lap Cross, who looks a bit heavier and rather less fit than he was at Lillie Bridge in the spring, takes the lead and keeps it until three laps have been completed. Beginning the last lap Nalder spurts to the front again in easy fashion, evidently having the race at his mercy ; and, although Cross, ${ }^{1}$ who is a tall and strong youngster, chiries him gamely up the back stretch, Nalder gradually gets further away from his taller rival, and, coming down the straight looking very fresh, wins easily by twelve yards in 4 mir. $25 \frac{2}{5}$ sec. - a fine performance, as it is evident that he had a bit in hand if wanted. Cross, finishing gamely, just stalls off Bryden at the end, and beats him by two yards for second place, both Bryden and Mabey, who finishes fourth, beating 4 min. $30 \mathrm{sec}$, and gaining the standard medal. Four men inside 'four-thirty' is rarely to be seen, and when it was done ten years ago by Slade, H. A. Bryden, L. U. Burt, and T. R. Hewitt, it was thought that such a feat would never be repeated. However, that was at the time when $4 \mathrm{~min} .26 \frac{2}{5} \mathrm{sec}$. was the record, and not $4 \mathrm{~min}$. $18 \frac{2}{5} \mathrm{sec}$, as it is now. Then the next hour is taken up with the Seven Miles Walking Race. Walking races are hardly so satisfactory now as ten years ago, for judges are lenient and walkers aspire to fast times; consequently most of the walking seen on the running-path is of shifty character, and, if not absolutely a run, is more like a shuffle than a fair heel-and-toe walk. The walking race to-day is also to be marked with an unfortunate incident. C. W V. Clarke, of Reading, starts at a great pace, when he unfortunately loses a shoe, and Jervis, of Liverpool, a very doubtful goer, leads at the end of a mile, which is finished in $7 \mathrm{~min}$. I $5 \mathrm{sec}$. At two miles Clarke has caught Jervis again ( 14 min. $57 \frac{1}{4} \mathrm{sec}$.), and at three miles (22 min. $59 \frac{1}{5} \mathrm{sec}$.) the pair are still together. Before the fourth

1 Cross afterwards developed into the best miler of his day, and was, when fit, the best half-miler I ever saw run. He won the Inter-'Varsity mile four years running, was champion both at the Mile and Half-mile in I887, and at Oxford, in March 1888, covered the half-mile in I min. $54 \frac{2}{5} \mathrm{sec}$, still the best ou recoid. 
mile is reached, however, Clarke has shaken off Jervis, and as the latter has been cautioned by the judges for moving unfairly, he decides to leave the course. Clarke, however, begins to go very queerly, and finally, just before the fifth mile, staggers and falls from sunstroke, and has to be carried off the course. As most of the other competitors have by this time retired, $\mathrm{J}$. H. Jullie, who is still plodding along in the rear, is left, by the retirement of Clarke and Jervis, with the lead, and he eventually carries off the race in the poor time of $58 \mathrm{~min}$. $5 \circ \frac{1}{5} \mathrm{sec}$. For the High Jump, which followed, Ray, the pole jumper, E. J. Walsh, Nuttall and Purves, two old Cambridge blues, and Rowdon, from Teignmouth, in Devonshire, are the competitors. They jump off turf over a lath placed between upright posts, and not off cinders, as is sometimes done at sports, and as is better on wet days when the grass is slippery. The Devonshire man, a slim, boyish-looking athlete, takes but a short run and then goes straight over the bar. He easily beats his opponents, and wins with $5 \mathrm{ft}$. II $\frac{1}{8}$ in., the exact height being afterwards measured from the centre of the lath to the ground. The Weight Putting takes but a short time, There are two competitors, and Mitchell, who won the Hammer Throwing, wins the other heavy weight competition with a 'put' of $38 \mathrm{ft} .2 \mathrm{in}$. The weight ( $16 \mathrm{lbs}$.) is 'put' from the shoulder, the men being placed in a seven-feet square of cinder, marked off by boards projecting an inch from the ground. Within that square they can swing their bodies as they like, but if they 'follow' their throw outside the charmed square the judge cries 'No throw,' and no measurement is taken. The Long Jump is also a moral for one jumperJ. Purcell, of Dublin, last year's champion. The men have a long run of fifty yards or so (if they like to run so far) over cinder, and the 'take off' is from a board about an inch wide fixed level in the ground. Beyond the board the ground is hollowed out, so that if they over-run the mark the jump is sure to be abortive. It requires, however, much skill and practice not to 'take off' before the mark. Purcell, who in 
his six tries four times gets over $22 \mathrm{ft}$., wins with $22 \mathrm{ft}$. 4 in., E. Horwood, of Brackley, being second with $2 \mathrm{I} \mathrm{ft}$. $7 \frac{1}{4} \mathrm{in}$.

These last three events have been going on in the centre of the ground, while the long walking race is being held on the track. Next comes the Steeplechase, an event which did not appear in the championship programme until I879. Two countrymen-Harrison from Reading, and Dudman from Basingstoke-oppose Painter, the best representative of the metropolis. There are four circuits, over hurdles, mounds, and a water-jump, to complete the two miles. This contest also introduced a surprise, as Dudman and Painter, making a race between them, ran each other off their legs 600 yards from home ; and Harrison, who had seemed out of it, sailed by them as if standing still, and won anyhow. The last race of the day, however, produced another fine performance. Six of the best metropolitan cross-country runners had to meet E. D. Rogers, of Portsmouth, a runner who was little known until he made a good show in the Southern Counties Cross-Country Championship at Sandown Park in the early spring. Rogers is a stiff, ungainly runner, but apparently with tremendous strength; and, taking the lead from the start, he lurched over the ground at a great pace, completing his first mile in $4 \mathrm{~min} .50 \frac{1}{5} \mathrm{sec}$. and the second in $9 \mathrm{~min} .50 \frac{2}{5} \mathrm{sec}$, in itself a very fine performance. By this time he had the race at his mercy, having run W. H. Coad-the best Londoner-off his legs. In the third mile, in ${ }_{5} 5 \mathrm{~min}$. $25 \frac{3}{5} \mathrm{sec}$., Rogers did little more than keep his lead, and he finally won with great ease in $2 \mathrm{I}$ min. $\mathrm{I} \frac{4}{5} \mathrm{sec}$, not in itself a first-class performance, but the winner's two miles showed of what stuff he was made. So ended a great day's racing; and as the winners came up to receive their prizes it was only natural that most of them should have received a hearty we.come from the crowd.

The day's sport was remarkable in itself for more than one reason. For one thing, the average of merit shown by the winners was greater than had ever been seen before at a single meeting. The Hundred in Io seconds; the Hurdles in 16 seconds; the 
Quarter in $49 \frac{4}{5}$ seconds ; the Half in I min. 59 sec. ; the Mile in $4 \mathrm{~min} .25 \frac{2}{5} \mathrm{sec}$. : no such performances had ever before been done together upon one day by amateurs. But the meeting was also significant for another reason, though whether for good or evil to the sport it is hard to say. In the early days of the championship sports, from 1866 onwards, the majority of the events were carried off by the University athletes; and for the first ten years the struggle was between the 'Varsity runners and the old Public School men, the gentlemen amateurs from London and elsewhere who came forward to try conclusions with the Inter'Varsity runners. Of later years, since the championship in I880 was altered from the spring to the summer, fewer of the 'Varsity runners have competed, partly, no doubt, because it is awkward to train in the summer terms at Oxford or Cambridge, but partly, too, from the fact that the 'Varsity cracks are often not good enough to meet the highly trained and seasoned athletes who are the pick $0 \hat{i}$ the amateurs of the present day. At the championship of 1886 it became clear that the supremacy of the path had passed away for the present from the metropolitan to the provincial runners. The difference between the old style of London athlete, or the 'Varsity athlete, and the modern athlete from the provinces is not one of locality nor yet of degree ; it is a difference of class, of which we shall have to speak again; but the Stamford Bridge championship of 1886 shows that, until another development takes place, three-quarters of our amateur champions will be drawn from the masses. 


\section{CHAPTER III.}

RUNNING AND RUNNERS.

ALL must agree that running, walking, and leaping are the most simple and genuine of all competitions. When a Derby is won it is always a point for argument whether the greater credit is due to the horse or to the jockey; and when Cambridge is badly beaten over the Putney course there is always the critic to say that the Oxford weights were better arranged, that erratic steering threw away the race, or that the losers were underboated. The athlete who wins a big race owes nothing to his apparatus, and his success can only be due to his own excellence or his opponent's shortcomings. And even if running be more unsociable than rowing, it has the counterbalancing advantage for the individual that his success cannot possibly be ascribed to others. In every eight on the river there is said to be one duffer, and every one of the eight can be certain that someone considers him to be the man. In athletics a 'duffer' can only win by the help of a handicap; the cause of his success is then evident, and if he gets the prize he takes little credit with it. When the athlete has got a pair of the best shoes, a zephyr, and a pair of silk or merino drawers (called by courtesy knickerbockers) just not coming down to the knee, so as to leave that useful portion of the leg free, he has got all the stockin-trade required to win half-a-dozen championships. The science of athletics, then, consists in the scientific use of the limbs ; the tools of the athlete's trade are the thews and muscles of his own body, which God has made and man cannot refashion. Of the athlete, therefore, it can be said, more than of 
any other sportsman, nascitur non fit. Much, no doubt, can be done by training and practice, but no amount of either can make a man with small thighs a sprinter, or a man with a short 'fore leg,' that is leg between knee and ankle, a high jumper. To acquire excellence in these branches of sport demands knowledge of how to utilise the natural advantages of the body. Many men possessed of great natural excellences have, by a careful system of self-exhaustion, neutralised their

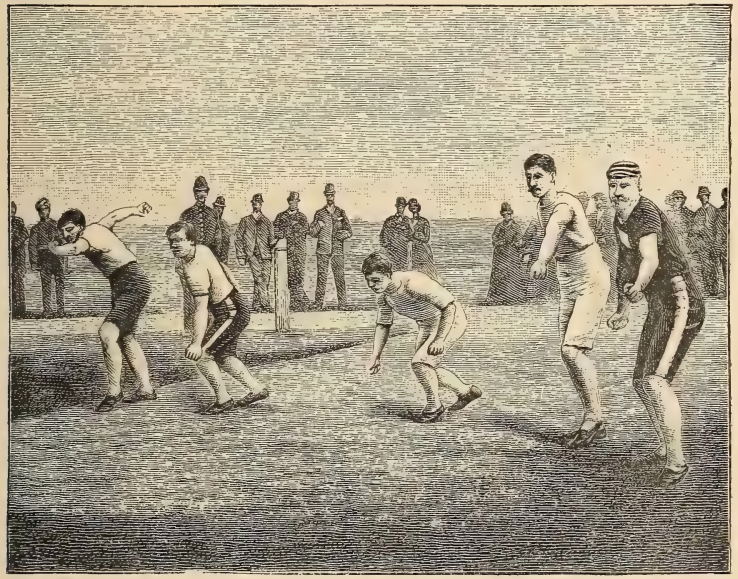

Ready to start.

gifts ; some others have also within our knowledge appeared almost to have acquired fine form from mere practice; but these latter are very rare examples. Of runners and the art of running -in so far as there is an art in running-we propose in the ensuing pages to offer some reflections and reminiscences, without actually going so far as to elaborate an actual manual of training. Of books on training there are already numbers, more or less valuable and more or less harmful, but books on 
training must always tend to fail in proportion as they are elaborate, because the end to be acquired is perfectly simpleto become hard and muscular, and at the same time to be in perfect and robust health, and sound in every organ, and no rigid rules can possibly suit all persons alike. Just as every man over thirty should, it is said, be his own doctor, so every man who has been a couple of seasons 'on the path' should be able to train himself. At the same time there are certain general rules which help a man to attain his best form, and these we shall not fail to enumerate.

First of all, then, before a man begins to train for any event of any kind he should have a good substratum of health and strength to start upon. If the would-be athlete is very badly out of condition, and fat and flabby from laziness and high living, it will do him no harm to take a Turkish bath to start with. Some smart five-mile walks followed by a good rubbing down with a rough towel on returning will soon make him fit to begin his training, if he has in the meantime kept regular hours and lived on a modicum of good healthy food of the kind to which he is usually accustomed. Without this preliminary care, not only will the runner get stiff and jaded by beginning violent exercise too quickly, but he will incur the greatest possible chance of straining or snapping a muscle, and thus placing himself hors de combat for a season. Granting, however, that our novice is, from the effects of football, walking, tennis, or cricket, in fair ordinary condition, we will follow his course through the different branches of athletics. And first as to sprinting.

SPRINTING, or SPRINT-RUNNING, is the technical name given to the running of those short distances over which a man can spurt or 'sprint' at top speed without a break. The roughand-ready experience of the last generation, which almost stereotyped the distances and conditions of racing, decided that 300 yards was the limit of sprinting distance, and that the next distance for racing purposes - the quarter of a mile-was something sui generis, and distinct from sprinting. Probably 
for the generality of runners the old and popular division of distance was right, but those who saw Myers and Phillips race for the English championship at Aston in I88I, or saw the American crack win his quarter-mile handicap at Lillie Bridge in 1884 , when he ran round his field and came in a winner in $48 \frac{4}{5}$ seconds, can hardly help arriving at the conclusion that with some phenomenal runners a quarter is only a sprint 'long drawn out.' But whatever be the limit of sprinting powers, sprint-running, which is always the most popular of all kinds of athletic sports with the public, is certainly something entirely different both in the action and in the essentials of success to the running over longer distances. In sprinting, the front muscles of the thigh, which bring the leg forward, are the most important factors for speed, as it is on the rapid repetition of the stride that the main result depends; in running of longer distances the back muscles of the thigh, which effect the propulsion, bear the chief strain. Both sets of muscles are of course used in every race, but the longer the distance the less important the front muscles become. And here we may perhaps give vent to a reflection which must often occur to those who consider a meeting of foot-races far superior in point of interest to a set of cycling matches. At a cycling meeting the same man who wins the mile race will probably win the five or ten mile races, and may even, like H. L. Cortis during his time, hold all the records from one to fifty miles. The reason is simply that, although there are differences of degree in stay. ing powers with cyclists, the same muscles are used for every race, while between the sprinter and the miler there is a difference not of degree but of kind. At a meeting of foot-races there is an infinite variety of different kinds of excellence. It is common for a runner to manage two distances well; he may be able, like F. T. Elborough or Colbeck, to run any distance between 100 yards and half-a-mile, but the man who can beat his compeers at every distance has not yet been found, and is not likely to be.

But to return to our subject of sprinting. The rapidity of 
motion, we have said, is derived from the front muscles of the thigh. The push comes from the back muscles of the thigh and from the small of the back. To convey to an uninitiated reader a notion of what real sprinting includes, he may be reminded that in longer races a man who wishes to pass an antagonist makes a rush or spurt for a few strides. Sprinting consists in a continued rush or effort at high pressure, and as such is far more exhausting than it seems. The foregoing reflections may serve to explain in some measure the many surprises and anomalies that a consideration of sprinters and sprinting suggests. Sprinting ability consists in the capacity to make a violent effort in the way of speed. It is therefore not a paradox to say that it requires as much cultivation as a capacity for any other kind of athletic sport. You may find the capacity in men who appear of all shapes and sizes to a superficial observer. Certainly your sprinter may be tall or short, may be of any weight up to thirteen stone, though he is rarely a feather weight. $\mathrm{He}$ is more often inclined to be fleshy than to be thin, and may be of any height, though he rarely is over six feet. Of some famous sprinters the unspoken reflection of many a spectator must have been, 'Well, you are the last man I should ever have thought could run fast.' When Junker, the Russian, who won the Hundred Yards Championship in 1878 , first appeared at an athletic meeting, a patriotic and jocose journalist described him as a 'bulky foreigner.' Another well-known sprinter, also a champion at the same distance, was advised by a competent authority to try some other distance, as he was too fat to run fast. Another curious thing about sprinting is the varieties of action in which good performers indulge. Junker sprinted as if he were badly bandy-legged, although we never knew that he was so. Lockton, of the L.A.C., who in his day was, we think, even faster than Junker, ran in the style most affected by professional pedestrians, with his body low and well forward. W. P. Phillips, who managed to beat Lockton for the championship in 1880, ran almost erect, looking even more than his full height of six feet. Trepplin, one of the fastest of the many fast sprinters who have hailed from the Universities, 
was a vision of whirling arms and legs. Junker was flatfooted and erect; Wharton, the champion of 1886, is flatfooted, yet manages somehow to bend his body far forward as well. Yet many and various as are the forms which sprinting ability takes, there are one or two signs by which a sprinter can be recognised. Whether his legs be short or long, he has large muscular thighs and a broad back. A sprinter, too, to use a cant phrase of pedestrianism, 'strips big'-i.e. looks bigger stripped than he does in his clothes; or, in other words, is a heavier man than he appears to be in his ordinary life.

But, before we discuss the best forms of sprinting and its exponents, we must say something of the practice and exercise which a sprinter should take in order to reach his best form. The best practice for a Ioo or I 20 yards race is to have continual bursts of thirty yards or so with another man, who is about as good or rather better than yourself. If practising with a man who is inferior, you should give him a short start in these 'spins' and catch him as soon as you can. Such practice both helps a man to get into his running quickly and 'pulls him out,' to use a trainer's expression; that is, the striving to keep pace with a better man, or to catch a man in front whom you can catch, involuntarily forces a man to do a little better than his previous best if he is capable of it. A man should never practise sprinting alone; he becomes sluggish, and can never really tell whether he is doing well or ill. If he is simply training for a I 00 or a I 20 yards race, after half-a-dozen of these spins he should take a few minutes' rest and then run the full distance, or at any rate a burst of seventy or eighty yards, before he goes in to have a rub down and resume his clothes. If he is training for 220,250 , or 300 yards he must, of course, accustom himself to longer trials; but in general, even for the longest of these distances, it is quite enough to run 200 yards at full speed. In fact, as a general rule, for all practice it may be laid down that a man should very rarely run a trial for more than two thirds of the distance for which he is training. In writing this we know that to many trainers such an opinion will beconsidered a rank heresy; but that it is a sound rule, at any rate 
to amateurs who have other daily avocations to attend to, which must occasion more or less fatigue, is our firm conviction. The great point in every race, and especially in a sprint or in a quarter of a mile, is to come to the scratch fresh. Our experience of amateurs is that two out of three of them come to the scratch in a big race a little bit overdrawn; but of this we shall have something more to say anon.

In the short sprints the start is, of course, almost half the battle, and a man should be continually practising a start and a ten-yards run-and very trying to the back the performance is. It is, of course, advisable to get accustomed to start from a pistol, but if there is no friend handy to fire a pistol or say ' $\mathrm{Go}$ ' without any warning, it is not a bad device to fling a stone over one's head in the air and start as soon as it is heard to fall to the ground. Some men we have known to improve a yard or even two by frequent practising at starts, and most hundred-yard races are lost or won by less than a yard. We need, perhaps, hardly describe the right attitude of the body for a start in these days when everyone has seen an athletic meeting. The runner should be on his toes, with the right foot seven or eight inches behind the left foot, which is on the line, and so that the chest is almost parallel to the line and bent slightly forward. Some in starting stretch their right arm forward so as to bring the chest completely straight to the line, but this is not adopted by all, and if overdone is, we think, a great mistake. The body should be balanced on the toes with the weight pressing slightly upon the right or rear foot, so that a good kick niay be obtained from it with the slightest possible delay when the pistol-shot is heard.

A large number of the best runners now start bending forward with their fingers resting upon the ground. When the pistol is fired they begin to run and raise themselves simultaneously. An additional impetus is said to be gained from the push from the fingers and the recovery to the perpendicular. There can be no doubt of the success of the method with many of its exponents. The new method of starting originated, $w=$ belicve, in America, and the first amateur 
who practised it with any success in England was T. L. Nicholas of Monmouth, the amateur champion quarter-miler of 1890. He soon found many imitators, and at first the exponents of the new style were allowed to start with their front foot upon the starting line and their hands touching the ground in front of it, but as this was found to give a very great advantage over those

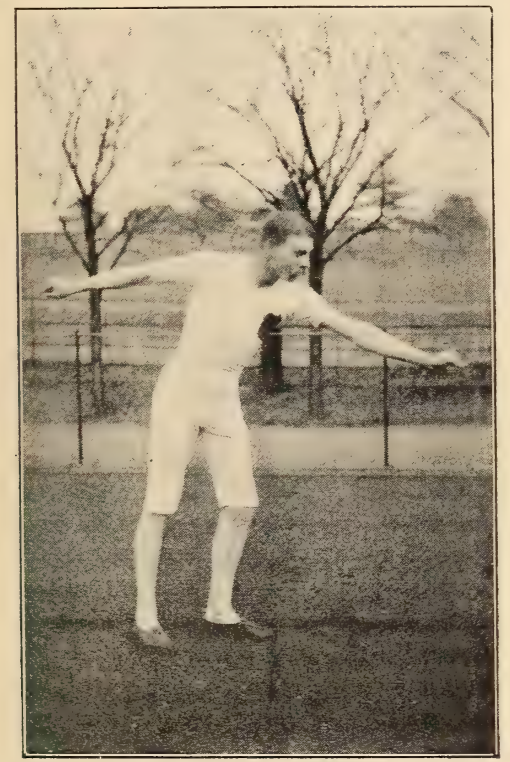

Starting-Old Style

who started erect with their foot upon the line, the rule was changed, and the starters of the new style have now to put their fingers upon the starting line and have their feet and body entirely behind it. There can be little question that those who can really master the new style profit by it, but there can be equally little doubt that the style is less suitable to tail and 
heavy men than to those who are shorter and more lissom. In the two illustrations which are given in this volume the exponent of the old style is E. C. Bredin, whose performances are given elsewhere, who has found, after trial, that the new style is not suitable to him. The second picture represents H. T. Bell of the London Athletic Club, who ran second in the

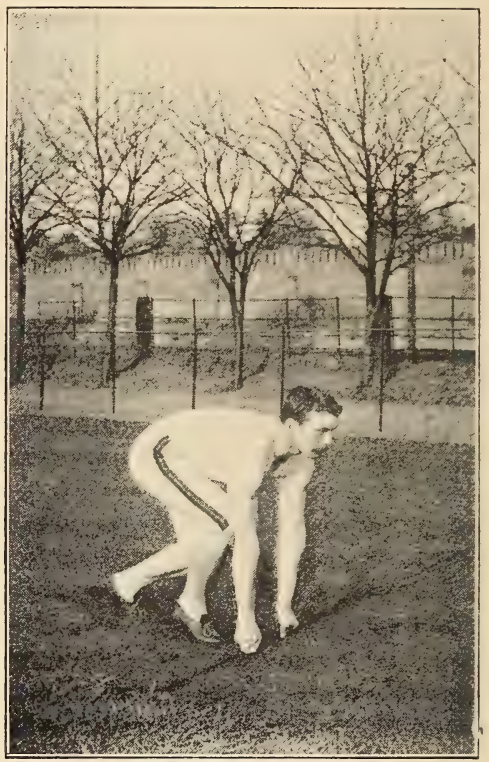

Starting-New Style

Hundred Yards Championship of $\mathbf{1} 893$. Bell is a shorter and slighter man, and scrambles off his mark with great rapidity from the new position.

Little more need be said of practising on the path for sprints. It must not be forgotten, however, that the sprinter wants to keep himself hard and fit during the time that all his 
racing practice consists of hard bursts for very short distances. A few miles' walking during the day is always good for health, but great care must be taken by the sprinter never to get stiff, for he has no time during his race to run off even the slightest stiffness. A trot once round the track at a moderate pace with a springy action to stretch the legs is also a good thing; but in these trots the sprinter should never let himself 'get off his

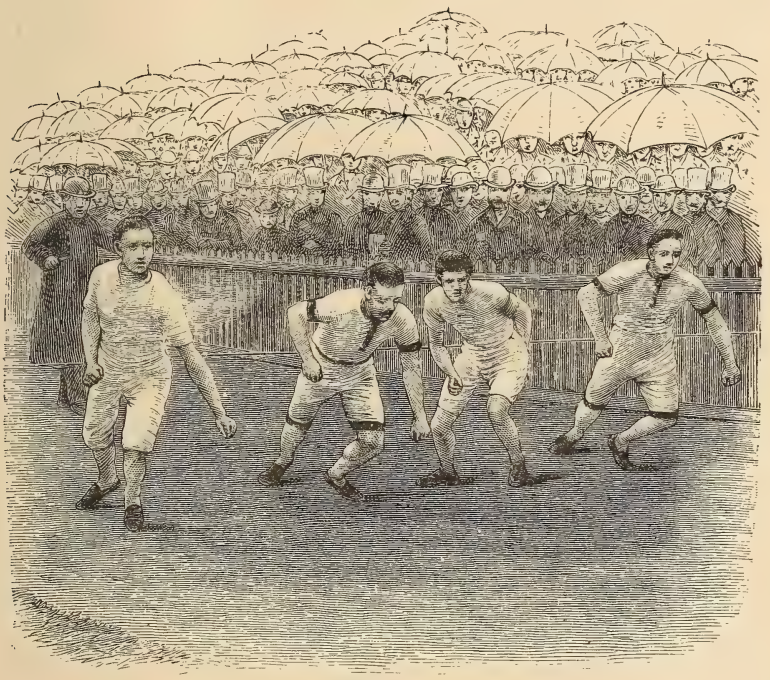

Started.

toes'-i.e. run so that his heel touches the ground; when his heel begins to come down on the ground it is a sure sign that he is getting jaded, and he had better leave off and walk back to the dressing-room.

The problem, therefore, which a sprinter has to solve, is how to get strong and muscular without getting stiff or slow from too much exercise. One aid to the solution of the problem is of a 
kind which would hardly be suspected by the uninitiated. It is to have a rubber. We do not mean that the sprinter should cultivate the study of whist (although we are sure that, if he is sensible, he will do so), nor do we mean that he should wear a golosh and use the American name for that article. A rubber is a man, occasionally a friend, usually a hireling, generally one's trainer, who sometimes with a glove or towel, but mostly with his horny hand, rubs you all over the body, but chiefly over the legs and back, until you are as muscular as a gymnast and as smootheci-skinned as an infant. Well can we recollect the vigorous rubbings of $\mathrm{Bob}$ Rogers and the cast-iron hand of old Harry Andrews at Lillie Bridge and the delicious glow and feeling of 'jumpiness' with which we used to stride out of the dressing-room after the operation was over. Well also can we recollect how a kindly fellow-undergraduate, now a muscular Christian, and himself, we hope, in training for a bishopric, essayed to keep the present writer in training when laid up for a fortnight by a sprain, by vigorous respertinal rubbings. But your amateur rubber is too perfunctory in his ministrations, and cannot vie with the professional exponent of the art.

The old professional trainers were strongly prejudiced against the use of cold water applied externally. A bath they thought weakening and relaxing, but though we cannot altogether agree with them in this dogma, we thoroughly concur in their belief in the efficacy of the 'dry rub.' It prevents any chance of stiffness, minimises the liability to catch colds, and its effect in hardening the muscles can only be known by those who have tried it. Most mell-advised athletes now take their shower-bath first and have their rub afterwards. Some men we have seen combining the maximum of rub with the minimum of wash in the following manner: The rubber fills his mouth with water from a glass, blows it in fine rain over a portion of the victim, and then proceeds to polish that portion first with a towel and then with his hand. The process may be efficacious, but we never felt inclined to try it.

Although a hundred yards takes a very short time in running, a good many amateurs have earned a long and lasting 
reputation by their performances over the distance. We have heard many speak of W. M. Tennant, of Liverpool, who won the championship in 1868 , but to this generation of runners he is but a name. A contemporary of his was E. J. Colbeck, undoubtedly the best amateur of his time, but scarcely so good at 100 yards as at 300 yards or a quarter of a mile. We can recollect Colbeck running a dead heat at Lillie Bridge in a hundred yards with A. J. Baker, who won the championship in 1870 , and who was probably the fastest Londoner over the distance until quite recent times. Colbeck was a very tall, heavy man, who sprinted with his chest thrown back, and he owed his speed, we think, more to his tremendous stride than to any true sprinting capacity to make a rush. Baker was a sprinter pure and simple, and, as far as we recollect, 'ran low,' in what is to our mind the best and most workmanlike sprinting style, with his body bent well forward. Whether a man can change his sprinting style is, we think, rather doubtful; but it is obvious that, if the chest be not thrown well forward, the stride must be shortened by the drag which the weight of the trunk will put upon the legs. This, we think, the pedestrian trainers must well know, as nearly all, and even the mediocre, pedestrians 'run low' when sprinting. The trainers also, we think, believe in the efficacy of their craft and of coaching to completely alter a man's style, for we know on good authority that a Sheffield trainer came up and accosted one of the London heavy-weight sprinters, whom he had seen running at a Northern meeting, and told him if he would learn to run a bit more forward he would beat ten seconds in a month. We have, however, seen so many men get over sprinting distances with all sorts of actions that we feel doubtful about the wisdom of interfering with a man's natural action as far as sprinting is concerned. As a rule, when the sprinter has settled down to his practice and is improving in pace, his style involuntarily begins to approximate in a greater or less degree to the best model.

From the year I869, when J. G. Wilson, Worcester College, Oxford, scored his first win in the Inter-University Hundred Yards, to the year I879, when E. C. Trepplin, of 
B.N.C., Oxford, scored his last win at the same meeting, it is hardly too much to say that the pick of the best amateur sprinters came from Oxford and Cambridge. With Trepplin the race of University sprinters seems unaccountably to have reached an end, for from 1880 to the present there has been no really fine sprinter at the Universities, although there have been plenty of fine performers at longer distances. Of these University sprinters, Wilson, who won in 1869,1870 , and 1871 , and secured the championship in 1869 and 1871 (Baker being the winner in 1870 ), was perhaps the pick of the lot. $\mathrm{He}$ was a well-made man of medium height and weight, and ran in irreproachable style with a free stride, his body slightly forward and chest perfectly square. After Wilson's retirement, W. A. Dawson, a Cambridge athlete who won both the Inter-University and Championship Hundred Yards, was decidedly the best runner of the next year. Dawson was a shorter man than Wilson, but ran in much the same style, and though a small man was thick-set with a strong-looking chest and back. Of the succeeding University runners, Urmson, of Oxford, a tall thin man with a very long stride, who was a capable performer at any distance from 100 yards to a mile (a rare phenomenon), was better at a quarter-mile than a sprint. As with some others, his speed came from his long stride more than from a rapid repetition of the stride; and he was an inferior man at a sprint to Trepplin, the last and perhaps the best of the Oxford sprinting celebrities. Trepplin, who won at the Oxford and Cambridge sports in 1877,1878 , and 1879 , had a contretemps at the start of the Hundred Yards race at the championship meeting in 1877 , and declined afterwards to compete at the championship meeting. He was over six feet in height and weighed close upon thirteen stone, being big and muscular all over. His style was anything but pretty, for, although he bent his body well forward when sprinting, he had a great deal of ungainly arm action, and until fit found it difficult to run as straight as an arrow on his course, as most sprinters do naturally. Strangely also, though possessed of great muscular strength, he was quite incapable of staying any distance, and though he could, when trained, run $5^{\circ}$ 
yards in a level 5 seconds, could not rely upon himself to run 220 yards, and was unable to stay home in any longer sprint than 150 yards. Had Trepplin competed in the championship of 1878 , however, he could hardly have beaten the Russian, L. Junker, who was the Hundred Yards champion of that year. Junker, like Trepplin, never attempted anything but the shorter sprints, and was only once beaten in his brief and brilliant career upon the running-path during the season of 1877 and I 878 , when in July $\mathbf{1} 877$, in a level Hundred Yards race at Birmingham, he ran third to J. Shearman and H. Macdougall, both of whom, though sprinters of the first class, were lucky enough on that occasion to meet Junker on one of his off days. Junker was $5 \mathrm{ft} .9$ in. or $5 \mathrm{ft}$. Io in. in height, and had a very stiff action, running almost on the flat of his foot; but though ungainly he was of great strength in the legs and back, and to these qualities his speed was doubtless due. The story of his introduction to the running-path in England is rather a quaint one. On one occasion he appears to have been 'chaffed' by some business acquaintances in the City as to his clumsiness and slowness. Upon this he remarked that he was a good runner-a remark which was followed by a roar of laughter. The Russian thereupon waxed warm and volunteered to run one of the mockers for a bottle of champagne. The match was made and came off at Stamford Bridge, when Junker beat his opponent, who was a fair athlete, by the 'length of the street.' The result was that he joined the L.A.C. After winning a few handicaps he soon found himselt at scratch, and able to win from that position; and, as was noticed above, was only once beaten. Unfortunately he did not meet Trepplin during his year of supremacy upon the path, but Bob Rogers, the ground-man of the L.A.C., who trained both athletes at different times, was strongly of opinion that in a match between them there would have only been one in it, and that one Junker. Indeed, the opinion of Rogers was that Junker would have found a more dangerous opponent in C. L. Lockton, who was undoubtedly the best sprinter of I879. Lockton had a very long career upon the path, having 
been something of an 'infant phenomenon.' When a schoolboy of fifteen he was quite able to hold his own amongst good company, and was only sixteen when he won the Long Jump championship in I873. He soon seemed to deteriorate from overwork, but in 1875 again he cleared over twenty-two feet in his school sports at Merchant Taylors', and was then almost the best sprinter and hurdler in England. Some unlucky accidents kept him from the path, and he was not really seen at his best until 1879 , when, at one of the rival championship meetings, he won the Hundred Yards, Hurdles and Long Jump in the same day. Lockton was, we think, the most beautifully-proportioned runner we ever saw on the path, and would probably have been first class at any distance he chose to take up. Unfortunately he left behind him, as some others have done, the reputation of being a 'fine runner but a poor racer.' In practice his trainer timed him to do level time over a hundred yards day after day, but on more than one occasion he succumbed to his inferiors, notably in the championship of I880, when he was beaten by a few inches by W. P. Phillips and Massey. Lockton both sprinted and hurdled in a very graceful and taking style, and the contrast between him and Phillips when they ran together was most marked, Lockton running low and Phillips perfectly erect. For the next three years (I880, I88I and I882) the Championship Hundred Yards was won by IV. P. Phillips, the best English amateur at a quartermile before Tindall's day, whose untimely death from heart disease in $188_{3}$ came as a shock to the athletic world. Phillips, who was over six feet, was, like Lockton, a model of manly strength, and was a splendid oar as well as runner. From 220 yards to a quarter-mile he was unrivalled, but a hundred yards was hardly long enough for him. His three championships were each won by a few inches, and in each case a lucky start had something to do with his victory. His runner up in I88I and I8S 2 was J. M. Cowie, who afterwards took the championship at this distance for three years, and was possibly superior, and certainly not inferior, to Lockton and Junker and the older cracks. Although only of medium height and calibre, he, like 
the other celebrities, was very strong in the back and thighs, and his superlative form was in a great measure due to years of persistent and careful training ; for though he was of firstrate ability as long ago as 1880 , it was not until r 884 or 1885 that he showed his very best form. The other celebrities of the day at sprinting, Wharton, Ritchie, and Wood, have been previously described. Wharton was undoubtedly the speediest at roo yards, but Wood excelled him at the longer sprints, and

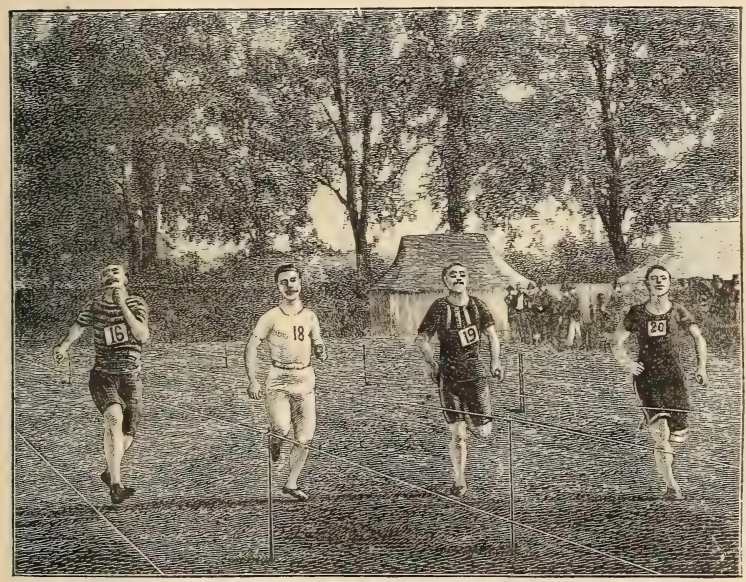

Sprinting of to-day.

in 1887 'cut' all the old records from $I 50$ to 300 yards. Wharton has recently joined the professional ranks. It is always an unsatisfactory task to attempt to compare the athletes of past and present days in any branch of sport, and, although in longer races the time test can be applied satisfactorily, the conditions of wind, weather, and ability of timekeeper prevent timing in short sprints from being an absolutely certain guide. As far, however, as any line can be taken through times, there seems to be but very little difference between 
the merits in sprinting of the chief cracks during the last fifteen years. $^{1}$

The next distance beyond the 300 yards sprint which is regularly run is the quarter of a mile, although managers of athletic meetings who desire a novelty, or ambitious competitors who flatter themselves that they will obtain some credit by making a record over a distance which no one has ever tried before, occasionally promote a race at some intermediate distance. As a general rule, however, it may safely be said that the experience which decided what distances should be regularly run was not at fault, for of the distances of 220 yards, a quartermile, half-mile, and mile, each brings forth a totally distinct class of runner, who may excel at his own single distance and at that alone. Generally the quarter of a mile is a most interesting race, as it gives an opportunity both to the man who has real sprinting pace and to the man who has stay and strength. As an example of how much reliance can be placed upon the popular manuals of sport, of which so many are published, we may perhaps quote with advantage the sapient remarks contained in one of these publications which is no:v before us. 'The quarter-mile race,' says our author, ' is about the severest course that can be run; it requires both pace and stamina.' So far he is doubtless right, for runners have been known to 'run themselves blind' before reaching the tape in this race; that is, have been so exhausted that they could finish and feel the tape, and yet were unable to see anything. After stating, however, how severe the 'course' is, the practical directions given for preparation for the race are that the athlete 'should run the racing distance only once a day.' A moment's reflection should show even the uninitiated how absurd this advice is ; for it practically amounts to this : 'To make a man fresh and strong, to give him both spurt and reserve of energy upon an approaching day, you should make him thoroughly

1 C. A. Bradley of Huddersfield was the amateur champion of 1892 and I893. He was a strong thick-set man of moderate height, who ran erect and straight as an arrow. In the championship race of 1893 he ran slightly up-hili and against a slight wind and reached home in Io seconds, a record which speaks for itself. 
exhaust himself at least once a day.' It is advice of this sort which sends athletes into the hospitals or to an early grave, while, if they had passed their youth in a sensible and rational course of training and practice, they would have laid in a stock of health and strength which would have rendered them independent of a doctor's advice for the rest of their lives.

It may seem a paradox, but it is, we think, true, nevertheless, that there are two entirely different ways of preparing for a quarter-mile race. The reason is this, that the distance is a common ground for two entirely different classes of runners. On the one hand, the best quarter-miler of the day is often the man who is the best sprinter as well, and has found that this distance is not beyond his sprinting powers when he is very fit. On the other hand, the sprinting quarter-milers sometimes find themselves outclassed by a runner who is of nothing more than second-class sprinting ability, but whose stay and strength enable him to keep his stride from shortening up to the very end of a quarter-mile or even farther. To take some examples from the present day. To Cowie and Wood the quarter is really a sprint, and nothing else. But a pair of Cambridge runners, IV. H. Churchill and R. H. Macaulay, occur to our mind who were indifferent sprinters, and yet could beat $5 \mathrm{I}$ seconds for a quarter-mile, and could probably have reached 50 seconds if pressed; while H. R. Ball is another example of the same class. Even Myers, the best quarter-miler by a very long way who ever appeared in the amateur world, was of no particular account at any distance shorter than 200 or 220 yards. The first class of quarter-miler can rarely (if ever) attempt any distances over the quarter, even the 600 yards race being beyond his powers. On the other hand, the second class is often seen at the top of the tree at 600 yards or half a mile as well, as were Colbeck, Elborough, and Myers. ${ }^{1}$ With regard,

1 H. C. L. Tindall and E. C. Bredin have since shown themselves runners of this class. At the championship meeting of 1889 Tindall won the Quarter in $48 \frac{1}{2} \mathrm{sec}$. and the Half in $I$ min. $56 \frac{2}{5} \mathrm{sec}$. on the same day. At the championship of 1893 Bredin won the Quarter in $49 \frac{1}{5}$ and the Half-mile in I min. $55 \frac{\mathrm{l}}{\mathrm{s}} \mathrm{sec}$. on the same day. What a race there would have been could the pair have met at 600 yards, both fit and well! Neither of the men was up to championship form at roo yards. 
then, to training for a quarter-mile, it is easy to understand that the two classes of runners should not prepare themselves for a quarter upcn exactly the same system. To lay down a short and comprehensive rule for the first class, we should say that the sprinter who trains for a quarter-mile should train for it in the same way as he does for a sprint. His trial spins should be over longer distances up to 220 or 300 yards, and his stretches round the path or the grass - we mean the slow stride round upon the toes which we have already described-should be longer; but, being a sprinter, he should recollect that it is upon his speed and freshness that he must rely to win, and he should on no account let his practice jade or exhaust him. Once and once only (if at all) should he run the full distance of the quarter at full speed, and after that should take a day of almost complete rest. A hard quarter-mile run out is likely to exhaust and impair the energies for a long while, and if once a man in training gets a bit stale, it is a far harder task to bring him back to fitness than to make him fit in the first instance. A personal reminiscence may perhaps avail to point a moral while this subject is under discussion. The writer and his brother were both training for the Amateur Championship in I878. Unfortunately they were ill-advised enough to run two matches before the event to find out for certain which was the better man, but in the second race they were so closely matched that they ran each other to a standstill. This was a week before the race, and the consequence was that on the day of the race both were utterly and hopelessly stale. From the result of the race it became evident that their only two opponents were in an equally 'weary, flat, stale, and unprofitable' condition, for the race was won in the slow time of $52 \frac{4}{5}$ seconds. When such a fact occurs as the only four entrants for a championship race coming to the scratch orertrained, it may be gathered that a warning against doing too much work is not unnecessary.

The sprinter then who trains for a quarter-mile should take his starts and short sprints daily, and finish up two or three times a week with bursts of 200,220 , or occasionally 300 yards, and at the same time should from time to time take his practice 
strides upon his toes more frequently than if he were merely training for 100 yards; but he should never forget that he is a sprinter training for a sprint, and that his speed must be retained at all cost. The same reflection should be present in his mind when he is in the race. It will be the height of folly to try and make the race slow in the hopes of his sprintin:; powers bringing him in at the end. At the end he may be jaded and unable to utilise his speed, and if he be not near the front then his chance of winning is gone. His right course is to use his speed while he has it, and in the first 100 or $15^{\circ}$ yards he may have made a gap of five yards between himself and his slower opponents, who are relying on their staying powers. Then let him slacken if he likes, but only to go off again when his opponents are again at his heels; and if he be not overtrained, his speed and reserve of energy will serve to bring him up to the finish first.

Most of the advice given by books and by trainers as to the practice for a quarter-mile race comes down from the times when it was thought that 300 yards was the limit of a sprinter's powers, and sprinters accordingly did not think of attempting so long a distance. The result is that an amateur training for a quarter of a mile is usually persuaded to overwork himself, and he not only runs himself stale, but may perhaps impair his health. Ali this eril arises because trainers, and those who rely upon books and precedents more than upon their own common sense, act as if the desideratum must always be the reduction of weight and the acquisition of staying powers.

The second class who are found competing for quarter-mile races are those who have moderate sprinting ability, and owing to a naturally long stride and good staying powers never flag over the distance and finish as strong as lions. These runners can, no doubt, stand a good deal more work than the mere sprinter. They can run their quarters without that amount of exhaustion which is felt by the runner the limit of whose tether is the quarter, and they may doubtless run their trials over the whole distance half-a-dozen times during their month of training without doing themselves anything but good by such a large 
amount of exercise. They must not, however, on any account neglect their speed, and frequent starts and short spins must be practised in addition to their longer trials; for some time or another during the race, if a quarter-miler of this class is to win, he must spurt past his speedier opponents. Even with these, however, cur own experience has shown us that more men come to their rare overdrawn than unfit. As it is with diet, so it is with exercise; each man must be treated in the preparation for a race with that amount and that quality which will suit his individual case, and the mistakes that are made come from following a system with unreasonable subservience without recollecting for what ends the system was originally adopted.

In considering the performances of celebrated sprinters we have seen that it is hard to say whether those of the present or the past day are better, but in coming to the quarter-mile and longer distances there can be no doubt that the runners of the last few years have done better times over these courses. The reason is not only that the men are better trained, and that out of the larger number of competitors there is more chance of finding a veritable champion, but there is this further consideration, that it is only by slow degrees that athletes have discovered of what amount of speed and stay the human body is capable.

In the early days of athletics a quarter-mile was often treated by good runners as a waiting race, and the times of good races were accordingly very slow. For the first two years after the establishment of the championship in I 866 the quarter-mile race was won by Ridley, an Eton boy, who certainly must have been a phenomenon, as in 1867 , while still at school, he won the Hundred Yards and Quarter-mile Championships in the same day. The times, however, can show nothing of his real ability, as they were as follows : in 1866,55 seconds; in $1867,52 \frac{3}{4}$ seconds. In the following year, when Ridley was at Cambridge, he showed something of his true powers, for in the Inter-University meeting of that year he won the Quarter-mile in $5^{1}$ seconds, winning with some ease. That year, however, he was not destined to 
be champion, for it was then that E. J. Colbeck appeared in his best form. Colbeck is one of the first great figures that stand out in the history of amateur athletics. Few could beat him at 100 yards, while from 220 yards to half a mile no one was in the hunt with him. He was a tall, strongly-built man, with a tremendous natural stride, to which and to his strength he owed his remarkable success. Unfortunately, he, too, like W. P. Phillips, whose performances in some sense recall those of Colbeck, was doomed to find an early grave. The tale of Colbeck's celebrated quarter-mile at the championship meeting at the old Beaufort House grounds in I 868 is one that has beer. often told. Coming along at a great pace, he led all the way round the ground, and was winning easily when a wandering sheep found its way upon the path and stopped still there, being presumably amazed at the remarkable performance which the runner was accomplishing. The athlete cannoned against the sheep, broke its leg, and then went on and finished his quarter in $50 \frac{2}{5}$ seconds. This time was never equalled until $\mathrm{J}$. Shearman in 1877 covered the distance in exactly the same time at Lillie Bridge, and was never surpassed in England by an amateur until Myers paid his first visit to England in I881. Since that time Myers has shown what can be done by running a Quarter-mile handicap at Lillie Bridge in $48 \frac{4}{5}$ seconds, and since r88I several English amateurs have shown themselves capable of beating 50 seconds. Probably, what might have been learnt from Colbeck, and what was not really learnt by English amateurs until Myers put the Englishmen to shame, was that it is possible for an amateur to make a sprint of a quarter-mile and rush at full speed over the whole distance. However, none of the subsequent times can take away from Colbeck the honour of having made a record (and certainly under unfavourable circumstances) which stood its ground for thirteen years during times when every other record made by Colbeck's contemporaries had been long since surpassed and forgotten. Furthermore, it is evident that Colbeck was by no means rendered hors de combat by his wonderful performance, for upon the same 
afternoon he won the Half-Mile Championship in 2 min. 2 sec., then a record and at all times a fine performance, and made a good show in the Hundred Yards against the winner, W. M. Tennant. If there ever was an English amateur able to hold his own with Myers, Colbeck was probably the man. ${ }^{1}$

The next pre-eminent performer at a quarter-mile after Colbeck was R. Philpot, of Cambridge. Curiously enough, while Oxford was for so long famous for her sprinters, Canıbridge produced a long line of famous quarter-milers. Pitman, Ridley, Philpot, Churchill, and Macaulay all came near to Colbeck's time, but could never quite approach it. Of this line, as far as it is possible to judge between men who were not contemporaries, Philpot, by general consent, was the best ; indeed he was credited with having beaten 50 seconds at Cambridge, although the sporting authorities could never be induced to accept the record. At his first appearance at Lillie Bridge he was beaten by R. V. Somers-Smith, of Oxford, as well as by his colleague, A. R. Upcher, the winning time being $50 \frac{4}{5}$ seconds under exceptionally favourable conditions. However, in the Inter-University meeting of $187 \mathrm{I}$, Philpot, upon a cold and windy day, covered his quarter in $5 \circ \frac{3}{5}$ seconds, running Colbeck's time very close, and in 1872 he won the same race again as well as the championship. Philpot, though not so tall as Colbeck, was of the same style, tall and strong, and was a good enough sprinter to run J. G. Wilson to a yard in I $S_{7} \mathrm{I}$, but he was par excellence a quarter-miler, that distance being his real forte. Philpot, however, at that time would have found no mean opponent in J. C. Clegg, of Sheffield, who during the summer season in the provinces could almost count on sweeping the board at any meeting of all events from roo to 600 yards. Clegg was a very tall man, hardly so thickly built as Colbeck or Philpot, whose pace, as with Colbeck, came from his stride, but as most of his performances were over grass, the times show nothing of his merits. In 1874 nnother of the great figures of athletic history, F. T. Elborough,

1 In the championship meeting of $1889, \mathrm{H}$. C. L. Tindall ran the quarter in $48 \frac{1}{2}$ secs., beating Myers' English record, but we never saw any quartermiler so good as Myers at his best. 
appeared upon the scene, and before his appearance another provinciai runner, W. L. Clague, of Burslem, somewhat unexpectedly displayed in London an extraordinary performance at a quarter-mile. Starting in a handicap at Lillie Bridge in 1873 , in which he was unable to get nearer than third, he undoubtedly covered his distance, untimed, in something well under 50 seconds. Clague originally made his appearance as a hurdler, and, as a rule, in sprints and quarters used to be unable to beat J. C. Clegg, but at the time of which we speak, when he appeared in London, he struck us as one of the finest natural runners we ever saw. He was of medium height and weight, but ran with his body low, and with the smallest possible appearance of effort, although his stride was very long for his height, indeed the length of stride seemed in no way due to length of leg. He took long and easy bounds over the ground, and both in build and style of running was not unlike Cowie, although the latter had not that peculiar ease and lightfootedness which distinguished Clague. Unfortunately Clague never met Elborough, who was the leading figure amongst amateur runners of short distances, during the three seasons of 1875 , I 876 , and 1877 , and who during that time divided with Walter Slade, the miler, the reputation of being the most famous amateur upon the path.

Elborough was well above the medium height, being quite $5 \mathrm{ft}$. Io in., and weighing, we believe, about I s st. in training. Although not so strong physically as Colbeck, who must have been a couple of inches taller and a stone heavier, in his capacities he was a second Colbeck, as his long stride made him a sprinter hard to beat at 100 or 150 yards, and invincible at 220 or 300 yards. As a quarter-miler he had no one to extend him, and as, although he trained assiduously, he was somewhat fitful and fanciful in his appearance on the path, he did no performance at this distance at all worthy of his reputation. A line, however, can perhaps be drawn by collateral form which would show his powers. In two quarter-mile races in two successive years at the Civil Service Sports a handicap of seven yards brought Elborough and J. Shearman together. The 
latter was doubtless an improved man when in $1 \delta ; 7$, in a match with H. H. Sturt, he covered the quarter at Lillie Bridge in $5 \circ \frac{2}{5}$ seconds, but at any time Elborough at his best could, we think, have given five yards to the elder Shearman. Indeed, his trainers and the public never doubted that Elborough, had he been wound up for a quarter, could have got well inside 50 seconds. In those days, however, the feverish desire for making records (which we think the athletes have caught from their cycling brethren) was not raging, and runners like Elborough liked to win their races and their championships without troubling to scamper over so many yards of cinder a shade faster than some predecessor. In style Elborough ran very erect, shooting his legs out in front of him. He was cleanly but not strongly built, and his excellence as a runner must be set down to his perfect proportions. Up to the spring of 1876 we believe he never attempted more than 600 yards, and was in training for the Hundred Yards and Quarter Championships of 1876 , but being dissatisfied with his speed, altered his mind at the last moment, and started for the Half Mile and the Quarter, winning both with great ease. Ultimately he proposed to extend his practice to mile running, but being beaten in the provinces in the summer of 1877 at I,000 yards by C. Hazenwood, he never afterwards made a show upon the path.

In I880, IV. P. Phillips, who had been doing some fine performances at 220 yards, turned his attention to quarters, and had he run with a little more judgment in his initial attempt in the championship of that year might have earned the title upon the first occasion he ran a quarter in public. Phillips, however, who was a very fast sprinter, seemed by some fatality bound to make a fiasco of all his attempts to win the Quarter-Mile Championship, and, although undoubtedly capable of a better performance at this distance than any Englishman since Elborough, either from nervousness or bad judgment, invariably spoilt his chances by running ton slowly in the early part of the race. Thus he was beaten in I 880 by M. Shearman, in $\mathrm{I}_{88} 2$ by H. R. Ball, and in $\mathrm{I}^{8} 88_{3}$ by Cowie, 
although he was undoubtedly a better man than any of the three over this distance. In I880, after racing off fast, he slowed in the middle until he had allowed the winner to get seven or eight yards away from him, and then was only beaten by two yards at the finish. In 1881, when he met Myers, who was undoubtedly too good for him, he pushed the American crack along the whole way, was not shaken off until Ioo yards from home, and then only finished three yards behind the winner in

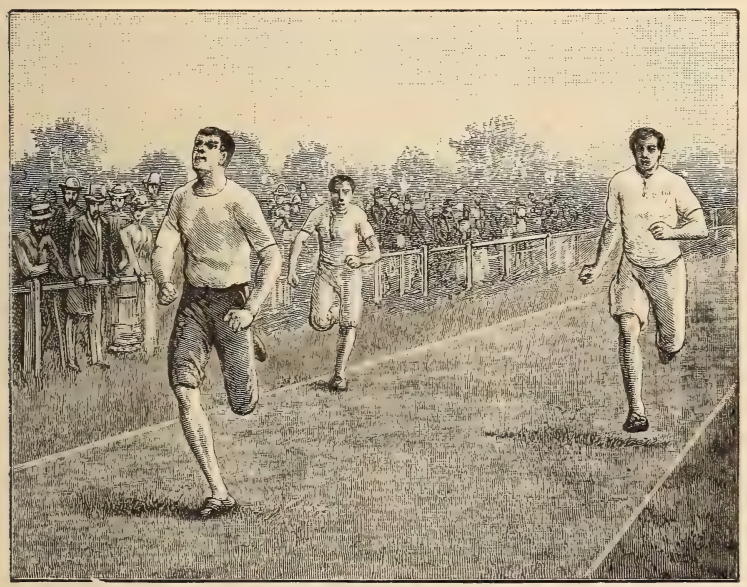

A very fast sprinter.

$48 \frac{3}{3}$ seconds. The Aston track, upon which this race was run, is certainly very fast for a quarter, the last 300 yards being downhill; but whatever the time was, Phillips showed his extraordinary excellence by being the only man who could ever make a race with Myers at this distance. In $\mathbf{I} 882$, therefore, with Myers out of England the Quarter Championship seemed a moral for Phillips ; but, to the intense astonishment of everybody, he started as if he were going for a mile race, and never 
had the least chance of catching H. R. Ball, who sprinted throughout, and won in the fine time of $5 \circ \frac{1}{3}$ seconds. Probably Phillips, who was certainly not deficient in pluck, as his race with Myers showed, suffered all along from the 'weak heart' from which he suddenly died in the next year, and to this must be ascribed the disappointing form he displayed on some occasions.

During the last few years, Cowie, Wood, Ball, and Tindall, the old Cambridge 'blue,' have all done performances equal to or better than $5 c$ seconds for a quarter. Probably, however, the improvement in quarter times since Myers appeared in England is due to the lesson taught by that runner, that to run a good quarter one must be prepared to 'spin' all the way, and there will very likely yet be seen some further developments in the way of fast quarters in the next few years. $^{1}$

Our survey of famous quarter-milers may aptly be concluded with some notice of Myers. There is very little doubt that this runner, while in his best form, some years ago, could have approached very near to 48 seconds in his quarters, a performance which it is improbable that any other runner, amateur or professional, could have compassed. Myers, in more senses than one, was a phenomenon; his physical conformity was somewhat marvellous, and of a kind not likely to be soon met again. Although about $5 \mathrm{ft} .8 \mathrm{in}$. in height, his weight was only just 8 stone, and from a glance at a photograph which we have before us of the American in running costume one fact strikes the eye at once: that his legs are disproportionately long as compared with his body. According to his own account his mother died young of consumption, and Myers himself, although not appearing in the least consumptive, certainly was not troubled with an ounce of superfluous flesh. Being, then, little more than a long pair of wiry legs, with a very small and light body upon the top of them, it is hardly surprising that he should have made a very good

1 Since this was written H. C. L. Tindall has run a quarter in $48 \frac{1}{2}$ sec. at Stamford Bridge. 
running machine. Certain it is that Myers' extraordinary times over a quarter and a half mile arise from the fact that, as he begins to tire and labour in his running, his stride appears to lengthen instead of shortening. Those who have noticed him running quarters have seen that about the middle of the race, when the English heary-weight sprinters take their first breather, Myers is enabled to shoot away and place a gap of half-a-dozen yards between himself and the second man without an apparent effort. Having, in fact, no weight to carry, no distance under a mile can tire him, and this it is, we think, which enables him to run right away from any opponent at any distance where staying power is a necessity as well as speed. Certainly Myers is unlike any of his predecessors at this distance; whether another will ever appear like unto him it is hard to say.

A very favourite distance at athletic meetings is 600 yards ; but, although the race is so common, it can hardly be considered a distance in itself, as it is very rarely that the winner who can manage 600 yards is not capable of doing a half-mile as well. The fine sprinter, who may be able, by a certain amount of staying power, to make a first-class quarter-miler, cannot, as far as ordinary experience goes, manage 600 yards. In fact, at any distance over the quarter, one may say that staying powers are more important than speed. The man who can run 600 yards comfortably can probably do any distance whatever creditably, while many sprinters could hardly cover a mile as fast as a schoolboy. In a 600 yards race, therefore, the sprinting quarter-milers are found conspicuous by their absence. It is a race which cannot be won by the winner rushing off fast and making use of his pace while he has it. In a word, the man who can run 600 yards comfortably may safely train for a half-mile as well, and it is not necessary to consider the runner of 600 yards apart from the half-miler.

The medium distances, however (600 yards, half-mile, I,, 00 yards), produce a distinct type of runner, who mus $i$ be trained in a distinct way. Many men, like the Hon. A. L. Pelham, H. W. Hill, of the L.A.C., and T. E. Wells, the Oxonian, were half-milers pure and simple. The half-miler is 
sure to be good at a quarter and good at a mile, for he must have speed and stride, and must have as well good wind and staying powers; but many and many a runner can only find his true distance at half a mile or I,000 yards, and until he trains for these distances misses his real vocation upon the cinder-path. The system of taking exercise for races changes completely as soon as sprinting distances are left behind. The man training for medium distances will, of course, do himself all good and no harm by sprinting to improve his speed, but his sprinting is only an accessory, and not the essential, to success. He has got to improve his legs, wind, and all the muscles of his body in strength, and the way to do this is not gradually to lengthen the distances of practice so much as gradually to increase the pace over those distances. As we have said before, the man who is training for half a mile will do enough to take his trials over 600 yards, or thereabouts. As he gets fitter he should accustom himself to go faster over his spin. Once or twice befure the race he may have 'a full-dress rehearsal' - a veritable trial over the whole distance, that he may know exactly what he has to do in the race, and the more walking he can get in the day the better, as there is nothing so healthy, and so little exhausting, to a man in training as brisk walking in fresh air.

Suppose, then, the half-miler has got himself into the state of preliminary fitness, and is going to give himself three weeks of training for a race. On the first day he will do with a steady equable 600 yards. On the second day a brisk 600 yards, which will stretch his limbs a bit, and remind him that running is not all pure enjoyment. On the third day he may take it easy again, and do a very slow, steady half-mile, without making any attempt to spurt, or quicken, or push himself along at any part of the course. On the fourth day he can do the brisk 600 yards again; on the fifth a steady and slower 600; on the sixth a rather brisker 600 yards than he has done before; and then, if he takes a good walk on the intervening Sunday, he will feel himself at the end of his week a good deal more like a 
runner than he was at the beginning. A similar programme will do for the remaining three weeks of training, but his full trial should be at least a week before the race, and for the last few days before the event he should take no spin at all that can possibly exhaust him. Indeed, on the day before the race a sprint or two will be quite sufficient to maintain him in the state of fitness to which he has arrived. Above all, if on

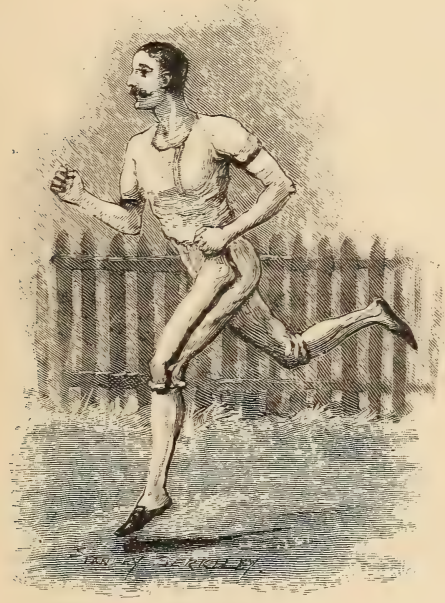

In condition.

commencing practice any day he feels that he has not got over his yesterday's exertions, he should make a point of having a light day's work upon that occasion, as it is always better to do too little work than too much. But the runner, while practising, should never forget that the main object of all his practice is to improve the even pace which he can accomplish over the distance. In medium and long-distance races the runner must accustom himself to run at an even pace, and at as fast 
an even pace as he can command over the distance, keeping his spurts for when they are wanted, either to pass an antagonist or to get in front at the finish; so that, in training for these distances, it is of importance to know how fast one is going. It is wise, therefore, to be timed from day to day by a trainer, who will tell the man what pace he ought to go for the distance he is running for the day, and whether in the actual spin he has got inside it or not.

A word might here be interposed as to the tactics of a race. In medium or long races an immense deal in the way of success depends upon the judgment with which a race is run. If you decide to pass an antagonist you had better spurt to do so, and not try to pass him slowly, as this may end in his shaking you off again. If you spurt by an antagonist you may possibly take the heart out of him, and he may shut up 'like a telescope' on the spot. Another reflection which a runner should always bear in mind is, that when the dreadful thought occurs to his mind that he is 'done,' it should be succeeded by the reassuring idea that his opponents are probably equally 'done' also. If this latter rule were always borne in mind we should not see, as we often do, cases in which the race does not fall to the swift but to the plucky. As a corollary to the two practical rules given above we may mention an anecdote which aptly illustrates them. We saw a match at Oxford between two cracks at 600 yards. The distance was rather beyond both runners, who were really quarter-milers. Before the run home was reached both parties had shot their bolt. The one in the rear, feeling himself 'done,' decided that a desperate state of affairs required a desperate remedy, and pulling himself together, rushed clean past his antagonist with a spurt. The antagonist immediately shut up, but the winner was so much done that he could hardly crawl home in very slow time. We have since seen many important races where it has struck us that, had the beaten man made another effort, he could have turned the battle; but iie has allowed himself to be defeated by some plucky 'cutting down' tactics of an inferior opponent. In the 
spring champronship of 1879 , M. R. Portal, the Oxonian, a beautiful mover and a magnificent runner, was cut down at the end by E. Storey, who won in $5 \mathrm{I} \frac{2}{5}$ seconds at a time when Portal was quite equal to doing time a second better. In justice to Portal however, of whose merits Bob Rogers thought unutterable things, it must be said that he came to the scratch far from fit on that day. Want of condition is an admirable thing to

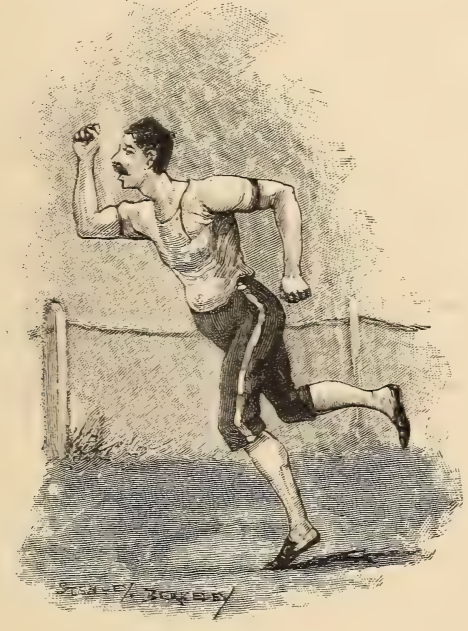

Out of condition.

breed irresolution in a race, and while it is easy to be game when one is fit, it is far harder for a jaded man to keep his gameness and a good head upon his shoulders. One game little runner, E. A. Sandford, the Oxford miler, certainly won both his Half-mile Championships in 1874 and 1875 from faster men by pluck and judgment.

Although the half-mile has always been an event at the 
championship meeting since its foundation in I 866 , the halfmile races were usually competed for by the long-distance runners alone, until Colbeck won the Half-mile Championship) in 1868 ; indeed, in 1867 an Oxford runner won the Halfmile Championship with a time of 2 min. $5 \mathrm{sec}$., which is what any moderate performer can now achieve. Colbeck's successor in the championship for two years was R. V. Somers-Smith, the Oxonian quarter-miler, after which the Hon. A. L. Pelham attained the honour. Pelham was the tallest man whom we ever recollect to have seen figure on the running-path. He made his first appearance in London while, we believe, he was still a schoolboy at Eton, and being as long and leggy as a colt and some three or four inches over six feet, excited great astonishment by his prodigious strides. At Cambridge he was a contemporary of $\mathrm{G}$. A. Templer, who was also a fine quartermiler, and who ran in 1872 a dead heat for the Half-mile Championship with T. Christie, the Oxford miler, in what was then the unbeaten time of $2 \mathrm{~min}$. I sec.; but in a race at Cambridge soon afterwards Pelham eclipsed the performance by beating for the first time 2 minutes over Fenner's path, finishing in the race in front of Templer. Pelham, with his prodigious stride, was too tall and leggy to spurt, and accordingly was not a first-rate performer at a quarter, and at the same time had not sufficient staying powers for a mile, so that he never made a good show for his University, as there is (more's the pity) no half-mile race in the Oxford and Cambridge programme. He was purely a half-miler, and undoubtedly the best of his day, and no one until 1876 contrived to repeat his performance of finishing the distance within 2 minutes. A year or two later H. W. Hill appeared in his best form, and showed himself, when thoroughly fit, to be as good at a half-mile as any of the champions, although he occasionally had to succumb at this distance to Walter Slade, the miler. Slade in I 874 was holding undisputed sway over every distance from half a mile to four miles; but twice in the races for the L.A.C. Challenge Cup was beaten by Hill in the autumn. Hill, 
strangely enough, seemed never to be able to get fit until late in the summer, and, indeed, his running excellence apparently was quite as much due to persistent practice as to natural ability. Still, however Hill's speed and stay were obtained, he was certainly a magnificent performer at half a mile and r,, 00 yards. He was of about medium height, and weighed, we suppose, less than Io stone, but, although not a sprinter, ran with the greatest dash and determination, and being faster than Slade, when he could beat him, won by sheer pluck in running the mile champion off his legs by forcing the pace. Strangely enough, about this time another famous runner, who, like Hill and Pelham, was a half-miler and nothing more, appeared upon the scene in Ireland-L. H. Courtney. On two occasions Courtney met and beat Slade at this distance in Ireland, although he was by no means Slade's equal at a mile. Courtney was taller than Hill, and ran, like Clague and some other fine natural runners, with a springy action, bounding over the ground with a very light foot. However, at the end of $I S ; 5$ Courtney retired, and early in I $8 ; 6$ Slade appeared to be the best half-miler left upon the path, as he had managed to beat Hill in the spring of that year, while Pelham had also apparently retired. In this year Slade again did some fine performances in Ireland, once beating 2 minutes in Dublin, and at Belfast soon afterwards beating I min. $59 \mathrm{sec}$, over grass. By this time great things were being whispered about of Elborough's capabilities at this distance, and by a happy thought the committee of the L.A.C. managed to get together all the four cracks of the dayElborough, Slade, Hill, and Pelham-to compete for the L.A.C. challenge cup at the autumn meeting in $18 ; 6$. The meeting attracted an immense crowd and produced a race the recollection of which can never be effaced from the memory of anyone who witnessed it. Pelham, bounding array in front with his gigantic strides, led by several yards until the first quarter had been completed, when the others began to draw upon him, Slade being in front of Hill and Elborough acting as whipper-in. Along the top stretch, 250 yards from home, Slade closed upon 
Pelham and took the lead into the straight. Once well into the straight Hill made his effort, however, rushed past the pair, and took a lead of several yards. Then came the shouts for Elborough; the champion was seen striding up to Hill, and a hundred yards from home he took the lead. Hill, however, ran with the greatest determination, and chased the winner home, being only beaten by about three yards. Half-a-dozen yards or so behind Hill came Slade, and about an equal distance behind Slade came Pelham, all four finishing within 2 minutes, Elborough's time being I min. $57 \frac{1}{2} \mathrm{sec}$., Hill's I min. $58 \mathrm{sec}$, and Slade's and Pelham's a shade inside I min. $59 \mathrm{sec}$. and 2 min. respectively. Here, as in other cases when good men meet, they serve to extend each other, and some fine performances are the result.

In 1877 Elborough was beaten at $\mathrm{I}, 000$ yards by C. Hazenwood, a Northern runner, who afterwards came to London. The latter, like the others we have mentioned, although a fair miler, was only first class at the medium distances. Of his powers while still a provincial runner many tales are told, and he is freely credited by some of his admirers with having done I min. $56 \mathrm{sec}$. or thereabouts in practice. He was a small man, with by no means a taking style, and after he came to London certainly never displayed any remarkable performance. We believe that when he defeated Elborough he was better trained than any amateur before or since ; for, according to one enthusiastic admirer, he was so fit that his face and skin absolutely shone.

In I88I when Myers paid his first visit to England he met the best English cracks at half a mile at Stamford Bridge in June, and after forcing the pace for three-quarters of the distance left the others as if standing still and won at his ease in I min. 56 sec. That Myers could have knocked off a second or two from this record if pressed we have very little doubt, and his easy win was hardly wonderful. What is more wonderful was that the second and third men, S. H. Baker and S. K. Holman, both sterling good runners, but who had never got within 2 minutes before, were so far 'pulled out' by having the pace 
forced by a better man that both, we believe, finished the distance well within I min. $59 \mathrm{sec}$. Neither Baker nor Holman, however, was in our opinion so good at half a mile as William Birkett, the champion of $188_{3}$, who was a veritable half-miler, being too heavy in build to be as successful at a mile. Birkett was a tall, broad-shouldered man with much stay and strength, and was probably better than any of the half-milers who have run during the last few years, with the possible exception of George, whose semi-professional training even while he was an amateur made him too good even at the shorter distance for any other amateur under ordinary circumstances. Recently, however, the Oxonian, F. J. K. Cross, has surpassed all previous performers by covering a half-mile at Oxford in the spring of 1888 in $\mathrm{r}$ min. $54 \frac{3}{5}$ secs.

In training for long-distance races, in which category we should place those at a mile and upwards, improvement of speed is of course the object of attainment as in every other race, but the improvement is that entirely which comes from increased staying powers and wind; and for the purposes of training it is these latter alone which must be cultivated. The system of training, therefore, is substantially the same in kind as that we have recommended for the half-mile runners; and as the miler is necessarily one who is possessed of natural stamina, he is able to bear the increased amount of exercise and longer spin, which he must necessarily get through to acquire the requisite strength of muscle and lungs. The system for all training for long distances, to describe it shortly, is to take continual and daily spins of half a mile and upwards, the pace being gradually increased as the man finds he can stand it. If the runner takes a long spin or a very fast spin one day and finds upon turning out the next day that he feels slack from the previous day's exercise, he will do well to take an easier day's work on that occasion. The same system in the main will apply whatever the distance to be run, only if it be a very long distance the daily spins must be lengthened correspondingly. One runner may of course be at his best at one mile, another 
at four, and another at ten miles, but all the three are runners of the same class, bring into exercise the same muscles, and require in varying degree the same essentials to success. The exercise they need is such as will get the limbs hard and the wind abnormally good. All will do well to walk as much as they can without making themselves stiff; when they start their running on the path in earnest they must get over a daily spin of half or two-thirds of the distance, and when they run the full distance should aim not at spurting from time to time, but at discovering what is the best even pace they can maintain over their full journey. It is hardly necessary, therefore, to point out what essential assistance is given by a 'watch-holder,' who can tell the runner at what pace he is doing his laps, so that he can know whether he is keeping up the speed he wishes. In these longer distances it is hard to give advice as to the actual daily work which should be undertaken. The following table is supplied to us by two successful distance runners who used it :

\section{One Mile.}

First day.-Two-thirds of a mile at steady pace.

Second day.-Half-mile.

Third day.-Slow mile.

Fourth day.-Fast half-mile.

Fifth day.-Six hundred yards at steady fast pace. Sixth day.-A fast three-quarter mile.

Four Miles.

First day.-Two miles sluwly.

Second day.-A mile.

Third day.-Three miles.

Fourth day.-A mile, faster.

Fifth day.-Two-thirds of a mile steady fast pace.

Sixth day.-Two miles steady fast pace.

On the seventh day, wind and weather permitting, each runner would take a brisk Sunday walk, of from six to ten miles, taking care not to catch a chill, and to be well rubbed down after the walk as well as after the runs. 
To the statement that the miler and ten-miler are all of the same class, there is one important qualification. The longdistance runner is rarely over middle height or middle weight, and frequently is undersized. Whatever his weight is, the runner has to lift it all at every stride, and consequently all the weight of the body, except that of the muscles which are actually used for travelling over the ground, is simple dead weight which has to be carried. As the distances are lengthened, the heavier man gets more and more handicapped, and at ten miles, or in long cross-country races, the smaller and lighter men come more and more to the fore. The crack long-distance runner rarely weighs more than ten stone, and a man of the calibre of Walter Slade, six feet high, and weighing over II stone, is rare on the path. There are occasional exceptions ; thus Deerfoot was, we believe, a very heavy man for his height, which was medium. Some of the best professionals, however, were very light men; Jack White, who at the time of writing still holds the five-mile record $(2+\mathrm{min} .+0 \mathrm{sec}$.), weighed 7 stone rolbs. ; Howett, of Norwich, 7 stone 8 lbs. ; while Lang and Cummings were both under ro stone. Indeed, on comparing crack amateurs at shorter and longer distances, the difference is striking; Colbeck, who was a six-foot quarter-miler, weighed over I 2 stone; Slade the miler, who was of the same height, was more than a stone less.

And at this juncture, we feel inclined to offer a respectful suggestion to our brothers, the 'coaches' on the river. It is a constant occurrence for the newspapers to record how the coach, after taking the crew for a long course, afterwards took out Nos. 5 and 6 , the heavy weights, for some tubbing practice. Apparently then the coach believes that Nos. 5 and 6, being the biggest and most muscular of the crew, can stand the greatest amount of work. This may be so: there are no invariable rules as to physique and stamina ; but it is abundantly proved from military, as well as athletic, experience, that the biggest men are not those who can stand the most work. In average cases, then, the coach had much better give some extra 
work to bow and No. 2 than to Nos. 5 and 6 . We should not offer the advice if we had not seen so many big men trained stale, and then abused for laziness, in every branch of sport.

The supremacy of a sprinter is sometimes short-lived, as a man's best pace often leares him when he is still young and perhaps only a year or two over his majority. The long-distance runner, however, rarely rises to the top of his profession until re has been a season or two upon the path, and then remains the acknowledged champion for years. The first Inter-'Varsity Mile Race was won by C. B. Lawes, then at Cambridge, a magnificent all-round athlete who stroked the Cambridge boat, besides winning the Inter-'Varsity and Championship Miles in different years. In the following year, $186_{5}$, another Cambridge man, R. E. Webster (a gentleman who has since risen to the top of the legal profession, and has been Sir Richard Webster, Attorney-General), was without doubt the best distance runner of that year. Webster's opponent in the Inter-'Varsity Mile of $186_{5}$ was the Earl of Jersey, then at Christ Church, Oxford. Both Sir Richard Webster and Lord Jersey are still popular figures in the athletic world, the former being always received with rapture by the 'Varsity athletes of the year when he presides at the annual dinner which follows the sports, while Lord Jersey has been President and Trustee of the Amateur Athletic Association and an active worker for its benefit since the foundation of that society in I880. We never saw either of these athletes run, but are told that Webster was a great man at a spurt, and was very active and bustling, and indeed, we believe that Sir Richard lays claim to having possessed sprinting abilitiesa claim, however, which at this lapse of time we have been unable to verify. We have recently seen a very interesting cut, which appeared in the 'Illustrated Sporting News' of April I8, I $86_{5}$, representing the Inter-'Varsity sports of that year. The explanatory letter-press at the foot of the picture is 'The Mile Race-Mr. Webster putting on a spurt opposite the Grand Stand.' Mr. Webster is represented as spurting gaily away from Lord Jersey, who appears to be in difficulties. The portraits 
of both seem to be fairly good ones, and the cut certainly does justice to Mr. Webster's freshness and vigour. The Oxford men of that day, however, aver that Webster was not as good a runner as J. W. Laing, of Oxford, who won the Mile and ran a deadheat with C. H. Long, a Cantab, in the Two Miles Race at the Inter-'Varsity sports in I866. Laing did not start in the Championship in 1866 , and that race fell to C. B. Lawes, who had been unplaced in the Inter-'Varsity Mile. The third man in the championship of I 866 was destined to eclipse the fame of all his predecessors. This was W. M. Chinnery, of the L.A.C., still well known as an active patron of all sorts and. conditions of sport. Chinnery won his first championship in I 868, and his last in I87 I, and in '68 and '69 won both the One and Four Miles Races at the championship meeting Although in the latter years of his career he was run very close by J. Scott, of the same club, he managed to beat that athlete in a mile at one of the L.A.C. meetings in 1870 , this being, we believe, the only occasion upon which they met at that distance. During his career, Chinnery was the leading figure at all long races : he was tall, weighed, we should say, over Io stone, and ran with a long easy stride, but with very little dash. Probably he was so seldom pressed that he got into a monotonous way of running, relying on his stride and stay, and not on any other tactics. His opponent, Scott, was thought to be better at four miles than a mile, although we think that both he and Chinnery were capable of beating $4 \mathrm{~min}$. $30 \mathrm{sec}$. at the latter distance when put to it; and at that time $4 \mathrm{~min}$. $30 \mathrm{sec}$. was considered an almost superhuman performance, as the runners usually went off slowly, and waited upon one another until half-way. Scott was a shorter and slighter man than Chinnery, and ran with a much lighter tread, holding himself more erect than his great rival, and shooting his legs out in front of him. Another sterling good man, who was a contemporary of Chinnery's, was Sydenham Dixon, of the Civil Service. Dixon, although a lighter weight, had, we think, greater pace than Chinnery, but the latter could outstay the Civil Service runner. From I 868 to. 
I 87 I inclusive, Dixon won the Civil Service Mile, his usual pace-maker being C. J. Michôd, the best steeplechaser of the time. Michôd, with great regularity, would make the pace year after year, only to be cut down by Dixon at the end ; but in 1873 Dixon found the tables turned upon him by G. F. Congreve, who played him exactly the same trick, and just managed to shoot him upon the post, amidst the wild indignation of the crowd, who thought Dixon had acquired a vested interest in the race after so many wins from year to year. Scott would, we think, have done a fine performance at ten miles, but in his day four miles was the utmost limit ever run by amateurs, and at this distance he made, in the championship of $I 87 \mathrm{I}$, a very fine time $(20 \mathrm{~min} .38 \mathrm{sec}$ ), which was never beaten until the famous match in 1875 , between Walter Slade and J. Gibb. In the Four Mile Race, Scott was running quite alone, and winning with inconceivable ease, so that it is most likely he was capable of very great things. The same remark applies to the celebrated Oxonian, J. H. Morgan, who (as the historians say) 'flourished' circa I868-IS70. No one could ever get near him in the three miles race at the Inter-'Varsity sports, and in one of his races he trotted in 200 yards in front of the next man, in $I_{5} \mathrm{~min}$. $20 \mathrm{sec}$. Morgan was a short strong man, a light weight with a good deep chest - the best type of runner for long distances.

When Chinnery had retired from the path Scott was not left for long in undisturbed possession of the field. In the summer of 1872 , a tall strong healthy-looking lad who had not long since left Tonbridge School began to astonish the handicappers by the number of races he was winning. However far Walter Slade was put back he always managed to win, so rapidly was he improving, until one fine day at some sports of the Thames Hare and Hounds, at Wandsworth, it was discovered that Slade, who had fifty yards or thereabouts from Scott in a handicap mile, had come in considerably more than fifty yards in front of him. This a't once settled Slade's position as a 'crack.' As Scott soon afterwards left the path we do 
not think the pair ever met level at a mile, but from this time onwards until he left the pati in 1877 Slade was never beaten at the mile.

Slade, as we have said before, was a tall man, about six feet in height and weighing over eleven stone when in strict training, and he ran heavily, crunching the cinders as he sped over the path. In 1874 he lowered the amateur mile record to $4 \mathrm{~min} .26$ sec. when he won from scratch the Open Mile at the Civil Service Sports in this time. The Strangers' Open Mile at these sports has always, indeed, been one of the classic handicaps of the year. In I868 Chinnery won this race in $4 \mathrm{~min} .29 \mathrm{sec}$, then a record ; after Slade's time W. G. George, the now famous professional, won the same race from scratch in $4 \mathrm{~min}$. I $9 \frac{2}{5} \mathrm{sec}$., and the year afterwards W. Snook won the same race from scratch in $4 \mathrm{~min} .20 \mathrm{sec}$. In 1875 Slade eclipsed his previous performance by covering his mile in $4 \mathrm{~min} .24 \frac{1}{2} \mathrm{sec}$. at a meeting of the L.A.C. at Stamford Bridge in a celebrated race when he met H. A. Bryden and L. U. Burt, both the others being, like himself, tall men. Bryden, who ran in beautiful style, had, however, little dash, or he might, perhaps, have lowered Slade's colours; while J. U. Burt was too tall and heavy to hold his own in such company, unless very highly trained. On this occasion of lowering the record, all three covered the distance within 4 min. 30 sec.

Another contemporary of Slade's deserves notice for his mile performances. This was W. H. Seary, who, at the time of his zenith on the path, was an Oxford scout, and if report be true, used to utilise, for training purposes, his journeys across 'Tom" and 'Peck' quads, and stride across the gravel in great style. Any way he was a superb runner, with a long stride and light of foot. His entry was, we believe, refused at the championshipmeetings and in London, but he often figured at the provincial gatherings, and had he met Slade would have had a good deal of money put on him by the Northern enthusiasts. On the only occasion when he and Slade were entered together, 
at Widnes, the meeting was postponed on account of wet weather, and at the adjourned meeting Slade was unable to be present. Another fine miler, in the years 1876 and 1877 , was E. R. J. Nicolls, of Christ Church, Oxford, who won the Inter'Varsity Mile in 1876 in $4 \mathrm{~min}$. $28 \mathrm{sec}$. Nicolls was in even better form in the succeeding year, but a family bereavement prevented his taking part in the Inter-'Varsity and championship sports of that year. Unlike most runners, Nicolls seemed to delight in running as a pastime, but to have little ambition to take part in a big race, although this was certainly not from nervousness, as his performances were chiefly due to dogged perseverance and pluck and most careful training.

Slade was beaten in the Four Mile Championship of 1875 by James Gibb, a pretty runner with a short stride and of light weight, who was seen at his best in longer distances than a mile. A match was afterwards made at four miles between Slade and Gibb, which came off at Lillie Bridge on the evening of April 26 of that year in presence of a large crowd, nearly the whole of the Stock Excliange (or at any rate the younger members of that institution) turning out to support Slade. After a close and magnificent race, Slade, who hung at his opponent's shoulder all the way, rushed past and won in 20 min. $22 \mathrm{sec}$., Scott's old record being disposed of by this performance. Besides Gibb, however, Slade had several famous contemporaries at longer distances, chief of whom was James (better known as 'Choppy') Warburton, a North-countryman of much the same build as Slade, whose weight and style of running made hirn more successful over a grass course than over cinders. Warburton, as the hero of a hundred fights on the running path, reaped a large harvest of prizes, and, after the manner of his kind, became a Boniface, and used to exhibit himself in costume, together with his trophies, for a small fee to an admiring public. He afterwards turned professional runner, an example which has been followed by several of his more famous successors. 
Another fine performer, who had a very long career on the path, was C. H. Mason, a good light weight who won the Mile Championship in 1872 , before Slade's appearance on the path, and the Ten Mile Championship in 1879 and 1880 , long after Slade's retirement. Mason always ran with consummate judgment, and had a fine turn of speed in the middle or at the end of a race, as well as a great deal of dogged pluck. In one ten-mile handicap, where he started at scratch with W. E. Fuller, he was compelled to stop over and over again from stitch, but with undaunted perseverance he refreshed himself with nips of brandy, and eventually getting rid of his enemy, went off again at a great pace, overhauled Fuller, and passed him with ease.

In the Four Mile Championship of 1876 , however, Mason met another runner of similar staunchness, Albert Goodwin, of Oxford. Goodwin had made a great reputation in early life as a sprinter, hurdler, and jumper, and went to Oxford late in life as a married man with a family. His age and matrimonial condition, however, did not prevent his becoming the best three-miler Oxford ever sent to Lillie Bridge up to 876 . In the Four Mile Championship there was a fine race between Goodwin and Mason, and each, knowing that he could sprint at the finish, waited upon the other; but the Oxonian was a bit too fast for Mason at the end, and won in slow time.

In 1879 the Spring Championship was won by B. R. Wise, of Oxford, and the Summer Championship by W. G. George. As George was for many years before the public as amateur and professional, he hardly needs a description. He is a tall, thin man with a prodigious stride, which arises from his bringing his hips into play more than any distance-runner we have ever seen, and years of training and practice have cultivated his staying powers to an extraordinary degree. During his career as an amateur, which lasted from I879 to the end of 1884 , he had only two serious rivals on the path at a mile or upwards. In 
1882 he started very unfit for the Mile Championship, having only just recorered from illness, and was beaten by Wise. The latter, not a strong man, was a tall light weight with a springy stride, a successful runner from the fact of his knowing exactly what a mount of training would suit his constitution. He took no hard practice at all, going only short spins, and sometimes knocked off work altogether. As a result he came to the post in all his races fresh and confident; and on the occasion when he beat George ran with wonderful judgment, steadily increasing his pace all round the last lap at Aston, until he had his man settled at the top of the straight, when he came away and won in $4 \mathrm{~min} .24 \frac{2}{5} \mathrm{sec}$. Wise, who was a man of great enthusiasm for athletics, was the first Vice-President of the Athletic Association, and that body lost much by his return to his native country, New South Wales, in $I 883$. $\mathrm{He}$ has since held the post of Attorney-General of that colony.

George's other great rival was IV. Snook, of Shrewsbury, a runner of very remarkable physique. A short, thick-set mars with tremendous legs, shoulders, and chest, he certainly lookec most unlike a runner of long distances ; but he, too, like George, trained his strength and staying powers to an extraordinary pitch of excellence, and although most unlike George in build, resembled him in striding straight from the hips, and thus covering more ground in each stride than would have been thought possible from his height and make. When at his best Snook was very little inferior to George at any of his distances, and George's amateur record for a mile of $4 \mathrm{~min}$. $18 \frac{2}{5} \mathrm{sec}$. was made after a hot race with Snook in the championship of 1884 . In one year (1883), when George was again a bit off colour, Snook was too good for him in the Mile and Four Mile Championships, but on all the other occasions when matches were made between the pair, and both were fit and well, George proved himself the better man. Still Snook, when he won the Civil Service Mile from scratch in $\mathrm{I} 88_{3}$ in $4 \mathrm{~min} .20 \mathrm{sec}$, was certainly not pressed at the finish, and a hard race on that day 
would, we think, have made him do an astonishing performance. Since George has turned professional he has in a match with Cummings completed a mile in $4 \mathrm{~min}$. I $2 \frac{3}{5} \mathrm{sec}$, and this seems to set at rest for ever the question which, in spite of George's victories, was always being debated-who was the better man upon his best day.

Since the days of George and Snook there have been so many fine long-distance runners upon the path that io give a history of them would be difficult. The performances of F. J. $\mathrm{K}$. Cross have already been mentioned. His best performance at a mile was 4 min. $23 \frac{3}{5}$ sec., made in 1889 . He was a big man who required a lot of training, and was fittest in $\mathbf{1} 888$, when he could have done something wonderful at a mile had he ever been pressed. In the following year II. Pollock Hill covered his mile at the Queen's Club in 4 min. $2 \mathrm{I} \frac{3}{5} \mathrm{sec}$, the best ever done at an Inter-'Varsity gathering. ${ }^{\text {' }}$ Pollock Hill was wonderfully fit when he made this record; he was certainly not such a good miler as Cross. In I893 W. E. Lutyens, of Cambridge, a light elegant runner, still quite a youngster, covered the mile at Queen's Club in 4 min. 22 sec., winning quite easily. In the Championship of 1893 Lutyens was beaten by F. E. Bacon, a Northerner, in 4 min. $22 \frac{1}{5}$ sec.; but Lutyens is still so young and slightly built that he is sure to improve as he gets older. ${ }^{1}$

The year $\mathrm{I}^{892}$ was made memorable by the fine performances of Harold Wade of the L.A.C. Wade had for many years shown good average form, but in 1892 came out wonderfully, and won the Championship Mile in 4 min. $19 \frac{1}{5} \mathrm{sec}$., the second best mile time ever done by an amateur. Wade's style is not taking, as he runs with one shoulder higher than the other, but his stride and stamina are wonderful, and he runs with great pluck even when appearing dead-beat.

Amongst other milers may be mentioned J. Kibblewhite, of

1 Since these words were put into print, Lutyens covered the mile, at the Oxford and Cambridge Sports of 1894 , in 4 min. $19 \frac{4}{5} \mathrm{sec}$, a record for the InterUniversity meeting. 
Swindon, who was good at any distance from one to ten miles. He was very strong, got very fit, and was very plucky, and by these aids won six championships - three at a mile (1889, I890 and $\mathrm{I} 89 \mathrm{I}$ ), two at four miles ( 1890 and $\mathrm{I} 892$ ), and one at ten miles (1890)-a wonderful record. Another fine miler, W. J. Fowler, has in four successive years (I890 to 1893 inclusive) run second for the championship, a piece of ill-luck which so fine a runner ill deserved.

At longer distances W. H. Morton of the Salford Harriers, Sidney Thomas of the L.A.C., C. E. Willers of the Essex Beagles, and C. Pearce of the Buckfield Harriers, have all done wonderful performances. Morton was a small lightfooted runner, who was capable of doing wonderful times at very long distances, and though he never beat W. G. George's ten mile record of $5 \mathrm{I} \mathrm{min}$. $20 \mathrm{sec}$., was by many believed capable of doing this if he tried. The performances of the other trio, Thomas, Willers, and Pearce, were the great fea-

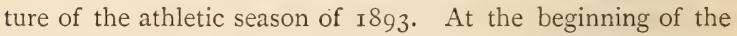
year Thomas, who runs with a very pretty style but with an action rather too high and springy, commenced the year by cutting many records from one-and-a-half to five miles. However, in June he was beaten by both Willers and Pearce over four miles, the winner, Willers, covering the four miles in I9 min. $33^{\frac{4}{5}} \mathrm{sec}$ - $\mathrm{a}$ record. The trio met again at the championship at Northampton, when Pearce had his day, winning the championship title in comparatively slow time. Another long-distance runner of great promise is F. S. Horan, of Cambridge, who covered his three miles in $14 \mathrm{~min} .44 \frac{3}{5} \mathrm{sec}$. at the Queen's Club in March I893, this being the best time for that distance at the Inter-'Varsity Sports. As Horan was in his 'freshman's year' when he accomplished this performance, his athletic future promises to be brilliant.

Although steeplechases were popular in the early days of athletics, they fell into disuse at important meetings for many years, and were not included in the championship programme 
until the summer meeting of 1879 . In the very early days of athletics something of the nature of a steeplechase or long hurdle race was always included in a programme, and naturally so, for the impromptu races and matches from which the sport arose were often from point to point over a piece of country. But as athletics began to reach the artificial stage, and the natural runner was unable to keep pace with the trained athlete in his spiked shoes on a cinder-path, steeplechases began to drop out of fashion except where they were retained to please spectators; for the British public, in the true style of those who rejoice in gladiatorial shows, like to see somebody or something coming to grief or rendered ridiculous. The result was that for many years the steeplechase was considered as forming the comic part of the entertainment at a meeting, and the managers of sports made huge water-jumps which it was impossible for anyone to clear, so that the lookers-on might see runner after runner tumble into a filthy pool and emerge muddy, bleeding, soaked, and groaning. However, not even these silly exhibitions could spoil a sport in itself admirable; for nothing can really be a prettier or surer test of a combination of staying power, agility, and pluck than a race of some distance over hurdles or obstacles which are not too high or broad to prevent the runners from having a chance of clearing them. As soon, therefore, as the paperchasing movement, which is described elsewhere, had taken firm hold of the athletic public, steeplechases at athletic meetings began to regain popularity, the distances selected being from three-quarters of a mile up to two miles, but seldom over the latter distance. We are sorry, however, to see that the old form of steeplechase, with impossible water-jumps and prodigious prickly obstacles, is still retained at some meetings, in order that the public may laugh while the miserable performers wallow in the mud or make ugly faces when they may happen to fall back into the brambles or furze, and we must confess to thinking still that the best steeplechases are those across well-selected 
country, and not round an artificially prepared and enclosed course.

The good steeplechaser must, of course, be a long-distance runner, as no one without staying powers can hope to last the distance ; he must be a good jumper as well, and in addition there is a very great art in clearing the obstacles which can only be learnt by constant practice. The object of the clever steeplechaser is to exhaust himself as little as possible over the jumps. He therefore takes the hurdles of ordinary height according to the regular hurdling manner in his stride, never rising an inch higher than is absolutely necessary. The waterjump has to be taken in a different way. The regular practice is for a high hurdle studded with furze branches to be placed on the edge of the water. If the water is too broad for his powers the runner makes no attempt to clear it, but jumps carefully so far into it that, by leaning well forward, his hands may immediately seize the bank, and he then pulls himself cleverly out without losing time. If, on the contrary, he thinks he can clear it with a kick, he gets one foot on the top of the hurdle and thence gets a kick off, which takes him over the water; but this is a very clever piece of jumping which requires great practice. Some runners, especially in the shorter steeplechases, come with a rush and a bound clear over the hurdle and water, and this bit of 'gallery' is always enthusiastically applauded; but, as a rule, it is a waste of strength in the long run, and the old hands are seldom seen to indulge in such display. As the obstacles may be of all sorts of height and stiffness, however, it is difficult to lay down any general rules to suit all runners and all obstacles, but in no case should the 'chaser alight on both feet from a jump, as he then comes to a dead stop. Most runners take their spring from the right foot, and get over their obstacles a bit sideways with the right leg in the rear.

A steeplechase of two miles was one of the events in the first Inter-'Varsity gathering on the Christ Church cricketground at Oxford in I864, when R. C. Garnett, of Cambridge, 
proved himself too good by six yards for the present AttorneyGeneral, of whom, as a runner, we have already spoken. In the following year, however, the event was changed to a twomile flat race; and there have been no more steeplechases at Inter-'Varsity gatherings. For the four or five years before I 875 the few steeplechases that were included in meetings round London were nearly all won by C. J. Michôd, a Civil

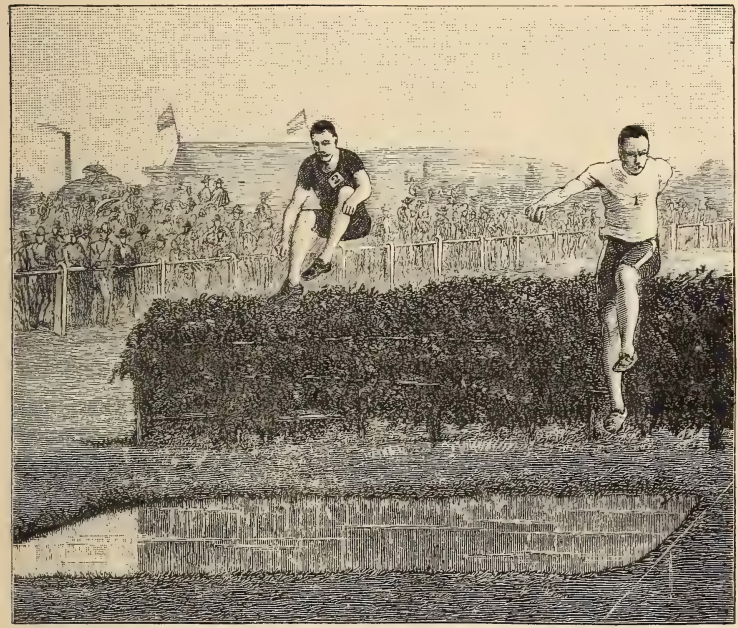

Steeplechase-Water-jump.

Service runner, who was very clever over the obstacles and water-jumps, and would have been a fine distance-runner had he been gifted with a little more pace for a spurt. We can recollect on one occasion Slade starting at scratch with Michôd in a steeplechase at the Richmond Cricket Club Sports ; but the crack miler blundered so much over the hurdles, banging his shins, and occasionally falling prostrate, that Michôd before 
long sailed away from him, and eventually won the race outright, Slade giving up. In the summer championship of 1879 a two-mile steeplechase was included in the programme, and was won by H. M. Oliver, an old London paperchaser, who for some years previous to that date had settled in Birmingham and become the leader of the athletic movement in the midlands, and founder of the famous Moseley Harriers Club. Oliver was only a moderate performer on the flat, but was certainly a very clever jumper, never wasting an ounce of his strength, and he beat, in 1879, C. L. O'Malley and the other Londoners by the clever way in which he got upon the top of the hurdles and jumped from them clean over the water-jump without an effort. Of late years the best steeplechasers have nearly always been the best paperchasers of the day, the ordinary flat-race runners having little opportunity to practise jumping without taking part in crosscountry runs. The best Londoners have been C. L. O'Malley, who, however, never, we believe, figured as a paperchaser, and J. T. Wills, an old Oxonian, who was good on the flat also. Strangely enough, as the sport is a very genuine and interesting one, steeplechasing is quite unknown at athletic meetings at the Universities; and what makes this still more strange is that in hurdle-racing-a kindred sport-the 'Varsities uniformly produce some of the best men in every year; indeed, of the twenty-nine hurdle-racing champions up to the date of writing, seventeen have hailed from Oxford or Cambridge.

HURDLE-RACING.--In the early days of amateur athletics hurdling and steeplechasing were considered as kindred sports, the former being a test of short-distance running plus jumping, the latter of long-distance running plus jumping. So much was thought of this judicious combination that the first Inter-University meeting at Oxford, in I864, had two hurdle races and a steeplechase out of eight events, the remaining items being three flat races and two jumps. The two hurdle races were at $\mathrm{I} 20$ yards and 200 yards, each having ten flights of hurdles. The former distance, however, soon became the more popular; and the committee who drew up the programme 
for the first championship meeting settled the future of hurdleracing by fixing upon $\mathbf{2} 20$ yards race with ten flights, the hurdles being $3 \mathrm{ft}$. $6 \mathrm{in}$. high, at even distances of ten yards, with fifteen yards between the start and the first hurdle, and a similar distance between the last hurdle and the finish. As soon, however, as the distance between the hurdles became stereotyped the runners were not long in finding out that in the race invented to test running and jumping powers in combination the more running there was, and the less jumping, the faster the time over the distance would be. Experience soon taught that three strides would take a man from hurdle to hurdle, and that he could spring off one leg and alight on the other, taking the hurdle in his stride. The result was that hurdle-racing over the recognised distance soon became a very difficult and pretty but highly artificial performance. The 'crack' hurdler takes every stride of exactly the same length, rises exactly the same height at every jump, and moves with the regularity and precision of clockwork. Some jump off the right, some off the left, foot ; in either case, when the spring is taken the front leg is jerked up enough to enable the runner to get his shin or knee over the bar; that leg then is dropped again, so as to enable him to alight on the ball of his toe; meanwhile the hind leg is lifted in similar style over the bar and straightened at once as soon as the bar is cleared, and directly the other toe has alighted the next stride is taken almost without a pause. It will be obvious how slight a delay is caused by clearing the hurdles when it is considered that men who are equal to little better than $12 \frac{3}{4}$ seconds over 120 yards on the flat have covered 120 yards over ten hurdles of $3 \mathrm{ft}$. $6 \mathrm{in}$. high in $\mathrm{r} 6$ seconds. The sport is a pretty one, requiring great skill, speed and agility, and a 'light foot,' but we cannot help expressing a wish that in addition there might be seen other short hurdle races at meetings where the runners should not know the exact distance between each hurdle, and the exact height of the jump, and so would be unable to calculate the precise length of the stride and the precise amount, to the 
smallest fraction, of the power required to lift them over the hurdle. Running is nothing if not natural, and graceful as hurdling is, in our opinion it has been brought to too high a pitch of artificiality. We have seen $\mathrm{H}$. K. Upcher, one of the best of the Oxford hurdlers, take two spins over hurdles, when in each spin his feet fell in exactly the same track (and we may add the same part of his shin scraped the top of the hurdle in exactly the same spot), so that a Red Indian following him by his tracks would hardly have seen that he had been twice over the same ground.

The hurdle-racer must, as we have seen, have a light foot, and so he is rarely a heavy man, but he must also have a strong back and thighs, so as to take his spring and his fresh start without any pause. Thus he is always one who runs in a 'springy' style, but a good high jumper is rarely of any use as hurdler, as he has a natural inclination to jump too high and waste time in his spring into the air. Hurdle-racing and long-jumping ability more often go together. Indeed, the main point in hurdle-racing is not to learn to jump well over the hurdle, but to learn not to jump too high. The best way to attain this is, in our opinion, to practise over hurdles the top bar of which is loose. It may seem a paradox, but we think it is true, that the runner can best learn by having no fear of coming to grief by crashing into the top bar. Upcher, of whom we have spoken, probably took as much care over his practice for hurdling as any man has ever done, and so fearful was he of getting into the habit of rising too high, that when he began, whether the hurdles had a loose top or not, he would crash through half-a-dozen of them, leaving a track of desolation behind him. His shins certainly suffered in the performance, as he was in the habit sometimes of carefully bumping them against each hurdle to see that he was going all right. The hurdles at the Old Marston running-grounds at Oxford, over which so many cracks practised, had loose tops which came off when struck by the leg, but recently the Oxonians have practised over ordinary hurdles, 


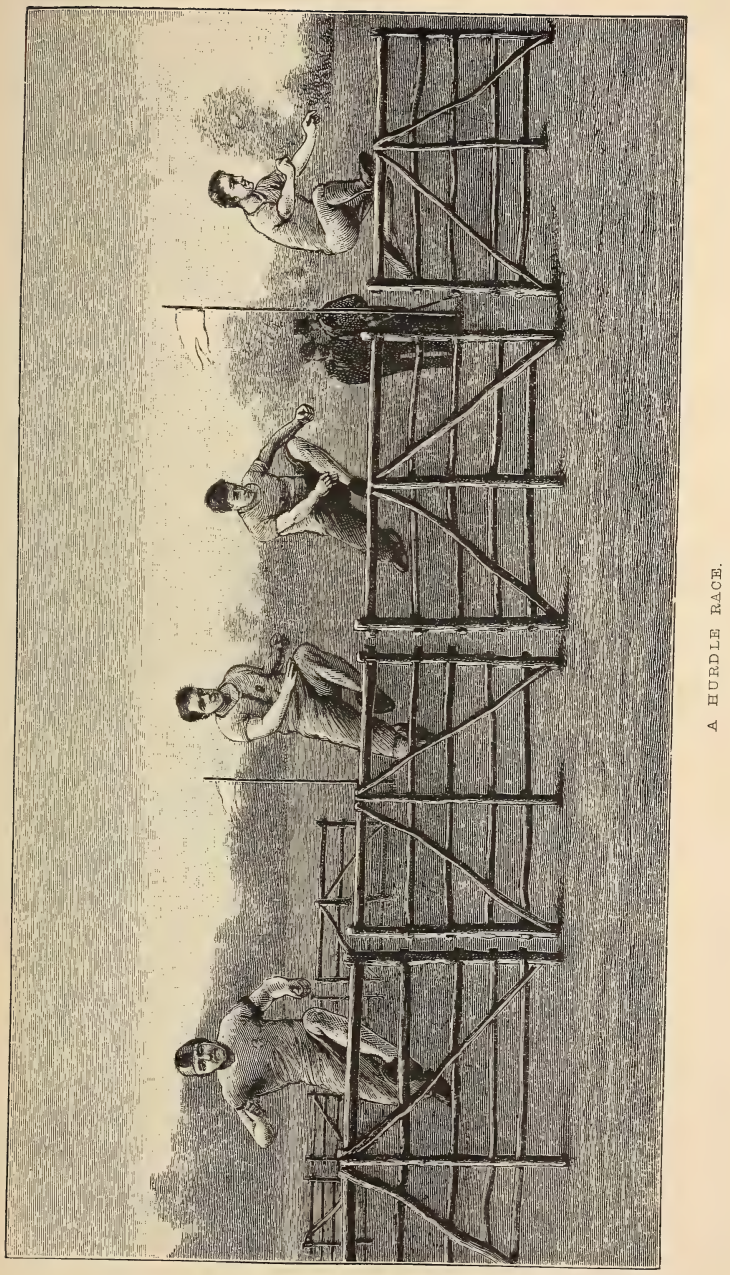



it being thought by some that the 'loose-top' system encouraged rashness, and led to catastrophes at Lillie Bridge.

The beginner always finds himself unable to do the regulation 'three stride' with any success over hurdles of full height, and either has to practise over low ones placed the proper ten yards apart, or to slope the obstacles forward so as to make the height less and the jumping more easy. The secret of success lies more in assiduous practice than in anything else. Probably any athlete with fair abilities at sprinting and long jumping can with practice make himself a good hurdler if he be not too heavy-footed, and so unable to recover from the spring. The really brilliant hurdler, however, is always a cleanbuilt man with little weight at the buttocks to drag him backward, and the heavy-weight sprinters who try hurdling are usually failures. Some of the best hurdlers have been small men who have found their natural stride long enough for the three-stride system, while a man with too long a natural stride can hardly reduce it with success. Great strength of back is naturally required for the rise to the hurdle, and the hurdler not only needs assiduous practice, but must come to the post very fit and without a trace of stiffness. As regards the amount of exercise and practice, he must train in much the same style as the sprinter, taking great care over starts and spurts on the flat in addition to his daily spin over the timber. We need scarcely say that it is not in the least necessary to cover the full distance every day in practice. The hurdler probably benefits quite as much as the sprinter by the rubbing process which we have before described.

Hurdle-racing is undoubtedly more popular at the Universities than anywhere else. The University element in London brought the sport forward in the metropolis very early, but until quite recently it was very rare to find a good hurdler, except from Oxford or Cambridge. It is not too much to say, indeed, that only two first-class hurdlers have hailed from London -Reay and Lockton ${ }^{1}$ - and hardly any of note from any

${ }^{1}$ It is difficult to class Godfrey Shaw the best English hurdler between 989 i and 1893. He was first at Cambridge, then in New Zealand, finally in London. 
other part of the country except Nottingham, which of late years has been quite a centre of hurdling ability. After all it is hardly surprising that hurdlers should only be found in a few places, for the sport cannot well flourish in any locality where there are not great facilities for its practice.

The first champion at the I 20 yards hurdle race was a Cambridge man, T. Milvain, a gentleman who has since passed the post first in several contested parliamentary elections at Durham. The third man in the race was C. N. Jackson, the well-known treasurer of the O.U.A.C., and also treasurer of the A.A.A. since its foundation. Of Mr. Jackson's services to the cause of athletic sport at Oxford, as well as elsewhere, it is almost unnecessary to speak, but his reputation as a hurdler while he was still an active athlete may fitly be mentioned. In the year $\mathbf{1 8 6 7}$ Jackson was the winner of the Oxford and Cambridge hurdle race, and but for a contretemps would, no doubt, have been champion in that year as well. In his heat he disposed of Milvain with great ease, but in the succeeding attempt there was a dead heat between R. Fitzherbert, of Cambridge, and J. B. Martin (the present president of the London A.C.). The result was that a fifth hurdle was added in the final heat, upon some ground which, we believe, had not even been mown. In the draw for places Jackson unluckily found the rough ground allotted to him. and was unable to make any show in the race. His great performance, however, had been done previously in the autumn of 1865 , when he covered the distance in what is still the record time-I6 seconds. Jackson was a strongly-built light weight of rather over medium height, the most successful type of hurdle-racer. In I 868 and I 869 the championship went away from the Universities, falling in the former year to W. M. Tennant, of Liverpool, the sprinter, and in the latter year to G. R. Nunn, of Guy's Hospital. In ı870, however, with J. L. Stirling, of Cambridge, began the long line of University cracks which has continued almost without interruption until the present time. Stirling made his first and only appearance at the Oxford and Cambridge Sports in 1870 , 
when he won with ridiculous ease by half-a-dozen yards, in I $6 \frac{3}{5}$ seconds. In the same year he won the championship, a performance which he repeated in $\mathrm{i} 872$. He was, we believe, never defeated in a hurdle race, and, if our recollection is right, was a taller and heavier man than the successful hurdler usually is. He ran also in a style somewhat different from that of many of his precursors, his right leg not being doubled back at all, but hanging behind him, as he strode clean over the hurdle. The best University hurdler of $187 \mathrm{I}$ and 1872 was E. S. Garnier, who ran with great dash, but was a trifle too heavy to fly over the sticks. Garnier, who was a thick-set man, also represented his University at hammer-throwing -an unusual circumstance, hammer-throwing and hurdling being almost the opposite poles of athletic sport. Garnier won the championship in $187 \mathrm{I}$, but in the following year he met Stirling at Lillie Bridge, and the Cambridge runner beat him. In the following year Upcher made his first appearance, and probably he was as good as Stirling. He was a strong muscular man, but not heavy in spite of his strength, and was a fine natural broad jumper, being able to leap over hurdles, hedges, and other obstacles with great agility when in boots and great-coat. He practised hurdling exclusively upon his own system, and was in his time regarded as the best exponent of the art ever known. He won the Inter-'Varsity and Championship Hurdles in 1873 and 1874 , and so great was the belief in his powers that the astonishment was unbounded when, at the Inter'Varsity meeting of 1875 , a Cambridge man, A. B. Loder, was seen to be holding Upcher in the hurdle race. Neck and neck the pair raced over the jumps and reached the tape apparently together, but the judge decided that Loder had won by a few inches, amidst the wild cheers of the Cambridge partisans. Three days afterwards the pair met over the same course in the championship, when another neck-andneck race resulted in a six-inch victory for Upcher. This, we believe, was Upcher's last appearance on the path, and the next year Loder had matters all his own way at both meetings. 
Loder was a trifle taller than Upcher, and was a trifle faster than his opponent over the flat, but the Oxonian was, we think, a bit cleverer over the hurdles. In I 877 the hurdle race at the Oxford and Cambridge Sports fell to the Oxonian S. F. Jackson, who was yet fresh at the game, and unable to make 2 show with J. H. A. Reay, the Londoner, who won the championship this year. Reay was a fine all-round athlete and excellent hurdler, who had for some years been unrivalled in London, but was unlucky in appearing during the days of Upcher and Loder. He ran more in the Stirling style than the other pair, trailing his leg well behind him, and so jumping slightly higher than was necessary. In the following year S. F. Jackson rarı a greatly improved man, being only beaten a foot in $16 \frac{2}{5}$ seconds by S. Palmer, of Cambridge. Palmer was a 'converted sprinter,' that is to say, a sprinter of first-class merit who took to hurdling after trying sprinting for a year or two first. His success at the latter sport may be gauged from the fact that he won four championships, and was credited with I6 seconds in his championship of 1878 . Palmer left Cambridge in 1878 , but was frequently seen on the path for the next five years. Wonderful as his success was, he was probably more of a sprinter than a hurdler, being wonderfully fast between the sticks but rather clumsy as a jumper, giving his shoulders a twist as he cleared each obstacle. He was not, we think, quite so good as the Oxonian G. P. C. Lawrence, who was champion in 1880 and I88I. Lawrence was a tall slight man, a good all-round jumper and runner, who for some years, until he conquered his inclination to jump too high over his hurdles, had no great merit. As soon, howerer, as he had learnt to skim instead of leap over his jumps he became the best hurdler of modern times, having a peculiar nervous power (although not physically strong) of making a prolonged spurt. In the championship of I88I he decisively defeated Palmer, haring in the previous year scored an equally decisive rictory over Lockton. The latter was undoubtedly the best hurdler the metropolis ever produced. Of his wonderful capacities as a sprinter we have 
already spoken, and when, as sometimes happened, he took part in hurdle races when the hurdles were a few inches below the regulation height, his speed over the obstacles was something extraordinary. At a hurdle handicap at Catford Bridge, at the meeting of the Private Banks, we saw him start 24 yards behind the scratch man, and clear the 144 yards and ten hurdles (below the regulation height) in I 8 seconds. In the championship of I 880, however, Lockton probably lost his head, and came to grief in the Hurdles, besides failing in the Hundred Yards. Lockton was never in his best form again after I880, and when Lawrence retired Palmer again won the championship in 1882 and 1883. For the last few years the Universities have not produced a hurdler of the calibre of Lawrence or Palmer, and the centre of hurdling activity for some years shifted to Nottingham, which has produced in turn three fine performers-F. F. Cleaver, C. W. Gowthorpe, and C. F. Daft, twice champion. Cleaver for some years, in the absence of the 'Varsity cracks, used to sweep the board at the chief provincial meetings, being very fast, although a bit clumsy in his jumps. After his retirement and that of Palmer, Gowthorpe, like Cleaver a member of the Notts Forest Football Club, won the championship of I884, and Daft, the champion of $\mathrm{I}_{88} 5$ and $\mathrm{I} 886$, also represented the same club. Here, as at the Universities, is seen the value of a 'tradition' in producing skilful performers. There were good hurdlers in Nottingham long before Cleaver, one of them, S. W. Widdowson, having earned a great reputation in the provinces a dozen years ago.

Occasionally in the provinces there are hurdle races of 300 yards or a quarter of a mile where the runners have the opportunity of showing their natural and not artificially cultivated abilities in contests which combine sprinting and jumping. Such races, however, are unfortunately so few and far between that they can hardly be said to give scope to a special class of runner. Perhaps a new fashion may some day call into existence a class of short-distance steeplechasers. 


\section{CHAPTER IV.}

\section{WALKING AND WALKERS.}

ArHLETIC sports, practised as they are now, are often attacked on the utilitarian ground that the skill acquired in sprinting, or hurdling, or running many miles on a cinder path in spiked shoes, is such as can be of no practical advantage in ordinary life. Without discussing the general question at present, it can safely be said that there is one branch of sport to which, if properly practised, the objection cannot possibly apply-we refer to walking. To learn to be a strong and fast walker must be of utility to almost everyone, and for walking matches there is therefore very much to be said. They lack popularity, doubtless partly because they are not exciting, and partly because it is still true, as was remarked by Charles Westhall the pedestrian twenty-five years ago, that 'walking is the most useful and at the same time the most abused of the athletic sports of old England.' Now, as then, the public does not care for walking races, because when they go to see an athlete walk the probability is that they will see him shuffle, trot, or run.

To the uninitiated observer it may seem absurd that men who take part in walking races should, while they run, pass muster as walkers ; because running and walking are perfectly different modes of progression. Running is a succession of leaps, walking a succession of steps ; in running the weight of the body is thrown upon the toe, in walking upon the heel. In running, therefore, the body must be more or less thrown forward ; in walking it must be almost, if not quite, erect. How then, they may well say, can it possibly happen that a man can 
run in a walking race without being discovered and disqualified? The question is a pertinent one and requires careful answering, but the real solution of the mystery is in our opinion this-that athletes, professional and amateur, have never yet

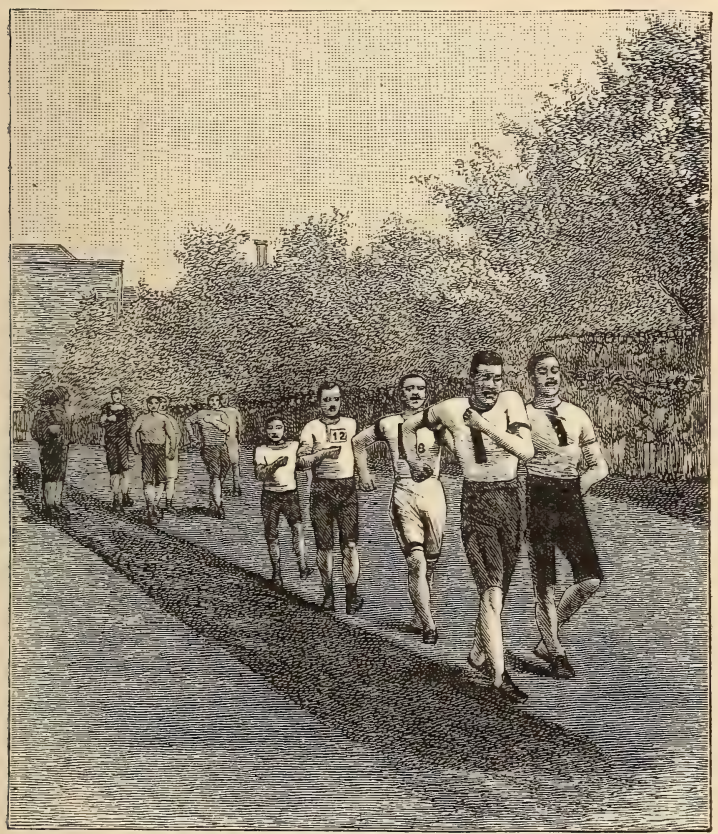

Walking race.

arrived at a satisfactory definition, founded on a rational basis, of what fair walking is.

Westhall, writing in $\mathbf{I} 862$ and speaking of professional pedestrians especially, says the unsatisfactory state of walking 
races arises 'not so much from the fault of the pedestrians as from the inability or want of courage of the judge or referee to stop the man who, in his eagerness for fame or determination to gain money anyhow, may trespass upon fair walking and run.' As Westhall was not only a good critic but a fine exponent of the art of fair walking, we can harclly do better than add some further extracts from his little manual. "The term "fair toe and heel" was meant to infer that as the foot of the back leg left the ground and before the toes had been lifted the heel of the foremost foot should be on the ground.' (IVe might here observe that the more usual expression now is fair 'heel and toe' walking, meaning that the walker places his heel to the ground before the toe.)

'Even this apparently simple rule,' Westhall proceeds, ' is broken almost daily in consequence of the pedestrian performing with a bent and loose knee, in which case the swing of his whole frame when going at any pace will invariably bring both feet off the ground at the same time, and although he is going heel and toe he is not taking the required succession of steps, and he is infringing the great and principal rule of one foot being continually on the ground. The same fault will be brought on by the pedestrian leaning forward with his body, and thereby leaning his weight on the front foot, which, when any great pace is intended or the performer begins to be fatigued, first merges into a very short stride and then into a most undignified trot. . . . To be a good and fair walker the attitude should be upright or nearly so, with the shoulders well back, and the arms when in motion held well up in a bent position, and at every stride swinging with the movement of the legs well across the chest, which should be well thrown out. The loins should be slack to give plenty of freedom to the hips, and the leg perfectly straight, thrown out from the hip boldly and directly in front of the body, and allowed to reach the ground with the heel, being decidedly the first portion of the foot to meet it. The movement of the arms will keep the balance of the body and bring the other leg from the ground.'

To these practical directions should be added another, which is implied in Westhall's description, but not explicitly stated, that at each stride the hip should be twisted well round, the right 
leg being stretched out a little to the left, and the left leg in the next stride to the right, so that the walker's feet step almost in a direct straight line. By this twist round, each stride is lengthened a few inches and a corresponding increase of pace acquired.

Probably no one will disagree with the foregoing description of what the style of a fair walker should be. He should walk with a perfectly straight leg, he should step not spring, and he must never have both feet off the ground for an instant at the same time. Unfortunately, however, the judges of walking for a great many years have seized upon the last essential, that of one foot being always on the ground, as if that, and that only, were the only characteristic of fair walking. As long as a man can get over the ground in such a way that daylight cannot be seen under both his feet at once, the judge of walking is willing to 'pass' him, and he goes on his way to the end of the race in whatever style he likes. The evil, which has now grown to a great height, can hardly be ascribed to the fault of any one or more particular judges, and certainly to none of the judges of the present day, who have had to take the system as they found it; and if ever they have boldly interfered to disqualify a shifty walker, have seen their action criticised for weeks in the columns of the sporting papers, and the whole question of their sentence debated in acrimonious controversy. At the present day it will want a very Daniel to inaugurate a new system of judging in walking races.

The results of the loose practice of allowing ' shifty' walkers to remain on the path are serious. The many naturally fair walkers who take up the pastime, when they find in races that more unscrupulous opponents 'trot' past them with impunity, soon arrive at the conclusion that honesty' is not the best policy, and upon the principle that corruptio optimi pessima become the worst offenders themselves. W'e believe that $\mathrm{H}$. Webster the Northerner was a fair and fast walker in his early days, but in the championship of 1877 he simply 
trotted away as he liked from H. Venn, the London repre. sentative. The next year Venn had learnt a lesson, and although when he had first appeared on the path his fair form had been unmistakable, in the championship of 1878 , when he met Webster again, the pair both ran more or less the whole way, Venn running rather faster than Webster and winning in the time of 52 min. $25 \mathrm{sec}$, which is in some quarters accepted as a best on record. Another result of the system is that novices learning to walk imitate their betters and so soon break into a run, leaning their body forward to trot as soon as they begin to tire. The result is what Westhall calls an 'undignified' trot. The attitude is not only undignified, but is in most cases hideously ugly, which no fair running or fair walking is. In an ordinary walking handicap the public is thus treated to an exhibition in which more than half the competitors are in ridiculous and contorted attitudes. Naturally spectators are more inclined to laugh than to admire, and neither treat the affair as serious, nor take any interest in the result except upon the occasions when that rarest of specimens, the fast fair upright walker, is in the contest, when the interest immediately becomes genuine and unbounded. Once therefore let the walking be so reformed as to be unexceptionable in style, and walking matches will suffer from no lack of popularity. Then probably we shall see a new and improved class of fair walkers arise.

So much as to the evils in vogue at present; it remains to suggest a means of remedying them. To put it shortly, the judges must all see that each man is walking fairly, and not that he is not walking unfairly, by which dark saying we mean this: the three characteristics of walking which distinguish the exercise from running are these: (I) The weight of the body is on the heels when the step forward is taken; (2) One foot is always on the ground; (3) The knee is perfectly straight as the foremost foot reaches the ground. The judges should see that each of the three essentials is rigidly adhered to, and promptly disqualify the man who either gets on to his 
toes, bends his knees, or has both feet off the ground together. Then, and not till then, we shall see none but fair walkers upon the path.

From what we have said it will be seen that there is an art of walking fairly and another art of walking unfairly, but not so unfairly as to involve certain disqualification. About the latter art, the art of shuffling or of running on the heels, we do not propose to give any practical directions, although we have seen plenty of examples of it in high places, and will content ourselves with saying that it does not require any particular capabilities, but a good deal of staying power, and is certainly easier to acquire than the true art of walking fast. Indeed, any of our readers who likes to try for himself can find how easy it is to do a slow run on the heels, and what a relief it is to change the action to that style of progression when the legs are aching from fast walking.

All walking races are contests of more or less endurance, and staying powers are thus essential. Before beginning practice for a race the walker should therefore get his muscles as hard as possible with as much walking on the road as he can manage. Once in training for his race, however, he should be very careful not to get into slow walking, but should always go at a brisk pace with a good swing of the arms, and for the last two or three weeks should do all his practice on the racing track. Walking is perhaps the one sport where a man cannot afford to knock off work and trust to natural freshness to get him through. In this of course, as in other phases of athletic sport, if a man has got stale from overwork he must take it easy, but in walking it is absolutely necessary to have the muscles so hard all over the body that 'knocking off' for any space of time becomes fatal to all chances of success. It is not necessary, as in other races, to do the full distance at top speed often or even at all before a race, but the walker in his practice must take some laps at top-speed every day for fear of being taken with a 'fit of the slows.' It is almost indispensable, therefore, to have the assistance of a watch-holder, to learn 
how fast one is travelling; the walker practising should do at least a mile every day at top speed, and, as in training for longdistance races, at a uniform rate of speed, and moreover at the fastest of which he is capable. A week's training for a three-mile race would probably be something such as this: On the first day 2 miles, on the second $\mathrm{I} \frac{1}{2}$ mile, on the third 2 miles, on the fourth 3 miles, on the fifth I mile, on the sixth 2 miles, and for a seven-mile race double these distances. A thorough good rubbing after each day's exercise is almost indispensable, as there is nothing like fast walking to bring out aches and pains all over the body, and especially down the shin-bones. The walker is also liable to blisters and sprains, more perhaps even than the long-distance runners; but of the treatment of these we shall have to speak later.

In the early days of the athletic movement a seven-mile race was considered the proper test of a man's ability in this branch of sport, and a seven-mile race was the walking event included in the original championship programme. At the present day the public find an hour's walking race rather a slow event to watch, and in most club meetings shorter races of three or two miles, and occasionally of one mile, are more usual. The result is that there has recently been some considerable agitation in favour of the championship event being reduced to something less than seven miles, or for the inclusion of a second walking race for a shorter distance in the championship programme. At the American championship meeting there are three walking races, at the Irish and Scotch championship there is only one race, at three miles, while in Canada the same distance determines the title of champion walker for the year. We think, however, that the Amateur Athletic Association will be right in retaining their present championship programme unaltered in regard to the walking race. There are already plenty of temptations towards unfair walking and the production of a vicious style of progression, and with a shorter championship race the temptations will be increased. At present the one satisfactory thing about the 
championship walking event is that some of the shifty goers find it impossible to conceal the true secret of their mode of progression after the first few miles. The longer the distance is the more likelihood is there that a real walker will prove the winner, for besides the chances of detection we believe it is really very hard to run on the heels for more than a mile or two.

The first walking champion was J. G. Chambers, a gentleman who was one of the pioneers of the athletic movement both at the Universities and in London, and whose name will always be remembered in connection with the Amateur Athletic Club, now extinct. Chambers was not what we should call now a first-class walker, and his only opponents in the championship of 1866 were three other University men, the time being only 28 seconds within the hour; but as regards Chambers' reputation as an athlete, it must be recollected that he could not only walk his seven miles within the hour, but was, if not the very best oarsman and sculler of his day, at least one of the best. It is, perhaps, worthy of note that the work from which we

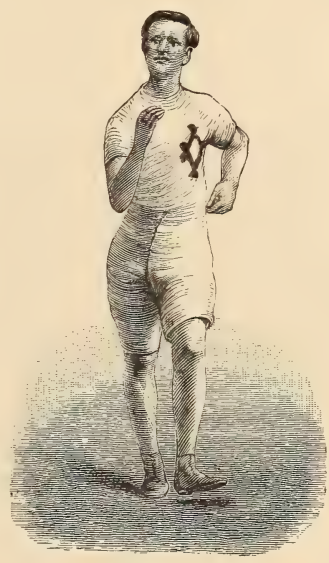

Short stride. have studied the account of Chambers' championship defines 'fair walking' as 'having one leg on the ground at the time,' and adds, 'the straightness of the legs does not prove or alter fair walking.' It is scarcely any wonder, therefore, that walking should have begun very early to be open to abuse. The account we have seen of the championship of 1867 is rather curious. The three men who were really in the hunt were Chambers, T. H. Farnworth, the Northern celebrity, and R. M. Williams, of the Civil Service, a fine walker, who travelled 
perfectly upright, but with a very short niggling stride. Williams and Farnworth disputed the lead for nearly five miles, when Chambers, who was well in the rear, began to gain. Half a mile from home Chambers caught the leaders, and the three began to race together. At the end of the last lap but one Williams retired, finding himself unable to keep pace with the others, and Farnworth and Chambers began to have a 'ding dong' race. 'At the last corner,' says our reporter, 'the two were level: the shouts were tremendous: each of the two became very suspicious in their style (sic); neck and neck they came down the straight, Farnworth winning by a foot.' Eyewitnesses have declared that the style of both first and second men was by no means suspicious, being an open undisguised run for the last lap and a half, and that if the judges had been up to their work both would have been disqualified, and Villiams, who was walking fairly, would have become champion of the year. After this year we hear nothing more of walkers from the Universities, and from that day to this it is a curious fact that no walker of any merit whatever has appeared on the path from Oxford or Cambridge. Indeed, some ten years ago walking races were dropped out of the programme at both the Universities, owing to the paucity and inferiority of the performers, and, we believe, the only walking race in which undergraduates now figure is that for the valuable silver cup given yearly by Sir Edward Joddrell, Bart., to the students of Queen's College, Oxford. This prize usually brings out a performer who can do his three miles well inside half an hour, and the utmost that can be said for the performers is that they all walk with strict fairness if not with speed. It appears that at the Universities no competition which does not give the athlete a chance of winning his 'blue' will be followed with much zest.

About the time that Chambers retired from the path, some new walkers began to appear on the scene in the metropolis, the best of these being Walter Rye, S. P. Smith, and T. Griffith. All of these were tall men, Smith, however, being the tallest of 
the three, and, if we recollect rightly, over six feet. Rye walked with a perfectly straight leg, very erect, and was certainly a better walker than any who had preceded him. He held the L.A.C. Challenge Cup for the seven-mile walking race through the year 1867 . Towards the end of that year, however, Smith and Griffith had begun to make their mark, and in the last L.A.C. meeting of that year Smith, Griffith, Rye, and Williams all met in a two-mile handicap, the two last named being at scratch and Smith and Griffith with $25 \mathrm{sec}$. start. In the result Smith astonished the spectators, gaining $2 \mathrm{sec}$. upon Rye, and finishing in $\mathrm{I}_{5} \mathrm{~min}$. $\mathrm{I}_{5} \mathrm{sec}$., the best time on record at that period. Smith, though then only a lad of nineteen or thereabouts, is said to have walked in splendid style and with great fairness, and would probably have done something notable had he persevered on the path; but in the spring of the next year he abandoned the pursuit as suddenly as he had taken it up. In the race to which we are alluding Griffith finished second, after being once cautioned, his time being $15 \mathrm{~min} .32 \mathrm{sec}$; Rye third, in the time of $15 \mathrm{~min}$. $17 \mathrm{sec}$; and Williams fourth, in $\mathrm{I}_{5} \mathrm{~min}$. $35 \mathrm{sec}$. In the succeeding year Rye won the championship easily enough ; but in the two following years Griffith was the winner, Rye not being a competitor. Griffith, who has long been a familiar figure as the representative of 'Bell's Life,' certainly disputed with Rye the reputation of being the best walker of his time, but although, in 1870 , he beat his rival's times when he won the championship from R. H. Nunn in 55 min. 30 sec., we believe he never beat Rye when the pair met in a race. R. H. Nunn, who made so fine a race with Griffith in 1870 , was beaten by Rye, who took the L.A.C. Cup again in the autumn of r869, this being the last time he competed for it. Rye, Griffith, Nunn, and Williams retired about the same time, and their places were taken by inferior men. The next celebrity in the walking line was W. J. Morgan of the Atalanta R. C., who was champion for the three years from $1873-75$ inclusive. Morgan was a short man, hard and thick-set, and was, we believe, about five-and-twenty when he took to the path. His first appear- 
ance was at the spring sports on the Richmond cricket ground in 1872 , when he was immediately spotted by the connoisseurs as the coming man. He walked perfectly erect and with a fair heel and toe action, but with a springy stride, and we always used to think that when he spurted his style was by no means irreproachable. Undoubtedly he could and often did walk with great fairness, but his springy style and quick stride rendered the passage from walking into trotting very easy for the walker and very puzzling for the judges. Morgan, in his third championship win, covered his seven miles in $53 \mathrm{~min} .47 \mathrm{sec}$, then a record, and was also the maker of athletic history in another sense. It was about this time that the ring-fence of gentlemanamateurism was being broken down in London. Morgan, who was an employe in Shoolbred's establishment, had his entry accepted at many meetings, and finally the officers of the London Athletic Club accepted his entry for a London Athletic Club meeting. The result was a strong cabal amongst some of the older members of the club, who threatened to resign if the entry were not refused. Eventually, when the meeting came off, about half the entrants declined to run on finding Morgan's name in the programme, but eventually the malcontents yielded to a compromise and returned to the club, most of them following the lead of Walter Slade, who declined to persevere in his opposition. The point, however, was practically settled, and in a year or two both the club and its entries gained in number what they had lost in social standing. Before leaving the subject it is only fair to state that no personal objection to Morgan was ever expressed, the opposition to him being simply to the representative of a class. The incident, though apparently trivial, had important results, as after this one protest no further objection was ever raised to the system of popularisation of the London Athletic Club meetings, which was carried out by the managers of the L.A.C. in a most thorough manner.

While Morgan was unrivalled in his career of success in the South, another celebrity was arising in the North, H. Webster 
of Knotty Ash, a representative of yet another class of the athletic community. Webster, like the greater part of the Northern amateurs of the past and present day, was of the artisan class, and before he was seen in the South, rumours of his fame as a walker reached the metropoiitan athletes; but in those days Southerners who ran on carefully measured cinder-tracks used to be very sceptical of the fast times alleged to have been done by provincial runners upon grass tracks, or at unimportant meetings. However, in the summer of 1874 , Morgan had practical proof of the ability of the Northern walkers at the meeting held at Lurgan in the North of Ireland. Lurgan then had one of the most interesting meetings of the year, as the Northerners, Southerners, and Irishmen often met there for the first time. In the walking race in 1874 Morgan only finished third, Webster being the winner, and Hughes of Liverpool second, and an acrimonious controversy followed as to whether the judge had not been too lenient. Webster, however, made no appearance in the South till after Morgan had retired and his place as

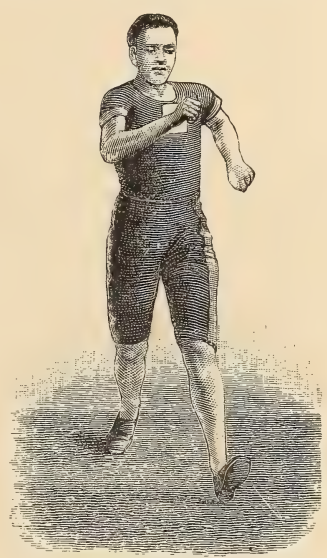

A fine free stricle. champion had been taken by $\mathrm{H}$. Venn, jun., who was the best walker that the L.A.C. had produced since Rye's retirement. Venn first appeared on the path in 1875 , and, although quite young, walked in irreproachable style, and with a fine free stride. Although slightly built and only of medium height, his staying powers seemed very great, and he walked very erect, and without a suspicion of a 'lift' when he first came out. $\mathrm{He}$ won the championship very eariy in 1876 , and whenever he was in training was indulged with a walk over for the I.A.C. 
Challenge Cups, no opponent being able to hold him. In 1877 , however, he met Webster in the championship and suffered defeat; Webster finishing the seven miles in $53 \mathrm{~min} .59_{5}^{\frac{3}{5}} \mathrm{sec}$. Both men certainly walked fairly enough at the start, but Webster, who could undoubtedly walk both fast and fairly upon occasions, was in the habit when tiring of getting into a very jumpy action, although it was hard to say at any time that he had both feet off the ground at once. On this occasion, when he beat Venn, he was in our opinion by no means walking fairly; but, on the other hand, Venn, who was making great efforts not to be outpaced, was also not going in the best of styles; indeed, Venn's style was by this time rapidly deteriorating, and we have already stated our opinion that in the succeeding year, when he turned the tables on his opponent, both men were running under the nose of the referee of walking. The succeeding year (1879) did not see the pair meet, the L.A.C. men showing their opposition to a spring fixture by refraining from entering at Lillie Bridge, and Webster, who came up for the event, finished the full distance in $5^{2} \mathrm{~min}$. 34 sec., only 9 seconds slower than the time in which Venn had won in the preceding year. At the summer championship at Lillie Bridge Venn walked orer, and as he soon afterwards retired from the path the pair never met again. In 1880 Webster again competed for the championship, and finished an easy first, but after passing the post the judges told him he was disqualified for unfair going, and awarded the race to the second man, G. P. Beckley. The decision naturally gave rise to some unpleasantness, and when the prizes were given away there was a noisy demonstration. A month or so later we saw Webster win unchallenged the Three Mile Championship of the Northern counties at Southport, and took occasion to watch his style narrowly. His gait was certainly not that of a walker, if the upper part of his body and hips only were looked at, as each step was undoubtedly a spring; but as long as walking is to be judged solely by the criterion of there being always one foot on the ground, it must be admitted that when not 
turning round a sharp corner Webster was within the definition. The present writer, on the occasion in question, upon which Webster completed his three miles in $2 \mathrm{I}$ min. $28 \mathrm{sec}$, lay flat on the ground at different places to watch Webster's feet, and it certainly could not be said that in the straights he had both feet off the ground at once. To this day controversy rages about the fairness of Webster's walking, some averring that he never walked a yard in his life, and others that he never should have been disqualified. Our own opinion is that his gait was not the gait of a true walker in the sense in which it is understood by the public, although he probably knew how to keep upon the right side of the line drawn by judges, who only look to the requirement of both feet not being off the ground at the same time.

The next year saw Merrill, the famous American walker, in England, he and Myers visiting the country together as the guests of the L.A.C. Merrill was a watchmaker from Boston, and was, we think, the fastest fair walker at any distance up to three miles who ever appeared at amateur sports in England. Although he was a bit springy in his stride, he walked erect, with a straight leg, and with his weight fairly on his heels, and no exception could be taken to his style. He was over the medium height, and strongly built about the hips, although not a very heavy man, and was very carefully trained and in admirable condition. The championship of $\mathrm{I} 88 \mathrm{I}$ seemed a moral for him, as Webster was by this time falling into the 'sere and yellow' stage, and going more shiftily than ever. The race, which was won for England by a novice, J. W. Raby, of Elland, Yorks, was a memorable one. Merrill went off very fast, and Webster, trying to keep pace with him, soon became so shifty that he was disqualified by the judges. In the meantime, Raby, who was a tall, gaunt lad of the class which has recently received the franchise, stuck doggedly to the American, wore him down before five miles had been covered, and finished alone, Merrill giving up from exhaustion. The enthusiasm of the crowd-the largest that ever attended a champion- 
ship meeting, being over 10,000 in number-was extreme, for the English sportsman is always intensely patriotic, and especially so when he has put his money upon the native product against the foreigner. In that year, too (I88I), the public had lost a lot of its coin to Americans upon the turf, and an unexpected British victory on the cinder-path was refreshing. Raby, at the time, walked in wonderfully fair style, with exactly the same action, in spite of his great speed, as an ordinary pedestrian on the road. He was not allowed long to remain an amateur, and soon joined the professional ranks. As has been the case with many another fine, natural walker, a little artificial cultivation soon made him walk as shiftily as the rest.

The champion of the next two years was $H$. Whyatt, of the Notts Forest F.C., who is also credited with having walked a mile at Birmingham, in $188_{3}$, in $6 \mathrm{~min} .34 \frac{4}{5} \mathrm{sec}$. Whyatt was a tall, wiry man, who progressed with a very short stride; and we can only express an opinion of him that he never walked at all, but merely trotted on his heels, taking care upon such occasions never to have both feet off the ground at once. His action was very like that of Webster in his later days, only 'very much more so' ; but as long as a man was considered to be walking because one foot reached the ground before the other quite left it, it became impossible to disqualify him.

In 1884 two Americans were in this country, F. P. Murray and IV. H. Meek. The former arrived here as the guest of some English clubs, and under some mysterious arrangements, in which 'gate money' played an important part, he was unable to appear at the championship meeting: Meek, however, who came over independently, and with a desire, as we are informed, of showing that the invited guest was not the best American walker, reached England a day or two before the championship meeting, and won the walking race with great ease, in most excellent style. Like his compatriot Myers, he had a most remarkable physique. He was a very little man, with a large pair of thick, strong legs. His stride was long, and his walking of a perfectly fair road-going style. At Stam- 
ford Bridge, a little later on in the same year, he covered his four miles in $29 \mathrm{~min}$. Io sec., going perfectly fairly, a really remarkable performance ; and there is very little doubt that if put to it he could have beaten the record for seven miles, as he was a fine stayer, having so little weight to carry upon his great legs. During his visit he met Murray, and was beaten by him, but there was some suspicion that Meek was not trying to do his best. Of Murray's style we feel great difficulty in speaking. We do not consider him to have been a fair walker in the sense that Merrill and Meek were fair walkers, but, at the same time, we must admit that he never had both feet off the ground together in a race. We watched him at one meeting, as we had before watched Webster, and could see that the toe of his hind foot left the ground at exactly the same instant that the heel of his front foot touched it. Upon anything but a perfectly level cinder-track he must have broken into a trot, but did not do so when we saw him walking. He had rather a short stride, with a very great deal of arm action, and to look at his body he seemed to be trotting, not walking. Perhaps we may say that he was not a genuinely fair walker, but was within the received definition. He is credited in America with having covered a mile in $6 \mathrm{~min} .29 \frac{3}{5} \mathrm{sec}$; two miles in $13 \mathrm{~min}$. $48 \frac{2}{5}$ sec. ; and three miles in 2 I min. $9 \frac{1}{5} \mathrm{sec}$. No doubt at these shorter distances he was faster than, if not so fair as, Meek; but, like so many of the doubtful goers, he was better at short than at long distances. Since Meek's departure we have seen little fast and genuinely fair walking in England, and at the short distances, which are those in vogue at all athletic meetings, there is a great deal of that doubtful style of which Murray was the most able exponent. ${ }^{1}$

We must confess to noting with pleasure a revival at the

1 These words were written before the appearance upon the path of $H$. Curtis, the amateur champion of $1890,1891,1892$, and 1893 . Curtis was at his best in 1890 , when he walked erect, with a fine stride and with irreproachable fairness. On July I2, I89o, at the championship meeting at Birmingham, he walked in perfect form and covered his five miles in $37 \mathrm{~min}$. I7 sec.; six miles in $44 \mathrm{~min} .57 \mathrm{sec}$., and seven miles in $52 \mathrm{~min} .28 \frac{2}{5} \mathrm{sec}$. - all 'records' for the distances. 
present day of walking races along the roads for considerable distances. In such races the doubtful goers are conspicuous by their absence, as nothing but genuine road-walking will pay in a road-race, and such contests afford fine exhibitions of power and endurance. In 1886 a really remarkable performance was done in the great road-race to Brighton F;y the winner Mackintosh, who covered the distance from Westminster Bridge to Brighton Aquarium (about 52 miles) in 9 hours $25 \mathrm{~min} .8 \mathrm{sec}$. The success of the winner has, we beliere, been taken to show that the old race of running-footmen has not died out without leaving a worthy exponent amongst the profession of the equally fine pastime of walking. 


\section{CHAPTER V. \\ JUMPING, WEIGHT-PUTTING，ETC.}

IN no branch of athletics have practice and cultivation led to such an extraordinary improvement as in high and broad jumping. At the first Oxford and Cambridge meeting in I 864, the High Jump was won with $5 \mathrm{ft}$. 6 in., the Long Jump with $18 \mathrm{ft}$., and even at the present day foreigners hear with incredulity that men can jump more than $6 \mathrm{ft}$. in height, and clear more than $23 \mathrm{ft}$. on the flat. The improvement is perhaps more marked in long jumping than in high jumping, but even in the latter, careful training and assiduous practice has shown that the human body is capable of greater feats than were thought possible before jumping became an organised sport. Probably 'Christopher North' would have found it as hard to believe that M. J. Brooks jumped $6 \mathrm{ft} .2 \frac{1}{2}$ in. high in I 876, as did Donald Dinnie, the S: otch 'professional,' who, on seeing an account of Brooks' jump, promptly wrote to the papers to show that, upon $\dot{a}$ priori grounds, such a feat was impossible.

Perhaps nothing is so pretty and interesting as a High Jump, and a light-weight jumper who leaps straight over his obstacle and alights on the balls of his feet is almost certain to be graceful in his movements. Still there are a variety of different styles of high-jumping, and some successful performers get over the bar sideways with a crab-like motion which is more effective than beautiful. The muscles used for the spring are those in front of the thigh which pass down to the knee-cap. The knee is bent when preparing for the spring, the muscles are contracted, and from the sudden and violent straightening of the leg with a jerk, the impetus is given. A high-jumper, therefore, must have these muscles not only strong but naturally 
springy and elastic, and from this it follows that in a certain sense the high-jumper, like the sprinter, is born, not made; for though muscles can be hardened and strengthened by practice, nothing but nature can make them elastic. As a matter of fact the high-jumper is nearly always short-thighed, with a well-shaped knee, a rather long leg from knee to ankle, and with an ankle, like the knee, cleanly and delicately shaped.

It is always said, and with some show of truth, that a highjumper is fanciful and uncertain. The reason is easy to see, for not only will a touch of cold or stiffness in the joints spoil a man's form, but the greatest possible difference is made by inability to take off at exactly the right distance from the bar. Thus, if the 'take off' is a little up-hill, a little down-hill, or so slippery as to make the jumper nervous of falling, he may rise from the wrong place, and jump into the bar instead of over it. It is sometimes amusing to act as judge in a highjumping contest. One man wants to jump with the sun on his right, another with the sun on his left, one likes to alight upon the mattress which is always kept for the purpose, another is 'put off' if he sees the mattress in front of him; another sticks a bit of paper into the ground to guide him as to his take-off, while yet another hangs a blue handkerchief on the bar to show him where he is to jump to. To all this a courteous judge can raise no reasonable objection, but the competition in consequence becomes unduly prolonged and wearisome to the public, as each competitor has three tries at each height, and the mattress, handkerchief, and paper have to be shifted about at each jump. Luckily, even the most obliging officials cannot be asked to put a curtain over the sun for the jumpers' convenience.

The jumper has to get himself fit in the same way as the sprinter. He must become strong, light, and hardy without becoming stiff. As a bye-play, then, he will do no harm if he indulges in a bit of sprinting and takes exercise canters, being careful to keep upon his toes; and the more he avails himself of the services of a rubber the better. For his main practice he must jump over the bar daily, being cautious not to overdo himself any day, and if he be wise he should learn to take off both 
against the wind and with it and under all sorts of atmospheric conditions, as he will then be less likely to be 'put off' when he appears upon a strange ground to take part in a competition.

Of late years it has been the practice to put the posts upon the cinder-path or to have a 'take off' of cinders for the jumpers. Some of the performers, however, prefer taking off from grass under any circumstances, and no doubt they are right in thinking that good dry springy turf is better than cinders. At the same time we have plenty of rain in England; the grass is sometimes too slippery for fair jumping, and in such a state that even a sprinkling of cinders or sawdust is insufficient to get it into condition. The managers of a meeting should be careful, if they intend their jumps to be upon the grass, to cover up their 'take off' for a day or two beforehand. At the same time the jumper will be wise if he can get the opportunity to practise both upon cinders and turf, and he will thus be prepared for all emergencies.

The usual practice in competition is for the bar to be raised one inch each time, and not more, when the jumpers are beginning to approach the end of their tether; but they are usually given a few jumps at lower heights to start with to get their legs into form. In the championship the bar is usually placed at first at $5 \mathrm{ft}$., then raised to $5 \mathrm{ft}$. 2 in., then to $5 \mathrm{ft} .4 \mathrm{in}$., and then to $5 \mathrm{ft}$. 6 . in. if all the competitors agree, but if any object, after $5 \mathrm{ft} .4$ in. the bar is raised an inch each time.

Although the jumping was very poor at the first two Inter'Varsity competitions, the first championship meeting in I 866 brought out two fine performers, both Cantabs, T. G. Little and J. H. T. Roupell, who tied at $5 \mathrm{ft} .9$ in., a height which remained the 'record' for the next five years. In the next year Little again won the championship with a tie, his partner on this occasion being another Cantab, C. E. Green. In 1868, however, the 'Varsity men were no longer in sole possession of the field, for in this year that wonderful athlete R. J. C. Mitchell, of Manchester, made his first appearance on the scene in London, winning the high jump with $5 \mathrm{ft}$. 8 in., the long jump with $19 \mathrm{ft} .8 \frac{1}{2} \mathrm{in}$., and the pole jump with Io ft. $6 \frac{1}{2}$ in. Two 
years later Mitchell won all these three events again with the weight-putting into the bargain, and in $187 \mathrm{I}$ he sgain was champion in these four competitions, his high jump on this occasion being $5 \mathrm{ft} .9 \frac{1}{2}$ in., half an inch better than the old record. Mitchell's performances in 187 I certainly show him to have been a fine all-round athlete, his high jump being, as we have said, $5 \mathrm{ft}$. $9 \frac{1}{2}$ in., his long jump (in which he tied with E. J. Davies) $20 \mathrm{ft} .4$ in., his pole jump ro ft., and his weightputting $38 \mathrm{ft} .8 \frac{1}{2} \mathrm{in}$. In these later days the competition is so kcen that would-be champions have to become specialists, and we thus hear less than we used to of 'all round champions.'

Mitchell's performance was never eclipsed until M. J. Brooks, a freshman from Rugby, came up to Oxford. Brooks in his first year jumped $5 \mathrm{ft}$. $10 \mathrm{in}$. at the Inter-'Varsity sports, and a few days later eclipsed this by a performance of $5 \mathrm{ft}$. I I in. at the championship meeting. He was a tall, cleanly built, and rather thin man, with a good deal of strength as well as spring, and his manner of jumping was very striking, although not very graceful when he got over great heights. He took very little run, and in fact almost walked up to the bar, springing straight over it with his legs tucked up high and well in front of him, and invariably looked, when his legs were once over, as if his body would fall crashing on to the bar; but he nearly always managed to jerk his body forward again and to alight upon his toes. When he did knock down the bar he did so with his elbows or body, being apparently able to get his feet over almost any height. The year after his first appearance Brooks was in no sort of form, and was beaten by M. G. Glazebrook, another Oxonian, who did 5 ft. $9 \frac{1}{4}$ in. at the Inter-'Varsity gathering, and was credited with $5 \mathrm{ft}$. II in. at the championship meeting. Wie can recollect, however, that Glazebrook's $5 \mathrm{ft}$. II in. was rather a doubtful record, as he knocked the bar pretty heavily, but without bringing it to the ground. In 1876 Brooks disposed of his own and Glazebrook's joint record by jumping $6 \mathrm{ft}$. at the University sports at Oxford. For so many years it had been considered an impossible feat to jump $6 \mathrm{ft}$. that the excitement at the performance was very great, and the Honorary 
Treasurer of the O.U.C.A., then as now an enthusiastic admirer of 'records,' threw his hat into the air, oblivious of the fact that the old Marston Ground was covered with puddles, in one of which the hat alighted. On this occasion the take-off was from cinders, but at the meeting at Lillie Bridge a fortnight later the competitors, who had a very fine warm day, took off from the grass, and Brooks cleared on this occasion $6 \mathrm{ft}$. $2 \frac{1}{2}$ in. We have heard from 'Bob Rogers,' who was on the ground as official time-keeper and was standing close by, that Brooks' feet went two or three inches above the bar when he cleared this remarkable height. At the championship meeting three days later Brooks again cleared 6 feet, another magnificent performance, as he took off from very wet spongy grass. This was his last performance in public.

The next few years produced one or two good jumpers, but Brooks' record still seemed quite unapproachable. In 1878 a Northerner, G. Tomlinson, who in face and figure seemed a smaller edition of F. T. Elborough, won the championship with $5 \mathrm{ft} .1 \circ \frac{1}{2} \mathrm{in}$., and we believe on other occasions cleared 6 feet. $\mathrm{He}$ was a very pretty jumper, but took his leap a bit sideways. Another fine performer was the Cantab, R. H. Macaulay, another all-round performer, who, when he became after some seasons of football a bit too heavy and stiff for jumping, developed into a fine quarter-mile runner. Macaulay when in his first year at Cambridge was able to clear nearly 6 feet, and in 1879 he won the championship with $5 \mathrm{ft} .9 \frac{1}{2}$ in. $\mathrm{He}$ was a very strong, loosely built man, and his style of jumping was to take off a long way from the bar and go over with a great bound and with his head and shoulders well up, so that at the moment of the clearing the bar the body was almost perpendicular, not leaning back as was the case with Brooks.

One of the few jumpers who up to the present have rivalled the reputation of Brooks is the Irish athlete P. Davin, a member of a very well-known athletic family, his elder brother, M. Davin, having made a great reputation as a weight-putter, and another brother, T. Davin, having won several Irish championships at high and long jumping. In 
1880 P. Davin is reported to have beaten Brooks' record by clearing $6 \mathrm{ft} .2 \frac{3}{4}$ in. at his native place at Carrick-on-Suir, and in proof of the record we believe that the certificates of two local justices of the peace as to the correctness of the measurement were lodged with the Field. There is indeed not the least reason to doubt the bona fides of the performance, but it is perhaps natural that a good many Englishmen should have suspicions that Irish patriotism might manage to elongate a measurement by a quarter of an inch when the downfall of Saxon supremacy could be secured thereby. In I88I Davin came over for the English championship and won with a leap of $6 \mathrm{ft}$. $\circ \frac{1}{2}$ in. His appearance was watched with great interest, and he certainly showed magnificent power on that day, winning the long jump as well with a leap of $22 \mathrm{ft}$. I I in. Davin was a tall strong man of quite 6 feet in height, and might almost be described as a young giant, being, although very well-shaped, a strong, heavy man. His style of leaping was quite different from that of Brooks, as he trotted up towards the posts and with one prodigious bound in the air went clean over the bar. In one of his leaps, when he was clearing about $5 \mathrm{ft} .9$ in. height, we saw him take off six feet before the bar and alight six feet on the other side, and when over the bar his body was almost perpendicular. In fact he took a downright honest leap at the bar in much the same way as a man would leap over a hedge and ditch from a road. In 1887 , however, those two giants, Brooks and Davin, were surpassed by a diminutive American, W. B. Page, who, though only about $5 \mathrm{ft} .6$ in. in height, cleared $6 \mathrm{ft} .3 \frac{1}{4}$ in. at Stourbridge. ${ }^{1}$

Of late years Ireland has certainly produced many fine jumpers, and there can be little doubt that it is an amusement for which the Celtic race has a natural aptitude. For the half dozen years preceding I886, both the high and long jump championships have fallen more often to Irish and Scotch competitors than to native Englishmen.

1 At the championship meeting of 1887 Page tied with G. W. Rowdon of Devonshire. Rowdon is said to have jumped $6 \mathrm{ft}$. $5^{\frac{3}{8}}$ in. at some volunteer regimental sports at Haytor camp in August I89o, but the record is a doubtful one. Rowdon afterwards exhibited his wonderful leaping powers at the music halls. 
The Scotchman J. W. Parsons, who was English champion in $\mathrm{I} 880$ and $\mathrm{I} 883$, deserves a word of notice. Compared with Drooks and Davin, he may be ranked as a small man, and, if our recollection serves us aright, stands about $5 \mathrm{ft} .9$ in. ; yet in 1883 he cleared $6 \mathrm{ft}$. $\circ \frac{1}{4}$ in., which, when compared with his height, shows him to be a performer almost of the calibre of the other two. The champion of 1885 -Kelly, an Irishman-cleared $5 \mathrm{ft}$. I I in., and it may probably be said with truth that the

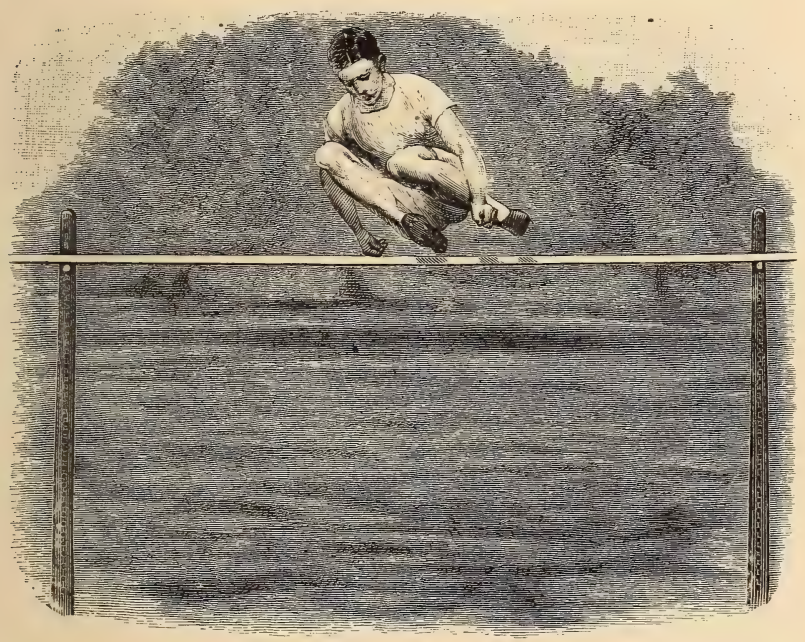

High jump.

average of high jumping at country sports is better in Ireland than in England. Except, however, in jumping and weightputting, the average performer at English sports is better than the average Irishman.

The improvement made of late years in long jumping is even more marked than it has been with high jumping, and it seems almost absurd to us nowadays, when almost every fair sprinter can clear $20 \mathrm{ft}$., to know that up to 1870 every championship 
was won with a leap of less than $20 \mathrm{ft}$. The truth is that it was not till some years after sports had been instituted that the value of speed as a factor in long jumping was discovered. The old jumper took a short run and a big spring; the modern longjumper starts fifty yards from the take-off, sprints up as hard as he can, and is going his hardest when he takes his leap. The result is that the mere impetus takes him the extra foot or two over the ground by which the moderns excel their predecessors.

In practising, therefore, for the long jump the athlete must prepare himself in much the same way as the high-jumper and sprinter, taking care not to get stiff. There must also be a constant and assiduous practice in jumping, as the main element of success is to get a good take-off at full speed from the right spot, and this is much easier said than done. Indeed, it is the commonest thing, even in championship and other firstclass competitions, to see the competitors 'muff' their take-off, or sometimes take off a foot before the line, and so be credited with having jumped a foot less than they have actually covered.

The theory upon which the rules of long jumping appears to be founded is that the jumper is clearing a river or a pit. Thus a board is placed flat with the ground, or a line marked, and the jump is measured from the starting line. The ground after the line should be hollowed out, so as to make it impossible for the jumper, if he over-run the line, to get a jump at all. If he fall back after alighting from his jump, the jump is lost; and the distance is, of course, measured from the taking-off line to the first part where the hindmost heel touches the ground upon alighting.

We have said before that it is no uncommon matter to find a sprinter clearing his 19 or 20 feet, not really because he is a born jumper, but simply from his pace, and from his having learnt to take-off when going at full speed; but out of the scores of men who can cover 20 feet, only very few can reach 2I feet, and the man who can jump that extra foot is a good performer. Nearly all these good jumpers seem to attain the extra foot or more by the kick or jerk which they get from the back either at the moment of taking-off or in mid-air. We 
have seen many jumpers in mid-air throw out their legs well in front of them with a jerk of the back, and alight a foot farther than the place where they seem bound to touch the ground. There is a good deal of art in knowing exactly how far the legs can be safely shot out, for if this be overdone the jumper will fall backwards and lose his jump. In fact, there is a great deal more skill in long jumping than is generally believed, and it is one of the competitions in which men show most uncertain form, for the slightest attack of the nerves may prevent a man getting anything like a decent take-off, or may make him forget his usual trick of throwing out his legs, causing him to skim along the ground, or jump too high in the air. Year after year sees men who have jumped $2 \mathrm{I} \frac{1}{2}$ or 22 feet at Oxford or Cambridge, fail to reach much more than 20 feet at Lillie Bridge ; and there is little time to recoup a bad beginning, as at most each jumper does not have more than six tries.

The long-jumper, like the sprinter, may be a man of almost any size or weight. He may be a giant like Baddeley or Davin, or a little light-weight like E. J. Davies, a short middle-weight like the Irishman Lane, or a tall middle-weight like Lockton. All these, together with J. W. Parsons, of whom we have spoken before as a high-jumper, have probably been capable of clearing 23 feet upon a good day, and yet it would be hard to say that as regards phisique they presented any one quality in common.

We have said that it was not until $187 \mathrm{r}$, when Davies and R. J. C. Mitchell tied for the championship with $20 \mathrm{ft} .4$ in., that 20 feet was cleared at a championship meeting, and before Davies appeared on the scene only one Inter-'Varsity winner had cleared $2 \mathrm{I}$ feet, this being in $\mathrm{I} 868$; and at that time A. C. Tosswill, the hero of the performance, was considered an absolute phenomenon. In 1882 , however, Davies, who had by this time developed into his true form, threw all the preconceived notions of jumping ability into the shade by showing himself capable of clearing 22 feet almost any day he liked. He won the Inter-'Varsity jump, in 1872 , with $21 \mathrm{ft}$. 5 in., and the championship of the same year with $22 \mathrm{ft}$. 7 in. In the championship of 1873 he did not compete; but in 1874 
he again covered $22 \mathrm{ft} .5 \mathrm{in}$, having in the Inter-'Varsity jump of that year, a few days before, cleared $22 \mathrm{ft}$. $1 \circ \frac{1}{2} \mathrm{in}$., then the record of the sport. Up to that time, indeed, Davies was as much the superior of the jumpers who had preceded him as was Brooks a few years later in the kindred sport of high jumping, and his case was like that of Brooks in another point, that the first man who rivalled his great reputation came from Ireland. In the Irish Civil Service sports of 1874 Davies was beaten by J. Lane, who cleared $23 \mathrm{ft}$. I $\frac{1}{2}$ in $\mathrm{IVe}$ never saw Lane jump, but gather from a sporting annual that he was $5 \mathrm{ft}$. $8 \mathrm{in}$. in height, and weighed I I st. $2 \mathrm{lb}$., a good weight for a man of that height. It is still somewhat a moot point whether Lane's jump ought to be received as a genuine performance, as it has been averred with vehemence, and denied with equal vehemence, that there was a fall in the ground. In truth, however, it is very difficult indeed, when it comes to an inch or two, to judge between one jump and another, as a little wind more or less behind the jumper, or a slight drop in the ground, may make a good deal of difference. It is seldom, also, that the run for the jump is on perfectly level ground, as it is impossible to place the jumping ground, with its prepared surface and hollowed pit, in the middle of the levelled running path. For several years, therefore, and we might almost say up to the present day, the question must remain undecided as to which of the pair was the best of all jumpers. Their performance was never even approached for several years.

In 1878 the Universities turned out simultaneously a pair of fine jumpers, C. W. M. Kemp of Oxford, one of a very wellknown athletic family, and E. Baddeley of Cambridge. At the Oxford and Cambridge meeting, Kemp, who was a light-weight, wiry, and of more than medium height, beat Baddeley by a few inches, winning with $22 \mathrm{ft}$. $2 \frac{3}{4}$ in. Kemp was, we think, not quite so good, but more certain than his opponent, and always jumped with great coolness and judgment, never failing when fit to get a good jerk in mid-air and fling his legs well out in front of him. At the championship meeting, in the same year, Baddeley furned the tables on his opponent, winning with the fine jump of 
$22 \mathrm{ft} .8 \mathrm{in}$. on perfectly level ground. Baddeley was a very tall, heavy man, weighing over. I3 stone, strongly and loosely built, and was also the hammer-throwing champion in 1878 and 1882 . He occasionally made a poor show at long jumping, through failing to jump sufficiently high and skimming too near the ground. As he had a great natural spring in his muscles, it suited him better to leap a trifle higher than his lighter opponent Kemp.

Lockton, who made his mark also as a sprinter and hurdler,

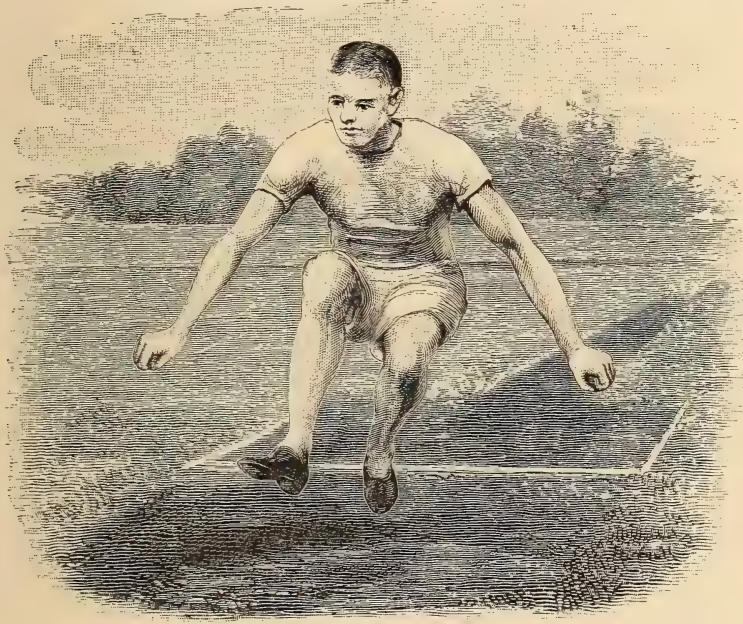

I,ong jump.

was another magnificent long-jumper, having time after time done over 22 feet in public. IVhen a lad of seventeen at school he entered for the long-jump championship, and as Davies, who was also entered, did not put in an appearance, Lockton was indulged with a walk over. In 1875,1879 , and 1880 he also won this championship, on the two latter occasions clearing over 22 feet. Indeed, Lockton, from the time he was eighteen, was always good for 22 feet; and cleared within an inch or two of this distance at his school sports, when still at school. 
Lockton did not figure prominently at sports after 1880 , and since his time it is hardly too much to say that most of the best long-jumpers have been Irishmen or Scotchmen. Parsons, of Edinburgh University, who was, as we have described, a light-weight of medium height, not only cleared $6 \mathrm{ft}$. o $_{\frac{1}{4}}^{1}$ in. at the championship at Lillie Bridge in 1883 , but on the same day won the long-jump championship with $23 \mathrm{ft}$. $\circ \frac{1}{4} \mathrm{in}$. The weather was fine and warm, but as he was neither aided by wind nor drop in the ground, the double performance on the same day marks him as a marvellous jumper. Parsons, like Kemp, jumped always with great judgment, never taking off short of the line, and throwing his legs well out in front of him.

In I88I P. Davin won the English championship at the Aston Grounds, Birmingham, with a jump of $22 \mathrm{ft}$. I I in., but was aided by a decided drop in the ground. Davin's long jumping was like his high jumping; he had a remarkable natural spring in his muscles and jumped well into the air with perfect grace and no twisting of the back or jerk of the body. Two years later he is credited with having, at Portarlington, in Ireland, covered $23 \mathrm{ft}$. 2 in., just half an inch more than Lane's jump of 1874 , and there does nct seem to be any fair reason for disputing the record. In $\mathrm{I} 882$ the champiorship again fell to an Irishman, T. M. Malone, who was a slighter man than Davin, but jumped in exactly the same style. Malone, who was also a fine sprinter, has since earned a great reputation as a professional runner in Australia. Since then an Irishman, J. Purcell, has won our championship, jumping in exactly the same style, being able to clear over 22 feet. In fact there is no doubt that there is an Irish style of long jumping which most of the English jumpers are physically unable to imitate. Experience may almost be said to show that in natural 'springiness' the Celtic muscle is superior to the English.

Quite recently all previous performances at long jumping have been eclipsed by those of the Oxonian, C. B. Fry. Fry, who is a marvellous all-round athlete, obtained a 'triple blue,' that is to say, represented his University at cricket, football, and athletics. He has several times jumped over 23 feet either 
at the Iffley Road Ground at Oxford, or at the Queen's Club. His best performances are $23 \mathrm{ft} .6 \frac{1}{2}$ in. (a world's record), made at Oxford in March I893, and $23 \mathrm{ft} 5$ in., made at the Queen's Club at the Inter-'Varsity gathering of 1892 . Both the places upon which these performances have been made have admirably prepared jumping-grounds, and in each of them the ground is 'banked up ' very slightly just before the 'take-off.' A distinguished ex-champion jumper has expressed his opinion that the slight rise in the approach to the 'take-off' gives a material assistance to the jumper, but even if this be so (and I consider it doubtful), Fry's superiority to his predecessors can hardly be questioned.

\section{WEIGHT PUTTING.}

At first sight it would seem that jumping and heavy-weight throwing were the very opposite poles of athletic sport, but experience shows this to be very far from the truth, and in many cases the champion at weight-putting or hammer-throwing will be found to be either an active or a retired jumper. The truth is that both strength and elasticity of muscle are required for weightputting and hammer-throwing, and it is therefore not hard to understand why both these latter competitions are more natural to, and are more practised by, the Celts of Scotland and Ireland than by the English. Both competitions, however, form part of the regular programme of an English athletic fixture, and are included at the Championship and Inter-'Varsity meetings.

The rough-and-ready experiences of the pioneers of the athletic movement decided that a I6-1b. weight and a 16-1b. hammer would give the best test of an athlete's ability to manipulate a heavy weight ; at the present day, therefore, in England nearly all the weight-putting competitions are with a I6-lb. weight, which is put 'without follow' from a 7 -foot square. In Ireland, Scotland, and America, however, the putting, hurling, or slinging of heavier weights is often practised. In the present work we think it better to confine ourselves to noticing the English practice of the sport alone.

The English rule for the sport of weight-putting as formu- 
lated by the Athletic Association runs as follows: 'The weight shall be put from the shoulder with one hand only, and without follow, from a 7 -foot square. The weight shall be of iron, and spherical, and shall weigh $16 \mathrm{lb}$. All puts shall be measured perpendicularly from the first pitch of the weight to the front line of the square or to that line produced.' The definition requires perhaps a few words of explanation. The weight must first be 'put' from the shoulder, not 'bowled.' There have been cases where men with fine muscles of the arm and

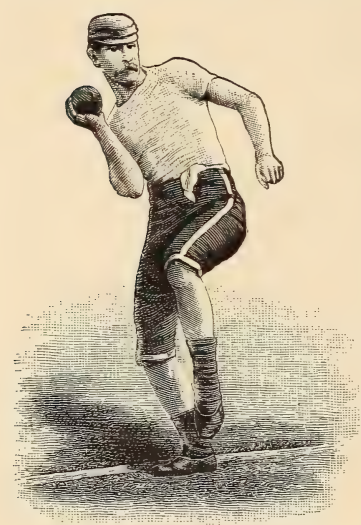

Putting the shot-first position. chest have been able to 'bowl' a $16-$ lb. weight like a cricketball farther than it can be put in the legitimate style. In a legitimate 'put' the elbow is directly below the hand and close to the side where the weight is delivered. Secondly, there must be no 'follow. that is, after the weight is delivered the 'putter' must draw back and not allow the impetus given to his body to carry either foot over the front line, or he will be 'no-balled,' to borrow a phrase from cricket. Thirdly, the weight must be of iron. There really seems to be very little reason for this restriction, which, as a matter of fact, gives an advantage to men with large hands. A leaden weight is smaller and more handy, and a man with a small hand has better command over a leaden ball, and can certainly put further with it. The restriction of the nature of the metal has probably been instituted for the purpose of getting one fixed standard for estimating the relative value of performances at different places.

The main point to learn in weight-putting is to 'get one's 
weight on '-to use a rowing phrase-that is to say, to employ mere arm-work as little as possible, and to get the impetus for propulsion from a rapid spring and turn of the body. The method adopted for securing this by all good weight-putters is the following. The putter balances his body on the right leg (supposing him to be right-handed and putting with the right arm), with his right shoulder thrown back and the weight on his right hand close to the shoulder; he then raises the weight up to the full stretch of his arm two or three times to stretch the muscles, the left arm and leg usually being thrown forward to balance the body. A quick hop is then taken about three feet towards the mark; at the end of the hop the left leg touches the ground, but the right shoulder is kept back, and the weight of the body is still on the right leg. A sharp spring is then taken towards the scratch line and the body swung rapidly round a halfturn, so that when the weight leaves the hand the right shoulder and leg are forward, and the left shoulder and leg behind. The weight is thus propelled more by the swing of the body

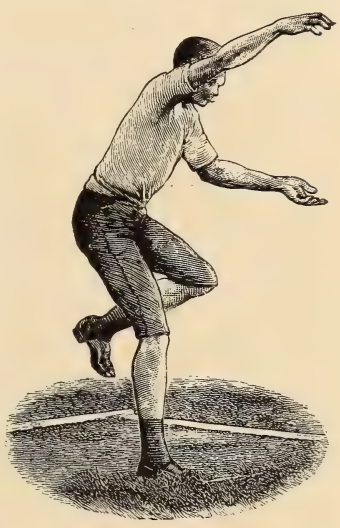

Putting the shot-second position. than by the jerk of the arm. The best weight-putter, therefore, is not necessarily the tallest, heaviest, or strongest man, but he who can bring, roughly speaking, the greatest momentum by the turn of his body to the delivery of the iron ball. It thus . gives a scope for agile strength; youth has its opportunity to compete with the matured power of riper age, and often a quite small light man is able to put really great distances; of course, however, height and weight have great advantages. An attempt was, indeed, we believe, once made to induce Chang, 
the Chinese giant, to enter for one of the champronship meet ings, it being thought that he must necessarily be able to put a great distance, as he would have been like an ordinary mar throwing the weight out of a first-floor window. We fancy, however, that had the Celestial competed he would not have been in the hunt with the more skilful Britons.

For many years the weight-putting record was held by E. J. Bor, a gigantic member of the L.A.C., who put $42 \mathrm{ft} .5$ in at the championship of 1872 . This was never surpassed until I885, although there were plenty of fine weight-putters in the interval. R. J. C. Mitchell, the high and long jumper, twice won the championship with puts of over 38 feet, and the two brothers J. and T. Stone, of Newton-le-Willows, also figure in the list of champions, the elder brother having won in 1867 and 1868 , and the younger in 1875,1876 , and 1877 . The latter was a fine specimen of manhood, weighing 14 stone and being over six feet, but beautifully proportioned, and no mean performer at a sprint. He was, however, beaten in Ireland in 1876 by M. Davin, an elder brother of the two famous jumpers; although, in 1877 , Stone in England beat the Irishman, putting over $4 \mathrm{I}$ feet with a leaden weight. In I878, I879 (summer championship), and r 880 the champion was IV. Y. Winthrop, an ex-Cantab and popular member of the L.A.C., whose prodigious feats of strength in other matters would require a volume to record them adequately, the most famous being, if report be true, the upheaval of a flagstaff by his own unaided efforts at a well-known watering-place in the North. In I882 the championship fell to a Northerner, G. Ross of Patricroft, who was, we believe, a policeman. Ross 'put' in a most unusual style, and was rather a puzzle to judges and referees. He commenced as if about to bowl the weight, but straightened his arm with a jerk, which brought the elbow into the side just before the weight left the hand. In the championship of 1882 he put $42 \mathrm{ft}$. 4 in., only one inch less than Bor's record. Ross was not a very big man, nor yet very agile, but had enormous strength of arm, and his remarkable ability was, we think, due to his 
style of putting, of which he was, as far as we know, the first and last exponent. The next two years' championships fell to Owen Harte, a giant from the Irish constabulary. In $I 8 S_{5}$ Scotland had her turn, the champion being D. J. Mackinnon, of the London Scottish Football Club, the best weight-putter we ever saw. He was quite a young man, about $6 \mathrm{ft}$. 6 in. in height, and broad in proportion, although not fleshy. He was always a conspicuous object in the football field, where his gigantic form towered over the scrimmages. He put in his championship win $43 \mathrm{ft}$. $\frac{1}{2}$ in., thus finally disposing of the old record. A few days afterwards, however, this performance was beaten at the Irish championship of I 885 by J. O'Brien, another member of the Irish constabulary, whose performance was $43 \mathrm{ft} .9$ in. This has since been surpassed by the 'put' of a Canadian, G. R. Gray, who accomplished $44 \mathrm{ft}$. 9 in. at Dublin in July, I888. Gray was only of medium height and size, which makes the performance still more wonderful.

It is hardly to be expected that the youthful undergraduates of Oxford and Cambridge should produce weight-putters of such excellence as their runners and jumpers. The best exponent of the art at the Universities, J. H. Ware, who won the event four years in succession from I 882 to I 885 , was, however, a really first-class performer, having on occasions put over 39 feet, and it was unfortunate that he was unable to compete at the championship in I886. Ware, like most of the other fine weight-putters, was a giant in height and build.

\section{HAMMER.THROWING.}

Hammer-throwing is a sport which in its present form has come to us from over the Border, although the 'hurling of the bar or sledge' was, as we have already seen, one of the sports of merry England. Since the introduction of the sport into modern athletic meetings, the weight of the hammer has always been the same as that of the weight used in weight-putting, viz 
I5 $\mathrm{lb}$; but the rules as to length of handie, the length of run allowed, and measurement still vary. The original rules, followed both at the championship meeting and the Oxford and Cambridge sports, allowed the hammer-thrower to use a hammer of any length, to take as much run as he liked, and throw from any place he liked, the judge marking the place where the thrower had his front foot at the moment when the hammer left his hands. The measurement was then taken in a straight line from the thrower's foot to the pitch of the hammer. At the championship meeting after 1875 a 3 -ft. 6 -in. hammer and a 7 -foot run without follow alone were allowed, although at the Oxford and Cambridge sports the old rules went on until I88I, and even now the Oxford and Cambridge rule is different to that used at the championship meeting. In America, and at some Scottish meetings, the hammer is thrown standing, without a run at all. The rule of the Athletic Association, however, which was used at the championships until 1886, and followed at nearly all the places in England where the sport is practised at all, ran as follows : 'The hammer shall be thrown from within a circle of 7 feet in diameter. The head of the hammer shall be of iron, and spherical, and the handle shall be of wood. The head and handle shall weigh together $16 \mathrm{lb}$. The total length of the hammer shall not be more than 4 feet.' In 1887 the circle was enlarged from 7 feet to 9 feet. We must confess to thinking that the limited run, short hammer, and no follow make hammerthrowing a fairer, prettier, and more skilful sport than the original form of the competition.

The main point to learn in throwing the hammer is to get as much impetus as is possible upon the body by rapidly spinning round, the arms being held perfectly rigid with the hammer grasped in the hands. At the moment when the greatest impetus is obtained, the hammer is let go, an extra push being given at the last moment by a jerk of the whole body. No actual arm-work is used at all, the strain falling mainly upon the back and loins; indeed, one or two famous 
hammer-throwers, like W. Lawrence of the O.U.A.C., have only used one arm to hold the hammer. The hammer is swung round, when once the thrower has begun his spin, at right angles to the body in its vertical position, and the arm and handle thus act as one and the same lever. A very slight grasp of mechanical principles will show that the hammer-head is, as it were, attached to the circumference of a revolving circle, the motive power being supplied by the spinning human body at the centre. At the moment of leaving go, the centrifugal force

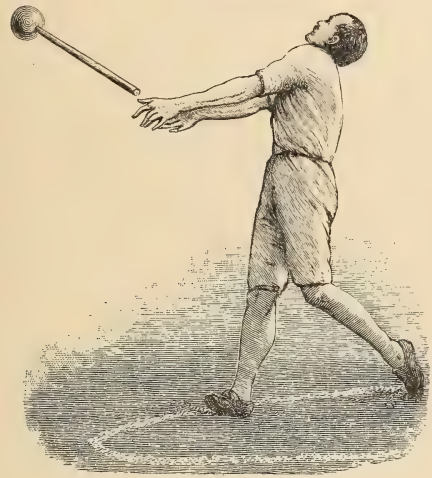

Throwing hammer.

causes the hammer to fly off in a straight line. It follows that the hammer will fly farthest when the greatest momentum, i.e. weight and speed combined, can be produced. It is therefore obvious that, where an unlimited run is allowed, the heaviest man, provided he can acquire enough skill to spin round fast without falling over, must inevitably be able to throw the hammer farthest. Height also will be a great advantage, as it will enable a larger handle to be used, and the weight starting from a higher point, will travel farther before touching the ground. Under the old system, when the art had been brought 
to the highest degree of perfection, the spectator could hardly help arriving at the conclusion that one athletic sport at least had passed the line which divides the sublime from the ridiculous. Three or four heavy men would come out, wielding what looked like a poker of 5 feet in length, and would spin round five or six times like teetotums with almost inconceivable rapidity, after which the missile would hurtle forth north, south, east, or west, no man knowing in which direction it would be likely to fly off. As a result, not only was the sport dangerous to spectators, but it came with many of them to be considered as the comical element of the meeting. Dangerous we say it was to spectators. On one occasion an Oxford athlete neatly picked off a college scout, who, however, escaped with a broken arm; but the unfortunate judges were almost in peril of their lives at each throw, being somewhat in the same enviable position as we have recently been told is the engineer who fires a big gun on one of her Majesty's ironclads. With unskilful performers also there was even more comedy and more chance of a tragedy, as they had absolutely no control over their weapon, and in their efforts to spin round rapidly found often that, instead of having thrown the hammer, the hammer had thrown them.

Hammer-throwing was introduced into the Oxford and Cambridge programme in 1866 , and has always since been cultivated both at Oxford and Cambridge. It has, however, never taken root at any other athletic centre in England, and the championships have, with one exception (when a Londoner beat the Cambridge winner by 6 inches, with a very poor throw), been won either by University men or by Scotchmen or Irishmen. The sport is very popular in Scotland, and has also taken firm root in Ireland.

In 1873 an Oxford man, S. S. Brown (known as 'Hammer Brown,' to distinguish him from numerous other Browns of the same college), eclipsed all previous performances by throwing over I 20 feet; but in the succeeding year another and a greater hammer-thrower appeared at Cambridge in the 
person of G. H. Hales. Hales was an immensely tall man, $6 \mathrm{ft} .4 \mathrm{in}$. or so, we should say, and practised hammer-throwing more assiduously probably than any one has ever done before or since. For some years he was continually making records and then eclipsing them with better ones, his final perform. ance being $\mathrm{I}_{3} 8 \mathrm{ft} .3 \mathrm{in}$. in 1876 . He used a handle of very great length with a leaden head, and certainly was a magnificent exponent of the science, spinning round many times with great rapidity, and being able on nearly every occasion to throw the hammer where he wished, which was not the case with some of the preceding champions, who threw very erratically.

Under the rule of the A.A.A. the thrower has only room for a couple of turns in his circle of 9 feet, and is bound to keep himself and his weapon under proper control, as if he 'follow' his hammer outside the circle he loses his throw. For the last ten years most of the championships have been won by Irishmen. One of these, Dr. W. J. M. Barry, is credited with the record under these rules, having thrown I 34 feet 7 inches, a magnificent performance. The received record for a standing throw is $99 \mathrm{ft} .7 \mathrm{in}$., which was thrown by C. A. J. Queckberner at New York, though I have been informed that a Scotchman, K. Whitton, has covered over roo feet with a standing throw. It is difficult to settle records with so many varying rules.

Another pastime which is very popular in Scotland, but has never found favour in England, is that of 'tossing the caber.' It is an interesting sport which combines both strength and skill. The caber is a beam or small tree, or trunk of a tree, heavier at one end than the other. The athlete holds this perpendicularly, with the small end downwards, balancing it in his hands against his chest. He then 'tosses' it so as to make it fall on the big end. The usual performance at show meetings is to bring out a caber so big that none of the competitors can toss it clean over. A piece is then sawn off, and another round is tried. If more than one of the men 
toss it clean over, the farthest toss and the straightest fall mark the winner.

Another sport which is less frequent at athletic meetings than was the case a dozen years ago is that of throwing the cricket ball. The secret of a good throw is, as all cricketers are aware, to keep all the joints of the arm loose until the throw is taken, and then to stiffen at once with a simultaneous jerk the muscles of the shoulder, elbow, and wrist. The Oxford cricketer, W. H. Game, has we believe thrown the farthest distance on record, something over 127 yards with a good strong wind behind him ; and the Etonian, W. F. Forbes, is credited with having done some magnificent throws while he was still a schoolboy. It is a pity that so fine a sport, which ought to attract the entries of many cricketers, is being allowed to fall out of the programme at open meetings.

Yet another sport, not often practised, but very popular with spectators, is pole jumping. A pole of from ro to $\mathrm{I} 2$ feet in height, shod with one or in some cases three iron spikes, is used, and is grasped with palms facing each other, one hand above the other, that hand being uppermost which is on the opposite side to the foot from which the spring is taken. As a rule, the lower hand is placed upon the pole a little below the height of the bar which the jumper is about to clear. A short run is then taken, the pole planted firmly in the ground, and the holder makes his spring. When the pole reaches the perpendicular, the jumper, who holds his body perfectly rigid, by strength of back, arms, and wrist swings himself horizontally over the bar, throwing the pole back behind him so as not to knock down the bar with it. The skilful jumper often raises his body some way above his hands, and so clears a height which at first seems impossible. Of course the high-jumper has a great advantage at this sport, as his first spring is a great deal higher than that of any ordinary novice attempting the sport, and it is an almost invariable rule that the good pole-jumper is a fine 
performer at a high jump, as is the case with Ray, the exchampion.

A friend has told us that he once saw a small acrobat at a circus clear far greater heights by the simple process of clambering up the pole like a monkey as soon as it was poised, and then dropping over the bar; but we have always

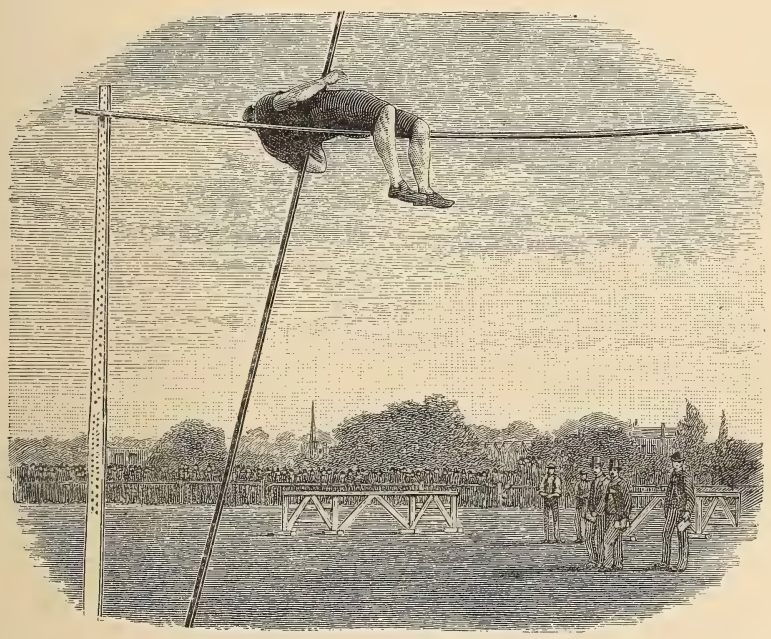

Half over.

felt inclined to believe that this story was on a par with that other, of an Indian juggler who threw a rope up in the air and then climbed up it and disappeared. Something, however, of the trick suggested is employed by Ray, who shifts his hands up the bar when his pole is poised in the air. The sport certainly gives scope to fine athletic qualities, as the pole-jumper must be a high-jumper, and also agile 
enough to raise his body by help of the pole over the bar. The pole-jumper is thus usually a light-weight, but this is not the case with Ray, who is a well-shaped man of decidedly heavy build. His success is no doubt partly due to the effect of an athletic tradition, as he comes from Ulverston, a place which has produced many fine pole-jumpers, one

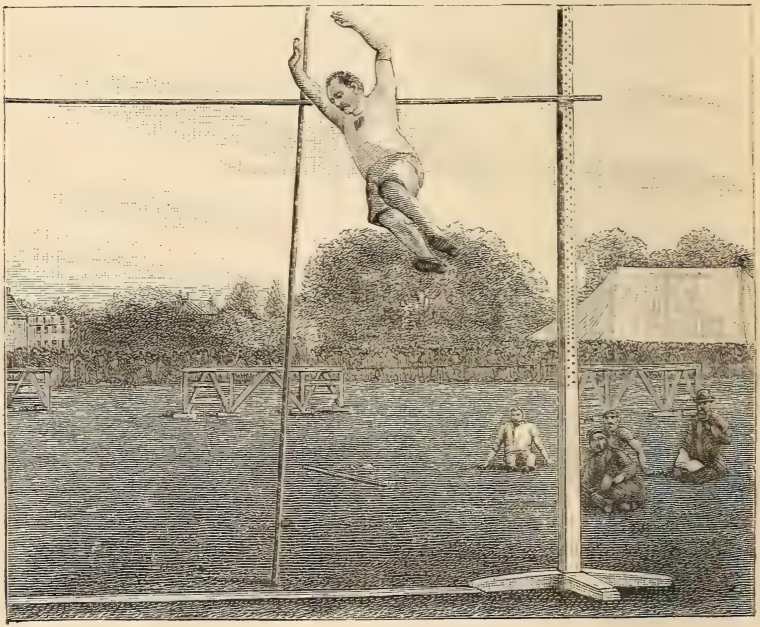

Well over.

of whom was $\mathrm{E}$. Woodburn, the champion of $\mathrm{IS}_{74}$, who probably ranks next in order of merit after Ray and Stones. We believe that the Ulverston lads are often to be seen after their day's work practising pole-jumping on the cinder heaps which are so conspicuous an ormament of that flourishing town.

Broad jumping with poles, which has been practised for 
centuries in the fen countries for reasons of utility, has never been adopted at athletic meetings, which is somewhat strange, as it would be a fine branch of legitimate sport. There are one or two other games or sports which occasionally find a place in an athletic programme. In country meetings especially the spectators often like the introduction of the comic element,

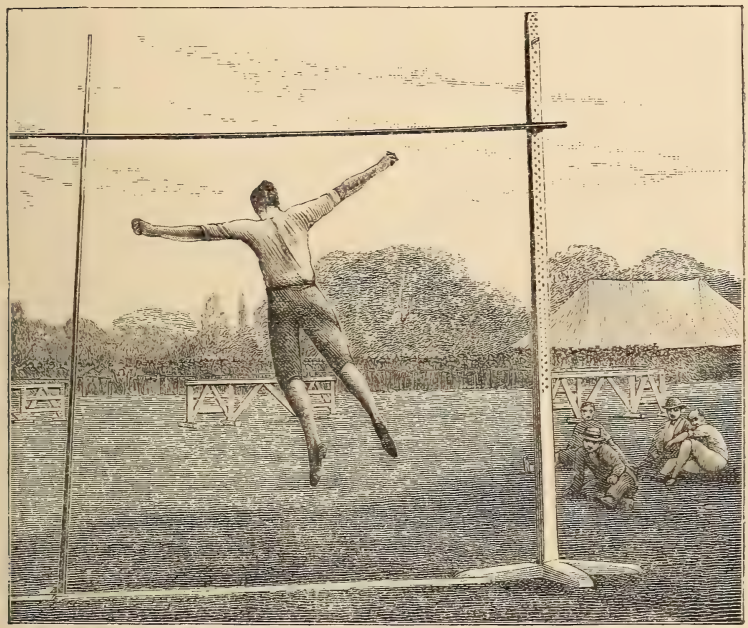

Dropping.

and this taste is provided for in different ways. 'Three-legged races,' or as they are sometimes called, 'Siamese Twin' races, are competitions between pairs of men running stride by stride with the left leg of one runner tied to the right leg of the other. If they fail to keep in stride the pair necessarily tumble over. Then there is the 'sack race,' in which every competitor gets inside a sack, which is tied round his neck, and some shuffle 
while others bound towards the winning-post. Of late years, however, the place of these two old-fashioned sports has been taken by what is known as the 'tug of war,' which is the dignified title given to a pulling match, in which teams of equal numbers pull against each other. This is really one of the oldest of English sports, and long before it was cultivated as a regular sport was played at schools under the title of 'French and

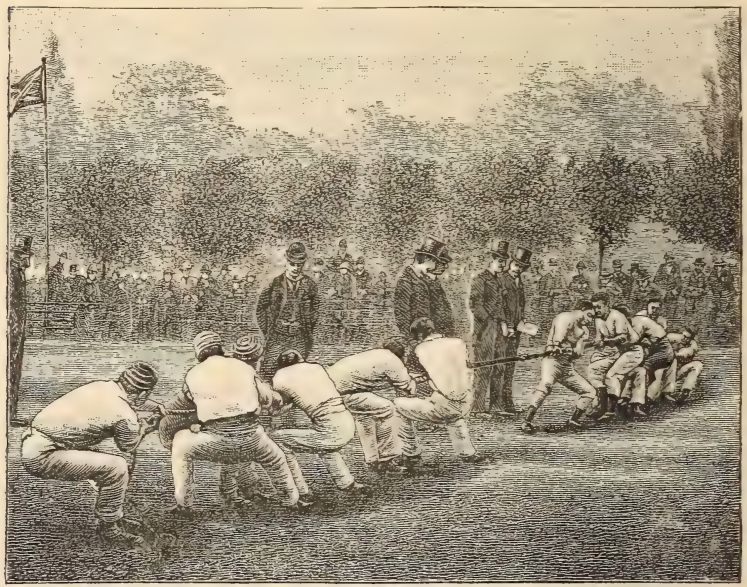

Tug of War.

English,' and even, we believe, forms part of a nursery game known as 'Oranges and Lemons,' a somewhat mysterious title, of which we have been unable to discover the origin. Quite tecently the Athletic Association, at the urgent request of many club committees, have framed a special rule for the tug of war, as disputes were frequently arising as to the right of competitors in dig holes in the ground, or to sit down during the pull to prevent themselves being pulled over. The present rule, which 
is printed later on amongst the other competition rules of the A.A.A., obliges the competitors to keep on their feet and prevents them making holes in the ground before the start. There is no doubt that the sport is a highly popular one, and there is equally little doubt that combination is most important for success. The experienced team does not attempt to shift ground, but pulls in the rope by a series of tugs, taking the time from the leader. One of the strangest of the athletic competitions we have ever seen is the tug of war as practised in the United States. There the opposing teams sit down, facing each other, in two pits filled with soft earth, and pull sitting, getting into a dreadful mess during the process. The hindmost man of each team wears a broad belt with iron bars on it, and, directly an inch of rope is pulled away from the other side, this hind-man (called 'the anchor') whips the rope round the bars to prevent its being pulled away again. After five minutes or so the miry opponents are told to desist, and ustually one side is found to have won by a few inches. We must confess to thinking the English tug of war a better test of skill and pluck than the American game. ${ }^{1}$

1 I believe that the 'pit of soft earth' has now been dispensed with, and that the combatants sit facing each other on a board, their heels pushing against a 'cross-piece' or 'stretcher.' The principle is the same : the men never move from their positions; they strive to pull the rope away from their antagonists. 


\section{CHAPTER VI.}

TRAINING.

WHEN the great athletic movement first became popular in England there was much strenuous opposition to it, not only from timid parents but also from the medical profession. Upon whatever ground this latter opposition was based, there is no doubt that the parental prejudice was not so much to the athletics as to the 'training.' To the athlete of early times as well as to his friends and relations the essential part and chief characteristic of training was not the taking of proper preparatory exercise, but the sudden and violent change of diet. 'Going into training' was taken to mean the commencement of a peculiar diet of half-cooked beefsteaks and dry bread and the reduction of the daily drink to a minimum, and not to imply the beginning of the proper training or cultivation of the muscles required for a race. Even to the present day the word 'training' is applied in its popular connotation to the choice of diet alone. It is scarcely to be wondered that, in an age which considered that eating and drinking would do more to make a runner than the practice of running, the system of training adopted would be a mistaken one, and that the mistake should be glaring. Men going into training adopted a course of diet which did not agree with them, and accordingly became ill in body and ill in mind.

Of the very oldest system of training, which is now thoroughly obsolete, little need be said, as no amateur of recent years has thought of following it. It was a method which may almost be called pre-athletic, as it was in fact nothing but that 
adopted for training for the prize ring. The weight was to be reduced to its minimum at all hazards; the liquid consumed was to be a maximum of two pints a day, the edibles were almost entirely meat and bread, and the natural physical result of such a diet was counteracted by daily purging medicines. Sweating, meat-eating, and purging constituted the old system of training, and those who wonder how such a custom could ever have been adopted must recollect that it was chiefly applied to men of the lower classes, used to coarse food, and with no highly-organised nervous system. It needs no argument to show that such a method could not be beneficial, or even practicable, to an amateur, who takes up athletic sports as a recreation, and not as a business.

However, while from the first amateurs admitted that the old plan was wrong, a movement happened which is well known to historians. The old creed was overthrown, but some of its principal errors were admitted in a modified form into the new system. Although common sense and practical experience are beginning at last to convince the athletic public that the less alteration a man makes in his ordinary diet when he goes into training the better he will fare, yet there are many who still start training for races handicapped by the traditional belief in the efficacy of a meat diet, daily 'sweating' runs for the sole purpose of reducing the weight, and the rigid abstinence from every drop of liquid which can possibly be dispensed with. The present writer, who has practised the opposite method, although according to the old canons of training he is by build and habit of body the very man to whom the rigid rules should have been applied, steadfastly declines to believe in any system of diet whatsoever which leads to eruptions of the skin or of the temper.

There is certainly this apparent justification for the traditional course, that, as a rule, people in modern times do not adopt as frugal and temperate a habit of diet as they should, and a great many of them are either without the inclination or without the opportunity of taking sufficient exercise. There is 
no reason why an athlete who desires to get fit should lead other than a natural life, or alter an ordinary natural diet more than is rendered necessary by the increased amount of exercise which he has to take. The ideal diet for a man who is engaged in active training of his body for a race is, and should be, that which under ordinary circumstances would be best for a healthy man who is obliged to take a very large amount of active exercise. What that diet is, is a matter for scientists to decide (or to differ upon, as they usually do in such matters), and a practical athlete can only speak of it empirically; but, happily, scientists and practical athletes are of one opinion at the present day in thinking that no diet which obliges a daily course of physic can be a healthy one. Physic may be, and often is, necessary during training, to remedy any mistake which has been made in diet; but it should be used as a remedy, and not as a part of the diet.

A further difficulty which arises in laying down any regimen for training is the indubitable physical fact that no two men are alike in their internal economy any more than they are in their outward features; and when proverbial philosophy informs us that 'one man's food is another man's poison,' it becomes impossible to speak merely from practical experience with any absolute confidence. When, however, it is understood that the problem 'What should an athlete eat and drink when in training?' resolves itself into nothing more than this, 'What is a healthy diet for a young Englishman who wants to get his muscles hard and keep his wind good?' it will be seen that it should not be difficult to give some short and simple rules for guidance.

Plain cooked meats, and a reasonable quantity of fresh fruit and vegetables, should form the staple articles of diet. Beef, mutton, and chicken are, no doubt, more digestible than veal and pork, and therefore should be more frequently eaten, as indeed is the usual custom in ordinary life ; but to treat veal and pork as so much poison, as some trainers do, is simply silly. Taken occasionally by a man who is accustomed to 
them, they form a pleasing change, and, where a healthy man has an appetite for any food, one can pretty safely say that he is able to digest it. Fish is light and nutritious, and may judiciously be taken at any meal in the day. Soup is, doubtless, not so strengthening as meat, and not so good for the wind; but if a man is fond of soup, he is much better with it than he would be in vainly attempting to relish the mutton of which he is sick. In fact, as long as the food is plain and simple, and neither too much of it is taken nor too little, the athlete is not likely to go far wrong. Eggs, when not hard-boiled, are both light and wholesome, but to take them upon the top of a heavy meal of other things is usually a mistake, and leads to the usual result of over-feeding-biliousness.

The most rigid of the trainers of the present day give chops or steaks and eggs for breakfast; beef or mutton again, with watercress, \&c., and vegetables for lunch; and beef or mutton again in the evening, together with stewed fruit or rhubarb, and blancmange or rice-pudding. This is a good sample of diet, we have no doubt ; but variety is pleasing, and as soon as any food, however healthy, begins to pall, it should be changed for something which, although less digestible, will please, and therefore reinvigorate the trainee.

As regards eatables, ordinary common sense can tell a man that heavy pastry, or 'stodgy' sweet puddings, or highly spiced dishes, are not healthy food, and that the less that is taken of them the better for the athlete; but, at the same time, one requisite for a healthy diet is that a man should like it. Porridge makes an admirable dish for breakfast, but not to a man who doesn't like it. Pepper and mustard may possibly be deleterious (as we have heard) to the coats of the stomach, and tea without sugar may possibly be healthier than tea with sugar ; but if a man dislikes his beef without mustard, or his tea without sugar, he had much better use these condiments than go without them, and he will do well to have kidneys and bacon (which after all are not poisonous) for breakfast, rather than to force down his throat the admirable porridge which he may not 
happen to like. Nothing which is unpalatable should be eaten as a duty.

Another point to which an athlete in training should attend is the quantity of his food. The youthful aspirant to athletic honours usually begins by gorging himself, thus falling a victim to the same old error that for feats of strength the one thing needful is to eat strengthening food. The old system, as we have before said, was applied chiefly to pugilists of the lower classes, who, when not in training, probably got less and worse food than they really required; accordingly it suited them to eat more when they went into training. At the present day the well-to-do classes, with their three meat meals a day, eat more than they need. Doubtless their natural powers of digestion increase when they begin to take the increased amount of exercise which training for a race involves; but if, as soon as fresh air and exercise increase their digestive powers, they immediately increase the amount of food they take, they will end their training as they began it-short-winded and overfed. In this, as in other matters of diet, it is difficult to give exact advice, but our strongly expressed opinion is that it is better to run the risk of eating too little in training than to run the risk of eating too much. A strong and healthy man may easily weaken himself by over-feeding, but he will not be at all likely to reduce his strength by taking less food than he absolutely requires.

Many men in training have their chief meal in the middle of the day, and a great many doctors recommend this as more healthy, saying that the digestion is stronger in the earlier part of the day, and that when the body is jaded after the day's work it is not fair to put a strain upon the digestion in its weakened state. Whether this view be right we do not pretend to say, and content ourselves with offering the practical advice that the athlete should dine at that hour when he feels most hungry. Men who are accustomed to dine in the evening may, we think, advantageously stick to their old practice when in training, and take their chief meal after their day's work. Of 
one thing only we feel convinced, that a man in training, unless his consumptive powers be as abnormal as those of Milo of Crotona) does not want a heavy lunch and a heavy dinner as well. If he dine in the middle of the day, his breakfast and supper should be lighter in proportion, and if he dine late he will want only a light lunch of a chop, or a plate of cold beef and vegetables, with little or nothing else. On the whole we prefer the system of a good breakfast, light lunch, and a moderate dinner after the day's work.

Of recent years trainers of crews or athletes have come round to a sensible view of what should be eaten. In our opinion, however, their views on the question of what should be drunk are not equally sound. For one thing it is obviously unreasonable to prescribe exactly the same amount of liquid for a small man and a big man, and to say that this quantity, and no more, must be taken whatever the amount of the day's work has heen, and whether the day has been cold or warm. Yet this is a course which we have constantly seen adopted. The old theory was, as we have said, that a man, to get down his weight and make his body hard, should take the smallest quantity of liquid that he could possibly get on with. That theory is practically extinct, but it has left its legacy behind in the fixed notion of the trainer that there must be a definite amount of liquid fixed for each man and each meal. In speaking on this point we necessarily have to follow the same line of argument which we have adopted with regard to eating. It stands to reason that a man taking violent exercise and perspiring freely requires more liquid than he does during his ordinary life. But-and it is a very important 'but'-the majority of men drink a great deal more than they want, by which we do not mean that they take too much alcoholic stimulant, but that they take too much liquid, to the great harm of their digestions ; and in this kind of over-drinking we believe teetotallers are the worst offenders. It is also a well-known fact that taking too much liquid does more to make the body fat and heavy than taking too much solid food. The conclu- 
sion we arrive at is, therefore, that a man who goes into training needs more drink than he does at other times, but should take less than he is in the habit of taking, unless he is more temperate than the majority of his fellow-creatures are. The athlete in training should never drink between meals unless he is absolutely thirsty, in which case he should drink to assuage his thirst and not for enjoyment; and at meal times he should drink as much as he reasonably feels a craving for. If the drink be unnaturally stinted, the man will soon break down, his skin will get unhealthy, and his sleep and digestion will be impaired. Doubtless it is quite true that a couple of good-sized cups of tea at breakfast, half a pint of liquid for lunch, and a pint at dinner is enough for most men in training ; but to hold that a man who finds himself parched after his exercise at four o'clock is to wait until his dinner at seven before he can touch a drop of liquid is to turn a useful generalisation into a ridiculous rule. Rigid rules as to the quantity and quality of diet and exercise are not to be relied upon, and the effect of giving a man so much beer for dinner, and telling him he must under no circumstances have any more, leads to most absurd scenes and unsatisfactory results. Some great brawny fellowperhaps the strong man of the crew-eyes his pint of beer with a wistful gaze, and does not take anything more than just a sip when he cannot possibly get his food down without it, in the vain hope that at the end of dinner he will have enough left to have a really good drink, and cease to feel thirsty for the first time during the day. It needs no doctor to say that the man who eats his dinner under such circumstances will fail to get the full benefit out of it, notwithstanding that he has fulfilled the requirement so dear to dyspeptics of eating his food dry.

It is often urged in reply to the argument that rigid rules of diet are a mistake, that if you give a man carte blanche to eat and drink whatever he thinks good for him, his wishes will be fathers to the thought that everything for which he has contracted an unhealthy fondness will be beneficial. To this we answer that a man knows perfectly well when he has eaten 
enough, and, in fact, cannot eat too much when in active exercise without finding it out ; that the same rule applies to drink, and that if a man is unable to keep himself from taking solids and liquids which he does not require he will never be of any account as an athlete. The absurdity of the old system is shown from the fact that it was the frequent custom of the 'owners' of professional pugilists and pedestrians to put a watchman in attendance to see that their particular 'pet' in training did not sneak surreptitiously into public-houses or carry little bottles of liquid about with him in his pocket.

So much must be said as to the quantity of liquor. In the meantime there are other vexed questions as to the drink of the athlete. Until quite recently a man who trained upon teetotal principles was considered a rara avis, and the old English trainers believed in English beer as much as they believed in English beef and mutton. Of recent years, however, not only have temperance principles been widely preached, but the larger number of the oarsmen and athletes from America and Canada have adopted the system of training upon water alone, and taking no alcohol in any shape during training. From the views we have expressed above it will be seen that we are not likely to take one side or the other with great ardour, as we believe that there should be no violent change in the manner of living when a young and healthy man goes into training. We must confess, however, to have a strong leaning towards the Transatlantic or teetotal method of training. Whether alcohol be good or not we leave doctors to decide, but of all people in the world the athlete who is not overtrained least requires its stimulus. We believe doctors still differ upon the question as to whether it is nutritious to any degree, but all agree that it is very hard to digest, and this alone should be a strong argument against its use. Of one thing we feel confident, that if a man drinks water at his meals as a natural habit he will be very unwise to leave it off for beer or claret. If, however, he is accustomed to drink beer or wine, it is a hard thing to say that the athlete should give either up 
and take to water if he doesn't like it. We have seen men weil trained upon beer, upon claret, and upon weak whiskyand-water, and are quite willing to admit that these beverages have done no harm. Any other wines, however, for a man in robust health are, we think, bad in training, as they excite the nerves and interfere with sound and quiet sleep. Of course, if a man is getting stale, good strengthening wine may do him a world of good; but as long as the athlete is not in this state, the glass or two of port, which he is often recommended to take, is exceedingly likely to do harm, and can hardly do any good. While, however, advocating training upon temperance principles, we wish to make it clear that circumstances and idiosyncrasies alter cases. A man with a naturally weak nervous organisation may find that old ale or a glass of port after dinner may prevent his training off through the work he has to undergo, and if such men take to the practice of athletic sports they must train on principles that suit their particular cases. With strong healthy men, however-the only men who in the present age of keen rivalry can indulge with perfect safety in athletic sports-we think that upon general principles the less alcohol they take the better.

So far it will be seen we have not suggested that a man in training should undergo any very serious trials and privations. There is one thing, however, which he must learn to do without, and that is smoking. While we are quite ready to admit that a moderate use of the comforting weed is not injurious to the health, there can be very little question that it tends to shorten the wind, and does so more especially when tobacco is indulged in between meals and not after them. Very probably many men, and especially sprinters training for short races, have smoked during training and done themselves no appreciable harm, as their smoking has been confined to a cigar or a pipe immediately after dinner ; but even these cases, we should think, are rare. The uses and functions of tobacco may almost be described as totally incompatible with the cultivation of athletic excellence. Tobacco is a narcotic; it is no doubt not only 
pieasant, but may be wholesome, to men whose nerves require soothing after hard brain-work and worry, but, except under abnormal conditions, an athlete in training can hardly want a narcotic; he wants to be brisk, vigorous, and robust, and

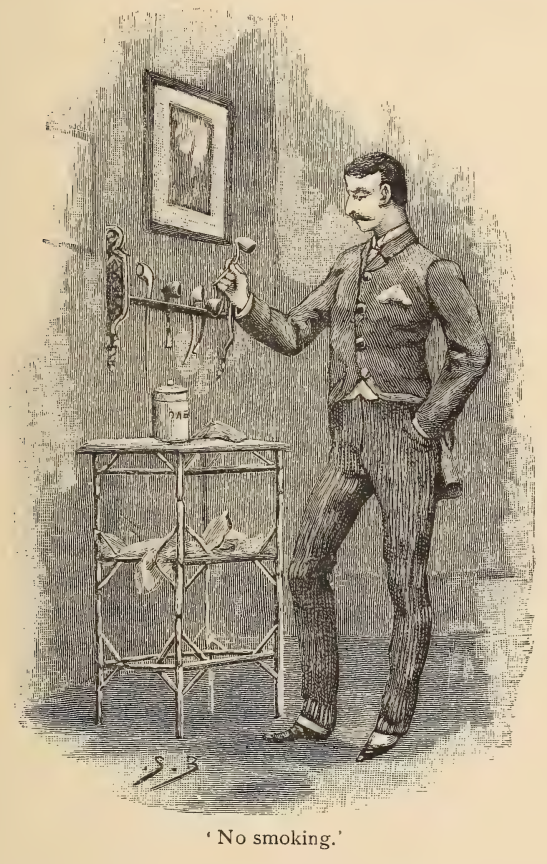

anything which tends to make him lazy must do him harm for athletic purposes. In fact, to take a broad view of the uses of tobacco-smoking, it appears obvious that the men of the present day are almost universally adopting it, not because they are a degenerate and dissolute lot, but because the high 
pressure and forced mental activity of modern life have rendered a craving for it as a sedative only natural. But a man who requires a sedative to maintain his nervous balance is hardiy likely to be a fit subject for the trainer's hands. By all means, then, let the man in training avoid smoking, and if from suddenly giving up the habit he finds he is unable to sleep, let him wean himself from smoking as quickly as possible.

Another mistake which a young lad just taking to training often falls into is to take too much sleep. With the old maxim that 'six hours' sleep is enough for a man, seven for a woman, and eight for a fool,'we do not altogether agree, but experience shows that in ordinary cases seven hours of sleep are quite enough for a man who has not been taking any enormous amount of exercise during the previous day, and that eight hours is the maximum which can under any circumstances be beneficial to a man who is living a regular and temperate life. A young lad of eighteen or nineteen probably requires more sleep than an athlete who has passed out of his nonage and is fully developed, but at the outside more than eight hours' sleep should never be taken. Too much sleep engenders fat and makes the athlete slack, listless, and disinclined for his day's work. We have always wondered how the University freshmen, when they are just sent into training for the spring races, manage to survive the ordeal. They are gorged on meat, eggs, etc., three times a day. They have port wine and figs in the evening, and are sent to bed at ten to sleep until they rise in the morning again at eight o'clock to commence a fresh attack upon mountains of steaks and chops. Even quite apart from the food they take, the men would be slack and torpid from the amount of lazy sleep to which they are condemned.

Another point which is often disputed is the advantage of early morning work. All are, we think, agreed that a man should get into the open air and clear his lungs before breakfast. By these means he gives himself an appetite for his food, and the improvement in the wind which comes from thus getting out must soon be obvious. But it is a far more difficult matter 
to decide whether a man should do anything more before breakfast than get air into his lungs. Some men we have known actually to go hard spins before breakfast, others have taken walks of a mile or two, others merely stroll out and walk a quarter of a mile or so just for an 'airing.' Which of these courses should suit any particular individual depends both upon his constitution and his previous habits. Our own opinion is that as a general rule a man should never neglect to get out before breakfast, be it wet or fine, but should refrain from anything like work. We have seen so many men collapse in their training as soon as they tried work before breakfast, that wc are sceptical of its good results. But a walk of not more than a mile before breakfast is sure to do good to a healthy man. IVe need also scarcely say that, wet or fine, warm or cold, he should sleep with his window partly open. There can be no quiet sleep for a man in a confined atmosphere.

There is no reason why an athlete who makes his training consist of a sound and healthy system of living should break down in health, but without doing that he may nevertheless find himself hors de combat from some minor evils. Before a runner puts on his first pair of running-shoes he should pare his toenails close down to the flesh, or the pounding on the toes will result in the nail being pushed up at each stride. In a few days after this the nails will probably turn black, and in a week or two the runner may find himself minus one or two of them. All danger of this, however, is obviated by not allowing the nail to protrude in the slightest degree beyond the end of the toe. Occasionally the feet get tender from the exercise, and when this happens the athlete will do well to give up the cindertrack for the grass for a day or two. Soaking the feet in alum and water is also much recommended as a cure for tender feet. Prevention, however, is better than cure, and the best preventative is a soft washleather sock coming over the ball of the foot. This is also comfortable, and acts as a safeguard against blisters. With blisters the best thing is to prick them 
with a needle as soon as the water has collected in them; after this has been squeezed out, the old skin should be left on to protect the new skin growing underneath. If there are blisters on the foot half-formed, and the athlete is liable to them, the skin is best toughened and rendered least liable to them by taking a salt-and-water footbath in the evening. The tight shoes which are necessarily used by runners are also apt to create corns, which must be treated by the usual remedies which are known to housewives or to practitioners for the removal of these unwelcome visitors. The best means, however, to avoid blisters, corns, and such like ailments is to take a great deal of care in selecting a perfectly fitting pair of shoes; but of this we shall speak anon.

Strains of the muscles are more serious matters, and are sometimes very hard to cure; there is always, too, a danger that a slight strain of a muscle may get worse if rest be not taken. Experience shows that there is very little risk of the muscles giving way from anything but overwork in warm weather, but in cold weather muscles strain or snap without any warning; indeed, so many accidents of this kind happened at Oxford that notices were posted in the dressing-room at the old Marston ground warning runners not to go out into the cold without first rubbing their legs with a horsehair glove or with the hands, and not to undergo any violent exercise without taking a short trot to warm the muscles.

This precaution should certainly never be neglected at any time when the weather is at all chilly, and in the winter especially it is foolhardy to dispense with it. Slight strains of muscles are best treated by partial rest and the use of opodeldoc, or a mixture of arnica and opodeldoc as an embrocation. Of late years, too, the runners have frequently taken to using Elliman's embrocation, a mixture which was originally used by trainers of horses alone. A composition still frequently used by pedestrians is that which was recommended by Charles Westhall in his little book to which we have referred before in terms of praise. Westhall's recipe is as follows: 'Spirits of 
wine, $\frac{1}{4}$ pint; spirits of turpentine, $\frac{1}{4}$ pint; white vinegar, $\frac{1}{4}$ pint. Mix these with a fresh egg beaten up, and give the bottle a good shake before using the mixture.'

If the strain of the muscle be very severe, something else besides an embrocation is required. Complete rest must be the rule, and if there is a swelling from injury to a joint this should be reduced by bathing in hot water. People frequently make the mistake of putting a sprained ankle immediately under a stream of cold water; cold water is invaluable to strengthen the muscle after the inflammation has gone down, but a hot fomentation is what is required to reduce the swelling. When the swelling has gone down, the 'cold tap' and embrocations are useful. Upon the same principle, too, that horses are 'fired,' the outside of the ankle is often painted with iodine.

We have said before that one of the most satisfactory features about athletic sports, both to competitors and spectators, is that the winner wins on his own merits, and not from any superiority he may have obtained in equipment or apparatus. The oarsman may be helped to victory by a good boat, and the cyclist by a good machine, but the athlete can hardly win a race by having better shoes or knickerbockers than his opponent, though he often does win a race with worse legs than his rival, but with a better head. The apparatus of an athlete is simple and requires little description. His shoe should be of thin, good leather, which cannot possibly stretch, so that when once it fits the foot it may never wear loose. A shoe which slips on the foot in the slightest degree may not only impede the runner, but will assuredly blister the foot. The athlete, therefore, should get a pair of shoes to fit him like gloves, and then he will have all that mechanical skill can do for him. As we have said before, he will probably find it wise to wear a thin chamois-leather sock over the ball of the foot and toes. The ordinary running-shoe has only a single thickness of leather over the heel, and of course no spike there. The hurdler and jumper, however, who have to take every pre- 
caution against slipping, have two spikes in the hecl of their shoes in addition to those in the toe, while the walker has a similar shoe with double thickness at heel and toe, and without any spikes. One other point only has to be attended to, and that is the length of the spikes. Obviously the harder the track is the shorter the spikes should be, so that upon a grass-track longer spikes are needed than upon cinders. For the tracks at Oxford, Cambridge, or Lillie Bridge, spikes of less than $\frac{1}{2}$ inch in length will probably suffice if they be sharp; but the hurdler or a sprinter, who may be called upon to run over heavy grass, wants a shoe with at least $\frac{1}{2}$-inch or $\frac{3}{4}$-inch spikes. Most 'cracks,' therefore, have several pairs of shoes with spikes of different length, and make their choice according to the state of the track over which they have to travel. In races over very long distances, shoes with very short spikes, and sometimes without spikes at all, are used, as the jar and concussion of travelling so far with a thin spiked sole may make the feet so blistered or tender as to drive the runner off the path or knock him to pieces before the end of the race.

Of the rest of the athlete's stock-in-trade there is little to be said. The knickerbockers or drawers, whether they be made of silk, merino, or thin flannel, are just knickerbockers and nothing more. They should be roomy enough not to interfere with the movement of the thighs, and should be short enough not to hamper the knee. A primrose to some people is a primrose and nothing more, and even to an athletic author a jersey is only a jersey. A word may perhaps be said, however, about the practice which some men have recently tried to introduce from America of wearing sleeveless jerseys, which display the whole of the shoulder and the armpit. There is nothing to be urged in favour of the practice. A light sleeve over the shoulder cannot possibly impede a runner any more than a cobweb would, and the appearance of a runner with his shoulders and armpits uncovered is far from picturesque. Happily, when a runner appears so clad, his usual fate is to be marched off the track, and told that he will be allowed 
to come on again as soon as he is properly dressed, so we are little likely to be troubled with sleeveless jerseys in the future.

As regards the athlete's dress, it is very curious to notice the difference of custom in and out of the Universities. In London and the provinces the different competitors appear in different colours of knickerbocker and jersey, and, in addition, many clubs have a club-badge or emblem which each runner of that club sports upon his jersey. The result is that a big handicap shows a pretty variety of different hues. At Oxford or Cambridge every runner appears in virginal white, save the selected few who have represented their University at Lillie Bridge, and are therefore privileged to wear their white knickerbockers and jerseys trimmed with the blue ribbon of their club. 


\section{CHAPTER VII.}

\section{ATHLETIC MEETINGS.}

IF there be little to say of the individual athlete's requisites, there is much that is interesting to note in the requisites for the meeting at which the athlete figures. The days are now gone when the champions of each neighbourhood met upon the village-green, and took off their boots to run upon the nearest level piece of turf which was handy. A club which undertakes to hold a meeting has now to find a ground, prizes, officials, and a variety of implements and conveniences, which render the undertaking anything but a simple one. The first requisite of all is of course to get a ground, and it is of grounds, therefore, that we first propose to speak.

In London, Birmingham, Oxford, Cambridge, and other great centres of amateur athletics there are regular running grounds, which can be engaged by a club which requires them. Nearly all the regular paths are 'cinder tracks,' although of late sears one or two have been made (chiefly for cycling purposes) not with cinders, but with burnt ballast or red brickdust. The making of a good path is a difficult and expensive undertaking, including as it does levelling, draining, and laying down of the cinders or brickdust. Excavation is made to the depth of from 12 to 18 inches, 12 inches being generally considered sufficient with a dry gravelly soil, while in a clay soil the full 18 inches is required. If the excavations be of 12 inches, about 5 or 6 inches of this is filled up with large brick rubbish, or what is known as ballast gravel-i.e. large stones which allow the water to drain through. Over the top of this, 3 or 4 inches of rough 


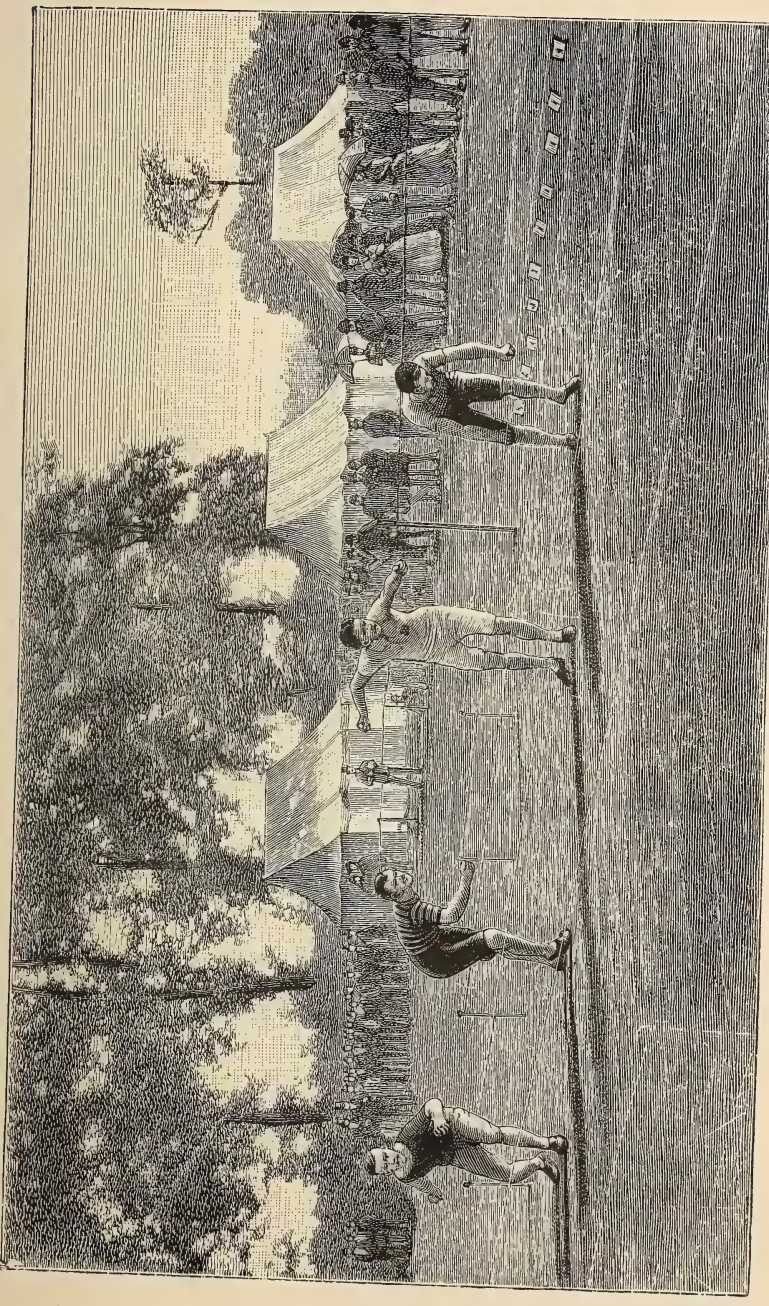



cinders are placed, so as to leave room for a layer of 3 inches of fine sifted cinders or brickdust upon the top. These 3 inches of fine stuff have to be put on in thin layers, to be watered from time to time and continually rolled. For the purpose of assisting the drainage, the centre of the path is usually raised slightly higher (not more than an inch) than the sides, and gullies are made at the side leading down to cesspools to carry off water which may collect after a sudden shower. When a good path is once made it wants little but rolling in wet weather and watering and rolling in dry weather to keep it in good condition. After many years, when the fine stuff off the top has been blown or carried away, and the coarser stuff below is working up, the top dressing may have to be renewed. Perhaps the better course is after each season to sprinkle a thin layer of cinders over the top of the path to keep it fresh.

Just at the present it would seem that fashion is changing round from black cinders to red brickdust as a top dressing for running tracks. The brickdust was, as we have said, originally used for cycling, but upon the inner path made at Lillie Bridge for wheels many foot-races were held with great success. No doubt the brickdust which has a slight mixture of loam is harder, and thus better suited for wheeling, and the fact that both Myers' $48 \frac{3}{4} \mathrm{sec}$. for a quarter and George's 4 min. I $2 \frac{4}{5} \mathrm{sec}$. for a mile were accomplished upon the red track at Lillie Bridge seems to show that it is hardly less fitted for pedestrian contests. Probably, however, Myers and George both chose the inner track at Lillie Bridge, well knowing that the old cinder track upon the outside was getting worn out and in poor condition. The drawback of the red paths is that they get very hard and dead in wet weather, while a really welldrained cinder path like that at Oxford or Stamford Bridge keeps its lightness, in spite of the rain, in a wonderful manner. We should not be surprised if the cinder track of the future for running purposes were to be a mixture of cinders and burnt brick ballast in equal proportions.

Until I866 the Oxford and Cambridge sports were held 
upon grass courses either at the Christchurch cricket ground at Oxford or at Fenner's cricket ground at Cambridge. In 1867 , however, the Universities moved up to London to the cinder track at the old Beaufort House at Walham Green, upon which the championship meeting of the previous year had taken place. The Beaufort House track was certainly not a good one, being loose and ill-drained, nor was its oval shape well suited for fair racing; however, it sufficed for championship and Inter-University meetings until I 869 , when both meetings were shifted to the newly opened ground of the A.A.C. at Lillie Bridge. After it was got into working order the Lillie Bridge ground was certainly a very good one, perhaps as good and as fair a track as has ever been made. Like most other good paths, it was a third of a mile in circumference, but its chief merit in our opinion lay in the fact that the turns were well graduated. Although the corners were apparently sharp, by making the path slope downwards to the corner, the runners were prevented from running wide, and were given four straight stretches, one on each side of the ground. This, we think, is the right shape of path for every race under a mile, and especially for handicap races. The Cambridge ground at Fenner's is also constructed on this principle, there being no long gentle curves as there are at both ends of the ground at Oxford and at Stamford Bridge. Until I 876 the London Athletic Club used Lillie Bridge for their meetings, but the following year they took possession of their own private ground at Stamford Bridge. After that the Lillie Bridge track was undoubtedly left neglected, and in its latest years the old outer track was not good, the gravel underneath having worked up. In many places also the path was treacherous, the new cinders which had been placed at the top giving way under the feet of the runners. The Stamford Bridge track is, we think, about as badly shaped as a ground can be for any short races, but the track itself underfoot is almost as good as possible. The path is only a quarter of a mile in circumference, the lap consisting of two straight stretches of 120 yards each at the sides and two gradual curves of 100 yards 
each at the ends, and the quarter-mile races, as they were originally run upon the ground, were run over 200 yards out of 440 upon a curve. The ground was soon improved by a very long 'straight' of 250 yards extending up one side. The 250 yards and 220 yards races were run off on this long straight, and the first 250 yards of the quarter-mile races were also contested over this ground, which accounts, in a great measure, for the fast times done some years ago in short races at Stamford Bridge. In long races, where the pace is not so great, probably the long slight curves do not interfere with the times. Recently the long straight has been built over, and the ground is again left with the old defects. We are strongly of opinion that in every path there should be as much straight and as little corner as possible, or, in other words, that the path should be quadrangular with rounded corners, and not an oval with the two sides flattened. The fault of long curved stretches is also conspicuous at Oxford, though not to such a degree as at Stamford Bridge; but, on the other hand, there is no long straight at Oxford, and in a 300 yards' race on the Oxford ground half the distance has to be run round a curve. The long curves are most unfair in handicaps, and also in any race where there is a large field, as one runner passing another may have to come right out from the inside of the track and then have to come in again at once so as not to lose ground; besides this, the continual running in a curve must necessarily shorten the stride, and more ground is lost thereby than upon a short but sharper turn. The old Marston ground, although laid in a swamp and rightly deserted by the O.U.A.C. in 1877 , was, we think, made in a better shape than the Iffley Road ground, although the cinder track at the latter place is certainly very fast and dry. The Cambridge track at Fenner's is both welllaid and well-shaped, the only drawback to it being that the levels are not true. The starting-points of the quarter-mile, 300 or 220 yards races are higher than the finish, so that many of the fast times made over these distances at Fenner's are really untrustworthy. The Fenner's track, too, was built with the 
intention of making competitors run with their left hand to the inside of the track, the contrary being the practice at most other running grounds. Of recent years, we believe, the Cambridge runners have accommodated themselves to the general system, and run the other way round the ground, so that any times made by Cantabs running up-hill can scarcely be disregarded. Another well-known track, which has been remarkable for several fast times--that of the Aston Lower Grounds at Birmingham - was open to the same objection as Fenner's, on the ground of levels. In the Aston ground there was a drop of over 6 feet in the 300 yards course, and rather more, we think, in the quarter-mile course, the part between the finish and the beginning of the quarter being a stiff up-hill. As a result, the Records Committee of the A.A.A. has declined to take any notice of any performance done over less than a lap of a track which is not properly levelled; but it accepts performances where competitors have covered more than the full lap, and so run both up-hill and down-hill. Even this, however, can hardly be considered strictly fair, as experience shows that more time is gained running down a long and steady decline than is lost by coming up a short stiff incline. The Aston records can hardly, therefore, be considered satisfactory under any circumstances.

In considering the famous running grounds upon which so many cracks have toiled and 'spun,' we have rather wandered from our main subject, that of athletic meetings. All the classical events of the year are held over regular running paths, but for an immense number of country and provincial gatherings there is no cinder track at hand. The committee arranging for the sports have therefore to procure the best field obtainable, which is usually the local cricket ground, and this has to be staked out with flags and ropes, so as to obtain as long a lap. and as good turf as is possible. We are by no means so certain that where a well-shaped lap of really good dry level turf is obtained there is much difference in point of speed between cinders and turf; but it is very difficult indeed to get a piece of turf 
which will satisfy the requirements of a good running path in point of level and dryness. The majority of the fields used for local sports are cricket grounds of which the 'pitch' in the middle is perhaps beautifully level and in good condition, while the outside parts of the ground, upon which the races must necessarily be run, have probably been neglected. The majority of grass courses, therefore, are considerably inferior in every way to the regular running paths. Athletic 'cracks' of I.ondon and the Universities have got into the habit of thinking that no good thing can possibly come from grass courses, and are inclined to scout reports of any records having been made upon them. Still we would remind critics that there are grass courses and grass courses, and that a country cricket field mowed for the occasion round its edges is very different from the Private Banks cricket ground at Catford Bridge, Kennington Oval, or the Trent Bridge ground at Nottingham. The first and last of these are, we think, when the weather is favourable, little, if at all, inferior to the best cinder tracks that have ever been made, and we can quite understand how in longer races a grass course may suit some athletes better than cinders, there being less concussion at each stride. For a proof of our opinion we may point to the facts that $H$. R. Ball did his best and fastest quarter at Catford Bridge, Slade his fastest two miles at the Oval, Scott his fastest mile and Myers his fastest I, 000 yards at Trent Bridge. At the same time it is perfectly reasonable to feel doubtful about 'records' made over turf. The ground may not be level, the measurements may not have been accurately taken, and may be incapable of subsequent verification, the only boundaries being posts and ropes which are usually removed as soon as the day's sport is over.

When the ground is secured, the next thing for the secretary (to whom, as a rule, all preliminary arrangements are entrusted) is to get the entries. This for club meetings is often not so easy as it would appear. For the purpose of attracting a good 'gate,' a Saturday afternoon or a public holiday is the favourite day for sports, and in the season the athlete has so many 
meetings to pick and choose from that something attractive is required to entice him. The usual enticement, we regret to say, is the best and most valuable prize which the finances of the club can stand and which the rules of the A.A.A. allow. Some years ago the A.A.A. stepped in to try and put a stop to pot-hunting, and limited the value of prizes which can be given in handicaps to Iol. Ios., a sum which in our opinion is much more than is sufficient. At the present day, however, prizegetting is so much a business with the amateur athlete that the charge of 'pot-hunting,' which a dozen years ago was considered discreditable, has now practically ceased to be a reproach at all with the sporting community, which reads with avidity notices in the paper that Mr. A. or Mr. B. has won 6ol. worth of prizes 'during the past week.' At the present day secretaries are glad enough to get the entries of men who really keep the prizes they win and do not, under the mask of amateurism, earn a living by selling their winnings. But our business at present is with the competitors as they are, and not with competitors as they should be, and we hasten to admit that there are still a few just men in Gomorrah.

Partly, however, to keep out the semi-amateur class, and partly to give the handicappers every opportunity of adjusting the starts fairly, every competitor is compelled to send in his entry for a meeting upon a regulation 'entry form.' By filling up and signing this he pledges himself to the assertion that he is an amateur within the meaning of the A.A.A. definition, which is printed on the paper, and he also gives an account of his last three performances in public, stating the amount of his start and the result in each race. If any wilful misstatement is found on these entry forms, the committee of the A.A.A. punishes the offender by suspension or disqualification.

Entries are usually made to close a week before the day of the meeting, to allow the handicappers (for at a club meeting the majority of events are handicaps) a few days' leisure to allot the starts. As a rule, however, when the meeting is on a 
Saturday, entries are frequently received on Monday morning, a very reasonable practice, as men who have run well on one Saturday are often inclined to enter for a meeting on the next Saturday, and might be unable to do this if their entries for the next meeting were bound to be in by the Saturday evening. The regulation entrance fee for a handicap is half-a-crown, and one of the most useful regulations of the A.A.A. enjoins that no entry shall be accepted unless accompanied by the fee. Secretaries of sports being anxious, however, to get as good fields and as many half-crowns as possible, to help to defray the cost of the prizes, are continually infringing this regulation, and in consequence unpleasantness frequently results. Secretaries of clubs enter their members, or friends enter their friends, and now and again the man whose name is entered fails to put in an appearance, being dissatisfied with his start, or is wrongly handicapped with too great a start, owing to the handicapper not having sufficient information with the entry to be able to identify the runner or gauge his abilities. In the first case, the absent runner now and then repudiates his liability for the fee; in the second case, if the runner turns up and wins the race the other competitors are loud in expressing their dissatisfaction. All this would be obviated if the secretaries would only do their duty and decline to take any notice of an entry not made upon a proper form and accompanied by the proper fee. In the long run we think this honest course would be the best policy, for if there is unpleasantness at a meeting one year the entries are sure to fall off at the next meeting promoted by the same club.

The secretary's duties before the meeting are by no means light; every competitor expects to see the starts published in the sporting papers a few days before the meeting, to have a programme and ticket of admission sent to him in due course, and the interests of the press have also to be studied. The press men expect interleaved programmes which will enable them to make their notes with more convenience, and a free right of admission to every part of the ground. With the old 
and capable representatives of the recognised papers this claim is no doubt a perfectly proper one, and clubs which want their meetings properly reported have no right to expect that this should be done unless they are willing themselves to afford facilities for the report. Sometimes, however, the representatives of papers which have very little concern with athletic meetings act in a way that is not above reproach. Knowing perhaps little or nothing of athletics, they freely criticise the decisions and proceedings of competent officials and stir up ill-feeling amongst athletes; and if by any chance they are not allowed in the centre of the ground, or are not treated with the amount of respect to which they deem themselves entitled, the readers of their paper are informed that the mismanagement of the meeting and the incompetence of the officials were outrageous. Happily, we think, of later years this nuisance has somewhat abated, and another practice which threatened to become a greater nuisance, the providing of reporters with liberal refreshments, has also been pretty well discontinued. The 'chicken and champagne' method of dealing with critics cannot fail to be pernicious, in however humble a manner it is employed.

Another and most important duty of the secretary before the meeting commences is to provide proper accommodation for the competitors. If the sports be on a running ground which has regular dressing-rooms upon it this is easy enough; but at country meetings tents have to be erected, and a liberal supply of towels, baths, water, chairs, \&c., provided, as nothing is more disagreeable for competitors than insufficient accommodation. Care must also be taken to see that all the implements and apparatus required for the meeting are ready. Upon one occasion an important meeting had to be put off for half an hour because there was no pistol upon the ground to start the race with; and often have we seen a similar pause in the programme because there was no worsted or tape for the winningpost, starts were not marked out, and no measure was handy, no bar for the jumping-posts, no ground set apart for the weight- 
putting, and so forth. It need also scarcely be said that it is a grave offence for judges and officials to neglect their business, or to arrive late upon the ground. We have already given in a previous chapter a sketch of an athletic meeting and its officials, and, whether the meeting be a championship or a small local affair, the same requisites and the same method of conducting it apply. It is rare nowadays to see an ill-conducted meeting, and the rapidity and smoothness with which a big fixture is got through in a few hours is often highly creditable to the organising and administrative ability of voluntary sporting associations. It is no uncommon thing for heats of sprinting handicaps to be run off with only three minutes between each heat, the clerks of the course getting their men out upon the ground to the very minute. One thing we can say with confidence is, that the rule-always rigidly enforced-for putting back a competitor who oversteps his mark before the pistol is fired has not only reduced sprint racing from chaos to order, but has rendered the work of starters and officials easier, and has largely tended to improve the management of meetings. It would be, perhaps, unnecessary, after what we have written, to enlarge upon the right method of getting through a meeting, and we had better, perhaps, leave the following laws and rules for competitions to speak for themselves.

\section{LAWS.}

Thase Laws must be observed at every Athletic Meeting held under the sanction of the A.A.A.

\section{Qualification OF COMPETITORS.}

I. All competitions must be limited to amateurs. This Law does not interfere with the right of any Club to refuse an entry to its own Sports.

'An amateur is one who has never competed for a money prize or staked bet, or with or against a professional for any prize, or who has never taught, pursued, or assisted in the practice of athletic exercises as a means of obtaining a livelihood.' 
(a.) The following exceptions shall be made to this Law, viz. :Amateur athletes shall not lose their amateur status by competing with or against professional football players in ordinary Club matches for which no prizes are given, or in Cup competitions permitted by the National Football Associations or Rugby Unions of England, Ireland, Scotland or Wales, providing that such com- petitions or matches form no part of, nor have connection with any Athletic Meeting.

(b.) 'Competitions at arms between Volunteers and Regulars shall not be considered as coming within the scope of the A.A.A. Laws.'

(c.) 'Competitors in Officers' Races at Naval and Military Athletic Meetings (such races being for officers only, and for which money prizes are not given) shall be exempt from any of the laws of the A.A.A. disqualifying runners for competing at mixed meetings.'

(d.) That the 'Championship of the Army' Race at the Aldershot Sports be exempt from the effect of this Law.

(e.) No person must be allowed to compete while under a sentence of suspension passed by the A.A.A., National Cyclists' Union, Amateur Swimming Association, Scottish A.A.A., or Irish A.A.A.

( $f$.) No one shall be allowed to compete at any meeting held under the Laws of the A.A.A. as 'unattached' for more than one season.

(g.) The names of all persons who have been expelled from Clubs affiliated to the A.A.A. for non-payment of subscription and other liability shall be placed in a book to be kept by the Secretary of the A.A.A., and such persons shall neither be allowed to join another Club nor compete at meetings held under A.A.A. Laws until such liability be discharged and the name erased from the book.

\section{PRIZES.}

2. No 'value' prize (i.e., a cheque on a tradesman) must be offered.

3. No prize must be offered in a handicap of greater value than Iol. Ios. 
4. Every prize of the value of $5 \%$. or upwards must be engraved (when practicable) with the name and date of the meeting.

5. All prizes shall be of the full advertised value, that is, without discount, and must be publicly presented on the grounds on the day of the Sports.

6. In no case must a prize and money be offered as alternatives.

\section{BetTing.}

7. All open betting must be suppressed.

\section{ADVERTISEMENTS.}

8. All Clubs must hold their Sports 'under the Laws of the Amateur Athletic Association,' and so advertise them on all prospectuses, entry forms, programmes, \&c., and must have printed on their entry forms 'the definition of an amateur.' (See Laws I and I2.)

9. All Clubs affiliated to the A.A.A., Northern Counties A.A.A., or Midland Counties A.A.A., must state that fact on their advertisements, entry forms, prospectuses, \&c. (This Law 9 does not apply to Clubs or meetings merely registered as approved.)

\section{ENTRIES.}

I0. Sports Committees may reserve to themselves the right to refuse any entry, without being bound to assign a reason, or to disqualify a competitor at any time, if his conversation or conduct is unbecoming, or if it is shown that his entry was made under false pretences.

II. Entries shall not be received unless accompanied by the entrance fee. Any competitor winning a first prize in an open handicap shall be penalised for all handicaps in which he may compete during the four days following such wins, Sundays not included. No person, other than the Handicapper, shall be permitted to alter the starts or to accept additional entries after the starts have been published. The penalties to apply to the scratch mark as well. Competitors must notify to the Judges before the race is run that they have incurred a penalty, otherwise they will be disqualified and render themselves liable 
to suspension. Handicappers to state on their handicaps up to what date they are made, which must be published on the programme.

12. Competitors in Handicap Competitions shall be required to send with their entries full and definite particulars as to their last three performances (if any). No Club shall be affiliated to the Association or registered as 'approved' unless it agrees to adopt the A.A.A. entry form.

13. All entries shall be made in the real name of the competitor, and this name shall appear on the programme.

\section{YOUTHS AND NOVICES.}

14. Competitors in youths' races must state their age and previous performances, and, if required, must furnish certificates of birth. In Open Races for Boys and Scholars under sixteen no entry shall be accepted from a competitor residing more than three miles from the ground at which the races are held, unless the age of the competitor be certified by his schoolmaster or a clergyman. For novices' races a novice is held to be one who, at the time of competing, has never won a prize in a similar class of competition -i.e., winning a prize for walking would not disqualify for running, or vice versâ; but winning a prize for running any distance would disqualify for running. (N.B.-This rule does not apply to School and Boys' races.)

\section{PROTESTS.}

15. All protests against a competitor or against a competitor's qualification to compete shall be made to the Secretary of the Club, in writing, before the prizes are distributed ; and if the protest shall not be made good within one calendar month the prizes shall be awarded. Every protest must be accompanied with a deposit of five shillings, which shall be forfeited in case the same shall appear upon investigation to have been made on no reasonable ground.

\section{Stations.}

16. In handicaps, stations shall be awarded according to the number on the programme. 


\section{Attendants.}

I7. No attendant shall accompany any competitor on the scratch (except in cycle races), nor in the race; nor shall a competitor be allowed, without the permission of the Judges, to receive assistance or refreshment from anyone during the progress of a race. In cycle races attendants will be allowed for the sole purpose of lending assistance in starting. Any attendant who steps or follows the machine over the mark of the competitor whom he is assisting to start will cause such competitor to be disqualified.

\section{FOULING.}

I8. Wilfully jostling or running across or obstructing another so as to impede his progress shall disqualify the offender.

\section{STARTING.}

19. All questions as to starts shall be in the absolute discretion of the starter. All races (except time handicaps) shall be started by the report of a pistol. A start shall only be made to the actual report of the pistol. The starter shall place the competitors on their allotted marks, and shall, if necessary, have the assistance of marksmen for this duty. No competitor shall touch the ground in front of his mark with any part of his body. If any one competitor overstep his mark before the pistol has been fired the starter shall put him back one yard for distances up to and including 220 yards, two yards up to and including 440 yards, three yards up to and including 880 yards, and five yards up to one mile or more. These penalties to be doubled for a second offence, and disqualification to follow a repetition of the same offence. (Committees of Sports are specially desired to print this rule in extenso on their Sports programme.)

\section{WALKING RACES.}

20. In Walking Races cautions and disqualifications shall be left to the decision of the judges of walking, who may appoint assistants if necessary. A disqualified competitor shall at once leave the track. 


\section{The High Jump and Pole Jump.}

21. Each competitor shall be allowed three jumps at each height. Crossing the scratch without displacing the bar shall not count as one jump. All measurements shall be made from the ground to the centre of the bar. In the High Jump neither diving nor somersaulting shall be permitted.

\section{THE BROAD JUMP.}

Each competitor shall be allowed three jumps, and the best three competitors of the first trial shall be allowed three more tries each for the final. The farthest jump of the six attempts shall win. If any competitor fall back or step back after jumping, or crosses the taking-off line with either foot, or so swerves aside that he pass beyond the taking-off line, such jump shall not be measured, but it shall be counted against the competitor as one jump. All jumps shall be measured to the taking-off line, from the edge to the heelmark nearest that line, along a line perpendicular to that line.

\section{Steeple Chasing.}

22. For Steep?echases the hurdles thall not be higher than $3 \mathrm{ft}$. Every competitor must go over or through the water; and anyone who jumps to one side or the other of the water iump shall be disqualified.

\section{Throwing THE CRICKET Ball.}

23. In Throwing the Cricket Ball the distance thrown shall be calculated from the centre of a scratch line; and the thrower, in delivering the ball, shall not cross such scratch line. Three tries only shall be allowed, and crossing the scratch shall count as one try.

In addition to the foregoing, the following RULES FOR COMPETITIONS and the MANAGEMENT OF Athletic Sports, adopted by the Amateur Athletic Association, are recommended to Clubs holding Sports under the Laws of the A.A.A. :- 


\section{OFFICIALS.}

The officials of a meeting shall consist of -

24. A Committee, in whose hands shall be placed all matters which do not relate to the actual conduct of the meeting itself, and who shall have a final decision in all cases not provided for in the rules of the meeting.

Two or more Judges, whose joint decision shall be final in every competition, and with whom shall rest the power to disqualify any competitor.

A Referee, who shall decide in the event of a difference of opinion between the Judges. The decision of the Referee shall be final in all cases.

Two or more Stewards, or Clerks of the Course, whose business shall be to call out the competitors for each event, and to assign to each his distinctive badge.

One or more special Judges of Walking, a Timekeeper, a Starter, and one or more Marksmen.

\section{STATIONS.}

25. Competitors in level races shall draw lots for their respective places on the post before leaving the dressing-room. Each competitor shall be supplied with and wear during each contest a distinctive number corresponding to his number in the programme.

26. Only the winners of the trial heats (first round) in spring handicaps run over a stringed track shall be eligible for further competitions. In cases where the track is not stringed and in distance races the first and second, or first, second, and third, may compete in second round or final heats, at the option of the Judges.

\section{Track Measurements.}

27. All tracks shall be measured twelve inches from the inner side of the path.

\section{Clothing.}

28. Every competitor must wear complete clothing from the shoulders to the knees (e.g., sleeved jersey and loose drawers).

Any competitor may be excluded from taking part in the sports unless properly attired. 


\section{STRAIGHT SPRINT RACES.}

29. Straight Sprint Races shall be run on a part of the cinder path or grass so staked and stringed that each competitor may have a separate course. The width between the strings shall not be less than four feet, and the stakes shall not be less than thirty feet apart.

\section{HURDLE RACES.}

30. The Hurdle Race shall be orer ten flights of hurdles on a level grass course of I 20 yards straight. The hurdles shall stand $3 \mathrm{ft} .6 \mathrm{in}$. from the ground, and shall have level top-rails and shall be placed to yards apart. The first flight of hurdles shall be 15 yards from scratch. Each competitor shall have his own line of hurdles, and shall keep to that line throughout the race.

\section{Throwing the Hammer and Putting the WEIGHT.}

3r. The hammer shall be thrown from within a circle of $9 \mathrm{ft}$. in diameter. The head of the hammer shall be of iron and spherical, and the handle shall be of wood. The head and handle shall weigh together I6 lbs. The total length of the hammer shall be not more than $4 \mathrm{ft}$. Each competitor shall be allowed three throws, and the best three competitors of the first trial shall be allowed three more throws each. The farthest throw of the six shall win. All distances shall be measured from the circumferenceof the circle to the first pitch of the hammer, along a line drawn from that pitch to the centre of the circle.

32. The weight shall be put from the shoulder with one hand only and without follow, from a $7 \mathrm{ft}$. square. The weight shall be of iron and spherical, and shall weigh 16 lbs. All puts shall be measured perpendicularly from the first pitch of the weight to the front line of the square, or to that line produced. Each competitor shall be allowed three puts, and the best three competitors of the first trial shall be allowed three more puts each. The farthest put of the six shall win.

33. In Throwing the Hammer and Putting the Weight crossing the scratch shall count as a try. 


\section{TUG OF WAR.}

34. The teams shall consist of equal numbers of competitors. The rope shall be of sufficient length to allow for a 'pull' of twelve feet, and for twelve feet slack at each end, together with four feet for each competitor ; it shall not be less than four inches in circumference, and shall be without knots or other holdings for the hands. A centre tape shall be affixed to the centre of the rope, and six feet on each side of the centre tape two side tapes shall be affixed to the rope. A centre line shall be marked on the ground, and six feet on either side of the centre line two side lines parallel thereto. At the start the rope shall be taut, and the centre tape shall be orer the centre line, and the competitors shall be outside the side lines.

The start shall be by word of mouth. During no part of the pull shall the foot of any competitor go beyond the centre line. The pull shall be won when one team shall have pulled the side tape of the opposing side over their own side line. No competitor shall wear boots or shoes with any projecting nails, springs, or points of any kind. No competitor shall make any hole in the ground with his feet, or in any other way before the start. No competitor shall wilfully touch the ground with any part of his person but his feet. If the competition is for teams limited in weight, each competitor shall be weighed before the start. The final heat shall be won by two pulls out of three.

\section{Programmes, etc.}

35. The A.A.A. recommend that a programme of any proposed meeting (showing the entrants for, and the starts allotted in, each event) shall be forwarded by post to each entrant, to the address given in his entry form, and shall be posted not later than the day before the day appointed for the meeting, or that such a programme as aforesaid shall be advertised the day next before the day appointed for the meeting in one of the public papers circulating in the district of the proposed meeting.

36. It is recommended that all Athletic Clubs and Sports Committees have the following notice conspicuously printed on their entry forms and programmes :-

'The prizes offered at this meeting will be awarded, subject to the statements of previous performances given on the entry forms being strictly accurate." 
The rules are, we think, so plain and straightforward that they require but little comment as to their practical working. One or two remarks, however, naturally suggest themselves. As regards officials, it is a truism to observe that the best laws in the world are no good unless they can find capable administrators; and the first and most important thing to make an athletic gathering successful is to get officials who are up to their work. In London and large athletic centres this is now by no means difficult, as every year there is an increasing number of old athletes who retain sufficient love for the sport to give their aid. At country meetings, however, the difficulty is much greater, not only from there probably being no men with great experience in the neighbourhood, but sometimes also because there are local interests to be conciliated, and some of the subscribers to the meeting have to be asked to officiate in order that no offence may be given. The presence of these willing but incapable officials sometimes leads to most remarkable results. We have seen a country J.P. (and a staunch old sportsman too) officiating as starter with a blunderbuss. His method of starting was as follows. He told the competitors that when he turned his back upon them they were to get ready, and were to start when they heard the gun. He no doubt thought, with great artfulness, that he must turn his back lest the competitors should see his finger tighten on the trigger. But as soon as this sapient starter's back was turned, off went all the competitors, and usually when they had gone about twenty yards the gun blazed. Another starter whom we saw (the local rector) rolled up his handkerchief in his hand, and prepared to start his men with the following successive formulas : 'Get ready. Are you ready? One, two, three-off,' dropping his handkerchief at the 'off.' Early in the day his men found that he never called them back for starting before the word, so they first started about the word 'One,' then at 'Are you ready ?' and finally at 'Get ready.' The starter did not like to confess himself beaten, and, like a conductor who when he finds his orchestra will not follow him decides to follow his 
orchestra, as soon as his men started he gabbled out the remainder of his sentences and dropped the handkerchief as speedily as possible; by the time he had well settled down to something like 'Ge-ready-aready-wun-to-throff,' the competitors were never more than five yards in front of him. The judges, too, have to be no less competent than the starter, for many sprint races are won by a few inches. The judge of sprinting contests should stand some yards away from the winning post, and directly opposite the tape or worsted. When he has watched whose chest breaks the line first, he should let his eye follow that man, and immediately discover his name. At all well-managed sports every competitor is now obliged to carry a large number pinned upon his breast, so that the judges may identify him at once, and the clerks of the course take care that no man shall be without his number. Real deadheats are very rare, many races being won by an inch, and even an inch is unmistakable to the experienced eye of a tried judge; but a man who has had little practice is often inclined to give a 'dead-heat' when there has been nearly a foot between the two runners. An untried judge, too, is often misled by a man who has been gaining on his opponent shooting past him after the post has been passed, and this is a mistake into which spectators very often fall. We have seen very bad decisions given by untried judges; at one meeting there was no tape, the only line being a chalk line marked on the ground between the winning posts, and the judging, which would in any case have been thus rendered difficult, became almost a farce, for whenever there was a close finish each man rushed up to the judges and claimed the race, and a general muddle and wrangle ensued. There is no more odious practice for a competitor than to claim the race from the judges by flinging up his arm or going up to speak to them, and it is with great regret that we have seen athletes who are good enough sportsmen to know better indulging in it. This, however, is by no means the worst offence we have seen perpetrated at a meeting. where the officials have been weak. In such a case the motley 
team of competitors of all classes is very liable to get out of hand, although a little display of timely firmness might have kept everything in order. If, as soon as a man misbehaves himself by jostling a competitor on purpose, or by declining to obey the judges' decision, he is promptly sent to the rightabout and disqualified for the rest of the meeting, the probability is that there will be no further trouble of any sort. An instance in point-rather a ridiculous instance certainly-was furnished at a Northern meeting, where a number of professional pedestrians entered themselves as amateurs, not desiring to take prizes, but merely to win money by betting about the heats for which they had been handicapped with a moderate start as ' unknowns.' Shortly before the racing came on the committee discovered the fraud, but were in a difficulty, as the 'pros' were attended by a number of backers, and stated that they would come out on the ground and run at all hazards. When the first offender appeared, as he had threatened, nothing was said until the men got upon their marks, when two stout officials quietly went up to the man, and without more ado seized him by the head and legs and sat upon him until the race was over. The man was then released and retired threatening vengeance, a threat which he never executed, and none of his companions appeared for the subsequent heats. The local committees of the A.A.A. give a very short shrift to a man who has declined to obey the judges, and the nuisance of disorderly meetings is being rapidly abated.

It will be noticed that the A.A.A. give a very free hand to the officials in the conduct of a meeting. The judges' decision is final, when they agree as to the result of any race, or as to the necessity of disqualifying a competitor on the ground. If the judges differ, the referee's decision is final. It has been found in practice that if there is a right of appeal even to the committee from the officials' decision there is much time wasted, and a great deal of friction; as in a loose body like the general committee of management, opinions may difier, and there may be conflicting interests, rival committee-men having rival protégés towards whom 
they may be apt to lean, although perfectly honest in their opinions. The committee, however, have left in their hands everything which does not relate to the racing itself and the declaration of the winners. Just as the judges' decision is final as to who are the winners of the races, the starter has an absolute discretion to call back the men even after he has fired the pistol, and either to declare a start or 'no start.' On one point only -a point which was only settled after much anxious discussion, and some considerable opposition--has the starter no discretion at all. If a competitor oversteps his mark before the pistol is fired, the starter is bound to put him back a yard in a sprint race, 2 yards in a quarter, and so on. It is contended by many that such a rule should not apply to a championship meeting; by others, that it is wanted more at a championship than at any other, as the temptation to get a flying start is stronger. A compromise between the conflicting views, that in a championship meeting the starter should be allowed a discretion to put back men or not as he thought fit, was finally rejected by the committee which framed the rules, it being thought, and in our opinion wisely, that a rigid and inflexible rule was better, as the starter could only judge of acts, and not of intentions, and would be unable to decide whether the overstepping of the mark was accidental or intentional. As it is, experience has justified the framing of the rule in its present shape, and under the present rigid laws there has been no attempt at a repetition of the fiascos of some old championship meetings, where men running in the hundred yards race were kept five minutes at the post making false starts, while there was every opportunity for the worst man to win by wearing out the patience of the starter.

The judges of walking have a similar discretion in deciding as to the fairness or unfairness of the walkers' gait, and this, too, is a decided improvement upon an old rule often employed, which obliged a certain number of ' cautions' before disqualification, although there was a special exception that there shouid be no 'cautions' in the last lap. The maxim upon which the 
A.A.A. rules were founded, was to give the officials a free exercise of their discretion; but it is obvious that for the rules to work well the officials must be men whose discretion is guided by experience and knowledge of the sport. A dispensing and discretionary power in the hands of a novice is apt to lead to blunders, but, as we have said before, there is seldom any difficulty, now that athletics have been in full swing for a generation, in finding judges who are both willing and able to act when asked, and the occasions therefore upon which the rules of the A.A.A. do not work well are very rare.

One of the officials, upon whom in a great measure success depends, although he is often not present at the meeting itself, is the handicapper. At most gatherings nowadays, there are more handicaps than level races; often indeed, especially in London, there are no level races at all. In fact, the ordinary programme for a club meeting near London is something of this kind : a hundred and twenty yards handicap (open), a quartermile handicap (open), a mile handicap (open), a three-quarter of a mile steeplechase (open), a two miles walking race (open), a hundred and fifty yards, half a mile, and two miles handicaps (confined to members of the club giving the race). Perhaps also there is a level race at some special distance arranged on purpose to bring two or three 'cracks' together, or perhaps a handicap with a short limit (say a quarter of a mile, with a limit of 25 yards from the best runner of the day), this last race being designed to produce a field where there are no 'platers,' but only good class runners. As meetings of this description take place by scores in every part of the country, it is obvious that none but trained handicappers, who regularly study the art, can be trusted to bring the men together. Before competitors became so numerous, handicappers could be found to do the work without reward, but first one and then another of the well-known handicappers began to demand payment for their services, and at the present day at least a score of men in one or another part of the kingdom are making a comfortable addition to their income by the exercise of their talents in this 
direction. ${ }^{1}$ The system in shorter races is to handicap by giving so many yards start, but in the longer races, whether of walking or running, the competitors often have so many seconds start of the scratch man allotted to them. A novelty in the way of handicapping was introduced in a cross-country race by the Thames Hare and Hounds Club some years ago, the runners all starting together, but being handicapped, in horse-racing style, by the apportionment of different amounts of weight, each runner being allowed to carry his weight in any way he chose. The novelty, however, was hardly a success, the runners who were heavily weighted (the top weight carried, we believe, $28 \mathrm{lbs}$.) making most ungainly efforts, and the result would seem to show that man, as a running animal, is not able to carry anything more than his own weight with ease and elegance. We do not anticipate any change, therefore, in the old and received system of handicapping for man-racing.

The advantages of giving up a club meeting to the handicaprunners have been much questioned, and there can be little doubt that the rapid increase of handicaps was a necessary step towards the popularisation of athletic sports with the runners themselves. To make all open races level no doubt not only encouraged 'pot-hunting,' but prevented those who were not really first class from taking part in races at all, as they would naturally object to form part of a procession at every meeting. Undoubtedly, also, there are many 'cracks' who were first encouraged to come upon the path by handicap prizes, and who have gone gradually down in the handicapscale until they have found themselves good enough to compete in level races or championships. The club treasurer, too, often feels that he cannot do without the handicaps, for while a level sprint might only produce four entries, i.e. four half-crowns, a sprint handicap might well produce eighty entries, i.e. eighty half-crowns, and there is a vast deal of difference between ten shillings and ten pounds of entrance fees. In the days, too, when there was

1 No handicapper is now allowed to act for an open race unless he holds a license from the A.A.A. 
something of a novelty and a pleasing surprise for any man to find hirnself a runner at all, the friends, sisters, cousins, and aunts of the handicap runners come to see their heroes run, and athletic clubs flourished and waxed rich ; while many a cricket, rowing, or football club netted a nice little sum out of its annual sports, which came in as a handy addition to the club's revenues. At the present day there is rather a plethora of athletic meetings, and while the handicaps still draw large entries from competitors, who expect there will be at least three valuable prizes, we have something more than a suspicion that the public has been driven away from attending sports by being bored with a succession of these dreary competitions. In sprint races one heat is very much like another, and, as a rule, the really good runners are unplaced, or give up against the unequal odds; while in a mile race, where there is a cloud of runners, none but the experienced eye can see who is making his way to the front, or really running above his form, and so doing well. The effect of this is that the public is beginning to get tired of the monotony of athletics, and of late years the attendance, of ladies especially, has become less and less frequent. In London the waning of the popularity of athletic sports with the paying public has been very marked of recent years, much more so than in the provinces, but generally it is admitted with perfect frankness by the promoters of athletic meetings in all large towns that there is 'very little money in athletics now.' At Birmingham there have been very few athletic meetings recently, and in London, Liverpool, Manchester, etc., the clubs are not so flourishing as they were formerly, owing to the falling off of 'gate money.' As we have hinted before, we believe one cause of this decadence is the mistake made by the managing committees of meetings in giving so few level open races. Certainly the big provincial meetings of the North, where there are plenty of level races, and where, even in the handicaps, the 'cracks' are leniently treated and encouraged to enter, command bigger 'gates' and better fields; and even I.ondoners are at last beginning to learn that one ' $\mathrm{crack}$ ' will do more to make a success of a meeting than fifty 'crocks.' 
At every meeting, however, there must be a certain number of handicaps, and for this it is indispensable that the handicappers chosen should be men up to their work. For the 'short limit' handicaps (which are such a success at the Civil Service meeting, and which we should like to see at every fixture, as they bring 'cracks' together, and yet prevent the same men from always winning) the handicapping has to be equally a matter of care and study, as a yard more or less may make or mar a good race; and there is little danger, when there are none but well-known men competing, of all calculations being upset by the appearance of a 'dark horse.' So far, indeed, has specialism proceeded in the athletic art that at many meetings there are different handicappers for the long and short races. The professed handicappers keep a book in which every man's performances are recorded, and their duties are certainly arduous, as to be exact in their calculations they have to get the best accounts of every event that has taken place in the country. It is not at all unusual for the athletes of one district to take journeys into other districts, while some of the semiprofessional amateurs flit about all over the kingdom picking up prizes. As soon as any athlete wins or is placed in a race his scale of start has to be reconsidered.

About a decade ago the amateurs thought they could borrow with advantage a system employed by handicappers of professional pedestrians of framing all the starts with reference to a fixed standard, and not with reference to the pace of the man who is the best of the entrants. Under this, which is known as the 'Sheffield system,' the standard fixed by the handicapper for 100 yards would be, say Io sec., or for the quarter $50 \mathrm{sec}$., and each competitor would be handicapped according to the number of yards he would be outside Io sec. or $50 \mathrm{sec}$., as the case might be. 'The result necessarily was that in nearly every case the best man in the handicap was not at 'scratch,' but at some yards start. The system, no doubt, had its advantages, for it saved the handicapper a good deal of trouble in readjusting all the starts for each race according to the varying ability of the man at 'scratch.' There was also this 
further advantage, that the handicappers throughout the country all adopted the same standards of merit for the imaginary scratch men, and it thus became very easy to handicap a stranger from another district, by simply finding out upon what mark his own local handicapper considered this stranger should be placed. The Sheffield system, however, was swept away by the growing desire, both of the public and of the men them selves, to see 'bests on record' accomplished at meetings. Several instances occurred of the real scratch man in a handicap. starting, under the 'Sheffield system,' with some yards from 'scratch' and winning the race with a performance which would have been a record had the whole distance been covered. The 'crack' who had done a record performance was thus deprived of the credit of it, as it was obviously impossible to establish a 'record' for I $48 \frac{1}{2}$ yards, 436 yards, or 596 yards, in cases where the scratch man had had a few yards start from the imaginary 'Sheffielder.' The Sheffield system was soon given up at Oxford-we believe it was never tried at Cambridgeand it was abandoned by the L.A.C. in 1877 . At the present day it is entirely unknown in the South, though sometimes employed elsewhere.

No meeting now is without an official time-keeper, and at some important gatherings, as we have seen, there are three such functionaries, all of whom time each race. There are, of course, many advantages in having each contest timed. The athletes themselves and the spectators like to know whether the races have been fast or slow; and for purposes of future handicapping, or of comparing the worthies of one period with those of another, timing is indispensable. Indispensable, however, though it may be for certain ends, timing is merely a means, and not in any way an end in itself : a fact the present generation of athletes-which has simply gone mad upon 'times' and 'records'-appears to have forgotten. By saying that the athlete of to-day considers timing an 'end' and not a means, we mean that he thinks it is a fine display of skill on his part to cover so much ground in so little time, without taking. 
any other fact into consideration-an opinion upon which we venture to differ with him.

There can be no question about the public fondness for a 'record.' A club which owns a ground of its own is rather inclined to give races at distances where there is a particularly good chance of lowering the existing record; and committees of clubs giving sports frequently advertise in the sporting papers that such and such runners will compete, and that it is confidently expected that 'the record will be lowered,' \&c. To such an appeal spectators never fail to respond by attending in large numbers. For the manufacturers of bicycles or the owners of running-grounds which are let to the public, we can quite see the advantages of promoting records with a view to bold advertisement ; but amongst athletes and others, the present writer is heretical enough to believe that the worshipping of records is idolatrous, and inconsistent with the creed of the true sportsman.

But before we go into this question at any length there is something more to be said as to the practice and difficulties of timing.

'Timing' in foot-races requires even more care than 'timing' in other sporting contests, for a mistake of a fifth of a second may make all the difference between a good or an ordinary performance. To ensure accuracy of timing there must not only be a good watch, but a person who knows how to hold it. In most stop-watches the watch is started by a simple pressure of the thumb or forefinger upon a knob or pin which removes the catch and puts the works in motion again. To drop for the moment the fact that some watches start quicker than others, the apparently simple process by which the man who holds the watch sets it going is not so simple as it seems, and there are plenty of opportunities for differences to arise between one timekeeper and another. If, say in a hundred yards race, the timekeeper waits for the sound of the pistol to start his watch, he himself standing at the winning-post, about $\frac{1}{10}$ of a second elapses before the sound reaches him. If he takes the start from the motions of the body, it is a most 
difficult question, when the men are upon tip-toe at the mark, to know which motion of any one of them is a motion made after the pistol is fired. In either case when the sound of the pistol is heard or the first motion noticed, the timekeeper has to arrive at a determination to start the watch from the sensations of his eye or ear ; he has then by will to convey that determination to the muscles of his finger, and the watch is then started by him. Recent experiments in physiology have shown not only that the process of thinking and volition takes an appreciable time, but that there is also an appreciable difference between the rapidity of thought and volition in different individuals. Practice and experience, as in everything else, tend to quicken the rapidity of the action of the will or thought, which travels auicker over beaten tracks. We of course wish to steer clear of physio. logical discussion as far as possible, and to confine ourselves to practical experience of timekeeping; but it is necessary to point out that the individual qualities of timekeepers may make the results they arrive at untrustworthy. As a general proof of the truth of what we say, we may call attention to the fact that novices who try to time races invariably make the times 'fast,' i.e. they are very slow in staring the watch, although they are not so slow in stopping it at the moment the tape is reached, as by watching the runner up to the tape they know almost the exact moment when the pressure of the finger to stop the watch will be required. Before quitting the subject of the liability of the timekeeper to arror, we would suggest that there should be a definite rule laid down by the A.A.A. for the guidance of starters as to what point should be taken for the start-the flash of the pistol, the report, or the first motion of the runner. Most tirnekeepers profess to start from the motion of the runner's body, but we are inclined to think with some of them this is a mere profession. Obviously they must only look at one runner, and if he were left upon the mark they would be 'out' altogether, a fact which we never yet heard an official timekeeper admit. In any case the starting from the 
motion of the body is fallacious, as one runner usually begins to move perceptibly before the others.

Besides these complications, there is the further set of difficulties created by the watch itself, though with the splendid pieces of mechanism which are now made expressly for this purpose the uncertainty is minimised. The dial of the stopwatch is usually marked into fifths, and with some of the older watches there was this fact to be considered: the hand 'jumped' from fifth to fifth round the dial, there being of course a fifth of a second between each jump. Obviously, therefore, there might be almost a whole fifth of difference between two occasions when the same time was registered on the dial. For instance, upon one occasion when $10 \frac{1}{5}$ was registered on the dial, the hand might, just at the instant before the watch stopped, have made its jump to the fifth, while upon the other occasion the hand might have stopped at an infinitesimal period before it took its jump to the twofifths mark upon the dial. It is clear, therefore, that, as a good sprinter travels a shade over two yards in a fifth of a second at the end of a hundred yards race, two men might each have been fairly timed at $1 \circ \frac{1}{5}$ seconds in a rsce, although the one was two yards in front of the other. As for a very long time there were nothing but watches which jumped fifths even at first-class meetings, it is obvious that as regards the times made at these meetings, they are quite untrustworthy as to one-fifth of a second's variation. At the present day there are some watches (although there are not many belonging to private individuals, their cost being large) which, at any rate as far as the human eye can distinguish, travel evenly over the dial. As a matter of fact, the wheel which regulates the motion has such small cogs that the jumps are divided into twenty or thirty per second. The hand, therefore, can really be stopped at any place on the dial between the fifths, and the dial then has to be surveyed through a magnifyingglass, and a conclusion arrived at how far it has travelled between one fifth and another. 
All this process, however, though exceedingly wonderful and the result of admirable workmanship, is also liable to error. The slightest warp of the straightness of the hand between the fifths may lead to doubt, and even supposing the mechanism perfect the human eye can and does make mistakes in deciphering the result which the machine has registered. The watches of which we speak are of course so made that the 'seconds' hand travels round the whole of the dial; but the watch is made to be carried in the pocket, so that there is very little space between the fifths of seconds on the dial, as each fifth occupies $\frac{1}{300}$ of the circumference of the dial. It is thus obvious that the human eye can easily be deceived in reading the dial, and it must be recollected that as soon as the next race comes on the watch has to be got ready again for this, so that it becomes impossible to verify afterwards the result registered on the dial. On account of the difficulty of reading the results on the watch many timekeepers carry a magnifying glass with them, and although this makes the reading easier and perhaps more accurate, the whole process becomes still more complex. On the whole, therefore, it appears that there is every possibility of a mistake being made to the extent of a iffth of a second, or even rather more, in the timing of races ; and some years ago when timekeepers had less experience and timing instruments were inferior, there was even a greater possibility of error than there is now. We cannot help thinking how strange it is that in these days of science no more satisfactory method of timing races has been invented than that of a watch started by a man who observes the start from some distance off. In these days of electric science it seems to the unscientific mind of the present writer that it ought not to be difficult to time by an apparatus, which could be fixed on every recognised running-ground, set in motion by the firing of the pistol, and stopped by the breaking of the thread at the winningpost. In such an apparatus the difficulty of deciphering the result marked on a small dial need not occur, as the hand or hammer registering the result might work upon a dial of any 
size. There need be no difficulty in the size of a dial in a fixed apparatus, and the consideration of expense hardly ought to arise when it is considered that sixty, eighty, or a hundred guineas are often given for the best timing watches.

Closely connected with the subject of 'timing' is that of 'records.' We have already given our opinion that in short races it is somewhat unsatisfactory at present to place reliance upon a 'fifth' of a second, and it is well known that in any race up to 220 yards the difference of a fifth of a second may make a 'record.' But quite apart from questions of timing, the state of the path, or of the weather, and especially the direction and force of the wind, may make a difference of two- or three-fifths of a second in a sprint, or of the same number of seconds in longer races. The inference would seem to be obvious that the fact of a man having covered a certain space of ground in a shorter time than any other runner, does not by any means necessarily prove that the man who has performed the feat is the best man who has ever run that distance. If this result is borne in mind, we can see no reason for placing the acquisition of a 'record' as the summit of an athlete's ambition. Yet this is exactly what is done by both athletes and the public at the present day, who consider the possessor of a 'record' a man far more to be envied or admired than his companion who has met one by one his best opponents and beaten them. The popular opinion, too, having once laid down a record as the highest possible distinction, has encouraged athletes to the most absurd limits in honouring the record. Records are gravely chronicled at distances which are never run as races, and we hear that Myers has made a record at 130,360 , or I, 100 yards, or that George has shifted the record for three miles and three-quarters, these record times having been taken by a man stationed at a particular post to note the time as the runnor went by. Another practice which in our opinion is illegitimate is that followed by the cyclists who allow a record to be secured at any time whether in a race or not provided they are satisfied of the 'timing'; and an aspiring amateur accordingly may go 
down accompanied by a time-keeping friend, and may try day after day to lower the record for six or seven miles, which he at last does when he is favoured by exceptional conditions. After this he retires happy in the possession of a record, and his satisfaction remains undiminished until his bosom friend comes down the next week and after another set of futile efforts at last 'cuts' the record by a second. However, our concern at present is not with cycling records, and we only state our grievance against their system because we think that the 'record nuisance' has in a great measure been promoted by enterprising manufacturers of bicycles, and first forced upon the cyclists by the 'makers' amateurs,' while from the cyclists the infection has spread again in its most virulent form back amongst the athletes. Recently the Amateur Athletic Association has been engaged in revising and settling the athletic records, and in arriving at the results (which are printed elsewhere) they were guided by the following principles, which, as it will be seen, carefully exclude all 'times ' not made in legitimate competitions.

It is decided that the running records to be dealt with shall be the ' $100,120,150,200,220$, and 300 yards, quarter-mile, 600 yards, half-mile, I,, 00 yards, three-quarters of a mile, one mile, one mile and a half, and then each mile up to ten, after which the only distances to be examined and authenticated shall be the fifteen, twenty, twenty-five, thirty, forty, fifty, seventy-five, and 100 miles.'

The walking records to be dealt with shall be only the mile records as above mentioned, but the one, three, and twelve hours walking record shall also be examined and settled.

The other competitions to be investigated shall be the 120 yardis hurdles, long, high, and pole jumps, putting the (I6 lb.) weight, and throwing the ( $16 \mathrm{lb}$.) hammer.

The only records to be accepted shall be those made in public competitions, and held under A.A.A. Rules and by a recognised club.

Questions of gradients, wind or other favourable conditions, shall be taken into consideration when deciding any individual record.

A record shall include any performance in the United Kingdom.

The record of a foreigner or colonial done anywhere in the United Kingdom shall be considered an English record. 
It will thus be seen that in future the A.A.A. propose to restrict the making of records within reasonable limits by only recognising those which are authenticated and made upon fair grounds under fair conditions, in legitimate competitions and at recognised distances. These regulations will prevent any second-rate runner from securing a record, and will make it more likely than of yore that the 'record-holder' will be the best man over the distance. In spite, however, of these reforms in the system-reforms which it is as yet doubtful whether the public or the press will be content to accept-we are still inclined to object to record-worship upon wider and deeper grounds than that the system is inconclusive and carried to absurd limits.

Our general indictment against the system of paying reverence to a record because it is a 'record,' is that the system is unsportsmanlike, and has demoralised the whole of the present generation of runners. The essential merit of every athletic contest, as of every other contest of skill or endurance, is for one man to be pitted against another man. The rivalry and the desire to win and not to lose bring out the pluck, the skill, and the endurance of all the competitors. It is in a contest with his equals or his betters that a man becomes, as the Greeks would have said, 'better than himself,' and our own poets have expressed in many different ways the joyous exultation of the brave warrior when he knows he will meet a foeman worthy of his steel. From the days of chivalry up to modern times one of the things which has made the English nation brave has been the praise bestowed upon the knight, swordsman, boxer, or runner who was ready to encounter any one who challenged him. At the present day that part of the nation which patronises the athletic ground awards more praise to the man who has scampered past a field of inferior runners quickly than to the man who has pluckily met and beaten other 'cracks' in a level race. Had this view prevailed in the Middle Ages the champion knight would not have been he who kept the ring against all comers, but he 
who knocked down with his lance twenty 'dummies' in the quickest time.

Our complaint against the athletes and the public is that they do not see that it is the competition of equally matched antagonists which brings out all the manly qualities of the Englishman, and that this alone is the true raison d'être of athletic sports. They did not come into vogue to show the capacities of the human body as a running or jumping machine, but to teach young Englishmen to train themselves in coolness, courage, endurance, and good temper, by pitting themselves against their equals in fair contest. When a man makes a record (as in bicycling) with several pace-makers and no opponent, or when (as often occurs on the running path) a crack starts at scratch in a handicap especially made (as freely stated in advertisements) to give him an opportunity of beating the record, he has everything to win and nothing to lose; he wants no pluck nor skill to defeat his antagonists, as there are none who start level with him. All he has to do is to lay his feet to the ground as fast as nature will permit him, and if he accomplish the task set him, one feels inclined to parody the familiar sentence and say, 'it is magnificent-but it is not sport.'

It would, however, make little difference to the welfare of the sport whether the public liked level races or record-handicaps best, if the taint had not spread to the athletes themselves. A suspicion of bias always attaches to the laudator temporis acti, but at the risk of incurring that suspicion we feel compelled to express an opinion that the great 'cracks' of the present day are not over-fond of meeting each other. The desire of winning the title of champion is still strong enough to bring most of them together once a year, but upon any other occasion it is the greatest difficulty in the world to induce two ' cracks' at the same distance to meet in a race. One day one is seeking a record in the South, and on the same day another is running at a country handicap in the West, while a third who is great at the same distance is at a big Birmingham meeting, also trying for records on the Aston track. On a Bank Holi- 
day the same phenomenon is also to be observed, although the motive on this occasion is not to make records but to win 'pots.' If there are three good quarter-milers in London in the spring, it may be predicted with great confidence that one of them will be at Woodbridge, another at Colchester, and the third at Newmarket. All this cowardice (to use a plain word) is discreditable to the sport, and it is fostered and encouraged by the system which takes as the test of a man's merit, not the quality of the opponents whom he has beaten, bur the 'time' in which he has performed. The sooner, therefore, that athletes learn that time is a test of speed but of nothing else, the better for the sport. The race is not always to the speediest, and to possess speed without pluck or judgment is to have very little title to genuine merit. To conclude with an old athletic aphorism, 'Fast times do not make the runner,' and with this remark we will close our case against timing and records.

There is one other practice which, in our opinion, has been carried to absurd limits at athletic meetings. At a great many meetings boys' races are included in the programmes. That a good, strong, lusty schoolboy, who is continually playing cricket or football, should come out and race in public is sensible enough. Athletic sports have now been in full swing for a generation, and many of the runners of the past are bringing up possible young champions of their own. At first sight, therefore, it seems a genial and sportsmanlike notion for races to be given at meetings for the sons or young brothers or nephews of the members of clubs. But this idea, like some other good ideas, has led to cruel absurdities. At the Civil Service and Private Banks and other meetings, little boys of six years old, and even less, are to be seen racing in boys' handicaps, having, of course, prodigious starts from the scratch markers, who are much bigger lads. For our own part, we think it is neither good for the minds or bodies of little boys to run hard races at public meetings at all, and we should like to see boys' races restricted to those over twelve. But even of races for elder boys there are far too many. There are so many, in fact, that a regular class. 
of boy-champions is springing up, and certain boys run at twenty or thirty meetings during a summer, and bring home as many prizes. This early 'forcing' of juvenile talent can hardly be considered a healthy system, and yet the practice is yearly extending rather than decreasing. Every school, great or small, has its athletic meeting now, and we think that schoolboys had much better confine themselves to their own school races, and their own games and paper-chases, until they are good enough to compete at men's meetings in men's races. Another drawback about these boys' races is the immense amount of squabbling to which they give rise at country meetings. The only way for the handicapper to get his boys together at the finish is to find out the age of each, and a very large number of frauds are perpetrated by boys who either themselves understate their ages or whose friends do the cheating for them. So many of these 'mistakes' have there been that the Athletic Association has been obliged to pass a very stringent rule which confines boys' races in most parts of the country to purely local events. Only a short time ago a case came before the Southern Committee of the A.A.A. of a boy who had been entered at different sports under four different names, his ages being variously given from $\mathrm{I} I \frac{1}{2}$ years to $\mathrm{I} 4$ years, and his height from $4 \mathrm{ft} .2$ in. to $4 \mathrm{ft}$. 8 in. His real age was r6, and his real height 5 feet. This is no doubt an exceptional case, but the number of instances in which a boy's age has been understated . a year, 'quite by accident,' is large enough. A system is not bad in itself because bad people abuse it, but apart from these abuses we think the practice of encouraging boys' races at open -meetings a pernicious one. If there are to be boys' races at all, let them be confined to those introduced by members of the club holding the meeting, and to competitors who are over 'twelve years of age.

Having dealt with the boys, we will end our criticism of athletic meetings with the veterans. Some clubs give races to 'veterans'-a 'veteran' in the athletic sense being usually a 
man over thirty-five years old. We do not see that there is anything wrong in giving those who are 'rude donati' an opportunity of coming out again to exhibit themselves to the rising generation of runners, but in practice the veterans' race is usually rather an absurd sight than otherwise. At one of these competitions, which is an annual affair, an old gentleman, who must by this time have passed his allotted span of three score years and ten, comes out regularly to exhibit himself, many

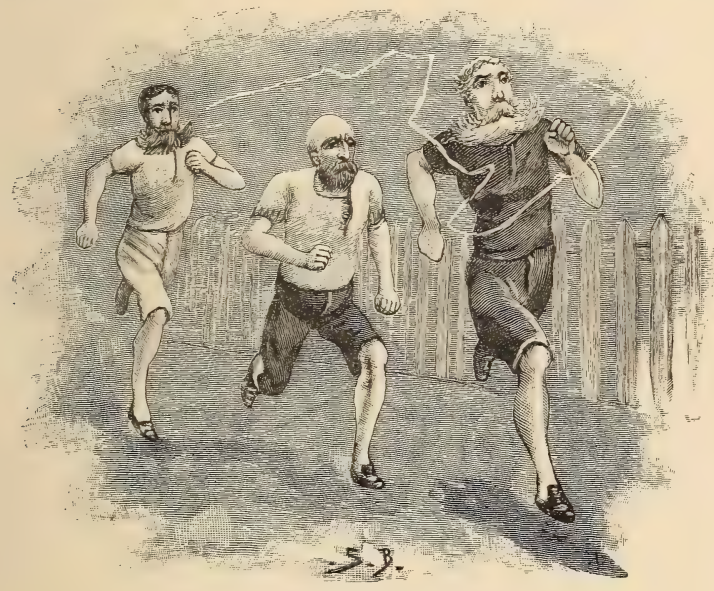

Veterans' Race.

others who are well over fifty appear in the race, while a good many younger men compete whose bodies from disuse have so far thickened about the middle as to render their movements anything but graceful. On the whole, we think that the veteran who is too slow to take part in the ordinary races 'lags super. fluous on the stage' of athletic sports. 


\section{CHAPTER VIII,}

\section{ATHLETIC GOVERNMENT.}

ONE of the most remarkable features about modern English athletic life is the capacity of the athlete for self-government. As soon as any game or sport becomes popular in any district, or throughout the country, clubs are formed; the clubs conglomerate into district associations; and the latter finally become gathered together into a national governing body. All these bodies, from the smallest club to the largest association, are the outcome of voluntary effort; they are worked, as a rule, in a sensible and businesslike manner, and the officers, in almost every case, are unpaid. Football, cricket, cycling, athletics, paper-chasing, have all their governing bodies; and at a week's notice the best team at any sport can be picked from the whole country, or the popular opinion as to any change or innovation in the sport ascertained. All this discipline and organisation is so well known nowadays as to excite little notice ; but when fairly considered, it is really marvellous, and most creditable to the capacity and sound sense of the English sportsman.

The 'Jockey Club' of athletics, the Amateur Athletic Association, did not take its rise until comparatively late in athletic history. For a great many years the Amateur Athletic Club, which was formed in London from the chief University and London athletes of the day, and which instituted the championship meeting in 1866 , assumed a position in athletics like that of the M.C C. in cricket, and no other governing body was needed. From various causes, however, the chief of which 
was the rising strength and popularity of the other great metropolitan club, the L.A.C., the A.A.C. gradually began to decay. The original members of the A.A.C. ceased to take any active part in its welfare, and the few new members who joined became members simply for the purpose of training upon the clubground at Lillie Bridge, the club holding no other sports except the championship meeting. To such a stage of apathy had the club sunk in 1876 that an unfriendly critic declared it had only three active members - the secretary, the pony, and the roller. Up to this time the L.A.C. meetings-the most important in London-were held on the A.A.C. ground at Lillie Bridge; but in 1876 a final rupture occurred between the A.A.C. and L.A.C. over 'gate-money' arrangements, and in I 877 the L.A.C. departed to its own ground at Stamford Bridge. In 1877 and 1878 the championship meeting still was held without objection under the management of the A.A.C. at Lillie Bridge, upon the Monday following the Oxford and Cambridge sports, although a strong feeling was growing up in London and the provinces that the date of the fixture gave an unfair advantage to University men. The real truth of the matter was that in the twelve years that had passed since the foundation of the championship meeting, the state of athletic society had undergone a vital change, and the A.A.C. had failed to 'move with the times.' In I866 and the next few years the University runners were by far the most important section of the athletic community, both in number and merit, and provided about two-thirds of the entries to the sports, while the few Londoners and provincials who were athletes were in a social position which enabled them to find leisure enough to train in the spring to meet the University runners. Before I 878 a new class of runners had sprung up both in London and the provinces. The provincial runners were (as they still are) for the most part drawr from the 'mechanic, artizan, and labourer' class of the community. In the North they were accepted as amateurs; at Lillie Bridge, where the Henley definition of an amateur held good, they were, according to the 
rule, excluded; although, as a matter of fact, either from accident or from design, their entries were often accepted. The bulk of the London runners, although of quite a different class from the provincials, were clerks or business men who were tied to their desks during the day, and were unable to train except in the evening. The only chance, therefore, that many of them had of getting fit for a spring championship in March or the beginning of April necessitated their practising in the dark. From different reasons, therefore, in London and the provinces athletics had become a summer pastime, while at Oxford and Cambridge they were pursued mainly in the winter months. The three University terms are short, and the various sports have all to be accommodated; so the arrangement both at Oxford and Cambridge is, that athletics and football are cultivated in the two winter terms, the summer term being reserved for cricket and boating (and examinations). It became obvious, therefore, that a summer championship would place the University men at a disadvantage, while a spring fixture would give them a decided 'pull.' Soon after the opening of the Stamford Bridge grounds, the L.A.C., then under the management of Messrs. James and William Waddell, placed itself at the head of the agitation for the summer championship; and, after much fruitless negotiation and discussion, the L.A.C. runners in a body 'boycotted' the spring championship at Lillie Bridge in the spring of 1879 , and it was accordingly confined to the University men and a few provincial athletes, including Webster, the walker, and Warburton, the long distance runner. In the summer of I879 an oppositior. championship was held on the Stamford Bridge ground, under the management of a committee consisting almost entirely of London runners, together with some few secretaries of clubs from the Midlands; but the Northerners, who had by that time formed themselves into a Northern Counties Athletic Association, held aloof, as they were standing out for the contention that a championship meeting should be open to any amateur, of whatever social position, provided he had never run for money. 
The summer championship was a decided failure, in spite of the presence of W. G. George, who won both the mile and five-mile races, two-thirds of the winners being from the L.A.C alone. Early in the spring of I 880 the Lillie Bridge championship was again advertised for the usual date, and again notices were given by the London runners that they should decline to compete. The dispute also with regard to the amateur definition was still unsettled, the provincials maintaining in a body that the 'mechanic, artizan, or labourer' class should be admitted as amateurs, provided they had never run for money. The wide definition had already been accepted by the Northern Counties Association - a body then consisting of some sixteen strong clubs-while in the Midlands a similar body, consisting of some eight or nine clubs, was already in process of formation. Under the circumstances, it occurred to some of the leading athletes at Oxford, early in the spring of r880, that the best way to settle both burning questions was by a general conference of representatives of leading clubs; and it was further thought that the invitations to such a conference should be issued in the joint names of the Oxford and Cambridge clubs. A notice was accordingly issued in March by the presidents of the two University Clubs, inviting secretaries of all recognised athletic clubs to meet at Oxford on April 24 . As soon as the notice was circulated the advertisements of the usual Lillie Bridge championship were withdrawn, and it was tacitly agreed between the disputants to settle the question of spring or summer championships at the Oxford meeting.

It is probably no breach of confidence after so long an interval to say that the 'Oxford Conference' had several narrow escapes of falling to the ground. Each different party was anxious to keep away from the meeting unless some guarantee for the preservation of its interests was given, and this was of course impossible. Even at Cambridge some opposition was got up in the University club against the holding of the meeting, and early in April the guiding spirits of the movement at Oxford were at their wits' end for an expedient to realise their cherished project 
of founding a general governing body for amateur athletics. Finally the well-known tastes of Englishmen were recollected, and it was decided to invite every delegate to attend a meeting in the afternoon and a dinner in the evening. How far the latter part of the suggestion availed to overcome scruples it is, of course, impossible to conjecture; but in the result the meeting came off on April 24, I880. A set of resolutions to submit to the assembly was drafted by Messrs. Wise, Jackson, and Shearman of the O.U.A.C., and on the evening before the meeting they were further discussed in conjunction with Mr. Walter Rye, who had come down from London for the purpose. The gathering was attended by twenty-seven delegates representing fifteen clubs, the Northern Association (sixteen clubs), and the Midland Association (nine clubs), and at that meeting was founded the Amateur Athletic Association, which, at the end of six years, consisted of I 54 clubs representing about 20,000 athletes.

As the foundation of the A.A.A. represents a new and im. portant era in the history of athletic sport in this country, it may perhaps not be amiss to give a few further particulars of the men present at this first meeting at Oxford and of the resolutions there come to. The representatives present were J. G. Chambers and A. G. Payne (of the A.A.C.); E. Storey, L. Knowles, and R. H. Macaulay (of the C.U.A.C.); C. Herbert and H. Tomlinson (of the C.S.A.A.); J. W. Macqueen (of the German Gymnastic Society); J. Waddell (of the L.A.C.); J. Anderton and Frank Smith (of the Midland Counties Association); R. Mullock (of the Newport, Monmouth, A.C.); C. E. Barlow, T. G. Sharpe, H. C. Faram, and T. M. Abraham (of the Northern Counties Association); J. Ingman (of the Northampton A.C.); C. F. Turner and J. E. Dixon (of the North of the Thames Cross Country Union); C. N. Jackson, W. N. Bruce, and M. Shearman (of the O.U.A.C.); J. Suddaby (of the Reading A.C.); J. Gibb. (of the South London Harriers); W. Rye (of the Thames Hare and Hounds); W. Waddell (representing the United Hospitals A.C.); E. R. Wood (of the Woodbridge A.C.); and B. R. Wise, who, as President of the O.U.A.C., took the chair. At this- 
meeting it was decided that the Championship Meeting should take place in the summer, and be held in rotation in London, the Midlands, and the North, and that it should be open to all persons who had never competed for money; that the clubs present should associate themselves into a body, to be known as the Amateur Athletic Association; and that the objects of the body should be: (I) To improve the management of athletic meetings, and to promote uniformity of rules for the guidance of local committees; (2) to deal repressively with any abuses of athletic sports; (3) to hold an annual championship meeting. It was also decided that 'all races held under the sanction of the Association be confined to amateurs, and that the following be the definition of an amateur: "Any person who has never competed for money, with or against a professional for any prize, and who has never taught, pursued, or assisted in the practice of athletic exercises as a means of obtaining a livelihood." ' In order, however, to guarantee the independence of individual clubs it was understood that this rule should not interfere with the right of any club to refuse the entry of any person to its own sports whenever it thought fit. As regards prizes it was arranged that in no handicap should a prize of greater value than Iol. Ios. be allowed, and that every prize of a greater value than $5 l$. should be engraved with the name and date of the meeting. The execution of these provisions was to be entrusted to a committee, consisting of certain ex-officio members, the representatives of a few leading clubs, and of elected members. A large number of names were proposed for election, but the following ten were chosen for the first year: The Earl of Jersey, and Messrs. Anderton, Barlow, Herbert, Jackson, Lockton, Macaulay, Rye, Shearman, and Waddell. Probably it was in recognition of the services of the Oxford men in setting the Association on foot that in the choice of the officers for the first year Lord Jersey was elected President, and Messrs. Wise, Jackson, and Shearman, Vice-President, Treasurer, and Secretary of the new body.

Since its institution the Amateur Athletic Association has 
had a career of even success. Although it proceeded cautiously at first, as there was a good deal of opposition to be met, it has of recent years assumed a wholesome arbitrary power over all athletic meetings held in England; and it insists that the main provisions which are necessary for the maintenance of fair play and genuine amateurism shall be respected. The body occupies in fact the same position as the Jockey Club in the sport of flat racing on the turf, insisting that all meetings shall be held under its laws, proclaiming meetings at which such laws are not followed, and punishing athletes for any unfair practice in connection with athletics. Rule XVIII. of its present code provides for the suspension of any athlete who wilfully competes at a meeting held by any club or managing body which is not either, (I) affiliated to the Association, or (2) registered as an 'approved' club after application to the local officer of the Association, and both the affiliated and the registered clubs are bound to advertise their sports as being held 'under A.A.A. laws.' Such advertisement does not necessitate the adoption of the 'competition rules' given before, which are merely recommended, although as a matter of fact they are now almost universally adopted; nor, as we have seen above, is the club giving sports ' under A.A.A. laws' obliged to accept any entry of which it may for its own reasons disapprove. The only compulsory laws of the A.A.A. which must be observed at every meeting are the following, and it will be admitted that they are not such as to interfere unduly with the freedom of any club which is desirous of giving sports :

I. All competitions must be limited to amateurs.

'An amateur is one who has never competed for a money prize or staked bet, or with or against a professional for any prize, or who has never taught, pursued, or assisted in the practice of athletic exercises as a means of obtaining a livelihood.'

2. No person must be allowed to compete while under a sentence of suspension passed by either the A.A.A., National Cyclists' Union, Swimming Association of Great Britain, Scottish A.A.A., or Irish A.A.A. 

offered.

3. No 'value' prize (i.e. a cheque on a tradesman) must be

4. No prize must be offered in a handicap of greater value than Iol. Ios.

5. Every prize of the value of $5 l$. or upwards must be engraved with the name and date of the meeting.

6. In no case must a prize and money be offered as alternatives.

7. All prizes shall be publicly presented on the grounds on the day of the sports.

8. All open betting must be put down.

9. All clubs holding and advertising their sports 'under the laws of the Amateur Athletic Association' must have printed on their entry forms 'the definition of an Amateur' as adopted by the Amateur Athletic Association.

It will be seen that it has throughout been the main principle of policy of the A.A.A. to insist upon the orderly management of meetings and the suppression of unfair practice, but yet not to interfere with the free right of any club, whether affiliated or 'approved,' to appoint its own officers and manage its own meetings, provided they respected the essential laws of amateurism. Unfortunately, during the whole of the year I 885 the amateur world was thrown into disorganisation by a vehement dispute between the A.A.A. and the National Cyclists' Union, a body which occupies a similar position as the recognised governing body of amateur cyclists. Like many other party conflicts, this arose out of a very small matter and grew into serious proportions, rather through misunderstandings than through illwill, on both sides. The point in dispute was the management of cycling races given by athletic clubs, and generally of all meetings where there were both foot-races and cycling races, the cyclists claiming to have absolute control over every cycling race, wherever held, and the A.A.A. resisting the claim of the Cyclists' Union to interfere with the management of meetings of the affiliated clubs of the A.A.A. Happily, at the end of the year 1885 , terms of arrangement were concluded between the belligerent associations, which we think were, to use a well- 
worn phrase, 'honourable to both parties concerned,' and have certainly made the interests of both bodies so far identical as to strengthen the position of each with the amateur public. All mixed meetings since the arrangement are advertised under both rules, the foot-races and other athletic sports being under the A.A.A. rules, and the cycle races under the N.C.U. rules, the N.C.U. undertaking, in the case of meetings held by the clubs affiliated to the A.A.A., not to make any order (except at the invitation of the A.A.A. club) upon the committee of that A.A.A. club to alter its decision.

We have probably said enough of the A.A.A. and its objects and principles to convey some idea of the work it performs. Soon after its foundation it was found necessary to put the greatest possible administrative power into the hands of the local associations in the North and Midlands, and the A.A.A. may now practically be said to consist of three bodies in the North, South, and Midlands, the general committee only sitting as a court of appeal from the decisions of the local committees, and the general body of clubs rarely meeting more than once a year, to effect alterations in the rules, and to supervise the management and expenditure. It has naturally been a matter of time and trouble to get the Association known and its power felt throughout the kingdom, and for its present strong position the A.A.A. owes a great debt of gratitude to its present honorary secretary, Mr. Herbert, of the Civil Service Athletic Association, in whose hands the management of the body has been since I883. In the early days of the Association also, it owed much of its success to the support of the Press, most of the sporting papers of influence giving assistance and encouragement to the movement for the organisation and purification of amateur athletics.

So far, however, we have presented the bright side of the picture in sketching the history of a body which has undoubtedly by its influence brought all classes of athletes and all districts into communion, and has also done much to remedy some of the grosser abuses of the sport. On the other hand, 
chose who are familiar with the working of athletic meetings and athletic clubs know that outside the Universities, and a few other similar places, the state of amateurism has never been so bad as it is at the present day. When open races were first thought of, nearly all the competitors were 'gentleman amateurs.' It was soon found that, hard as it was to define an amateur, it was still harder to define a 'gentleman' for athletic purposes. The 'gentleman amateur' was replaced by the 'amateur,' who was what his name represented, a man who competed for love of the sport, and respected the rules of honour and fair play. Then came the time when athletics were at the height of their popularity, when the 'gate-money' taken at the meetings was enough to support a club without paying much attention to subscriptions of members, and when meetings began to spring up throughout the country. This prosperity has led perhaps almost inevitably to decay. Thousands of men of every class of the community, but, for obvious reasons, chiefly those of the lower class, found that by taking up amateur athletics there were prizes to be won, which were readily exchangeable for cash, and opportunities also could be provided for making money by betting in those mysterious ways which had long been so familiar upon the turf and with the professional pedestrians. The result is that the last state of amateurism is worse than the first, and that the ranks of so-called amateurs are crowded with athletes who have absolutely no further thought in entering for races than the amount of money they can, by fair means or foul, extract from them. Probably not one tithe of the malpractices that are committed are so obvious in their nature as to render it possible that they can be brought before the notice of the Athletic Association; but we imagine that an evening spent with any of the committees of that body would astonish an uninitiated patron of athletic sports, for he would discover the existence of an amount of petty swindling, deceit, and unfair play, which would give him but a poor opinion of the modern amateur. Men who have belonged to clubs and have run under their club-names refuse to pay sub- 
scriptions ; they enter for races, and when unsuccessful decline to pay their entrance fees; they attempt by every conceivable kind of trick, such as making omissions or ambiguous statements in their entry forms, to induce the handicapper to give them longer starts than they would obtain if they made a full and fair disclosure of their last three performances ; and lastly, there is over and over again grave suspicion of 'roping,' men who ought to win suddenly losing in a way which is unaccountable, except upon the hypothesis that they are paid to lose. All this has tended in a great many districts to drive gentlemen. out of the field, as they do not care to associate with the semiprofessional amateur, or take part in a sport where such practices are rife. The existence of these abuses, too, has even led to the corruption of the genuine amateur. Knowing well that many of those with whom he may find himself competing are dishonest, and being too honourable himself ever to indulge in malpractices, he fancies he has discharged his duty to the community by always running to win, and respecting the laws of the meeting, and that when this is done nothing further is to be expected from him. Thus, of late years, many amateurs, against whom no suspicion of dishonesty can possibly arise, are ready to go off to any meeting where they can pick up a 'pot,' and when they lose to raise protests against the winner. It is sad to find that the 'win, tie, or wrangle' policy has increased a good. deal upon the running-path within the last few years.

Upon the whole, therefore, the state of amateur athletics throughout the country can hardly be considered satisfactory. A great many athletes who pass as amateurs are not only professionals in truth and fact, who make a living out of the sport, but, what is worse, many of them are making a living out of it by dishonest means. It is difficult, however, to see how, in the turn which the movement has taken, things could have happened. otherwise. The athletic movement which commenced with the 'classes,' and first drew its strength from the Universities. and public schools, has finally, like most other movements. and fashions, good or bad, spread downwards to the 'masses.' 
The encouragement and interest given to the amateur contests by the non-athletic public caused the popularisation of the sport to be very rapid, and when the taste caught the 'masses,' it became easier for them to take part in amateur sports than in professional pedestrianism. Without casting any reflection upon the conduct of the masses as a whole, it is obviously impossible to expect that with many of them the money to be gained by betting or 'squaring' races will not offer irresistible temptations. Nor, again, is it to be expected that the 'mechanic, artisan, and labourer' ranks will always have, when a valuable prize is at stake, as much sportsmanlike feeling and nice sense of fair play as one could rely upon finding in the much-ridiculed 'gentleman amateur' of past days. As soon as any sport has become so popular that money is to be made out of it, and men engage in it upon whom the loss of reputation has little effect, it may be prophesied with certainty that abuses will arise. Such abuses have arisen in athletics; but it is of more importance to find a remedy for them than to discuss their origin.

The foregoing will, however, serve to explain in some manner the true position of the Athletic Association. The objection has often been brought against this body, as well as against other similar bodies, that it has been productive of no good because it has failed to purify the sport which it governs. All that a governing body of sport can be expected to do is to keep order and punish open offences against its laws, and it can no more render its subjects good sportsmen and amateurs than an Act of Parliament can render citizens virtuous. What the A.A.A. does for the true amateur is this : it assures him that wherever he goes to run under A.A.A. laws he will find competent management and fair play-a fair field and no favour-but it cannot prevent the genuine amateur from rubbing his shoulders against many a false amateur whose motives in running as an amateur are obvious, though no complaint can be made of his public behaviour.

Before discussing the possible remedies for the present state 
of amateur athletics, a few words may be said as to some of the leading athletic clubs. We have already pointed out that in some respects the runner has an advantage over the oarsman or the cricketer in being independent of his fellows, able to choose any time for training which may suit him, and that in competitions he wins or loses upon his own individual merit. This independence of the athlete, however (employing the term to include the walker, runner, hurdler, and so forth), is rather a serious drawback to the success of athletic clubs. Rowing, cricket, football, cycling, tennis, and gymnastics, are pastimes as well as competitions, and the members of clubs devoted to pastimes have plenty of reason to bring them together at other times than the days of competition. A club devoted to athletics alone had, until paper-chasing came into vogue, little social attraction, as compared with other clubs. The popularity of paper-chasing during the last few years has caused a large number of clubs to spring up throughout the country, which exist to promote paper-chasing and cross-country racing during the winter, although they hold athletic meetings during the summer season. However, with paper-chasing clubs it is not our business to deal in the present chapter, although it is worth mentioning that quite a fourth part of the clubs affiliated to the A.A.A. are Harriers or Hare and Hounds clubs. But if the paper-chasing clubs are put out of the question, it may almost be said that there are no clubs in the true sense of the word which exist purely and solely for the cultivation of running, jumping, and throwing of weights, with the exception of those which are fortunate in possessing running grounds with a cinder-track of their own. Of these the number is very limited, but their work in collecting, promoting, and forming athletic talent is wide and far-reaching. Ever since the time when athletics became part of the regular University life, the Oxford and Cambridge University Athletic Clubs have brought out and brought together all the men with athletic capabilities in their different colleges. The management of the two clubs, and the system pursued for the cultivation of athletic skill at 
the two Universities, is so identical, that it can hardly be of any advantage to give separate sketches of both; the writer will, therefore, in the main give an account of his Oxford reminiscences.

The Cambridge athletes formed themselves into a club in I863, and their home has always been the cricket-ground at Fenner's, which they share in common with the University Cricket Club, the latter using the ground and pavilion in the summer term, and the athletes in the autumn and spring terms, the cinder-path of course running round the cricket pitch. Until the end of 1876 the Oxonian cinder-track was out in the fields at Marston, quite a mile from the centre of Oxford, and in some very low-lying meadows, which made the track and grass decidedly swampy. In the next year, however, the Oxonians removed to their present ground in the Iffley Road. The University athletic clubs are open to every member of the University without any formalities of proposing and seconding, but every one who wishes to train upon the club grounds, or run in the Freshmen's or University Sports, must pay his subscription to the University club and become a member. There is, however, at Oxford, and we believe also at Cambridge, an exception. For a limited time before any college gives its sports a member of that college, who is not a member of the University club but wishes to have a few days' practice upon the ground, can obtain permission through an arrangement between his college and the University club. As a general rule, however, those members of the colleges who run at their college sports are members of the club. At Oxford, in the writer's time, the only formality necessary for membership was to go to Rowell's, the silversmith's, in 'The High,' and pay the subscription over the counter.

The athletic season begins immediately after the commencement of the October term, and at Oxford after luncheon the athletes in twos and threes may be observed wending their way over Magdalen Bridge to the ground. Before long they may be seen scampering also in twos and threes over the path or: 
over the hurdles, or essaying the hurling of weight and hammer. At Oxford athletics are an eminently sociable sport. You run 'spins' with your friends, or take the long-distance runner a lap upon his way; then, perhaps, a try at the long jump or the weight, or you hold the watch for the practising half-miler; then the final breather, and the return to the pavilion; then a warm at the fire, and the walk back in the dusk of the short winter day with the friend, when the form of the 'coming: Balliol man is discussed, or the chance of the London stranger winning the 'Exeter Half.' Oh, glorious days of youth and training, before the race of life has begun, and some companions have shot to the front and others have fallen to the rear, while some have dropped out of the running, and will never more meet an antagonist in any field !

A man whose soul delights in running can get as much as he wants at Oxford. The season begins in the autumn with the 'Freshers' alias the Freshmen's Sports, open to all who are in their first year at the university, and from these it is soon seen what new men will have a chance of their 'blue' in the spring. Then come the series of college meetings, some score in number, about half of which are in the autumn term and half in the spring. Every college meeting has its strangers' race, open not only to strangers from Cambridge, London, and elsewhere, but to all those of colleges other than the one holding the meeting. To enter for the race all that is needed is to write one's name in the book at Rowell's, entrance fees to college strangers' races being things unknown, and you will be handicapped by two members of the O.U.A.C. committee, to whom the particular distance is allotted. A college meeting itself is always a festive scene. It is not promoted for the benefit of the few cracks in each college. Men turn out for the handicaps who have never put on a shoe before, and in the level races the winners of previous years are penalised. Every one has a chance of a prize, the value of the prize is happily small, and no one is aggrieved at losing. As a rule, too, a 'man who is a 'blue' - that is, has run for his university at any 
particular event-stands out of the races at his own distance in his college sports to give the other men a chance. All is good sport, even though the winners' times are sometimes so slow as to promote the mirth of the London 'crack.'

When the 'college grinds' are over the 'Tarsity sports come to finish up the season. They always take place about a week before the end of the Lent term, and it is from the result of the different races at the 'Varsity sports that the representatives for the Inter-'Varsity gathering are selected by the committee of the Club. From the very earliest time the Oxford men took a sensible course with regard to the prizes at the University meeting, and for the last fifteen years the winner and second man in each race get exactly the same prize-a silver medal. To have earned the 'O.U.A.C. medal' is honour enough for the Oxford athlete, and it is better far to give the winner a trophy which shows upon the face of it in what sports it was earned than to give valuable prizes to a class of amateurs who ought to be above coveting them. There is something, however, which the University athlete corets more than his medal, and that is the 'blue.' The system of 'Varsity 'colours' certainly has its amusing side, and a stranger may well be bewildered at the number of coats and caps of gaudy hue which are in the possession of an Oxford or Cambridge athlete. Every college has its colours; then there is something distinctive for each club of every college from which the initiated observer can gather whether the wearer of the coat and cap he sees is a cricketer, or an oarsman, or something else. Then with the cricket coats there must be a fresh difference, to mark the man in the college eleven and the man who is not in it; and similarly with the votaries of the river, a man gets a different cap when he reaches his college 'torpid,' and yet another when he is promoted to the 'eight.' The outward and visible sign, then, of the 'Varsity man's uprard progress in an athletic career is the donning of a fresh coat or cap, or a piece of ribbon which he wears proudly as a badge of merit. Mere college colours, however, are considered to count for but little as compared with the dark or 
light blue colours which show that the wearer has represented his University in a contest against the rival University. The Oxford eight each year is clad in dark blue flannel coats and caps ; and the Oxford eleven who meet Cambridge at Lord's, and the nine athletes who are sent up to London as the 'first strings' to compete against Cambridge, have a like honour, although there is of course a slight difference which distinguishes the rowing, cricket, and athletic coats and caps, the oarsman. wearing a white badge of crossed cars, the cricketer a white crest, and the athlete a white laurel wreath upon the cap and the breast pocket of his coat. This hierarchy of coat-wearers doubtless causes wonderment to the astonished stranger, but those who, from experience in other parts of the kingdom, know how soon a genuine sport can be corrupted by greed and money-making considerations, cannot see anything but good in a system which makes the chief distinction something which cannot possibly foster any undesirable quality except perhaps a little harmless vanity.

To return to our athletes then, the Oxford or Cambridge runner looks forward, as the supreme goal of his ambition, to the right to wear a blue coat or cap. Only the winners of the nine events which are included in the programme of the InterUniversity meeting are awarded this honour, and those who run as 'second' or 'third' strings in London only hold the 'half-blue' - that is, they can wear blue trimming upon their jerseys and knickerbockers when running, but may not sport the blue coat or cap. With the conclusion of the University sports the athletic season closes at the Universities, and the ground is handed over to cricket until the following October.

It remains to speak of the organisation and management of the University athletic clubs. Generations of undergraduates come and go, and the President of one year is not in residence the next year. Neither at Oxford nor Cambridge then could the clubs be placed upon a sound and lasting basis without the assistance of some permanent official. Luckily for both. Cambridge and Oxford, they have been fortunate in this respect. 
in obtaining permanent treasurers. At Oxford, the old athlete, C. N. Jackson, tutor of Hertford College, has long and ably managed the business concerns of the O.U.A.C., while at Cambridge the popular Dean of Jesus, the Rev. E. H. Morgan, has long held a similar position with his club. With the exception, however, of the permanent treasurerships, the remaining offices of the University clubs are entirely managed by the undergraduates themselves. At the beginning of every October term at Oxford (and we believe at Cambridge a term earlier) a general meeting of the representatives of the college athletic clubs is called. One man attends from each college to give the vote of those he represents. At this general meeting a president, secretary, and four other committee-men are chosen from amongst the athletes who will not have passed their fourth year of residence before the next Inter-'Varsity sports, and will therefore still be eligible to compete against Cambridge. The president, secretary, treasurer, and committee manage the club affairs, fix the dates of sports, and choose the representatives for the Inter-'Varsity contests. The Oxford and Cambridge meeting in London is managed jointly by the committees of both clubs, each of them deriving a substantial addition to its income from the 'gate money' taken from the large crowd of old University men and others who never fail to attend the 'Inter-'Varsity Sports.'

To pass from the Universities to London. Here we find one club based almost upon the same lines as the University clubs, and, like them, doing excellent work in promoting the growth of a healthy amateurism in the metropolis, although of late years it has had far greater difficulties to contend with than are ever likely to befall the University clubs. The London Athletic Club was founded in $186_{3}$ under another title, but in I 866 took its present name. Like the Oxford and Cambridge clubs it first held its sports at the old Beaufort House Ground, and then moved in 1869 to the new ground of the A.A.C. at Lillie Bridge, where its meetings were held until 1876 , and it has now been for ten years upon its own ground at Stamford 
Bridge. The Amateur Athletic Club, which started with great prospects and seemed even more permanent than the L.A.C. in 1869 , when it opened its ground at Lillie Bridge as the head-quarters of English amateur athletics, gradually died a natural death, and now does not even exist in name. Up to I 880 the L.A.C. had an unbroken career of success, and, in fact, really became rather overgrown. The business of a club carried on by unpaid officials naturally must fall into the hands of one or two energetic men who carry it on with little interference from the rest of the committee. It can hardly be disputed that the method in which the membership of the L.A.C. was for several years thrown open to many who neither had any connection with nor took an interest in athletic pursuits, tended to dissipate the esprit de corps which is so vital to the well-being and success of a club. The rising generation of athletes began to betake themselves to the less important paper-chasing clubs, and even when they belonged to the L.A.C. as well as to other bodies most frequently ran under the names and colours of the smaller institutions to which they belonged. Such a sign might have warned the committee of the L.A.C. that the club was ceasing to cohere as it should. However, all went prosperously until about the year I880, when that rapid popularisation of sport began which, as we have seen before, has tended in some measure to withdraw the support of the paying classes from athletics to other pastimes. The business of attending to a large ground and pavilions and keeping them in order is expensive, and little assistance can now be obtained from gatemoney. The result was that when the L.A.C., in the autumn of $188_{3}$, suddenly lost its managing directors there was a debt of 1,000 . to be cleared off, as well as a ground, which was acquired under very onerous conditions, to be carried on. It speaks much for the vitality of the old club that it has stood the shock and still keeps its place at the head of the London athletic organisations. Last year, when the members subscribed a sufficient sum to clear off the greater part of the debt, the club was reorganised and registered (with leave to 
omit the word 'Limited') as a company under the Companies Acts, with a liability limited to a small guarantee by each member. It is not too much to say of the L.A.C. that in times gone past it collected, formed, and brought out all the athletic capabilities of the metropolis; and it would have been a bad day for genuine amateurism had the club failed to weather the storm of $\mathrm{I}_{88}$.

Besides the L.A.C. there are many paper-chasing clubs around London which cultivate flat-racing in addition, and may be considered as athletic clubs quite apart from their functions as promoters of cross-country racing. Two of these, the South London Harriers and the Blackheath Harriers, are old-established clubs, and the former owns a cinder-path of its own at Balham. All the paper-chasing clubs round London have a strong esprit de corps, which occasionally, we regret to observe, manifests itself in the expression of ill-will towards rivals. The L.A.C., however, occupies a different position from them all, having amongst its roll nearly all the leading London athletes of the last twenty years, and affording a centre and a ground for the meetings of most of the others.

There is little that need be said of the other clubs throughout the country which hold athletic meetings. Few of them are athletic clubs in the same sense of the word as the University clubs or the L.A.C. In a country district it is obviously out of the question for a club to exist upon athletics apart from other kinds of manly pastime. Neither Manchester, Liverpool, nor Birmingham has a club which owns a running ground and encourages athletic practice all the year round as does the leading London institution. In purely country districts the athletic meetings are promoted and managed by the local cricket, football, or paper-chasing club, or by a committee which is got together annually for the purpose of holding a meeting, and except for the purposes of that particular meeting has no corporate existence. Many of the large provincial towns, such as Huddersfield, have clubs with a permanent existence jointly devoted to cricket and athletics, as well as other sports, 
separate committees managing the different branches of sport. One of these clubs - the Huddersfield C. and A.C.-was, long before the London A.C. took a similar course, registered as a limited company with leave to omit the word 'Limited' from its name. These provincial clubs for combined athletic purposes are amongst the most flourishing and best-managed organisations in the kingdom, and perform excellent work in the cultivation and development of athletic energy.

The difficulties, then, which beset the path of a genuine amateur do not arise from want of material, but from the irruption into the amateur circle of men whose money-making propensities have gotten the better of their honesty. Thousands of men come annually from the Universities and public schools as well as from elsewhere, who could do nothing but good to themselves by competing in honest contests in running and jumping matches; but all present efforts have failed to separate from the genuine amateurs the class of those who take up athletics nominally as amateurs, but really as a means of livelihood. There are plenty of sheep and plenty of goats, and the questions which naturally arise are whether it is possible to separate them, and if so by what means; also, whether, if it be impossible to separate them, there are any means of preventing the decadence of athletic sports.

The genuine amateurs are all of one kind; they run because the exercising of their bodies gives them delight, and because, being Englishmen, they find it pleasant to have beaten an honest adversary in an honest competition. The summit of their ambition is to have met all comers and won a championship, or to have met all opponents from their club or district or from their University, or from the two Universities, and to have borne away the palm. The prizes they win are to be kept as trophies, and not to be parted with; and whether they care for handsome prizes much or little, their chief pleasure derived from the sport is the honour they have gained in their chosen pursuit. Let no one imagine we are drawing an ideal picture of the English athlete. There is a good deal 
of human nature in man, and there are very few runners, jumpers, or what not, who are above the temptations of winning a handsome prize. There have been plenty of genuine amateurs who have carried their love of 'pots' to an illegitimate extent, and have gone touring round the country to meetings at which they could not increase their reputation by winning, and which they have simply attended for pot-hunting purposes. These men, however, have won the prizes with the desire to ornament their homes with them, and not with the object of increasing their weekly stipends with the gains of athletics. Such are the sheep; but the goats are of various kinds. Some of them are men who run honestly enough on the whole, but as soon as they get a prize dispose of it promptly for what it will fetch ; and we fancy that silversmiths and dealers in fancy articles could, if examined before a Royal Commission upon athletics, make some strange disclosures as to the number and importance of this class. Such men soon degenerate into the other class, who find there is more to be made out of betting or 'squaring' a race than out of the prizes, and who therefore never run honestly if it pays them better to do otherwise. As for a championship with these gentry, it is not worth running for unless the 'market' can be worked, or unless the competitor meditates taking a public-house and trading upon the reputation of being an ex-champion. The number of these sham-amateurs is large, and it is a serious question whether it is possible to exclude them from the amateur fold.

At the time when amateurism first came into existence upon the running path, the amateurs, looking at the state of professional pedestrianism, were rather inclined to consider running for money as being a bad thing in itself. Whether there is anything degrading in the notion of a man gently bred running, or playing cricket or football, for money, is a wide subject which we do not care to discuss at present, and upon which public opinion would probably adopt more liberal views now than it did a quarter of a century ago. The line taken up 
by the earliest 'gentleman-amateurs' was, however, that it was degrading to run for money, and that amateur athletics should be confined to gentlemen. Possibly the eventual solution of the present problem will be a return to the old practice, and the gentlemen who run and jump in matches will be able to confine the amateur competitions in which they take part to their own class. Such social distinctions, however, are very hard to preserve anywhere, and particularly hard in sport, and the difficulties of defining an amateur are nothing compared to the difficulties of defining a gentleman. One thing is certain : the attempt to confine open competitions to gentleman-amateurs broke down. In the country especially, where the sports were promoted by the help of subscriptions from the neighbourhood, people naturally declined to see the money they subscribed devoted to prizes to be competed for solely by gentlemen, and the gradual stream of public opinion from 1870 to I 880 flowed steadily in the direction of allowing any one to compete for a prize, whatever his social position might be, provided he cared to run for prizes in preference to running for money like a professional 'ped.' The result has been as we have seen, that with the rapid extension of the athletic movement throughout the kingdom, a large number of those who in former times would have become professionals have turned amateurs because amateurism is more lucrative. Of this class it may be safely said that they will never abandon the amateur ranks until they find there is more money to be made as professionals. The recognition and encouragement of an honest and open professional athleticism throughout all districts of the country would be the best possible means of purging the amateur ranks of those who have no business to remain in them. As soon as the large number of the mechanic classes, who cannot afford to despise the money which they can make out of their athletic powers, find that it is just as lucrative and just as honourable to compete as professionals, they will cease to call themselves amateurs, and amateurism will be the better for their departure. 
As regards the lowest class of runners, be they professionals or amateurs, who run to the orders of their bookmakers, and win or lose races just as the monetary arrangements make it advisable, nothing can be done to drive these off the path but a vigilant exercise of power of disqualification, and a rigid suppression of all open betting upon the ground. Every sport which comes to the state of merely being a resource for betting will arrive eventually at a condition of rottenness which will make it the despair of a reformer; and if amateur athletics eventually get into the hands of the bookmakers, the sooner the sport ' goes under' the better.

If, therefore, amateur athletics are to be purged of their abuses, one can safely point to the direction which the reform must take. The suppression of betting upon the ground must be rigidly enforced at every meeting great or small, for if the runners are to become simply animals with so much 'money on them,' it cannot matter a straw whether the stake for which they run is money or a cup ; and, indeed, the running is much more likely to be honest with a money prize than with a cup which is not readily converted into money. Unless the runners are all genuine amateurs, running for honour and not for money, it is impossible when betting is rife to keep the sport pure, and the Amateur Athletic Association had better dissolve and cease its labours than try to stem a tide which will be too strong for it.

Granting, however, that betting can be suppressed or kept within reasonable limits, the movement to purify athletics from the sham amateurs must be in two directions. The real amateurs must try to encourage professionalism open and undisguised, for the establishment of recognised professional sports throughout the country would draw off from the quasi-amateur ranks those who take it up from interested motives. The other remedy is easier, and rests with the genuine amateurs themselves without requiring any assistance from the public patronage. The bon $\hat{a}$ fide gentleman-amateur must give up the idea of earning valuable prizes, and must take to the system of running for medals 
of little value, or to earn his 'colours,' as at the Universities, without any further reward.

In other sports, gentlemen are willing enough to toil and practise to gain honour alone. The cricketer plays assiduously for seasons, and is sufficiently rewarded by gaining a place in his county eleven, and athletics could be placed upon a sounder footing if there were more representative competitions which it would be recognised as an honour to win, or even to take part in, without any special stimulant. The body athletic has become corrupted by too much prosperity, and the proper method for its recovery is a severe course of ascetic training. When amateur athletics are again confined to men who show by their acts that they run for sport and not for gain, then the tide of public favour will flow back to them with full force, and athletes will have full honour in their own country.

We have purposely refrained during the writing of these chapters from rhapsodising upon the advantages of the cultivation of athletic excellence to the individual and the nation. In these days of endless writing, when many articles are indited which, like bad sermons, consist of a few texts largely diluted, it is usual to found all the possible praises of athletics upon two texts : the one from a classical source alluding to the necessary connection between mental and bodily soundness, and the other from a native source alluding to the connection between military excellence and playing fields. As no book upon athletics is considered complete without some allusion to these timehonoured friends, we have thus cursorily alluded to them at the end of our task, but have before preached no sermon upon these passages, for a very simple reason. We take it that at the present day it is but a waste of labour to demonstrate to Englishmen the advantages of manly sports, of hard exercise, and friendly competition. For the last five-and-twenty years the young men of England have flung themselves into the pursuit of hard bodily exercise and sporting competitions upon foot. The youth of the present day fresh from school, instead of spend- 
ing his leisure time in seeing cocks fight or terriers kill rats, goes off to the football or cricket field, to the river or the running path, and finds his recreation in the exercise of his own body. The result of a generation of athletic sport has made the nation stronger, manlier, cleaner, and more sober than it was before the pursuit of athletics became a national characteristic. When the athletic movement first came into full force it found vigorous opponents. Mr. Wilkie Collins in particular wrote a novel in which the wicked brother was an athlete-a heartless villain, without manners or brains, and the sworn companion of swindlers and sharpers ; while the virtuous brother, who detested hard exercise and played the fiddle, had every conceivable virtue of morals and intellect. The public was thrilled by the novel but not convinced by it, and with reason. If any one will take the trouble to study a school, a college, or any large body of men, he will find that the dozen best cricketers, footballers, or oarsmen will provide more clever scholars, andwhat is quite as important-more capable and better mannered men than any average dozen of the others ; and, indeed, it may safely be added that a dozen athletes will produce as many violinplayers as a dozen non-athletes. There may be, and doubtless are, plenty of strong hulking fellows in whom athletic propensities are joined with rough behaviour; but the manners of these are none the more rough because they have taken to athletics. Were there no field upon which their strength and spirits could be curbed and disciplined, it may safely be said that they would have been worse. No; the athletic movement has benefited the people at large. The lad or man who is a keen athlete is rarely mean, vicious, or a coward; the black sheep of the community are the loafers, and from a host of these a love of athletics has delivered England.

Other and graver objections are sometimes raised to the pursuit of athletics in individual cases. There are, no doubt, many instances of men who have undermined their health by too much training and competition, and there are doctors who shake their heads when they hear that their patient has been an 
athlete. Most athletes also know of a case here and there of a man breaking down or even dying in his prime under circumstances which at any rate point with some probability to a sport in which he indulged as the cause. We have already expressed our strong opinion that for many years a vicious habit of training was in force, and that even in the present day mer are inclined to overwork themselves in their practice. Every system has its victims until it is understood, and the men who have suffered loss of health from an overdose of athletics are men who have abused a blessing, and, in the name of health and exercise, have placed themselves under an absurd and unhealthy diet and have worn out their vigour by persistent overwork. The present writer is hardly one who by his practice and his preaching can be taken for an alarmist, but he feels constrained to end what he has to say upon athletics with an appeal to the votaries of the sport not to abuse a good system. The number of those who have gained health, strength, courage and character from the practice of one form or another of athletic exercise is legion, and to a statistician dealing with averages a victim more or less is of small concern ; but there is really no reason whatever why athletic sport properly conducted should have a single victim. When fervid athletes keep little boys from running in boys' races at public meetings, when school committees will put a stop to 'junior miles' and 'junior steeplechases,' and when 'twenty-four hour' races and go-as you-please competitions are no more heard of, athletics will be purged of some current evils. When going into training means nothing more than living a regular and healthy life, and the daily exercise is taken to increase the strength and skill, and not to see how much the human body can do without failing, then no one except by his own fault can suffer any harm from athletic sports. 


\section{LIST OF BEST PERFORMANCES ON RECORD BY AMATEURS}

\section{RUNNING}

\begin{tabular}{|c|c|c|c|c|c|}
\hline Distance & Name & Time & Place & & Date \\
\hline $\begin{array}{c}\text { Yards } \\
100 \\
120 \\
120 \\
120 \\
\\
150 \\
\end{array}$ & 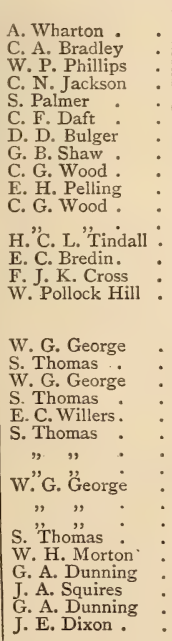 & 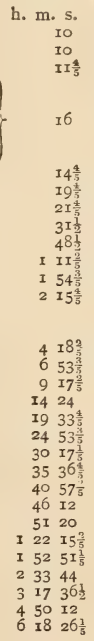 & $\begin{array}{l}\text { Stamford Bridge } \\
\text { Northampton. } \\
\text { Stamford Bridge } \\
\text { Cowley Ground, O } \\
\text { Lillie Bridge . } \\
\text { Stamford Bridge } \\
\text { ", ", } \\
\text { ", ", ", } \\
\text { ", ", } \\
\text { ", ", ", } \\
\text { Iffley Road,"Oxford } \\
\text { ", ", }\end{array}$ & 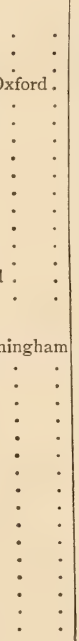 & 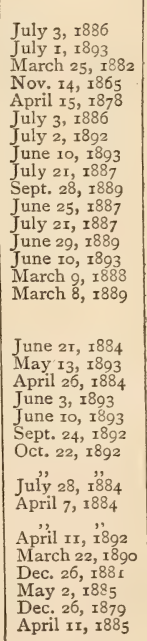 \\
\hline
\end{tabular}




\section{WALKING}

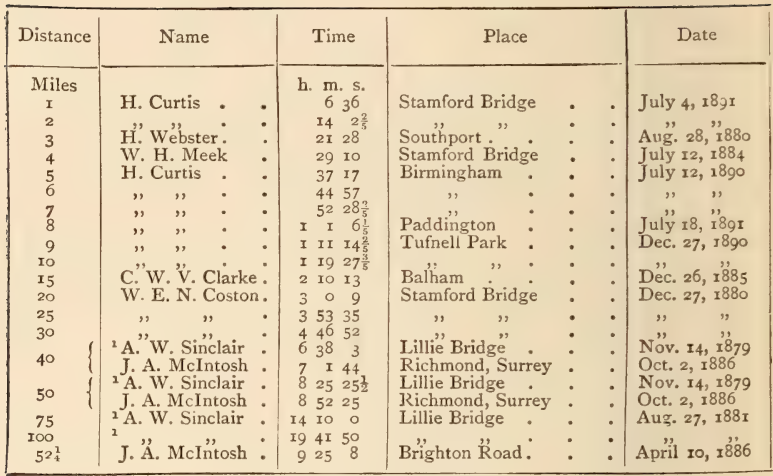

${ }^{2}$ In a Match against Time.

\section{ODD EVENTS}

\begin{tabular}{|c|c|c|c|c|c|}
\hline Event & Name & $\begin{array}{c}\text { Dis- } \\
\text { tance }\end{array}$ & Place & & Date \\
\hline $\begin{array}{l}\text { High Jump } \\
\text { Pole Jump } \\
\text { Long Jump } \\
\text { Putting the Shot (i } 6 \mathrm{lb} \text {.) } \\
\text { Throwing the Hammer } \\
\text { ( } 6 \text { lb.) from a } 9 \mathrm{ft} \text {, circle }\end{array}$ & $\begin{array}{l}\text { W. B. Page } \\
\text { R. D. Dickinson } \\
\text { C. B. Fry } \\
\text { G. R. Gray } \\
\text { W. J. M. Barry }\end{array}$ & \begin{tabular}{rl}
\multicolumn{2}{|c}{ ft. in. } \\
6 & $3 \frac{1}{4}$ \\
$\mathbf{1 1}$ & 9 \\
23 & $6 \frac{1}{2}$ \\
44 & 9 \\
134 & 7
\end{tabular} & $\begin{array}{l}\text { Stourbridge : } \\
\text { Kidderminster } \\
\text { Oxford : } \\
\text { Dublin : } \\
\text { Manchester : }\end{array}$ & : & $\begin{array}{l}\text { Aug. } 15,1887 \\
\text { July 4, } 1891 \\
\text { March 4, 1893 } \\
\text { July } 7,1888 \\
\text { July } 23,1892\end{array}$ \\
\hline
\end{tabular}




\section{PAPER-CHASING}

AND

\section{CROSS-COUNTRY RUNNING}

BY

WALTER RYE,

President, Thames Hare and Hounds 



\section{PAPER-CHASING AND CROSS-COUNTRY RUNNING.}

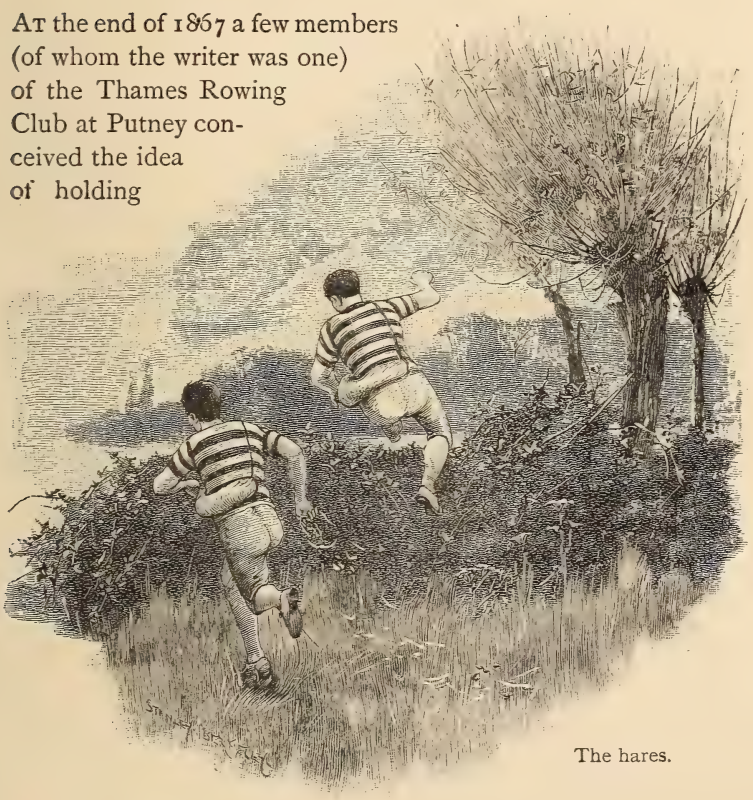

some cross-country steeplechases during the winter season, with the idea of keeping themselves more or less in condition until rowing began again. As may well be imagined, the 
arrangements of Thames Handicap Steeplechase No. I, as it was called, were primitive in the extreme, and, indeed, the whole affair was treated more as a joke than anything else. The competitors were taken up to the starting place on Wimbledon Common-the edge of the Beverley Brook by the bridge in a bus, and had to dress how they could, and the race was run in the dark over about $2 \frac{1}{4}$ miles of the roughest and boggiest part of the Common, then very different indeed, as to its surface, from what it has now become after recent drainage. Still, there were a dozen starters out of twenty entries, and the affair being the first cross-country steeplechase (not being at a school) that had ever taken place, attracted much attention in the athletic world, which was then getting fairly sure of its foundation after its five years of actual existence.

The next race was made an open event, and attracted over fifty entries and twenty-four starters, the scratch man being W. M. Chinnery, who did not, however, come to the post, though he afterwards ran regularly with us. Considerable interest was felt in this race, from the fact that two or three old public schoolboys took part in it, and notably Hawtrey of Eton, Rugby and Marlborough also sending representatives; but, as at most other sports, the native Cockney proved equal to the occasion, ${ }^{1}$ and early training did not have the effect of showing any superiority in the old boys over the Londoners.

The race was one of the finest ever seen, eight men being together at the cross roads -300 yards from home-King beating Webster by little over a yard, while Chappell, fifteen yards off, was only half a yard in front of Hawtrey. The fine finish was no doubt due to the men not knowing how fast they could go, and so massing together; for the winner took I2.55 for $2 \frac{1}{4}$ miles of easy country, which will not for a moment bear comparison with the times of to-day.

1 Foreigners do not seem to take to the game kindly, and Karoniare, the full-blood Indian, who came over with the La Crosse team, was beaten fairly and squarely by C. H. Mason, then our crack runner. 
Next winter (1868) it was thought that, as a good many men who were fond of cross-country running had been got together by these steeplechases, there was no reason why they should not try whether paper-chasing proper would not succeed as well among men as among boys. The graphic description of the Barby Hill run by Mr. T. Hughes in 'Tom Brown's Schooldays' had long been before the eyes of paper-chasers, and as he had taken a kindly interest in our movement, and had come down and judged T.H.S. No. 2 for us, there was an additional reason why we should try ; though when the writer started the idea, he never thought that the new sport would spread as it has done (roughly speaking, there are now quite thirty clubs in London alone), nor that we should ever have among our members two old Rugbeians, who had both held the records over the Crick and the Barby Hill run, although, singularly enough, neither of them was able to make a record over either of our courses.

Our first run took place on October $\mathrm{x} 7, \mathrm{I} 868$, from the King's Head, Roehampton, then, as it still is, our headquarters, and the beau ideal in many respects of a paper-chaser's home, being a quaint old wooden-built inn, squatted behind a great wych elm, covered with creepers, and in the middle of real open country. We had secured the written leave of Earl Spencer, who then owned Wimbledon Common, to run over it, and still claim to be the only club who can drop paper over the heath, as having the right before there were such things as conservators and their bye-laws, and all existing rights were saved by the Act.

Among our first visitors were two well-known Cambridge athletes-G. G. Kennedy, now one of the metropolitan police magistrates, and the late J. G. Chambers.

We were not long before our success brought imitators, but they were not very successful at first, for the country they chose was not at all adapted for cross-country running, the Peckham A.A.C., which was the second club, not finding much open land round about Peckham Rye, and having 
chiefly to confine themselves to path-work. They have now, by circumstances not unlike those which befell the Irishman's knife, come to be known as the Blackheath Harriers, and have a pretty country, a large number of members under a very energetic management, and are by descent the second oldest English paper-chase club. They and the South London Harriers, the next best known club running south of the Thames (between the two a ceaseless feud has always existed), suffered much from the undisciplined zeal of early secretaries, who, not having the faintest knowledge of the ' language of the fields,' used to make themselves supremely ridiculous in the eyes of those who had by the constant use of such words as 'saplings,' while referring to young harriers, and so on, being obviously ignorant of their real meaning.

In the north of London the Spartan Harriers long reigned supreme, but lost their ablest man both as a runner and a secretary when H. M. Oliver left for Birmingham. His advent there, where he was received with open arms, had the result of starting, or rather greatly pushing forward, paperchasing in the Midlands. Whether his administrative ability operated for the general benefit of the sport is, however, an open question among those who know anything of the subject, the general impression being that the eagerness with which men are caught up into clubs and imported into crack teams has spoiled the old feeling of bonâ fide competition. Still, as trained teams are mostly composed of men in the same social position as professional cricket and football players, there is no doubt that teams such as the Moseley or Birchfield Harriers are not often beaten, especially by gentlemen teams who do not go away to train and who pay their own expenses.

There had been matches between teams of various clubs before 1876 (the T. $H$. and $H$. had two matches with the Gentlemen of Hampstead in November 1870), but it was not till this year that the first real championship race was started, though 
the attempt to bring it off in the wilds of Epping Forest proved a great failure, everyone losing his way separately on his own account. Next year a carefully laid out course was chosen, from Roehampton over the Common by Merton and Morden, West Barnes and Crooked Billet home, about I $1 \frac{3}{4}$ miles. The T. H. and $H$. won the first time, scoring 35 as against the S. L. H. 58, and the Spartans 94 ; but the last named club turned the tables on the others the next year. P. H. Stenning of the Thames, who finished actually first of all starters in 1877,1878 , I 879, and I880, has run the course in 68 minutes-considerably better than ten miles an hour all the way, up hill and down dale.

In 1879 the Thames were lucky again, but in I880 had to go down before a very well trained, if rough, team of the Birchfield Harriers. In I88I (when no fewer than I05 ran) the Moseley Harriers came up for the first time, and beat the holders easily, and the next year exactly repeated the performance. Since then the affair has degenerated into a gate-money meeting held on enclosed grounds, and forms the nedium of heavy betting and little sport, the change having been effected chiefly at the instance of the countrymen and their allies, ostensibly because they wanted a 'rougher, more open country,' but really because they wanted to take the management of the meeting from its original promoters, who would have nothing to do with gate and betting.

Some day, when the loathsomeness of the roping and betting has disgusted the better class of runners, a championship, in which gentlemen can take part without loss of self-respect, will probably be again instituted on the old lines. But betting must be literally stamped out, and the prizes made quite nominal before we can see who runs for the sport, and who for the profit. Meanwhile nearly all the clubs (except the oldest) belong either to the Northern, the Midland, or the Southern Counties C.C. Association, which are supposed to govern their members by the A.A.A. rules, but which all are either unwilling or unable to stop the abuses of betting and team 
concoction, which have much injured the pastime in the eyes of real sportsmen.

The system of scoring in matches is, that the order of arriva! of the different men is taken, and the club that scores the lowest aggregate wins. This certainly ensures that the best average team has the best chance, but it is possible that a club which scores, say, the Ist, 2nd, 3 rd, $4^{\text {th }}$ and $5^{\text {th }}$ men in, but whose 6 th man does not reach home earlier than 40 th, may be beaten by a team which has men finish 6 th, 7 th, 8 th, 9th, roth and IIth. Thus

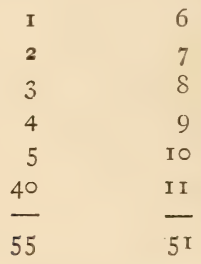

The only really fair way is that which was suggested six years: ago, viz., taking the aggregate times of the first six men of each team. But perhaps this would be too much strain on the observant powers of the judges, who have plenty of room to muddle and mistake in the plain placing of the men without attempting to take each individual man's time as well.

The stock-in-trade necessary to start a paper-chase club is small. A long sausage-shaped canvas bag slung over each hare's right shoulder, with an open mouth under the left arm where the head and tail of the bag are hooked together (the hare looking as though he had a soldier's rolled greatcoat on his back), holds a quantity of torn or cut paper-the latter (bookbinder's cuttings 6 or $8 \mathrm{in}$. long are best) shakes down to the mouth of the bag as the hare runs. A small handful should be dropped by one or other of the hares every twenty yards or so. Whenever the country gives an opportunity, a 'false' scent should be laid, e.g. at cross roads. An artful hare will often drop his 'false' faintly only and lay his real scent strong and 
clear, most of the hounds rushing to the conclusion that he is trying to take them in, and that it is very unlikely that he would, when the scents bifurcate, give a good one on the real track. One hare will often take a false straight up a ploughed field over the brow of a hill, so that it is impossible for the hounds to see its cessation without following it to the bitter end. Then they have to retrace it carefully till one, more sharp-sighted than the others, will see a tiny handful behind a tree, and the real scent will be traceable, probably up a dry ditch or on the further side of a hedgerow.

It is hardly necessary to say that unless one hare is a vastly better runner than the other (in which case he takes all the falses, thereby giving his slower companion welcome rests) the hares lay the falses alternately, the layer, when he ceases his deception, cutting across to join the real scent at the most convenient angle. In very long runs, two bags of scent will not suffice, and spare bags are sent on by trap or otherwise. The law given varies from ten minutes to a quarter of an hour. When the country is fairly enclosed even less will be enough, but in an open country in which the hares can be seen afar off at least ten minutes should be given, for if the hounds run the hares to sight the recognised rule is that they need no longer keep to the trail. When the hares have got rid of all their scent they should lay their empty bags at the end of the trail and make for home the best way they can, the hounds being at liberty to do the same when they reach and pick up the bags. Sometimes all the pack is not sent off at one time, it being divided into slow and fast divisions started five or ten minutes apart. There are, however, several objections to this, for the slow pack has to puzzle out the falses and do all the hunting for perhaps half the journey, and in the great majority of cases are then caught by the fast pack, who have simply been running them to sight. The real sport of slow paper-chasing used to be the hunting and jumping, but it would be safe to say that there is not a single pack (not even excepting the oldest club) that knows how to hunt in the systematic way of nearly 
twenty years ago. Then, as soon as 'no scent' was called the hounds spread out ten yards apart in a fanlike form and swept every yard of ground till it was recovered, but now much is left to chance.

Hares are very seldom caught by the hounds, and never if they know the rudiments of 'false' laying, for a hound must be lucky indeed if he has not to go a mile or so more than the hares in a moderately long run.

The distance run varies much, and usually consists of a ring of eight to ten miles from the club-house, which is generally an old-fashioned suburban inn. Some clubs go much less, and there is a standing joke that no member of one well-known club had ever been seen off an equally weli-known common of about two miles square, till one of them was found roaming about disconsolately quite lost three miles from home. The longest run we remember was round Ewell and Epsom and half-a-dozen other villages, about twenty-four miles. J. Scott finished first in a little over three hours.

Hares and hound alike should run in the colours of their club. Canvas shoes with india-rubber soles, worsted socks, flannel knickerbockers, and white or dark blue watermen's sweaters are the best things to wear in the winter, for if a brook has to be forded or a river swum the warm wet wool prevents any chill being taken in the coldest weather, and those who have tried it are aware that it is cold after sunset running over two miles of heath, fagged out, in wet things. On no account, however tired, should the runner walk more than a few yards at a time, but go on home at a jog-trot, however slow. We remember a narrow escape from very serious results when a runner, far from home, sat down in a dry ditch to rest. Had he not been picked up and dosed with hot drink, and rubbed till his skin came off, the consequences might have been grave indeed, for his hands and arms were 'dead' up to the armpits. We can, however, speak from an experience now covering nearly twenty years, and can positively say that we know of no man of the hundreds with whom we have been acquainted who 


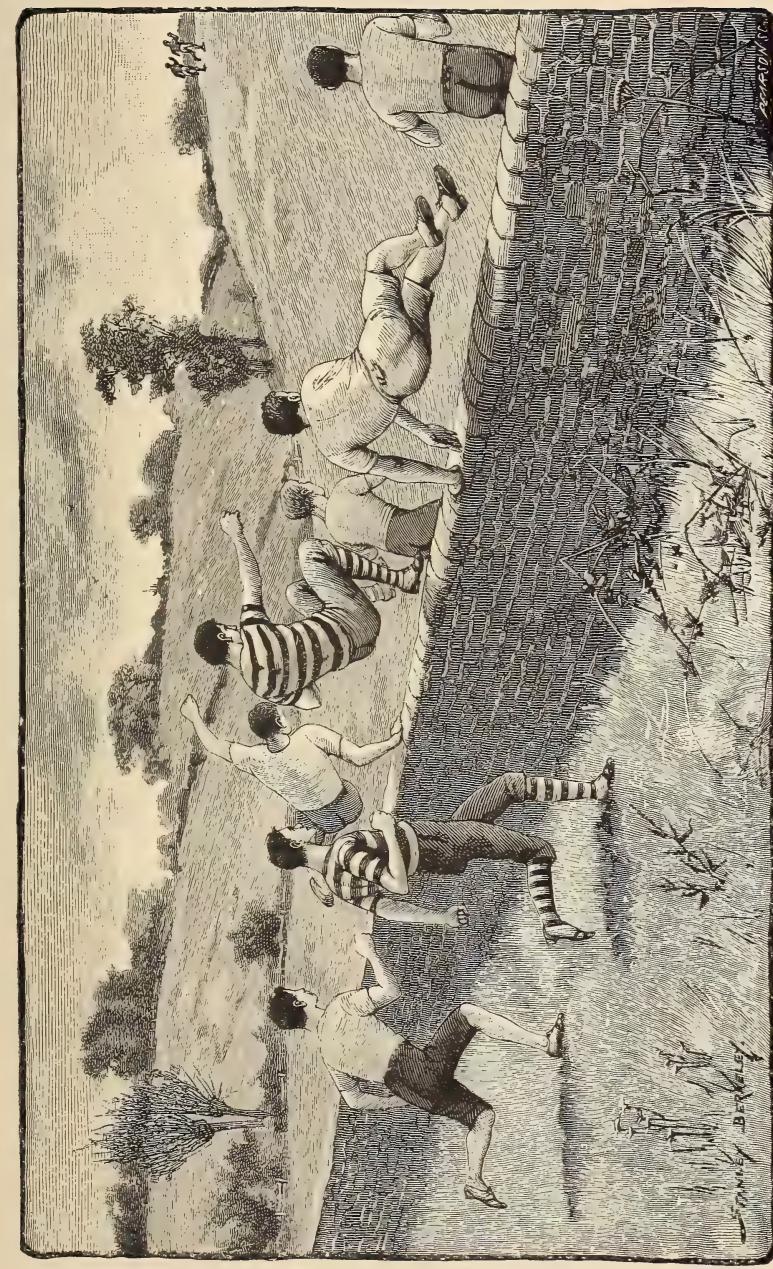



has been injured by distance running, and the rate of mortality among running men is singularly small.

Hounds should be strongly cautioned against 'larking' over unnecessary jumps or doing the least avoidable damage. Farmers are mortal, and are therefore generally fond of sport, and if no great damage is done and if what is done is cheerfully and voluntarily paid for, will generally let a moderately sized pack cross their land; but near London monster packs of thirty or forty runners become a nuisance. Like hunting the scent, jumping for the sake of jumping is dying out a great deal. We have no fine jumpers nowadays, like the two Burts who learnt the art at Wellington and would take every gate through a long run, or A. P. Smith who would jump at anything, or tricky jumpers like Bentley, who used to land with both feet on the top of a five-barred gate with a clatter and a rattle, and jump off the top far into the next field.

In fact, jumping does not pay in the cross-country racing which has to a great extent supplanted the old paper-chasing proper, for it takes too much out of a man. The new class of men get over the ground wonderfully fast and can scramble and 'jump up anywhere,' but do not aspire to jump over obstacles. Still they are so handy in a very cramped grass country with plenty of difficult wood-grown banks and thick hedges, that a picked team of runners would take the conceit out of most riders to hounds.

When the run is over, the tub-lukewarm if it can be had -is in universal request, followed, if possible, by a cold douche by means of a bucketful of water from the hands of a stable. helper. If the run has been extra wet or cold, a steaming glass of port negus may be wisely taken as a precaution; but it is a singular thing that both before and after the meal which terminates the evening, 'ginger beer and gin' is the favourite drink, having probably been found by long experience to best carry off the extra heat of the body caused by a long run. While on the subject, we may say that though many of our best shortdistance runners were actually teetotallers, e.g. J. C. Clegg, 
J. Shearman, and others, we have only known one abstainer (Coad) who was anywhere in the first flight of cross-country runners. The tea, which is usually followed by a formal meeting ' and a 'sing-song,' used to close the evening very pleasantly. Too often, nowadays, however, the card-playing which has spoiled and ruined so many a young athlete is introduced by a selfish few, who are not satisfied with simple sociability. The round game of spelling-bee, in which the sport is to close a word as soon as possible against your left-hand neighbour, is, however, very popular, and may be said to have originated at Roehampton. With a room full of athletes, friendly chaff often leads to matches, and two or three times we remember offhand races coming off late at night, one especially of sixteen miles (twice round the Thames long course), which resulted in the scratch man coming to the front about 300 yards only from home, and both men reaching the goal smcthered with mud and bleeding from innumerable scratches.

Of the use of paper-chasing and, in moderation, of crosscountry steeplechasing and team racing, there can be no doubt. To be a good runner over country, a man must be abstemious, patient, and good-tempered. A sprinter may indulge up to a certain point both in smoke and drink, but woe betide the ordinary long-distance runner who takes too much of one or the other before a hard race. Stenning was an example to the contrary, for he seldom had a pipe out of his mouth when he finished first for four consecutive years, but he was an exception that proved the rule, and nobody knows what he might have done had he not smoked. He was also very fond of all sorts of pastry, which cannot be recommended to runners as a rule. That cross-country work has heightened the standard of long-distance running immensely is certain, for not only are all times from two miles up much faster than of yore, but they have all been made by men who are notoriously cross-country runners ; in fact, it would be hard to find a man in the first flight who is not a member of some paper-chase club or another. Of late

1 For the election of new members, and other business. 
years Gibb, George, Rogers, and Coad are brilliant examples of the truth of this statement.

It is probably no exaggeration to say, that a hundred men could now be found in paper-chase clubs who could run ten miles in the hour, and a score who could run eleven. How valuable such a body of men would be in time of war for scouts or messengers need hardly be explained, and even when war is not imminent they have their uses.

The future of paper-chasing is doubtful. The evils of importing members solely to run in match teams, of running matches round enclosed courses for gate-money, and of winking at, if not tolerating, regular betting by lists, have taken firm root, and have injured it greatly as a sport. The mechanic, artisan, or labourer, who used to be barred from competition with gentlemen, is now not only allowed to run, but, if fast, is a welcome member of all country, and many London, clubs, there being only one which insists on all its members being gentlemen by profession and education. If cricket recognises class distinction, why should not paper-chasing? The bricklayer or carpenter who can do 'thirty under' for a mile, and to whom 20l. is a mine of wealth, is too apt to accept that sum from a bookmaker not to try at the 'Championship.' Roping is too often overlooked, and treated more as a joke than anything else. Another feature which has tended to lower the sport, is the ridiculous number of prizes given in steeplechases, and the 'pewters' and medals presented to the first men in, or first bicyclist in, and so on, in ordinary runs. Men ought to take enough interest in the sport, for the sport's sake, to come down and run without these paltry bribes. If they do not care for sport only, let them stop aray. The explanation of all this is, that the management of many of the clubs has got into the hands of men who have had no practical experience of the sport, and who simply run them as athletic rather than cross-country clubs, for the sake of the popularity or prestige which is supposed to attach to the officials of an athletic club, though they may have been outsiders or duffers and be in 
no way in touch with the real wants and feelings of genuine athletes. The snobbery, too, of touting for the use of the names of local celebrities, M.P's. and so on (who neither know anything of, nor care anything for, the sport), as presidents, vicepresidents, and so on, and the degradation of accepting challenge cups from the publicans at whose houses the clubs meet, have greatly tended to bring the sport into disrepute. 
FOOTBALL 



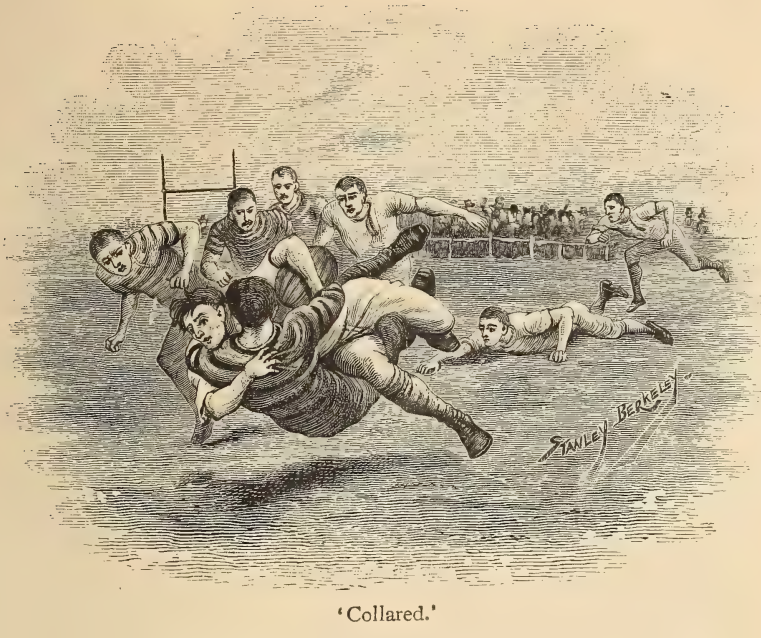

\section{CHAPTER I.}

\section{HISTORY.}

THE game of football is undoubtedly the oldest of all the English national sports. For at least six centuries the people have loved the rush and struggle of the rude and manly game, and kings with their edicts, divines with their sermons, scholars with their cultured scorn, and wits with their ridicule have failed to keep the people away from the pastime they enjoyed. Cricket may at times have excited greater interest amongst the leisured classes ; boat-races may have drawn larger crowds of spectators from distant places; but football, which flourished for centuries before the arts of boatıng or cricketing were known, may fairly claim to be not only the oldest and the most characteristic, but the most essentially popular sport of England. Football has now developed into a variety of highly 
organised games, and the difficulty of finding its actual origin is as great as that of discovering the commencement of athletic contests. If men have run races ever since the creation, it may almost be said that they have played at ball since the same date. Of all the games of ball in which Englishmen are naturally so proficient the original requisites were simply a ball and a club ; from the simple use of the ball alone came the 'caitch,' fives or hand-ball and football, and when to these requisites a club is added we find all the elements for tennis, cricket, hockey, golf, croquet, and the like. As balls and clubs are provided with the slightest exercise of skill and trouble from the resources of nature, we may be certain upon abstract reasoning that ballplay became popular as soon as the aboriginal man had time and leisure to amuse himself.

It is scarcely necessary to say that the Greeks and Romans both played at ball; even as early as the days of the Odyssey we find Nausicaa and her maidens 'playing at the caitch,' as King James I. would have termed it. TWhat is perhaps of more importance is that the Greeks had a game in which the kind of ball known as the $\alpha \rho \pi \alpha \sigma \tau$ ò $\nu$ was employed, and this game bore a rough resemblance to football in England. The players of one side had to carry the ball over a line defended by the other, by any means in their power. The $\alpha \rho \pi \alpha \sigma \tau o ̀ v$ was, as its name betokens, a small ball. The Romans, however, had another pastime with a large inflated ball, the follis; with which, as many of our readers will recollect, Martial the epigrammatist advises all to play.

Folle decet pueros ludere, folle senes.

The follis, however, was undoubtedly a handball, and the game was probably the same as the 'balown ball' of the middle ages, which consisted in simply striking into the air and 'keeping up' a large windy ball, a sport which is still to be seen exhibited with great skill in Paris. All this, however, has little concern with football, except that it is pretty clear that the 'follis' or 'baloon ball' was the same that is used in the game of football, and it is a matter of some importance 
to discover whether football is merely a game brought by Roman civilisation into Britain, or a native product. It is hardly to be believed that it should never have occurred to a man playing with the 'follis,' to kick it with his foot when his arms were tired, but be that as it may, we know of no mention of a game played by the Romans where the feet were used to kick the ball, and of the game known from the middle ages to the present time as football no trace can be found in any country but our own.

Before we come to a definite record relating to football, it may perhaps be worth while to point out that the legends connected with football at some of its chief centres point to its immense antiquity. At Chester, where hundreds of years ago the people played on the Roodee on Shrove Tuesday, the contemporary chroniclers state that the first ball used was the head of a Dane who had been captured and slain and whose head was kicked about for sport. At Derby, where (also on Shrove Tuesday) the celebrated match of which we shall have to speak later on was played for centuries, there was a legend (as stated in Glover's 'History of Derby') that the game was a memorial of a victory over the Romans in the third century. The free quarrymen of the Isle of Purbeck commemorate the original grant of their rights at a time beyond that within legal memory by kicking a football over the ground they claim. These and other signs, apart from any written record, would be sufficient to show the antiquity of the sport.

FitzStephen, who wrote in the twelfth century, and to whom we have referred in the former part of this work, makes an allusion to a game which there is very little doubt must be football. He says that the boys 'annually upon Shrove Tuesday go into the fields and play at the wellknown game of ball' (ludum pila celebrem). The words are of course vague, but they undoubtedly refer to one special game and not to general playing with balls, and no other game of ball is ever known to have been specially connected with Shrove Tuesday, which there is abundant material to show was afterwards the great 'football, day' in England for centuries. 
There is also ample proof of the fondness of the London boy's and 'prentices for football in succeeding centuries, which makes the inference irresistible that by 'Iudum pilce celebrem,' the writer refers to football. It is also noticeable that FitzStephen probably refrains from describing the game because it was too well known throughout the country to require a description.

By the reign of Edward II. we find not only that football was popular in London, but that so many people joined in the game when it was being played in the streets that peaceable merchants had to request the king to put down its practice. Accordingly, in I3I4, Edward II., on April I3, issued a proclamation forbidding the game as leading to a breach of the peace : "Forasmuch as there is great noise in the city caused by hustling over large balls (rageries de grosses pelotes) . . . from which many evils might arise which God forbid : we command and forbid on behalf of the king, on pain of imprisonment, such game to be used in the city in future.' We believe the expression 'rageries de grosses pelotes ' has puzzled many antiquarians, possibly because they were not football players, but a footballer can hardly help surmising that 'rageries' means 'scrummages,' and 'grosses pelotes' footballs. As football acquired royal animadversion as early as I3I4, it would seem that the early footballers played no less vigorously, if with less courtesy, than the players of the present day.

There can be no doubt that from the earliest days football was an obstreperous and disreputable member of the family of British Sports, and indeed almost an 'habitual criminal' in its character, a fact to which we owe most of the earliest references to the game, as many of these records refer to little else but crimes and grievances. In I 349 football is mentioned by its present name in a statute of Edward III., who objected to the game not so much for itself, but as tending to discourage the practice of shooting, upon which the military strength of England largely depended. The King writing in that year to the Sheriffs of London, says that 'the skill at 
shooting with arrows was almost totally laid aside for the purpose of various useless and unlawful games,' and the Sheriffs are thereupon commanded to suppress 'such idle practices.' The injunction can hardly have been of much avail, however, for forty years afterwards Richard II. passed a similar statute (I2 Rich. II. c. 6. A.D. I389) forbidding throughout the kingdom 'all playing at tennise, football, and other games called corts, dice, casting of the stone, kailes, and other such importune games.' The same statute had to be re-enacted by Henry IV. in I 4 or, so that it is tolerably obvious that, like some other statutes still in force and relating to sporting matters, it was more honoured in the breach than in the observance. Football was evidently too strong for the House of Lancaster, and all attempts to coerce the merry Englishman into giving it up were hopeless failures. Similar measures in Scotland in the next century altogether failed to persuade the Scottish sportsmen to give up football and golf. In I457 James III. decreed that four times every year reviews and displays of weapons were to be held, and 'footballe and golfe be utterly cryed down and not to be used;' but as in I $49 \mathrm{r}$ his successor had again to prohibit golf and football by a fresh statute providing that 'in na place of this realme ther be used futeball, golfe, or other sik unprofitable sportes,' it appears that in Scotland as well as in England football was strong enough to defy the law. In the sixteenth century the House of Tudor again tried to do what the House of Lancaster had failed in doing, and Henry VIII. not only reenacted the old statute against cards, dice, and other 'importune games,' but rendered it a penal offence by statute for anybody to keep a house or ground devoted to these sporting purposes. The English people, however, both in town and country would have their football, and throughout the sixteenth century football was as popular a pastime amongst the lower orders as it has ever been before or since. The game was fiercely attacked, as some of the succeeding extracts will show, and the same extracts will suggest that the nature of the game played at that period rendered the attacks not altogether unreasonable. In 
1508 , Barclay in his fifth eclogue affords evidence that football was as popular in the country as in the town. Says Barclay

The sturdie plowman, lustie, strong, and bold, Overcometh the winter with driving the foote-ball, Forgetting labour and many a grievous fall.

Not long after this, Sir Thomas Elyot in his 'Boke, cailed the Governour,' inveighs against football, as being unfit for gentlemen owing to the violence with which it was played. Sir Thomas, however, had a courtly hatred of anything energetic : he prefers archery to tennis ; 'boulynge,' 'claishe' and 'pinnes' (skittles), and 'koyting' he calls 'fur:ous,' and the following remarks therefore about skittles, quoits and football, are only such as one would expect. 'Verilie,' he says, 'as for two the laste' (i.e. 'pinnes' and 'koyting ') 'be to be utterly abjected of all noble men in like wise foote-balle wherein is nothing but beastlie furie and exstreme violence whereof procedeth hurte, and consequently rancour and malice do remain with them that be wounded, wherfore it is to be put in perpetual silence.' Doubtless 'hurte procedeth' from football upon occasions, but if there had been 'nothing in' football but beastly fury, it would hardly have held its own so bravely to the present time. Sir Thomas Elyot had some foundation for his strictures, as the coroner's records of the day show; but before we proceed to give these, we should describe in some sort the nature of the game as it was played in the sixteenth century. There is no trace in ancient times of anything like the modern 'Assuciation game,' where the players only kick the ball and may not strike it with their hands, throw it or run with it. Probably the name 'football' was first used to describe the ball itself, and meant a ball which was big enough to be kicked and could be kicked with the foot. The game of football was the game played with this kind of ball, and it was simple to an extreme degree. The goals were two bushes, posts, houses, or any objects fixed upon at any distance apart from a few score yards to a few miles. The ball was placed mid-way between the two goals at starting, the players (of any number) 
civided into two sides, and it was the business of either side to get the ball by force or strategy up to or through the goal of the opposite side. Then confined to a street, or field of play, it is obvious that the sport was the original form of what is now known as the Rugby Union game. At the times before any settled rules of play were known, and before football had been civilised, the game must of necessity have been a very rough one, and an unfriendly critic may well have thought that the ball had very little to do with the game, just as the proverbial Frenchman is unable to see what the fox has to do with fox-hunting. Undoubtedly the game of football was until quite recent times a vulgar and unfashionable sport, as indeed were cricket, boat-racing, and most other athletic pastimes. For many centuries in England any pedestrian sport which was not immediately connected with knightly skill was considered unworthy of a gentleman of equestrian rank, and this will account in a great measure for the adverse criticisms of football which proceed from writers of aristocratic position.

That Elizabethan football was dangerous to life, limb, and property, is made plain by many records. The Middlesex County Records contain several entries which are of interest to the historian of football, and show how rough was the game. In the eighteenth year of the reign of good Queen Bess, the grand jury of the county found a true bill

That on the said Day at Ruyslippe, Co. Midd., Arthur Reynolds, husbandman [with five others], all of Ruyslippe afsd, Thomas Darcye, of Woxbridge, yeoman [with seven others, four of whom were 'husbandmen,' one a 'taylor,' one a 'harnis-maker,' one a 'yoman'], all seven of Woxbridge afsd, with unknown malefactors to the number of one hundred assembled themselves unlawfully and playd a certain unlawful game called foote-ball, by means of which unlawful game there was amongst them a great affray likely to result in homicides and serious accidents.

In the 23 rd year of Elizabeth, on March 5 th, football seems to have led to something more serious than a breach of the peace. 
Coroner's inquisition-post-mortem taken at Sowthemyms, Co. Midd., in view of the body of Roger Ludforde, yoman there lying dead with verdict of jurors that Nicholas Martyn and Richard Turvey, both late of Southemyms, yomen, were on the 3rd instant between 3 and 4 P.M. playing with other persons at foote-ball in the field called Evanses field at Southmyms, when the said Roger Ludford and a certain Simon Maltus, of the sd parish, yomen, came to the ground, and that Roger Ludford cried out, 'Cast hym over the hedge,' indicating that he meant Nicholas Martyn, who replied, 'Come thou and do yt.' That thereupon Roger Ludforde ran towards the ball with the intention to kick it, whereupon Nicholas Martyn with the fore-part of his right arm and Richard Turvey with the fore-part of his left arm struck Roger Ludforde on the fore-part of the body under the breast, giving him a mortal blow and concussion of which he died within a quarter of an hour, and that Nicholas and Richard in this manner feloniously slew the said Roger.

Some years later, the Manchester Lete Roll contains a resolution, dated October I2, I608:-

That whereas there hath been heretofore great disorder in our towne of Manchester, and the inhabitants thereof greatly wronged and charged with makinge and amendinge of their glasse windows broken yearelye and spoyled by a companye of lewd and disordered psons vsing that unlawfull exercise of playinge with the ffote-ball in ye streets of ye sd toune breakinge many men's windowes and glasse at their plesures and other great enormyties. Therefore, wee of this jurye doe order that no manner of psons hereafter shall play or use the footeball in any street within the said toune of Manchester, subpœnd to evye one that shall so use the same for evye time xiid.

These extracts not only show that the number of players was unlimited, but that the game was played in the street and over hedges in the country, although it was still unlawful by statute. It is hardly to be wondered at that the citizens of great towns objected to promiscuous scrimmaging in the streets in front of their windows. The records of the Corporation of the City of London contain two entries in the time of Elizabeth, (November $27, I_{572}$, and November $7, x_{5} 81$ ), of a proclamation having been made that 'no foteballe play be used or suffered 
within the City of London and the liberties thereof upon pain of imprisonment.' In spite of this, however, we still hear in later times of football in the streets.

The great week of sports and pageants at Kenilworth, in 1575, produced no football-playing, for Elizabeth and her court seem to have cared little for the athletic sports of the people; but there is a casual reference to football in the description of the Kenilworth revels in Robert Laneham's letter. One of the characters who appeared in the 'country brideale,' and 'running at the quintain,' and who took the part of the bridegroom, is described by Laneham as being 'lame of a legge that in his youth was broken at footballe.'

It was only to be expected that the grave and demure Puritans, who objected to all sports not only for themselves, but because they were played on Sundays, should have a particular and violent objection to football, for football even when played on a week-day does not seem to be wholly compatible with a meek and chastened spirit. The strictures passed by Stubbes, the earnest author of the 'Anatomie of Abuses in the Realme of England,' show pretty clearly the Puritan attitude towards football. Amongst other reasons for concluding that the end of the world was at hand in $I_{5} S_{3}$, he gives the convincing reason that 'football playing and other develishe pastimes' were practised on the Sabbath day. As we have seen before, he speaks of 'cards, dice, tennise, and bowles, and such like fooleries.' Football, however, he must have thought something worse than mere foolery, since he calls it 'develishe.' $\mathrm{He}$ goes on :-

I.ord, remove these exercises from the Sabaoth [by which he meant Sunday]. Any exercise (he says) which withdraweth from godliness, either upon the Sabaoth or any other day, is wicked and to be forbiden. Now who is so grosly blinde that seeth not that these aforesaid exercises not only withdraw us from godlinesse and virtue, but also haile and allure us to wickednesse and sin? for as concerning football playing I protest unto you that it may rather be called a friendlie kinde of fyghte than a play or recreation-a bloody and murthering practice than a felowly sport or pastime. 
['Friendlie kinde of fyghte' is good; in fact 'develishe 'good.] For dooth not everyone lye in waight for his adversarie, seeking to overthrow him and picke him on his nose, though it be on hard stoncs, on ditch or dale, on valley or hill, or whatever place soever it be he careth not, so he have him downe ; and he that can serve the most of this fashion he is counted the only felow, and who but he?

Thus we see that football was played not only in streets and roads, but across country, and that 'tackling' was not only allowable, but that it was an essential feature of the game. In fact from Stubbes' remarks we think it clear that he had frequently played football himself : his remarks therefore are valuable as coming from a 'converted footballer.' He goes on :-

So that by this means sometimes their necks are broken, sometimes their backs, sometimes their legs, sometimes their armes, sometimes their noses gush out with blood, sometimes their eyes start out, and sometimes hurte in one place, sometimes in another. But whosoever scapeth away the best goeth not scot free, but is either forewounded, craised, or bruised, so as he dyeth of it or else scapeth very hardlie; and no mervaile, for they have the sleights to meet one betwixt two (this reminds one of poor Roger Ludforde), to dash him against the hart with their elbowes, to butt him under the short ribs with their griped fists, and with their knees. to catch him on the hip and pick him on his neck, with a hundred such murthering devices. (The writer here shows that he knew all about 'tackling,' and that there were many well-known dodges.) And hereof (he concludes) groweth envy, rancour, and malice, and sometimes brawling, murther, homicide, and great effusion of blood, as experience daily teacheth. Is this murthering play now an exercise for the Sabaoth day?

One other hostile criticism of football in that age should be mentioned. King James I., in his 'Basilikon Doron, or Manual of Precepts for his Son and Successor,' praises, as we have seen, some other sports as good for the body, but makes a reservation of football. 'From this count,' he says, 'I debar all rough and violent exercise as the football meeter for laming than for making able the users thereof.' King James, however, copied so much of his sentiments from Sir Thomas Elyot that perhaps his views on football were simply borrowed and not original. 
Football, however, survived criticism as it had before survived repressive legislation. Throughout the whole of the sixteenth century, and that part of the seventeenth century before Puritanism gained the upper hand, it remained one of the favourite sports of the people. We have already seen in the earlier part of this book how in 1540 the annual football match played on Shrove Tuesday at Chester was discontinued and a foot race substituted. The extract, however, from the Harleian MSS. which gives the information is valuable as showing the extreme antiquity of the game. For the chronicler says that 'it hath been the custom time out of mind for the shoemakers' to deliver to the drapers one ball of leather called a football to play at from thence to the Common Hall of the said city. No doubt the football match on Shrove Tuesday was discontinued for a time, but the game continued to flourish upon other occasions.

About A.D. 1600, football was still in full vigour. Amongst the country sports mentioned by Randel Holme in the lines which we have also quoted before, the Lancashire men challenge anybody to

Try it out at football by the shinnes.

Some of their talented successors in the county who have figured at the Oval upon the occasion of the 'Football Jubilee Festival ' and elsewhere, are still capable, it appears, of upholding the boast of their bard; but times are changed, and as their association players wear 'shinguards,' the game is no longer tried out by the shins alone. Other and better bards than Randel Holme have spoken of football. Shakspeare in his 'Comedy of Errors,' Act ii., has :-

Am I so round with you as you with me

That like a football you do spurn me thus?

You spurn me hence and he will spurn me hither ;

If I last in this service you must case me in leather.

Another extract too from ' King Lear' (Act i. Scene 4) shows that 'tripping' and 'hacking over' were then regular parts of the game. 
Lear. Do you bandy looks with me, you rascal?

'Bandy' was originally another name for hockey, and to ' bandy' a ball meant to strike it backwards and forwards, which may account for the context.

Stervard. I'll not be strucken, my lord.

Kent. Nor tripped neither, you base football player

(tripping up his heels).

Lear. I thank thee, fellow.

Lear's faithful courtier then is made by Shakspeare to understand the art of 'tripping,' which seems significant.

Burton, in his 'Anatomy of Melancholy,' the greater part of which was written early in the seventeenth century, mentions footballs and 'balouns' (i.e. handballs of the size of footballs to be kept up in the air like shuttle-cocks) amongst the common recreations of the country folk; but there is ample evidence that both footballs and baloons were used in the towns as well. In the lines we have referred to before of Neogorgus who was 'Englyshed by Barnabe Googe,' we hear of the universal practice of people to indulge in sports after dinner on Sunday, and amongst the other games of sport we hear that some go

To toss the light and windy ball aloft with hand and foote.

Indeed the game of baloon long enjoyed popularity, and Waller speaks of it with enthusiasm as a winter sport:--

And now in winter when men kill the fat swine They get the bladder and blow it great, and then With many beans and peasen put therein

It rattleth, soundeth, and shineth clere and fayre.

While it is thrown and caste up in the ayre

Each one contendeth and hath a great delite

With foot and with hand the bladder for to smitc, If it fall to ground they lift it up again, And this way to labour they count it no payne.

However, this 'baloon play' is hardly football, although it is just possible that it may have suggested if it did not originate the Association game, where no collaring or catching hold of the 
antagonist is allowed. To return however to football. In the earlier part of the seventeenth century it is clear that it was not only a country game as Burton describes it, but was played in town also, and even in the streets. Besides the London and Manchester records which we have already quoted, there is a description of London in $\mathbf{6}_{34}$, by Sir W. Davenant, quoted by Hone in his 'Table Book' :-

I would now (says the writer) make a safe retreat, but that methinks I am stopped by one of your heroic games called football; which I conceive (under your favour) not very conveniently civil in the streets, especially in such irregular and narrow roads as Crooked Lane. Yet it argues your courage, much like your military pastime of throwing at cocks, since you have long allowed these two valiant exercises in the streets.

This seems to give an absolute proof that the statutory repression of football never was enforced at all, or even recognised except in cases where death or at least a riot resulted from the game. In fact, about A.D. r6oo the game must have been played from one end of the kingdom to the other. One of the most sensible and kindly critics of the game is Carew, who mentions it in his 'Survey of Cornwall,' published in I602, as being popular throughout the West country. We should say that Carew describes the game as 'hurling.' The name 'hurling' was afterwards generally appropriated to a game more resembling hockey than football, at which a small ball was knocked through the goals with hurlets or hurling-sticks; but the game of hurling, as described by Carew and others under different names, is simply football with much running and little or no kicking. Carew discusses two games, called 'hurling to goales,' and 'hurling over country.'

For hurling to goales there are fifteen, twenty or thirty players, more or less, chosen out on each side, who strip themselves to their slightest apparel and then join hands in ranks one against another : out of these ranks they match themselves by payres, one embracing another and so passe away, every of which couple are especially to watch one another during the play. After this they pitch two 
bushes in the ground some eight or ten feet asunder, and directly against them ten or twelve score paces off other twain in like distance which they term goales, where some indifferent person throweth up a bali the which whomsoever can catch and carry through the adversaries' goals hath won the game.

The remainder of the description, which is too long to give in full, says that no one was allowed to 'but or handfast under the girdle' (i.e. to charge or collar below the waist) or to 'deal a foreballe' (i.e. to 'pass forward'). From this it is evident that even at this period there were definite rules and tactics of the game. There must also have been care and skill in choosing sides, since before the game began the opponents were selected in pairs, and each player had one of the other side 'marking' him. Besides, however, this orderly and carefully managed game, there was also the other (and no doubt the original) game, the 'hurling over country.' The description shows this to have been something like a 'cross-country bigside.' Says Carew, 'Two, three or more parishes agree to hurl against two or three other parishes.' The goals were trees or buildings which could be seen, or were known as landmarks, three or four miles apart, and in Carew's words :-

That company which can catch or carry the ball by force or slight to the place assigned gaineth the victory. Such as see where the ball is played give notice by crying 'Ware east,' 'Ware west,' as the same is carried. The hurlers take their way over hilles, dales, hedges, ditches, yea and thorow briars, mires, plashes and rivers whatsoever, so as you shall sometimes see twenty or thirty lie tugging together in the water scrambling and scratching for the ball.

It is a relief to find in this writer some kindly criticism which shows that he was manly enough to see the good points of the rough game.

The play (he says) is verilie both rude and rough, yet such as is not destitute of policies in some sort resembling the feats of war; for you shall have companies laid out before on the one side to encounter them that come with the ball, and of the other party to succour them in the manner of a fore-ward. The ball in this 
play may be compared to an infernal spirit, for whosoever catcheth it fareth straightways like a madman struggling and fighting with those that go about to hold him; no sooner is the ball gone from him than he resigneth this fury to the next receiver and himself becometh peaceable as before. .. I cannot well resolve whether I should the more commend this game for its manhood and exercise or condemn it for the boisterousness and harm which it begetteth; for as on the one side it makes their bodies strong, hard. and nimble, and puts a courage into their hearts to meet an enemy in the face, so on the other part it is accompanied by many dangers some of which do even fall to the players' share, for the proof whereof when the burling is ended you shall see them retiring home as from a pitched battle with bloody pates, bones broken and out of joint, and such bruises as serve to shorten their days, yet all is good play and never attorney or coroner troubled for the matter.

Staunch Cornishman! Thy opinions are better than those of forty Stubbeses. The game of hurling, however, was by no means confined to the West country. The same, or a similar game, was known throughout the Eastern counties as 'camping,' or 'camp-ball.' An old book of Norfolk antiquities quotes a fifteenth-century couplet :-

Get campers a ball

To camp there with-all ;

and there are frequent references in documents of this century to 'camping closes ' and 'camping fields.' In Cullum's 'History of Hawstead' there is also a reference, under the date I 466 , to the 'camping-fighte,' which serves to justify Stubbes' description of the game as a 'friendlie fyghte.' It is not, however, until ${ }^{6} 673$ that any actual description of the game is given. A more modern writer, however-Moor, writing in I 823-gives a long description of the game, which evidently had not changed its character for centuries :-

Each party has two goals, ten or fifteen yards apart. The parties, ten or fifteen on a side, stand in line, facing each other at about ten yards distance midway between their goals and that of their adversaries. An indifferent spectator ('indifferent' is the very word used by Carew also) throws up a ball the size of a cricket 
ball midway between the confronted players and makes his escape. The rush is to catch the falling ball (no doubt the 'indifferent' person under the circumstances is no longer indifferent to 'making his escape'). He who first can catch or seize it speeds home, making his way through his opponents and aided by his own sidesmen. If caught and held or rather in danger of being held, for if caught with the ball in possession he loses a snotch, he throws the ball (he must in no case give it) to some less beleaguered friend more free and more in breath than himself, who if it be not arrested in its course or he jostled away by the eager and watchful adversaries, catches it ; and he in like manner hastens homeward, in like manner pursued, annoyed and aided, winning the notch or snotch if he contrive to carry or throw it within the goals. At a loss and gain of a snotch a recommencement takes place. When the game is decided by snotrhes seven or nine are the game, and these if the parties be well matched take two or three hours to win. Sometimes a large football was used; the game was then called 'kicking camp'; and if played with the shoes on 'savage camp.'

These extracts show that in the original game of Rugby football, the football itself was hardly essential to the game. The original game from which both Rugby and Association football have been developed, as well as hockey and lacrosse, was simply the getting of a ball to or through a goal in spite of the efforts of the opposite side to prevent it. When a small and hard ball was used kicking was naturally but little good, and either carrying, tossing, or striking it with a stick, was found more useful; and hence we observe that this rariety of games arises from the same source, which was the same as the Roman game with the harpastumn. This consideration also serves, in some measure, to answer the charge which used so frequently to be made against Rugby football in the days of bigsides, that it was not football at all, as there was so little kicking. The game was an old one handed down for centuries, and there is no trace in the original form of it to suggest that nothing but kicking was allowed. The game in which kicking and nothing but kicking was allorred was a subsequent development about which we shall speak later, and, doubtless, the name of 'football' is more suitable to that game than to the other. 
The foregoing descriptions of hurling' and 'camp-ball' also explain the meaning of the extract so frequently quoted from the 'Statistical Account of Scotland'; it is given by Hone, and was always considered mysterious by footballers. This is the well-known account of the game of football at Scone, in Perthshire, where no person was allowed to kick the ball. The game was the same as that known as 'hurling' in Cornwall, as 'camp-ball' in the eastern counties, and football elsewhere. The ball was 'thrown up' at the market cross at Scone, and 'he who at any time got the ball into his hands ran with it till overtaken by one of the opposite party, and then if he could shake himself loose from those of the opposite party who seized him, he ran on : if not he threw the ball from him, unless it was wrested from him by the other party, but no person was allowed to kick it.' The game was an annual one between the bachelors and the married men, and the object of the married men was to hang it, that is to put it three times into a small hole in the moor which was the 'dool' or limit on the one hand ; that of the bachelors was to drown it, or dip it three times in a deep place in the river, the limit on the other; the party who could effect either of these objects. won the game; if neither won the ball was cut into equal parts at sunset. In the course of the day there was usually some violence between the parties; but it is a proverb in this part of the country that, 'All is fair in the ball at Scone.' The origin of the Scone game, like the origin of the annual game at Chester, Derby, Kingston, Corfe Castle, and elsewhere, is shrouded in obscurity, and is attributed to a victory gained by a parishioner of Scone over a foreigner in ancient times. What is curious. about the Scone game is that every man in the parish was compelled to turn out and play, so that the 'compulsory football' of some schools seems to be only a modern revival. The same book also gives an account of another Shrove Tuesday match between the spinsters and married women of Inverness, in which the married women always won. This seems curious unless, as Addison says of the athletic maidens who performed 
in his time at country fairs, the women won their husbands on the football field; this might account for their always beating the spinsters, as the married women would be those who had earned their partners by success in games of football, and every year their ranks would be recruited by the best spinster players. However, to return to our history. There is no doubt that hurling, football, and camp-ball were in their origin the same. The name hurling was eventually adopted for a kind of hockey played with sticks, called hurlets. Camp-ball has perished in name, just as stool-ball is dead or dying, to be recalled, however, by the stumps of cricket which originally represented the legs of the stool at which the ball was thrown: and pall-mall is also gone, leaving as its legacy the green cloth of the billiard table which represents the smooth green on which pall-mall was played. Now that the original game of 'hurling,' 'camp-ball,' or 'football' has produced three such excellent and entirely dis. tinct games as hockey, Rugby Union football, and Association football, it is only natural that it should itself pass away; but as a matter of fact, it still survives in one or two out-of-the-way corners of England, as we shall point out afterwards.

To return to the history of football. As far as can be gathered from extracts, taken in their chronological order, it appears certain that the triumph of Puritanism considerably reduced the popularity of football. The political ascendency of this ascetic creed was short, but the hold that it took upon the manners and feelings of the nation not only put a stop in a great measure to Sunday football, but rendered the game less acceptable upon other days. We have seen that up to the age of the Puritans football was a national sport. From the time of the Restoration and onward for 200 years or thereabouts, until the athletic revival came in, there was a slow but steady decrease in the popularity of the game as a sport for men, although there is also no doubt that during the period football became a regular and customary school sport. Still, from the slight number of references made to football by eighteenth-century writers, it would appear evident that in that century the game 
was no longer of national popularity. In London, however, in the reign of Charles II., football still appears to have gone on merrily, and this was only to be expected, for Charles was, as we have seen, a great patron of athletic sport; indeed, there is a precedent for the royal patronage of football which was seen when the Prince of Wales visited Kennington Oval, in March, r886. One hundred and ninety-five years before this date Charles II. attended a match which was played between his own servants and those of the Duke of Albemarle. Some years before this too ( $16_{6}$ ) Pepys tells us that on January 2, there being a great frost, the streets were full of footballs. Modern footballers give up their games in frosty weather for fear of accidents upon the hard ground, but the 'prentice lads who played in the streets were probably doing little more than 'punt-about' to keep themselves warm. Even the 'prentices of the period, however, were occupying their leisure hours with more serious pursuits than football, for as a scornful contemporary writes :-

They're mounted high; contemn the humble play

Of trap or football on a holiday

In Fines-bury fieldes. No; 'tis their brave intent

Wisely to advise the King and Parliament.

The Tappertits of this day, however, had not all of them souls too big for football, for the oft-quoted M. Misson, who published, in Paris in 1698 , his 'Mémoires et Observations faites par un Voyageur,' apparently saw many games of football during his visit to England. His description shows plainly that the 'street football' which he saw cannot have been the original 'friendly-fight' game, but must either have been something in the nature of a dribbling game, or, what is more likely, simply boys or men kicking the ball about for amusement. He says :-

En hiver le Footbal est un exercice utile et charmant. C'est un balon de cuir, gros comme la tête et rempli de vent; cela se balotte avec le pied dans les rues par celui qui le peut attraper: il ny a point d'autre science. 
The passage is interesting, although it is evident that M. Misson cannot be describing the same game which evoked the wrath of Stubbes and the disparagement of James I., for surely no Frenchman would describe the old rough-and-tumble game as 'charmant.'

Whether he saw a real dribbling game, or merely saw men 'punting about' a ball for amusement, is perhaps of little importance, as there is little doubt that the dribbling game arose out of the practice of kicking about a football without doing damage to limbs or clothes; but the extract is interesting at any rate in showing that the ball itself had by this time assumed its present shape and make.

The same number of the 'Spectator' from which we have already quoted in our account of the history of athletics, also makes mention of a football match. The 'Spectator,' while on a visit to Sir Roger de Coverley, visits a country fair, and there sees, besides athletes and cudgel-players, a game of football.

I was diverted (he says) from a further observation of these combatants (i.e. the cudgel-players) by a football match which was on the other side of the green, where Tom Short behaved himself so well that most people seemed to agree it was impossible that he should remain a bachelor until the next wake. Having played many a match myself, I could have looked longer on the sport had I not observed a country girl.

One can hardly fancy the courtly Joseph Addison playing at football, unless he did so when he was a boy at Charterhouse, but he certainly writes as if gentlemen played the game as well as rustics, though unluckily he gives no description of the style of play he saw upon the village green.

Unfortunately also, the great historian of English sports, Joseph Strutt, gives but a short description of the game of football, but from what he says it is evident that at the time he wrote (ISor) the game was fast decaying. 'Football,' he says, ' is so called because the ball is driven about with the feet instead of the hands.' It is not likely, however, that he means that kicking alone was allowed, as his paragraph on football 
Immediately follows that on 'hurling,' which he describes in his day as being played with sticks or bats, with which the ball was struck. The following is the only description he gives of the game :-

When a match at football is made an equal number of competitors take the field and stand between two goals placed at a distance of eighty or an hundred yards the one from the other. The goal is usually made with two sticks driven into the ground about two or three feet apart. The ball, which is commonly made of a blown bladder and cased with leather, is delivered in the midst of the ground, and the object of each party is to drive it through the goal of their antagonists, which being achieved the game is won. The abilities of the performers are best displayed in attacking and defending the goals; and hence the pastime was more frequently called a goal at football than a game at football. When the exercise becomes exceeding violent the players kick each other's shins without the least ceremony, and some of them are overthrown at the hazard of their limbs.

The last sentence shows pretty clearly that Strutt was describing not the dribbling game, but the old hacking and tripping game which in its civilised form is now known as the Rugby Union game. What is perhaps the most significant part of Strutt's description is that he says 'The game was formerly much in vogue among the common people, though of late years it seems to have fallen into disrepute and is but little practised.' Indeed, the decline in the popularity of the game which Strutt noticed at the opening of this century seems to have gone steadily on for the next fifty years, in England at any rate. Hone, in his 'Year Book,' 'Every Day Book,' and ' Table Book,' ( 1838 to 1842 ) treats of football and football customs more as interesting survivals of past ages than as contemporary pastimes. Although he says nothing of the celebrated Derby and Corfe Castle games, he quotes from Hutchinson's 'History of Cumberland' an account of an annual Shrove Tuesday match at Bromfield. By ancient custom the scholars of a certain school at that place were allowed to 'bar out' their master, and after a sham fight a truce was supposed to be concluded 
whereby the scholars were allowed to have some cock-fighting and a football match.

The football was thrown down in the churchyard and the point then contended was, which party should carry it to the house of his respective captain, to Dundraw perhaps or West Newton, a distance of two or three miles. The details of these matches were the general topics of conversation amongst the villagers, and were dwelt on with hardly less satisfaction than their ancestors enjoyed in relating their feats in the border wars.

A relic of a lay of a local minstrel upon one of these contests is given by the same authority and is decidedly amusing :-

At Scales great Tom Barwise got the ba' in his hand, And 't wives aw' ran out and shouted and banned, Tom Cowan then pulched and flang him 'mong t' whins, And he bleddered od-white-te tou's broken my shins.

In another place ('Every Day Book,' vol. i. p. 245) Hone gives a letter written in I8I5, describing 'Football Day' at Kingston-on-Thames at that date. A traveller journeying to Hampton Court by coach 'was not a little amused upon entering Teddington to see all the inhabitants securing the glass of all their front windows from the ground to the roof, some by placing hurdles before them, and some by nailing laths across the frames. At Twickenham, Bushy, and Hampton Wick they were all engaged the same way.' The game is then described as follows :-

At about twelve oclock the ball is turned loose, and those who can kick it. There were several balls in the town of Kingston, and of course several parties. I observed some persons of respectability following the ball ; the game lasts about four hours, when the parties retire to the public-houses.

Altogether it appears that the Kingston game in 18 I 5 was not what M. Misson would have called ' utile et charmant.'

There is another allusion to football in the 'Every Day Book' (vol. ii. p. 374) which is also interesting. A correspondent, 
'J. R. P.,' writes a letter to say that when he was a boy football was played in his village, in the west country, on Sunday mornings before church-time, the field of play being the 'church-piece'; and the same writer also says that at that date (184I) football was played on Sunday afternoons, in fine weather, in the fields near Copenhagen House, Islington, by Irishmen, who played from about three o'clock until dusk. 'I believe,' he says, 'as is usual in the sister kingdom, county men play against other county men. Some fine specimens of wrestling are occasionally exhibited in order to delay the two men who are rivals in pursuit of the ball.' Whatever the last words may mean, it appears certain that the Irishmen played the collaring and not the dribbling game.

It is obvious from Hone's extracts, therefore, that football as a national pastime was, in the first half of this century, dying out in England. In Scotland, however, it appears to have been more flourishing. Scott would hardly have written in the 'Lay of the Last Minstrel' :-

Some drive the jolly bowl about,

With dice and draughts some chase the day, And some with many a merry shout,

In riot, revelry, and rout,

Pursue the football play-

if he had not seen plenty of football in his time. Indeed, Hone assists us in another place to an account of a great football match in Scotland with which Sir Walter Scott was personally concerned. In his 'Every Day Book,' vol. i. p. I554, he says: 'On Tuesday, the 5th of December, I8I5, a great football match took place at Carterhaugh, Ettrick Forest (a spot classical in minstrelsy) betwixt the Ettrick men and the men of Yarrow, the one party backed by the Earl of Home and the other by Sir Walter Scott, sheriff of the forest, who wrote two songs for the occasion.' One of the songs is given in extenso, but space forbids our quoting more than a couple of verses:- 
From the brown crest of Newark its summons extending, Our signal is waving in smoke and in flame;

And each forester blithe from his mountain descending Bounds light o'er the heather to join in the game.

Then strip lads and to it, though sharp be the weather, And if, by mischance, you should happen to fall, There are worse things in life than a tumble on heather, And life is itself but a game at football.

Luckily, however, though football steadily decreased in popularity throughout the first half of this century, it was rather in a state of dormancy than of collapse, and was not long in picking up again when in 'the fifties' the revival came from the public schools. It is not too much to say that the present football movement can be directly traced to the public schools and to them alone, though, in a great many centres, when the revival came the game was still known not only as a game for boys, but as a pastime for men. In many corners of England, indeed, the old time-honoured game, without rules or limit to the number of players or size of ground, was being carried on, and even is carried on to the present day. The writer cut the following extract from a local paper of 1887 :-

$\mathrm{J}-\mathrm{B}-\mathrm{h}$ has attained notoriety. In pursuance of a custom which has been in vogue for centuries, the tradesmen and countrymen of the little town of Sedgefield, County Durham, held a week or two ago their annual football carnival on the old plan, the players being without limit and the field of play about half a mile long, the goals at one end a pond and at the other end a spring. At one o'clock the sexton put the ball through a bull-ring and threw it into the air, and a scrimmage of 400 persons ensued. After a series of ' moving incidents by flood and field' $\mathrm{J}-\mathrm{B}-$ collared the ball and dropped it into the stream, dived for it, and gained the victory for the tradesmen, who carried him shoulder high.

The most celebrated, however, of these time-honoured games were those at Derby and Corfe Castle, and both of these deserve some mention before we leave ancient football and turn away to trace the beginnings of modern football in 
the public schools. The following is the account of the Derby game given by Glover in his 'History of Derbyshire,' published in $1829:-$

The contest lies between the parishes of St. Peter's and All Saints, and the goals to which the ball is taken are 'Nun's Mill' for the latter and the Gallows balk on the Normanton Road for the former. None of the other parishes in the borough take any direct part in the contest, but the inhabitants of all join in the sport, together with persons from all parts of the adjacent country. The players are young men from eighteen to thirty or upwards, married as well as single, and many veterans who retain a relish for the sport are occasionally seen in the very heat of the conflict. The game commences in the market-place, where the partisans of each parish are drawn up on each side, and about noon a large ball is tossed up in the midst of them. This is seized upon by some of the strongest and most active men of each party. The rest of the players immediately close in upon them and a solid mass is formed. It then becomes the object of each party to impel the course of the crowd towards their particular goal. The struggle to obtain the ball, which is carried in the arms of those who have possessed themselves of it, is then violent, and the motion of the human tide heaving to and fro without the least regard to consequences is tremendous. Broken shins, broken heads, torn coats, and lost hats are amongst the minor accidents of this fearful contest, and it frequently happens that persons fall owing to the intensity of the pressure, fainting and bleeding beneath the feet of the surrounding mob. But it would be difficult to give an adequate idea of this ruthless sport. A Frenchman passing through Derby remarked, that if Englishmen called this playing, it would be impossible to say what they would call fighting. Still the crowd is encouraged by respectable persons attached to each party, who take a surprising interest in the result of the day's sport, urging on the players with shouts, and even handing to those who are exhausted oranges and other refreshment. The object of the St. Peter's party is to get the ball into the water down the Morledge brook into the Derwent as soon as they can, while the All Saints party endeavour to prevent this and to urge the ball westward. The St. Peter players are considered to be equal to the best water spaniels, and it is certainly curious to see two or three hundred men up to their chins in the Derwent continually ducking each other. The numbers engaged on both sides exceed a thousand, 
and the streets are crowded with lookers-on. The shops are closed, and the town presents the aspect of a place suddenly taken by storm.

The whole is a good piece of description, and the expression of amusement at respectable persons encouraging the sport is decidedly refreshing. It is very obvious that there could have been no kicking in the Derby game any more than there was in the game at Scone; and this is made clear by another extract from Glover, who says, 'A desperate game of football in which the ball is struck with the feet of the players is played at Ashover and other wakes.'

The Corfe Castle game was one of the same nature as those already described, and is still played up to this day, anyone being at liberty to join in the general hustle which takes place on Shrove Tuesday and on Ash Wednesday ; the ball is kicked from Corfe to Owre quay to preserve the ancient right-of-way claimed by the company of Marblers of Purbeck. The freemen marblers, who are a body existing from time immemorial, have always been regulated by articles the earliest extant copy of which bears the date I553. The seventh article of the regulations of this date runs as follows : "That any man in our companie the Shrovtewsdaie after his marriage shall paie unto the wardings for the use and benefit of the companie twelve pence, and the last married man to brynge a footballe according to the custome of our companie.' The game, therefore, was a customary one in I553; it has certainly been an annual affair ever since, and the fact is noteworthy that the game at Corfe has survived in such an out-of-the-way corner of England as the Isle of Purbeck, where athletic sports or Rugby Union or Association matches are seldom even heard of.

So far we have traced the history of football as it was played by the people at large, and have shown that it had a continued existence for at least six centuries as a recognised manly sport. We have seen also that at the end of the last and beginning of the present century, the game was certainly waning in popularity, and that the writers of the early part of this century are inclined 
to treat it as a sort of interesting relic of antiquity. To-day, however, football can be fairly described as once again the most thoroughly popular of all British sports. The game attracts as many spectators, and as many players in the winter, as the national sport of cricket in the summer. All that remains to complete the history of football is to describe the causes and progress of the modern revival of the game.

The present writer has already, in conjunction with Mr. J. E. Vincent, written a small book upon the history of Football, ${ }^{1}$ which has not only covered a good deal of the ground which has been traced in this chapter, but discusses the origin of the various forms of school football. The conclusion arrived at in that work was that 'in each particular school the rules of the game were settled by the capacity of the playground; and that as these were infinitely various in character so were the games various.' It might also have been added that the Association game, or at least the various forms of game where kicking alone was allowed, and collaring and therefore running with the ball forbidden, also arose entirely in the schools, where either from the want of a sufficient playground, or from other causes, the old rough game was impracticable. There can be no doubt that the game which we have described in the preceding pages was not only risky to limb (that perhaps was a slight consideration for English schoolboys) when played upon a good grass plot, but when played in a walled-in space such as the cloisters of Charterhouse, or on a very small and confined playground with a flagged pavement, would have been probably dangerous to life. In any case too the collaring game must have been highly destructive to clothing of every description; and it is therefore small wonder that at the majority of schools the running, collaring and hacking game should have been tabooed, probably by order of the school authorities or the parents. Now at the present day every large school has a good large grass playground either in the grounds of the school itself or within convenient reach; but in the olden times little or no

1 Football: Its History for Five Centuries. Field \& Tuer, 1885. 
provision for 'playing fields' appears to have been made by pious or other founders. One school alone seems to have owned almost from its foundation a wide open grass playground of ample dimensions, and that school was Rugby; hence it happens, as we should have expected, that at Rugby School alone do we find that the original game survived almost in its primitive shape. Nor is it difficult to see how the 'dribbling game' arose at schools where the playground was limited. Given a number of boys with that common vehicle of amusement a football, and no space where they could play the traditional game, they would soon learn to dribble it about with their feet for amusement and soon attain to skill and pace in their pastime; indeed we have seen from the extract from M. Misson's account of England that something very like the dribbling game was witnessed by him in the streets of London in 1696 , played by those who were forbidden or unwilling to break their heads or limbs by pursuing the sport on hard pavements. It would require very little ingenuity when the original game was impracticable to borrow the goals and touch-lines from the field game, and simply allow kicking as the only method of propulsion. In proportion therefore as the school was limited in the size of its playground we should expect to crace less of the old 'friendlie fyghte' and more of the dribbling game. Again, we find the very examples which we should expect to prove our theory in the London schools. The Charterhouse boys had originally no ground but their cloisters to play in ; we believe the Westminster boys were for a long time similarly ill provided with a playground; and it is from Charterhouse and Westminster that the dribbling game as it is played at present under Association rules came almost in its present form. At Winchester the ancient custom appears to have been to play football upon small strips round the edge of the 'Meads,' the centre being reserved for cricket, and it is from this practice that the peculiar characteristics of the Winchester game arose. 'There was no danger in shoving upon the Winchester strips of grass, so the shoving of the old game remained in the Winchester 
rules; and dribbling consequently remained at a discount. At Harrow, where there was probably more room, a large amount of catching and free kicking was allowed, but running and collaring found no place in the game. It is thus that we obtain the clearest illustrations of the theory that the different schools adapted the old game to the necessities of their own playgrounds. At Eton formerly the only original playground was a small field near the College buildings. Consequently their 'field game' was chiefly a kicking game, but long-kicking and scrimmages were not barred, as they were of necessity bound to be at Charterhouse and at Westminster. The other Eton game, the well-known 'wall-game,' probably drew its rules and character from the space against the wall upon which it was played. In a subsequent chapter we shall give short descriptions of some of the old school games in their turn, and here we can only make sufficient allusion to them to show that historically they owe their characteristics to the ground on which they were played.

The different schools, in adopting as a pastime the national game of football in which any and every method of getting the ball through the goal was allowed, included only such parts of the game as were suitable to their ground, or to put the case in another way, eliminated from the game every characteristic which was necessarily unsuitable to the circumstances under which alone the game could be played. As far as we can discover, however, no school but Rugby played the old style of game where every player was allowed to pick up the ball and run with it, and every adversary could stop him by collaring, hacking over and charging or any other means he pleased. No doubt the majority of schoolmasters thought, with Sir Thomas Elyot, that the original football was unworthy of a gentleman's son, and dangerous to limb as well as to clothing, and in the days when butcher's meat was cheap, and cloth was good but dear, the clothing question was a matter of some consideration. What causes led the Rugby authorities to differ from the managers of other schools it is difficult to see, but it is tolerably 
plain that the 'Rugby game' was originally played at Rugby school alone, while other schools adopted more or less modified forms of the kicking game. That other schools did play football is clear enough from the annals of Eton, Westminster and Charterhouse, and private schools played the game also without doubt.

When 'Tom Brown' arrived at Rugby as a new boy he said to his cicerone East, 'I love football so and have played all my life. Won't Brooke let me play?' 'Not he,' replied East, 'it's no joke playing up in a match, I can tell you. Quite another thing from your private school games. Why, there's been two collar-bones broken this half, and a dozen fellows lamed, etc.' East's description is of course merely given to impress the new boy with awe, and we need scarcely quote any more extracts from the work, as most of our readers doubtless know it as well as ourselves. Chapter V. of 'Tom Brown,' which gives a kindly and appreciative description of football as it was played at Rugby school in the boyhood of Mr. Thomas Hughes, shows that the Rugby game was essentially the same game which evoked the wrath of Stubbes. The whole school of three hundred played either between or behind the goals on that immense field which is still the scene of the Rugby lads' matches, and which even affords trees whereon to crack the skulls of innocent visitors, and by dodging round which the wily ones can exercise their sleight as well as their violence, and as Mr. Hughes points out often for long spells together the ball was invisible amongst the struggling mass of scrimmaging competitors. The match also, it may be noticed, lasts for two hours or thereabouts on the first day, and is continued on subsequent occasions. Somewhere about the year 1835 , therefore, the original game of football was having a hearty and healthy existence at Rugby School.

At no other public school, however, as far as we are aware, was the running and collaring game kept up. At many of the other chief schools there were games where more or less 'scrimmaging' was allowed, but at all of these the only method 
of propulsion allowed was kicking. Some schools allowed 'free-kicking' and catching, some allowed while others disallowed the stopping of the ball with the hands, some allowed 'off-side' play, and some forbade it. But until the revival of football came all the other public schools but Rugby played the game in which running with the ball was not allowed. Now as it was discovered as soon as attempts were made to codify and assimilate rules some quarter of a century ago, the essential distinction between the two entirely distinct games which are now played under the names of 'Rugby Union' and 'Association' football, is that in the former running with the ball, and therefore tackling, is allowed; in the other it is entirely forbidden. As soon as any running with the ball under however stringent conditions was permitted, the running became the important feature of the game, and no compromise between running and non-running games was possible. It is therefore not too much to say that the running game came entirely in its modern form from Rugby, although doubtless before it began to be followed by the public at large, other schools, such as Cheltenham and Marlborough, had adopted with more or less modification the game so lucidly described in 'Tom Brown's School-days.' The Association or 'kicking' game came before the world from Eton, Harrow, Westminster, Charterhouse, and other schools where something of the same style of game was played. All these schools had rules differing in many essential characteristics from one another, but all agreeing in forbidding any seizing of the ball and running with it.

It is of course difficult to trace in any detail the steps by which both games gradually spread from the chief schools to the smaller schools, and from both to the public at large. From enquiries we have instituted it appears that between $185^{\circ}$ and I860, the same period in which 'Athletic Sports' were taking root in schools and colleges, all the schools adopted football as part of the regular athletic curriculum, and as the chief school game for the winter months. Gradually the old public school boys started the game again after they had left school, at 
the Universities and around the large towns. At Cambridge old members of the schools which played the dribbling game appear to have been indulging in matches as early as 1855 : and about the same time the game was begun again regularly in Sheffield. Two clubs, the Sheffield and Hallam clubs, were founded simultaneously in I 857. We believe, however, that a club which played the dribbling game under the title of the 'Forest Club,' and existed near Epping Forest, claimed before its untimely decease the honour of being the first football club of modern times. In I 858 some old Rugbeians and old boys of the Blackheath Proprietary School started the famous Blackheath Club to play the Rugby game, and in the following year their great rivals in the game, the Richmond Club, came into existence. Soon after I 860 there was a great football 'boom' at Sheffield, and several fresh clubs sprang up, and indeed from that time for the next fifteen years the Sheffielders could put an eleven into the field able to meet any other eleven in the kingdom. Meantime in London several dribbling clubs were being established, the Crystal Palace in I86I and the Civil Service and Barnes in $\mathrm{I} 862$. So far the dribbling clubs were decidedly in the majority, as besides Richmond and Blackheath and the Harlequins we believe there were no other regularly constituted clubs playing the Rugby rules before $\mathrm{I}^{86_{3}}$. In $\mathrm{I} 86_{3}$ the first move towards football organisation was made, and after much exposition in the columns of the press of the necessity for assimilation of rules, an attempt was made in the autumn of that year by the leading London clubs to settle a uniform code of rules for all players. The suggested compromise between the essentially different games which were being played was to allow running either when the ball was caught on a fair catch, or caught on a bound, and it was even proposed before the committee which met to frame the 'compromise' rules that hacking and tripping should be allowed when the adversary was running with the ball. Before the discussion of the rules was over in London, however, some of the dribbling players at Cambridge had also elected a committee and drawn up a set of rules upon which the 
old players of Eton, Harrow, Westminster and Charterhouse could agree. The Cambridge rules naturally excluded all running with the ball, and the 'hacking over,' 'tripping' and 'tackling' which were the means used by the Rugbeians to stop the runners. The next move was a joint conference of the London and Cambridge committees, and the dribbling players of the metropolis naturally cast their vote against the running and tackling which they reluctantly inserted in their draft of rules in order to conciliate the London players of the Rugby game. The result was that the combined influence of the Cambridge and London dribblers was too strong for the London Rugbeians, who accordingly withdrew from the new combination which started in 1863 under the name of the Football Association, and has since worthily governed the dribbling game. Even from its formation, however, the question of how to deal with the off-side rule proved a stumbling block in the way of the Association. The Etonians in playing their field game had a rigorous rule against 'sneaking' or playing off-side, and the Harrovians also favoured a strict 'off-side' rule. The Westminster and Charterhouse boys, however, always played the game of 'passing forward,' and were not in favour of a strict off-side rule. For the time the Etonians had their way, and it was not until I 867 that the Association adopted its present off-side rule, which provides that no man can be 'off-side' unless there are less than three players of the opposite side in front of him when the ball is passed. The Sheffield Association, a body of associated clubs who played in the Sheffield district, went even further than the Association in their off-side rule, and only obliged one opponent to be between the players and the goal to prevent offside play. For the next ten years the Sheffielders played a different game from the Londoners, until they at length succumbed to the increasing power of the Association, and adopted the prevalent rule. In the meantime, the clubs playing the Rugby game remained unassociated for nearly another eight years, although between 1863 and 1870 the Rugby Union game was making decidedly more way in the country than the Association 
game. As, however, all the players of the Rugby game agreed in not allowing off-side play, few causes of dispute arose, and in general disagreements were avoided by a rule that in matches between clubs the rules of the home club were always to be adopted. In $\mathbf{1} 87 \mathrm{I}$, after some preliminary negotiation between the Richmond and Blackheath clubs, the principal London clubs were summoned together, and in the early part of that year the Rugby Football Union was formed. The more unpleasant features of the hacking and tripping, which were parts of the old Rugby school game, were eliminated, but no other substantial alteration was made in the old method of play, and the main details of the game have ever since remained unaltered, much as the style of play has changed in recent years.

It is from about this time only that football has really become a national game, known throughout the country. Most of the provincial clubs playing under either set of rules have been established since that date. The first international match between England and Scotland under Rugby Union rules was played in $187 \mathrm{I}$, and in the next year the Association players followed suit with a similar fixture; while it was not until the season of $1873^{-74}$ that the Universities of Oxford and Cambridge first tried conclusions with each other, the players of both games starting an Inter-'Varsity match in that winter. For the last dozen years the popularity of the game, both with players and with spectators, has spread marvellously, until at the time of writing football is as much the national game of winter as cricket is of summer. If antiquity of origin is to be considered as constituting an additional claim to honour, the game the history of which we have chronicled in this chapter stands pre-eminent amongst English sports. 


\section{CHAPTER II.}

\section{THE SCHOOL GAMES.}

WE have already explained in the preceding chapter how in each public school a game of football was developed which suited the capacities of the school playground; a few only of these widely varying school games need be described in detail. The schools which like Marlborough and Cheltenham played the running and tackling game drew their ideas from Rugby, and copied with greater or less modification the style of play which we shall afterwards deal with in an account of the ' Rugby Union Game.' Other schools, like Westminster and Charterhouse, played games which varied so little from the present Association rules that nothing need be said of them separately. Shrewsbury, where from a very early time compulsory football was played-'dowling' was the school term-had an independent game of its own in which catching with the hands was allowed, and after a catch a drop kick or 'hoist' (as the Salopians termed a 'punt') was permissible. At Shrewsbury, too, the off-side rule was as strict as in the Rugby game, and another peculiarity was that the goal had no crossbar, and provided the ball passed 'through or above' the space between the posts a goal was counted. No running with the ball or collaring was, however, allowed, and the Shrewsbury game has now yielded to centralising influence and has been replaced by the Association game. Three of our great public schools, however, Eton, Harrow, and Winchester, have so far steadily resisted pressure from outside and play their own time-honoured games. When school is left behind the old Etonians, Harrovians, 
and Wykehamists furnish a full contingent to the ranks of Association players. The 'Eton Wall,' 'Eton Field,' 'Harrow, and 'Vinchester' games are not, however, merely interesting as showing how a host of players are trained for the dribbling game. As healthy and vigorous survivals of the age of football previous to Associations or Unions of every kind, they claim separate attention. The accounts which follow of the Eton and Harrow games are from the pen of a well-known Old Etonian and Old Harrovian respectively, that of the Winchester game is mainly taken from the description in the little book we have referred to before, for which the coadjutor of the present writer in that task was responsible.

The Eton Wall Game appears to be a species of 'passage football' played out of doors. 'Passage football' is common enough in most of the houses at Eton, as doubtless it is at other schools, and is frequently played during the winter evenings with a small ball, the players being shod with slippers, in the passages outside the boys' rooms. Very likely the boys played passage football in former years, and when they wished to renew the game out of doors, having no open fields as now to play in, they went to the most suitable place-viz. along the side of college field, where there is a wall about I 20 yards long and about Io feet high. At right angles to the wall at the one end is another wall, bounding one of the masters' houses, with a door in it about 4 feet wide by 5 feet high, some I 5 yards from the angle, while at the other end stands a large elm tree; this door and the trunk of the elm tree are the two goals. Parallel to the wall and along its whole length a small boundary line is cut in the turf about 6 yards from the wall, and inside this space, i.e. about r 20 yards long by 6 yards wide, is the scene of play. Outside the boundary is an open field; about Io yards from either end of the wall a white chalk line is drawn on the wall; the space within this line at the 'door' end is known as 'good calx,' that at the other or 'tree' end as 'bad calx.' It should be noticed that neither goal is exactly at the end of the play, the door and the tree being both 
some little distance outside the boundary line, and that both the goals are very small.

There are eleven players on either side, 3 called 'walls,' 2 'seconds,' I 'third,' I 'fourth,' I 'line,' I 'flying-man,' I 'long behind,' and I 'goals.' The 'walls' are clad in heavy sweaters padded on the back and sleeves with rough canvas to protect the players from the surface of the wall ; they also wear caps covering the whole of the top and back of the head and ears and buttoned under the chin. The 'seconds' also generally wear caps of a similar description.

The game is begun by a 'bully' in the centre of the wall. The 'wall' whose turn it is to 'go in,' forms down with his shoulder against the wall, taking turn and turn about with the opposite side to form under and over; the two other 'walls' back him up by supporting him behind, also with their shoulders against the wall. The two 'seconds' form down alongside the 'walls' under or over their opponents as the case may be; under when the walls form over, and vice vers $\hat{a}$, and act as a kind of prop to the 'walls' of their side ; 'third' stands outside the bully about half-way between the wall and the boundary line ; 'fourth' next to him, and 'line' next to 'fourth' and at the boundary line. 'Flying-man' stands behind the bully and corresponds to 'half-back' in Association, 'long behind' be. hind him, and 'goals' behind him. The players of the opposing side station themselves in the same manner. So much for the formation of the bully. As to the play, the ball is placed against the wall between the feet of the two first opposing 'walls,' and the game begins. The players in the 'bully,' i.e. the 'walls' and 'seconds,' begin to shove and push with all their might, their object being to force the ball from the centre of the wall into the opponents' 'calx.' If the 'walls' and 'seconds' of the one side are stronger than those of the other, they may be able by crawling along with the ball at their feet and shoving back their opponents, to force their way along the play several yards at a time, i.e. between each bully, for the moment the ball is 'loose,' and is kicked across the boundary line into the 
open field or over the wall, the next bully is formed at a point in a line with the spot where the ball is stopped by a player out in the open field or at the spot where it went over the wall. The ball, it should be stated, is a small round one, little more than half the size of an Association ball.

If the 'walls' cannot force their way through their opponents, the ball finds its way out to the 'seconds,' who in their turn try and gain ground, generally by kneeling on the ball, and with hands on the ground or not as they are able, crawling along and often forcing their opponents to retire several yards. On such occasions the 'walls' back up the 'seconds' and are ready to take the ball again when the 'seconds' are obliged to relinquish it; all in the bully should, in fact, be ready to assist one another, and when the ball is 'loose ' or one of their number is down, to get hold of it with their feet and try to move further on.

If, as is generally the case, the ball comes out from the bully amongst the 'outsides,' i.e. the 'thirds,' 'fourths,' and 'lines,' it is their duty to try and charge the ball through their opponents and kick it as far as possible towards the enemy's calx, but always out into the field, so as not to give the opposing 'behinds' a chance of returning it. And again, if the ball rolls out from the bully to any of the three behinds, it is their duty to kick it as far as possible in the same direction, but as above mentioned, always into the open field and for the same reason. An 'outside,' when the ball is 'loose,' not unfrequently attempts to dribble the ball down the play; but this rarely pays, the ball being light and the space confined. It is when the ball is amongst the outsides that the most exciting play takes place, the opposing sides kicking at the ball and at one another in the wildest manner, so much so that an inexperienced spectator would probably characterise this part of the play as very rough. These 'loose' bullies seldom last more than a fer moments, one of the kicks soon taking effect and landing the ball out of play. When the ball is kicked over the boundary line, it is the duty of at least two or three of the side and always 
'of the 'line,' to run out into the field, the one side to stop it as soon as possible, and the other side to prevent it being stopped.

It sometimes happens that those in the bully of one side are able to hold the ball for a long time and keep it to themselves. This is always very tedious for both spectators and the rest of the players, and unless a side is playing for a draw or having scored is afraid of yet being defeated, it is always better and is generally customary to break the bully early, and by a series of charges, 'loose' bullies, and scrimmages to gain ground.

Anyone who has both feet in front of the ball is said to be 'sneaking,' or 'off-side,' as it is termed in other games, and must at once get back amongst his own players. A player may be 'sneaking' whether in the act of playing the ball or not. The only penalty for this is a fresh bully, but if the ball is being held tight at the time when the offence is committed, no advantage can accrue to the other side, and the penalty is therefore not demanded; if, however, the ball is 'loose' and the offender gains an advantage, the penalty is claimed and allowed or not by the umpire, and the fresh bully formed against the wall at the spot where the offence was committed. It is permissible also for any player to catch the ball or stop it with his hands and then to kick it in any way he can; but if the ball hits the hand or wrist accidentally, the penalty if demanded and allowed is a fresh bully.

A point is scored by either side getting a goal or a shy. A goal can be obtained from any part of the play; a shy only in calx. A goal outweighs any number of shies, but is very seldom obtained. A shy is obtained in the following manner: When the ball is forced into calx the bully is formed in a slightly different manner. The side who have forced the ball into calx have the advantage of forming down under; one of their players called a 'getter' forms down with his head to the wall, and has with his foot to raise the ball when placed in the bully against the wall; another forms down behind him and has to prevent the opposite side drawing or 'furking' it out (these two 
are backed up by the heavy weights of the side) ; another called 'a toucher' has to assist the 'getter,' and when the ball is off the ground and against the wall and resting on his own foot or on that of one of his own side, to touch it and claim a shy. Anyone besides the 'toucher' can obtain a shy, but he must be behind the ball, i.e. on side. If the shy is allowed the player who touched it throws it at the goal, i.e. the tree or the door according to which calx it is, which he hits or not according to the accuracy of his throw and the quickness of his opponents in running out of the play to the goal and stopping the ball with their hands. The rest of the side except (say) two 'behinds' stand outside the bully ready to charge and prevent the ball being forced out of calx. The defending side in calx forms down by one of their number standing against the wall, leaning over the 'getter' ; he is called a 'stopper,' and his duty is to prevent the ball being raised and a shy gained, and also to try and get the ball out of the bully to the 'kicker-out' behind him ; another next to the 'stopper' to assist him, one or two to back these up, one to 'furk' the ball back, one to kick the ball out of calx at the door end and to touch it down over the base line at the tree end, and the rest to stop 'running round.'

The game generally lasts an hour, and ends are changed at half-time. It is peculiar to Eton, and would in all probability die out altogether except for the annual match between the collegers and oppidans on St. Andrew's Day.

The Eton Field Gane is played in an open field about I 00 to I 20 yards long by 80 to 100 yards wide. The boundaries are defined by a small line cut in the turf; the goals are in the middle of the two base lines, and are about I 2 feet wide by 6 feet high, formed by two upright posts with a slender crossbar at the top.

There are by rights eleven players on either side, though in ordinary games there is no objection to a larger number, and this is one of the advantages of the game, that with sides of small boys very often far more than the orthodox number can play. 
The ball is a small one of the same size as that used in the wall game, and little more than half the size of the Association ball Taking a side of only eleven players, they arrange themselves as follows : first, the bully, consisting of a 'post,' 'back-up post,' and two or three 'side posts,' four or five in all; secondly, those outside the bully, viz. a 'corner' on either side of the bully corresponding- exactly in position to the 'half-back' in the Rugby Union game (occasionally the third 'side post' is placed to play 'extra corner'), and a 'behind-the-bully' or 'flying-man,' the first of whose names defines his position, and thirdly, the 'behinds,' three in number, 'short behind,' 'long behind,' and 'goals.' The game is commenced by a bully in the centre of the ground, the players in the bully forming down under and over alternately; the ball is placed in the centre of the bully by one of the 'corners,' and the play begins.

The object of the players in the bully is to force the ball through their opponents, the ball being usually held tight and not kept 'loose' and moving as in the present style of Rugby Union play; the rest of the players await events in their respective positions. The bullies, as a rule, only last a few moments, and directly the ball is 'loose' and finds its way out at the side, the 'corner,' or if it finds its way out behind, the 'flying-man,' immediately starts off at full speed dribbling' it close in front of his feet towards the opponents' goal. The game now becomes essentially a dribbling one, and it is wrong for a forward to let the ball go more than a few paces in front of him. It is also essential to go as straight down the field as possible, though this is extremely difficult, since by so doing the player in possession of the ball has to get straight through the majority of his opponents.

One player, then, having got possession of the ball and begun dribbling it, the rest of his side follow in his wake, close behind and ready to take his place at the head of the pack the moment he falls, overruns, or loses the ball. The two bullies may be said at such a moment to resemble two packs of hounds, the foremost player sticking to the ball as long as he can, like a 
hound to the scent. It rarely happens, however, that one player can keep the ball very long; for either he kicks it too far in front of him, or loses it in a charge of the other side (and charging when in possession of the ball is a chief characteristic of the game), so that the opposing 'behinds' are sure to get a kick sooner or later. And as soon as this occurs, it is the duty of a good behind to lift the ball well and almost invariably to kick it as far and as high as possible, the higher the better, since his side has the more time to charge down the opposing behind, who would otherwise return it. And it may here be mentioned that the behind is supposed to take the ball exactly as it comes to him, to volley, half volley, or kick it whilst rolling, and it is this ready resource in taking the ball in any position and exactly as it comes to him wherever he is standing that makes the Etonian excel as a back when he tries his hand at the Association game. The ball remains 'loose' as a rule for a few minutes or more, the forwards charging the behinds and dribbling the ball when they get possession, and the behinds returning it whenever it comes over or through the bully until by a behind making an inaccurate kick, or the forwards being prevented from going straight down the field and so forced towards the side, the ball is impelled over the side boundary. A new bully is then formed some twenty yards in the play in a line with the spot where the ball went out. It is unnecessary to follow the various phases of the game between each bully, as the play is more or less of the same description; suffice it to say that it is, or should be, remarkably fast, and that the chief characteristics of a good 'forward ' player are that he should be always 'on' the ball, should dribble always, nezer 'pass' the ball, be constantly 'backing up ' when he is not playing the ball, and always prepared to charge his opponents, going straight at them, while the behinds should be able, as mentioned above, to kick hard and clean, and in any position, and with either foot. There are two misdemeanours a forward can commit : 'sneaking ' or 'cornering.' A player is said to be 'sneaking' or 'off-side' when he gets in front of the ball, and 
when on the ball being sent forward again either to him or in front of him, he goes on with it or in pursuit of it. He should wait till the majority of his co-forwards have come up level with him and so put him 'on side,' otherwise he is sneaking, and the penalty, if claimed and allowed, is a free kick for the claiming side from the place where the offence was committed. 'Cornering' is when a player is outside the pack or bully, and on the ball being kicked towards him well to the side of the main body of players, he proceeds to play the ball. The penalty, if claimed and allowed, is a bully where the offence was committed. The 'flying-man,' however, is allowed 'to corner,' the reason being that he acts in the double capacity of a forward and a behind.

A point is scored by the ball being forced down to the opponents' base or goal-line. If the player who is in possession of the ball is tolerably near the goal-posts, it is better play to shoot at once for 'goals,' and if this is done, a point is not unfrequently scored, small though the goal is, for the goal-keeper does not remain immediately in goals as in Association, but follows up the 'long behind' at a reasonable distance, and he may not use his hands.

If, however, there is no chance of shooting a goal from midfield, the player with the ball runs it down to the goal-line and takes it along the line towards the posts, and then makes his shot, or more frequently endeavours to secure a minor point, called a 'rouge.' A 'rouge' is when an attacking player kicks the ball over the goal-line whilst in the act of charging an opponent, and himself or one of his side touches the ball before any of the other side. A rouge may also be obtained by one of the repelling side miskicking the ball behind the goal-line, or the ball going off one of the repelling side in any way over the goal-line, and one of the attacking side touching it first. It takes four rouges to equal one goal, and a rouge may be converted into a goal; for when a rouge is claimed and allowed, a bully is formed in front of the goals thus : the defending side form down one yard from the centre of the goals by one 
of their number, called 'post,' taking up his position in the centre with the ball between his feet, and three or four placing themselves close up behind him, with others called 'sides' on either side to support him ; the remainder, some two or tirree, 'look out' to get the ball away when it becomes 'loose.' On the attacking side, four players, also called ' sides,' form down against the defenders' bully, two on either side, leaving a small gully in front of 'post' just large enough to admit some four of the attacking side, and these headed by one who is said 'to run in' charge in a compact body, one close behind the other, against the centre of the opponents' bully, so that when they have closed, the whole is one consolidated mass.

If the attacking side is stronger, and the 'sides' do their work properly, the bully of the defenders is sometimes pushed bodily through goals; if, however, the two bullies are equal in weight or strength, the ball eventually breaks 'loose,' and the play continues as originally begun.

If no rouge is allowed, or the attacking side kick the ball ' cool' over the line (i.e. while not being charged), it is a ' kick off' from the goal-line for the defending side. If the defending side kick the ball bchind their own goal-line, and one of their own number touches it first, a bully is formed where the ball was kicked.

If the ball hits the hands or forearm below the elbow, a bully can be claimed by and allowed to the other side. The game lasts an hour, and ends are changed at half-time.

The Harrow Game has been played in substantially its present form for upwards of half a century. Changes in the rules have undoubtedly been made from time to time; and in recent years the adoption of the Association rules at the principal preparatory schools has affected in some measure the style of play. The distinctive features, however, of the Harrow rules remain unaltered, and being in a sense the natural offspring of local circumstances, it is probable that they wil! retain their hold on the School for many years to come. Everybody knows that Harrow is on a hill. It follows, therefore, 
that the football fields are at the bottom of a hill, and are difficult to drain, especially as the soil is a stiff clay. The grounds, in fact, are often half under water, and in the height of the football season are generally a mass of trampled mud. This state of things necessitates the use of a heavy ball and rules which compel the players to be continually on the move.

In matches eleven play on each side, the usual disposition of the players being as follows: a 'whole back' and a 'half back' (formerly called 'base' and 'second base'-terms probably unknown to Harrow boys of the present generation) form the rearguard; two players keep each 'side,' called respectively 'top side' and 'bottom side,' and the remaining five 'follow up.' It will be noticed that whereas the Association game has five or at most six 'forwards,' the Harrow game has nine.

The rules as they at present stand are not hard to master, although they differ in some essential characteristics from those of any other game of football. There is a strict off-side rule as at Eton. A player who is nearer the opponents' base than the kicker of the ball is out of the game until the ball has been touched by one of the opponents' side. As regards the mysteries connected with the word 'yards,' the Harrow rules may perhaps best explain themselves. Rules 6,7 , and 8 of the Harrow code say :

Whoever catches the ball is entitled to a free kick if he calls ' Yards'; but whoever catches the ball, and does not call ' Yards,' is liable to have the ball knocked out of his hands. The ball must be kicked without delay; and the preliminary run must not be longer than three yards (i.e. the utmost length to which three running strides would extend). When a player catches the ball, he may take his three yards, or each of them, in any direction he likes. If a player catch the ball near the opposite base, he may try to carry the ball through by jumping the three yards. If he fail in this attempt, no second try is allowed, but he must return to the spot where he caught the ball, and from there may have a free kick at the base ; none of the opposite side may in this case get in his way nearer than the spot to which his jump brought him. 
This system of 'free catching' was no doubt originally introduced to meet the supposed difficulty of 'shooting' a base with a heavy ball under a strict off-side rule. In theory the base is unlimited in height, for the ball may be kicked between the poles a solo usque ad calum.

The Harrow player is always at first a 'selfish' Association player, because he has learnt under the strict 'off-side' rule to stick to the ball till it is taken away from him by an opponent.

Another feature of the rules which an Association player can hardly fail to notice is that there is practically no penalty for breaking any of the rules. It has been found after many years' experience quite unnecessary to inflict one. In important matches two umpires are appointed, who have vested in them the power of sending a 'rule-breaker' off the field, a power, however, which in practice has very seldom to be exercised.

To return, however, to the game itself. Although the ball is heavy and of an awkward shape, Harrow boys attain a complete mastery over it and learn to dribble it with wonderful accuracy. Evidently it represents the most rudimentary form of football, being a kind of irregular oval in shape, and really, in fact, nothing more than a bladder enclosed in three pieces of thick shoemaker's leather, two being circular and the third a broad strip equal in length to the circumference of the ball. Until quite recently all boys below the first ninety or so, with the exception of those who had been in the school for three years and those excused by medical certificates, were compelled by the school rules to play football at least twice a week. As late as I 864 those who went down to play were divided into only two games according to age, the result being that scientific play was quite out of the question. In recent years great improvements have been made in this direction, thirty or forty at the most playing in one of these 'compul.' games as they are called. Harrow football is essentially a game for boys and those who love hard exercise. It has simple rules, is fast and manly, and has no penalties or ceremonies which waste time. It probably takes more out of a player who goes in to win heart and soul than any other form of the game. 
Tine Winchester Game differs in its general character from every other game of football. The ground upon which it is played is about 80 yards long and 25 yards wide. Thus upon the college 'meads,' which are more or less square with an irregular excrescence upon the side nearest to the college, it was possible for four games to be played simultaneously, while the central portion was reserved for cricket. To keep the ball within the prescribed limits, the ancient custom is generally believed to have been first to mark out the space with stakes and ropes, then outside the ropes to place a line of shivering fags. In time, humanity and genius combined discovered that hurdles served the purpose as well as small boys; and in later days the hurdles have given place to tarred nets spread out upon an iron framework some ten feet in height. The ropes still remain, and are placed about a yard from the netting, and when the ball (which is round, and heavier than an Association ball) is 'under ropes,' i.e. between the ropes and the netting, it is still in play in a certain sense. The game begins with a 'hot,' which is formed in the following fashion. In 'sixes,' or six-a-side matches, there are two backs or 'behinds,' on each side, and four forwards or 'ups.' Of the 'ups' one is 'over the ball,' and takes the centre place, and two back him up with their knees behind his, and their arms interlaced round his body. All these keep their heads down, and the fourth with his back and shoulders propels the centre man. In 'sixes,' notwithstanding the closeness of the packing, the duration of a 'hot' is not usually long, but in 'fifteens,' where the same principle of packing is observed, ten minutes or more may be occupied with a 'hot.' When it is added that the performance is deliberately repeated every time the ball is kicked over the netting, and that there is no other penalty than a 'hot' for any infringement of the rules, it may be imagined that 'hots' occupy the greater part of the hour which is devoted to a match. The ball, however, is not kicked out as often as might be supposed probable, for one of the most stringent rules of the game is, that it may not be kicked 
higher than five feet, which is supposed to be the average height of a man's shoulder, unless, at the time when it is kicked, it is either bounding or rolling at a distinctly fast pace; nor may it be kicked up unless the last person to touch it was an opponent, for, in the contrary case, it is a 'made flier.' This is a rule which causes almost as many hots by being infringed as it sares by preventing the behinds, who alone do much in the way of kicking, from driving the ball over the netting. Still it is a necessary rule, for the goal consists of the whole twenty-five yards or thereabouts, that is to say, of the whole width of the arena, and but for the rule concerning 'kicking up,' there would be no end to the number of goals obtained. It should be mentioned, however, that if a ball before passing over the goal-line, or, as it is called, 'worms,' is touched ever so slightly by any opponent, no goal is scored. The distinguishing features of the game, apart from those already mentioned, are, in the first place, that no dribbling is permitted under any circumstances ; and in the second place, that the 'off-side' rule is stricter than in any other game. It is not legitimate for two players on the same side to touch the ball in succession, unless it rolls behind the first kicker ; nor may one player 'back up his partner's kick' by charging the adversary, unless, at the time when his partner kicked, he was behind the ball, or, since that time, has returned to the place from which the ball was kicked. When the ball is caught upon a full volley kicked by one of the opposite side, it is 'punted ' and not 'dropped;' but if the person catching it is charged, then he who charges is said to be 'running him,' and may 'collar' him as in the Rugby game, and the holder of the ball may run until his adversaries cease to 'run him,' but then he must halt and take his punt.

The only remaining feature of the game which requires notice is the 'under ropes' play. No ball kicked from 'under ropes,' or which has touched the netting or ropes after being kicked, can score a goal, nor can a fair catch be made when the ball was either kicked from or-caught in 'under ropes.' 
It is often, therefore, good generalship for a heavier side which is a goal ahead, when the game is nearing an end, to keep the ball under ropes to prevent any further score being made.

It will be seen that the Winchester game not only teaches accurate kicking and dashing play, but also gives an opportunity for skill in scrimmaging. Consequently, although the Wykehamist as a rule takes to the Association game in after life, there has been more than one instance of a player bred up to the Winchester game earning the highest honours in the Rugby Union field. The majority of players, however, of the Rugby Union game, which it will be our next duty to describe, come from the public schools, such as Rugby, Clifton, Marlborough, or Cheltenham, where they learn the running, scrimmaging, and tackling game in their school-days. 


\section{CIIAPTER IIY.}

THE RUGBY UNION GAME.

Although the forms of the dribbling game were many and various, as we have seen, the running and tackling game has always been played, since it first became an organised sport, substantially in one way, that in which it came from Rugby school to the country at large. That form, it will have been perceived, is historically an adaptation of the original scrummaging game to a field of play when there was plenty of room for a number of boys to overthrow each other 'without hazard (or any great hazard) to their limbs.' The ground not being unlimited, like the field of play of 'hurling across country,' boundaries at the end and sides, or 'goal lines' and 'touch lines,' were established, and the ball when beyond these was considered out of play as soon as 'touched down.' Save for this the original features of the game remained only just altered so far as to prevent any actually dangerous violence. As soon as the game came from boys to men, however, further modifications became necessary, as the adult shin and neck could not stand the amount of ' hacking' or 'scragging' which used to be seen in matches at the Rugby game before the rules were definitely settled and promulgated by the Rugby Football Union. Now we do not intend in the present work to describe in minute detail the rules either of the Rugby Union or Association games, taking it for granted that those who do not know the games, by actual acquaintance as players or spectators, will care nothing for what we have to say about them ; while those who do so know them will not require to be enlightened about the $\mathrm{ABC}$ of the sport. We may also at once say that we do not propose in any 


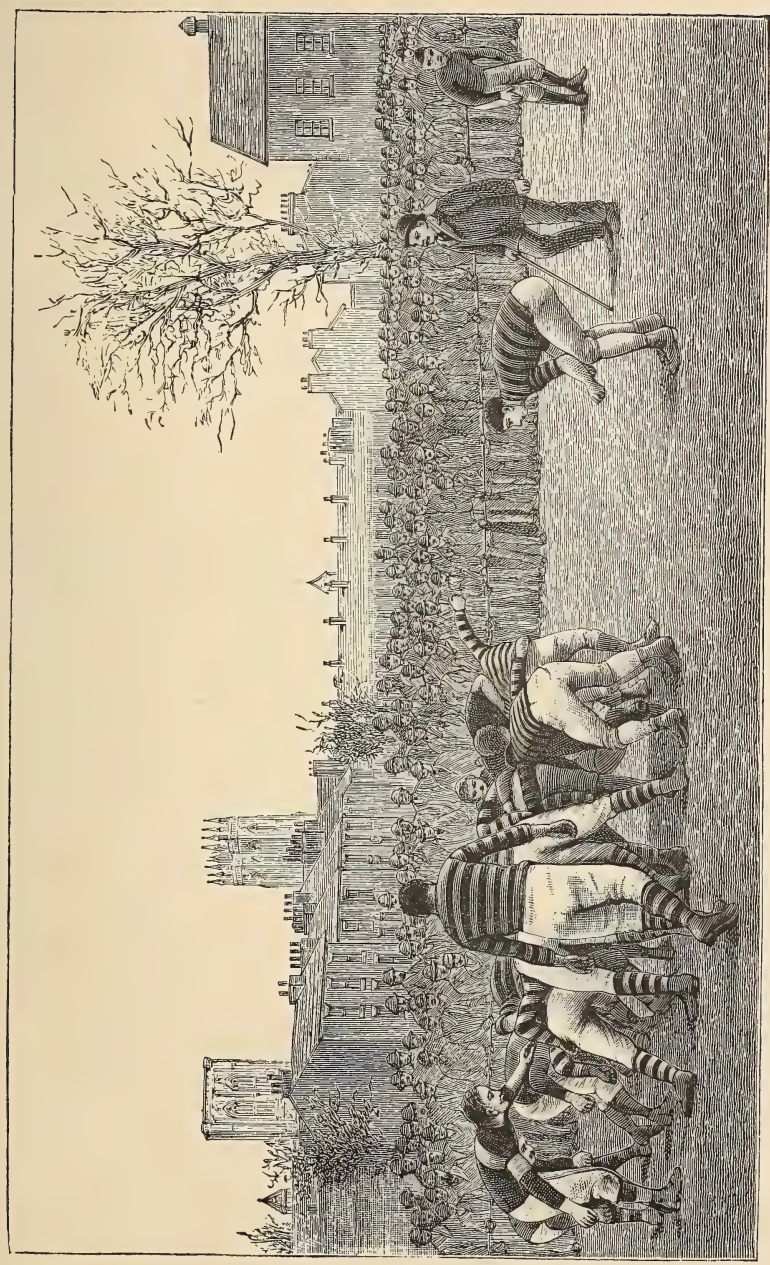



of our criticisms of the past or present games under either set of rules, to take sides in the old and threadbare controversy as to which is the better game-Rugby or Association football. To start at once with a piece of advice, we recommend both players and spectators to pay their money and take their choice, and for preference to try both, not together but 'singly in quick succession.' At the outset, therefore, we may begin by saying, we hope, without offence, that the early matches at the Rugby

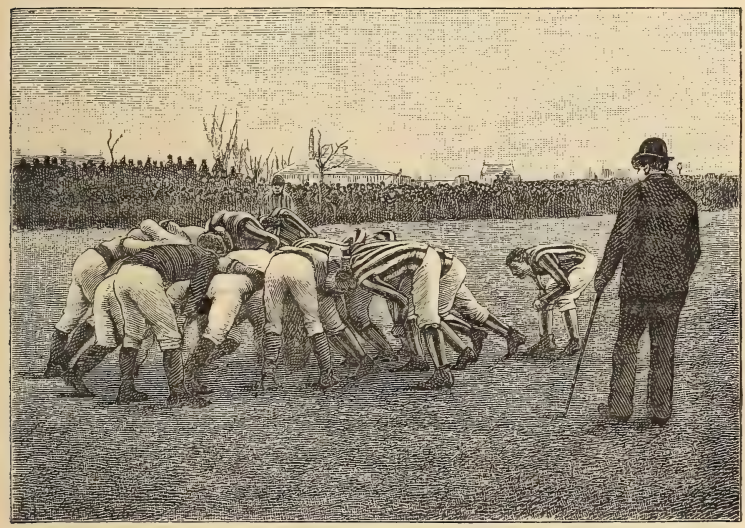

Rugby football.

game were very dull affairs, and that it is only very slowiy and tentatively that the Rugby Union rules and style of play have been altered so as to render skill of more avail than force in the settlement of matches. Rather more than a dozen years ago we saw a shoving match between rival teams of Scotchmen and Englishmen which was dignified by the name of an 'international match.' A quarter of a hundred of heavyweights appeared to be leaning up against each other for periods of five minutes or thereabouts, while occasionally 
the ball became accidentally disentangled from the solid globe of scrummagers, and the remaining players then had some interesting bursts of play between themselves while the globular mass gradually dissolved. The plain truth of the matter was that the Rugbeian traditions of 'big-sides' still remained an article of faith with players, and that the main thing which kept big-sides from becoming shoving matches was first the smallness of many of the boys who could thus move about in the scrummage, and secondly the hacking which kept the scrummage open and the ball moving. For the dozen years or so during which the Rugby game was played before the foundation of the Rugby Union the shoving was the great hindrance to its popularity. True it is that the matches as a rule were only between fifteens and not twenties, but the grounds used were often very small, and were described as 'large enough for fifteens' by the players, who still thought that twenty was the minimum for a model side. So far also did the notion go that scrummaging was the essence of the game, that some clubs played the rule that no man who was tackled was obliged to call 'down' unless he liked; and in one match in which the present writer played, the heavier side, when one of their own men was collared, used the tactics of never calling 'down,' but of shoving the whole of the opposite forwards down the ground until the accidental or intentional 'tripping up' of the whole scrummage by the side losing ground necessarily caused a halt, and the ball was then at last put down. The Rugby Union, immediately after its establishment in I87 I, determined to put a stop to this 'mauling,' before the ball was down, and the I 8 th law was especially framed to deal with this abuse. This law has since been altered, as we shall see later, but as originally framed it ran as follows : "In the event of any player, holding, or running with the ball being tackled, and the ball fairly held, he must at once cry "dozen," and there put it down.'

A few words might perhaps here be said with reference to the Union code of laws, which are too long to discuss seriatim, and will therefore, in their present form, be placed in the 
Appendix to this work. By reading them, one can perhaps obtain as good an idea of what the game is as can be given by any bald scientific description of a moving scene of life. The original laws have naturally been altered from time to time as the character of the game changed, and as abuses arose which it became necessary to prevent, but there can be no doubt that they were very admirably and carefully drafted.

The original code of laws was the work of three old Rugbeians-L. J. Maton, A. Rutter, and E. C. Holmes, and it is doubtless due to this fact that those who now play the running and tackling game are substantially playing the same game which the founders of the Union played at Rugby School. After twenty years' use the original laws became so overlaid with a mass of amendments and additions that the Union decided upon a new codification. The present code, which is printed in the Appendix, was mainly the work of W. Cail, of Northumberland County. It came into force at the commencement of the season $189^{2-3}$, and has stood the test of practice well, as very few amendments or explanations have been necessary since the game has been played under this set of laws.

To return, however, to the Rugby Union game during its first or 'shoving' age. The Union code very properly abolished hacking, tripping, and scragging, the last named of which practices consisted in the twisting of an opponent's neck round, with a gripe of the arm, to make him cry 'down,' if he had any available voice; but the abolition of all these practices, and especially of the hacking, tended to make the game 'tight,' and to render of little value the best and most skilful forward play, which can be only exhibited in 'loose' scrummages. But what kept the old system alive was undoubtedly the retention of twenty a side in the international contest with Scotland. The bulk of the 'forwards ' chosen for the twenty-a-side contests were strong, heavy men, and without strength and weight a player had little chance of making his mark amongst the forward brigade. 
The result was that under the old regine the typical forward was a man who knew how to 'shove,' and very likely could do very little else. So firmly, indeed, was the traditional notion of the 'big-side' impressed upon the chief players of the Rugby game, that as late as 1875 the 'Football Annual,' which is what a political writer would term a 'semi-official' publication, was still advising captains, in its 'Hints upon the Two Styles,' to play twenty-a-side if they could get the men to play. By this time, however, twenties had been abandoned in all but the classical matches of the year, and in the winter of 1875 the Oxford and Cambridge authorities agreed to have fifteens instead of twenties for the Inter-'Varsity match. In the following season the example was followed by the English and Scottish Unions. Up to 1876 , however, the first period which we have called the 'shoving' age, lasted, and during this period the light and speedy forward was seldom heard of. The character of the forward players, too, influenced the arrangement and style of play of the rest of the field, and as the old game is now only recollected by few-for spectators at football matches were scarce in those days, and even international matches were sometimes financial failures - it may be worth while to describe what manner of game was played in the days of 'English twenties.'

Matches between clubs were played with sides of fifteen as is usual now, but not only was the style of forward play different from the present, but the arrangement of back players in the field was also necessarily different, the greater part of the offensive play falling upon the half-backs and of the defensive upon the full backs alone. The original notion was to have only two classes of players behind the scrummage, half-backs and backs, there being two half-backs, three backs, and the remaining ten players being forwards. The earliest development of the game was to put the 'centre' back a few yards in front of the two backs at the sides, to enable him occasionally to get away on a run after a drop kick from the back ranks of the other side. Such was the arrangement of the field which the present writer 
first recollects. Now as to the points which made a good player of the game at that time. IVe have already said that the forward was expected to do his best to keep the scrummage tight and shove the other side down the ground. The half-backs, standing well away from the compact scrummage, would exhort their forwards to be 'steady with it,' to go ' not too fast,' and to 'keep it together.' The same authority from which we hare already quoted as 'semi-official' (and a very competent authority the writer was) says :-

Some players are given to putting their heads down in a scrummage so as to look after the ball better, but it is a plan not to be commended as it loosens the mass, a man with his head down taking up the space of two. A scrummage should be formed as compactly as possible, every man pressing firmly on the man in front of him, bodies and legs close together, so as to form a firmly packed mass to resist the weight of a like mass of opponents, . . . the great point to be aimed at being to stop the progress of the ball towards one's own quarters.

A scrummage so formed naturally took so long in breaking up that the behind players of one another's side were off and away with the ball in most cases before the mass of the forwards could get thoroughly loose. The 'behinds' then did most if not all of the brilliant play, the running and the tackling, while the forwards did the scrummaging, which was their main business during the game. Of course we do not want our readers to think that the course of every game was this invariably; no doubt the tactics of some clubs differed from those of others, and gradually from year to year the advantages of 'loose play' came to be more and more recognised. The style of play, however, altered very gradually for the better, and we have known more than one forward to remark in the field after half an hour's play that he had not yet touched the ball.

One or two things tended to keep up the tight scrummage game longer than it would otherwise have lasted. It was considered 'bad form ' for a man to put down the ball immediately 
he was collared; for one thing, the runner was nearly always a behind, who had to get back to his position in the field, and there was thus plenty of time for the scrummage to collect and pack itself, and indeed the ball was as a matter of courtesy never put down until the scrummage was well formed. Again, too, for a long time there was a controversy as to when a man was 'fairly held' within the meaning of the rule, many averring that there must be at least two opponents on the ball before it became obligatory to cry 'down.' This rule of football etiquette was, however, definitely disposed of in 1878 , when law 18 of the Union code was altered to its present shape, and the player was obliged, 'when fairly held,' to 'at once cry down, and immediately put it down.' This alteration at once made dribbling an essential feature of Rugby forward play. Another rule of football etiquette was to consider it more or less of a 'low trick' to 'heel out' the ball to the half-backs, a course which was obviously advantageous to the side when its back division was strong and its forwards weak. Many were the casuistical distinctions drawn as to this piece of etiquette by those who were divided in their desire to do the correct thing and to score a try when the scrummage was near the adversaries' goal-line, and to this day many think it admirable play for the forwards to open their legs to let the ball through, but not good form to heel out, a distinction with about as much difference in moral character as there is between one who steals and one who receives stolen goods-that is to say, supposing that the practice is to be considered wrong at all.

If the forwards, however, had a dull time of it, these were the palmy days of half-backs. The 'half-backs' were then the heroes of the field, and had pretty well all the 'gallery' play to then sselves, although the three-quarters-backs gradually and surely rose in importance. The half-backs then stood five or six yards away from the scrummage, and the chief requirement for the place was a capacity to start quickly and to dodge the opponents' half-back ; for once well past the half-backs the runner had the whole field clear with only three players 
between himself and the goal, and the forwards already too far behind to have any hope of catching him. His duty was, in the words of our friend the semi-official authority, to 'get away with the ball at full speed directly it makes its appearance through the forest of legs,' and to stand well back from the scrummage, as by going too near men have 'less time to pick up the ball' (strange words, but true enough in the days of tight scrimmaging) 'and lose sight of the movements of their opponents' half-backs.' It is not difficult, then, to see that the most enviable position in the field was that of half-back, and that most 'tries,' most sensational 'tackles,' and most glory fell to these fortunate players. The best of them, we think, who ever played under the old game was W. C. Hutchinson, of Cooper's Hill. He had a marvellous faculty of dodging without slacking pace just out of reach of the back who awaited his coming, and woe betide the opponent who hesitated for a moment to rush head-down at him and tackle at once. The man who waitcd for him was lost.

Three-quarter-back play during this period had some points of similarity with the present style of play in that place, but there was less for the 'three-quarter' to do, as most of the attack was carried on by the halves, and passing was much less practised than it is now. The 'Rugby Union Football Annual' for 1875 , in an article written by an 'Old Rugbeian,' says that for the post of 'three-quarters' a man 'of good speed and a safe tackle should be chosen' (good enough advice at all times), 'and like the backs, it is not so imperative that he should be a fast starter as a strong runner when he has got well away.' In the last clause lies the distinction between the old and present style of three-quarter; the three-quarter of old times was little troubled by the forwards, and seldom had to fall on the ball to stop its progress under a forward rush. One threequarter was considered sufficient for the English twenty for several seasons, even although the Scotchmen were playing two or three according to the more modern style. What was mainly expected of a three-quarter was that he should be an 


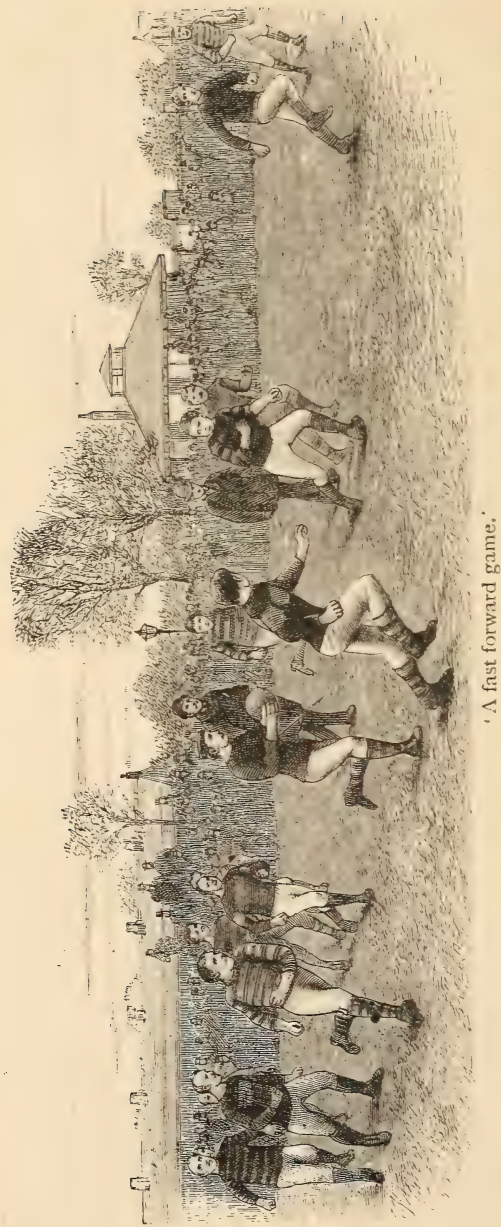

admirable drop and able to score a dropped goal when opportunity offered. In H. Freeman, the Marlborough Nomad, the English twenty found just the man it wanted. For two years running, in 1874 and 1875 , he won the international match for England by dropping a goal, the magnificent leftfoot drop with which he scored upon the first occasion being a traditional theme for discussion amongst football coteries.

With regard to the full-backs under the old game, little need be said at present, as the style of back play never has and never can vary in the Rugby game. Your back is a purely defensive player, and must be able to drop or punt well, and be a deadly tackle. Good backs are the rarest of all rare 
players to find, as the place is responsible and uninteresting in a winning game. That the right article was even harder to come across in the early days of big matches than now we can readily believe, and time after time the backs chosen for international matches made wretched shows upon the ground; but we shall have more to say of backs later on.

After the substitution of fifteens for twenties in international matches in 1877 , the change in the style of play became rapid, and the loose game came into fashion. Many clubs have claimed the honour of introducing the loose game. A Scottish football enthusiast has told us that the Scotchmen at last taught the Englishmen how to play the real game ; in London the great rivals Blackheath and Richmond still dispute as to the honour of instituting the new style. In the present writer's humble and perhaps biassed opinion, the change emanated from Oxford. Certainly he knows that when, after playing in London in the season of $1875-76$, he played at Oxford in the spring of that year against the best London clubs, the Oxford forwards playing a loose game surprised the Blackheath and Richmond players as to the merits of loose play, and by this time, it must be recollected, the Universities had given up their twenties for fifteens. At any rate, whether any club or county can claim the especial honour of originating loose play, certain it is that it was from about 1876 that the small thick-set forward began to make his appearance upon the field, and the words 'fast forward game' began to be heard of in connection with Rugby football. Speaking roughly, and in order for the sake of conrenience to divide the description of that game into periods, we say that as from the institution of the Rugby Union the first or 'shoving' period of the game lasted for half a dozen years, so the next, or 'loose scrummaging' period, lasted for about a similar time, until the latest development of the game, the age of 'passing,' began.

One change which was made in the rules of the game and helped to alter its character ought first to be mentioned. $\mathrm{Be}$ fore 1875 a match could only be won by a majority of goals, 
this having been the original Rugby rule. Amongst men, however, place-kicking is never so good as it is with schoolboys, and the result was that in very many matches no goal was scored from the tries which were gained, and it became a common thing for a match to remain 'drawn,' although one side had secured several tries. As an example of the absurdity of the system it may be mentioned that the present writer played in one match when nine tries were obtained by one side, and yet it was declared drawn. The rule as altered in 1875 provided that one goal should be better than any number of tries, but that if no goal should be obtained the match should be won by a majority of tries ; and this method of scoring remained for eleven years, although efforts from time to time were made to reduce the importance of the goal. Since then the rule has been frequently altered, and at present the game is decided by a majority of points, a try counting three, a penalty goal three, a dropped goal four, and a goal from a try two in addition to the try.

In the second period the good forward not only had to be a good scrummager and tackler, but was bound also to be a good dribbler, and fast in following up. If nine or ten of the desired players could not be found in a club, it became necessary to choose some for thcir scrummaging, and others for their dribbling and following up ; but it was necessary at any rate for the team as a whole to show a combination of activity and power, and not to rely on strength alone. As soon as this was recognised, and it was seen that games were mainly won by good combined forward play, the object of the forwards on the winning side became not to keep the scrummage tight, but to break it up as soon as possible, and if this could not be done by straight shoving through the middle of the pack, to effect the same object by screwing the scrummage round with the ball still at the feet of that layer of the scrummagers which was borne to the front. With the scrummage once broken down, the ball was away in a moment, and borne down the field by the combined rush of the forwards. As soon, then, as the new game came in, every forward had to go into the scrummage head 
down, for by standing well up and shoving blindly he became of more harm than good. Above all things he had to learn to dribble, and keep the ball close to him, and not to kick the ball right away from him into the hands of the opposing threequarters. The new forward had to be a sturdy vehement player, but with his feet well under his control. In fact, he is the forward of to-day, save that he was not taught to cultivate 'scientific passing.'

As the system of 'tight scrummaging' gradually gave way, the half-backs began to find themselves with less and less offensive and more defensive work to do. The half-back could not afford to stand away from the scrummage so as to get well away from the ball, for the loose scrummagers were on the ball the instant it came through the scrummage. The chief business of the half-back then became to snap up the ball like lightning as soon as it came away from the pack, and then to run, punt into touch, or pass back to the three-quarter, as opportunity offered; but it was seldom in a fast match upon a dry ground that the half-back had a really good chance of himself getting away direct from the scrummage, his best chance of a run being after a pass from one of his own forwards. The immediate results, therefore, of the loose scrummaging system were these : the great requisites for a half-back became readiness of resource and nimbleness and deftness in picking up the ball ; speed of running being a comparatively minor consideration. The proper place for the speedy runner was at three-quarter back, and the slow runner did little good at three-quarter unless he happened to be a marvellously good and quick 'drop-kick' In the later game then we find the three-quarter backs doing the majority of the long runs, sensational drop-kicks and brilliant play, and the half-back having to content himself with being 'useful' only in all the 'outsidescrummage play,' although he often got his opportunities for dedging over the line if he followed up the three-quarter after a run, or got hold of the ball after a loose rush of his own forwards who had overrun the ball. 
The first alteration of tactics when the new game had fairly come in was the experiment of playing three half-backs outside the scrummage. The practice, however, never properly took root, although we believe the Blackheath Club steadily played this way throughout one season; the three 'halves' often got in each other's way, and there soon became little doubt that it was a mistake. Two 'backs' were always played at that time, and to play seven men behind the scrummage was considered then a dangerous risk, nor could one threequarter be reasonably expected to do all the work behind the three halves. The game then settled down for a bit with six players behind the scrummage, two halves, two threequarters, and two backs, the remaining nine playing forward. The best halves were strong, thick-set men, rather under than over middle height, who could both whip up the ball and tackle unerringly, and were hardy and elastic enough to come up smiling after half a scrummage had fallen plump upon the top of them. In these days also there was more room for a half to be brilliant than there is at present, as he was expected to snap up the ball and run or punt into touch from the mêlée, and not to 'sweep' the ball straight back to the three-quarters as soon as he could get his hands upon it.

The real feature of the loose game, however, was the additional importance it gave to the three-quarter back. In the old days when most tries were gained by a straight 'run-in,' the main defence rested with the backs, who could be relied upon to tackle the runner before he reached the goal-line; but now, when the most dangerous assault was a rush of the forwards in line, the single defensive line of the backs could not be relied upon, and the three-quarters had at all costs to keep the ball in front of them. Thus they came to do the bulk of the really important defensive work ; they also rapidly came to do most of the long brilliant runs. The half-back was too close to the loose scrummage to get round, and thus constantly passed to the three-quarters, who then found a chance of getting away. Often, also, this chance arose through the clumsiness 
of an opposing forward, who kicked hard when he should have dribbled, and thus sent the ball past the half-backs into the hands of the three-quarters. The three-quarters thus were the only players behind who had much prospect of scoring a dropped goal, or of getting 'well away' with a hope of running round the opposing field. Thus the three-quarters found most of the brilliant attack fall to their share, and as they formed also the main defence of the field, the 'full-backs' had little to do. First one and then another club started the new custom of playing one back and three three-quarters. The Scotchmen and the North-country players began the practice before it was regularly adopted in the south; but by the winter of $x 880$ both teams in the North and South match played one back, although the Southerners still relied on a couple of three-quarters, while the Northerners played three. Soon after this, however, the second 'back' was generally dispensed with in first-class teams, and the field for many years was arranged in the following order : nine forwards, two halves, three three-quarters, and a back.

During the second stage of the game which we have just been describing, the merits and advantages of passing the ball were always admitted both by players and by writers on the game, and yet it is only in the last few years that the science of passing has been so far cultivated as to make the game of to-day distinctly different from what it was in 1880 or $\mathrm{r} 88 \mathrm{I}$. Again, we may say that it is difficult to fix a precise period at which the game changed, and quick and low passing into the open became the predominant feature of the play as it un. doubtedly is at the present time. The style of playing a game alters so slowly, that probably the players themselves of the last few years have noticed less than the spectators how different the game of Rugby football is, as it is now played by the leading clubs, from the game exhibited before it came to be recognised as a leading principle that a player must 'pass' before he was in difficulties himself if his pass was to be relied upon to do good to his side. Probably the playing public 
were converted to the new style by the wonderful play shown by the Oxford University team between $\mathrm{I} 882$ and I884. Certainly, since that time up to the present day, passing has been one of the most important points of the game, and one that has been practised until a wonderful amount of skill in the new game has been acquired. If one comes on to a field before play has commenced, the men waiting for the game are not taking drop-kick practice, or dribbling the ball about to ' keep their feet in,' as was their wont before the passing game came in, but are now to be seen playing at catch-ball, and slinging the ball from hand to hand, not high in the air, but about the level of the hands from the ground. The clever half-back, too, does not pick up the ball and then pass it to his three-quarter, but sweeps it off the ground straight into the hands of its destined recipient in one movement. Forwards, half-backs, and three-quarters, alike, vie with each other in their efforts to make brilliant 'passes,' the ball sometimes passing from hand to hand half a dozen times before it reaches the open, and an attempt is made by a p'ayer to have a clear run, and show his pace down the field. That the game fails unless skilfully done is clear, but experience has conclusively shown that with good and well-trained teams the best way to score tries is for the players to have thoroughly mastered the modern scientific 'passing' game.

The introduction of the 'passing' game and its gradual adoption throughout the country has led to a further change in the arrangement of the field, or, to use the technical phrase, to the institution of the 'four three-quarter system.' The system originated in Wales, where some of the leading clubs soon discovered that for a 'pass' to be accurate it must be short, and that four three-quarter backs who had learnt to back each other up and take short passes were almost irresistible in attack, and that they also afforded a formidable wall of defence against the runs of the opposing back players. For some years the Welsh clubs and the Welsh international teams appeared in the field with four three-quarters, but the rest of the country 
looked with some scepticism upon the practice, as it was pointed out how materially the forward division was weakened by the abstraction of the ninth forward. Gradually, however, the Welsh system gained favour throughout the country, first the North and then the South succumbing to the innovation. In the winter of 1892 the Northern team in the North $v$. South match played with four three-quarters, and, although it was stated at the time by some of the Rugby Union committee that this was merely an experiment, little was then wanted to convert the innovation into an established practice. In the winter season of $1892-3$ the Welsh international fifteen carried all before them, and administered a decisive beating both to England and Scotland, and this, no doubt, had an important effect upon public opinion; and the ensuing season of I893-4 saw not only both Universities but all four international teams -England, Scotland, Ireland and Wales-with four threequarters in the field. The new system is no doubt an inevitable corollary to the passing game, and is likely to remain an established part of the game, although a good many clubs who play the safer and old-fashioned game and rely mainly upon their forwards, are still content with three three-quarter backs and nine forwards.

One great charm to spectators about both games of football is the simplicity of the main outlines of the game. Although the actual rules as to small points may be hard to comprehend, a spectator, seeing the game for the first time, can understand at a glance the object for which each side is striving, and can follow with interest the varying fortunes of the struggle.

To describe the main features of the Rugby game in a few lines: two parties of fifteen face each other on a rectangular piece of grass, of about $\mathrm{I} 20$ yards long, and 70 yards or so wide. In the centre of the boundary line of each end (the goal-line) are placed two upright posts, $18 \mathrm{ft}$. 6 in. apart ; ten feet from the ground these are connected by a cross-bar. The aim of each side is to kick the ball over the cross-bar of the opponent's 
goal. When the ball crosses the boundary lines of the sides (touch-lines) it is out of play, and has to be brought back into play. When it crosses a goal-line if one of the attacking side can 'touch it down,' i.e. place his hand so as to stop its rolling, he has gained a try, and his own side can take it out again into the field and have a free kick at goal. To gain a goal, either from the field of play or from a try, the ball must be kicked direct from the ground over the cross-bar, and to work the ball towards the opponent's line the player may run with it, kick it, or hand it to another of his own side. The main essential rule of the game, which determines its character, is that no one must kick or throw the ball forward to one of his own side, or the latter is guilty of 'off-side play.' When we add that striking the ball with the hand or arm is not allowed, the reader has before him the skeleton outline of the Rugby Union game.

We have seen that, as far as experience has shown at present, the most successful tactics have proved to be the playing of eight or nine men of the fifteen who form the side as 'forwards'; two as 'half-backs,' who stand close to the 'scrummage,' which is formed whenerer the ball is fairly held and put down unon the ground; three or four behind these, who are styled ' three-quarter backs,' and whose aim is to keep clear and away from the mass of struggling forwards, and one 'back,' who does not guard the goal alone, like the 'goal-keeper ' in the Association game, but has to defend the whole goal-line of his side. As it would be tedious and unfruitful to discuss the minor rules of the game, which can speak clearly enough for themselves, it remains for us to offer some criticisms and detail some reminiscences of the brave old game, and those who have played it. And first as to the forwards.

With football, as well as with other games of skill, it is a much easier task for a man to criticise the play of individual members of a team than it would be for him to make up the team himself. Nothing is more common than to hear an unfriendly or perhaps a disappointed player say that he cannot imagine how So-and-so ever 'got his colours,' or was put into 
the international team ; and this kind of criticism is especially applied to forwards, for a good deal of their best work is done where its merit can hardly be recognised by any but a careful and intelligent captain. Scrummages are still one of the main features of the game, for even if the play is exceptionally fast and loose, as a rule there is bound to be a scrummage when the ball is thrown in from touch; and a captain who chooses all the fast and brilliant players he can pick out, will find his side nowhere if he has nobody to 'hold the scrummage.' Time after time we have seen all the efforts of a brilliant team of back players rendered quite useless because their forwards were unable to keep their opponents from breaking down the scrummage.

One example is within the writer's recollection of a team which won a whole season's matches by carrying the scrummage. A certain college at Oxford for four seasons was undefeated by any other college; for the first two years of this success it had a good back as well as forward team. For the last two of these seasons the team was almost without competent backs at all, most of the back players being forwards converted into backs by necessity; yet the team could still win its matches, no other college team being able to 'hold the scrummage' against it. The critic, then, has always to recollect that the first and essential requisite to a forward team is that it should be able to 'hold,' if not always to 'carry the scrummage.' In the bygone shoving days a scrummage often did not break up at all of itself; the ball was heeled out or oozed out, and the forwards continued to shove until they heard a shout that the 'ball was away.' Nowadays a ball seldom comes out except when the scrummage is carried by one team, either by shoving clean through its opponents or by cleverly 'screwing' the scrummage and taking the ball out. There is, therefore, a good deal of skill to be shown in the way of scrummaging alone, and it is imperatively necessary, as long as football remains as it is, that a certain number of the forwards should be chosen for their scrummaging powers. The modern forwards, then, should be the 
possessors of three distinct qualities, of scrummaging, passing, and dribbling, but if these rarissime aves should not be procurable, the team of nine forwards as a whole should display all these qualities amongst their number, and we are not at all certain that a certain football critic said badly when he advised captains to choose three hard shovers, three good dribblers, and three clever passers for his forward team at the beginning of the season, and let them learn each other's game, and the result would be the combination required. No doubt the advice cannot be taken literally, but there is a good deal of truth in the seeming paradox.

The first thing, then, that the forwards must learn is the art of scrummaging. The man who from laziness or want of training puts his head into the pack and simply shoves straight forward, if he imagines himself to be scrummaging, is as great a self-deceiver as the ostrich who puts his head into the bush and imagines himself invisible. Many things go to make the real scrummager; first, he must always be ready to push into the fray at once; much is gained by being in position to shove as soon as the bail is put down, and the side which gets two or three men packed first with their heads underneath has, if the said three men know how to 'work' the ball and keep it with them when the scrummage gives or twists, half won the scrummage for that time already. Then those who are on the ball must gently 'work' it with their feet, so as to take it with them whenever the scrummage shows signs of screwing, or yields in any quarter, and if perchance the yielding is on their own side, even then by clever manipulation they may let the stream rush past them without taking the ball with it. We have often seen a scrummage scatter past one of the Gurdons or Thomson of Halifax, and lo, when it had gone by there was the old stager speeding away from them with the ball still in front of him.

These, however, are rare examples, and there is still plenty of unscientific scrummaging to be seen; men who are not on the ball keep their place in the hope of a sudden turn of the 
scrummage giving them a brilliant opportunity, and many are the lazy players who, having come through the scrummage without the ball, betake their way to the back of the scrummage again with considerable leisure. But there is many a good scrummager who packs quickly, shoves the instant the ball is down, and can steadily keep with the ball and never lose touch of it as the scrummage sways, and to those who play the right game there is plenty of skill as well as force in scrummaging.

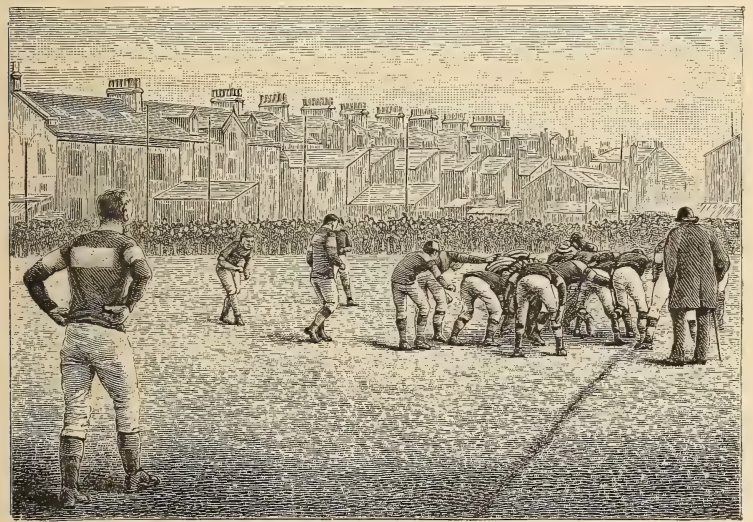

'A loose scrummage.'

The heroes of these mêlées often make little reputation with the public, and those alone who have played with them or against them know their merits. But some of these gentry there must be in any conquering team.

For play in the open two kinds of skill are required, skill with the feet and with the hands. At present it is the novelty of scientific hand-play which excites the most applause, but with forwards it is doubtful whether cleverness in passing should not be considered only a supplementary 
excellence, and the true merit of a 'brilliant forward' to lie in fast following up, clever dribbling and rapid tackling. Indeed, we are old-fashioned enough (and fashions have quickly changed in Rugby football) to think that the forward's business is to let the ball get upon the ground, and keep as close as he can behind it. Before, therefore, we discuss the subject of scientific passing - the favourite subject for the football essay of the present period-we propose to say a word or two as to the rest of the forward business.

The chief merit of a forward's p'ay in the open is to be always close to the ball. If he is after it and following it up with a rush, as soon as it is out of the scrummage he is bound to be of service provided he can control the only fatal fault of kicking hard, and so giving the opponents' back players a chance of drop-kicking, or getting well away with a run. His main duties, then, are to know how to dribble, to tackle (and to tackle the ball and not the man only), and to keep close to the ball wherever it be. To dribble the oval ball which is used in the Rugby game is no easy task, as it is seldom likely to roll quite true, and thus in Rugby dribbling it is of even more importance than in the Association game to take short steps, and never part with the ball for even a couple of strides, lest you may overrun it. The natural result is that, with very few exceptions, the best dribblers of the Rugby game are short, thick-set men, as they can get more pace combined with safety than their longer-legged brethren, although of course they must be 'strong on their pins,' or they will be swept off the ball at the first impact. When one gets a whole team of good dribblers who sweep up the ground with a rush, spreading out four or five yards each side of the ball and a few behind it to take on the ball in case it should be overrun, such a rush is not only an inspiriting sight, but is almost irresistible to the opponents. Like a wave the rush bears down the opponents' backs, and carries the game often from one end to another, and if captains would only coach their forwards to back up such a rush, and pass the ball with the feet when the ranks of 
the opposing three-quarters have to be met, we believe they would be more dangerous than forwards who play the handing game. A single error in the handing game may be fatal, and on wet days when the ball is greasy these errors are always made now and then in a match; but with a well-trained forward rush there is everything to gain and nothing to lose, for the worst that can happen is for the rush to be brought to a standstill by some opponent pouncing on the ball, when a new. scrummage is immediately formed which it is three to one will be again carried by victorious forwards who are already on the spot and ready to pack at once. The good dribbler, if he is to be of any use, mus: of course be good at following up, and by a forward who plays a good dribbling game, we mean him of whom it can be said that where the ball is there will he be, or thereabouts. A good dribbling forward game we shall always believe to be not only the most useful but the most enjoyable.

Every forward must also be a good tackler, a remark which can equally be said of every other player on the field. A poor tackler is almost useless anywhere, but luckily it is an art which aithough it takes time to learn can be learnt by anyone who has pluck and head enough to play football at all. There are usually said to be two rules, and two only, for tackling: to tackle the ball and not the man alone, and to 'tackle low,' both rules being, however, really directed to the same end, the stopping of the ball; for it is useless to stop the man who carries it if he can at once pass to a friend. What both rules really come to is this, that one arm at least of the person tackling should be thrown over the ball. The advantage of 'tackling low' is this, that when the tackler stoops to rush at the runner and grasp him tight round the body, it is almost impossible for the runner to shove him off. The novice who, standing upright, fumbles at the runner will find himself 'armed off' with a well-directed shove, he totters, and the runner is away. The tackler, on the contrary, who gets himself together by stooping well as he runs, either gets both arms round the 
runner's trunk, or one round the trunk near the waist, and one over the shoulder, and the adversary is caught as in a vice. To lay down any absolute rules as to how one man should tackle another running with the ball is in our opinion impossible. A big man may have to collar a little man, or vice versâ ; and, granting that the pair are of equal size, the tackler may have to take his man from the front, from the side, or even from the back, or his man may be standing, running, dodging, or stooping, and the tackler himself may have to 'go for his man' or wait for him. One fact can scarcely be gainsaid, that the tackler on any part of the field should seldom, under any circumstances, absolutely wait for his man; he should judge when he is the right distance off, and dash in at him. The maxim to 'collar low' also often cannot apply ; a very tall man sometimes cannot collar a very small man low, and we have a lively recollection, in a match in which we took part, of seeing that smallest of clever half-backs, R. T. Finch, of Cambridge, dodging through the Oxford backs who were too tall to get down below his shoulders, which he could always free by a well-studied wriggle. Indeed, there is a rumour, which we cannot verify, that the said R. T. Finch ran between the legs of the very gigantic back whom Oxford played in one year. 'This, however, we believe to be an undoubted libel on that plucky little Cambridge half-back, who was not nearly so small as he appeared to be in the football field, through 'running low.' To return, however, to the question of the perfect tackle, it is easier to say how a player behind the scrummage should tackle, for he has more time to get into the right position ; it is the forward's business to tackle as quickly as he can, to keep his eye on the ball, and get his grip at it as soon after as possible, and by all means to tackle 'low' if he can.

The forward then must be a good 'dribbler, tackler, and follower up' in the open, and at present is expected to have mastered the science and art of passing; but before we deal with the last, there are some other points of forward play which we must notice. The forward must always be ready to line up 
and face one man, and one only, when the ball is thrown into play from touch. When practicable he should mark the same man throughout the game, and when the ball is thrown he should always be on the alert; if his mind once be off the game and he be a bit unstrung, he may muddle the ball and miss a chance. To add the further advice, that a forward should use his judgment, and neither interfere with his own half-back nor another forward, is somewhat superfluous, as a man who has no judgment cannot have it preached into him, and those who have it require no stimulus to its exercise. The frequent exhortations which we notice in manuals of sport to players of football to play unselfishly and with judgment, always remind us of certain other regulations which we see daily for the precautions to be taken in case of fire, a leading rule being to 'be calm and collected.' We may deal in similar wise with the exhortation to play up hard and not be sluggish. Such exhortations may be admirable in the field but are useless in books. Playing up hard, exercise of judgment, unselfish combination, these are the very elements of success at football; but men do not learn such necessities from the reading of books.

Some years ago that well-known theorist of football, Mr. Budd of Blackheath (who, by-the-bye, was not a mere theorist only, but one of the best practical exponents of the art of forward play), wrote an essay in a sporting magazine on the theory of passing, and the substance of this is again to be found in a contribution made by the same writer, together with Mr. Vassall, the Oxonian, to the 'Football Annual.' 'What is passing, properly understood ?' say these writers. 'Its final cause is the transmission of the ball from the mass of players to the open. This is the sum and substance of the theory ... You must not only transmit the ball to your comrade, but he must be advantageously placed to receive it, and in a position in or towards the open and away from the mass.' From this they deduce the conclusion that passing should be made as nearly as possible in a straight line across the ground without offending against 
the rule which prohibits throwing forward, and that those who back up the runner and wait for the pass should back up on the side nearest the open and almost if not quite level with him. That such is the true theory of passing is indubitable; but what is doubtful is whether any theory can be worked to perfection by mortal men amidst the hurly-burly of the Rugby game. That a very great deal of skill has been shown by good teams in working out the theory cannot be denied, and this is always done when the passing has been started from the side of the ground. It is when the game has got entirely into the open and there is no scrummage left, that we have seen the game break down, and at present we have never observed any system of passing work successfully when the whole side, forwards and backs, have tried to join in the passing. Possibly this stage of skill may eventually be reached, but then the grievance that the old footballer will have against the game will be that the pastime will degenerate from the manly sport of footlall into the elegant art of catchball. Certain it is that the average forward should not forget that dribbling and tackling are his most important duties. It has appeared to us in more than one crack match of recent days that the forwards were not only inferior in dribbling, but were getting to collar with less precision and accuracy than they used to show through paying too much attention to the flying of the ball from hand to hand. In one of the Richmond $v$. Blackheath matches a few years ago we saw a back, who after countless successions of passes thought he would try a run, come clean through the Richmond forwards without having a finger laid upon him. However, time alone can show whether there will be still further developments of the handing game, or whether the passing will in future be left mainly to those behind the scrummage.

It remains to give, before we leave the subject of passing, some of the practical rules for the exercise of the art. Firstly, the passer should pass quickly and low ; he should not, as the 
old players did, toss it into the air, but throw or sling it, just at the height of his hands, straight into the hands of the 'passee.' Next he should pass to one definite man, and not attempt to pass to where several of his side are. Thirdly, he should, in order to pass accurately and low, pass before he is collared, i.e. as near before the collaring as possible, but when he is in a position to move his arm without being hampered. A man who attempts to pass when he is being collared may find the ball fly off in another direction through his antagonist pulling him round. Not unless he is quite firm in his position, and quite certain of being able to pass the ball where he likes, should he attempt the manœuvre. The great aim of a man bringing off a pass is to do it with accuracy, and yet so far monopolise the attention of those seeking to collar him that they will be unable in time to turn their attention to the 'passee.' What this precise moment is has to be left, like many other things, to the judgment of the player.

One point, however, must not be omitted with reference to the 'passing' game, that it is always liable to break down upon a wet day, when the ground is so slushy that it is hard for players, and especially for heavy players, to keep their feet. When fingers are numbed, and the ball as slippery and hard to hold as an eel, then the passing game becomes all but impracticable, and as fast running is also difficult the dribbling game 'comes off.' In all weathers, and under all conditions, the team which can dribble with skill and combination will always do well. The soundest advice then that we can give to forwards, although it has not a moral sound, is not only to play with the feet, but to 'play fast and loose.'

It is difficult to deal with footballers as with runners, and pick out the best players as easily as the best athletes, for the best player is but one of fifteen, and contributes but little more or less than one-fifteenth of the skill which gains the victory. Even in the historical matches of the year in which time after time we have noticed fine players playing beneath their form, through 
being associated with strangers, it is almost impossible to form a true estimate of each 'crack's' abilities. In addition to this, in speaking both of forwards and backs it is difficult to institute trustworthy comparisons, so much has the style of play varied from time to time. Some forwards have earned their places in international matches without possessing any great amount of skill, because strength and weight were required to hold their scrimmages and their men. Other very heavy men, however, have been genuinely clever players, like Fowler and Vassall, of Oxford, and E. T. and C. Gurdon, of Cambridge. The two Gurdons, indeed, were the best pair of forwards whom we have ever seen in the football field, and their excellence is the more remarkable as they have played through almost every stage of the game; when scrummaging was the chief essential they knew how to scrummage, when the dribbling game came in they proved themselves the best of dribblers, and when the rage for passing arose they adapted themselves to it with as much success as any of the youngsters ; but others, such as Arthur Budd and G. W. Burton, of Blackheath, H. G. Fuller of Cambridge, Harrison of Yorkshire, and many others whom it is impossible to name without being prolix, have owed no part of their reputation to their weight, so that it is no longer a reproach to the Rugby. Union game that skill is at a discount as compared with strength.

To turn now to play behind the scrummage, there is little more to add to what we have said before in our discussions of the tactics of the game, both in the past and in the present, and of the science and methods of passing and tackling. In the earliest days the half was expected to run; to-day he is expected to pass rather than run, and scarcely ever to run except when the ball is passed back to him from a three-quarter or he has no good chance of passing. If the ball comes out of the scrummage the business of the half-back is, as we have said, to fling to the three-quarter in the open with one motion-indeed, to sweep the ball clean from the ground into the three- 
quarter's hands. He must lose no time, or the 'halves' of the other side will be upon him. If they cannot pass, the best halves more often punt into touch than run, for in most cases it follows that if they cannot pass they are not in a position to do much good by running themselves. So much for the offensive part of their work; the defensive part is to pounce like lightning on the opposing halves or three-quarters before they can get away or pass, and to stop the rushes of forwards by nipping up the ball or falling upon it. In fact, quick picking up is the chief merit of a half in the latter-day style of play, and to be a speedy or dodgy runner is of less use in this place upon the field than it was. Indeed, as we have seen, this new style of play has been forced upon the halves by the increasing looseness of the play amongst the forwards, which gives the half-back little chance of doing much brilliant work by his own unaided efforts.

Before the importance of passing by the half-back became paramount, the half-back of the day was the strong dodgy runner and deadly tackler of the type of whom H. H. Taylor of Blackheath and R. T. Finch of Cambridge were the best examples. The latter was very hard to collar, and could fasten upon the biggest men like a burr and bring them to the ground, but though, perhaps, more brilliant than Taylor, the strength of the latter made him the safest player we ever recollect upon this place in the field, his strength of arm being so great that even the strongest could never break away from him. For the defensive part of the work of a half-back we have never seen his superior. The best half-back of his day, as far as running was concerned, was the Cambridge captain and Scottish international, A. R. Don Wauchope; but he also was not so strong and hard as Taylor. On the whole, however, we are inclined to class Don Wauchope and the Oxonian A. Rotherham as the two best half-backs of history since loose scrummaging became known. Rotherham more properly figures in a later stage of the sport, after the passing 
game had fully come in, and therefore, perhaps, it is only to his credit to say that he showed less brilliant form as a runner than Don Wauchope, but his strength and weight made him a perfect defensive player, and his clever passing and admirable following up entitle him to be considered one of the best halfbacks seen in the South since the passing game came in.

The pick of the play now falls to the three-quarter backs They alone in the field are sure (if the halves are up to their work) to have some opportunities of getting well away with a run. As we have seen before, no club now ever plays with less than three three-quarter-backs, while a very large number, including most of the leading clubs, put four three-quarters into the field. Of these all do not play quite the same game, although all have equally to learn how to give and to receive those accurate short 'passes' which are now the feature of the game as it is played in the open. But, apart from this, a different game is played by the three-quarter or the pair of three-quarters placed in the centre, to that played by those who play on the outside.

The steadiest defensive player who is a good drop-kick and safe in stopping forward rushes should be in the centre, and he must be always on the look-out for passing to whichever of the two outside three-quarters has the clearest field in front of him. But very often, and especially when the game is getting near his own goal, the middle three-quarter should neither pass nor run himself, but take a long drop or punt into touch, and when on the contrary the game is near the opponents' goal, he should be continually on the alert to drop a goal from the field of play.

It will thus be seen that, in the writer's opinion, the centre three-quarter should cultivate drop-kicking as the first and most important thing of all, and provided he be a safe and smart drop, and steady at stopping forward rushes by snapping up the ball or falling upon it, it does not matter so much whether he has any brilliant pace, great as is the advantage of pace upon any quarter of the field. 
Each and all the three-quarters must be good tacklers, and must always tackle low, and hold the ball at all costs, for as only one back is played and passing is understood nowadays, it is not safe to rely upon the single back. The outside three-quarters must do the bulk of the running, and get most of the tries, for when a pass is once well begun the outside three-quarter who is on the open side of the play (i.e. where there is the widest portion of field between the scrummage and the touch line) is sure to get the ball either from the half-back or from the centre three-quarter, who will pass after he has made a start himself and given his outside a chance of getting into the right position. It is therefore in the position of outside three-quarters that the very fastest runners should be placed, and many men have made a brilliant show in this position simply and solely owing to their pace.

However, though fast running alone can never make a footballer, the really fast runner has a great pull at three-quarters, for the best tackler in the world cannot

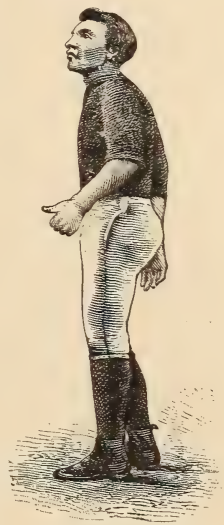

Three-quarter back : 'An anxious moment.' stop a man whom he cannot reach, and there have been many fast runners, especially in the earlier days, who have gained tries simply through their fleetness of foot. Useful therefore as drop-kicking is to every threequarter, the feature of outside three-quarter play is running, and in selecting the three men for the place in every team different qualities are required for centre and side. Lastly, all the three-quarters must recollect that they have only one back behind them, and if they miss a man or if from any cause a runner has passed them, they must be on his track at full speed without delay. They must in one word recollect that their business is defence as well as attack, and must continually 
see that they are covering the field between them and are not all massed together in their greediness to get the ball for a showy run.

Undoubtedly the best three-quarter of his day was L. Stokes, the Blackheath captain. There have been both before and since more brilliant runners and safer tacklers, but probably no better drop-kick, and none with more judgment and knowledge of the game. His command over the ball in drop-kicking was marvellous, and his drops at goal and long drops into touch were masterpieces. One great element in his success was the careful eye he kept on his halves and backs to ensure a safe defence of the field. In his time, first one, and then two three-quarters were played, but in the present game his style of play would have fitted him for centre three-quarter. We are rather inclined to think, however, that Wade, the Oxonian, was the best three-quarter we have seen. $\mathrm{He}$ and IV. N. Bolton, of Blackheath, were great rivals and contemporaries, both being strong, fast men, and very hard to stop, and one day one, on another day the other, pleased their critics best; Bolton, however, though perhaps faster, occasionally played clumsily and made mistakes, although always a very dangerous player to have on the other side. Lately, Stoddart of Blackheath has eclipsed both in reputation, being a very fast clever runner and a capital drop, and on his day marvellously good; but as a defensive player he was not in our opinion the equal of Bolton or Wade, and was more uncertain in his play than either of them. For all-round excellence at three-quarters few have ever surpassed R. E. Lockwood, a little Yorkshireman who was both sturdy and speedy.

Last but not least comes the full back, and of him it may be said that it is easy to describe him but difficult to find him. Two things only are required of him, that he should be an admirable and accurate drop, and a safe and strong tackler, who neither lets his man pass him nor can be knocked over or brushed aside by a rush. To find those who can answer to 
this description would not seem to be difficult, but the fact remains that backs are not to be found. The reason after all is plain enough, that most footballers play for the fun and the fun alone, and there is no pleasure at all in playing back unless one's own side is getting much the worst of the game. The goal-keeper in the Association game is sure to have something to do even in a winning game, but the Rugby back when his side is winning often has nothing but one or two drop-kicks throughout the game. The better the side the less work and the less practice the back is likely to have, and that is why even the backs of the best clubs often cannot be depended on simply through lack of practice. The work of the back requires but a short description; he must on no account come far enough forward to make it possible for a drop-kick of the enemy to go over his head, for otherwise he will have to run back and the rush will be on him before he can take his drop. When he gets the ball he must 'drop' into touch, as far up the field as he can reach the touch line, but still into touch the ball should go, for if it do not his own men will be off-side, and the drop will simply be returned. The back then must be he who never muffs a catch, and never misses a tackle, and can so far control his natural desire for emulation as to refrain from indulging in a run when he thinks he can see an opportunity. Above all things, he must not pass nor attempt to, and if collared with the ball should be glued to it and cry down. One other thing might be said, and that is, that it is often safer to 'punt' than to drop for a back ; indeed, some of the best backs we have seen have continually punted instead of dropping, both in dry and wet weather. In wet weather a dropped ball rises very slowly, and if perchance the opposing forward can charge it down before it rises all may be lost, and that is why the old hand punts in wet weather. If punting were studied as much as drop-kicking, and made an art of, we are not certain that it would not always be safer for a back to kick this way rather than drop; but as it is the back so often has played on 
other parts of the field and studied dropping, with the view to dropping goals, that he drops rather than punts, the dropping being certainly neater and prettier to look at. Every back player should learn to punt, for with our weather he may be called upon to play upon a sea of mud with a spongy ball, and on such occasions punting is the only safe course.

Such is, or should be, the back player, but, as we have said, he is and always has been hard to find. Though footballers, like all other English sportsmen, love to earn distinction, of them perhaps more than of any other athletes it may be said, that the motive which draws them to the game is not distinction but purely enjoyment. Hence it is that no one cares to play back regularly if he can help it, and hence also that at schools and colleges on the whole the most capable backs are to be found. Both at schools and colleges the 'back' of the representative team probably has other matches and games, when he can play three-quarter and have his practice in dropping and collaring; while in clubs, which only have a match on Saturday afternoons, the regular back has no such opportunity, and thus is often apt to degenerate. It is no secret that in choosing representative teams the Rugby Union is often hard put to it to find a safe back, and old stagers are played again and again because no fresh man can be discovered who is known to have had sufficient practice to make him trustworthy. It is said that one of the international backs was elected to his place simply on the strength of one brilliant drop-kick, which was all he had to do in the North $v$. South game. Be this as it may, backs have often so little work to do that it is hard to gauge their real merits, and we have often thought that a good sound centre three-quarter might well and safely be placed at 'back' when a back is wanted in any team whether of a country, county, or club. Usually the backs of one or the other of the Universities can be relied upon, as the ardent footballer can get three or four matches a week at Oxford or Cambridge. The danger of putting a three-quarters at full back is that he may be unable to resist the temptation 
to run when he ought to drop, and if he be unable to overcome this weakness he is worse than useless. One of the best sound backs we ever saw play was A. N. Hornby, the cricketer, who played with great judgment and knew the value of punting upon a wet day. Most of the English international backs of late years have come from the Universities, H. B. Tristram and A. S. Taylor for example.

While, however, it is difficult to compare the form of different players, it is easier to compare the different clubs and teams. As our own experience has been chiefly of the Southern teams, the provincial fifteens for various reasons appearing less often in the South than do their brethren of the Association game, we cannot speak so well of the balance of power in the North and Midlands as of the districts nearer London. The feeling amongst Rugby Unionist men is so strongly against cup ties that Yorkshire and the Midlands alone of the great football centres have such a competition. In London, almost since the institution of the game, supremacy has rested mainly between the rival teams of Richmond and Blackheath, and so strong has been the centripetal force which has drawn the chief players of London into one or other of these two clubs, that many of the old and strong clubs such as Ravenscourt Park, the Gipsies, Queen's House, and Walthamstow, first decayed and were then dissolved. Fortunately for sport (for the tendency of all the best players to gravitate towards Richmond or Blackheath can scarcely be considered sound and healthy), the Scottish national feeling has been strong enough to resist the influence, and for the last few years the London Scottish Club has been able to put a team into the field nearly if not quite equal in strength to the other two. The most interesting matches of the year are those between these three clubs, all of whom meet both the Universities; and occasional matches between these clubs and some of the best visiting teams, such as Bradford or Cardiff, evoke immense interest. The club match is the life and soul of the Rugby game: county matches in some parts of :the country fail altogether to bring out representative teams or 
excite but languid interest. Cup ties are little encouraged by the authorities, and the club remains the essential unit of the football community as far as this game is concerned. In the Association game the club that wins the National Cup can practically be considered the champion club of the year; but it would scarcely be correct to speak of any championship in the Rugby game. The championship of Yorkshire may perhaps be described as settled by the Yorkshire cup ties, even though several leading clubs hold aloof from this competition. In the Midlands there is also a series of cup ties to decide the local supremacy ; in the South the winner of most matches of the five clubs we have named, Oxford University, Cambridge University, Blackheath, Richmond, and London Scottish, could fairly claim to be the best club of the South, and we are far from sure that it is not a good thing to leave the question thus undecided. It is impossible for these reasons to pick out any one or two clubs as the strongest in England. The most brilliant single team, however, we may say with some safety, was the Oxford University team of $\mathrm{I} 882$ to I 884 . In I $88_{3}$ the Oxford team provided seven of the English fifteen which played against Scotland, and in I884 eight, or more than half the players-an unexampled achievement.

Each of the four nationalities of England, Scotland, Ireland, and Wales now puts an international fifteen into the field, which is chosen by its orn Union, and these international contests are the chief matches of the year, and the chief aim of every player is to win his international colours. The English Union has a very careful and elaborate system of choosing its players. A series of 'selectional matches' is played throughout the first part of the season. First there are matches between London, the Western Counties and the Midland Counties; then a team picked from London, the West and Midlands competes against the combined Universities. From these two teams is chosen the team to represent the South in the match North $v$. South, from such of the players as are qualified to play for the South. The Northern representatives of the 
committee choose the team to represent the North, making their selection chiefly from the county matches between the different Northern counties. That the Southern system of trial matches works better is tolerably plain from the fact that the large majority of the North $v$. South matches has been won by the South. The Southern system of selectional matches is not many years old, and the working out of the idea has owed much to Mr. G. Rowland Hill, the hon. sec. of the English Rugby Union, who is one of the rare examples of a sporting enthusiast who does not allow his enthusiasm to give any bias to his views. Footballers throughout the kingdom owe more to his energy and discretion than they are aware of. The North $v$. South match takes place early in December, and it is from the form they show in this match that players gain or lose the coveted honour of the international cap. The international matches all take place in the three months after Christmas ; the match between England and Scotland, which is the great event of the season, is played alternately in England and Scotland in March, and with this the season is brought to a close.

A word may perhaps be said about the strong prejudice which prevails with most Rugby Unionists against the system of cup ties. The objections to these contests are weighty even with respect to the Association game, as there is no doubt that they interfere with the ordinary and pleasant routine of club fixtures, and lead to great expense and trouble, besides exciting partisanship to a high degree. But of this we shall have more to say anon, when we come to discuss the Association game. It is something more than this, however, which makes the Rugby Union so strongly discourage cup ties. It is strongly felt that the Rugby Union game, with its collaring and throwing to the ground, its scrummaging and its collisions, is naturally so rough that not the least occasion should be given for allowing warm partisanship to lead to ill-temper, and illtemper to brutality. Experience has conclusively shown that, whatever be the class of the players, Rugby cup ties give 
an opening for ill-feeling and the exhibition of unnecessary roughness. The present writer has seen various Rugby Union cup ties, and never left such a match without feeling strongly that they are an abomination. The hospitals have their annual Rugby cup tie in London, and that the roughness is greater than that of any other match in which hospital fifteens engage
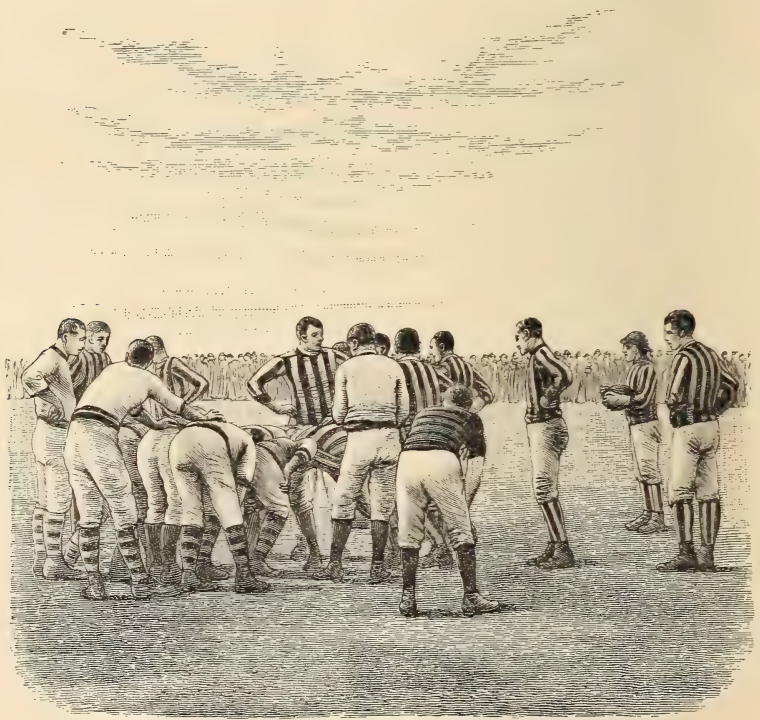

Partisanship.

seems apparent. As long ago as I 876, the Oxford Rugby Union decided to have a College championship, and the competition was abancloned after two years' trial on account of the roughness of the game. The writer still has a vivid recollection of playing in the final tie in 1877 , and can well recollect what a battered appearance was presented by his side when they met to celebrate 
the occasion in the evening. There seems to be little doubt that in the excitement of a cup tie the old Adam in the breast of the footballer will have its way, and probably nothing but a team of Neoplatonists could play a Rugby Union cup tie without roughness.

The Committee of the Yorkshire Union can hardly be ignorant of the way in which cup-tie play is liable to degeneration. Their book of rules is significant evidence upon the point :

15. In case of wilful breach of the rules of the game or any foul play, the referee may caution the offending player, or order him to retire from the game, and no substitute shall be allowed to take his place.

16. In order to prevent a rough style of play in Cup contests, the committee shall have the power (on a unanimous report of the referee and umpires) to disqualify a team for rough play, even if that team win their round.

No wonder the Captain of the Northern fifteen in I880 alluded with his well-known homely eloquence to 'those beastly cup ties.' Association players should understand that we only endorse this sentiment in its Pickwickian sense, and confine its application exclusively to the Rugby Union game.

The system of county matches which is the essential basis of antagonism at cricket seems hitherto to have failed, more or less, at football, and most especially so in the South of England. In the North there has certainly never been any lack of interest over the match between Lancashire and Yorkshire; but a few years ago county football had entirely ceased to raise any interest outside of the North of England. The authorities of the Rugby Union tried to remedy this state of affairs by instituting a competition for the county championship, and there can be no question that this competition has intensified the interest in county matches in the North, and has done something to quicken the interest in county fixtures in other parts of the country. The counties are divided into four groups, the North-Western (Lancashire, Cheshire, Cumberland, and 
Westmoreland), North-Eastern (Yorkshire, Durham, and Northumberland), South-Eastern (Kent, Middlesex, Surrey, and Midland Counties), and Western (Somerset, Devon, Cornwall, and Gloucestershire). The winners of the respective groups each play one match during the season with the winners of the other groups, and in this way the champion county is picked.

The new system has certainly been of son:e use to the authorities in bringing out new talent for the international matches, but can hardly be said to have had the desired effect of stimulating the South to take interest in county matches. The great county of Yorkshire is almost invariably too strong for the other counties, and save in 1890, when Lancashire managed to beat her old opponent, Yorkshire has always been, and seems likely at present to continue, the 'cock county.' At the end of the season it is usual for the champion county to play the 'Rest of England,' and Yorkshire has twice succeeded in beating the Rest. The matches in London between Surrey, Kent and Middlesex excite but a very languid interest.

We have said enough of the time-honoured and boisterous game of Rugby football in the past and in the present. It is perhaps idle to speculate whether it will take any altered shape or be subject to any altered conditions in the future. During the quarter of a century that it has reappeared as a popular sport for gentle and simple, it has gone through several phases. The first movement was to reduce scrummaging to its due proportion in the game; the second movement, to give increased importance to systematic passing. Whether either or both movements will continue and will lead to fresh developments, it would be rash to prophesy. Certainly many of the lay public who do not know the genuine delight nor understand the science of scrummaging, think there is still too much pushing in the game. What such a game as Rugby football without scrummaging would be like is hard to conjecture; the very suggestion would seem a heresy to most players; but 
one thing may be said with tolerable certainty, that if any future change is to be made, it will certainly not be in the way of a return to the old scrummaging order of things. From year to year the Rugby Union game has become faster and more skilful, and yet has shown no signs of being less manly than of yore. 


\section{CHAPTER IV.}

THE ASSOCIATION GAME.

'THE Association game, though it may bear less resemblance than the Rugby Union game to the original sport, certainly finds a more appropriate name in Football, as it is with the foot alone that the ball is urged to victory. Certainly, of late years, men play with their heads in more senses than one, and a goal may be lost or won by 'heading,' but the main outline of the game is simplicity itself, being to propel the ball by kicking with the feet between the posts and under the cross-bar of the opponents' goal, and to prevent the opponents from doing the like; no player but the goal-keeper being at liberty to use his hands or arms throughout the game. Such is the simple game which has now been brought to such an extraordinary pitch of skill that none but those who have seen can well appreciate, and which is so well appreciated by those who have seen that it is no rare thing for ten or twelve thousand spectators to watch and follow a match with interest.

The dribbling game, if the theory we have given above be correct, grew up entirely at the schools where running with the ball and tackling the runners was dangerous to clothes and limbs. Each of the old schools had, as we have seen, its own game, differing in almost every point except in the essential feature of the prohibition of tackling and running with the ball, and it was not until the old public-school boys felt drawn to form clubs to play the game again when their school-days were over, that the necessity for assimilation of rules arose. Then 


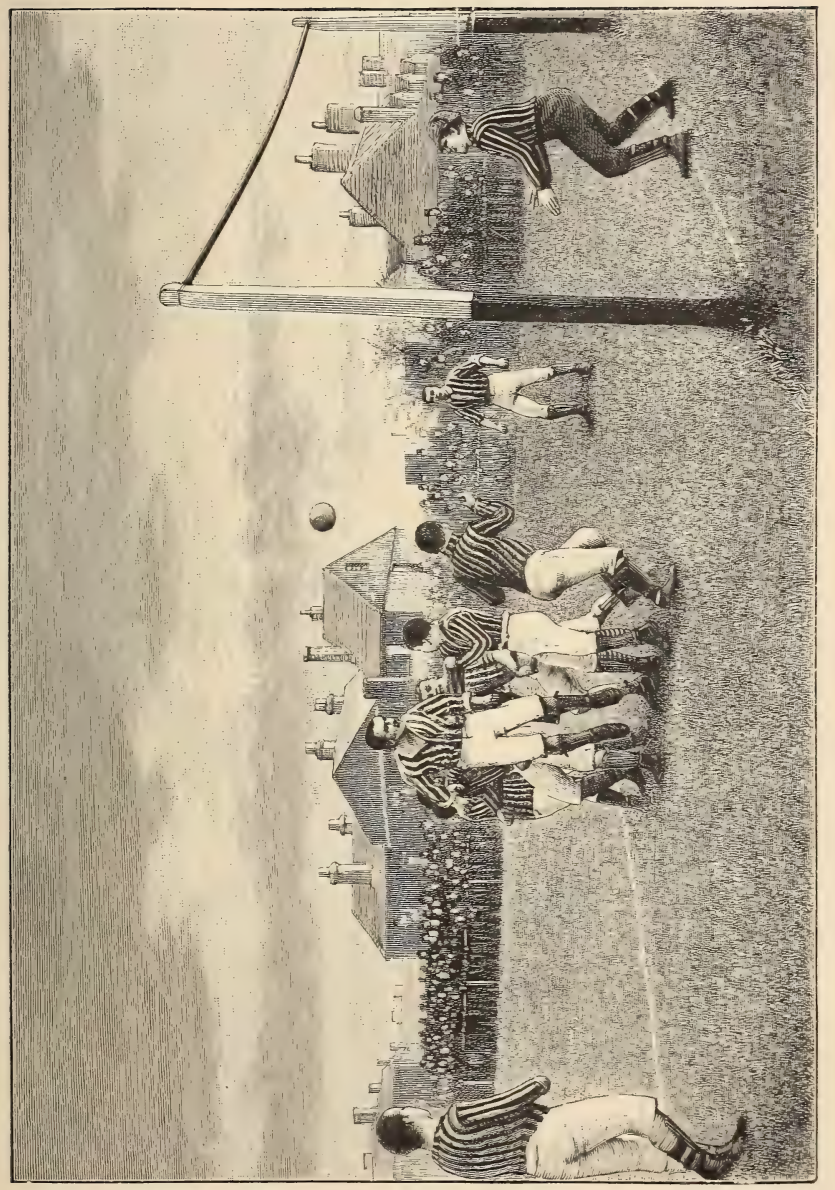



the dribblers associated themselves in 1863 , more than seven years before the Rugby Unionists, so that nearly a quarter of a century has already passed over the Association rules, which have varied but little, much as the style of play has altered during that time. Almost from its earliest days the Association has provided that 'a goal shall be won when the ball passes between the goal-posts under the tape, not being thrown, knocked on, or carried,' and that 'no player shall carry, or knock on the ball, and handling the ball under any pretence whatever shall be prohibited, except in the case of the goalkeeper,' and further that 'no player shall use his hands to hold or push his adversary ;' and so, without any substantial variation, has the game remained, and is likely to remain, as long as it is played.

So few have been the changes of rules and of tactics in the dribbling game that the task of describing the phases of Association play is simpler than to follow the changes of Rugby Unionism. From first to last the 'off-side' rule has been a trouble, and it can scarcely be said that the present rule (by which a player can have the ball passed forward to him if there are at least three players between him and the opponents' goalline) even now gives universal satisfaction, although it has been the rule of the Association for twenty years. The question of throwing in from touch has also from time to time divided Association players, and not long since the whole Association world was convulsed with the agitation that led to the recognition of professionalism. On the whole, however, save for one thorough and important change-the abandonment of individual dribbling skill for combined passing from foot to foot amongst the forwards - the game has remained substantially the same, although in our opinion the amount of skill exhibited to-day has quite surpassed the best efforts of the crack players of a dozen years ago.

The one change, however, the introduction of a combination of passing tactics from forward to forward to the discouragement of brilliant dribbling by individual players, so far revolutionised 
the game that we may fairly say that there have been two ages of Association play, the dribbling and the passing. The difference of play, however, in these periods belongs almost wholly to the formard field, and, although the practice of passing-forward has so far weakened the defence of the goal that a larger number of back players has become a necessity, the tactics and tricks of back play have always been the same. But before we come to describe the modern game and its players something must be said of the game of older days.

When it was founded in IS6 3 , the Association followed the same rule of 'olf-side' which was recognised at Rugby; no player being allowed to take the ball on from one of his own side who kicked on to him from behind ; and under such a rule it is obvious that individual dribbling was the only thing that could pay. In I S67, however, the adhesion of the Westminster and Charterhouse players was secured by the introduction of the present rule, and from that time both passing and dribbling became possible as a means to success. Neither the Association nor the Rugby game took a strong hold upon the public until the growing popularity of football led to the establishment of the international matches and the Association Cup Ties in I 8;2. Sheffield had early taken up the Association game, and had formed a powerful association of its omn in I S6 7, playing its omn rules, one of which, declaring no man to be 'ofi-side ' if the opposing goal-keeper was between him and the goal, was widely different from the Association rule. In spite of the difference of rules, however, the Sheffielders joined the Association in I870, with special freedom to play their own code, which they continued to do until IS;7. But before the institution of a London $v$. Sheffield match as an annual fixture in IS; I, it may almost be said that football, until that date, was rather a recreation and a means of exercise for a few old public-school boys than a really national sport, and it was not until 'the serenties' that football began to be an attraction to the general sporting and athletic public. Nor was it until some years later still that captains and teams had discorered that the way to win a match was not to 
dribble cleverly and to 'back up' the dribblers, but to pass and to trust to combination alone.

In the very early stages of the game, it was scientific in the sense that each player exhibited skill rather than brute force, but of scientific arrangement of elevens there was very little. Often there were but two back players besides the 'goals' or goal-keeper, and all the forwards played together, not having allotted sides, although some teams would have one 'wing' player on each side, who rather did the duties of 'half-back' than forward, in protecting from attack his own side of the field. Each forward then strove to distinguish himself by making sensational dribbles, getting the ball in front of him and piloting it by clever dodging and twisting clean through the gaps in the opposing ranks, and combination play was thought to consist in backing up the dribbling forward, so as to carry on the ball as soon as he was deprived of it by an opponent. In the Oxford and Cambridge Match of 1874 , each side played three 'behinds' only besides the goal-keeper, and we can well recollect how the winning goal of the match was scored by an Oxonian, who dribbled the ball nearly the whole length of the field, and then himself kicked it through. Very little attempt was made at this period to pass forward from behind, each forward striving, as in the Rugby game, to be always near the ball, so that the backs had much less ticklish work, and a smaller number of them was quite sufficient. By 1875 , however, 'passing on' as one form of play had begun to be known and recognised as dangerous, and every good team had followed the example already set by the Scottish clubs of playing two half-backs and two loacks, and making each forward keep strictly to his own place upon the field. It is from 1875 or I 876 , therefore, that the game began to be played substantially in its present form; and 'passing on' completely superseded dribbling about the same time that the great provincial centres suddenly came to the front, about 1878 or 1879 .

As both in the old and new games back, half-back, and goal-keeping play has varied but little, we need not describe 
here the old style of play behind ; but the old style of forward play deserves description, as it was brought to a marvellous degree of skill of a kind which is now almost useless. Doubtless each forward must still know how to dribble, in the sense in which dribbling means speeding along with the ball close in front of the feet and well under control ; but now, when once hampered by several opponents, he is taught that the presence of several attacking one must leave a gap elsewhere on the field, and he at once passes either to his own wing man, to the middle, or perhaps clear across the field. In the olden times, by dodging and twisting with the ball only a few inches from him, the forward steered it through what appeared to be a close mass of opponents. This special art of steering a ball up and down through opponents (and very pretty play it made) was one learnt in early youth at school, and few of the modern players have either the opportunity or the need for acquiring it. In the older days, however, it was a brilliant piece of play of this kind which brought down the gallery, and was the most highly admired of any kind of skill in the dribbling game. Our old friend the 'Football Annual,' writing of the best form of Association play, in 1873 , says :- 'A really good player will never lose sight of the ball, at the same time keeping his attention employed in spying out gaps in the enemy's ranks which may give him a favourable chance of arriving at the coveted goal. To see some players guide and steer a ball through a circle of opposing legs, twisting and turning as occasion requires, is a sight not to be forgotten. And this faculty or aptitude for dribbling or guiding the ball often places a slow runner on an equal footing with one much speedier of foot. Skill in dribbling necessitates something more than a go-ahead, fearless, headlong onslaught on the enemy's citadel : it requires an eye quick at discovering a weak point and "nous" to calculate and decide the chances of a successful passage. One of the greatest eyesores to a first-class player is the too prevalent habit of "dribbling" the ball down the side of the ground. Unless when absolutely necessary, a forward player 
ought ever to avoid diverting the game from the centre of the ground. It is an achievement of very rare occurrence to secure a goal with a kick from any remote corner of the ground.' Such was the old game where 'passing on' was all but unknown, and even the value of 'middling' for goalwinning purposes was hardly recognised. But such as it was the style of play produced some marvellously agile dribblers like C. J. Ottaway, and Vidal of Oxford, and Hubert Heror, who did great things in the later game but could never throw off the old Adam and play as unselfishly as the modern game requires.

For the modern game, however, each player keeps to his own allotted place in the field, and plays not for himself but for the whole forward field ; and so far is 'passing on' the very life and soul of the game, and so universally is it practised, that besides the goal-keeper two backs are a necessity, and at least two, if not three, half-backs; so that only five, or at most six, players form the forward brigade. Indeed, three half-backs are now the rule rather than the exception, and the forwards thus form the minority of the eleven players. The field of eleven players, then, is usually arranged as follows : a goalkeeper who defends the space between the posts, two backs, one for each side of the field, who should never get too far away from the goal to render it possible for the backs of the opposite side to kick over their heads and oblige them to run back and return the ball under difficulties ; three half-backs, who follow up with the game, but always keep their own forwards in front of them (of the half-backs one plays in the centre and one upon each side); and five forwards, one playing in the centre and two upon each wing. When, if ever, there are six forwards, the extra forward plays in the centre, and the two half-backs divide the ground between them. So arranged the two elevens face each other on a field which is, or should be, 120 yards long by 80 yards wide, and is bounded by goal-lines and touch-lines in the same way as in the Rugby Union game. When the ball crosses either line it is dead and out of play; 
but if a player kick the ball over his own goal-line the opposite side have a 'corner kick,' from which they have a fair chance of shortly lowering the goal. When the ball crosses the touchline a player (usually a half-back) of the opposite side to that which kicked it into touch throws it into play again from the point where the ball crossed the line. As the rule now stands, the player throwing in must face the field of play and hold the ball over his head and throw it with both hands in any direction he pleases into play again. The rule was not always thus; originally it had to be thrown straight into play as in the Rugby game; then, to prevent scrimmaging and charging, the rule was in 1879 altered to allow the throw in to be in any direction; but such adepts did the players become in hurling the round ball with one arm great distances down the field towards the opponents' goal, that the rule was again altered to permit only a throw with both hands, which is much less effective. The 'Associationists' play with a round ball proceedings commence by a 'kick-off' from the middle of the field, and then the players set to work each to do his respective duty.

The business of the forwards is to dribble and pass for offensive purposes, and to 'get away' the ball from opponents by stopping a dribble or intercepting a pass. To describe dribbling in the abstract is hard; it consists in running fast, giving the ball but slight kicks so as never to allow it to get beyond control; and further than this, the clever dribbler has to make feints with his legs and body so as to mystify his opponents as to the direction in which he proposes to take the ball. Nearly always it is advisable to slacken pace when the opponent is making for you, and watch his movements; if he rush down upon you, you may dodge away from him with the ball still in front of you, or if you see him stop you may fly past him in the same direction upon which you were originally bent. Some speedy runners when they have only one opponent near them have succeeded in passing him by kicking the ball out of reach of the opponent on one side and dodging round him upon the other. Experience, however, has shown that it 
seldom, if ever, pays for a forward to keep the ball long by himself; if he keep his eyes open he will soon see a companion free, while he himself is being borne down upon by approaching foes ; then he passes, and it is in this passing-the choice of opportunity, the judgment in noticing what friend is in good position, the accuracy and quickness of aim-that the chief science of the forward game lies. Each forward has to keep his own allotted position, and while the centre or centres should pass to the wings unless they are within shot of goal, the wing players should, as a rule, play to each other in pairs. Although this is the main rule, however, an inside wing player should never forget to play to the centre, or to 'cross' to the other wing when a good opportunity occurs. As the ball is taken down the ground the forwards follow up with it, not all hustling on the ball, but placing themselves in favourable position for

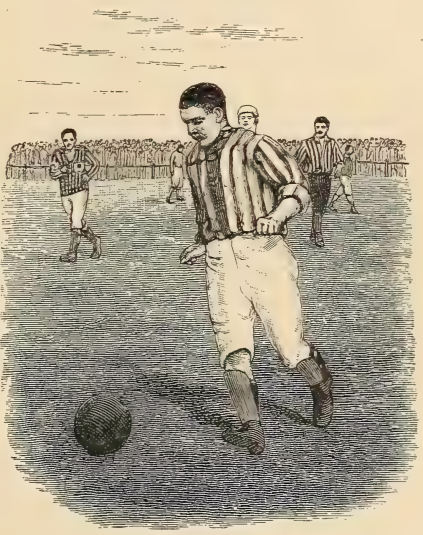

A forward.

2 pass. As regards the pairs, too-right wing, left wing, or centres - they should more especially back up each other and not get separated, so that they may dribble backwards and forwards to one another like two parts of the same machine. Still, 'crossing' or wide passing is often very effective, as the opposing backs are always inclined to edge away towards the side of the ground down which the ball appears to be coming; and a clever 'cross' may give the players upon the other wing 
a clear field before them. Passing should, as a rule, be low along the ground, as the 'passee' can then take on the ball with less trouble and with less chance of losing time, while he gets it under control before starting off with it. Upon other occasions, however, a high pass may pay better when a wing kicks to the centre in front of the opponents' goal and wants to give time to his own forwards to rush up and bear down the backs without being 'off-side,' and before the backs can get the ball to kick it away. When nearing the opponents' goal the passing should always take the form of 'middling,' or placing the ball before one's own centres to enable them to shoot at goal. Rarely, if ever, does a long shot at goal pay, for the goal-keeper has time to intercept it coming, and those who are unselfish enough to pass in the very mouth of the goal are rewarded by seeing the frequent success of their side in matches. The centre, whose object at other times is to get the ball away to his wing men, should, when the opponents' goal is near, keep the ball near the middle at all hazards. Then it is that the wings close up with precision until the goal is surrounded like a fortress, and either falls from one of the shots that are peppered away at it, or is cleared by the goal-keeper or backs. Often, however, from one defensive kick the ball gets into the control of the defending side, and the play surges away to the other end of the field before a minute has passed.

So valuable, it will be seen, is accuracy of aim with the feet in passing, middling, and shooting at goal, that it must be learnt by the brilliant player, and the man who is clumsy with his legs, slow and uncertain in the direction of his passes, and apt to overrun the ball in his dribbling, fails as a player until he can overcome these defects. A player, to learn accuracy of aim, must not only know how to score a goal with a swift low shot from his toes, but must learn to pass, middle, or dribble, with the sides of his feet. When running fast often the best way to make a pass is to use the outside of that foot which is nearest to the proposed recipient or the ball. The best 'middles,' too, 
are made by a hard kick with the inside of the foot, and many of the safest shots at goal have been made with the inside of the foot. A greasy ball on a wet day may slip away from the toe, while a side-stroke is much more likely to be accurate.

To sum up, then, the centre player should play to the wings except when near goal, and then he should play at the goal; the wings should play together closely, and always middle to

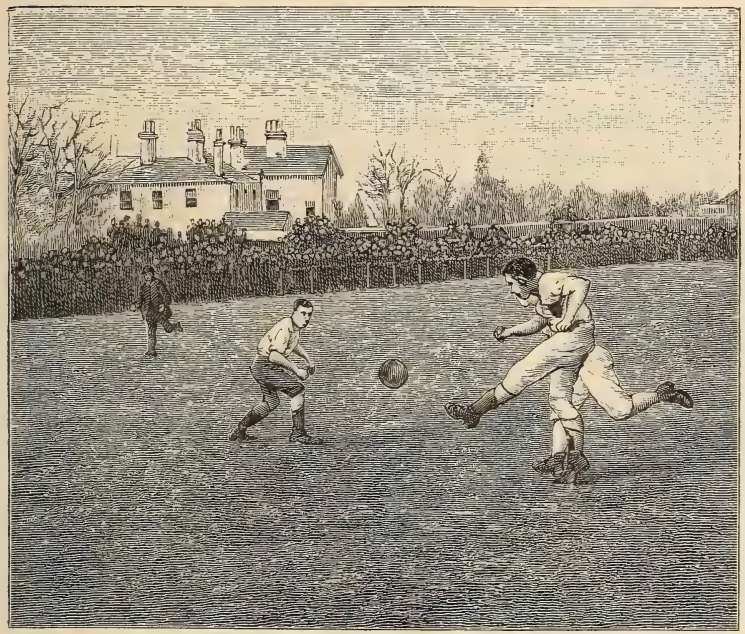

A nasty jar.

the centre when near goal, and should not wait too long to bring off their 'middle.' Nothing is more common than to see a wing player work the ball up to the extreme corner of the ground, and then turn and kick back towards the middle. The result is that not only are the men of his own side now in front of the ball if they have backed up, but even if they are not offside the defending backs have had time to raily round the goal 
and defend it. Bis dat qui cito dat should be the motto for the wing player when he nears the opponents' goal. The wing player also should do what dribbling there is to be done, should pass the ball before he is hampered, and should, like every other player, never move from his place on the field or lose touch of his wing companion. The centre should shoot quickly and low, and never shoot until he sees an opening for a goal.

As regards the defensive part of a forward's work, or the taking of a ball from another, the same rules apply to the forwards of every place in the field. They must not be misled by the movements of the man who has the ball, but should watch where the ball is and so plant themselves that they are bound to intercept it. Judgment alone can tell them whether they are to wait or to bear down for a charge. If a collision is inevitable, let the forward get his shoulder well down and be leaning well forward. If he be underneath in the charge his opponent will be forced up and will fall back, or if he be firmly planted and shoulder and hip are acting well in concert, he is likely to stand like a pillar while his adversary falls prone upon the field. Still, charging when unnecessary is always a waste of power, but the forward should never neglect to hustle, if not to charge, the opponents' half-backs, for by rushing at them he may do much to disconcert their aim.

Since these are the qualities of the good forward in the Association game, it will readily be seen that there is nothing to prevent the smallest man, if he be thick-set enough to be steady upon his pins, from surpassing his bigger brethren. In the older game, when dribbling and charging were the chief essentials, the heavier men scored more than they do at present, although of course even now, as collisions are necessarily frequent, weight must always tell. But big strong men like R. H. Macaulay, the old Etonian, whose weight, pace, and stamina are undeniable, are often inclined to play clumsily, and selfishly at times, although upon other occasions they seem unsurpassable. In one celebrated final tie for the Cup, the gigantic Scottish forward, Dr. Miller, played opposite J. Brown, a clever 
little thick-set player in the centre, and to our mind the little man showed all the best of the play, although the doctor had the reputation of being the best centre and goal-getter in Scotland. The best type of forward player, however, is the fast, sturdy man of medium height, like W. N. Cobbold the Cantab.

There is only one other feature of forward play upon which

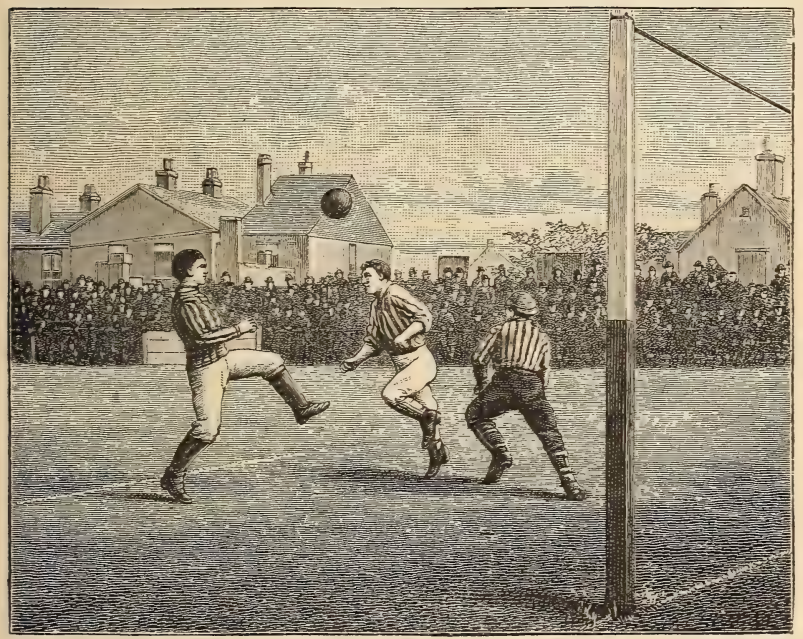

Heading.

we have not yet touched - the practice of 'heading,' in which all players, and especially the provincial teams, display such extraordinary proficiency. Backwards and forwards is the ball often bandied from head to head, each man having complete control over the force and direction of his blow. Goals are often 'headed' through, and for defensive purposes especially head-play is very effective. Upon the whole, however, 
spectators while admiring the skill can hardly help forming an opinion that this accurate 'heading' savours more of clowning than of manly play, and many would be glad to see some limit placed upon the exercise.

The necessity of playing three half-backs has arisen from the wing-forwards of well-trained teams availing themselves to the full of the privilege of receiving a forward pass -without being 'off-side' as long as the two backs and the goal-keeper are between them and the goal. These wings would hang about in front of the rest of their side for the chance of having the ball passed to them while they were standing behind the opposing half-backs; and this practice of waiting for the ball to turn up became so prevalent and so successful in scoring goals that for self-defence one 'half-back' has now to be told off upon each wing to keep an eye upon the prowlers. The remaining centre half-back bears the brunt of the regular halfback's work, which is to 'feed' the forwards of his own side. A good half-back must be a versatile player. He is so closely mixed with the forwards that he must know how to dribble upon an occasion, must be especially clever in taking the ball away from an opponent, must be a steady charger, standing as firm as a rock, never allowing himself to be brushed aside or sent sprawling, and above all, must be a steady kicker, kicking not hard and wildly, but lifting the ball when he wrests it from the adversary just over the heads of the surrounding opponents, and dropping it amongst his own forwards and just in front of that forward who is best placed to get away with a run. It will readily be seen, then, that the half-back must, of all players on the field, keep his head cool, and his eye steady, for he should know at once and discern the possibilities of each changing position of the field. Nor can he always, when mixed up with the players, kick from the ground; he must kick when the ball is nearing the ground or is high in the air ; he must often kick backwards over his head, and withal, know where to place the ball, though his eyes are for the moment turned the other way. Not only too must his kicking be accurate, it must not be too 
strong, for his business is almost entirely to feed his own forwards and not to kick to the opposing backs, who are strong kickers and will return it over his own head. Often, too, his best tactics are not to kick at all, but to hustle the on-coming forwards and to let his own back thus get a clear kick over his head; when he does kick, accuracy of aim is of such importance that he must not try to be showy, but must know when to kick with the toe, and when, as is usually safer, with the instep. Such is, or such should be, the half-back, and for choice, the safest kick should occupy the centre, and the best tacklers should play upon the sides. How much coolness and safety are preferable in the long run to brilliancy is well known to the authorities of the Football Association, and for ten years in succession the Old Westminster and Clapham Rover, N. C. Bailey, occupied this position in the International team, though, during this decade, several more brilliant players appeared and disappeared again. Campbell too, the Scottish International, was another cool and wary player, whose 'heading' was superb in the days before

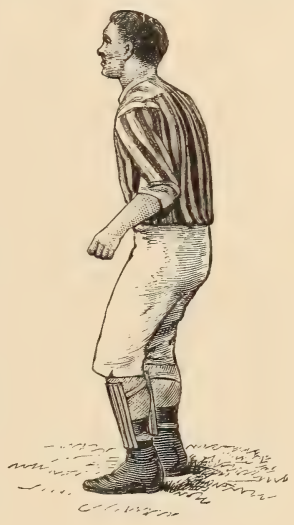

'To keep an eye upon the prowlers.' 'heading' became a universally practised science. Wonderful is the skill that veterans in the Association game display behind the forwards. The Old Etonians have never been in the foremost rank of clubs since the white trousers of 'Old Kinnaird' ceased to form a feature of their side in the field.

Before we leave the criticism of half-back play we should mention that there are one or two other points to which the half-backs must attend. They, at least, cannot be blamed for indulging in 'heading,' for heading is often quicker than 'footirig' when the ball is high in the air. The halves at the sides 
too must learn to throw in from touch, for this duty as a rule devolves upon them; and when, as is usual, three half-backs are played, the corner kicks should be taken by one of them, as the whole of the forwards can thus be left free to close round the goal. Sometimes, too, the half-back has, after a corner kick, an opportunity for a shot at goal. Finally, the half must not be lazy in 'falling back' when the tide of play has rushed past him. By such slackness in aiding the other defenders many a goal which might have been saved has been lost.

A 'back' player even more than a half-back must be strong with his legs and on his legs. Some years ago, to counteract the sneaking tactics of wing-forwards, several provincial clubs only played one back, as with this arrangement the attacking forward became 'off-side' as soon as he stood behind the defending half-backs, and being off-side could not take the ball when passed on to him. But in spite of the cleverness of this dodge of placing adversaries in the wrong, a single back was found unable to stop combined passing rushes of the forwards, who could always escape one back by judicious middling. The practice, therefore, never took firm root, and each team now plays two backs eren although they have three half-backs as well. The chief requisites for the backs are accurate and powerful kicking, and ability to kick not less efficiently, although charging or being charged at the moment. Above all, the two backs must play with each other. When one advances to charge the forward the other must drop back to receive the ball if the kick and charge of his companion are ineffective. Often it is the business of one back to hamper or harass an opponent while his fellow kicks the ball. Each back also must watch the half-backs, who, as we have seen, often adopt similar tactics and hamper the man, leaving the ball for the back. It is, however, the combination play of the two backs with each other which makes the defence really effective. To describe all the varying tactics is almost impossible, but any player knows well how the two regular backs of a club play together as it were by instinct, while perhaps in an International match when two brilliant backs, 
one say from the North and another from the South, are put together, each kicks splendidly, but the ball is often got past or between them. Perhaps, it is something more than long practice that made the brothers A. M. and P. M. Walters, the Old Carthusians, play such an admirable combination game with one another. It is this combination between backs which should be cultivated even more than it is at present, and we look to seeing in future years still greater excellence in this respect than is shown by the average club team, although the cleverness in kicking which can be seen to-day can hardly be surpassed. But to return to the several duties of each back player. Not only must he 'tackle' an opponent with precision, but when his companion is tackling a rush, should keep his attention open for the 'middle,' which is likely to be attempted, and which it is his duty to watch. Or again, when the player and ball have been taken past

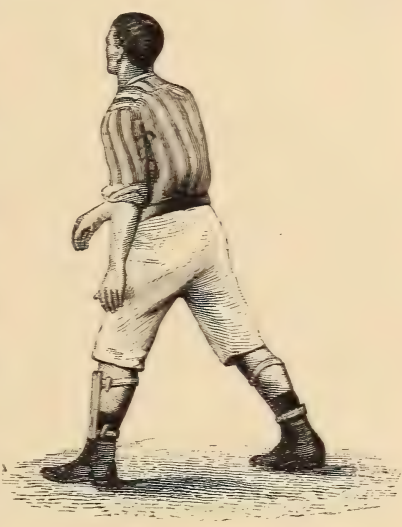

A back. him, he must follow back and hamper and liustle the forward whom he is catching up, never attempting to charge him from behind, but trying to shoulder him round and send him staggering off the ball when the leg which is nearest is off the ground and his weight is thus balanced to lean away from the back who is hampering him. When once he has separated the player from the leather the back may turn the ball with a screw kick, or the mere worrying and hustling of the dribbler will at any rate help to spoil his middle or his shot at goal. Nerer must the back allow an opponent who has passed him to get 
away. He must hustle and worry at him as long as the man retains the ball before him. But it must not be forgotten that as the best of wcrrying tactics cannot always succeed, the back should rarely risk the ball being kicked over his head by advancing too far up the field.

A back should not dribble; once or twice, perhaps, in a match when a forward is charging him he may dodge for an instant with the ball to get a freer kick, but his main aim is to send the ball hard back without the slightest loss of time. So he must be continually practising kicking from every position ; straight forward, straight backward, over the head or sideways, with every part of the foot, and with the ball high or low about him ; indeed, long-kicking has now reached the position of an art. The back knows almost as well as a lawn-tennis player when to 'volley' or 'half-volley,' and when to stop the ball before he kicks; and again, when he should kick with the toe or when with the instep, when he should kick true or when he should 'screw.' Finally, he must be what few lawn-tennis players are-ambidextrous; in other words, he must kick with equal accuracy with either foot. To describe all the different positions in which a back may have to kick is hardly possible, but a word or two may be said as to 'volleying' or 'punting,' and kicks which screw the ball round. The back who wishes to return the ball before it reaches the ground has usually time to face in the direction he wishes to kick, and he then receives the ball fair on the instep with the leg well raised, so that the thigh is almost horizontal ; occasionally he may have to volley over his head, when the leg must be lifted higher still, while the foot is at least perpendicular with the ground. Seldom, however, will the back kick over his head, as it is impossible to give much force upon such an occasion; more often, when receiving a ball straight from another back, or when kicking it on the bounce, the back who cannot get behind the ball gets at its side and swings round the outer leg with a sweep, striking the ball either with the toe or with the side of the foot. By such a blow the ball is often 'screwed' round into a curve, a com- 
paratively simple kick which looks wonderful to the spectator. As, however, the back is generally required to make long as well as accurate kicks, it is usually safer, if the field be clear, to stop the ball and kick hard from the ground. It is obvious that for force of kick a heavy leg and heavy boot give advantages; and, indeed, it is said that the larger his feet are the better it is for the back player. One celebrated back player of the famous Wanderers Club in former days was so well gifted in this last particular that he received the name of 'Spondee,' his feet recalling that metrical figure to the imaginative. There can be no doubt, at any rate, that a strong, heavy man, both for offensive and defensive play, has a great advantage at back; but it is difficult to find many heavy men who are active enough to succeed in the tricky kicking which is so often requisite.

Perhaps the most important position upon the whole field is that of the goal-keeper. He must have a cool head, a quick eye and hand, and the longer reach he has with his arms the better. Although, too, he has only to

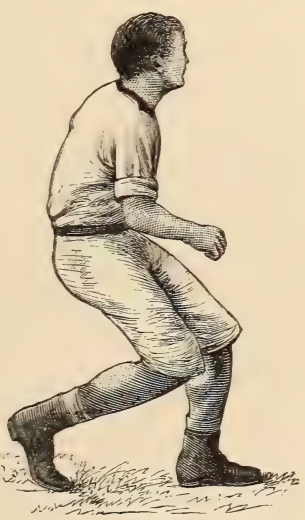

A half-back. defend the space between the posts, and all his work has to be done between the posts or within a few yards of them, he must be ready to display the greatest possible activity within his limited circle. In days gone by goal-keepers useä to kick far more than they do at present ; they 'dropped' and 'punted' often, and it was not unusual to see a Rugby Union back player set to defend the goal in the Association game. One player, indeed, R. H. Birkett, of the Clapham Rovers, achieved 
the distinction of earning his International colours in bath games, playing back in several years for the Rugby Unionists and in goal for the Association eleven. Several players, like II. Wace and D. B. Roffey of Cambridge, have represented their universities at both games; but Birkett, we believe, is the only player who earned the double International distinction. Nowadays, however, when the forwards close round the goal and make a combined attack upon it, kicking is at a discount, and the goal-keeper seizes the ball in his hands and throws it away or occasionally 'fists' it out, i.e. strikes it straight back with his fist without losing time in catching it. Some players, too, catch the ball first, and then instead of throwing it away strike it with the fist or fore-arm away from the goal. But as a rule, when a shot is made at goal, the goal-keeper catches the ball and throws it away with both hands almost in one motion. There are occasions when there is not even time to catch the ball, and the player has to kick with whatever foot is nearest to the ball; and as such emergencies may always occur, a goalkeeper must be selected who can be depended upon to kick well with either foot if required. As a rule he should seize the ball with both hands and then kick if the ground is clear; but if he is being attacked in the very mouth of the goal, he should throw away to one side or other and not straight in front of him, for the more to the side he throws the more difficult it will be for a foe to score a goal with the return which will inevitably follow if a friend does not get away with the leather. Of course, if time and his position permit, when he 'clears' the goal he will send the ball to a friend who can get away with it and thus avert the danger; but this is not always practicable. At all costs, when the shot is coming straight he must stop the ball and divert its course; sometimes, when the ball is coming high, the only chance of doing this is to knock it up so that it may pass over the goal, though this manœuvre gives a 'corner-kick' to the enemy. But whenever he can he should fling out well to the side, and then the goal may be relieved once and for all. 
A word should also be said as to the goal-keeper's duties when the enemy have a corner kick. First he must see that he is well surrounded by his own side, for if the ball drop well in front of the posts he may be sure that the opponents will try to charge him over and thus hustle the ball through the goal.

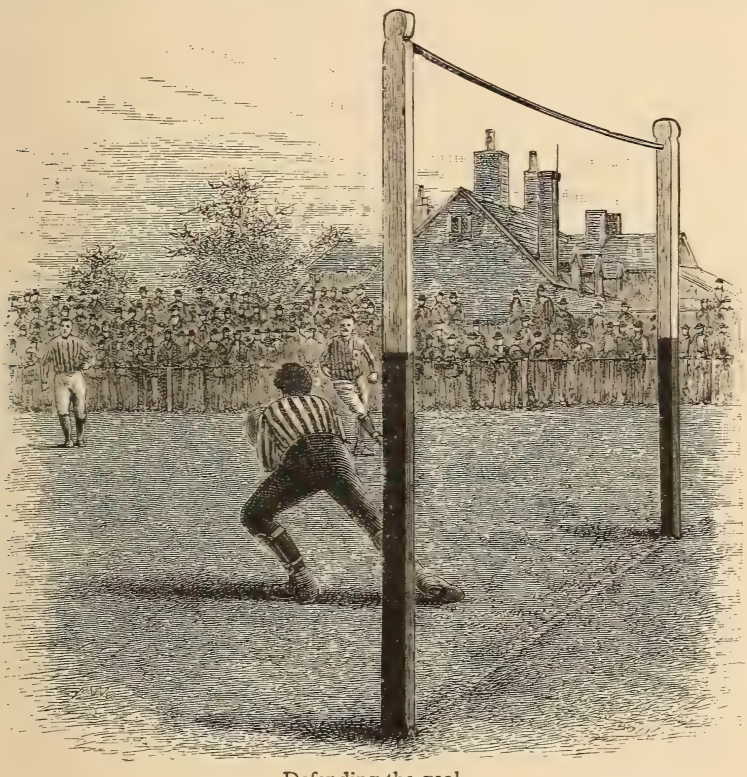

Defending the goal.

If he be well protected he can then stave off all danger, for by jumping at the ball as it comes within reach and having the advantage of being able to use his hands while the others cannot, he may be able to knock the ball well out of danger.

Good judgment is also of service to the goal-keeper in helping him to decide when he shall run out from the goal to take 
the ball. If he make a mistake in doing this the error is a fatal one, as the goal remains undefended. But there must always be occasions where by running out the 'custodian' can seize the ball and get it well away, whereas by waiting he may allow two or three of the enemy to make a combined assault upon the 'fortress.' The goal-keeper must on these occasions see with half a glance when he is perfectly certain to secure the ball if he run out, and then convert his decision into action at once. A goal-keeper has no time to think twice in Association football ; indeed, readiness of resource and agility of action are indispensable to success. When the enemy bear down the goalkeeper must be leaning forward with his weight upon the toes and not upon the heels, as he must not only be able to turn in any direction when the 'shot' is made, but must be ready to turn first in one direction and then in another as shot after shot now high and now low is sent back to him after each return. It is sometimes little short of marvellous to see goal-keepers like Arthur, of the Blackburn Rovers, or Macaulay, the Scottish International, stop shot after shot in rapid succession, turning from side to side without ever losing presence of mind or balance of body. The goal-keepers of to-day have no easy task when the attacking forwards have learnt to pass one to another in the jaws of the goal; and the best that can be said of the modern goal-keepers is that they have proved themselves equal to the task. Doubtless players in this position were as plucky and resolute in the days when Kirkpatrick kept goal for more than half an hour to the end of a match while one arm was hanging broken from his shoulder; but the modern players have better tactics to contend against and are equally successful in their defence. Perhaps we should add for the benefit of the uninitiated, before we finish our discussion of goal-keepers, that although they can use their hands to stop the ball, they may not do so to stop or hold an antagonist, and that unlike their brethrcn of the Rugby game, they may not run with the ball more than the step or two which they may require to take their kick. 
Such is the Association game, and such are the duties of the various players, but no description can avail to convey a thoroughly accurate idea of the game as a whole. The feature of modern Association play is essentially the combination shown. by the team. While each player has his own place to keep, the field at each kick changes like a kaleidoscope, each player

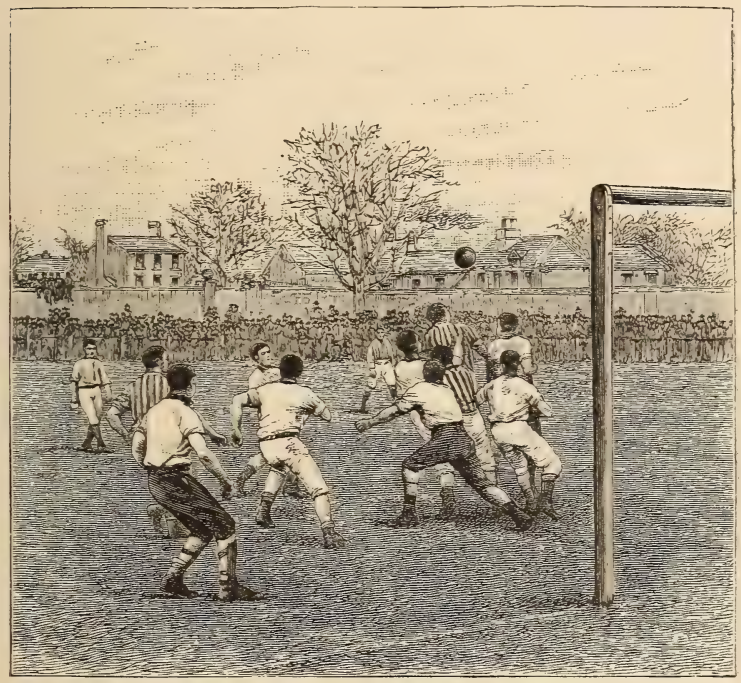

'The field at each kick changes like a kaleidoscope.'

shifting his place to help a friend or check an adversary in the new position of the game. Complete appreciation of a sport which has been brought already to an admirable pitch of skill can only come from playing in, or, at any rate, from watching with a knowledge of detail, games in which good men take part.

The one generally admitted drawback to the game is the frequency of the disputes which arise over the questions 
whether this or that player was 'off-side' when he took the ball on from a friend. Long before that useful official the referee became a regular feature of the Rugby Union game, he was a necessity in Association matches. While it is comparatively easy in Rugby football to judge whether a ball has been thrown forward or not, it may fairly be said to be impossible to judge infallibly at any given moment, while the ball is dodging to and fro, whether a player has three of his opponents between himself and his adversary's goal. To prevent disputes, then, as soon as the 'passing on' game was adopted, every match came to be attended by an independent referee; but even the ablest official in the world cannot be everywhere upon a football field, and often as the game is stopped by the referee's whistle, often again do the losers or the crowd feel a grievance at a decision or believe that a goal would have been disallowed had a claim been made. Some have suggested an alteration of the off-side rule, but no two critics are satisfied as to what the alteration should be. Some wish to return to the Rugby Union rule, and to allow no 'passing forward' at all; others think that there should be no off-side rule at all, and that passing forward should be allowed anywhere and everywhere ; others, again, would like to return to the old Sheffield rule. It must not be forgotten, however, that it is the legalisation of 'passing on' which has made the game what it is. If the old Rugby Union rule be again adopted, the game will once more return to the old style, when individual dribbling was of greater importance than skill in combination play. Still almost anything would be an improvement which would put an end to the frequent disputes and to the pauses in the game which occur when a claim is allowed and the whistle sounds. Sit finis litium is a maxim as admirable for sportsmen as for jurisprudents.

Te have not, however, as yet explained how disputes are settled upon the field, both in the Rugby and Association games. Some years ago each side appointed its own umpire, and both agreed upon an independent referee, the latter only interfering 
when the umpires disagreed. But it was found that not only was this system slow and cumbrous, but that there was a tendency with some clubs to appoint umpires who acted as mere partisans and always decided in favour of their own side. The present practice then was adopted by both Rugby Union and Association players, of having only one arbiter of disputes upon the field, an independent referee who has power at any time to stop the game by blowing his whistle.

From what we have said about Association football the reader will gather that in our opinion its history during the last fifteen years is simply a record of increase of skill both of kicking and passing on with the individual players and of combination with the team. Experientia docet, and it does not cast any reflection upon the players of a few years ago to say that when the Corinthians met Queen's Park in 1894 the form was rastly superior to that of the Wanderers and Old Etonians when they met about twenty years before. Those who can beat all comers in their orn day need fear no disparagement from subsequent comparisons. The old champions performed when Association football was in its infancy, and the capacities of the game for skilful development were not fully understood. Nowadays the game not only has professional exponents, but keenness of competition has forced up the amateurs to as high a pitch of skill as is shown by the professionals. The old school, howerer, console themselves with the assertion that eren if the skill be greater the enjoyment in the pastime is less than it was in days gone by. "In our time,' says the old stager, 'we played for fun, and we enjoyed the rough and tumble of a manly sport. Now, your footballers go into training for their matches, wear shin-guards to save their legs, and with all their skill have taken all the rough and tumble fun out of the game.' With these sentiments we can so far agree as to say that the pleasure of football-playing certainly does not come from the skill alone, but quite as much from the rough and tumble 'friendly fight' character of the game, which is one of the arguments which the Rugby 
Unionists use to exalt their game at the expense of the other ; but we can hardly agree that there is not plenty of rough and tumble in the Association game with all its present elaboration of skill and tactics.

In the early days of Association matches and ' $\mathrm{Cu}_{1}$ Ties,' the famous Wanderers Club was certainly the foremost organisation of the time. The 'Cup Ties' were started in 1872 , and during the first seven years the Wanderers were declared the winners five times. In 1878 the club, having won the cup three years in succession, became absolutely entitled to it, but they gave the trophy back to the Football Association upon the condition that it should never be won outright. During this period London, Sheffield, and the Universities were the only important centres of activity in the game, although the Royal Engineers, who won the cup in $\mathrm{I} \delta 75$, could always put a strong eleven into the field, and the Shropshire Wanderers made a brilliant and meteoric appearance for a year or two. From about 1875 to 1883 the Etonians were at their zenith, and during the whole of this period could turn out a very formidable team. They were the winners of the cup in 1879 and $\mathrm{I} 882$, and the 'runners up' in $1875, \mathrm{I} 876, \mathrm{I} 88 \mathrm{I}$, and $\mathrm{I} 88_{3}$. The Wanderers were never a large club, but their early success attracted many brilliant players from all quarters into their ranks, and they were thus enabled to maintain their supremacy. About I 876 or I 877 , however, the 'old school clubs' began to spring up in great numbers, and it became the prevailing fashion for a player when he left his school or University to devote himself entirely to his 'old boys' club. This movement undoubtedly led to the downfall of the Wanderers, who after winning the cup for the third time in succession in 1878 , suddenly ceased to be. In the first round of the Cup Ties of 1876 they met the Old Etonians, who had been reinforced by the Old Wanderer as well as Old Etonian, the Hon. A. F. Kinnaird (now Lord Kinnaird). The Etonians won, and the Wanderers, who had made their reputation entirely from cup ties, forthwith collapsed. From henceforth the old school clubs occupied the 
chief position for several years, and the final tie of the cup, in 188I, was fought out between the Old Carthusians and the Old Etonians, the former proving the winners. By this time, however, an entirely new movement was overspreading the country. Until about 1875 there was practically no Association football in the provinces except at Sheffield. About 1875 the provincial movement began, and the game was taken up in Lancashire, Staffordshire, and the whole of the Midlands by all classes of players, but chiefly by the mechanics and artisans. The rapidity with which the movement spread was little short of marvellous. In 1874 , only one club played Association football in Birmingham. In 1876 , an association of over twenty clubs was formed in the district. The rapidity with which the new class of players acquired their skill was equally remarkable. In 1877 the new Birmingham Association met London at the Oval, and were beaten by II goals to nil. Two years later, at the same place, Birmingham beat London by two goals to nothing. In Lancashire the progress was equally rapid. To the unbounded surprise of most footballers, in 1878 the Darwen Club played two drawn games with the Old Etonians in a cup tie before they were finally beaten. So many provincial clubs had joined the Association by this year, that in 1879 a new system of playing the cup ties was introduced, the clubs being divided into districts for all the preliminary rounds. It was not for some years, however, that the provincial clubs could secure the cup. In 1882 , the Blackburn Rovers were only beaten by one goal in the final tie by the Old Etonians; and in the following year another Blackburn club, the Olympic, beat the Etonians by a similar score. Since then the cup has always fallen to a provincial club. For the next three years the Blackburn Rovers won in succession, twice beating in the final tie the Scottish. Queen's Park Club, and once the West Bromwich Albion team. Since then the Association Cup has always been won by one of the numerous professional clubs from the provinces. Indeed, to-day the professional clubs, with their highly paid and highly trained players, are consider- 
ably superior to the amateur teams of the South. One amateur club, the Corinthians, at times puts a wonderful eleven into the field, but this is rather a picked team than a veritable club, as it has no local habitation, and merely plays matches from time to time with a team selected from the best old school clubs and from the Universities. The club is managed by Mr. N. L. Jackson, who was formerly the secretary of the London Football Association, and the performances of the Corinthians upon their tours are watched with the keenest interest, as the club has upon its roll all the crack players of the South. But with the exception of the Corinthians and the Universities, who never enter for the Association Cup ties, there are now no purely amateur clubs who have a chance in the cup ties with the crack professional teams ; and in consequence of complaints being made that the Football Association existed mainly for the benefit of professionals, the Association determined to start Amateur Cup ties. The first competition for this was played in the season $1893^{-4}$, and was won by the Old Carthusians.

So great is the interest shown in the progress of the cup tie competitions that it may almost be said that every other match is dwarfed in comparison. Certainly there is far less interest in the international matches than in the final tie for the cup, and even North $v$. South or Gentlemen $v$. Players excited comparatively but a languid interest. For better or for worse cups and cup ties are the life and soul of the Association game. However, the gaining of a place in the international eleven is still the highest honour open to the individual player. The English team is selected by that old and able body the Football Association, which has always shown itself capable of dealing with every problem of Association football which has arisen, and which has left no step undone to encourage the game in all parts of the kingdom. For more than twenty years the Old Harrovian, Mr. C. W. Alcock, has been the secretary of the Football Association, and the spread and popularity of the game during his term of office is the best testimonial that can be given to his work. 
As the Association game is in full swing in each of the four countries of the United Kingdom, and as each country has its own governing association, the dribblers, like the Rugby Unionists, have found that the only way to avoid disputes is to have a supreme imperial parliament attended by the delegates of each nation. The course of football history certainly seems to show the futility of an attempt to separate the government of our four nationalities, for the players of both games have discovered that with complete independence mutual difficulties and quarrels inevitably arise.

Affiliated to the old National Football Association are nearly thirty district or county associations, most of which have their own cup competitions and by these decide their local championships. Indeed, there is no doubt that as far as local organisation is concerned the Association is more advanced than the Rugby Union. In some centres both games are played, in some only one or other of the two, and the reasons for the choice of the one or the other game are difficult if not impossible to give. While there is Rugby football round Manchester and Liverpool, in the greater part of the rest of Lancashire the Association game is supreme. While the Lancashire mill-hand as a rule plays Association football, his brother in Yorkshire is devoted to the Rugby Union game. Of late years the matches which excite the keenest interest of all, with the exception of the cup ties, are those of the League competition. The chief professional clubs are banded together in a body called the Football League, and each of them plays an in-and-out match with the others during the season. The clubs are divided into two divisions, in much the same way as the counties at cricket are divided into first and second class counties. The first class clubs play only the first class, and the second class only meet their compeers. From the results of these matches, which go on throughout the whole season, the order of merit is determined, and to the club at the head of the list is awarded the title of the League champions. Strangely enough, it is seldom that the League champions also win the Association Cup 
IVe have said that there are not only the big cup ties, but there are also the minor cup ties of the different local bodies, and that cup ties in one form or another excite the greatest interest amongst spectators, and form the life and soul of the sport as it is carried on at present. What is harder, however, to say is, whether the system of 'cups' is not overdone. There is no doubt that with first-class clubs, whose teams are necessarily engaged in ties from time to time throughout the whole season, the sy'stem plays havoc with the genuine club fixtures, which are the foundation of the Rugby Union game. It is of little use for many clubs to arrange a club fixture, as they may always be obliged to send their best team for one or another round of this or that cup tie upon the day fixed. All club fixtures are thus thrown into confusion by the cup ties, and when two good clubs do happen to meet upon an open day for an ordinary club contest, the play is often languid, as each side feels the temptation to say, if beaten, that 'It was not a tie, you see, so it didn't matter.' So far have some leading clubs felt the nuisance and inconvenience of being obliged to travel about to play against all sorts of teams, often at places which are hard to reach, that they do their best to keep aloof from cup ties altngether. For many years past neither University has entered for the National Cup, and many leading London clubs do not enter for the London Cup. It is certainly a rea. sonable cause of complaint that the cup system has turned the game into more of a business than a sport. It is of little use, however, to complain of this, as the same movement seems inevitably to occur with every pastime, and even the comfortable tricycle and the social game of lawn tennis become the subjects of championship competitions. The time has long since gone by when the rustic population was contented to confine its own sports to its own village green. The evils consequent upon the prolongation of the National Cup ties were some years ago dealt with and partially remedied by the Football Association. Under the present rules the chief clubs are spared the necessity of playing in many preliminary rounds by 
the introduction of a new arrangement. Only 32 clubs take part in the competition, this number being made up of the 4 clubs who were left in the 'semi-finals' of the preceding year, I 8 clubs selected by the Association, and 10 winners of 'qualifying' competitions in the different districts. When once the 'qualifying' matches are over very few rounds are required to finish the competition, and even the last pair left in only have to play five matches. Those clubs, therefore, which desire without losing their prestige to hold aloof from too many cup competitions do not have their ordinary club matches so much interfered with as was the case ten years ago. 


\section{CHAPTER V.}

FOOTBALL AS A SPORT.

THE account which we have given of the revival and progress of the game in modern times will perhaps be deemed sufficient to show that football can legitimately claim the position of a national British sport. The accounts also which come to hand of the gradual establishment of the game in Canada, the United States, New Zealand, and Australia, seem to indicate clearly that before many years have passed football will be, like cricket, a common pastime for all the English-speaking nations of the globe, Our review, however, of football and footballers can hardly be considered complete without a short reference to a few of the principal questions which are discussed in connectior. with the game.

No words of ours can adequately describe the present popularity of football with the public-a popularity which, though great in the metropolis, is infinitely greater in the large provincial towns. It was estimated that over 40,000 spectators paid to witness the final tie of the Association Cup at Manchester in I893. This, however, was upon an exceptional occasion, but it is no rare thing in the North and Midlands for I0,000 people to pay money to witness an ordinary club match, or for half as many again to assemble for a 'Cup Tie.' If Aston Villa meet Notts County at Trent Bridge, special trains have to be run from Birmingham to carry the spectators who go over to see the match. Hundreds of pounds realised from the 'gates' are devoted to charitable objects, or go into the coffers 
of the competing clubs, or into the pockets of the professional players. In I 886 the Yorkshire County Union gave out of the gate money of three matches the sum of $\mathrm{I}, 000 \mathrm{l}$. to various Yorkshire hospitals, and similar generous contributions are made each year by local associations and unions throughout the country, in spite of the assertions of sarcastic opponents of football that such gifts are really debts due to institutions which the game has previously filled with patients. All classes are ready to put down their money to see the play, while the enthusiasm and excitement which follow each move in the game are unbounded. The writer has heard the roar that followed the scoring of a goal from a distance of more than half a mile.

All this popularity and power of making 'gate money' has naturally led to the institution of professionalism as a feature in the game. Long before professionalism was openly recognised by the Football Association, hundreds of fine players who devoted their services throughout a season to one club received in one form or another, either as 'expenses' or as 'testimonials,' or as wages for some nominal employment, a monetary return for their skilful play. At first the movement towards professionalism was strenuously opposed by the majority of the amateurs who attempted to debar any player from taking part in a match if he accepted any remuneration for his services. 'The only result was to drive professionalism beneath the surface, as the money was paid secretly instead of openly. Eventually, however, open and undisguised professionalism was not only allowed but encouraged by the Association, which made provision for the registration of 'players,' and gave permission for them to play in all club or cup tie matches, if born or resident for two years within six miles of the head-quarters of the club or ground for which they wished to play. We are thoroughly of opinion that these provisions and regulations were not only wise but sportsmanlike. No doubt it is unfair for one club to bribe a man to desert his own district and go to another, but such a system of deportation under the present rule is impossible 
On the other hand, none but a pedant could contend that there is anything more degrading or dishonourable per se for a mechanic to earn money by the exhibition of manly skill in a game of football than in a game of cricket. As soon as there was money to be made out of football playing, it became not only natural but inevitable that the mechanic and artisan class of players should desire to share in it, anci as undisguised professionalism is honest and sham amateurism dishonest, the Association wisely recognised facts.

Far different has been the case with the Rugby Union; but then, as we have seen, its history and circumstances have been different. The competition of cup ties led first to large 'gates' and then to professionalism, but it is almost in Yorkshire alone that the 'cup tie enthusiasm' has taken hold of the spectators of the Rugby game. Consequently, except in this one county, there has been little movement towards professionalism with the Rugby game. The movement, however, is at work, and the Rugby Union is resolved at present, in the words of one of its spokesmen, to 'throttle the hydra.' That we may not misrepresent Mr. Budd, whose opinion we are criticising, we had better quote in full what he has said about professionalism in the 'Football Annual.' His views are important, as the Rugby Union has adopted them and has now in force a long and stringent set of rules disqualifying any footballer who receives any money or money's worth for playing the game, and further disqualifying any club which plays with or against such an offender. As Mr. Budd is thus the spokesman of the Rugby Union, and as we differ for once from the views of that body, we feel justified in both quoting and criticising the following. Says the advocate for suppression :-

Very few of us give much thought to the problems of football, but we would ask all who have the welfare of the game at heart to consider what would be the effect of recognised professionalism in the Rugby game. To start then with a simple proposition, it is indisuutable that in no branch of athletics, except cricket, where gentleinev play as much as professionals, do amateurs stand any 
chance whatever with professionals. What chance, for instance, would any of our amateur sprinters have with Hutchens? What chance would Pitman have with Beach? What chance your best amateur billiard player with John Roberts?

To take a very close analogy, mark the progress of events in the sister game. The Associationists sanctioned professionalism because they had no alternative. When they took the problem in hand, professionalism was too big a child to be got rid of.

Note now this most significant and instructive fact. Only six months after the legitimisation of the bastard we see two professional teams left to fight out the final Cup tie. To what does all this tend? Why this : gentlemen who play football once a week as a pastime will find themselves no match for men who give up their whole time and abilities to it. How should they? One by one, as they find themselves outclassed, they will desert the game, and lcave the field to professionals.

And what sport, we would ask, has thriven when supported by professionals only? Why, none.

The Rugby Union Committee finding themselves face to face with the hydra, have determined to throttle it before it is big enough to throttle them.

We venture to differ from Mr. Budd, because in cricket, the one sport, so far as we know, in which amateurs and professionals have always joined in common, the conjunction has both kept professionalism pure, and has improved the form of the gentlemen without in the least causing them to 'find themselves outclassed,' and so 'desert the game.' It would be strange, indeed, were gentlemen to desert a game as soon as they met with a reverse from the 'players.' But apart from this we think the Rugby Union authorities are wrong for quite different reasons. Were gentlemen forced by any rule to meet opponents whom they disliked, we could well agree with him; but no club need ever play with any clubs but those it chooses, nor in the Rugby game, where there is no national cup tie, is there any moral obligation for a club of gentlemen to meet any crack club of 'players' to try conclusions. Surely, on the other hand, if the Yorkshire clubs prefer to play with or against professional teams, they should be left at itberty to do so. Nor 
will the edicts of the Union prevent professionals from playing Rugby football if once there is a genuine movement in that direction in the country. The Houses of Lancaster and Tudor in vain tried to suppress football, and the efforts of the Rugby Union will be equally vain to suppress professionalism if it once begins to pay. The effect of such legislation would only be to drive the movement beneath the surface, and we must still confess that we prefer a man who plays for money and says that he does so, to a 'gentleman' who receives liberal sums for 'expenses.' However, at present there are very few who have any opportunity of making money out of Rugby football, and it will doubtless be well for the sport if the case ever remains so. So far we are in sympathy with the Rugby Union; but if ever more money can be made out of the 'gates' of matches than the clubs know what to do with, professionalism either open or secret there will assuredly be. Until that time shall come the Rugby Union regulations against professionalism are bruta fulmina, and will in our opinion remain so.

We turn to another and more interesting question in conclusion: Both games of football, and especially the Rugby game, have been attacked by ignorant and prejudiced critics as being brutal, dangerous, and unhealthy. We hope that the description we have already given of the games will convince even a prejudiced critic of the immense amount of skill and judgment for which a scope is given in either game. A game which is in the highest degree skilful can scarcely consist of nothing but brutality, or deserve to be called brutal. What is true of the game is that it does give a scope to that delight in 'rough and tumble' which in a greater or less degree is part of every young Englishman's nature, and bred in his very bone. There is no gainsaying the fact that, while the typical Englishman is more humane than most foreigners, he does find pleasure more than any foreigner in mere animal roughness. Upon the highest principles, then, rough sports where a harmless vent may be given to animal spirits are good, not bad, for the race. 
Football may be rough, may be at times dangerous ; so is riding across country, so is boxing, so is wrestling. The very function and final cause of rough sports is to work off the superfluous animal energy for which there is little vent in the piping times of peace. Since football became popular with all classes there have been less wrenching off of knockers and 'boxing of the watch,' and fewer 'free fights' in the streets. Football has its national uses quite apart from the cheap enjoyment it has given to thousands. It may be rough, but it need not be brutal.

Next as to the danger. Doubtless there are accidents, as many in the one game as in the other, and doubtless men have been killed upon the football field. But during a quarter of a century how many thousands of men have played, and how many out of these thousands have lost their lives? Not half a hundred altogether, we should think. Fewer than those who have been drowned on the river, not a tithe of those who have fallen in the hunting field, are the victims of football. If the outcry against football because of its danger could be justified, not a single outdoor sport could survive. If the game be played by any club with unnecessary roughness the governing bodies can and may be relied on to suppress such practices.

Next as to the game being unhealthy. This charge is solely based on the fact that men have died of mischief to the lungs from football-playing upon wintry days. Doubtless a winter sport gives greater chance for such mishaps than a summer pastime; but the mishaps are not due to the game, but to the carelessness that has followed it. A footballer cannot play without getting warm, and if he change his clothes before the warmth has gone he has nothing to fear. Upon such principles walking along a road in the rain would be founc more dangerous than playing football upon a rainy day.

But now let us turn to the other side. For every one who may have been harmed by football, a thousand have benefited by it. Health, endurance, courage, judgment, and above all a sense of fair play, are gained upon the football ficld. A foot- 
baller must learn, and docs learn, to play fairly in the thick and heat of a struggle. Such qualities are those which make a nation brave and great. The game is manly and fit for Englishmen; "it puts a courage into their hearts to meet an enemy in the face.' 


\section{CHAPTER VI. \\ FOOTBALL IN THE UNITED STATES.}

TwENTy years ago the sport of foothall in the United States, though it was known, could hardly be dignified by the name of a game in the ordinary acceptation of the word. In the olden times here and there in New England it was the custom upon 'Thanksgiving Day, after the dinner had been properly discussed, for the gentlemen of the party to adjourn to the 'yard' of the old house and there kick an inflated pig's bladder about, amid shouts of merriment from the rest of the party. Looking back upon this time-honoured custom, one can, perhaps, trace a rude justice in the fact that so many New England Thanksgiving dinners are now deprived of the joyous presence of the young men of the family, who swell the crowd and join in the cheering of thirty or forty thousand at some final football match in the metropolis. But the Thanksgiving Day kicking was not the only phase of the sport, for after a number of years a rough game was indulged in, which was evidently derived from what has been known in England as the Association game of football. No British subject would have felt complimented at being accused of introducing this game could he have seen it played, and certainly he would have had great difficulty in recognising any marked resemblance to the Association rules. The truth was that every team made its own rules and no two teams played under the same code. When a match was brought about it was preceded by a meeting of the captains and a general compromising upon points of difference for the sake of a contest. Then the defeated team could, with a considerable 
modicum of truth, say that the game was not played under the rules to which they had been accustomed.

In these early days football at the colleges was merely a cloak for rough battles between the sophomores and freshmen, amounting to the same thing as the more modern 'rush.' In these football rushes the active classes joined, and there were no rules worth regarding. When the class of $\mathrm{i} 86 \mathrm{I}$ at Yale challenged the sophomores to the usual contest, the class of ' 60 prefaced their reply with the suggestive quotation,

Come !

And, like sacrifices in their trim,

To the fire-eyed maid of smoky war

All hot and bleeding will we offer you.

The faculties finally took a hand in the matter and prohibited these contests.

In the early seventies the sport approached more nearly the form of an acknowledged pastime, and several of the colleges played matches, one with another, which led to a greater harmony of rules. They were crude, and dependent largely upon the discretion of the referee, but some of the contests were not without interest. The ball that was used was the round black rubber ball, and the common number of players was twenty on a side. The uniform of the players was quite different from that of the present day, many of the men wearing long trousers, and jerseys well pulled down over the top of the trousers. None of the various codes provided for any off or on side, and players stationed themselves at such points along the field as they judged best. The general arrangement partook more nearly, therefore, of players in a Lacrosse match. No running with the ball was permitted, but it could be struck with the hand or foot. The fact that it could be played with the hand eventually led to something quite like running with it, however, as a man would knock it from one hand to the other as he ran down the field. This manner of babying the ball became far more developed among these early American 
players than did the dribbling with the feet in which the British Association players are so proficient. The dribbling was attempted and practised to no inconsiderable extent, but not with marked success. Nothing scored except goals, and these were made by sending the ball not over but under the bar across the goal-posts. The direct method of attacking an adversary was by butting him in the side with the shoulder, and in this art the American college players became exceedingly expert. The object was to knock the man out of the way or over to the ground, and it was wonderful how some of the most proficient would, by catching the man fairly under the shoulder and at the same time giving a judicious lift with the body, bow? an opponent head over heels.

In October of 1873 a convention was held in New York, at which Columbia, Princeton, Rutgers and Yale were represented, and a set of rules upon the above lines was drawn up. In the same year a team, composed of Englishmen and captained by an Eton man, played a match at New Haven with a Yale team. This game was played with eleven men a side, and the rules were modified to bring about a measure of harmony. It was more nearly approaching to the English Association than any game played up to that time. All the college games were played by teams of twenty men. In all these games, when a foul occurred, the kall was thrown perpendicularly into the air, and it was not allowable to touch it until it struck the ground. Many were the injuries received from the kicks that were directed at it as it struck.

In 1874 several games were played, but much dissatisfaction was expressed with the rules, and the contests provoked but little interest even among the collegians. Far from there being any great striving for positions upon the teams, in selecting a captain a man was always sought after whose chief qualification was that of possessing great powers of persuasion or influence, so that he might be able to collect enough men to compose a team.

This was the point reached by American football previous. 
to $S_{75}$. Outside the college teams there was but little playing and no permanent organisation. Meantime, for a year or two, Harvard had been seeking something new in the line of the sport by taking up the Rugby Union game, in which she could have matches with Canadian teams. After a few contests her men became so enamoured of the sport under this code that they looked for contests nearer home, and invited Yale to take up the English game. At first there seemed little likelihood of this, for Yale was playing under the old-fashioned American rules, having as competitors Princeton, Columbia, Rutgers, and, as above mentioned, an occasional contest with others. But between Harvard and Yale there had always been the keenest rivalry in matters of sport, and both base-ball and boating drew them together. It was not to be wondered at, then, that, sooner or later, they should adopt a set of rules for football under which they might have still another vigorous contest. In the fall of I 875 they did succeed, after a rather exciting convention of delegates, in adopting a most extraordinary compromise between the Rugby Union, which Harvard advocated, and the old American code, which Yale desired, and a match was arranged. Whether the Harvard adrocates were more expert in their diplomacy than the Yale delegates, or the inherent merit of the Rugby code made itself felt, the compromise rules were certainly nearer the Rugby than the old American. For all that, the strangeness of attempting to combine the two threw both teams badly out, and the match, from the point of view of both player and spectator, was a dismal failure. Harvard, in spite of the many fouls that occurred upon both sides, easily demonstrated her superiority, and defeated the Yale team by four goals and two touch-downs to nothing. One of the concessions made by the Harvard delegates to their Yale petitioners was that, when a foul occurred, the old American rule of throwing the ball into the air should govern. This, in itself, as one can easily imagine, seemed strange in a Rugby contest. But the seed of the Rugby Union was sown; the next season the Harvard and Yale delegates agreed upon a match under the 
regular Rugby Union code, and the contest took place again at New Haven. This time the Yale men had devoted far more time to preparation, and were better trained than the Harvard team. For all that, Harvard was so superior in skill and understood the science of the sport so much better, that the match was a very close one, and was finally won only by a bucking kick of one of the Yale half-backs which sent the ball over the Harvard goal. The Harvard team made two touch-downs but failed in both instances to convert the tries. From this match dates the real introduction of Rugby Football into the catalogue of American sports ; and although the present rules, as they appear in the Intercollegiate Association code, differ in many respects from those of the English, their foundation was the same.

Both games have undergone some changes since that day, but the American game by far the most. The principal reason for this lies in the fact that, while the Englishman had a school where the traditions of what was allowed and what was forbidden in football were as fixed and unalterable as the laws of the Medes and Persians, the American player had nothing but the lex scripta to guide him, and no old player to whom to refer disputed points, or from whom to obtain information. The result in the case of the American was that the first year of Rugby Union was simply full of questions as to interpretations of the code. At the present day the game of American football is played by eleven men a side upon a field 33 feet long by 160 feet wide. While not absolutely necessary, it is customary to mark the field also with transverse lines every five yards, for the benefit of the referee in determining how far the ball is advanced at every down. In the middle of the lines forming the ends of the field the goal-posts are erected, and should be 18 feet 6 inches apart, with a crossbar Io feet from the ground. The posts should project several feet above the cross-bar. The ball used is the same as that used in the English game, an oval leather cover containing a rubber inncr. A majority of the players wear canvas jackets. 
These fit closely, and lace up in front so that they may be drawn quite snugly. The trousers are of some stout materialfustian for example - and well padded. Long woollen stocking.s are worn, and occasionally, but not usually, shin-guards by men playing in the forward line. The most important feature of

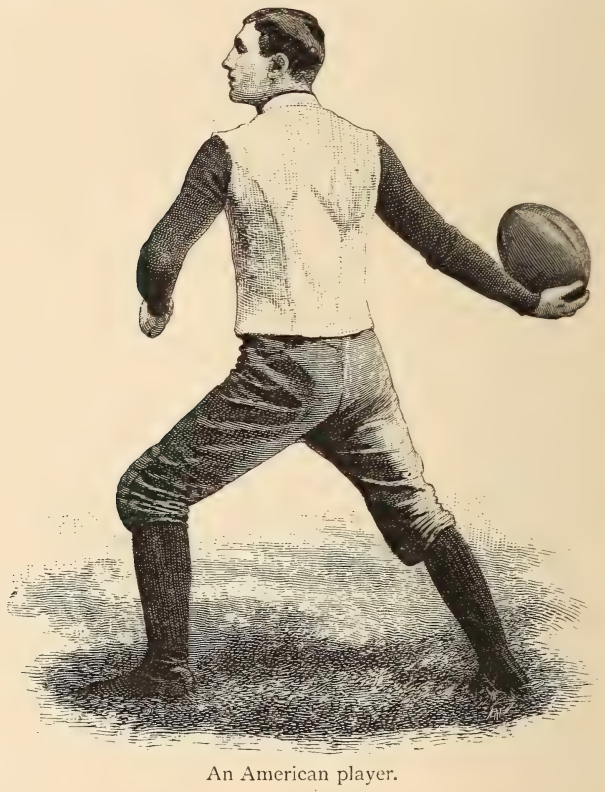

the entire uniform is the shoe. This may be the ordinary canvas and leather base-ball shoe with leather cross-pieces nailed across the sole to prevent slipping. This is the most inexpensive form, but the best shoes are made entirely of leather, kangaroo skin preferably, fitting the foot firmly yet comfortably, lacing well up on the ankle, and the soles pro- 
vided with a small leather spike which can be renewed when worn down. Inside this shoe, and either attached to the bottom of it or not, as preferred, a thin leather anklet laces tightly over the foot, and is an almost sure preventive of sprained ankles. The cap may be of almost any variety, and except in the cases of half-backs and back, does not play any very important part. These men, however, have caps with visors to protect their eyes from the sun when catching a long kick.

The team of eleven men is usually divided into seven rushers or forwards, who stand in a line facing their seven opponents ; a quarterback, who stands just behind this line ; two halfbacks, a few yards behind the quarter-back; and, finally, a full-back or goal-tend, who stands a dozen yards or so behind the half-backs. This gives the general forma-

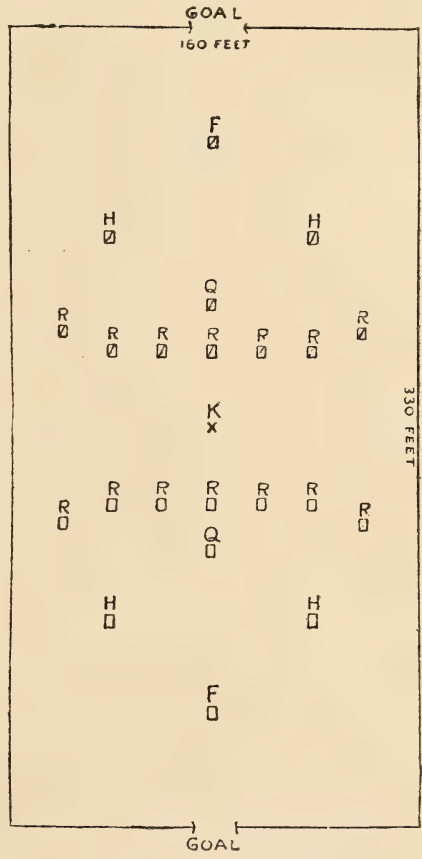
tion, but is, of course, varied according to circumstances. In beginning a game the two teams line up, the holders of the ball placing it upon the exact centre of the field, and the opponents being obliged to stand back in their own territory at least ten yards until the ball has been touched with the foot. There are several methods of starting the play. Primarily, however, 
the ball must be hit by the foot of the man making the kickoff. He may kick the ball as far as he can down the field or he may merely touch it with his foot and then pick it up and pass it, run with it, or even punt it himself. The method most commonly practised now is for him to touch it with his foot and then pass it to some runner of his own side behind him, while the other forwards mass in the form of a wedge in front of this runner, and the entire body of men, with the runner well protected in their midst, then plunges ahead as far as possible into the ranks of the opponents. This play is called the $V$ or wedge, and is affected by almost every team, although the methods may differ slightly. As soon as the ball is touched by the foot, the opposing side may charge, and the rushers, therefore, spring at this wedge-shaped mass of players, and get at the runner as speedily as possible, bringing him to a standstill.

As soon as the ball is fairly held - that is, both player and ball brought to a standstill - the runner must cry 'down,' and someone upon his side, usually the man called the snap back or centre rusher, must place the ball on the ground at that spot for a 'scrimmage,' as it is termed. The ball is then put in play again (while the men of each team keep on their own side of the ball, under penalty of a foul for off-side play) by the snapback kicking the ball or snapping it back, either with his foot or more commonly with his hand, to a player of his own side just behind him, who is called the quarter-back. The ball is in play, and both sides may press forward as soon as it is put in motion by the snap-back. Naturally, however, as the quarter-back usually passes it still further behind him to a halfback or back, to kick or run with, it is the opposing side which are most anxious to push forward, while the side having the ball endeavour by all lawful means to retard that advance until their runner or kicker has had time to execute his play. It is this antagonism of desire on the part of both sides that has given rise to the special legislation regarding the use of the hands, body, and arms of the contestants - and beginners must 
carefully note the distinction. As soon as the snap-back has sent the ball behind him he has really placed all the men in his own line off-side, that is, between the ball and the opponents' goal, and they therefore can theoretically only occupy the positions in which they stand, while the opponents have the legal right to run past them as quickly as possible. For this reason, and bearing in mind that the men 'on-side' have the best claim to right of way, it has been enacted that the side having possession of the ball may not use their hands or arms but only their bodies, when thus off-side, to obstruct or interrupt their adversaries, while the side running through in the endeavour to stop the runner, or secure possession of the ball, may use their hands and arms to make passage for themselves.

The game thus progresses in a series of 'downs' followed by runs or kicks, as the case may be, the only limitation being that of a rule designed to prevent one side continually keeping possession of the ball without material advance or retreat, which would be manifestly unfair to the opponents. This rule provides that in three 'downs,' or attempts to advance the ball, a side not having made five yards towards the opponents' goal or retreated twenty yards towards their own goal must surrender possession. As a matter of fact, it is seldom that a team actually surrenders the ball in this way, because after two attempts, if the prospects of completing the five-yard gain appears small, it is so manifestly politic to kick the ball as far as possible down the field, that such a method is more likely to be adopted than to make a last attempt by a run and give the enemy possession almost on the spot. In such an exigency no feint at a kick is allowed by the rules, but it must be such a kick as to give the opponents fair and equal chance to gain possession of the ball. There is one other element entering into this state of the game, and that is the fair catch. This can be made from a kick by the opponents, provided the catcher takes the ball on the fly, and, no other of his own side touching it, plants his heel in the ground at the spot where the catch is made. This entitles him to a free kick; that is, 
his opponents cannot come beyond his mark made by heeling the catch, while he and his side may retire such distance towardis his own goal as he sees fit, and then make a punt or a drop, or place the ball for a place-kick. He ordinarily, however, in these days of wedge-play, acts exactly as we have described for the first kick-off - that is, merely touches the ball with his foot in order to conform with the rule that he must put it in play by a kick, and then passes it to another of his own side for a run. His own men must be behind the ball when he kicks it, under penalty of off-side.

Whenever the ball goes across the side boundary line of the field, it is said to go 'into touch,' and it must be at once brought back to the point where it crossed the line, and then put in play by some member of the side which carried it out, or first secured possession of it after it went out. The methods of putting it in play are as follows : to throw it directly in at right angles to the touch-line, bound it or touch it in, and then pass it back, or finally, and most commonly, walk into the field and make an ordinary scrimmage of it the same as after a down. In this latter case, the player who intends walking in with it must, before stepping into the field, declare how many paces he will walk in, in order that the opponents may know where the ball will be put in play. We will suppose that the ball by a succession of these plays, runs, kicks, downs, fair catches, \&c., has progressed towards one or the other of the goals, until it is within kicking distance of the goal-posts. The question now will arise in the mind of the captain of the attacking side as to whether his best plan of operations will be to try a drop-kick at the goal, or to continue the running attenipts, in the hope of carrying the ball across the goal-line, for this latter play will count his side a touch-down, and entitle them to a try-at-goal, The touch-down itself will count four points, even if he afterwards fail to convert it into a goal by sending the ball over the bar and between the posts, while, if he succeed in converting it, the touch-down and goal together count six points. A drop-kick, if successful, on the other hand, counts but five points, and is, of 
course, even if attempted, by no means sure of resulting successfully. If it fail, the ball is almost certain to cross the goalline somewhere, and this gives the opponents the right to bring it out to the twenty-five yard line for kick-out, and then have a free kick, which results in still further gain for them, and usually puts their goal out of danger for the time being. $\mathrm{He}$ must, therefore, carefully consider both issues at this point, and it is the handling of those problems that show his quality as a captain. If he elects to continue his running attempts, and eventually carries the ball across the line, he secures a touchdown at the spot where the ball is carried over, and any player of his side may then bring it out, making a mark with his heel on the line as he walks out, and when he reaches a suitable distance place the ball for one of his side to kick, the opponents meantime standing behind their goal-line. In placing the ball it is held in the hands of the placer close to, but not touching, the ground, and then carefully aimed until the direction is proper. Then, at a signal from the kicker that it is right, it is placed upon the ground, still steadied by the hand or finger of the placer, and instantly kicked by the place-kicker. The reason for this keeping it off the ground until the last instant is that the opponents can charge forward as soon as the ball touches the ground, and hence would surely stop the kick if much time intervened. If the ball goes over the goal it scores as above indicated, and the opponents then take it to the middle of the field for kick-off again, the same as at the beginning of the match. The same result happens by the latest rules if the goal be missed, although formerly the opponents could then only bring it out to the twenty-five yard line.

There is one other issue to be considered at this point, and that is, if the ball be in possession of the defenders of the goal, or if it fall into their hands when thus close to their own goal. Of course they will naturally endeavour, by running or kicking, to free themselves, if possible, from the unpleasant situation that menaces them. Sometimes, however, this becomes impossible, and there is a provision in the rules which gives them 
an opportunity of relief, at a sacrifice it is true, but scoring less against them than if their opponents should regain possession of the ball and make a touch-down or a goal. A player may at any time kick, pass, or carry the ball across his own goal-line and there touch it down for safety. This, while it scores two points for his opponents, gives his side the privilege of bringing the ball out to the twenty-five yard line and then taking a kickout, performed like kick-off or any other free kick, except that it must be a drop-kick or a place-kick.

This succession of plays continues for three-quarters of an hour in a regular match. Then intervenes a ten-minute intermission, after which the side which did not have the kick-off at the beginning of the match has possession of the ball for the kick-off at the second three-quarters of an hour. The result of the match is determined by the number of points scored during the two three-quarters, a goal from a touch-down yielding six points, one from the field - that is, without the aid of a touch down-five points; a touch-down from which no goal is kicked gives four, and a safety counts two points for the opponents.

Toward the end of the first year of American Rugby, the latter part of November 1876 , a convention was held, and the rules were amended here and there, as the exigencies of the play had indicated.

In the Rugby code, Rules 8 and 9 read as follows :'The ball is dead when it rests absolutely montionless on the ground,' and 'A touch-down is made when a player, putting his hand on the ball in touch or in goal, stops it so that it remains dead, or fairly so.' As a touch-down was about the most important point to be achieved in the entire game, the words 'or fairly so' following such a definition as 'absolutely motionless' left much to be desired, and were eventually eliminated by the Americans to save disputes. It is easy even for one not versed in football to appreciate the difficulty under which any referee must labour when interpreting such a clause. Men would go tumbling and rolling over the ball, hitting it 
with their hands, 'patting it' as the expression had it, and he must decide which among them, if any, made it rest 'absolutely motionless on the ground, or fairly so.' This was but one of the many instances where custom must have guided the English player, but where the American had no guide. 'Off' and 'onside' were mysteries naturally; but, with the exception of two rules which seemed to conflict, the new players found less difficulty in interpreting the rules than in enforcing them. Nearly all of them had been accustomed to the free and easy methods of playing anywhere upon the field they chose, and it took weeks of practice to make them keep behind the ball. Even the first season of Rugby football in America brough of game that would have been laughed at by Englishmen, and it is no wonder that the alterations and amendments to the rules proved necessary. From the time of this first convention up to a convention held in April of I882, American football legislators amended and added to the rules they had adopted, through no less than a half-dozen annual meetings. During all this time the game had wandered farther and farther from the lines of the English Rugby. But it was in the scrummage, or, as the Americans call it, the scrimmage, that the radical difference between the two methods was most apparent. To go back into the remote history of football, to the days when there was no scrummage, but men struggled for possession of the ball indefinitely, one finds that the first and best reason for the introduction of such a law was to bring about a temporary cessation of the struggle between the holder and the would-be holders, and after this temporary cessation to start the more interesting and better progress of the ball once more in place of the mere struggle for possession. Now, as one writer has truly said, the American scrimmage far more nearly fulfils the requirements of such a case than the English scrummage, for two reasons. It preserves the original rights of the side holding the ball, and it sets the play speedily in motion again. It recognises and preserves, to a far greater degree, the original rights of the holder, in that the side having possession when the ball is held and a scrim- 
mage occurs is more securely guaranteed that same advantage when the play recommences. This can be appreciated when one considers that a scrimmage most frequently occurs as a result of a player who is running with the ball being tackled and brought to a stop. Now, in order to preserve these conditions most nearly when the play is started again, a scrimmage should insure for the player a fair chance to have the ball in his hands again. The English scrummage consists of a mass of men

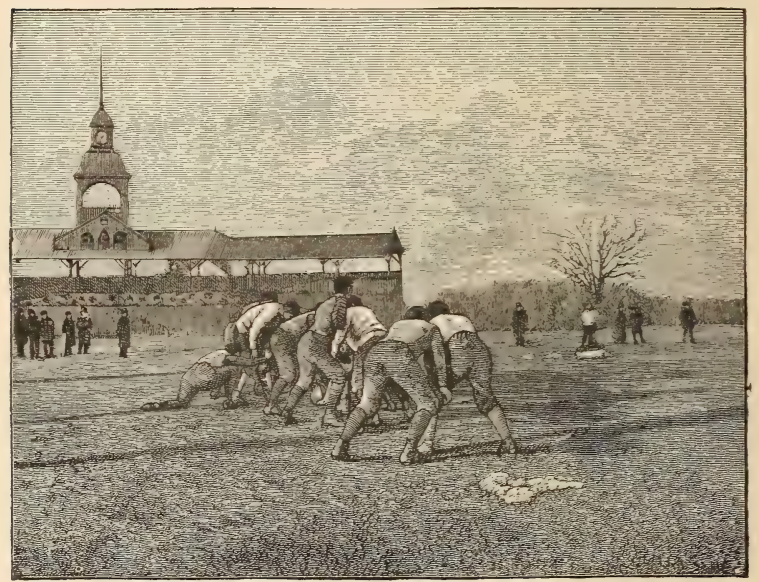

A good scrimmage.

kicking and pushing in the endeavour to drive the ball, which has been placed upon the ground, in the direction of the opponents' goal-line. The outcome of the English scrummage is thus ever a matter of doubt. The ball may pop out anywhere, and the method never can insure to the man or side which originally had possession of the ball the same privilege after the scrummage. It is in the development of the scrummage that the American game has made the most progress and has lost the features of the original Rugby. 
The point that it has at present reached can be judged from the following description of the way it is played at the present date, sixteen years after the adoption of the English rules. When a player, running with the ball, is tackled and the ball fairly held, he must cry 'down,' and a man of his side who has been particularly trained for this work, and who plays in the centre of the line of forwards, takes possession of the ball upon the spot. The two rusher lines spread out more or less across

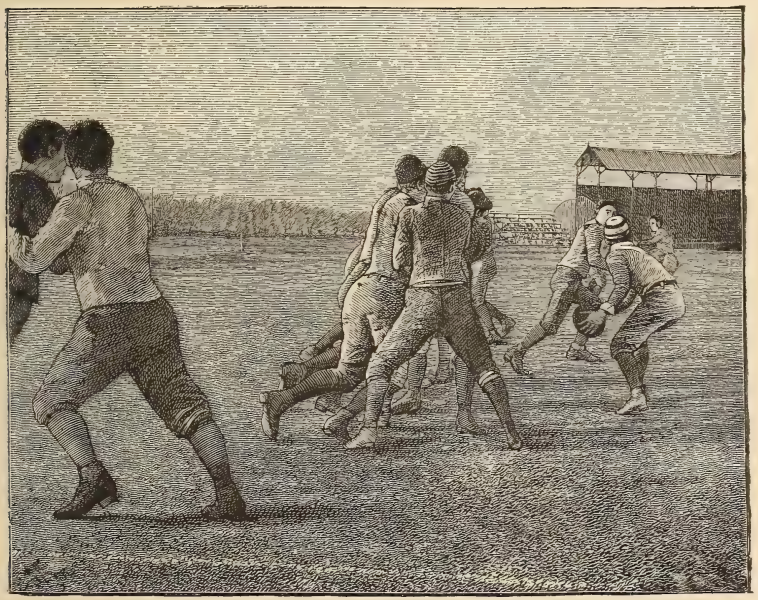

Snap-back and Quarter-back.

the field, and the man who has the ball (called the snap-back, from his work) places it on the ground with his hand resting upon it. Just a few feet behind him stands, or rather crouches, another player called the quarter-back. He it is who has been called, and with justice, the key to the American game, for, as will be seen, he practically has the entire direction of the play in his hands. At a certain signal which he gives the snapback, usually by touching him with his hand, this man with the 
ball snaps it back between his legs directly into the quarterback's waiting hands, and this player passes the ball to some particular player who has been given a signal and is waiting behind him for a kick or a run. The npponents cannot touch the ball until the snap-back has set it in motion; and while it is, therefore, among the range of possibilities for the play to be spoiled before the ball reaches the runner's hands, the chances are so strongly against this that it may with safety be said that the American scrimmage practically guarantees the side holding the ball the possession of it when the play recommences after every 'down.'

It has taken nearly a score of years for the scrimmage to reach this form, for the development has been a gradual and wellconsidered one. The Americans began upon the English scrummage, and the players massed about the ball, kicked hard and vigorously until they drove the ball out somewhere-anywhereno one could predict upon which side of the line. A year of this method was followed by a period of study as to how a man ought to act in a scrimmage, in order to gain the most advantage for his side. Should he push and kick, or should he not? If he could so manage it that, when the ball was in front of him, his opponent should kick it through, it was evident that was extremely desirable ; for while his opponent was unable to rush after it, being entangled in the scrimmage, one of his own half-backs could get the ball and run around the strugging mass. for a considerable gain. Hence the problem became, not how to kick the bail ahead in a scrimmage, but how to make the opponent kick it through. When both parties to the struggie understood this, it became difficult to make the ball come out. For a time the development seemed likely to follow the English fashion of slow close scrimmages, when clever forwards would kcep the ball in the scrimmage, and by steady pressure advance the mass towards the opponents' goal. But this did not last long, for the progress was too slow, and soon rushers acquired the trick of kicking the ball over to the side, and presently dragging it backward with the foot to one of their own side. This 
was the origin of the snap-back, and men became skilful at it. Before two years had passed it was quite the common play, and another season found the man who was best qualified for this work always stationed in the scrimmage where he might do this.

There arose the question, as to how much right to the ball the side had whose man was placing it for the scrimmage. It was eventually decided that the man who put the ball in play was entitled to but half the ball in performing this act, but that his opponents could not put it in play or disturb it until it was put in play. Then the rule was amended to read that the opponent could not interfere with the ball until it was actually in motion. All this time the foot only was used in snapping the ball back, although the player might steady the ball with his hand. It came to be quite common in this steadying process to use the hand in such a way that both hand and foot assisted in snapping the ball back. Greater accuracy was obtained in this manner, and the rules were again amended so that a man could use the hand only if he desired. This, in the last few years, has become the universal practice, and the ball is rolled back with the hand. One more point completes the comparison between the English scrummage and the American scrimmage, and that is the cessation of the play. 'When does a scrimmage end?' in other words. The original rules provide with great force that no man can pick up the ball in a scrimmage. The law reads: 'In a scrimmage it is not lawful to touch the ball with the hand under any circumstances whatever.' But again : 'A player may take up the ball whenever it is rolling or bounding except in a scrimmage.' Even prominent British players have had heated discussions as to the limits of a scrimmage, and the American players could hardly be blamed for finding even greater difficulty in interpreting this. Of course, if the ball rolled out clear of the mass of players, it was out of the scrimmage; but the players were never massed just alike, and often the formation was quite loose. Where, then, could the line be drawn? The American solution, while a singular one, was based upon the supposed 
reason for the rule against handling the ball when so surrounded. A man who attempted to pick up the ball in the midst of the kicking feet was liable to be injured, and hence the rule. The Americans limited their scrimmage finally as follows: The man who snapped the ball back and the man directly opposite him could neither of them pick up the ball until it had touched some third man; that is, any other one of the players. The rapidity with which the American scrimmage sets the play in proper motion again is fully as satisfactory as its preservation of the rights of the side holding the ball when the scrimmage occurred ; for no sooner is the ball placed than it is played, and instantly trarels to the open through the pass of the quarterback. The man to whom he passes may run immediately up into the line again, but by still another most praiseworthy rule he cannot repeat this indefinitely without material progress. This particular rule is known as the 'five-yard rule,' and has done much to raise football in America to a high standard of popularity. The rule is as follows : 'If in three consecutive downs or fairs (that is, scrimmages, or putting the ball in from the side of the field), the ball be not advanced five yards, or taken back twenty, it shall go to the other side.' As will readily be appreciated by anyone familiar with the Rugby game, this law insures the rapid progress of the play. The only way to avoid the issue is to kick the ball, and that acts doubly in farour of increased interest, for it changes the situation of the play and also gives the opponents an opportunity to secure the ball. There is one other feature of the American game worthy of especial mention, and that is what is known as interference. This is something of a very recent growth, and has only been practised for a few years. Its origin was in the assistance lent to a half-back when running through the line by two companion rushers. These would so obstruct the opponents as to prevent their seizing the half-back. At first this was really an infringement of the rule prohibiting a man off-side from interfering in any way, and it was not done in an open manner, and when detected was punished. But after a time the possibility 
of a system founded upon the use of this interference became so attractive that the play was legalised to a certain degree. The side whose man has possession of the ball may, so long as they do not use their hands or arms in the act, obstruct or interfere with anyone about to tackle the runner. Almost all the play in the American game now depends upon more or less of this interference, and it is this and the scrimmage play that would militate strongly against any contest between English and Americans.

The principal contests in the United States to-day are the final Intercollegiate matches, played toward the end of November. These attract audiences of from twenty to thirty or even forty thousand people, and the interest and excitement are at a fever heat. The matches have become a fashionable event, and the appearance of the crowd is such as one witnesses at no other meeting of any kind in the United States, Scores of coaches, gaily bedecked with the various college colours, and traps of all descriptions line the field, while the immense grand stands are packed to their utmost capacity with eager partisans. The cheering is quite an American feature of the assemblage, for each college has its own peculiar cheer, and although the match is between but two, almost all are represented among the spectators, and take the opportunity of declaring their favourites by first giving utterance to their own distinctive college cheer, and then adding the name of the college whom they favour. 


\section{CHAPTER VII.}

\section{AUSTRALIAN FOOTBALL.}

A GENERous partisanship in sports is on the whole a healthful thing. It is at least natural ; for he who has at his heart a throng of happy reminiscences of his own club, his own game, his own peculiar ground, has always a tendency to attribute to them in some degree the buoyant happiness of those early sports. The comrade who fought stoutly with him in many a hardly contested field, the rules which were once as the flag beneath which they all strove side by side, become to him in after years haloed with somewhat of the romance which makes the soldier glow at the sight of the colours under which he met and conquered danger. In all such cases reason is dominated by feelings too warm and hearty to be deplored, even when the impulses of boyish enthusiasm cause the listener to smile with incredulity.

Unless he is wilfully aggressive, therefore, in denouncing other games, the Australian footbalier is following only a natural and healthy impulse when he looks round on all the developments of his sport that the world possesses, and feels that there is none like his own. He visits England, and watches with interest and respect the great contests which are there to be seen, and then he turns back with satisfaction to his own outlying corner of the earth, and his heart warms within him to remember the 'Laws of the Australian Game of Football,' and all the jolly associations connected therewith. And perhaps we shall not be incautious or injudicious if we go with him so far as to agree that there is no football game which appears to a 
crowd of spectators so quick, so picturesque, and so interesting. What other city of half a million people can, like Melbourne, show its gatherings of from ten to twenty thousand people at its principal matches every Saturday and public holiday throughcut a whole season? It is not too much to say that fifty or sixty thousand people are assembled in one part or other of Melbourne every Saturday afternoon to behold their favourite matches, a single match having repeatedly attracted more than thirty thousand. And it is astonishing to see how deeply absorbed the great crowds are in the progress of the game, and to hear with what unanimity the spontaneous roar goes up at some sudden turn in the progress of the play-that hollow roar, short and deep, often heard a mile away on an afternoon of tempered winter sunshine.

Whether rightly or wrongly, the Australian footballer who has toiled in uniform for a few seasons, or the old stager who has 'barracked,' as it is locally called, for the club of his district during half a dozen winters, will agree in declaring that the game of football, as evolved under the guidance of Providence in Australia, is the crowning mercy vouchsafed to the human race.

Sydney and Melbourne are the two cities which in most things take the lead throughout Australia, and in football, as in many other matters, they have led along divergent lines. In both cities the football which was played a generation back was like that of England in the same period, uncertain and subject to a hundred local variations. In Sydney this vagueness has given way to the full adoption of the Rugby Union Rules, which have been altered from time to time to keep pace with the Union in England, the colonial divergences being slight. Queensland has followed the lead of the elder colony, and New Zealand is unswervingly loyal to the Rugby game.

In Melbourne there was a feeling, as far back as 1858 , that without strict rules football was apt to degenerate into a rough contest no higher in level than mere horse-play. And yet, the 
Rugby rules being generally voted slow, the players of the city were thrown back upon the necessity of developing a game of their own; the objects in view being very much the same as those of the English Association, to prevent unnecessary roughness, to make the game fast and interesting, and to encourage the development of skill as an element of at least equal importance with courage and strength.

The result has been favourable, and the Victorian game has worked out for itself solutions of various problems on different lines, but with strictly analogous results to those described as the 'Association Game' in a previous chapter. All Victoria followed the lead of Melbourne, then South Australia and afterwards Tasmania gave in their adhesion to the new system, and it is the game as played in these three colonies that is known by the name of the 'Australian Game.' The outcome of this development has been that a team now plays with a discipline, a self-abnegation, a solidarity of aim, which the game has never before known upon Australian soil.

To gain easily some idea of the manner in which the Australian game differs from the English, let us image to ourselves an afternoon spent in watching the pastime, dreaming that we occupy a place in the long rows of one of the grand stands in Melbourne or in Adelaide; that we look down on a turf of wintry green, flooded with the sunlight of an azure dome. Flags are fluttering, and forty athletes in close-fitting uniform are below-for the Australian game always plays twenty on a side, except where some handicap has been allowed.

Unlike the prastice of the English game, the players of both teams are dotted in pairs all over the field from goal to goal, each man of one team having a man of the other team beside him. As for the field itself, it is larger than is usual in England, the English maximum being the Australian minimum. In Australia the goals must be not less than I 50 yards apart nor more than 200 yards. The minimum width is roo yards and the maximum I50 yards. The additional room is probably an advantage in Australia, where the public reserves in 
all towns are spacious enough to make it possible. On the whole, there is an inclination to keep the size of the field at about I80 yards in length by about I40, which seems to be the space best adapted for the exertions of forty combatants.

In the Australian game there is no 'kick-off.' It is considered that this must-give, at the decision of a mere toss-up, a solid initial advantage to one side. At the minute appointed for the play to begin the field umpire takes the ball to the middle of the field and, giving it a bounce, retires a few yards, leaving the central men of each team to settle down to work. No sort of scrimmage is permitted, for no player is allowed to keep the ball unless he is running with it, nor is anyone allowed to hold another unless the latter has the ball in his hand at the time.

Away it goes, therefore, never at rest for one second until it finds half a minute of repose through the goal-posts. The play is completely open, and the ball is all over the ground in a minute, travelling backwards and forwards with surprising speed. Players are allowed to run with it, but in order to prevent it being tucked under the arm, and so productive of a dead-lock that would spoil the spirit of the play, the runner has to bounce it every seven yards at least, and as it is of oral shape the task is not an easy one. Generally a player is content to bounce it once or twice and then take his kick while he can. No pushing from behind under any circumstances is allowed, nor from the front unless when the player is running to catch the ball and is within five or six yards of it, nor is anyone allowed to push a player after he has sprung into the air to catch the ball for a mark.

The field umpire is vested with plenary powers for the en. forcement of the rules, and from time to time his whistle can be heard shrilling out to signify that something has been amiss. Then back comes the ball to the spot where the rules were violated, and the nearest player of the opposite side has the privilege of a free kick. But all this is done with such quick-

E E 
ness as to interfere in no way with the game; by the rules, a club which disputes a field umpire's decision therehy loses the match. No word of dispute is ever heard, for, by the rules, 'a player disputing the decision of an umpire shall be dealt with as the Association may think fit.' The power of the field umpire is so entirely autocratic that only those who have a licence from the Association are permitted to act in that capacity. A field umpire reported by any club for unfairness, and proved to have been guilty of partiality, would have his licence cancelled by the Association, and with it would disappear that guinea and a half per match which his services secure.

His position is one that requires hard work. He must always be as close as possible to the ball, and if he sees any closing up of players likely to lead to any sort of scrimmage his whistle rings out, the players retire a little from the ball, while he advances and bounces it on the spot, to set the fast play in motion once more.

Again, it is the field umpire who is in request when the ball goes 'out of bounds,' as it is called in Australia - that is, when it is 'in touch.' He carries the ball about five yards over the line, and knocks it evenly into the field so as to give no advantage to either side. The Australian player also is allowed to knock the ball with his hands if he likes, but no throwing of any sort is tolerated by the rules.

An innovation which an English visitor would be sure to note is that of quarter-time. When play has proceeded for twenty-five minutes a bell is rung, and from the first stroke of it the ball is dead and may no longer be played till the teams have changed ends; but if a player has just marked the ball as the bell was on the stroke of ringing, he is allowed his kick, and if a goal is made it is counted.

There is reason in the system of quarter-time, half-time, and three-quarter time, ${ }^{1}$ for if a strong wind is blowing down

1 Introduced by Mr. T. S. Marshall, the veteran secretary of the Victorian Football Association, with whom, for many years past, the most notable innovations have originated. 
the field it may easily happen that the favoured team will make so good a score in the first half of the match that, even if the wind continues as before, the other team, worn out by a heavy struggle against adverse fate, is incapable of rallying the game. And then there is so much chance that the wind may lull or wholly change its direction. The division of the time of play into four quarters, in each of which the ends are changed, is an undoubted means of securing fairness of conditions.

When the quarter-time has rung all players quietly pass to their new positions; the field umpire gives everyone time to get ready, then bounces the ball in the centre as before. At half-time the players are allowed to leave the ground for ten minutes, and again play is resumed by the bouncing of the ball in the centre.

The game lasts a trifle less than two hours, and as it is quick and moving throughout all that time, its capacity for awakening the interest of the spectator is almost unbounded. The goal-posts are placed a little closer to one another than in the English game, being only seven yards apart, and they are bound by the rules to be twenty feet high. To obtain a goal the ball must be kicked between these posts, no matter at what height, but if it touches a post or any player the goal is disallowed, as in the English game.

The goal unpire at each end has but the one duty, that is, to decide as to the validity of goals. He stands provided with a pair of hand-flags. When one of these is waved it indicates to all the field that what is called a 'behind' has been gained; two of them waved together signify a 'goal.' No goal umpire is allowed to raise his flag till the field umpire has signified his assent, which is done by raising one arm for a 'behind,' two arms for a 'goal.' The reason of this arrangement is that, while the goal umpire is the sole judge of the goal, there might perhaps have been, just before the goal was kicked, some infringement of the rules, for which the field umpire had intended to stop the play and award a free kick.

Once the flag is raised, however, the goal is settled and 
cannot be annulled. In place of the Assoziation 'tries' the Australian game has what it calls 'behinds.' On each side of the goal, and seven yards away from the goal-posts, there are 'behind-posts,' which therefore make, along with the seven yards between the goal-posts, an entire stretch of twenty-one yards. If a player, trying for a goal, fails in his aim, but goes within the 'behind-posts,' his success is scored as a 'behind.' The match is decided in favour of the club which has kicked the greatest number of goals, the arrangement of 'behinds' being merely to signify in the case of a draw which was on the whole the better team. It has no use except that it satisfies curiosity, for the public has no love for indecisive conflicts.

If a goal has been kicked, the ball is carried by the field umpire to the centre of the field and then bounced for the play to begin again; but if only a 'behind' is scored, the ball is kicked off by one of the team whose goal it is, from a line drawn seven yards in front of the goal and running the full distance from one 'behind-post ' to the other. If the ball passes behind the line of the goal in any other part, it is merely thrown back again by the field umpire ; but if any one of the defending side has wilfully kicked it behind his own goal-line, the field umpire bounces it five yards inside the boundary opposite the place where it crossed. At any time in the play, if the field umpire sees any tendency on the part of any player to obstruct the quickness of the game by wilfully forcing the ball out of bounds, he is permitted to give a free kick to some player of the other side.

As with the Association game of England, the great aim in the Australian game is to get a team well drilled and accustomed to play into one another's hands. Individual prowess is of no avail against a team which acts with automatic precision, each player's individuality lost in the concerted movements of the whole, each man's yearning for his own personal distinction being subordinate to the honour of the team.

A great deal of this concerted play depends on what is called the 'little mark.' As no throwing or passing of the ball 
is permitted, the only way in which one player can give it to a fellow-player is to kick it so that he can 'mark' it. But when the latter has caught it he is, for the time being, unmolested. $\mathrm{He}$ is master of the situation; if he makes his mark, none of the opposing players are allowed to cross it, or crowd nearer than four yards on either side of him while he takes a free kick. It thus becomes a point of extreme importance for players to give each other this advantage.

If a man can pick up the ball, yet sees that a crowd is almost on him, he kicks it quick as thought into the hands of the player of his own side who is nearest to him. The latter may take a long leisurely kick if such a course seems best ; but oftentimes it happens that if he sinks the personal gratification of seeing the ball rise from his foot in a giant curve towards the goal, he will do more real good for his side by merely kicking it a few yards further into the hands of a friend, who in his turn, if judicious, may perhaps work it up the field a few yards more, so that by degrees, without any brilliant play, a solid advantage may be gained.

To avoid the pettiness that would arise if this were overdone, when perhaps the ball might be bandied about fron toe to toe in a narrow space to little purpose, it is provided that in order to make a 'mark' valid the player who catches the ball must be at least two yards away from him who kicked it. The player who has 'marked' the ball is allowed reasonable leisure to take his kick, but if it be the opinion of the field umpire that he is wilfully wasting time, the ball is taken from him and 'bounced' on the spot. On the other hand, any unfair interference with the player who is taking his free kick is forbidden by the field umpire, and the player who refuses to submit himself to authority is reported to the Association.

So much power is left to the field umpire that if he exhibited any partiality the game must infallibly be ruined. Fortunately it always happens that the umpire, having a reputation to maintain, strives so sedulously to be irreproachably fair that a kind of tacit deference has grown up, and a sort of 
divinity hedges an umpire, so that his word is obeyed in silence, and the game never flags for a minute.

The following plan shows the most usual fashion of placing the players :-

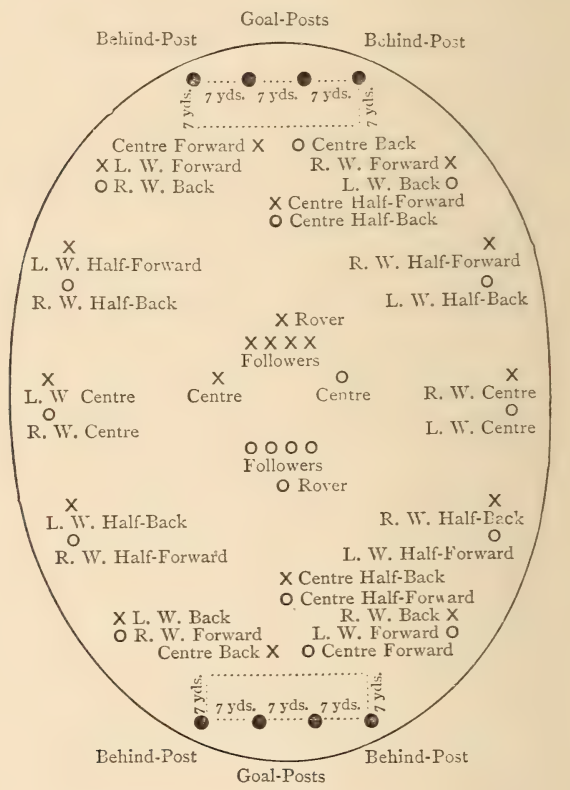

Players marked $X$ kick $\uparrow$, while plasers marked 0 kick $\downarrow$.

In the field as thus disposed there are fifteen men on each side, who have places to which they must in the main adhere. The four who are called 'followers' stand up to the field umpire when he bounces the ball, and follow it in its wanderings over the field. They ought never to be very far from it. 'The rover is an individual chosen for his quickness and readi- 
ness to go wherever he is wanted. He observes the turn of the game, and follows when he sees his own followers being over-weighted by their adversaries, leaves them if he finds they can hold their own, and stations himself wherever he thinks that extra work may be required.

The best and straightest kicker of the team is made centre forward. It is the duty of all the rest to 'feed' him, and place the ball in his hands, giving him the chance to 'mark' it if possible. Then, when the ball has been 'marked,' comes his chance to kick the goal. Other players must on no account take risky shots at the goal ; a difficult kick adroitly managed yields individual glory, but in the long run a taste for such display ruins the team that exhibits it. All such temptation has to be shunned, and the ball worked steadily up the field, ' middled' if necessary, until it reaches the hands of 'central forward,' who ought to put it through. 'The next best kickers are placed as right and left wing forwards.

The centre man is generally the most powerful in the team ; his position does not call for special smartness, but he ought to be capable of strong efforts to prevent the ball from being carried behind him. To right and left of him, on the wings, stand the two fastest runners of the team, men well versed in the art of bouncing an oval football, so as not to lose control over it, as they run.

If the ball, after having cleared the heads of the 'ruck,' reaches one of these outlying ends of the centre line, and he proves to be a quick runner who is capable of dodging one or two scattered men of the opposite side, he may readily carry it forward so as to place it with a drop kick fair in the hands of the centre forward or 'goal-sneak' as he is popularly called, who then has every chance of putting it through.

The half-forward men on the wings ought to be ready to protect these centre wing men in their running, and do all in their power to secure the ball for the centre forward. This process of protecting another player while he leisurely runs and bounces the ball as he goes is one of the most 
generous features in the game, and one that often gives scope for no little skill. It is popularly known as 'shepherding.' A man shepherds another who is running by keeping antagonists away. It can be done only for a time, as others eager for the fray soon bear down from all sides, and the play would become a 'scrimmage,' which, being stopped by the whistle of the field umpire, would leave the ball neutral with both sides evenly disposed around it. Judgment is shown in determining how long it is possible to 'shepherd' another, and the one who is 'shepherded' ought to take his kick at the right moment and in the right direction so as to put it well forward in the hands of a friend. Another way of 'shepherding' a fellow-player is to protect him against interference when he is going for a 'mark.' A man who can kick well ought to be assisted to get the ball, and if it is whirling through the air in his direction, his fellowplayers ought to have their shoulders ready to jostle and impede anyone of the opposite side likely to be a rival for the 'mark.' A match is often won by this species of subordination and organised assistance.

The three men who stand on the back line should be skilful in marking the ball; the centre back especially should be a good marker, a long strong kicker, and should have a cool head and good judgment, in order by his ingenuity and determination to divert the ball from the danger of proximity to the goal of which he is guardian.

If the players have all been judiciously chosen for their parts, and if they have had some practice together, everything ought to go forward as if the whole team were an organism possessed of the one mind and the one object: every man zealous to play into the hands of his fellow and to give him a chance of distinguishing himself in his own particular line.

Strength is needed, but it is not brute strength; not the strength of the bully, but a strength adorned with lightness and made efficient by skill. To prevent any tendency that players might have towards a reversion into savagery, the laws against roughness are stringently enforced. Before the match 
is begun the field umpire examines the boots of all the players, and declines to suffer anyone on the field whose soles are armed with projecting nails or with iron plates, and no Australian player ever wears the shin protectors which are an awkwardness and disfigurement to the English footballer.

If the umpire saw a player purposely kick the shins of another, the chirp of his whistle would at once be heard, and a free kick would reward the player whose shins were kicked, and prove an effectual warning to the kicker, whose own side also would have scmething serious to say to him for injuring the prospects of their game by infringement of rules.

All this means that the central or field umpire has to be close up to the play at all times. The English umpire, with his tall hat and neatly folded umbrella, would be out of place. The field umpire, dressed in a white tight-fitting suit, has to run in order to keep close to the ball; he has to watch the play, to bounce the ball, to decide instantly as to infringement of rules, and yet to keep himself out of the way so that the game may not be impeded by his presence.

In Victoria there are eleren of these umpires licensed by the Association, and told off each Tuesday by the Committee for their several matches on the Saturday.

The goal umpires also require a licence from the Association; but while the field umpire has a guinea and a half, they receive only half a guinea each for their services.

Thus it costs two guineas and a half to provide umpires for a match. This sum is paid by the competing clubs, but the umpires are in no way dependent on the clubs. Their business is faithfully to serve their employer, the Association, by carrying out the rules in perfect simplicity and impartiality, and no case has ever yet occurred in which an umpire has been dismissed or even, so much as reprimanded for unfairness, although from time to time a defeated club has been known to indulge in growls among its own members. They have growled, but only on two occasions have cases been stated, and neither complaint was sustained after full inquiry had been made. 
The field umpires are alone responsible for the enforcement of the rules, and it is from their official report that the Association makes its record of the result. In this report must be included a statement of any infringement of rules which cannot be met by penalties given on the field.

The umpires are of course an openly professional class ; but professionalism among players is strictly discouraged, the rules directing that 'any player receiving payment directly or indirectly for his services' shall be disqualified, and any club known to pay a footballer 'shall be fined ten pounds, and in addition lose the match, and be disqualified for the remainder of the season.'

But alas for human regulations ! There are so many ways in which remuneration can be given that the most elaborately drafted rules may not catch the infringer. It is so easy for a club to induce a good player to join them, and then-merely as a mark of esteem-contribute a hundred pounds with which to start him in business, or provide him with some other form of testimonial. And then a stalwart fellow can so easily be retained as a trainer, or caretaker, or something of that sort, that those who are determined to break the spirit of the laws will certainly find a way of doing so without infringing their letter. However, the evil is not one that has as yet caused any great inconveniences or unfairness; and although it is alleged that sooner or later the wealthier clubs will have the game entirely in their own hands, there is as yet no sign of anything of that kind.

But there is another canker to true sport that threatens mischief in the future. There is that sardonic Mephistopheles the bookmaker, who lingers in out-of-the-way places to sneak behind the elbow of the player and whisper golden promises in his ear ; whose muscles, thereafter, though they show no looseness such as may be detected by a crowd, are perhaps not exerted up to the winning point.

But this, in Australia, and not there only, is a jarring element in every form of healthful sport, and cannot be provided against. 
Wherever manly competition occurs there will the betting man appear, and what he may in secret be able to effect as a tempter can never be with certainty discovered.

But we are forgetting to watch our game. On the sward twenty forms in blue and white and twenty in black and red are sprinkled in pairs, every blue and white having a black and red to watch him. In the middle of the field some five or six of each colour are grouped around the man in white who is the field umpire. Down goes the ball in the middle with a bounce, and as it rises stalwart arms and legs bandy it for a second till it passes clear. A player seizes it, runs, bouncing the ball as he goes ; others career to meet him; he kicks; where the ball is likely to fall a concourse gathers; up go two or three figures boldly springing into the air to catch it.

This is a feature in an Australian game not so much noticed in the English, as the rules give a 'mark,' or free kick, to anyone who catches a ball from the foot of any other player, if not less than two yards away from him. Whenever the ball is seen curving through the air it becomes at all times a matter of importance to catch it. Up into the air, therefore, go the players, and it is sometimes pretty to see the neat way in which the ball is held. It is this practice which necessitates a rule forbidding anyone to interfere with a player already in the air. When he is running for the ball he may be jostled or hustled, if the hands are not used; but when he is well up in the air, to knock against his legs would probably enough bring him heavily to the ground on his side, and cause a dangerous fall Nothing of the kind occurs ; or, if there is a tendency to it, the field umpire's whistle stops the play, and a free kick is given. Any serious repetition of the offence would lead to the disqualification of the player.

Yonder we see the ball being closed in by a number of crowding players! Again the whistle sounds ; the field umpire hurries up, the players fall back a little, the ball is bounced, and away it goes. Soon it is over the boundary line; at once the umpire knocks it back. Now it is held by an active man 
who runs with it for a few yards, gives a 'little mark' to a friend, who passes it by a 'little mark' to another. He takes his kick leisurely behind his mark, but there is no lining up, there being nothing corresponding to 'off-side' in the Australian game. The ball clears the heads of the crowd; now the 'forwards' of the one team and the 'backs' of the other have to fight it out till the 'followers' come up. The ball rolls in front of the goal; the 'centre back' tries hard to send it to the wings, but the 'centre forward' or 'goal-sneak' of the assailants gets a 'little mark' from one of his men. Being the straight kicker of his team, he takes a leisurely kick, and puts it through amid a roar of voices as though human throats were of brass.

The ball is soon back in the centre, and off it goes again, the whistle of the field umpire being heard from time to time and obeyed with instant alacrity. As in the English Association game, the play is exceedingly quick, and the crowd have to watch with the closest attention if they hope to follow all the fortunes of the ball. In the deep absorption of the game any little piece of bad play is met by a low murmur; a bad miss is greeted with an instant growl as of thunder-checked at once in the eagerness to watch the sequel; parted lips are whispering to themselves, or burst out into loud warnings or injunctions which none of the combatants can possibly hear. And when a player is pitched headlong on the sward what a sharp laugh rings out for a second !

Off goes the ball again ; a player seizes it, bouncing it as he goes, 'shepherded' along the way by his friends. Suddenly an opponent bursts through the defence and flings himself upon the man with the ball, who then has reason to repent that he did not sooner kick when the chance was open. The instant that he feels himself touched he must drop the ball; the instant it is dropped his assailant must take his hands off. If the umpire considers that his grasp has not relaxed immediately when the ball was dropped, his whistle sounds, and a 'free kick' is awarded to the man who has been held; a salutary 
lesson which reminds the aggressor that he cannot be too prompt in obeying the rules.

Once the runner has dropped the ball and has himself been released, a tussle takes place, but being open, not closing up in any scrimmage, the ball soon goes away followed vigorously by the field. Back and forwards it bounds till it flies clear of the crowd. As it trundles over the sward towards the boundaries, two of the wing players, placed to watch each other as rivals, go in pursuit of it. Shoulder to shoulder, bumping as they go, they dodge each other for a chance of picking the ball up, or of dribbling it over to their own side for freedom to kick it to suit their taste. But if they hamper each other too long, up comes a fast runner, and bears it away unmolested. Sometimes judgment is shown by merely keeping an opponent off, if it is observed that a player of one's own side is the nearest and most likely to be the first on the spot.

It would be impossible for the 'followers' to keep up the pace of the game for the whole hundred minutes during which it lasts. It is usual, therefore, to give them places for two alternate quarters, and make them follow during the others.

In Melbourne there are, beside the Senior Association, the 'Senior Second Twenties Associations,' the 'First-rate Junior Association,' and the 'Second-rate Junior Association,' which play under the Association rules. What is called the 'Thirdrate Junior Association' consists chiefly of a multitude of clubs of lads, who make all the public parks and vacant lands resonant on a Saturday afternoon with games so interlaced one with another that the visitor is at his wits' end to distinguish where one begins and where another terminates. Yet the players themselves toil on without confusion, though, as everybody seems in some matches to be captain of his team, and spends his whole breath in screaming his instructions to everybody else, it is impossible to understand how they do it.

In the Senior Association great care is taken to discourage touting for players. No player is allowed to play with more 
than one club, and no player is allowed to change his club unless with the express and written consent of the permit committee, after having produced satisfactory reasons for the change he proposes to make. But on no account whatever will a transfer be permitted after midwinter, when the competition for premiership becomes keen, and touting for players might be expected to appear and grow aggravated.

A player can change his club only by showing that he has changed his residence so considerably that he conld not be expected still to play with his previous club, a fact for which that club must vouch in writing. Also if he can bring a written certificate that his own club does not propose to select him again to play in its team, he can change. Otherwise he must continue loyal to his own club.

There are few accidents in the Australian game; for some years past no serious hurt has happened where the rules of the Association have been enforced, though it would be too much to expect that in a city like Melbourne, where 3,000 footballers turn out to play every Saturday afternoon, reckoning the I34 recognised clubs alone, there should never be a mishap or a death. But, as the national poet Lindsay Gordon has put it in some doggerel rhymes-

'No game was ever yet worth a rap

For a rational man to play,

Into which no accident, no mishap,

Could possibly find its way.'

And football, as now played in the southern colonies of Australia, has as few accidents as cricket, a game which has not of late increased in popularity throughout Australia, for the employment of fielding under a summer sun during the height of the cricketing season is distinctly monotonous, and the more scientific the game becomes the less is there for the spectators to see. A few maiden overs soon tend to thin the crowd, and though people may be interested to read next morning in the papers that a stout batsman guarded his wicket 
for four or five hours, they would rather read about it than sit a whole afternoon in the heat to see him do it.

Football is beyond a doubt the national game in Australia. The schoolboy anticipates the season and extends it long after the time for cricket is duly arrived. The public who have languidly attended the matches where bowler and batsman have slowly fought out a three-days' contest awake with a keen interest to the fact that football has begun-football with its sharp contests always settled in some definite way within the two hours; always sprinkled here and there with comic incident for a laugh; always quick and moving, and with picturesque changes of colour, at short intervals presenting some critical moment when a champion gives a new complexion to the game —football, all animation and life, finds vastly increasing favour as compared with the slow and steady dignity of cricket. Of the two perhaps football is the better for a national game. There is no other like it to teach the eye to be quick and the will ready to decide. Instead of being the mother of accidents it is in part their cure, for the youth who has learnt the courage and address of the football field is one whose nerves are ready to meet an emergency, and whose wits are rapid to devise a course of safety. Moreover, it can more than hold its own in comparison with all other sports as a training for generous and unselfish co-operation.

The Australian game may in one sense be called a compromise between the English Association game and that of the Rugby Union, for it unites many features of both; but it has likewise new points of its own. Here and there an Australian player is heard to growl that there is too much field umpire about it. And indeed that functionary is plentifully in evidence. But then, as the majority of players say, in such a game you must trust your umpire, and if he does not abuse his autocratic powers, the more summarily everything is decided the smarter is the game; and if he does make crops of mistakes, they will be on the average as much in favour of one side as in that of the other, unless wilful partiality is displayed 
Such things can be left only to the test of experience, and experience seems to have shown in Australia that the new game entirely goes with the national taste. Apparently it is now only in the early stage of a lusty existence.

\section{LAWS OF THE AUSTRALIAN GAME OF FOOTBALL.}

I. The distance between the goals shall not be more than 200 yards nor less than 150 yards, and the width of the playing space not more than 150 yards nor less than 100 yards, to be measured equally through the centres of the goals. The goal-posts shall be 7 yards apart, of not less than 20 feet in height. The ball to be used shall be the No. 2 size Rugby ( 26 inches in circumference).

2. Two posts, to be called the 'kick-off-posts,' (or 'behind-posts') shall be erected at a distance of seven yards on each side of the goal-posts, in a straight line with them; the intervening line between such posts shall constitute the goal-line.

3. Matches shall be played with not more than twenty a side unless where handicaps are conceded. Any team detected, during the progress of the game, playing more than the number arranged for, shall have all goals kicked prior to the detection of same annulled. In the event of a club commencing play with less than twenty men, that club shall be allowed to complete its team at any stage of the game.

4. The captains of each side shall toss for choice of goal. The players shall then take their proper positions on the field, and the game shall be commenced by the field umpire bouncing the ball in the centre of the ground. When a goal has been obtained, the players shall again take positions as above, and the ball shall be bounced in the centre.

(a) When one-fourth, one-half, and three-fourths of the time arranged for play have expired, the players shall change ends, and the ball be bounced by the field umpire in the centre of the ground. At half-time the players may leave the ground for not more than ten minutes.

(b) Each club shall appoint a time-keeper, whose duty it shall be to keep time, and ring a bell, approved by the Association, at the times indicated above.

(c) An alarm clock, or any other suitable apparatus, may be substituted for a bell. 
(d) At the first sound of the bell the ball shall be dead, but in the event of a player having marked the ball before the bell has rung he shall be allowed his kick, and should he obtain a goal from it, it shall be reckoned. A goal obtained from a ball in transit before the bell has rung shall be also reckoned.

5. The game shall be won by the side kicking the greatest number of goals.

6. All matches shall be commenced and played out to the time arranged (unless interfered with by adverse weather), and shall not be stopped or cancelled immediately previous to the time arranged for starting, except by the consent of both captains; but in the event of the captains disagreeing, the field umpire shall be constituted sole referee, and the side disputing his decision shall lose the match.

(a) Should a match be cancelled (immediately previous to the time of starting), or be stopped through adverse weather, the game shall be reckoned a drawn one.

(b) No arranged match, other than those provided for above, shall be cancelled except by the written consent of the two secretaries, and the written consent of the permit committee, or of the local association.

7. All matches throughout the season shall be played twentyfive minutes each quarter.

8. A goal must be kicked by one of the side playing for goal kicking the ball between the posts without touching either of them (flags excepted), or any player, after being kicked. Should any of the spectators, standing between or immediately in front of the goal-posts, interfere with or stop the progress of the ball going through, a goal shall be scored, unless the goal umpire is of opinion that one of the players whose goal is attacked would have touched it, or that it would not have gone between the goal-posts if not interfered with or stopped.

9. The goal umpires shall be sole judges of goals, and their decision shall be final, except in cases where the ball becomes dead, either by the ringing of the bell or decision of the field umpire. The field umpire shall decide in all other matters during the progress of the game, and may appeal to a goal umpire.

(a) Goals and behinds shall be indicated by flags.

(b) The goal umpire must consult with the field umpire prior to raising the flags. A goal given in accordance with above and Rule 8 cannot be annulled. 
IO. In case the ball is kicked behind the goal-line by one of the opposite side (except when a goal is kicked, in whıch case the ball is bounced in the centre of the ground), any one of the side behind whose goal it is kicked may bring it seven yards in front of any portion of the space within the goal-line (to be indicated by a white mark seven yards in front), and it shall be kicked towards the opposite goal.

II. In the event of a player kicking or forcing the ball wilfully behind his own goal-line, it shall be bounced by the field umpire at right angles to, and not more than five yards from, the point where it crossed the said goal-line.

I2. When the ball goes out of bounds, it shall be brought back to the spot where it crossed the boundary line, and bounced by the field umpire at least five yards within the playing ground.

13. Any player catching the ball from the foot of another player two yards away may call 'mark.' He then has a kick in any direction from any spot behind and in a line with his mark and the centre of his opponents' goal-posts, even if he have to go out of bounds or behind his goal, no player being allowed to come inside the spot marked, or within four yards in any other direction.

(a) A free kick shall be treated as an ordinary mark.

(b) Should a player, having a mark, or in kicking off, unduly delay the play, the field umpire shall bounce the ball.

I4. The ball may be taken in hand at any time, but not carried further than is necessary for a kick, unless the player strikes it against the ground at least once in every seven yards. In the event of a player with the ball in hand trying to pass an adversary and being held by him, he must at once drop the ball.

I 5. If any player, when the ball is in play, wilfully kick or force it out of bounds, the umpire shall give a 'mark' to the opposite side from the spot where the ball went out of bounds.

16. The ball, while in play, shall under no circumstances be thrown or handed to a player.

17. Tripping, hacking, rabbiting, slinging, unfairly interfering with a player after he has made a 'mark,' or catching hold of a player below the knee, are prohibited; pushing with the hands or body is allowed only when a player is running within five or six yards of the ball. Holding a player is allowed only while such player has the ball in hand, except in cases provided for in Rules I3 and I4. 
(a) Pushing a player shall not be allowed under the following conditions :- -

(I) Pushing from behind shall not be allowed under any circumstances.

(2) From the front when a player is standing.

(3) When a player is in the air going for a 'mark.'

(b) A player reported by the umpire for unduly rough play shall be dealt with as the Association may think fit.

(c) Slinging, deliberately charging, or throwing a player after he has clearly made a 'mark,' or when the ball is out of play, will be considered unduly rough play, and the offender shall be reported by the umpire to the Association.

(d) A player disputing the decision of an umpire, or unduly interfering with or assaulting him during the progress of the game or within the enclosure on the day of the match, shall be dealt with as the Association may think fit.

(e) A player assaulting another player, or using foul language on the field, shall be reported to and dealt with as the Association may think fit.

18. The field umpire shall either award a 'mark,' call 'play on,' or stop the play, and bounce the ball, stop all attempts at scrimmages, enforce strictly the running, pushing, and holding clauses of Rules 14 and I7, and in every case his decision shall be final, and the club disputing same shall lose the match. In the event of an umpire refusing to decide upon the matter in dispute, clubs may appeal to the local Association, whose decision shall be final.

19. In case of infringement of Rules $14,15,16$, and 17 , a player of the opposite side shall be awarded a 'mark' from the place where the breach of the rule was made, the player nearest the place of infringement being the only one entitled to the kick.

20. The field umpire shall, prior to the match, examine the boots of players, and no one wearing protecting nails or iron plates thereon shall be allowed to play.

(a) If, during the progress of the game, any player is detected infringing the above rule, such player shall be disqualified for the remainder of the match, and be reported by the umpire to the Association.

21. Local Associations may disqualify players, for any term.

(a) The several Associations represented on this conference shall endorse the decisions of all the other Associations, whether 
made under the Laws of the Game, or the Articles of Constitution of such Association.

22. None of the above laws shall be altered or rescinded, nor shall any rule be repealed, altered, amended, or adopted without the concurrence of an absolute majority of inter-colonial delegates,

a meeting specially called for that purpose, or a majority of the Associations (in writing) represented on the 1890 conference 


\section{APPENDIX.}

\section{$\longrightarrow$ \\ THE LAWS OF THE GAME.}

\section{THE FOOTBALL ASSOCIATION.}

I. THE limits of the ground shall be:-maximum length, 200 yards; minimum length, I00 yards; maximum breadth, Ioo yards; minimum breadth, 50 yards. The length and breadth shall be marked off with flags and touch-line, and lines defining 6 yards from the goal-posts and 12 yards from the goal-lines shall also be marked out. The centre of the ground shall be indicated by a suitable mark, and a circle with a Io yards radius shall be made round it. The goals shall be upright posts, 8 yards apart, with a bar across them, $\delta$ feet from the ground. The circumference of the Association ball shall not be less than 27 inches, nor more than 28 inches; and in International matches, at the commencement of the game the weight of the ball shall be from I 3 to I 5 ounces.

2. The winners of the toss shall have the option of kick-off, or choice of goals. The game shall be commenced by a place-kick from the centre of the ground in the direction of the opposite goalline ; the other side shall not approach within 10 yards of the ball until it is kicked off, nor shall any player on either side pass the centre of the ground in the direction of his opponents' goal until the ball is kicked off.

3. Ends shall only be changed at half-time. After a goal is won the losing side shall kick off, but after the change of ends at half-time the ball shall be kicked off by the opposite side from that which originally did so; and always as provided in Law 2.

4. A goal shall be won when the ball has passed between the goal-posts under the bar, not being thrown, knocked on, or carried by any one of the attacking side. The ball hitting the 
goal or boundary posts, or goal-bar, and rebounding into play, is considered in play. The ball crossing the goal or touch line, either on the ground or in the air, is out of play.

5. When the ball is in touch, a player of the opposite side to that which kicked it out shall throw it in from the point on the boundary line where it left the ground. The thrower, facing the field of-play, shall throw the ball over his head with both hands in any direction, and it shall be in play when thrown in. The thrower shall not play until the ball has been played by another player.

6. When a player kicks the ball, or throws it in from touch, any one of the same side who at such moment of kicking or throwing is nearer to the opponents' goal-line is out of play, and may not touch the ball himself, or in any way whatever prevent any other player from doing so, until the ball has been played, unless there are at such moment of kicking or throwing at least three of his opponents nearer their own goal-line ; but no player is out of play in the case of a corner-kick, or when the ball is kicked off from goal, or when it has been last played by an opponent.

7. When the ball is played behind the goal-line by one of the opposite side, it shall be kicked off by any one of the players behind whose goal-line it went, within six yards of the goal-post nearest the point where the ball left the field-of-play; but if played behind by any one of the sicle whose goal-line it is, a player of the opposite side shall kick it from within one yard of the nearest corner flag-post. In either case no opponent shall be allowed within six yards of the ball until it is kicked off.

8. No player shall carry, knock-on, or handle the ball under any pretence whatever, except in case of the goal-keeper, who, within his own half of the ground, shall be allowed to use his hands in defence of his goal, either by knocking-on or throwing, but not carrying the ball. The goal-keeper may be changed during the game, but not more than one player shall act as goal-keeper at the same time, and no second player shall step in and act during any period in which the regular goal-keeper may have vacated his position.

9. In no place shall a goal be scored from any free kick (except as provided in Law I3), nor shall the ball be again played by the kicker until it has been played by another player. The kick-off, corner-flag kick, and goal-kick shall be free kicks within the meaning of this rule.

10. Neither tripping, hacking, nor jumping at a player shall be 
allowed, and no player shall use his hands to hold or push his adversary, or play in any manner likely to cause injury. No player may charge an opponent from behind, unless such opponent be not only facing his own goal, but is, in the opinion of the referee, wilfully impeding his adversary while in that position. The goalkeeper shall not be charged except he be in the act of playing the ball, or is obstructing an opponent.

I I. No player shall wear any nails, excepting such as have thcir heads driven in flush with the leather, or iron plates, or guttapercha on the soles or heels of his boots, or on his shin guards. If bars or studs on the soles or heels of the boots are used, they shall not project more than half an inch, and shall have all their fastenings driven in flush with the leather. Bars should be transverse and flat, not less than one and a half inches in length, and half an inch in width. Studs shall be round in plan, not less than half an inch in diameter, and in no case conical or pointed. Any player discovered infringing this rule shall be prohibited from taking further part in the match.

I2. A referee shall be appointed, whose duties shall be to enforce the rules and decide all disputed points; and his decision on points of fact connected with the game going on shall be final. He shall also keep a record of the game and act as timekeeper ; and, in the event of any ungentlemanly behaviour on the part of any of the contestants, the offender or offenders shall be cautioned, and if the offence is repeated, or, in case of violent conduct, without any previous caution, the referee shall have power to rule the offending player or players out of play, and shall transmit the name or names of such player or players to his or their (National) Association, in whom shall be solely vested the right of accepting an apology. The referee shall have power to terminate the game whenever, by reason of darkness, interference by spectators, or other cause, he shall think fit, and he shall report the same to the Association under whose jurisdiction the match was played, who shall have full power to deal with the matter. Two linesmen shall be appointed, whose duty (subject to the decision of the referee) shall be to decide when the ball is out of play, and which side is entitled to the corner-flag kick, goal-kick, or throw-in. Any undue interference by a linesman shall be reported by the referee to the National Association to which the linesman belongs, who shall deal with the matter in such manner as they may deem necessary. The referee shall have power to award a free kick without any 
appcal in any case where he thinks that the conduct of a player is dangerous, or likely to prove dangerous, but not sufficiently so as to justify him in putting in force the greater powers vested in him as above.

I3. If any player shall intentionally trip or hold or push an opposing player, or wilfully handle the ball, within 12 yards from his own goal-line, the referee shall, on appeal, award the opposing side a penalty-kick, to be taken from any point 12 yards from the goal-line, under the following conditions:-All players, with the exception of the player taking the penalty-kick and the opposing goal-keeper (who shall not advance more than 6 yards from the goal-line), shall stand at least 6 yards behind the ball. The ball shall be in play when the kick is taken, and a goal may be scored from the penalty-kick; but the ball shall not be again played by the kicker until it has been played by another player. If necessary, time of play shall be extended to admit of the penalty-kick being taken.

14. In the event of an appeal for any supposed infringement of the laws, the ball shall be in play until a decison has been given.

I5. The referee shall have power to stop the game for such a time as he may think fit, whenever he may deem it necessary to do so.

16. In the event of any temporary suspension of play from any cause, the ball not having gone into touch, or behind the goal-line, the game shall be re-started by the referee throwing up the ball at the spot where play was suspended, and the players on either side shall not play the ball until it has touched the ground.

I7. In the event of any infringement of Laws 2, 5, 6, 8, 9, Io, or I6, a free kick shall be forfeited to the opposite side, from the spot where the infringement took place.

\section{DEFINITION OF TERMS.}

A PLACE-KICK is a kick at the ball while it is on the ground, in any position in which the kicker may choose to place it.

A FREE KICK is a kick at the ball in any direction the player pleases, when it is lying on the ground, none of the kicker's opponents being allowed within six yards of the ball, unless they be standing on their own goal-line. The ball must at least be rolled over before it shall be considered played.

HACKING is kicking an adversary intentionally. 
TRIPPING is throwing or attempting to throw an adversary by the use of the legs, or by stooping in front of or behind him. Unless in the opinion of the referce a trip is intentional no punishment shall be imposed; thus within the twelve-yards line a referee must enforce Law I3, and has no power to mitigate the penalty.

KNOCKING-ON is when a player strikes or propels the ball with his hands or arms.

HOLDING includes the obstruction of a player by the hand or any part of the arm extending from the body.

HANDLING is understood to be playing the ball with the hand or arm.

Touch is that part of the field on either side of the ground which is beyond the line of play.

CARRYING is taking more than two steps while holding the ball.

The Council of the Football Association have placed the followin'erpretations upon Laws:-

(a) All reports by referees to be made within three days after occurrence.

(b) Linesmen, where neutral, must call the attention of the referee to rough play or ungentlemanly conduct.

(c) A player putting his leg from behind another player in order to get the ball, and thus throwing his opponent, should be penalised for tripping.

(a) Wearing soft indiarubber on the soles of boots is not a violation of Law I I.

(e) The corner tlag must not be removed when a corner kick is taken.

(f) The whole of the ball must have passed over the goal-line, or touch-line, before it is out of play.

(g) If after the goal-bar becomes broken or displaced, the ball passes between the goal-posts at a point which, in the opinion of the referee, is below where the bar should have been, it is a legitimate goal. 


\section{THE RUGBY UNION.}

The following are the Laws of the game of Football, as played by the Rugby Football Union :-

\section{INTRODUCTION.}

I. The Rugby game of football should be played by 15 players on each side. (Anyone coming under the laws of professionalism shall not be allowed to take part in any game under this Union's jurisdiction.) The field-of-play shall not exceed IIO yards in length, nor 75 in breadth, and shall be as near these dimensions. as practicable. The lines defining the boundary of the field-ofplay shall be suitably marked, and shall be called the goal-lines at the ends and the touch-lines at the sides. On each goal-line and equidistant from the touch-lines shall be two upright posts, callcd goal-posts, exceeding i I feet in height, and placed is feet 6 inches apart, and joined by a cross-bar Io feet from the ground; and the object of the game shall be to kick the ball over this cross-bar and between the posts. The game shall be played with an oral ball of as nearly as possible the following size and weight, namely :-

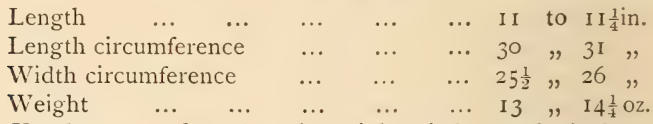

Hand-sewn, and not less than eight stitches to the inch.

\section{Glossary-Duties of OfFicials-Scoring.}

2. The following terms occur in the laws, and have the respective meanings attached to each :-

DEAD.BALL LINE.-Not more than 25 yards behind and equidistant from each goal-line, and parallel thereto, shall be lines, which shall be called the Dead-ball Lines, and if the ball or player holding the ball touch or cross these lines the ball shall be dead and out of play.

IN-GOAL. - Those portions of the ground immediately at the ends of the field-of-play and between the touch-lines, produced, to the dead-ball lines, are called In-goal. The goal-lines are ingoal. 
Touch.-Those portions of the ground immediately at the sides of the field-of-play and between the goal-lines, if produced, are called Touch. The touch-lines are in touch.

TOUCH-IN-GOAL. - Those portions of the ground immediately at the four corners of the field-of-play and between the goal and touch lines, if respectively produced, are called Touch-in-goal.

A DROP-KICK is made by letting the ball fall from the hands and kicking it the very instant it rises.

A PLACE-KICK is made by kicking the ball after it has been placed on the ground.

A PUNT is made by letting the ball fall from the hands and kicking it before it touches the ground.

A TACKLE is when the holder of the ball is held by one or more players of the opposite side.

A SCRummage, which can only take place in the field-of-play, is when the ball is put down between players who have closed round on their respective sides, and who must have both feet on the ground.

A TRY is gained by the player who first puts his hand on the ball on the ground in his opponents' in-goal.

A TOUCH-DOwn is when a player touches down as above in his own in-goal.

A GOAL is obtained by kicking the ball from the field-of-play, except from a punt, from a kick-off, or from a drop-out, direct (i.e., without touching the ground or any player of either side) over the opponents' cross-bar, whether it touch such cross-bar or the goalposts or not.

KNOCKING-ON and THROWING-FORWARD are propelling the ball by the hand or arm in the direction of the opponents' in-goal ; a throw out of touch cannot be claimed as a throw-forward.

A FAIR-CATCH is a catch made direct from a kick, or a knockon, or throw-forward, by one of the opposite side to the catcher, who must immediately claim the same by making a mark with his heel at the spot where he made the catch.

KICK-OFF is a place-kick from the centre of the field-of play; the opposite side may not stand within Io yards of the ball nor charge until the ball be kicked, otherwise another kick-off shall be allowed. If the ball pitch in touch the opposite side may have it kicked-off again.

DROP-OUT is a drop-kick from within 25 yards of the kicker's goal line, within which distance the opposite side may not charge, 
otherwise another drop out shall be allowed. If the ball pitch in touch the opposite side may have it dropped-out again.

At kick-off the ball must reach the limit of 10 yards, and at drop-out must reach the 25 -yards line. If otherwise, the opposite side may have the ball rekicked, or scrummaged, at the centre or in the middle of the 25-yards line, as the case may be.

OFF-SIDE.-See Laws 7 and 8.

3. In all matches a Referee and two Touch-Judges must be appointed, the former being mutually agreed upon. The referee must carry a whistle, which he must blow in the following cases:-

(a) When he allows an appeal.

(b) When a player makes and claims a fair-catch.

(c) When he notices rough or foul play or misconduct, when for the first offence he shall either caution the player or order him off the ground, but for the second offence he must order him off and afterwards report him to this Union.

(d) When a player is down in a scrummage and he considers it dangerous.

(e) When the ball has been improperly put into a scrummage.

(f) When he allows a decision given by a touch-judge.

$(g)$ When he wishes to stop the game for any purpose.

(h) If the ball or a player running with the ball touch him.

(i) At half-time and no-side, he being the sole timekeeper, having sole power to allow extra time for delays, but he shall not whistle for half-time or no-side until the ball be held or out of play.

(j) When a player in a scrummage lifts a fout from the ground before the ball has been put fairly into the scrummage.

The referee shall be sole judge in all matters of fact, but as to matters of law there shall be the right of appeal to the Rugby Union. All appeals must be made to him immediately, otherwise they cannot be entertained.

The touch-judges shall carry flags, and shall each take one side of the ground, outside the field-of-play, and their duty shall be to hold up their flag when and where the ball goes into touch.

4. The captains of the respective sides shall toss for the choice of in-goals or the kick-off. Each side shall play an equal tmefrom each in-goal, and a match shall be won by a majority of points ; if no points be scored, or the number be equal, the match shall be drawn. 
The following shall be the mode of scoring :
A try
A penalty goal ...
A goal from a try (in which case the try shall not count)
Any other goal ...
$\ldots$
$\ldots$
try
$\ldots$
equals 2 points
" 3 "
$" 5 \%$
" 4 "

5. At the time of the kick-off all the kicker's side shall be behind the ball; if in front, the referee, on an appeal from the opposite side, shall order a scrummage where the kick-off took place. The game shall be re-started by a kick-off-

(a) After a goal, by side losing such goal, and

(b) After half-time, by the opposite side to that which started the game.

\section{Mode OF Play-Definitions.}

6. When once the game is started, the ball may be kicked or picked up and run with by any player who is on-side, at any time ; except that it may not be picked up-

(a) In a scrummage.

(b) When it has been put down after it has been fairly held.

(c) When it is on the ground after a player has been tackled.

It may be passed or knocked from one player to another provided it be not passed, knocked, or thrown forward. If a player while holding or running with the ball be tackled and the ball fairly held, he must at once put it down in front of him.

7. A player is placed off-side if he enters a scrummage from his opponents' side, or if the ball has been kicked, touched, or is being run with by one of his own side behind him. A player can be off-side in his opponents' in-goal, but not in his own, except where one of his side takes a free kick behind his goal-line, in which case all of his side must be behind the ball when kicked.

8. An off-side player is placed on-side-

(a) When an opponent has run five yards with the ball.

(b) When the ball has been kicked by or has touched an opponent.

(c) When one of his side has run in front of him with the ball.

(d) When one of his side has run in front of him, having kicked the ball when behind him.

An off-side player shall not play the ball, nor during the time 
an opponent has the ball, run, tackle, or obstruct, nor may he approach within five yards of any player waiting for the ball; for any breach of this law the opposite side, on an appeal by them, shall be awarded, at their optionmark.

(e) A free kick, the place of such breach being taken as the

(f) A scrummage at the spot where the ball was last played by the offending side before such breach occurred.

Except in the case of unintentional off-side, when a scrummage shall be formed where such breach occurred.

9. If a player makes a fair-catch he shall be awarded a free kick, and he himself must either kick or place the ball.

10. All free kicks may be p'ace-kicks, drop-kicks, or punts, but must be in the direction of the opponents' goal-line, and across the kicker's goal-line, if kicked from behind the same. They may be taken at any spot behind the mark in a line parallel to the touchlines. If taken by drop or punt the catcher must take the kick, if taken by a place-kick the catcher must place the ball. In all cases the kicker's side must be behind the ball when it is kicked, except the player who may be placing the ball for a place-kick. In case of any infringement of this law the referee shall, on a claim by the opposite side, order a scrummage at the mark. The opposite sicle may come up to and charge from anywhere on or behind a line drawn through the mark and paraliel to the goal-lines, and may charge as soon as the catcher commences to run or offers to kick or places the ball on the ground for a place-kick, but in case of a drop-kick or punt the kicker may always draw back, and unless he has dropped the ball or touched it with his foot the opposite side must retire to the line of the mark. But if any of the opposite side do charge before the player having the ball commences to run or offers to kick, or the ball has touched the ground for a place-kick (and this applies to tries at goal as well as free kicks), provided the kicker has not taken his kick, the charge may be disallowed, on an appeal.

\section{Penalties.}

11. Free kicks by way of penalties shall be awarded on claims by the opposite side, if any player-

(a) Intentionally either handles the ball, or falls down in a scrummage, or picks the ball out of a scrummage ;

(b) Having the ball, does not immediately put it down in front of him on it being held; 
(c) Being on the ground, does not immediately get up ;

(d) Prevents an opponent getting up ;

(e) Illegally tackles, charges, or obstructs as in Law 8;

( $f$ ) Wilfully puts the ball unfairly into a scrummage;

(g) Not himself running at the ball, charges or obstructs an opponent not holding the ball ;

(h) Not in a scrummage, wilfully obstructs his opponents' halfbacks by standing on his opponents' side of the ball when it is in a scrummage ;

(i) Being in a scrummage, lifts a foot from the ground before the ball has been put into such scrummage. In this case the referee must allow a free kick to the opposite side without any appeal.

The place of infringement shall be taken as the mark, and any one of the side granted the free kick may place or kick the ball.

\section{GENERAL.}

12. The ball is in touch when it, or a player carrying it, touch or cross the touch-line; it shall then belong to the side opposite to that last touching it in the field-of-play, except when carried in. One of the side to whom the ball belongs shall bring it into play at the spot where it went into touch by one of the following methods :-

(a) Bounding it on the field-of-play at right angles to the touch-line, and then run with it, kick it, or pass it ;

(b) Throwing it out so as to alight at right angles to the touchline ; or

(c) Scrummaging it at any spot at right angles to the touch line, between 5 and 15 yards from the place where it went in:o touch.

If the ball be not thrown out of touch so as to alight at right angles to the touch-line, the opposite side may at once claim to bring it out themselves as in (c)

I3. When a side has scored a try, the ball shall be brought from the spot where the try was gained into the field-of-play in a line parallel to the touch-lines, such distance as the placer thinks proper, and there he shall place the ball for one of his side to try to kick a goal ; this place-kick is governed by Law Io as to charging, \&c., the mark being taken as on the goal-line. It is the duty of the defending side to see that the ball is taken out straight. 
On an appeal, the referee shall award a try if, in his opinion, one would undoubtedly have been obtained but for unfair play or interference of the defending side. Or, he shall disallow a try, and adjudge a touch-down, if, in his opinion, a try would undoubtedly not have been gained but for unfair play or interference of the attacking side. In case of a try so allowed, the kick at goal shall be taken at any point on a line parallel to the touch-lines, and passing through the spot where the ball was when such unfair play or interference took place.

I4. If the ball, when over the goal-line and in possession of a player, be fairly held by an opposing player before it is grounded, it shall be scrummaged 5 yards from the goal-line, opposite the spot where the ball was held.

15. After an unsuccessful try, or touch-down, or if the ball after crossing the goal-line go into touch-in-goal or touch or cross the dead-ball line, it shall be brought into play by means of a dropout, when all the kicker's side must be behind the ball when kicked; in case any are in front, the referee shall, on an appeal from the opposite side, order a scrummage on the 25 -yards line equidistant from the touch-lines.

16. In case of a throw-forward or knock-on, the ball shall, on a claim by the opposite side, be at once brought back to where such infringement took place and there put down, unless a faircatch has been made and claimed. If the ball or a player running with the ball touches the referee, it shall there be put down.

I7. If a player shall kick, pass, knock, or carry the ball back across his goal-line, and it there be made dead, the opposite side may claim that the ball shall be brought back and a scrummage formed at the spot whence it was kicked, passed, knocked or carried back. Under any other circumstances a player may touch the ball down in his own in-goal.

18. No hacking, or hacking over, or tripping up, shall be allowed under any circumstances. No one wearing projecting nails, iron plates, or gutta-percha on any part of his boots or shoes shall be allowed to play in a match.

19. In case of any law being infringed in in-goal by the attacking side, a touch-down shall be awarded, but where such breach is committed by the defending side, a scrummage shall be awarded 5 yards from the goal-line, opposite the spot where the breach occurred.

But in the case of any law being broken, or any irregularity of play occurring on the part of either side, not otherwise provided 
for, the opposite side may claim that the ball be taken back to the place where the breach of the law or irregularity of play occurred, and a scrummage formed there.

20. It is illegal for any member of any club in England in membership with this Union-(a) to take part in any match or contest where gate-money is taken, unless it is agreed that not less than 15 players on each side take part in a match; $(b)$ to play, between May 1 and August 3I, both dates inclusive, in any football contest of any character, either for charity or otherwise, where gate-money is taken.

Any player transgressing this law shall be deemed a professional, and may be dealt with under Rule 4 of the Rules relating to Professionalism.

At the annual general meeting held September 20, I893, the following resolution was adopted:- 'That this meeting strongly approves of the principle that the referee shall have sole control over the game, and may blow his whistle without waiting for any appeal, and recommencs that it be acted upon in matches in which both sides consent.' 



\section{N D EX.}

$A D T$

ADVertisemexts of athletic meetings, 197

Alcock, C. W. (sec, of Football Association), 384

Allardice, Capt. Barclay, 33 , 37,38

Alum and water for tender feet, I 8 I

Amateurism, 233, 245

Amateurs, 49-53 ; aristocratic, $32,35,38,40,47,50$; disputes about and definition of, $195,225,227,229-231$; decadence in character of, 233 , 234; true and false, 244, 245, 247; contending for money, 245, 246

Amateur Athletic Association, 53, I32, I90, I92, I93, 206, 208 ; rules, 55 , 195 ; on records, 218, 219; foundation of, 224-228; at the Oxford conference, 228 ; objects, 229 ; committee, 229 ; position as a controlling body, 230 ; compulsory laws, 230; dispute with National Cyclists' Union, 231 ; composition, 232 ; honorary secretary, 232 ; difficulties with the modern amateur, 233; dealings with the true
APP

amateur, 235 ; clubs affiliated with, 236

Amateur Athletic Club, 52, 53, I $33,224,242$

American athletic championship meeting, $\mathrm{I}_{32}$

American football, 395; early days of the game, 395; college matches in the seventies, 396 ; a set of rules drawn up in I873, 397 ; rivalry of Harvard and Yale, 398 ; introduction of Rugby football, 399 ; the game at the present day, 399 ; dimensions of the field, 399 ; costume of the players, 399 , 400 ; placing of the team, 40I; description of the game, $4 \mathrm{OI}-4 \mathrm{C} 6$; method of scoring points, 406 ; revision of rules: variations from the Rugby code, 405 ; the scrimmage, 407-4I 2 ; the snap-back and quarter-back, 409 ; the five-yard rule, 4I2; 'interference,' 4I2; popularity of the intercollegiate matches, 4 I3

American Intercollegiate Football Association, 399

Apparatus for an athlete, $I 8_{3}$ 
ASS

Association football, 299, 358387 ; rules, 437-44I ; see Football

Astley, Captain, 47, 50

Athletic government, 224-250

Athletic meetings in early times, 22-24

Attendants, 199

Australian football, 4I4; Melbourne and Sydney the chief centres, 4I 5 ; the Rugby game adopted by New South Wales, Queensland, and New Zealand, 4I5; Association rules followed by Victoria, South Australia, and Tasmania, 4I6; the latter known as the 'Australian game,' $4 \mathrm{I} 6$; its points of difference from the English game, 416 ; dimensions of the field, 416 ; the field umpire, 417,425 ; quarter-time and three-quarter-time, 418 ; the goal umpire, 419, 425; 'behinds,' 420 ; the 'little mark,' 420 ; positions of players on the field, 422 ; their duties, 422 ; the 'goal-sneak,' 423; 'shepherding,' 424; laws against roughness, 424 ; rule against professionalism, 426 ; description of the game, 427 ; the Melbourne Senior and Junior Associations, 429; touting for players, 429; regulations as to changing clubs, 430 ; rarity of serious accidents, 430; football the national game, 43I ; the laws, $432-436$

Authors quoted or cited :-Addison, 22, 288; Ascham, Roger, 8; Barclay, 9, 274; Budd, 390 ; Burton, I6, 280; Carew,
III. 1

28r ; Carter, 24; Cartwright, Thomas, I2 ; Collins, Wilkie, 27, 249; Cullum, 283; Davenant, Sir W., 28I ; Elyot, Sir Thomas, 7, 13, 274 ; Fitzstephen of Canterbury, 5, 27I, 272 ; Forest, Sir William, 7 ; Glover, 293, 294; Gonge, Burnabe, 12, 280 ; Gordon, Lindsay, 430 ; Heath, 24 ; Holmes, Randel, 9, 279; Hone, 24, 25, 28I, 285, 289, 290, 291 ; Hughes, Thomas, 298; Hutchinson, 289 ; Laneham, R bert, II, 277 ; Macaulay, I8; Misson, 287, 296; Moor, 283 ; Neogorgus, 280 ; Nichul, II ; Northbrooke, John, I2 ; Pace, Richard, 6 ; Pepys, I8, 19, 287; Phillips, Sir Erasmus, 21 ; Scott, 28, 29I ; Shakespeare, 8, 279; Stow, 22 ; Strutt, 4, 5, 6, 9, 23, 24, 46, 47, 288; Strype, 22 ; Stubbes, 277 ; Thom, 3437 ; Vincent, J. E., 295 ; Waller, 280 ; Westhall, I26I 28

BALOWN BALL, 270, 28 J

Barrymore, Lord, 32

Bath, use of the, 78

Beardsell, H., 57

Beauclerk, Lord F., 35

Belfast wake, 26

Bentinck, Lord F., 35

Betting, 197, 231, 247, 426

Birchfield Harriers, 258, 259

Birmingham Football Association, 383

Blackheath Harriers, 57, 243, $25^{8}$ 
BLI

Blisters, I 8 I

Books on training, 69

Boys' races, I98, 22 I

Broad jump, I43, I49-I 55, 200, 252

Brand, Hon. Mr., 36

CAmbridge University Athletic Club, 236, 237

Cambridge University sports, 48

Cameron, R., 57

Camp-ball, 283, 286

Casting of the barre, 6

Championship meetings, modern, description of, 54-67 ; spring or summer, 226, 227, 229

Chang, the Chinese giant, I 57

Charles II., I7, 19, 24

Charterhouse School, 49, 296, $301,303,360$

Cheltenham School, 46, 303

Cinder tracks, I86 ; see Tracks

Civil Service meeting, 52

Clerks of the course, 58, 203, 205

Clothing for racing, $20 \mathrm{I}$

Clubs, 224, 243

Coaches, river, advice to, I05

Columbia College, 397, 398

Committees, $20 \mathrm{I}$

Country clubs, 243

Country wake, description of a, 22

Crick Run at Rugby, 47, 257

Cripples racing, I7, I8

Cross-country running, 255 ; see Paper-chasing

Cutting down, 98

DiET, I70-I78

Disqualification, 207, 247

\section{FOO}

Dover, Captain, 23, 24

Drawers, 184

Dress, 184, 201, 265 ; of American football players, 399,400

Drink, $175-178$

ECCENTRIC matches, 29

Edwarc' II., 6, 272

Edward III., 6, 272

Elliman's embrocation, $\mathrm{IS}_{2}$

English athleticism, 248

Entrance fees, 193, 209

Entries, I9I, I97

Eton, athletics at, 47, 297

Eton School, 30I, 303, 304-3I2

Exeter College, Oxford, meeting, $4 \mathrm{I}-46,48$

FEeT, tender, I $8 \mathrm{I}$

Follis, the, 270

Football, early notices of, 8 , IO, I7 ; development of, 269 ; approximation of Greek and Roman games, 270; legends concerning, 27I; Shrove Tuesday matches, 27I, 279, 285 ; interdicted by Edward II. and Edward III., 272 ; forbidden by Richard II., Henry IV., James III. of Scotland, and Henry VIII., 273 ; in Elizabeth's reign, 275 ; in the streets of Manchester, 276 ; Puritan strictures on, 277, 287 ; Stubbes, the Puritan, a converted footballer, 278 ; James I.'s views, 278 ; references to, by sixteenthcentury writers, 279 ; in the streets of London, 29I, 287 ; statutory repressions, how enforced, 28I ; Carew's ac- 
FOO

count of, 28I ; known as hurling, 28I ; and as campball, $28_{3}$; Moor's description, 283 ; the Scone game, 285 ; compulsory, 285 ; spinsters $v$. married women, 286 ; in the time of Charles II., 287 ; Addison on, 288 ; the Rugby Union game in its unreformed condition, 289; a Shrove Tuesday match at Bromfield, 289 ; at Kingston in 1815 , 290 ; in Copenhagen Fields in $\mathrm{I} 84 \mathrm{I}, 29 \mathrm{I}$; Sir Walter Scott's song, 29I ; the game at Derby, 293; at Corfe Castle, 294; the dribbling game, 296, 360,364 ; adopted by the schools, 296, 297, 360 ; at Rugby, 298 ; Rugby Union and Association games, 299 ; rapid formation of clubs, 300 ; effurt to establish a uniform code of rules, 300 ; origin of the Football Association, $30 \mathrm{I}$; the off-side difficulty, $30 \mathrm{O}$; formation of the Rugby Union, 302 ; the Shrewsbury game, 303 ; the Eton wall game, 304-308; Eton field game, 308-3I 2 ; Harrow game, 3I 2 3I4; Winchester game, 3I5317; Rugby Union game, 318 ; the scrummage, 323, 335-337; half-backs, 324, 329, 334, 344, 370 ; the loose game, 327 ; fast forward game, 327 ; threequarter backs, 330, 334, 346 348; passing the ball, 33I, $332,341,366$; the 'four three-quarter system,' 332 ; main features of Rugby game. 333 ; forward play, 337-34I, $364,365,368$; tackling, 339 ;

\section{FOO}

passing, 34I ; fast running, 347 ; full backs, 348 ; club matches, 35I ; cup ties, 352, 382 ; international fifteens, 352 ; London v. Western Counties, 352 ; North $v$. South, 353 ; England v. Scotland, 353 ; international disputes, 353 ; roughness in cup ties, 353 ; Oxford Rugby Union College championship, 354; Yorkshire Union rules, 355 ; county matches, 355 ; Yorkshire v. Lancashire, 355 ; the Association game, 358387 ; the off-side rule, 359 ; Association cup ties, $360,382-$ 387 ; London v. Sheffield, 360 ; Oxford $v$. Cambriảge, 361 ; steering the ball, 362 ; the modern Association game, 363 ; middling, 366 ; heading, 369; back players, 372 ; goal-keeper, 375 ; kaleidoscopic changes in Association game, 379; settlement of disputes in Rugby and Association games, 380; rapid adoption of Association game, 383 ; Birmingham v. London, $38_{3}$; the Football Association, 384 ; county associations, 385 ; popularity in large provincial towns, 388 ; gatemoney, 388, 389 ; professionalism, 389; Rugby Union views on, 390, 39I ; dangers and unhealthiness combated, 392 ; explanation of terms, 440, 442. See also American football and Australian football.

Football Association, the, 30r, 384-386, 389 ; laws, 437-44r 
FOO

Football clubs:-Aston Villa, 388 ; Barnes, 300 ; Blackburn Rovers, 378,393 ; Blackburn Olympic, 383 ; Blackheath, $300,302,327,330,342,351$, $35^{2}$; Bradford, 35I ; Cambridge University, 352 ; Cardiff, 351 ; Civil Service, 300 ; Clapham Rovers, 375 ; Corinthians, 381 , 384; Crystal Palace, 300 ; Darwen, 383 ; Eton, 37I ; Forest, 300 ; Hallam, 300 ; Harlequins, 300 ; London Scottish, 35I, 352 ; Old Carthusians, 383 , 394 ; Old Etonians, 37 I, $38 \mathrm{I}-$ 383 ; Oxford University, 332, 352 ; Richmond, 300, 302, $327,342,351$, 352 ; Royal Engineers, 382; Scottish Queen's Park, 381, 383; Sheffield, 300, 360 ; Shropshire Wanderers, 382 ; Wanderers, 375, 381, 382 ; West Bromwich Albion, 383

Football League, the, 385

Footballers :-Arthur, 378 ; Bailey, N. C., $37 \mathrm{I}$; Birkett, R. H., 375 ; Bolton, W. N., 348 ; Brown J., 368 ; Budd, Arthur, 34I, 344 ; Burton, G. W., 344; Cail, W., $32 \mathrm{r}$; Camphell, 37I ; Cobbold, W. N., 369; Don Wauchope, A. R., 345 ; Finch, R. T., 340, 345 ; Fowler, 344 ; Freeman, H., 326 ; Fuller H. G., 344 ; Gurdon, C., 336, 344 ; Gurdon, E. T., 3.36, 344 ; Harrison, 344 ; Heron, Hubert, 363 ; Hill, G. Rowland, 353 ; Holmes, E. C., $32 \mathrm{I}$; Hornby, A. N., 35I ; Hutchinson, W. C., 325 ; Kinnaird, Hon. A.

\section{HAM}

F., 371, 382 ; Kirkpatrick, 378 ; Lockwood, R. E., 348 ; Macaulay, R. H., 368, 378 ; Maton, L. J., 32I ; Miller, Dr., 368 ; Ottaway, C. J., 363 ; Roffey, D. B., 376 ; Rotherham, A., 345 ; Rutter, A., 321 ; Stoddart, 348 ; Stokes, L., 348 ; Taylor, A. S., 35I ; Taylor, H. H., 345 ; Thompson, 336; Tristram, H. B., 35I ; Vassall, 34I, 344 ; Vidal, 363 ; Wace, H., 376 ; Wade, 348 ; Walters, A. M., 373 ; Walters, P. M., 373

Foot-baths, I 82

Footmen, running, 20

Foot-racing, early popularity of, I8

Forms of entry, 192

Fouling, 199

Four-mile race, daily training for, 104

French and English, I68

Gate-Money, I40, I9I, 2 IO, 233,265

Gentlemen amateurs, 233, 246

Gentlemen of Hampstead, $25^{8}$

Ginger-beer and gin, 263

Governing bodies, 224

Grass courses, I88, I9I

Grounds, running, I86 ; see Tracks

HAIF-MILE race, preparation for, 96

Hammer-throwers :-Barry, W. J. M., I63; Brown, S. S., I62; Gruer, J. D., 6I ; Halcs, (i. II., I63; Law- 
HAMI

rence, W., I6I ; Mitchell, J. S., 6I ; Queckberner, C. A. J., I63 ; Whitton, K., I63

Hammer-throwing, I4, I59; rules governing the sport, I60, I63; the throw, I60-I62

Handicap prizes, 192, 229

Handicappers, 192, 197, 208, 209

Hare and hounds, 46 ; sce Paperchasing

Harrow School, 46, 30I, 303, 3I $2-3$ I 4

Harvard College, 397-399

Henry $V$. as a runner, 5

Henry TIII., 6, 273

Herbert, Mr. (sec. A. A. A.), $5^{8,}, 232$

High jump, I43-I49, 200 ; best amateur jump, 252

Holmes, E. B., 56

Honourable Artillery Comp`ny, 50

Horse-racing, 16

Huddersfield C. and A. C., 244

Hungerford revel, 25

Hunter, C. V., 57

Hurdle, formation of a, I 20

Hurdle racers, style of, II 9 ; qualifications for, I2O, I2I ; beginners, I2I ; at practice, I2I ; paucity of good, I2I

Hurdle-racing, 47, 61, I 18-1 22, 202

Hurling, 28r, 286, 289

INTER-UNIVERSITY sports, $5 \mathbf{2}$

JACkson, N. L. (sec. Lond. F. A.), 384
JUII

James I. on sports, I3

Jersey, Lord, 106

Jerseys, I 84

Joddrell, Sir Edward, I 34

Joyce, William, the Kentish strong man, 2 I

Judges, 56, I29, I 30, I44, I95, 201, 205. 205

Jumpers, physical qualifications for, I +3 , I 44 ; training and practice, I44

Jumpers : -Baddeley, E., I5II 53 ; Bentley, 263 ; Brooks, M. I., 54, I43, I46-I 48 , 152 ; Burt, 253 ; Davies, E. J., I46, I 51-I 53 ; Davin, P., I47, I48, I 5 r, I 54 ; Davin, T., 147 ; Fry, C. B., 154 ; Glazebrook, M. G., I46 ; Green, C. E., I45 ; Horwood, E., 66; Kelly, I49 ; Kesip, C. W. M., 152, I 53 ; Lane, J., I5I, I52; Little, T. G., I45 ; Lockton, I5 I, I53; Macaular, R. H., I47 ; Malone, T. M., I 54 ; Mitchell, R. I. C., I45, I46, I5I ; Page, IV. B., I4S; Parsons, J. W., I48, I 5 I, I 54 ; Purcell, J., 65, I 54 ; Ray, Tom, 6r, 65 ; Roupell, J. H. T., 145; Rowdon, 65, I48; Smith, A. P., 263 ; Stones, E. L., 6r ; Thompson, F. G. F., 6I ; Tomlinson, G. , I47 ; Tosswill, A. C., I 5 I

Jumping, IO, I3, I 4, 27, 48, 54, $6 \mathrm{I}, 64,65$; the high jump, I43, 200 ; the take off, I45; on the grass, I 45 ; the long jump, I5o ; pole jumping, I64-167, 200 ; broad jump, 200 
KEN

Kexsington Grammar School, 46

Knickerbockers, I\&4

Koyting, 274

LAws of the Amateur Athletic Association, I95; of Australian football, 432 ; of the Football Association and Rugby Union, 437-449

London Athletic Club, 49, 52, I35, I 36, IS8, 212,225 ; foundation of, 24I; open membership, 242; in debt, 242 ; reorganisation, 242 ; good work done, 243

London, football in the streets of, $28 \mathrm{I}, 287$

London Football Association, 384

Long-distance races, training for, $\mathrm{IO}_{3}$

Long-distance runners, physical characteristics of, 105

Manchester, football in the streets of, 276

Marksmen, 57, 201

Marlborough School, 303

Mason, C. H., 56

Mason, Major, and the Necton Guild, 25

Matches, running, early, 30, 3 I

May Fair, 24

Medical profession, the, and athletics, 170

Meetings, athletic, I86; the ground, I 86 ; the track, I86 ; grass courses, I88, I9I ; shape of path, 188, I89; local cricket-grounds, I90;
MEE

records on turf, I9I ; entries, I9I, I97; prizes, I92 ; pothunting, 192, 209; entry forms, I92; entrance fees, I93 ; secretary's duties, I93 ; representatives of the Press, I94; chicken and champagne critics, 194 ; accommodation for competitors, I94; paraphernalia, I94; rules for competitions, I95; qualification of competitors, I95; prizes, I96; betting, 197 ; advertisements, I97; youths and novices, I98; protests, I98; stations, I98, 201 ; attendants, 199 ; fouling, I99; starting, I99; walking races, I99; the high, broad, and pole jumps, 200 ; steeple chasing, 200; throwing the cricket ball, 200; officials, 2OI; track measurements, $2 \mathrm{OI}$; clothing, $20 \mathrm{I}$; straight sprint races, 202; hurdle races, $2 \mathrm{O} 2$; throwing the hammer and putting the weight, 202 ; tug of war, 202 ; programmes, \&.c., 203 ; competent officials, 204 ; starters, 204 ; judges, 205 ; misbehaviour of competitors, 206 ; decisions, 206 ; walkers' gait, 207; cautions before disqualification, 207 ; handicapoers, 208, 2 II ; programme for club meeting, 208 ; decrease in popularity, 210 ; paucity of level open races, 2 Io ; short limit handicaps, 2 II ; Sheffield system, $2 \mathrm{II}$; timing, 212, 213-217; records, 213-219, 251, 252; true raison d'être of athletic 
MEL

sports, 220 ; boys' races, 22 I ; veterans racing, 222

Melbourne, football in, 4I5, 4I6, 429, 430; the Senior and Junior Associations, 429

Midland Counties C. C. Association, 259

Mincing Lane Athletic Club, 5 I

Monmouth, Duke of, as an athlete, 18

Moseley Harriers, I 8 , 258, 259

National Cyclists' Union, 230, 23 I

Necton Guild, 25

New South Wales, football in, 4 I 5

New Zealand, football in, 4I 5

Noblemen racing, I8, 2 I

Northern Counties Athletic Association, 226, 228, 259

Novices' races, 198

OFFICIALS, I95, 20I, 204

One-mile race, daily work for, IO4

Open races, institution of, 48 53

Oranges and lemons, I68

Oxford conference, the, 227

Oxford University Athletic Club, 236 ; beginning of the season, 237 ; Freshmen's sports, 238 ; strangers' race, 238 ; college meetings, 238 ; 'Varsity sports, 239; the 'blue,' 239 ; half-blue, 240 ; permanent officials, $24 \mathrm{I}$

Oxford University sports, 48
QUE

PAGeT, Lord, 32

Paper-chasing, 236, 255-266 ; Thames Handicap Steeplechase, 256 ; events 256-259; scoring in matches, 260; a club's stock-in-trade, 260 ; the hare's tactics, 260-262; the distance, 262 ; dress, 262 ; dangers to be avoided, 262 ; conduct of hounds, 263; jumping, 263; precautions after the run, 263 ; its future, 265 ; prizes, 265

Peckham A. A. C., 257

Pedestrians ; see Runners

Peppard revel, 25

Performances, best amateur, on record, 25I, 252

Pinnes, 274

Pole jumping, I64, 200; best amateur performance, 252 ; T. Ray, 165, I66; Stones, I66; Woodburn, E., I66

Portaferry wake, 26

Pot-hunting, I92, 209, 234, 245

Press, the, 193

Princeton College, 397, 398

Prizes, 55, 192, 196, 203, 229, $231,233,265$

Professionalism in football, $389^{-}$ $39 \mathrm{I}$; rule against in Victoria, 426

Programme for athletic club meeting, 203

Protests, I98

Puritanism and athleticism, Ir, I 2, I 5, 2I,

Puttick, A. J., 56

Putting the weight, 202, 252

QUARTER-MILE race, preparation for, 85-88

Queensland, football in, 4 I 5 
REA

REAY, JACK, 56

Records, 213-219

Referees, 57, 20I

Reforms in amateur athletics, 247

Riding, early notices of, $\mathrm{I} 3$

Rogers, Bob, 8I, 99, I47

Rogers, G. P., 56

Roping, 234, 265

Rubbers, 78

Rubbing, 78, 132

Rugby football, 299, 302, 318 357,385 ; in America, 399 ; in Australia, 4I 5 ; see Football

Rugby Football Union, formation of, 302 ; on professionalism, 390 ; laws, 442-449

Rugby School meeting, 49

Ruislip, football at, in Elizabeth's days, 275

Rules of the A. A. A. for competitions and the management of sports, 200

Runners, qualifications for, 69

Runners and walkers, past and present, amateur and professional :-Abron, 30 ; Aitken, James, 43, 44; Bacon, F. E., II3 ; Baker, A. J., 79, So ; Baker, S. H., IO2 ; Ball, H. R., 85, 92, 94, 19r ; Barrett, 35; Bassett 60; Batger, 6I ; Beal, Joseph, 35 ; Beckley, G. P., I 38 ; Bell, T. H., 76; Bertie, Peregrine, 21 ; Bessell, 59; Bindall, 35; Birkett, 103 ; Bowles, R. F., 4I-43 ; Bradley, C. A., 84 ; Bredin, E. C., 76,85 ; Brsden, H. A., I09; Bryden, T. R., 63, 64; Bulger, D. D., 6I ; Burt, L. U., IO9; Callow, C. M., 5I ; Chambers, J. G., I33, I34,
RLN

257 ; Chappell, 256; Chinnery, W. M., 50, 5I, IO7I09, 256 ; Christie, T., I00 ; Churchill, W. H., 85 ; Clague, W. L., 9I ; Clarke, C. W. V., 64, 65; Clarke, J. A. P., 59 ; Cleaver, F. F., I25; Clegg, J. C., 90, 9I, 263; Coad, W. H., 66, 264, 265 ; Colbeck, E. J., 79, 85, 89, 90, I00, I05; Congreve, G. F., I08 ; Cooke, 36 ; Courtney, L. H., IOI ; Cowie, 59, $82,85,91,92,94$; Cross, F. J. K., 63, 64, IO3, II3; Cummings, I05; Curley, the Brighton shepherd, 36 ; Curtis, H., I4I ; Daft, C. F, 6I, 62, I25; Dane, Captain, 35 ; Davies, J., 35, 40; Dawson, W. A., 80; Deerfoot, 50, I05; Dixon, Sydenham, I07, I08; Dudman, 66; Elborough, F. T., 85, 90-92, IOI, I02 ; Evars, 3 I ; Farnworth, T. H., I33, I34; Farrer, James, 35 ; Fenton, 40 ; Fitzherbert, R., I22 ; Fowler, W. J., II4 ; Frost, George, 40 ; Fuller, W. E., III ; Garnett, R., I 6 ; Garnier, E. S., I23 ; George, W. G., 62, IO3, IO9, III-II4, I87, 227, 265; Gibb, J., I08, IIO, 265; Goodwin, Albert, II I Gordon, Hon. Cosmo, 32 ; Goulbourne, 37 ; Gowthorpe, C. W., I25 ; Green, 49; Grey, 35; Griffith, T., I34 ; I35 ; Grinley, 36 ; Grosvenor, Captain, 32 ; Hague, John, 30 ; Haines, 58, 59, 63 ; Halton, J., 39 ; Harbord, Hon. Edward, 35 ; Hargraves, 


\section{RUN}

Capt., 40 ; Harrison, 66 ; Haselden, 35 ; Hawtrey, 256 ; Hayes, Tommy, 40; Hazenwood, C., 92, IO2 ; Headley, Joseph, 3I ; Hill, H. W., 95, 100-102 ; Hill, W. P., II 3 ; Holman, S. K., IO2 ; Horan, F. S., II4 ; Howard, Stuart, 58, 59; Howe, 35 ; Howett, I05; Hughes, I 37 ; Jackson, Billy, 40 ; Jackson, C. N., I22; Jackson, S. F., I24 ; James, P., 6o ; Jervis, 64,65 ; Jones, Norman, 62 ; Joyce, S., 61, 62; Jullie, J. H., 65; Junker, L., 72, 8I ; Karoniare, 256 ; Kennedy, 257 ; Kibblewhite, I., II 3 ; King, 256 ; Knight, E., 43; Lamb, Hon. Mr., 32 ; Laing, J. W., IO7 ; Lang, I05 ; Lawes, C. B., 106, I07; Lawrence, G. P. C., I24, I25 ; Levick, 60; Lock, W., 62, 63; Lockton, C. L., 72, 81, 82, I24, I25 ; Loder, A. B., I 23 ; Long, C.II., I07; Lutyens, W. E., II3; Mabey, 63, 64 ; Macaulay, R. H., 85 ; Macdougall, H., 8I ; Mackintosh, I42; MacNamara, 38 ; Martin, 49; Martin, J. B., I22 ; Mason, C. H., II I, 256 ; Massey, 82; Matthews, W., 39 ; Maxfield, Tom, 40 ; Meek, W. H., I40, I4I ; Mellish, 35; Merrill, I39, I4I ; Metcalf, James, 39 ; Michôd, C. J., I08, I1 7; Milvain, T., I22 ; Morgan, J. H., ro8; Morgan, W. J., 135-137 ; Morton, W. H., II4; Murray, F. P., I40, 141 ; Myers, 62, 63, 85, 89,

\section{RUN}

$93,94,102,139,187,191$; Nalder, T. B., 63, 64; Nicholas, 1. L., 75 ; Nicolls, E. R. J., IIo ; Nunn, G. R., I22; Nunn, R. H., I35; Oliver, HI. M., II 8,258 ; O'Malley, C. L., I18; Painter, 66 ; Palmer, S., I24, 125; Pearce, C. E., 114 ; Pelham, Hon. A. L., 95, I00; Phillips, W. P., 72, 82, 89, 92-94; Pbilpot, R., 90 ; Pope, 31 ; Portal, M. R., 99 ; Powell, 32, 33 ; Prest, C. H., $5 \mathrm{I}$; Purves, S. O., 6I ; Raby, J. W., I39, I40; Reay, J. H. A., I24; Ridley, 88 ; Ritchie, 59-6I, 83; Robinson, E. D., 58, 59, 62, 63 ; Rogers, E. D., 66, 265 ; Ross, Horatio, 38; Rye, Walter, 5I, I34, I35, I37 ; Sandford, E. A., 99 ; Savagar, 32 ; Sayers, Lieut., 47, 50 ; Scott, J., 43, 107, 108 , I9I, 252; Seary, W. H., I09; Shaw, G. B., 6I ; Shaw, Godfrey, I2I ; Shearman, J., 8I, 89, 91, 264; Shearman, M., 92 ; Shipley, 36 ; Skewball, 36 ; Slade, Walter, 100I02, 105, I08 - III, II7, II8, 136, I9I ; Smith, 33, 35; Smith, Lyle, 62, 63; Smith, S. P., I34, I35; Snook, 63 ; Snook, W., I09, II2, II3 ; Somers-Smith, R. V., 90, I00 ; Spicer, 50, $5 \mathrm{I}$; Stenning, P. H., 259, 264 ; Stirling, J. L., 122, I 23 ; Storey, E., 99; Sturt, H. H., 92 ; Temple, 30 ; Templer, G. A., I00 ; Tennant, W. M., 79, 90, 122 ; Tetlow, Johnny, 
RL'N

40 ; Thomas, Sidney, II 4 ; Tindall, 85, 90, 94; Trepplin, E. C., $72,79,80,8 \mathrm{I}$; Turner, Michael, 49 ; Upcher, H. K., 90, I20, I 23 ; Urmson, 80 ; Venn, H., I30, I37, 138 ; Wade, Harold, II3; Wallis, 35; Walpole, 3I ; Warburton, James (Choppy), I10; Warburton, 225 ; Warren, Lieut., 35; Webster, H., I29, I30, I36-I39, I4I ; Webster, Sir R., 49, 106 ; Webster, 226; Wellesley, Hon. A., 50 ; Wells, T. E., 95; Whaley, 50 ; Wharton, $59-63,73,83$; White, Jack, IO5; Whitehead, Levi, 35 ; Whyatt, H., I40; Widdowson, S. W., I25; Wild, 32 ; Wilkman, 35 ; Willers, C. E., I 4 ; Williams, 36 ; Williams, R. M., I33-135; Wills, J. T., II8; Wilson, J. G., 79, 8o, 90 ; Wise, B. R., III, I12; Woolfit, 3I ; Wood, Abraham, 35, 36, 38 ; Wood, $59-63,83,85$; Wyatt, H., 43, 44; York, 3 I

Running, early notices of, 4-6, 13,16 ; best amateur performances, 25I

Running footmen, 20

Rutgers College, 397, 398

SACK races, I67

Savagar's walking match, 32

Scholarship and athleticism, 249

Scone, football at, 285

Scoring in paper-chasing, 263

Scotland, football in, 29 i

Secretaries of sports, 193

Seven mile walking match, 132

\section{STO}

Sheffield Football Association, 301

Sheffield wake, 25

Shoemakers $v$. Drapers, 8

Shoes, 183

Shrewsbury meeting, 47

Shrewsbury School, 303

Six hundred yards race, 95,99

Sleep, I80

Smoking, I78, 264

Socks, 181,183

South Australia, football in, $4 \mathrm{I} 6$

South London Harriers, 243, 258,259

South Mims, football at, in Elizabeth's time, 276

Southern Counties C. C. Association, 259

Spartan Harriers, 258, 259

Spelling kee, 264

Spikes in shoes, 184

Sprinters, physical characteristics of, 72 ; practice and exercise for, 73 ; attitude at the start, 74-76; rubbing, 78 ; style, 79-82; at the quarter-mile, 88 ; as jumpers, I5O ; smoking, 178

Sprinting, Io, 36, 60, 62, 70, $79,202,205,210,215$

Standard judges, 57

Standard medals, 56

Standard timekeepers, 57

Start, the, in sprinting, 74-76

Starters, 57, 199, 201, 204, 2C7

Stations, 198, 201

Steeplechasers, qualifications for, II 6 ; at the hurdles and water-jump, I 6

Steeplechases, II4-118, 200

Stewards, 203

Stilts, racing on, $3 \mathrm{I}$

Stool-ball, IO, 286

Stop-watches, 2I 3-2I 7 
STR

Strains of muscles, I 82

Sydney, football in, 4I 5, 4I6

TActics of a race, 89

Tasmania, football in, 416

Teetotalers, 177,263

Tender feet, I8I

Terms used in football, 440444

Thames Handicap Steeplechase, 256

Thames Hare and Hounds Clvb, 209, 258, 259

Thames Rowing Club, 255

Thom's training rules, 34

Three-legged races, 167

Throwing the cricket ball, I64, 200 ; Forbes, W. F., I64; Game, W. H., I64

Throwing the hammer, IO, I3, I4, 6I, 202, 252

Timekeepers, 57, 201, 21 2, 213 , 216

Timing runners, 98, 104, 212, 2I 3-2I 7

Tollemache, Lord (the late), 38

Tossing the caber, I63

Track measurements, $20 \mathrm{I}$

Tracks:-Aston Lower Grounds, 55, 93, I90; Beaufort House, Walham Green, I88, 24I ; Christchurch cricket-ground, Oxford, I87-189; Copenhagen Grounds, 40; Fenner's cricket-ground, Cambridge, I88, I89, 237 ; Iffley Road Ground, I89; Kennington Oval, I9I ; Lillie Bridge, 54, I38, I47, I 54, I87, I88, 225 , 24I, 242 ; L. A. Grounds, Stamford Bridge, 55, I88, I89, 225 ; Lord's cricketground, 37, 38 ; Marston
WAL

cricket-ground, I47, I89 237 ; Private Banks cricketground, Catford Bridge, I9I ; Stamford Bridge, 187-189, 225, 226, 24I ; Trent Bridge Ground, Nottingham, I9I

Trainers, old professional, 78

Training, 34, 69, 70, 95-98, IO3, IO4, I3I, 250 ; opposition to, from medical profession, I70 ; diet, I70; the pre-athletic period, I70; a new system with old errors, I7I ; ideal diet, I72; physic, I72; what is a healthy diet, I72 ; porridge, I73 ; quantity of food, I74; drink, I75; teetotalism, I77 ; use of wine, I 78 ; smoking, I78; hours of sleep, I8o ; morning work, I80; work before breakfast, I80; care of the feet, I8I ; remedies for strained muscles, I82 ; Elliman's embrocation, I82; Westhall's recipe, 182 ; use of hot and cold water for strains, $\mathrm{I}_{3}$

Trinity College, Dublin, meeting, 49

Tug of war, I68, 202

UNIVERSITY sports, 48,49

VETERANS' races, 222

Victoria, football in, 416 ; the Football Association, 4I8, 425 Volunteer movement, 40

WAKES, 22, 25

Wales, Prince of, 287 
WAL

Walkers; see Runners

Walking, 64; usefulness of, I26 ; distinction between running and walking, I26 ; fair, I28, I29, I33 ; unfair, I29I32, I34, I38; bad, I30 ; remedy for bad and unfair, I 30 ; training for, I3I ; daily work, $\mathrm{I}_{32}$; rubbing, $\mathrm{I}_{32}$; distances, I 32 ; unpopularity at the universities, I34; on the road, 142 ; races, 199 ; gait in, 207; best amateur performances, 252

Washleather socks, I8I

Watch-holders, I05, I3 I

Weight-putters :--Bor, E. J., I $5^{8}$; Davin, M., I47, $15^{8}$; Harte, Owen, I59; Gray, G. R., I59; Mackinnon, D. J., I59; Mitchell, R. I. C., 65, I 58 ; O'Brien, J., I59 ; Ross, G., $15^{8}$; Stone, I., $15^{8}$; Stone, T., I58 ; Ware, J. H., 159 ; Winthrop, W. Y., 158

Weight-putting, 28, 65, 155; rules regulating, 156 ; first position, 156 ; second position, 157

Westminster School, 49, 30r, 303,360

Wilkinson, Tom, 57

Wilson, Professor (Christopher North), 47

Winchester School, 49, 303, 3I 5-3I7

Works quoted or cited :-Anatomie of Abuses in the Realme of England, I2, 277 ; Anatomy of Melancholy, I6, 280 ; Annals of King James and King Charles, I5; Athlete, 53 ; Barclay's Eclogues,
WOR

9 ; Basilikon Doron, 13,278 ;

Bell's Life, 39, 40, 47-49 ; Boke called the Governour, 7 , 8, 274; Book of Sports, 15 ; Comedy of Errors, 279; Corporation of London Records, 276 ; Football Annual, 34I, 363,390 ; Football, its History for Five Centuries, 295 ; Gentleman's Magazine, I6, 29; Harleian MSS., 279; Harrison's Description of England, II ; Henry IV., Pt. i., 8 ; Henry VI., Pt. i., 9 ; History of Cumberland, 289 ; History of Derby (Glover's), 271 ; History of Derbyshire, 293; History of Hawstead, 283 ; Hone's Every Day Book, 24, 25, 290, 29I ; Hone's Table Book, 28I ; Humphry Clinker, I9; Illustrated Sporting News, I06; King Lear, 279; Kingsley's Geoffrey Hamlin, 28 ; Knight of the Swan, 5 ; Knyghthode and Batayle, 5; Lady of the Lake, 28; Lay of the Last Minstrel, 29I ; Loyal Protestant, I7, I8 ; Luttrell's Diary, 29; Man and Wife, 27; Maitland's History of London, 22 ; Manchester Lete Roll, 276 ; Mémoires et Observations faites par un voyageur, 287 ; Middlesex County Records, 275; Modern Athletics, 48 ; Notes and Queries, 21 ; Peachan's Compleat Gentleman, I3, I4 ; Poesye of Princelye Practice, 7 ; Progresses of Queen Elizabeth, II ; Reading Mercury, 25; Rugby Union Fnotbal I 
WOR

Annual, 322, 325, 34I ; Rus. sell's History of Guildford, 9 ; Spectator, 22-24, 288 ; Sporting Magazine, 34, 39; Statistical Account of Scotland, 285 ; Survey of Cornwall, 28I ; Survey of London, 22 ; Thackeray's Rebecca and Rowena, 28; Thackeray's Virginians, 27 ; Thom's Pedestrianism, 34; Three Kings' Sons, 6 ; Times, 50 ;

\section{YOU}

Tom Brown's Schooldays, 257, 298, 299 ; Toxophilus, 8; Weekly Intellizencer, I6 ; Wilson's life of James I., I4

Wrestling, I 3

$$
\begin{aligned}
& \text { YaLE College, } 395-397 \\
& \text { Yorkshire County Football } \\
& \text { Union, } 389 \\
& \text { Youths' races, 198, 22 I }
\end{aligned}
$$



$25 n y, 56$ है

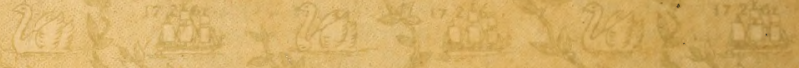

$29 h^{2}$

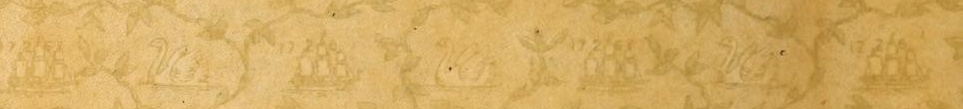

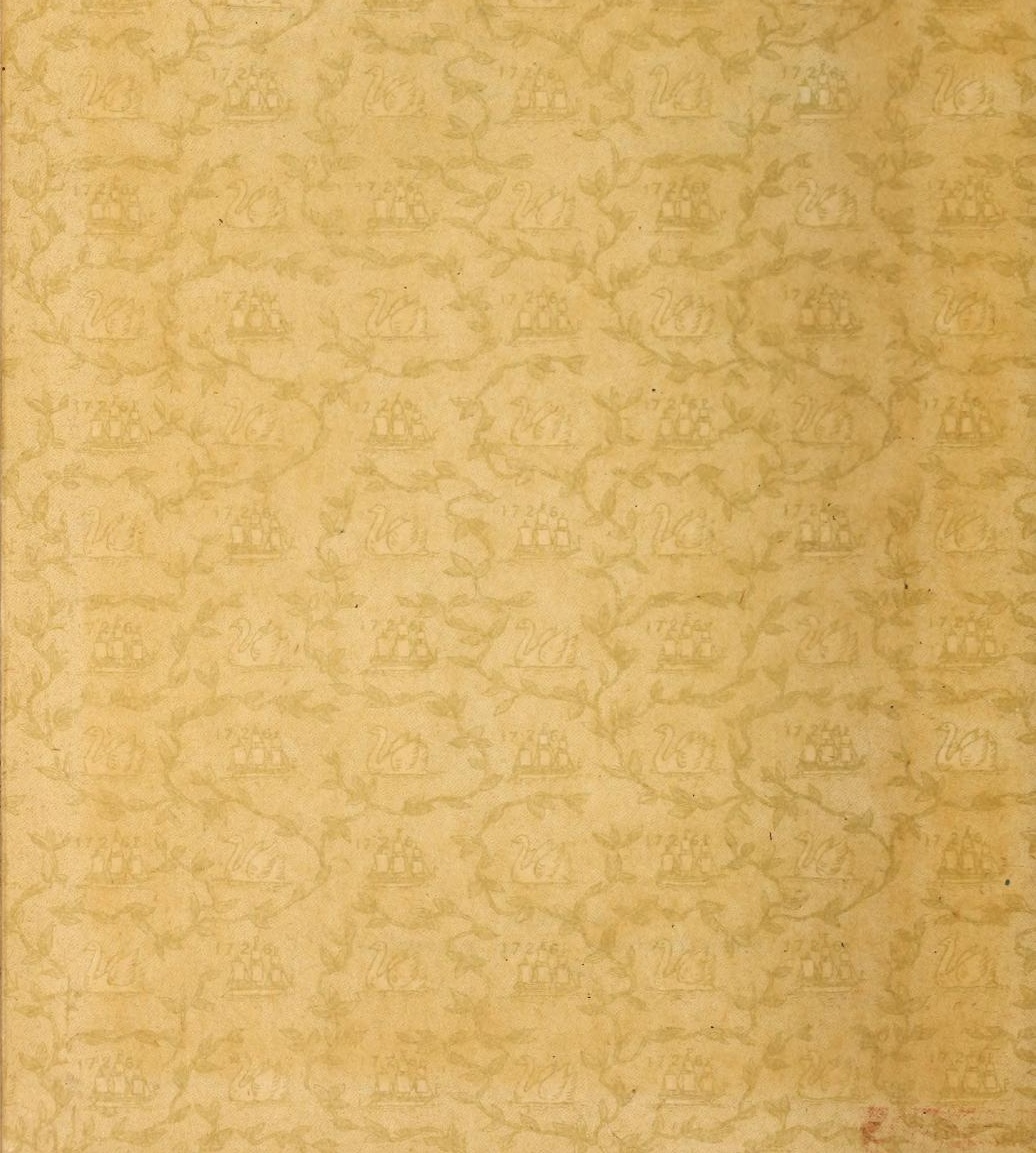




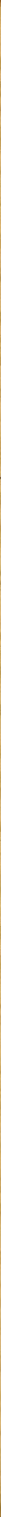




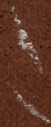

